MARJORIE MARIA BELINELLI

\title{
DESENVOLVIMENTO DE MÉTODO PARA SELEÇÃO DE POLÍTICA DE LUBRIFICAÇÃO DE MÁQUINAS CENTRADA EM CONFIABILIDADE: APLICAÇÃO NA INDÚSTRIA ALIMENTÍCIA
}

Tese de Doutorado apresentado à Escola Politécnica da Universidade de São Paulo para a obtenção de título de Doutor em Engenharia.

São Paulo 


\section{DESENVOLVIMENTO DE MÉTODO PARA SELEÇÃO DE POLÍTICA DE LUBRIFICAÇÃO DE MÁQUINAS CENTRADA EM CONFIABILIDADE: APLICAÇÃO NA INDÚSTRIA ALIMENTÍCIA}

Tese de Doutorado apresentado à Escola Politécnica da Universidade de São Paulo para a obtenção de título de Doutor em Engenharia.

Área de Concentração:

Engenharia Mecânica de Projeto de Fabricação

Orientador: Prof. Livre - Docente

Gilberto Francisco Martha de Souza 
Àos meus avós paternos Francisca Mercedes Belinelli e José Belinelli (in memorian), com amor, admiração e gratidão por sua compreensão, carinho e principalmente amor incondicional ao longo de toda minha vida. 


\section{AGRADECIMENTOS}

É com muita satisfação que expresso aqui o meu mais profundo agradecimento a todos, que diretamente ou indiretamente, tornaram possível o desenvolvimento deste trabalho.

Primeiramente agradeço a Deus e Nossa Senhora do Carmo (a qual eu sou devota) por me auxiliar em mais uma jornada de minha vida, guiando-me e fortalecendo-me dia a dia para enfrentar todas as dificuldades encontradas.

Agradeço ao meu orientador professor Doutor Gilberto Francisco Martha de Souza, pelo apoio, paciência e orientação relativa à estruturação desta Tese.

A Lilian Muller, Sueli, Barbosa, Edileuza Lima, Claudiliane Caldas e Anália Savoldi, as quais consideram não como amigas, mas sim família, por me apoiarem em todos os momentos alegres e tristes de minha vida.

Aos amores de minha vida, Apledinei Savoldi, Franscisca Mercedes Belinelli meus sobrinhos Felipe e Eduarda, que me alegram todos os dias e preenchem minha vida de felicidade, fortalecendo-me dia a dia.

Aos amigos Érico Félix, Camila Mancini e Carmem Patino, que apesar da distância, sempre me ajudaram e suportaram, e deixam sempre muitas saudades.

Um agradecimento especial ao professor Doutor Marcelo Rodrigues da UTFPR, por sua amizade e pelo apoio e incentivo na vida acadêmica.

Agradeço a Manolo Contreras, Soraia Banruque, Claúdio, Maurício e Nei Humberto pelo acesso e disposição de informações técnicas relativas à pesquisa em indústria de alimentos, as quais se tornaram a base da presente pesquisa.

Ao Departamento de Vigilância Sanitária de Curitiba pela disposição de informações e dados, os quais compuseram parte do trabalho.

Agradeço à CAPES (Coordenação de Aperfeiçoamento de Pessoal de Nível Superior) pela concessão da bolsa durante todo o período de realização deste doutorado.

Por último, um grande obrigado a todos os demais amigos, parentes e colegas de trabalho que ao longo dos meses de realização deste trabalho, demonstraram todo o apoio e incentivo, que me permitiu a conclusão desta tese. 
"Nós somos feitos do mesmo material dos sonhos"

(Willian Shakespare) 


\section{RESUMO}

Em indústria de alimentos são aplicados máquinas e equipamentos para processamento de alimentos, os quais exigem lubrificação para garantir seu pleno estado de funcionamento. Porém o mesmo lubrificante que auxilia o funcionamento do maquinário é considerado um risco potencial de contaminação do produto em suas etapas de processamento, vindo a interferir em sua qualidade. Além deste fator, uma inadequada gestão do processo de lubrificação de máquinas e equipamentos podem gerar eventos de falhas, impactando na disponibilidade e confiabilidade operacional do sistema industrial como todo.

O objeto da pesquisa desenvolvida nesta tese de doutorado é o desenvolvimento de um método de seleção de política de lubrificação industrial centrada em confiabilidade voltada especificamente para maquinário empregado na fabricação de alimentos, e visa analisar os eventos de falhas ocorridos no maquinário, os quais relacionados com o processo de lubrificação industrial, bem como, a relação das atividades de lubrificação na geração de foco de potencial risco que propicie perda de qualidade e inocuidade do produto.

O método é estruturado na identificação das variáveis envolvidas no processo de lubrificação industrial e análise de seus impactos sobre a geração de eventos de falhas e potencial foco de risco de perda de qualidade e inocuidade do produto, Esta análise visa direcionar a tomada de decisão quanto a estrutura da política de lubrificação industrial adequada a cada ativo industrial instalado na indústria de alimentos.

A validação do método de seleção de política de lubrificação centrada em confiabilidade deu-se através da aplicação de sua metodologia em um sistema reparável, uma máquina cobrideira, instalada em uma indústria de alimentos, localizada na região metropolitana de Curitiba. A análise estatística do comportamento da tendência de falhas neste ativo industrial conjuntamente com a análise funcional dos modos de falhas relacionados com o processo de lubrificação industrial, possibilitou estruturar uma política de lubrificação industrial adequada para máquina cobrideira. Esta política de lubrificação contempla ações que resultaram no aumento de produtividade anual da máquina cobrideira em $0,16 \%$, isto significa 280.830 unidades (equivalente a 7,02 toneladas) produzidas a mais no ano de 2014 em relação a 2013 , e na melhoria dos indicadores de desempenho de manutenção e disponibilidade operacional da máquina cobrideira.

Além disto, a aplicação do método desenvolvido estruturou procedimentos de modo de execução e monitoramento das atividades de lubrificação, os quais visam garantir a qualidade do produto durante as etapas de fabricação conjuntamente com a melhoria de desempenho e produtividade do sistema industrial.

Palavras-chave: Disponibilidade Operacional. Lubrificação Industrial. Risco de Perda de Qualidade e inocuidade do Produto. Indústria de Alimentos. Sistema Reparável. 
In the food industry, machinery and equipment for food processing are used. They require lubrication to ensure they're working properly. However, the same lubricant which assists the operation of the machinery is considered a potential contamination to the product in its processing steps, impacting on their quality. The improper management of the lubrication process of machinery and equipment may lead to fault events, impacting on the availability and operational reliability of the industrial system as a whole.

The research object developed in this doctorate thesis shows the development of a selection method of an industrial lubrication policy focused on reliability. Such policy is designed specifically for machinery used in the manufacture of foods. It analyzes the failure events in the machinery due to the lubrication process and. It also analyzes the connection between the lubricating activities and the potential risk of loss product quality and safety.

The method is structured to identify the variables involved in the industrial lubrication process and analyzes their impact they have on fault events and potential source of risk of product quality loss. This analysis aims to guide decision-making regarding the structure of the adequate industrial lubrication policy to each industrial asset installed in the food industry.

The validation of the lubrication policy selection method focused on reliability occurred through the application of its methodology in a repairable system, a coating machine, installed in a food industry located in the metropolitan region of Curitiba. The statistical analysis of the fault trend behavior in this industrial asset together with the functional analysis of failure modes related to the industrial lubrication process made it possible to structure a suitable policy for the industrial lubrication of the coating machine. This lubrication policy includes actions that resulted in the increase of the annual productivity of the coating machine by $0.16 \%$. It means 280,830 more units (equivalent to 7.02 tons) were produced in 2014 than in 2013. It also improved the maintenance performance indicators and the operational availability of the coating machine.

Furthermore, the application of the method structured procedures of execution mode and monitoring of lubrication activities. The aim was to ensure the quality of the product during the manufacturing steps together with the improvement of the performance and productivity of the industrial system.

Keywords: Operational Availability. Industrial Lubrication. Risk of Loss of Product Quality and Safety. Food Industry. Repairable System. 


\section{LISTA DE ILUSTRAÇÕES}

Figura 2.1 - Conceitos de Confiabilidade na Manutenção Industrial.

Figura 2.2 - Influência da Confiabilidade e Mantenabilidade sobre a Disponibilidade..... .66

Figura 2.3 - Casos de Ocorrência de Falhas em Sistemas Reparáveis. 68

Figura 2.4 - Perguntas que Direcionam a Implantação de MCC........................72

Figura 2.5 - Árvore Funcional de um Helicóptero de Caça..................................76

Figura 2.6 - Característica da Análie FTA...........................................................

Figura 2.7 - Modelo de Roteiro para Tabela FMEA .........................................

Figura 2.8 - Passos para Aplicação da Análise FMEA ……………...................82

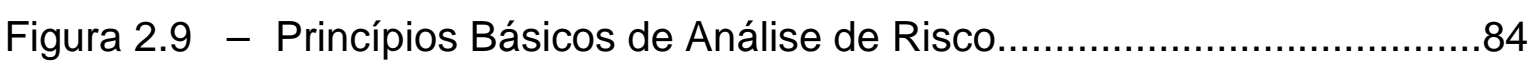

Figura 2.10 - Processo de Gestão de Risco: Visão Geral da Norma 31000:2009.

Figura 2.11 - Elementos de Análise para Identificação de Potencial Risco nas Tarefas de Manutenção Industrial.

Figura 2.12 - Ações Relacionadas à Área de Manutenção Industrial que Podem Causar Potencial Evento de Risco.

Figura 2.13 - Relação entre as Ações de Manutenção Industrial e Análise de Risco.

Figura 2.14 - Sequência para Aplicação do Sistema HACCP.

Figura 2.15 - Sete Princípios Envolvidos no Desenvolvimento e Operação do Programa HACCP.

Figura 3.1 - Visão Geral da Estrutura do Método de Seleção de Política de Lubrificação com Objetivo de Equilibrar a Gestão da Manutenção Industrial com as Atividades Exercidas pela Engenharia da Qualidade em Indústrias de Alimentos

Figura 3.2 - Etapas de Construção do Método para Seleção de Política de Lubrificação Centrada em Confiabilidade.

Figura 3.3 - Fluxo de Caracterização e Análise Quantitativa/Qualitativa das Variáveis Envolvidas no Processo de Lubrificação Industrial. 126

Figura 3.4 - Ciclo da Cadeia Alimentar para Análise de Qualidade desde a 
Obtenção de Matéria Prima até Consumo Final.

Figura 3.5 - Variáveis Envolvidas no Processo de Lubrificação com seus Valores/Pesos Identificados para Obtenção do Indicador de Nível de Confiabilidade Operacional e Potencial Risco à Qualidade do Produto por meio das Atividades de Lubrificação.

Figura 3.6 - Ciclo de Implantação e Avaliação do Método de Seleção de Política de Lubrificação Centrada em Confiabilidade. 146

Figura 3.7 - Modelo de Árvore Funcional para Identificação dos Pontos de Lubrificação.

Figura 3.8 - Fluxograma do Modelo para Mapeamento do Sistema Industrial.

Figura 3.9 - Leiaute do Modelo para Zoneamento do Sistema Industrial 153

Figura 3.10 - Requisitos para Identificação de Evidência ou Não Evidência das Variáveis Envolvidas no Processo de Lubrificação.

Figura 3.11 - Ciclo de Desenvolvimento e Aplicação do Método de Seleção de Política de Lubrificação em Indústria de Alimentos

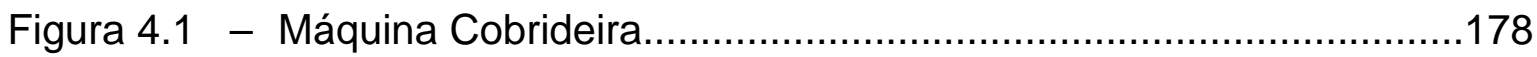

Figura 4.2 - Fluxograma do Processo Produtivo - Linha de Produção 1........181

Figura 4.3 - Árvore Funcional da Máquina Cobrideira. 185

Figura 4.4 - Leiaute Linha de Produção 1 no Formato de Ligação em Série com Identificação da Máquina Cobrideira dentro da sua Zona Critíca $-Z_{C}$

Figura 4.5 - (a) Gráfico dos Valores de Disponibilidade - $\mathrm{A}(\mathrm{t})$ ao Longo do Período de 2010 à 2013 com Todos os Eventos de Falhas Ocorridas na Máquina Cobrideira e (b) Gráfico com Simulação dos Valores de $A(t)$ da Máquina Cobrideira sem Contabilização dos Eventos de Ocorrência de Falhas Relacionados ao Processo de Lubrificação Industrial 200

Figura 4.6 - (a) Gráfico dos Valores da Taxa de Intensidade de Ocorrência de Falhas - $\rho(t)$ ao Longo do Período de 2010 à 2013 com Todos os Eventos de Falhas Ocorridos na Máquina Cobrideira e

(b) Gráfico com Simulação dos Valores de $\rho\left({ }_{t}\right)$ da Máquina 
Cobrideira sem Contabilização dos Eventos de Ocorrência de Falhas Relacionados ao Processo de Lubrificação Industrial.....201

Figura 4.7 - (a) Gráfico dos Valores de MTTR $\left.{ }_{\mathrm{t}}\right)$ e TTR Referentes aos Eventos de Falhas Ocorridos Entre o Período de 2010 à 2013 com Todos os Eventos de Falhas Ocorridos na Máquina Cobrideira e (b) Gráfico com Simulação dos Valores de MTTR(t) e TTR dos Eventos de Falhas Ocorridos na Máquina Cobrideira sem Contabilização dos Eventos de Ocorrência de Falhas Relacionados ao Processo de Lubrificação Industrial 205

Figura 4.8 - (a) Gráfico dos Valores de $\left.\operatorname{MTBF}_{(\mathrm{t}}\right)$ Variando ao Longo do Período de 2010 à 2013 com Todos os Eventos de Falhas Ocorridos na Máquina Cobrideira e (b) Gráfico com Simulação dos Valores de $\operatorname{MTBF}\left({ }_{t}\right)$ da Máquina Cobrideira sem Contabilização dos Eventos de Ocorrência de Falhas Relacionados ao Processo de Lubrificação Industrial. .206

Figura 4.9 - Cronograma da Implantação das Medidas Contempladas na Estrutura da Política Adequada de Lubrificação Industrial da Máquina Cobrideira 212

Figura 4.10 - Foto do Quadro de Gestão para Expor os Indicadores de Desempenho da Máquina Cobrideira.

Figura 5.1 - (a) Gráfico de $\rho(t)$ da Máquina Cobrideira entre 2010 à $2014 \mathrm{e}$

(b) Gráfico de $\left.\mathrm{A}_{\mathrm{t}}\right)$ da Máquina Cobrideira entre 2010 à 2014.....239

Figura 5.2 - (a) Gráfico dos Valores de MTBF $(\mathrm{t})$ e (b) Gráfico de MTTR $(\mathrm{t})$ e TTR's dos Eventos de Falhas Ocorridos no Período de 2010 à 2014 242

Figura 5.3 - (a) Gráfico dos valores de custos com manutenção corretiva da máquina cobrideira entre o período de 2010 à 2014 x Valor orçado para custos de manutenção corretiva na linha de produção 1 no ano 2013 


\section{LISTA DE QUADROS}

Quadro 2.1 - Categorias Food Grades Lubricants.

Quadro 2.2 - Parágrafos do Título 21 das Diretrizes da FDA CRF- "Food

Grades Lubricants".

Quadro 2.3 - Substâncias Aprovadas para Lubrificantes H1 pelo Parágrafo 21.CFR 178.3570

Quadro 2.4 - Portões Lógicos da FTA

Quadro 2.5 - Conceitos Aplicados em Indústria de Alimentos Direcionados para Engenharia de Manutenção e Qualidade.

Quadro 3.1 - Estrutura da Relação entre as Variáveis Envolvidas no Processo de Lubrificação na Construção do Indicador de Nível de Confiabilidade Operacional e Potencial Risco a Qualidade do Produto.

Quadro 3.2 - Análise do Indicador de Nível de Confiabilidade Operacional e Potencial Risco de Perda de Qualidade do Produto - $I_{C R}$.

Quadro 3.3 - Classificação do Zoneamento do Sistema Industrial para Grau de Risco de Qualidade e Inocuidade do Produto.

Quadro 3.4 - Comparação do Método de Seleção de Política de Lubrificação Centrada em Confiabilidade perante Características de Outros Métodos.

Quadro 4.1 - Maquinário da Linha de Produção 1

Quadro 4.2 - Análise Quantitativa e Qualitativa das Variáveis Envolvidas no Processo de Lubrificação da Máquina Cobrideira.

Quadro 4.3 - Plano de Manutenção Preventiva: Rota de Lubrificação da Máquina Cobrideira. 
Quadro 4.4 - Plano de Manutenção Preditiva: Rota de Lubrificação da Máquina Cobrideira.

Quadro 4.5 - Procedimento Padrão de Trabalho para as Atividades de Lubrificação da Máquina Cobrideira.

Quadro 5.1 - Medidas implantadas na Estrutura da Política de Lubrificação da Máquina Cobrideira. 235

Quadro 5.2 - Análise Quantitativa e Qualitativa das Variáveis Envolvidas no Processo de Lubrificação da Máquina Cobrideira (Resultado)....244

Quadro 5.3 - Análise $I_{C R}$ da Máquina Cobrideira após Aplicação do Método de Seleção de Política de Lubrificação Centrada em Confiabilidade. 


\section{LISTA DE TABELAS}

Tabela 2.1 - Valores $\beta$ para Indicar Tendência da Curva do Comportamento das Ocorrências de Falhas em Sistemas Reparáveis.

Tabela 3.1 - Variáveis Binárias Envolvidas no Processo de Lubrificação Industrial de Maquinário Empregado na Fabricação de Alimentos.

Tabela 3.2 - Requisitos para Determinação de Evidência ou Não Evidência da Variável Relacionada à Manutenção Preventiva.

Tabela 3.3 - Requisitos para Determinação de Evidência ou Não Evidência da Variável Relacionada à Manutenção Preditiva.

Tabela 3.4 - Requisitos para Determinação de Evidência ou Não Evidência da Variável Relacionada à Qualificação de Mão de Obra

Tabela 4.1 - Dados Comparativos de Produtividade da Máquina Cobrideira.....202

Tabela 5.1 - Resultados de Produtividade da Máquina Cobrideira com a Aplicação do Método de Seleção de Política de Lubrificação Centrada em Confiabilidade. 240

Tabela 5.2 - Custos Manutenção Corretiva - Máquina Cobrideira. 251 


\section{LISTA DE ABREVIATURAS, ACRÔNIMOS E SIGLAS}

ABNT Associação Brasileira de Normas Técnicas

AISI American Iron and Steel Institute (em português Instituto Americano de Ferro e Aço)

ANVISA Agência Nacional de Segurança Sanitária

ANP Agência Nacional do Petróleo

APPCC Análise de Perigos e Pontos Críticos de Controle

ASQ American Society for Quality (em português Sociedade Americana de Qualidade)

BNDES Banco Nacional de Desenvolvimento Econômico e Social

BPF

Boas Práticas de Fabricação

CAC Codex Alimentarius Commission (em português Comissão do Código de Alimentos)

CLP Controle Lógico Programável

CMMS Computer Maintenance Management Systems (em português Sistemas Informatizados para Gestão da Manutenção)

CRF Code of Federal Regulations (em português Código de Regulamentações Federais)

DIN Deutsches Institut für Normung (em português Instituto Alemão para Normatização)

ERP Enterprise Resource Planning (em português Planejamento de Recursos Empresariais)

EUA Estados Unidos da América

FAO Food and Agriculture Organization of the United Nations (em português Organização das Nações Unidas para Alimentação e Agricultura)

FDA Food and Drugs Administration (em português Agência Americana de Medicamentos e Alimentos)

FMEA Failure Mode and Effects Analysis (em português Análise de Modo e 
Efeito de Falhas)

FTA Fault Tree Analysis (em português Análise da Árvore de Falhas)

GMP Good Manufacturing Practices (em português Boas Práticas de Fabricação)

HACCP Hazard Analysis and Critical Control Point ( em português Análise de Perigos e Pontos Críticos de Controle )

ISO International Organization for Standardization (em português Organização)

KG Kilogramas

MAPA Ministério da Agricultura, Pecuária e Abastecimento

MCC Manutenção Centrada em Confiabilidade

MTBF Mean Time Between Failure (em português Tempo Médio entre Falhas)

MTTF Mean Time to Failure (em português Tempo Médio para Reparo)

MTTR Mean Time to Repair- Tempo Medio entre Falhas

MS Ministério da Saúde

NBR Norma Brasileira

NGLI National Lubricating Grease Institute (em português Instituto Nacional de Lubrificação a Graxa)

NSF National Sanitization Foundation (em português Fundação Nacional de Saúde Pública)

OMC Organização Mundial do Comércio

OMS Organização Mundial da Saúde

OS Ordem de Serviço

PCC Ponto Crítico de Controle

PCM Planejamento e Controle de Manutenção

PIB Produto Interno Bruto

PM Manutenção Preventiva

PPM Partes por milhão

$\mathrm{PPH} \quad$ Processo Poisson Homogêneo 
PPHO Procedimento Padrão de Higiene Operacional

PPNH Processo Poisson Não Homogêneo

POP Procedimento operacional padronizado

RCM Reliability Centered Maintenance (em português Manutenção Centrada em Confiabilidade)

RDC Resolução da Diretoria Colegiada

ROCOF Rate of Occurrence of Failures (em português Taxa de Intensidade de Falhas)

SGQ Sistema de Gestão da Qualidade

SSO Standard Sanitizing Operating Procedures (em português Procedimento Padrão de Higiene Operacional)

TBF Time Between Failure (em português Tempo Entre Falhas)

TPM Total Productive Maintenance (em português Manutenção Produtiva Total)

TPR Tempo para Reparos

TTF Time to Failure (em português Tempo até a Falha)

TTR Time to Repair (em português Tempo para Reparo)

USA United States of American (em português Estados Unidos da América)

USDA United States Department of Agriculture (em português Departamento de Agricultura dos Estados Unidos)

VG Viscosity Grades for Industrial Lubricants (em português Grau de Viscosidade para Lubrificantes Industriais)

WHO World Health Organization (em português Organização Mundial da Saúde) 


\section{LISTA DE SÍMBOLOS}

\begin{tabular}{|c|c|}
\hline$\beta$ & Parâmetro do Modelo de Crow \\
\hline$\alpha$ & Parâmetro do Modelo de Crow \\
\hline$\rho(t)$ & Taxa de Intensidade de Ocorrência de Falhas \\
\hline$t_{n}$ & Tempo da Última Falha \\
\hline $\mathrm{n}_{\mathrm{f}}$ & Número de falhas \\
\hline Ln & Logaritmo Natural \\
\hline$\Sigma$ & Somatório \\
\hline$R(t)$ & Reliability (em português Confiabilidade) \\
\hline$m(t)$ & Número Acumulado de Falhas ao Longo do Tempo \\
\hline$f_{i}$ & Sequencial de Falhas \\
\hline$A(t)$ & Availabilty (em português Disponibilidade) \\
\hline $\mathrm{I}_{\mathrm{CR}}$ & $\begin{array}{l}\text { Indicador de nível de equilíbrio entre a confiabilidade operacional e } \\
\text { potencial risco de perda de qualidade do produto mediante o } \\
\text { processo de lubrificação industrial }\end{array}$ \\
\hline $\mathrm{Z}_{\mathrm{C}}$ & Zona de Criticidade \\
\hline$U$ & União entre Elementos \\
\hline$x_{i}$ & Variável Identificada no Processo de Lubrificação Industrial \\
\hline h & Horas \\
\hline n & Número de Falhas \\
\hline
\end{tabular}




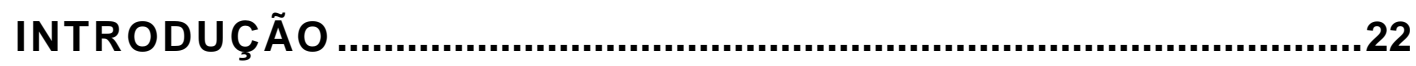

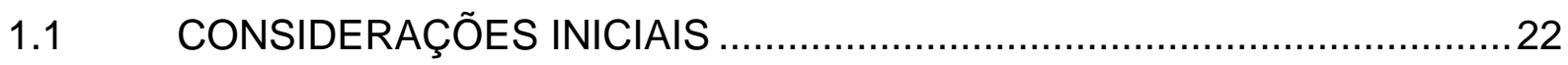

1.2 DESCRIÇÃO DO SETOR INDUSTRIAL DE PESQUISA …......................24

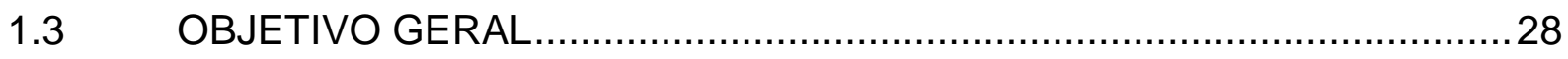

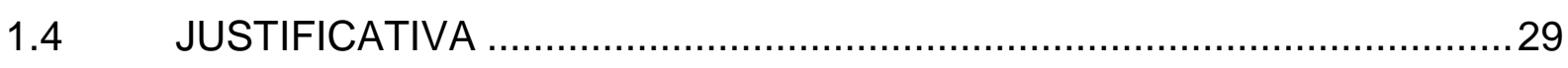

1.5 RELEVÂNCIA DA PESQUISA QUANTO À INOVAÇÃO TECNOLÓGICA .34

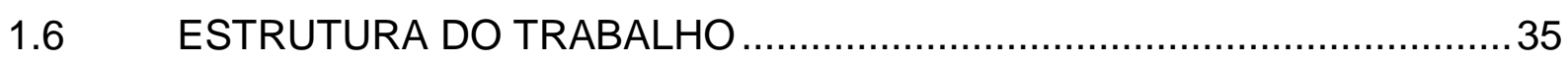

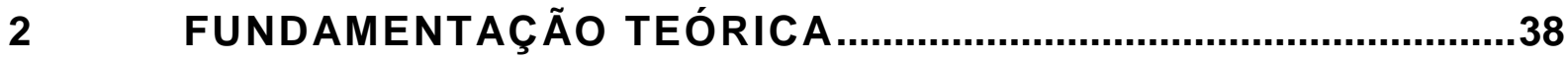

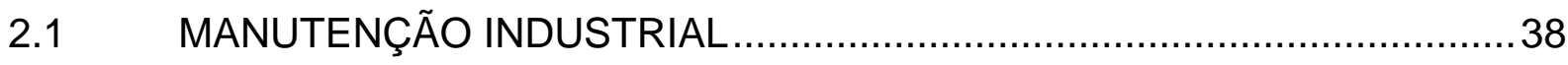

2.1.1 Classificação da Manutenção Industrial ...................................................40

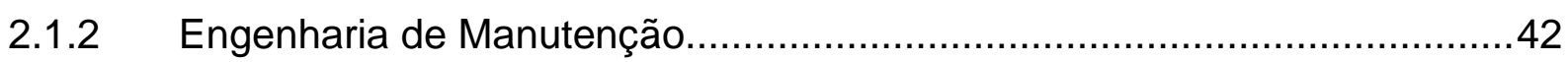

2.2 LUBRIFICAÇÃO INDUSTRIAL ......................................................... 46

2.2.1 Gestão da Lubrificação Industrial ........................................................ 48

2.2.2 Gestão do Processo de Lubrificação em Maquinário Aplicado à

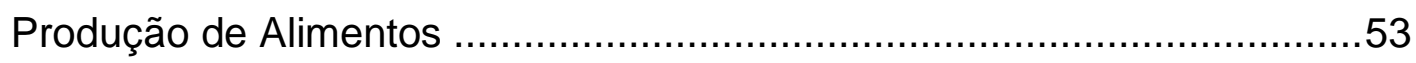

2.3 ENGENHARIA DA CONFIABILIDADE APLICADA A MANUTENÇÃO

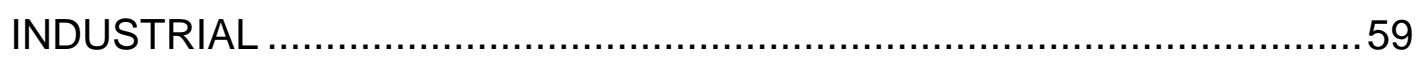

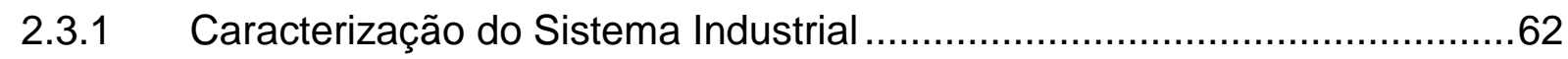

2.3.2 Sistemas Reparáveis e Sistemas não Reparavéis ...................................63

2.3.3 Análise Estatística de Falhas em Sistema Reparáveis................................64

2.3.4 Metodologias e Ferramentas para Análise de Falhas Aplicadas à Engenharia de Manutenção e Confiabilidade .............................................73

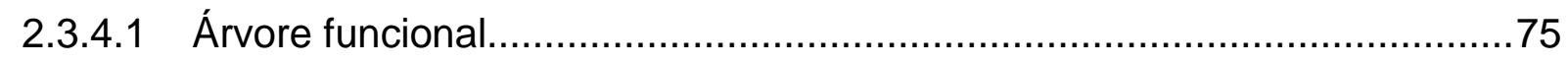

2.3.4.2 Método de análise de risco de falha: Árvore de falhas ( FTA ) ..................76

2.3.4.3 FMEA (Failure Mode and Effects Analysis) - Análise de modo e efeito de falhas .80 
2.4 GESTÃO DE RISCOS - ISO 31000 APLICADA À MANUTENÇÃO INDUSTRIAL

2.5 HACCP (HAZARD ANALYSIS AND CRITICAL CONTROL POINTS) ANÁLISE DE PERIGOS E PONTOS CRÍTICOS DE CONTROLE..............90

2.6 NORMAS E LEGISLAÇÕES APLICADAS A INDÚSTRIAS DE ALIMENTOS DIRECIONADAS A ENGENHARIA DE MANUTENÇÃO . 95

2.6.1 Instruções Normativas relacionadas à Engenharia de Qualidade e Engenharia de Manutenção. 105

2.6.2 ISO 21649 segurança de máquinas 110

2.6.3 Halal e kosher... 111

2.7 CONSIDERAÇÕES FINAIS. 112

3 DESENVOLVIMENTO DE MÉTOdO PARA SELEÇÃO DE POLÍTICA DE LUBRIFICAÇÃO INDUSTRIAL CENTRADA EM CONFIABILIDADE: APLICAÇÃO NA INDÚSTRIA DE ALIMENTOS

3.1 DESENVOLVIMENTO DO MÉTODO PARA SELEÇÃO DE POLÍTICA DE LUBRIFICAÇÃO

3.2 INDICADOR DE CONFIABILIDADE OPERACIONAL E RISCO DE PERDA DE QUALIDADE E INOCUIDADE DO PRODUTO.

3.2.1 Identificação e Caracterização do Sistema Industrial: Mapeamento do Processo de Fabricação de Alimentos ...

3.2.2 Identificação de Eventos de Riscos e Ocorrência de Falhas: Variáveis Envolvidas no Pocesso de Lubrificação Industrial de Indústrias de Alimentos. 154

3.3 IDENTIFICAÇÃO DE EVENTOS DE RISCOS E OCORRÊNCIA DE FALHAS E AVALIAÇÃO DE EFICÁCIA DO MÉTODO: INDICADORES DE DESEMPENHO DE CONFIABILIDADE E DISPONIBILIDADE EM SISTEMAS REPARÁVEIS. 160

3.4 FLUXOGRAMA DE APLICAÇÃO DO MÉTODO DE SELEÇÃO DE POLÍTICA DE LUBRIFICAÇÃO CENTRADA EM CONFIABILIDADE ......162

3.5 CONSIDERAÇÕES FINAIS. 169 
APLICAÇÃO DO MÉTOdO PARA SELEÇÃO DE POLÍTICA DE LUBRIFICAÇÃO DE MÁQUINAS CENTRADA EM CONFIABILIDADE: APLICAÇÃO NA INDÚSTRIA ALIMENTÍCIA 173

4.1 CONSIDERAÇÕES INICIAIS 173

4.2 APLICAÇÃO DO MÉTODO PARA SELEÇÃO DE POLÍTICA DE LUBRIFICAÇÃO CENTRADA EM CONFIABILIDADE 173

4.2.1 Apresentação do Sistema Produtivo de Fabricação de Alimentos 175

4.3 IDENTIFICAÇÃO E CARACTERIZAÇÃO DO SISTEMA INDUSTRIAL ... 180

4.3.1 Mapeamento do Processo Produtivo. 180

4.4 IDENTIFICAÇÃO DE EVENTOS DE RISCOS E OCORRÊNCIAS DE FALHAS. 188

4.4.1 Classificação da Zona Crítica - ZC e Atribuição de Valores das Variáveis Binárias. 188

4.4.2 Cálculo do ICR 196

4.4.3 Análise Estatística de Falhas do Sistema Reparável - Máquina Cobrideira

4.5 SUPORTE PARA TOMADA DE DECISÃO 209

4.5.1 Análise Funcional dos Modos de Falhas Relacionados à Lubrificação Industrial 209

4.5.2 Estrutura da Política de Lubrificação Centrada em Confiabilidade 211

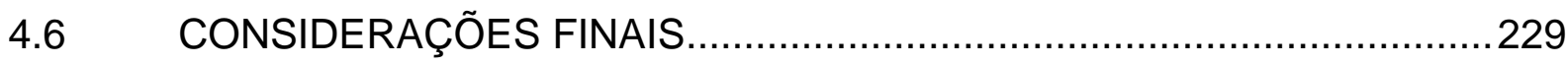

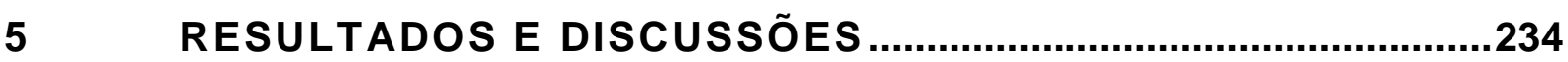

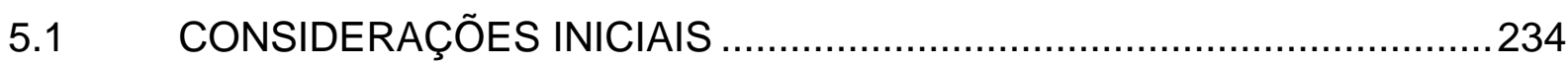

5.2 RESULTADOS QUANTO AOS INDICADORES DE DESEMPENHO DE MANUTENÇÃO E ICR DA MÁQUINA COBRIDEIRA 234

5.3 RESULTADOS QUANTO A REDUÇÃO DE CUSTOS COM EVENTOS DE FALHAS RELACIONADOS À LUBRIFICAÇÃO INDUSTRIAL 251

6 CONCLUSÕES E RECOMENDAÇÕES PARA TRABALHOS FUTUROS. 257

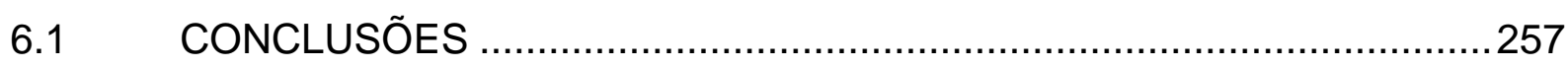

6.2 RECOMENDAÇÕES PARA TRABALHOS FUTUROS. 261 
REFERÊNCIAS.

APÊNDICE A - Dados de Falhas da Máquina Cobrideira (2010 á 2013) .279

APÊNDICE B - ANÁLISE FMEA DOS MODOS DE FALHAS RELACIONADOS

À LUBRIFICAÇÃO INDUSTRIAL - MÁQUINA COBRIDEIRA 287

APÊNDICE C - TABELA DE DADOS E INDICADORES DE DESEMPENHO DE MANUTENÇÃO DA MÁQUINA COBRIDEIRA ENTRE O PERÍODO DE 2010 À 2013 (SIMULAÇÃO DE VALORES COM A EXCLUSÃO DOS EVENTOS DE FALHAS RELACIONADOS COM O PROCESSO DE LUBRIFICAÇÃO INDUSTRIAL)

APÊNDICE D - TABELA DE DADOS E INDICADORES DE DESEMPENHO DE MANUTENÇÃO DA MÁQUINA COBRIDEIRA ENTRE O PERÍODO DE 2010 À 2014 


\section{CAPÍTULO 1 INTRODUÇÃO}

\subsection{CONSIDERAÇÕES INICIAIS}

Indústrias e organizações ligadas à fabricação de produtos alimentícios estão cada vez mais preocupadas em atender as legislações nacional e principalmente internacional nos quesitos de inocuidade e qualidade de seus produtos e processo de beneficiamento.

Este fator deve-se a competitividade de mercado, pois a logística de distribuição e abastecimento, o armazenamento, embalagem e principalmente o beneficiamento dos produtos, constituem-se de tarefas que propiciam fatores de risco para a inocuidade e qualidade do alimento.

A ocorrência de falhas em máquinas e equipamentos que compõe um processo produtivo de alimentos pode acarretar prejuízos a indústria de alimentos, pois as consequências destas falhas podem vir a impactar a qualidade do produto por meio de contaminação por resíduos químicos, físicos e/ou biológicos. A perda de qualidade consequentemente aumenta o custo do ciclo de produção de alimentos, afetando diretamente a competitividade da empresa com a perda de produto, retrabalho ou até mesmo dificuldades com a comercialização de alimentos por não atender os requisitos mínimos de qualidade.

Estabelecimentos de produção de alimentos são compostos por maquinário e instalações que executam funções durante seu funcionamento para fabricação de produtos. Para estas realizar estas funções são necessários equipamentos e componentes mecânicos e/ou rotativos que precisam de lubrificantes para garantir seu pleno funcionamento. Porém, o mesmo lubrificante que auxilia o funcionamento do maquinário oferece um risco potencial de perda de qualidade e inocuidade do produto, pois pode provocar contaminação por meio das substâncias químicas que 0 constituem.

Apesar da Engenharia de Qualidade direcionar seus esforços para implantar normas e legislações vigentes a área de produção de alimentos, nem todos os pontos críticos de controle (PCC's) fundamentados pelo sistema HACCP (Hazard 
Analysis and Critical Control Point) são de fácil identificação e monitoramento do risco, vindo o risco a existir e impactar na qualidade e integridade do produto.

Além do fator de risco potencial (como contaminante), a inadequada gestão do lubrificante conjuntamente com os procedimentos de sua aplicação (atividade de lubrificação) pode gerar falhas potenciais em máquinas e equipamentos e impactar na disponibilidade e confiabilidade desses, provocando redução de produtividade e aumento nos custos de manutenção e processo.

Assim, indústrias do ramo de alimentos devem, cada vez mais, almejar uma eficácia na gestão da manutenção do seu maquinário, com foco nas atividades de lubrificação, pois o impacto destas no processo de fabricação de alimentos pode elevar os custos produtivos e até afetar a imagem pública da empresa de forma negativa, seja por meio de atrasos na entrega de produto (devido falhas no maquinário), ou seja, por meio de contaminação (mesmo acidental) do produto.

A função da engenharia de manutenção tem um grande impacto sobre 0 faturamento de uma planta fabril, pois atua na seleção de apropriadas políticas de manutenção e análise de falhas para solucionar problemas crônicos que impactam no rendimento de máquinas e equipamentos.

Assim, a engenharia de manutenção deve gerenciar 0 processo de lubrificação em indústriais de alimentos como uma função essencial e estratégica, devendo adotar a adequada politica de manutenção e lubrificação com o propósito de cumprir os requisitos legais impostos pelos orgãos regulamentadores e fiscalizadores (em nível federal, estadual e municipal) e assim agir de forma ética com o estado e principalmente com a sociedade, assegurando a qualidade do produto e aumentando a disponibilidade das instalações industriais.

Analisando este cenário da gestão da manutenção em estabelecimentos produtores de alimentos e as legislações nacionais e internacionais impostas a este ramo de atividade, a pesquisa desenvolvida sustenta-se em dois subsistemas principais na gestão industrial: o sistema de gestão técnica de engenharia de manutenção, particularizada nas atividades de lubrificação, e o sistema de engenharia da qualidade a qual gerencia o SGQ (Sistema de Gestão da Qualidade) dentro da planta industrial.

A aplicação do método de seleção de política de lubrificação industrial permite a tomada de decisão dos adequados procedimentos que devem ser aplicados nas etapas de execução das operações envolvidas na lubrificação de modo que estas 
atividades sejam executadas cumprindo as exigências da engenharia de qualidade e, ao mesmo tempo, reduzindo a probabilidade de ocorrência de falhas no funcionamento do maquinário e risco de perda de qualidade e inocuidade do produto em suas etapas de processamento.

\subsection{DESCRIÇÃO DO SETOR INDUSTRIAL DE PESQUISA}

Indústrias de alimentos são regidas por normas e legislação oriundas do Codex Alimentarius, também chamado "Book of Food" (Código ou Livro de Alimentos), o qual fundamenta-se no sistema HACCP ( Hazard Analysis and Critical Control Points em português APPCC -Análise de Perigos e Pontos Críticos de Controle) e nas legislações nacionais vigentes oriundas de órgãos competentes como ANVISA (Agência Nacional de Segurança Sanitária) e MAPA (Ministério da Agricultura, Pecuária e Abastecimento). Estas normas e legislações estabelecem requisitos e etapas de controle e monitoramento do processo produtivo, desde o beneficiamento da matéria-prima até a obtenção do produto final como alimento inócuo e com qualidade. (FIGUEIREDO e COSTA NETO, 2001; SCHMIDT e RODRICK, 2003).

A execução da lubrificação industrial é essencial para o funcionamento de máquinas e equipamentos, porém apesar das normas e legislações impostas à engenharia de qualidade de indústrias de alimentos, caracterizarem o lubrificante como foco potencial de risco ao produto, não dispõem de procedimentos descritos de como proceder a execução das atividades de lubrificação a fim de reduzir e/ou eliminar este risco em potencial.

Os lubrificantes utilizados em maquinário instalado em indústrias de alimentos são chamados Food Grades Lubricants (Lubrificantes de Grau Alimentício), ou lubrificantes de grau alimentício. Apesar dos lubrificantes desta classe serem compostos por substâncias químicas adequadas ao ambiente de fabricação de alimentos, a aplicação inadequada e/ou a utilização de lubrificantes de classificação incorreta apresenta risco para o produto quando em contato com o mesmo, podendo acarretar contaminação química e/ou biológica do produto, levando a perda de 
qualidade do produto e/ou custo de produtividade. (HAVET et al.,2001; CARRETEIRO e BELMIRO, 2006; FITCH; GEBARIN; WILLIAMSON,2006).

A avaliação do comportamento sistema fabril de produção de alimentos em relação à lubrificação de suas máquinas e equipamentos é o fator de motivação de desenvolvimento da pesquisa. A aplicação de métodos de pesquisa como: de observação direta, estudo de campo, entrevistas, estudo bibliográfico e documental, em uma indústria de alimentos possibilitou a identificação das variáveis envolvidas no processo de lubrificação industrial do maquinário instalado em ambiente real de fabricação de alimentos.

O levantamento de dados e proximidade com o ambiente real de pesquisa deu-se em duas indústrias do ramo de alimentos de origem nacional, ambas situadas na região metropolitana de Curitiba. Por meio da observação do processo de lubrificação dessas empresas, adicionada de pesquisa bibliográfica relacionada à lubrificação industrial de maquinário empregado na fabricação alimentos e legislação nacional vigente a este tipo de indústria, obteve-se informações detalhadas sobre as particularidades do processo de lubrificação.

Estas informações e dados são aplicados para análise qualitativa e quantitativa dos impactos do processo de lubrificação na confiabilidade do processo produtivo e na qualidade do produto em processamento e/ou final, direcionando a estrutura do problema de pesquisa e desenvolvimento de método de seleção de política de lubrificação centrada em confiabilidade operacional e garantia de qualidade. Dentre as informações obtidas, elencam-se as pertinentes para análise e desenvolvimento da pesquisa:

I - Falta de conhecimento, por parte da equipe de manutenção, das legislações e normas existentes para manutenção e lubrificação em maquinário industrial para fabricação de alimentos, deixando por responsabilidade do fornecedor de lubrificantes a indicação dos lubrificantes a serem utilizados bem como a elaboração dos planos de lubrificação.

II - Falta de conhecimento e/ou displicência do setor de engenharia de qualidade industrial quanto às normas do HACCP, BPF (Boas Práticas de Fabricação, do sistema inglês GMP - Good Manufacturing Practices) e legislação quanto à 
manutenção e lubrificação de máquinas e equipamentos, deixando total responsabilidade da gestão da lubrificação por parte da equipe de engenharia de manutenção.

III - Deficiência nas normas e legislações nacionais quanto ao processo de lubrificação de máquinas e equipamentos empregados na fabricação de alimentos, o que propicia a falta de aplicação de lubrificantes de grau alimentício e/ou a incorreta aplicação destes durante a execução das tarefas de lubrificação.

IV - Custo elevado de obtenção de lubrificantes de grau alimentício (produto importado) e/ou ferramental para execução da lubrificação do maquinário industrial em comparação com os lubrificantes de ordem mineral e tóxica.

V - Falta de conhecimento e/ou treinamento do quadro técnico de execução da lubrificação quanto à lubrificação específica de máquinas e equipamentos industriais alimentícios e em geral, sendo a maioria com formação técnica em mecânica e elétrica não havendo formação e capacitação especifica em práticas de lubrificação e conhecimento de lubrificantes (aplicação em excesso e/ou falta, falta de limpeza e esterilização dos instrumentos de trabalho e do local de lubrificação).

VI - Inexistência e/ou deficiência na execução da manutenção preditiva e/ou falta de acompanhamento da evolução do comportamento dos elementos de máquina indicados nos gráficos de manutenção preditiva e nas análises dos lubrificantes, mantendo manutenção preditiva somente com intuito de auditora para manutenção de selos de qualidade.

VII - As legislações vigentes e normas de qualidade vigentes o lubrificante industrial como foco de risco de perda de qualidade e inocuidade do produto, devido risco de contaminação acidental durante a operação do maquinário. Contudo, não define, sistematicamente, como executar as atividades de lubrificação de forma a reduzir e/ou eliminar o potencial risco de perda de qualidade e inocuidade do produto que estas atividades podem propiciar, e nem mesmo, descrevem métodos de fiscalização da aplicação do correto lubrificante para cada tipo de ponto de lubrificação. 
VIII - Foco da gestão da produção na contenção de contaminantes biológicos e físicos efetuando limpeza diretamente no maquinário, sendo que durante a limpeza e desinfecção emprega-se com a utilização de água quente e/ou água pressurizada e aplicação de produtos químicos desinfetantes, processo o qual exigido por normas e legislações vigentes como na RDC no 216 (2004), emitida pelo órgão ANVISA, que regulamenta que "equipamentos, móveis e utensílios que entram em contato com alimentos devem ser de materiais que não transmitam substâncias tóxicas, odores, nem sabores aos mesmos, conforme estabelecido em legislação específica. Devem ser mantidos em adequando estado de conservação e ser resistentes à corrosão e a repetidas operações de limpeza e desinfecção".

Porém não se considera os impactos desta ação sobre o processo de lubrificação de máquinas e equipamentos, impactos como contaminação do lubrificante por substâncias químicas e/ou biológicas nocivas (perda de eficiência do lubrificante) e aumento de relubrificação, fatores que acarretam potencial ocorrência de falhas e custo com a utilização de mão de obra e insumos.

IX - Inexistência de aplicação de ferramentas de confiabilidade ao processo de lubrificação de máquinas e equipamentos beneficiadores de alimentos com intuito de redução de falhas e contaminação alimentar.

Estas informações oriundas do cenário fabril pesquisado possibilitaram relacionar particularidades do processo de manufatura, aspectos gerenciais e operacionais, que influenciam na eficácia do processo de lubrificação de máquinas e equipamentos, e motivaram a realização da pesquisa com foco no desenvolvimento de método de análise de falhas do maquinário e potencial risco a qualidade do produto (contaminação) que podem ocorrer através da execução das tarefas de lubrificação do maquinário.

O método de seleção de política de lubrificação em indústria de fabricação de alimentos visa a seleção da adequada política de lubrificação a ser implantada e direciona a uma eficaz gestão do processo de lubrificação e seus recursos empregados, direcionando para tomada de decisão das melhores práticas de execução das tarefas de lubrificação, visando garantia de qualidade do produto final 
e confiabilidade do sistema fabril, tornando-se uma ferramenta estratégica para competitividade deste ramo industrial.

\subsection{OBJETIVO GERAL}

Desenvolver método de seleção de política de lubrificação centrada em confiabilidade, objetivando a análise de potenciais falhas e riscos a qualidade e inocuidade do produto envolvidos no processo de lubrificação industrial em máquinas e equipamentos empregados na fabricação de alimentos, direcionando a tomada de decisão quanto à adequada política de lubrificação, a qual deve garantir o cumprimento de normas e legislações vigentes concomitantemente com garantia da disponibilidade e confiabilidade operacional e qualidade do produto.

A metodologia desenvolvida na tese tem por diferencial a unificação das técnicas de engenharia de manutenção e engenharia da qualidade aplicadas a um meio industrial complexo (produção de alimentos). A integração destas informações permite o desenvolvimento de um método para analisar os potenciais risco e falhas envolvidos nas atividades da lubrificação industrial aplicada em máquinas e equipamentos instalados em indústria deste segmento industrial de alimentos, as quais podem influenciar na qualidade do produto (por meio de contaminação química, física e até biológica).

O método estrutura-se com a análise de potenciais ocorrências de falhas e riscos à qualidade e inocuidade do produto que podem ocorrer pela lubrificante (contaminação química) e/ou por meio da execução das tarefas de lubrificação aplicada na área fabril, devolvendo como resposta escalas numéricas que indicam a probabilidade da ocorrência de falhas e nível de risco de contaminação do alimento que podem ser provocados e/ou intensificados com as atividades de lubrificação.

O principal objetivo do método é definir o ponto de equilíbrio entre a execução da lubrificação industrial em maquinário instalados em estabelecimentos de fabricação de alimentos e o cumprimento das normas e legislações requeridas a este ramo de atividade industrial, conferindo disponibilidade e confiabilidade ao sistema industrial. 


\subsection{JUSTIFICATIVA}

Assegurar a qualidade do produto mediante medidas higiênlco-sanitárias é o foco principal do conteúdo das normas e legislações vigentes ao ramo industrial de alimentos. Porém, para adotá-las, as empresas do ramo alimentício precisam realizar avaliações de seu processo produtivo e identificar os focos de riscos de contaminação do alimento, bem como, implantar ações e métodos para eliminá-los e ao mesmo tempo analisar as implicações de custo nas estratégias aplicadas, para mitigar e controlar os custos incorridos sem comprometer a qualidade do produto acabado.

No Brasil a indústria alimentícia cresceu 9,5\% em 2007, em torno de $\mathrm{R} \$ 240$ bilhões, ou $10 \%$ do PIB (produto interno bruto). Em franca expansão o mercado alimentício surge como potencial consumidor de óleos lubrificantes. No entanto, não se trata de um produto comum, mas sim de um produto com grande valor agregado. Para ser utilizado na indústria de alimentos o óleo lubrificante precisa atender rígidas exigências, principalmente quando as empresas exportam seus produtos para fora do país. (AZEVEDO, 2007).

Aliado custo maior para obtenção do lubrificante de grau alimentício (em comparação com o mineral comum), o Brasil ainda não possui uma regulamentação específica para lubrificantes de grau alimentício (Food Grade Lubricants) e nem mesmo procedimento detalhado para estruturar uma adequada gestão de manutenção e lubrificação (voltada ao maquinário empregado na manufatura de alimentos) em suas normativas de Boas Práticas de Fabricação e HACCP.

Normas e legislações como a portaria no 1428 MS - Ministério da Saúde (1993), portaria no 326 MS - Ministério da Saúde (1997), e portaria no 368 MAPA (1997), Resolução RDC o 275 ANVISA (2002) e resolução RDC № 216 ANVISA (2004), introduzem os conceitos de BPF e HACCP para indústria de alimentos no Brasil com o objetivo de definir parâmetros de qualidade por meio de ações higiênico-sanitárias e controle processo longo da cadeia alimentar e ainda estabelecer procedimentos de obediência aos parâmetros definidos.

Quanto à engenharia de manutenção, estas normas e legislações citadas definem os procedimentos de limpeza e desinfecção de máquinas e equipamentos, 
os tipos de materiais de construção desses a fim de impedir a contaminação direta e/ou indireta ao alimento, por meio de substâncias que possam transmitir odor, sabor e/ou interferir na integridade e qualidade do produto, durante as suas etapas de processamento.

Mesmo assim, essas normas e regulamentações não apontam procedimentos e parâmetros para estruturar um processo de lubrificação adequado ao maquinário empregado na fabricação de alimentos e nem mesmo incluem sistemática para fiscalização aos pontos de lubrificação em seus procedimentos de boas práticas (BPF) e pontos críticos de controle (PCC's), estes provenientes do sistema de gestão da qualidade e risco na fabricação de alimentos HACCP.

Adicionado a estes fatores, também não citam dentro do roteiro de implantação e fiscalização (auditoria) do sistema BPF os quesitos quanto a lubrificação de máquinas e equipamentos, apesar do lubrificante ser apontado como fator de risco/perigo de contaminação ao produto.

Tem-se por contaminante qualquer substância ou agente estranho, de origem biológica, química, física ou outras substâncias não intencionalmente adicionadas aos alimentos, que sejam considerados nocivos ou não para saúde humana ou que ainda possam comprometer a integridade e/ou qualidade do produto. (DECRETO DE LEI no 986 - MINISTROS DA MARINHA DE GUERRA, DO EXÉRCITO E DA AERONÁUTICA MILITAR 1969; PORTARIA 1428- ANVISA, 1993, PORTARIA no 326- MS, 1997; CAC/RCP REV.3,1997; RDC 216 - ANVISA,2004).

E aditivo incidental a toda substância residual ou migrada presente no alimento em decorrência dos tratamentos prévios a que tenham sido submetidos a matéria-prima aumentar e o alimento in natura e do contato do alimento com os artigos e utensílios empregados nas suas diversas fases de fabricação, manipulação, embalagem, transporte ou venda. (DECRETO DE LEI ํo 986 MINISTROS DA MARINHA DE GUERRA, DO EXÉRCITO E DA AERONÁUTICA MILITAR, 1969).

Um produto com qualidade não pode apresentar substâncias estranhas a sua composição e estar suscetível a agentes contaminantes que possam alterar a sabor, odor e/ou coloração, sendo, em um processo de fabricação de alimentos, a gordura e o açúcar as substâncias que mais absorvem odores e trazem cheiro para o alimento. (DEMAN, 1999; ASQ - AMERICAN SOCIETY for QUALITY: FOOD, DRUG, and COSMETIC DIVISION, 2014). 
Neste aspecto, o lubrificante industrial torna-se um risco á qualidade do produto como foco de contaminação, a qual pode ocorrer tanto pelo contato incidental (aditivo incidental) quanto pela utilização de classificação imprópria para o ambiente de fabricação de alimento, como o caso de lubrificantes minerais comuns (tóxicos), assim podendo inferir na cor, sabor, odor e até na composição do produto durante o processo produtivo.

Esta contaminação por lubrificante (alteração da composição, sabor, odor, entre outros), pode ser originada de vazamentos, provocando contaminação química no produto, além do potencial risco de contaminação biológica promovendo meio para o crescimento de microorganismos (leveduras e fungos,entre outros). (WILLIANSON, 2003; GRESHAM e TOTTEN, 2009).

Assim, o lubrificante necessário para funcionamento do maquinário também pode se tornar um risco de contaminação do alimento, onde um acidente grave pode exigir de uma empresa fazer um recall do produto em massa e/ou proporcionar a perda total de lotes de produtos acabados, o que poderia ser devastador à imagem $\mathrm{e}$ às finanças da empresa (RAJEWISKI; FOKENS; WATSON, 2000; HODSON, 2004).

Gebarin (2009) e Koel (2012),apontam alguns casos de contaminação de alimentos ocasionados por meio de lubrificação inadequada e/ou utilização de lubrificante de classificação incorreta:

I - Em 2000, a Farmland Foods Incorporation situada na cidade de Kansas nos EUA, recolheu do mercado 39.000 quilos de produtos de peru fatiado e embalado, devido a exposição do produto a um lubrificante que não fazia parte da grade (grau de alimentos) alimentícia. Os consumidores relataram que o produto apresentava odor e sabor não característicos e alguns consumidores que ingeriram o produto apresentaram desconforto intestinal temporário.

II - Em 1 de setembro de 2000, o conselho municipal de saúde da cidade de Stokeon-Trent no Reino Unido, confirmou que o teste em uma lata de alimento para bebê revelou uma substância tóxica. As investigações indicaram que uma lata deste produto fabricado pela empresa Heinz, foi contaminada com lubrificante de óleo mineral, possivelmente a partir de uma máquina que apresentava vazamento durante o processo de fabricação. Uma mãe reclamou que a comida tinha cheiro de alcatrão e alertou o órgão oficial da saúde local. 
III - Em novembro de 2002, um carregamento de refrigerantes foi recolhido devido à contaminação por lubrificante tóxico. O produto era "Big Thirst" distribuído através da NQR Grocery, em Victoria na Austrália. A secretaria de vigilância sanitária australiana indicou que a quantidade de lubrificante presente no refrigerante poderia provocar irritação se consumido.

IV - Em 2002, ARINCO, um fabricante de leite em pó em Vidabaek na Dinamarca, encontrou contaminação no seu produto. Um total de 1.100 toneladas de leite em pó fabricado entre 03 de janeiro e 28 de junho de 2002, foram contaminados por metade a três quartos de um litro de óleo lubrificante contendo finas partículas de ferro. Isto foi descoberto quando um cliente na Tailândia reclamou que o leite em pó tinha uma tonalidade cinza claro. A empresa fez a rastreabilidade deste lote e indicou que a contaminação ocorreu durante o processo de embalagem, onde havia um eixo desgastado na caixa de engrenagens, provocando vazamento de óleo mineral de grau não alimentício que entrou em contato direto com o produto.

No Brasil não existem regras específicas para lubrificantes de grau alimentício e os agentes envolvidos parecem não possuir condições suficientes para fiscalizar este setor. A ANVISA define apenas que as indústrias alimentícias devem seguir Boas Práticas de Fabricação (BPF). Já a ANP (Agência Nacional do Petróleo), para registrar um lubrificante de grau alimentício, solicita o registro do produto na organização sanitária dos Estados Unidos, a NSF (National Sanitization Foundation)." (BNDES, RELATÓRIO POTENCIAL DE DIVERSIFICAÇÃO DA INDÚSTRIA QUÍMICA BRASILEIRA - PARTE 3 ÓLEOS LUBRIFICANTES, 2014).

Este cenário possibilita que muitas indústrias brasileiras (do ramo de alimentos) utilizem lubrificantes minerais (tóxicos) comuns ou empreguem o lubrificante de grau alimentício de modo inadequado, ou ainda, não tenham obrigatoriedade de manter uma política de lubrificação adequada, gerando assim um potencial risco à perdade de qualidade e inocuidade do produto por meio de vazamentos, gotejamentos, excesso de lubrificante, entre outros.

Além disto, os órgãos competentes não dispõem de procedimentos direcionados a auxiliar a indústria de alimentos a estruturar uma adequada política de lubrificação, cconsequentemente, descritas em regulamentações, não há 
penalidades (sanções) quanto a infração relacionada aos métodos de gestão da lubrificação e lubrificantes em ambiente industrial

Logo, "o resultado desta lacuna regulatória é, de acordo com especialistas, que muitas fábricas brasileiras de alimentos não obedecem à determinação internacional de utilizar lubrificantes específicos food grades. Com regras mais claras e fiscalização mais rigorosa, as empresas que operam no ramo de alimentos teriam de se adequar". (BNDES, RELATÓRIO POTENCIAL DE DIVERSIFICAÇÃO DA INDÚSTRIA QUÍMICA BRASILEIRA - PARTE 3 ÓLEOS LUBRIFICANTES, 2014).

Normativas e manuais emitidos pelos órgãos ANVISA e MAPA, consideram uso de óleo minerall branco (white oils) na lubrificação de máquinas e equipamentos empregado em fabricação de alimentos referenciando que estes são aprovados pelo pelo Code of Regulations dos EUA (Code de Regulamentações dos Estados Unidos), ou seja, direciona para as regras contidas no parágrafo de Título 21 do Código de Regulamentações Federais formando as diretrizes da FDA ( Agência Americana de Medicamentos e Alimentos - Food and Drug Administration) (RDC 77 - ANVISA, 2000).

Evidencia-se que as regulamentações nacionais, também não apontam claramente os tipos de lubrificantes de grau alimentício e nem mesmo apresentam um procedimento para aplicação destes lubrificantes food grades que contemplem informações essenciais como: onde aplicar, quais tipos de equipamentos, quais tipos de riscos, quais métodos de monitoramento, entre outros argumentos necessário para uma adequada gestão da lubrificação dentro da indústria de alimentos.

Em face a este cenário, o método de seleção de política de lubrificação voltado ao maquinário empregado em indústrais de alimentos, justifica-se por construir uma metodologia de análise quantidade e qualitativa dos impactos das ocorrências de falhas trazem ao processo produtivo e os riscos que podem inferir na qualidade e inocuidade do produto durante as suas etapas de fabricação.

Trata-se de uma ferramenta gerencial, aplicada a tomada de decisão, nos aspectos relacionados a qualidade produto e na disponibilidade do maquinário industrial para produção de alimentos.

O método visa direcionar a ações que estruturem uma adequada política de lubrificação industrial que identifique os pontos críticos das atividades de lubrificação (variáveis envolvidas nestas atividades) e institua ações para monitorá-los com propósito de garantir confiabilidade e disponibilidade as instalações industrais 
concomitantemente com a gestão de risco (ao produto) relacionada as essas atividades.

Fundamentalmente, o método visa estruturar uma sistemática que gerencie o processo de lubrificação de modo que atendam ao SGQ (Sistema de Gestão da Qualidade) da empresa (baseado em legislações normas higiênico-sanitárias vigentes) promovendo qualidade ao produto e ao mesmo tempo reduza, ou até elimine, as ocorrências de falhas nas instalações industriais, melhorando os índices de confiabilidade e manutenção do maquinário, sendo este o principal objetivo da engenharia de manutenção.

\subsection{RELEVÂNCIA DA PESQUISA QUANTO À INOVAÇÃO TECNOLÓGICA}

Atualmente as indústrias de alimentos possuem o desafio de atender as legislações e normas de higiene e práticas de fabricação de alimentos ditadas pelos sistemas HACCP e BPF, ambos recomendados pelos órgãos competentes em nível federal (ANVISA e MAPA) conjuntamente com a redução de custos no processo e aumento de produtividade, a fim de conseguir acompanhar a competitividade de mercado em seu ramo de atuação.

Os mesmos métodos de higienização e limpeza que eliminam os focos de perigos e riscos aos alimentos colaboram com o aumento de ocorrência de falhas, por meio de sua interferência nas propriedades do lubrificante, reduzindo seus benefícios ao funcionamento do equipamento ao qual foi aplicado.

Em contrapartida, a aplicação de lubrificante de classificação incorreta e/ou de modo inadequado ou até da aplicação de um lubrificante mineral comum, fato que propiciar um risco à qualidade e inocuidade do produto por meio de uma possível contaminação, podendo levar até o descarte do produto e/ou desperdício de embalagem.

Mediante estes fatores, a pesquisa em questão propõe um método que objetiva a redução de falhas em máquinas e equipamentos aplicados na produção de alimentos, bem como, reduzir e/ou eliminar o foco de potencial risco que as 
atividades de lubrificação pode acarretar a qualidade e inocuidade do produto, apresentando como inovação tecnológica os seguintes aspectos:

I - Método que visa analisar as variáveis envolvidas no processo de lubrificação de máquinas e equipamentos e direcionar a uma sistemática de execução de tais tarefas de modo a equilibrar o cumprimento dos requisitos de higiene e boas práticas de fabricação (HACCP e BPF) e ao mesmo tempo prover confiabilidade e disponibilidade no funcionamento do maquinário industrial;

II - Criação de um método de seleção de política de lubrificação que atua de forma eficaz na análise e representação de falhas nos equipamentos envolvidos, devolvendo como resposta um indicador da criticidade de confiabilidade e risco à qualidade e inocuidade do produto relacionado à execução da tarefa de lubrificação;

III - Método que analisa e identifica os pontos críticos de controle relacionados ao processo de lubrificação em zonas de criticidade, nas quais indicam-se o lubrificante adequado a aplicação do maquinário;

IV - Desenvolvimento de uma ferramenta gerencial, que visa analisar os aspectos dos riscos da execução das atividades de lubrificação industrial no segmento alimentício, atribuindo indicador à criticidade de cada procedimento de trabalho.

\subsection{ESTRUTURA DO TRABALHO}

A presente tese está organizada em cinco capítulos, com as seguintes estruturas de tópicos:

I - Capítulo 1: descreve o enquadramento do tema ao ambiente da pesquisa e os objetivos e contribuições da tese, bem como sua inovação tecnologia, conjuntamente com a classificação da metodologia aplicada no desenvolvimento do trabalho. 
II - Capítulo 2: compõe-se a fundamentação teórica dos conceitos aplicados no desenvolvimento da tese, compõe-se de tópicos como introdução a manutenção industrial, sua função estratégica no meio industrial e o aprofundamento da relação dos aspectos da gestão da qualidade e legislação sanitária aplicada à gestão da lubrificação do maquinário fabril de produtos alimentícios. Também fundamenta a MCC - Manutenção Centrada em Confiabilidade (RCM - Reliability Centered Maintenance), as etapas a serem seguidas para sua execução conjuntamente com o detalhamento das ferramentas e métodos utilizados na estrutura da MCC, além dos métodos estatísticos aplicados na análise de falhas e riscos envolvidos no processo fabril e característicos a área industrial de alimentos.

III - Capítulo 3: descrição do método baseado na análise de falhas e potencial risco de perda de qualidade e inocuidade do produto (alimento) relacionados ao processo de lubrificação industrial proposto como pesquisa. Neste capítulo detalham-se as fases de desenvolvimentos do método de seleção de política de lubrificação centrada em confiabilidade e a comparação de suas particularidades diante dos outros métodos de análise de falhas existentes, demonstrando a sua inovação tecnológica e aplicabilidade.

IV - Capítulo 4: apresenta o detalhamento da realização da pesquisa, englobando as etapas de levantamento e organização de dados, análise de falhas e riscos envolvidos com as práticas de lubrificação em meio industrial de fabricação de alimentos. Também se detalha a estrutura da sistemática para análise e criação de níveis de classificação das atividades da lubrificação, e por final o teste para validação e ressalvas quanto a eficácia da ferramenta na tomada de decisão.

V - Capítulo 5: neste capitulo são apresentados os resultados e discussões da aplicação do método, bem como, seus pontos fortes e a serem melhorados para seu melhor desempenho na análise de falhas e riscos para aumento de confiabilidade de produto e processo. 
VII - Capítulo 6: por final apresentam-se as conclusões da pesquisa desenvolvida, bem como, propostas para trabalhos futuros, visando continuação ao desenvolvimento do tema dentro da área de pesquisa. 


\section{CAPÍTULO 2 FUNDAMENTAÇÃO TEÓRICA}

\subsection{MANUTENÇÃO INDUSTRIAL}

A abertura comercial, proveniente da globalização mundial, acirrou a competitividade industrial. As indústrias e corporações, para ganhar mercado e manter-se atuante dentro de seu ramo de atividade, direcionam seus esforços para obtenção de produção em larga escala, com máxima qualidade e buscando redução de custo a fim de obter maior faturamento e possibilitando novos investimentos para ampliação do negócio.

Para alcançar o ganho de produtividade em busca de aumento de competitividade da empresa, é necessário analisar todos os fatores que a influenciam, visando o controle e atuação sobre as variáveis do processo, obtendo confiabilidade do processo industrial. A interrupção do funcionamento do parque fabril em momentos inoportunos impacta drasticamente na produção de bens de consumo e serviços, gerando perdas irrecuperáveis perante o concorrente, pois são agregados ao valor final do produto os custos adicionais relativos a: despesas associadas ao conserto do maquinário, valor de mão de obra aplicada, matéria prima inutilizada e/ou retrabalhada, consumo energético, entre outros, influenciando em sua competitividade dentro do mercado em que atua. (TAVARES, 2001; MISHRA, 2006).

A produção é o processo pelo qual se beneficia matéria prima transformandoa em produto acabado, o qual é distribuído ao consumidor. Para executar as operações necessárias à transformação desta matéria prima é preciso o funcionamento de uma complexa cadeia de máquinas e equipamentos, os quais apresentam falhas e defeitos com o aumento de tempo de utilização. Tal situação cria a necessidade da execução de atividades de manutenção de forma contínua e eficaz para o ganho de produtividade e competitividade das organizações.

De acordo com Narayan (1998), Branco Filho (2004) e Kardec e Nascif (2009), manutenção industrial é definida como sendo o conjunto de ações 
responsáveis para a preservação ou restauração da função pretendida de um determinado processo com o menor custo total possível.

Mobley, Higgins e Wikoff (2008) complementam que a manutenção industrial deve ser considerada como uma ciência, desde a sua execução até a análise das causas falhas. Pode ser considerada uma arte porque os problemas aparentemente idênticos demandam e recebem várias abordagens de análise e ações diferenciadas para correção, além da mão-de-obra técnica empregada nas atividades de manutenção apresentar perfil e maior aptidão para esta função do que os demais integrantes do sistema produtivo.

A manutenção deve atender às necessidades do processo produtivo de forma a melhorar o desempenho da máquina e a qualidade do produto fabricado, sempre buscando aperfeiçoamento contínuo e combatendo os desperdícios.

Pode-se considerar, num sentido mais amplo, que o objetivo da manutenção não é somente o de manter ou restaurar as condições físicas do equipamento, mas também manter suas capacidades funcionais (o que o equipamento pode fazer) almejando confiabilidade.

\footnotetext{
"A manutenção, como um sistema, desempenha um papel fundamental para alcançar metas e objetivos organizacionais. Contribui para a redução de custos, minimizando o tempo de quebra do equipamento, melhorando a qualidade, aumentando a produtividade, e o fornecimento confiabilidade a máquinas e equipamentos, garantindo $o$ atendimento a prazos de produção e entrega aos clientes". (DUFFUAA; RAOUF; CAMPBELL, 1999).
}

Assim a Manutenção Industrial não só restabelece o funcionamento de máquinas e equipamentos, mas torna-se função estratégica dentro da organização, como fator capaz de oferecer um diferencial competitivo às empresas. (LEVITT, 1997; PALMER, 1999 apud ALVES e FALSARELLA, 2009).

Com a exigência de aumento de qualidade e agilidade de entrega de produtos e serviços pelos consumidores, a manutenção passou a ser um elemento fundamental no desempenho de máquinas e equipamentos, visando à redução de custos e garantia da qualidade através da confiabilidade e produtividade do maquinário industrial, evitando a ocorrência de falhas que interrompem o funcionamento da instalação fabril de máquinas e equipamentos.

Para aumentar a produtividade e obter confiabilidade no processo através da manutenção industrial, as atividades relacionadas a esta função devem ser 
gerenciadas. Controlar e gerenciar a manutenção envolve a utilização de métodos e controle para execução das atividades, planejamento de mão de obra e insumos aplicados, além da utilização de técnicas para aumentar o desempenho operacional de máquinas e equipamentos, almejando a redução de falhas e o aumento de disponibilidade do maquinário para produção.

A gestão da manutenção é motivada pela busca de redução de custos através do aumento de disponibilidade e confiabilidade e pela busca da anulação das falhas que provocam intervenções não programadas no maquinário e instalação industrial, impactando na produtividade final.

A organização e administração da manutenção também pode ampliar o tempo de vida útil dos equipamentos através de ações que retardam a degradação dos elementos que os compõem, além de propiciar o aumento de qualidade $\mathrm{e}$ produtividade de produtos acabados com a ação de evitar reprocesso e/ou retrabalho destes.

\subsubsection{Classificação da Manutenção Industrial}

A forma mais recorrente de manutenção aplicada desde a revolução industrial é a manutenção corretiva. Esta ocorre geralmente de forma não planejada (em alguns casos é possível efetuar manutenção corretiva planejada por meio de identificação inicial da falha) e constitui-se de atividades rotineiras. As ações corretivas têm por finalidade reestabelecer a capacidade funcional do maquinário industrial dentro dos parâmetros requeridos, após a ocorrência de falhas envolvendo a interrupção na produção e/ou redução no desempenho de máquinas e equipamentos. (NARAYAN, 1998; TAVARES, 2001; PERCY, 2008; YADAVA e DESHMUKH, 2011).

Para Viana (2002) e Kardec e Nascif (2009), a manutenção corretiva é necessária em casos de ações imediatas a fim de evitar consequências graves ao maquinário e instalações industriais que possam impactar na segurança da integridade pessoal dos trabalhadores e/ou ao meio ambiente.

Este tipo de manutenção impacta no custo de manutenção devido a perda de produtividade e, geralmente, envolve troca de peças, além de não eliminar a causa 
raiz da falha podendo esta ter probabilidade de reincidência. Uma das metas da gestão de manutenção é minimizar estas ações corretivas, através da aplicação de métodos de análise para a identificação das ocorrências que geram manutenção corretiva e se possível atuar sobre a cauza raiz das mesmas antes de se concretizar a falha efetivamente.

Outro tipo de manutenção utilizada no meio industrial é a preventiva. Branco Filho (2004), Mobley, Higgins e Wikoff (2008) classificam a manutenção preventiva como sendo a realização de ações que visam reduzir e/ou evitar a falha ou a queda no desempenho, obedecendo a um plano previamente elaborado baseado em intervalos definidos de tempo.

\begin{abstract}
"A manutenção preventiva (PM) é realizada em intervalos regulares, para manter o sistema para boas condições de operação. As ações preventivas são usadas para controlar o processo de degradação e reduzir a probabilidade de ocorrência de falha. Inspeção, limpeza, lubrificação, ajuste e calibração, substituição de componentes degradados e grandes revisões (como grandes paradas para manutenção geral) são algumas tarefas comuns que são realizadas no âmbito da PM. O efeito da acão de PM é para melhorar a confiabilidade do equipamento, através da redução da intensidade de falhas e aumento da vida útil do maquinário". (MURTHY e PONGPECH, 2008).
\end{abstract}

As atividades de manutenção preventiva têm por objetivo evitar a deterioração de componentes do maquinário, mantendo o equipamento em boas condições de funcionamento. Um programa de manutenção preventiva eficaz alcança o aumento de disponibilidade e confiabilidade do sistema produtivo (EDWARDS; HOLT; HARRIS, 1998).

A incapacidade de realizar tarefas de manutenção preventiva (inspeções, lubrificação, calibrações, ajustes, etc.) em tempo hábil e com recursos adequados e de forma otimizada, impossibilita sustentar a confiabilidade do funcionamento do maquinário, além de aumentar os custos de manutenção, sendo assim um investimento sem retorno.

"A eficiência e eficácia do sistema de manutenção preventiva desempenha
um papel central no sucesso e capacidade de sobrevivência da
organização. Por isto estas atividades devem ser planejadas e
controladas, evitando falhas e reduzindo custos. Para a maioria das
empresas, os custos de manutenção são uma parte significativa do custo
operacional total. Além disso, a ocorrência de avarias que provocam
tempo de inatividade no sistema produtivo tem impacto sobre a
capacidade de produção da instalação industrial, a qualidade do produto, e 
custo de produção, bem como saúde, segurança e meio ambiente". (PARIDA; KUMAR, 2006).

Por último tem-se a manutenção preditiva ou manutenção preventiva por condição, a qual tem por conceito o conjunto de ações e atividades de acompanhamento das variáveis ou parâmetros com a aplicação de modernas tecnologias e métodos que indicam as condições, de modo sistemático, de operação de máquinas e equipamentos, visando definir a necessidade ou não de intervenção de manutenção. (YADAVA e DESHMUKH, 2011).

Assim, a execução de reparo e/ou conserto ocorre em um momento ideal prédeterminado, utilizando o máximo da vida operacional do elemento de máquina e evitando a intervenção de conserto desnecesária no maquinário, contribuindo com a redução de custos em mão de obra e troca de peças e/ou insumos, além de evitar tendência a defeitos, estes muitas vezes ocasionados por excesso de ações de manutenção.

As técnicas de manutenção preditiva oferecem informações valiosas em relação ao estado de funcionamento e conservação do maquinário. Apesar do custo inicial de investimento em instrumentos e mão-de-obra qualificada para realização destas atividades, a viabilidade financeira de monitoramento do estado de operação do equipamento visa reduzir os custos de manutenção. (EDWARDS; HOLT; HARRIS, 1998; KARDEC e NASCIF, 2009).

A aplicação da correta abordagem de manutenção em máquina e equipamentos, mediante suas particularidades, é de fundamental importância para atingir confiabilidade no sistema fabril e aumentar a disponibilidade operacional do maquinário a um custo de manutenção adequado e se possível reduzido.

\subsubsection{Engenharia de Manutenção}

As empresas, em busca de maior desempenho para produtividade, constantemente buscam modernizar máquinas e equipamentos e evoluir a gestão de manutenção para obter o máximo de seu rendimento operacional. Com esta atual complexidade do sistema industrial, a gestão da manutenção teve crescente importância devido ao aumento do número de máquinas e equipamentos, fazendo- 
se necessária a gestão técnica e financeira dos ativos envolvidos na produção de bens de consumo e serviços, bem como a aplicação de métodos e ferramentas para aumentar a disponibilidade e confiabilidade ao maquinário fabril, através da engenharia de manutenção.

Mjema (2002), Ahuja e Khamba (2008) argumentam que a gestão da manutenção de máquinas e equipamentos tem recebido atenção significativa durante os últimos anos na indústria de transformação devido a característica dinâmica da mudança constante que o complexo industrial sofre e o custo crescente de bens de capital. Estes fatores impactam diretamente na competitividade da empresa e assim tem aumentado a importância da confiabilidade e disponibilidade dos equipamentos envolvidos no processo produtivo, fazendo-se necessário cada vez mais gerenciar as atividades de manutenção com qualidade e com custo reduzido, com intuito de atender as metas da organização.

Conforme Dhillon (2002) e Kelly (2006), apesar dos métodos de gestão da manutenção industrial terem avançado desde a revolução industrial até a atualidade, ainda é um desafio o controle do custo e a complexidade técnica e das ações humanas envolvidas nas atividades de manutenção.

Há uma clara necessidade de estruturação da engenharia de manutenção no âmbito industrial, para gerenciar os ativos e práticas de manutenção, pois esta função influencia positivamente fatores críticos no meio industrial, tais como a inocuidade, a qualidade do produto, preço, rentabilidade e entrega do produto acabado em tempo confiável. Logo, a engenharia de manutenção torna-se uma vantagem competitiva, pois influencia positivamente na qualidade total do produto final e na estrutura de custos gerais da organização.

A engenharia de manutenção é a função da manutenção que aplica conceitos técnicos de manutenção, qualidade e tecnologias disponíveis, para a otimização dos recursos humanos e materiais envolvidos na manutenção de máquinas e equipamentos conjuntamente com o controle dos custos aplicados nas atividades na manutenção, com o objetivo de aumentar disponibilidade, mantenabilidade e garantem a confiabilidade no sistema industrial. (DHILLON, 2002; MOBLEY, 2004; KOBBACY; MURTHY e PRABHAKAR, 2008). 
"......a automação e mecanização dos processos de produção deslocou grande parte do trabalho humano para as máquinas. Consequentemente, a qualidade do processo, o desempenho do maquinário bem como o controle e otimização das atividades de manutenção e seus custos aplicados nunca foi tão essencial. Para obter o máximo de rendimento do maquinário industrial, este deve operar dentro dos parâmetros estabelecidos em projeto e requeridos pela produção, somente a ligação entre a qualidade do serviço de manutenção executado e o gerenciamento adequado dos custos e insumos envolvidos na manutenção são capazes de proporcionar este objetivo". (BEN-DAYA e DUFFUA, 1995).

A engenharia de manutenção faz a ligação entre a aplicação de métodos e ferramentas da qualidade e atividades técnicas de manutenção (preventiva, corretiva, preditivas, TPM, RCM, entre outros) com auxílio de conhecimentos estatísticos e financeiros objetivando a redução de falhas obtendo confiabilidade e disponibilidade do maquinário fabril com custos adequados a realidade financeira da empresa. (CABRAL, 2006; BERTOLINI; BEVILACQUA e MASON, 2006; PARIDA e KUMAR, 2006; LEE e WANG, 2008; SILVA; MATIAS e CABRITA, 2008).

Ainda Kister e Hawkins (2006), Mishra (2006), Heisler (2008) e Dabbs (2008), completam que a engenharia de manutenção tem por finalidade assegurar que as técnicas de manutenção sejam eficazes para assegurar mantenabilidade $\mathrm{e}$ disponibilidade operacional, tendo assim como principais responsabilidades:

Otimização dos serviços de manutenção;

Avaliação, de forma eficaz, das necessidades em termos de materiais e de mão de obra para uma manutenção;

$>$ Revisão da adequação dos materiais de reparo e/ou serviços em geral utilizados na manutenção;

Determinação das peças críticas e a adequação do estoque de peças sobressalentes;

Avaliação das necessidades em termos de qualificação técnica e profissional do pessoal de manutenção;

$>$ Elaboração de instruções de trabalho e/ou procedimentos para execução de atividades críticas e especializadas, a fim de padronizar as etapas de execução, reduzindo tempo e probabilidade de erro durante a execução; 
> Avaliação das necessidades em termos de renovação de equipamentos e estabelecimento de cronograma do projeto de renovação;

Assegurar mantenabilidade das novas instalações e equipamentos industriais; Identificação e correção de problemas crônicos e custosos de máquinas e equipamento;

Assessoria técnica para manutenção e produção;

Elaborar e monitorar um programa de manutenção preventiva (inspeções, ajustes, limpeza, substituições de peças, revisão, etc.) eficaz e economicamente viável;

Implantar, monitorar métodos, metodologias e/ou ferramentas ligadas a melhoria contínua da manutenção como TPM (Total Productive Maintenance ou Manutenção Produtiva Total), RCM (Reliability Centered Maintenance) Manutenção Centrada na Confiabilidade, programa de manutenção preditiva (como vibração, ferrografia, termografia e outras análises preditivas necessárias), e-maintenance, entre outros;

Garantir apropriada operação e cuidados para os equipamentos, bem como, garantir a proteção de equipamentos de condições ambientais adversas;

Estabelecer um programa de lubrificação eficiente;

Manter e analisar dados de falhas repetitivas e crônicas provenientes dos registros e histórico de máquina para prover ações que confiram confiabilidade ao maquinário industrial e consequentemente ao processo;

> Monitorar a eficácia dos treinamentos relativos a manutenção;

$>$ Elaborar, monitorar e analisar os indicadores de desempenho de manutenção;

Identificação e eliminação dos riscos em termos de segurança associados à manutenção e ao processo.

Estruturar uma base adequada de engenharia de manutenção e aplicar os seus conceitos significa deixar de executar reparos continuadamente e reduzir e/ou eliminar as causas básicas que ocasionam as falhas.

Modificar situações permanentes de perda de desempenho do maquinário e assim evitar a ocorrência de problemas crônicos, melhorar padrões e sistemáticas de análise de causa raiz de falhas e execução de tarefas, desenvolver e prover mantenabilidade e confiabilidade as instalações e maquinário fabril, gerenciar 
eficientemente os custos envolvidos nas atividades de manutenção, perseguindo melhoria continua através do desempenho indicado nos indicadores ligados à manutenção industrial são os objetivos da engenharia de manutenção dentro de um sistema fabril.

\subsection{LUBRIFICAÇÃO INDUSTRIAL}

A manutenção industrial tem como principal característica assegurar a confiabilidade e a disponibilidade da função dos equipamentos e instalações de modo a atender a um processo de produção ou de bens de serviço, com segurança e preservação do meio ambiente a custos adequados. (MOBLEY, 2004; KARDEC e NASCIF, 2009).

Os elementos de máquinas requerem lubrificação, pois eles formam superfícies que movem respectivamente uma a outra, deslizando, rolando, avançando ou retrocedendo. Caso ocorra o contato direto entre as superfícies, o atrito gerará altas temperaturas nas mesmas e possivelmente o desgaste ou avaria acontecerá. Logo a interposição de um lubrificante entre essas superfícies previne ou reduz o contato direto entre elas, sem lubrificação, a maioria das máquinas funcionaria por curto período de tempo e logo interromperiam sua operação. (PIRRO e WESSOL, 2001).

Lansdown (2004) e Castle (2006) complementam que o principal causador de falhas mecânicas é o atrito, porém com a execução adequada da lubrificação entre as partes móveis de elementos de máquina, a fricção tende a ser reduzida ao máximo, logo ter um processo de lubrificação ativo significa reduzir o risco de ocorrência de falhas por atrito entre as partes metálicas do maquinário industrial.

Mobley (2004), Lansdown (2004), Palmer (2006) e Mang e Dresel (2007) definem a lubrificação como uma forma de manutenção preventiva que interpõe um fluido lubrificante entre superfícies deslizantes metálicas, proporcionando redução de atrito e do desgaste e tendo como benefício a diminuição de falhas e o aumento de disponibilidade de máquina. 
Além disto, a lubrificação abrange uma vasta gama de atividades relacionadas com óleo, graxa, filtros, tratamento de lubrificantes, equipamentos de lubrificação, respiradores, análise de óleo, armazenamento de lubrificantes e dispositivos de lubrificação, bem como, o gerenciamento destas atividades e controle de insumos, ferramentas e mão de obra aplicada.

As atividades de lubrificação são as de maior importância dentre as responsabilidades do setor de manutenção em um ambiente fabril, pois além de propiciar o funcionamento de elementos mecânicos, aumentam a disponibilidade do maquinário e reduzem custos de manutenção, uma vez que estão diretamente relacionadas com a vida dos elementos mecânicos e a integridade de máquinas e equipamentos.

\footnotetext{
"A lubrificação industrial aparece como uma forma primitiva de manutenção preventiva que, quando administrada de forma correta, aumenta a disponibilidade das máquinas, definindo-se assim como uma ferramenta eficaz na diminuição de custos e aumento de produtividade nas indústrias". (CARRETEIRO e BELMIRO, 2006).
}

Para Mobley (2004), Dressel (2007) e Alverson et al. (2008), gerenciar as atividades de lubrificação é importante para o aumento de confiabilidade do sistema fabril, pois o máquinário moderno automatizado é de maior precisão em produtividade, assim requer um sistema de lubrificação adequada e eficaz. Um planejamento correto das ações de lubrificação, bem como, de seus insumos e técnicas de execução irá reduzir a probabilidade de ocorrência de falhas, evitando reparos, tempo de inatividade do maquinário e perda de produção.

De acordo com Silva e Wallbank (1998), a redução do desgaste e o aumento de disponibilidade trazem consigo o aumento da vida útil do maquinário e melhor eficiência no seu funcionamento, proporcionando crescimento na taxa de produtividade da empresa.

O planejamento da lubrificação em uma empresa deve agregar valor a produção através da otimização dos serviços de lubrificação, reforçando melhores práticas de manutenção que tangem a redução de paradas de máquinas e melhoria no desempenho do maquinário durante a fabricação do produto.

Segundo Mobley (2004), Lansdown (2004) e Neale (2006), a lubrificação como uma das funções bases da manutenção industrial tem por objetivo:

> Proporcionar funcionamento do sistema mecânico; 
> Transformar o atrito sólido em atrito fluido, evitando assim a perda de energia;

$>$ Controlar $\mathrm{o}$ atrito;

> Controlar o desgaste;

$>$ Controlar a temperatura (líquido refrigerante);

> Controlar a corrosão;

$>$ Proporcionar isolamento (elétrico);

> Transmitir potência em sistemas hidráulicos;

$>$ Redução de consumo energético;

$>$ Amortecer choques (amortecedores, engrenagens);

> Agir na remoção de contaminantes (limpeza);

> Aumentar o tempo de vida útil do equipamento;

$>$ Formar vedação (graxa).

Também se deve acompanhar a execução das atividades de lubrificação através de indicadores com a finalidade de avaliar e melhorar um serviço existente. Uma vez estruturado um sistema de gestão da lubrificação industrial, o resultado deve incluir uma redução de custos na lubrificação e uma melhoria da disponibilidade em linhas de produção. (PEENS, 2007).

Para que os objetivos (alcançar confiabilidade e disponibilidade) da lubrificação se concretizem é necessário que a execução de suas tarefas seja gerida adequadamente sob os aspectos de procedimentos, recursos materiais e humanos envolvidos. Devem-se manter boas práticas de lubrificação, estas definidas, pela aplicação do lubrificante adequado, respeitando tanto a quantidade a ser aplicada quanto o intervalo de relubrificação, caso contrário ao invés de benefícios a lubrificação industrial pode trazer prejuízos tanto como a perca de produtividade, aumento de custos e redução do tempo de vida útil e de máquinas e seus elementos mecânicos.

\subsubsection{Gestão da Lubrificação Industrial}

Sistemas produtivos empregam máquinas e equipamentos na fabricação de seus produtos e/ou serviços, os quais necessitam da aplicação de lubrificantes para 
o seu funcionamento dentro de parâmetros pré-estabelecidos, para aumento de produtividade e competitividade.

As organizações buscam sempre alcançar um ponto de equilíbrio entre o aumento da produtividade e a estabilidade financeira dos custos diretos e indiretos aplicados no sistema produtivo, assim faz-se necessária a administração destes custos através do correto gerenciamento das atividades envolvidas na área de manufatura, sendo que a lubrificação é uma destas atividades.

Carreteiro e Belmiro (2006), Palmer (2006) e Peens (2007), corroboram com o conceito que a adequada gestão da lubrificação industrial deve buscar 0 monitoramento e o controle dos recursos técnicos e materiais, tais como: lubrificantes, mão de obra e dispositivos de aplicação (ferramental); sendo a execução das atividades de lubrificação em si, fundamentada nos planos preventivos e procedimentos de manutenção.

As atividades de lubrificação devem ser planejadas e programadas, seguindo um roteiro de atividades estruturado em um plano preventivo, qual sendo realizado dentro de uma adequada gestão, pode minimizar e, até eliminar os seguintes problemas:

Falhas no maquinário por lubrificação deficiente;

$>$ Perca de eficiência no funcionamento;

Aquecimento do equipamento por lubrificação excessiva;

Corrosão, abrasão e ferrugem no maquinário por lubrificante contaminado (contaminação por água, condensado, elementos químicos e limalha de ferro ou qualquer material sólido, além de oxidação no lubrificante).

Para Mobley (2004) e Palmer (2006), o planejamento das atividades de lubrificação industrial tem como objetivo principal aplicar a quantidade adequada do correto lubrificante no local exato e com periodicidade apropriada. Isto se traduz em redução de quebras (paradas de manutenção), custo de manutenção, mão de obra e redução e custos de energia. 


\begin{abstract}
"As atividades vinculadas a manutenção preventiva tem por objetivo evitar a ocorrência de falhas nos equipamentos e o custo correspondente ao reparo e tempo de inatividade do equipamento. Este processo garante que limpeza básica, inspeção e lubrificação são atividades necessárias para a saúde do equipamento e devem ser realizadas em tempo apropriado". (KISTER e HAWKINS, 2006).
\end{abstract}

Os planos de lubrificação representam a base da gestão da lubrificação, pois são eles que procedimentam todos os passos para uma correta execução, além de conter dados essenciais, como a localização do equipamento, o tipo de ferramental a ser utilizado, o tipo de lubrificante e muitas vezes instruções para a segurança do trabalhador.

$\mathrm{Na}$ gestão da lubrificação deve-se, primeiramente, elaborar os planos preventivos de manutenção. Estes planos preventivos devem conter corretamente a descrição de lubrificantes, quantidades, periodicidade e ferramentas adequadas para execução, pois só através de uma lubrificação organizada e adequada é que esta atividade trará benefícios para o maquinário e a produção.

Um fator importante para a elaboração dos planos de manutenção é o amplo conhecimento dos equipamentos. Programas de lubrificação envolvem pessoal da administração e funcionários de chão de fábrica, por isso, é preciso que o grupo de pessoas esteja envolvido nesta atividade (mecânicos, lubrificadores, planejamento de manutenção e fornecedor de lubrificantes da empresa), possuam grande experiência em campo e aprofundado conhecimento do funcionamento do maquinário a ser lubrificado, para melhor eficácia na elaboração e gerenciamento dos planos preventivos. (MOBLEY; HIGGINS e WIKOFF, 2008).

A fim de estabelecer um programa de lubrificação em toda a planta, a gestão deve providenciar para que uma pesquisa seja realizada em cada parte do equipamento, observando as recomendações do fabricante além de parâmetros e condição da máquina como: velocidades de operação e cargas, condições de operação (contaminantes e temperaturas), histórico da máquina e de seus componentes, entre outros.

Estas informações podem ser alimentadas em um sistema informatizado a fim de facilitar o gerenciamento e organização das mesmas em um roteiro de lubrificação, além de facilitar a execução através da geração automática dos planos de lubrificação e identificar os intervalos de relubrificação. 


\begin{abstract}
"A composição do plano preventivo de lubrificação, eficiente e padronizado, exige dados detalhados a serem coletados e posteriormente analisados e armazenados.Recomenda-se que o gerenciamento destes dados, bem como o tratamento das análises, deve ser auxiliado por um sistema informatizado, por este possibilitar backup das informações (segurança) e facilitar o acesso e identificação dos dados para todas as áreas industriais envolvidas com a lubrificação". (PEENS,2007).
\end{abstract}

A coleta de dados e tabulação das informações em um plano preventivo é, normalmente realizada pelo departamento de manutenção, com o envolvimento de especialistas em lubrificação, técnicos de lubrificação, engenheiro de manutenção e fornecedores de lubrificantes. Desta forma, busca-se racionalizar e padronizar as tarefas e racionalizar os tipos de lubrificantes aplicados. Além disto, o planejamento de manutenção tem por responsabilidade elaborar o cronograma de distribuição dos planos de lubrificação, bem como, identificar a equipe de serviços que irá executar as tarefas dentro das recomendações de melhores práticas sobre as necessidades de lubrificação da planta industrial.

Segundo Mobley (2004), Viana (2002), Johnson (2006), Kister e Hawkins (2006) e Alverson et al. (2008), planos eficientes de lubrificação devem contemplar os seguintes aspectos, informações e procedimentos:

> Eficiente tabulação das informações, contemplando todas as informações necessárias de forma organizada e objetiva;

$>$ Identificação dos equipamentos que devem ser lubrificados, bem como, os pontos de aplicação do lubrificante;

> Tarefas sequenciadas de maneira linear em relação ao TAG e ponto de lubrificação, evitando disperdício de tempo na procura do ponto de aplicação do lubrificante;

> Identificação completa e correta do lubrificante a ser aplicado;

> Escolha de lubrificantes adequados, reduzindo o máximo de tipos utilizados na planta industrial como um todo, facilitando o armazenamento e redução de custos com a aquisição de lubrificantes e/ou degradação deles;

> Identificação do método de aplicação (bomba manual ou automática, almotolia, pincel, spray, entre outros);

> Requisitos de frequência ou intervalo de lubrificação (periodicidade) ;

$>$ Frequência ou intervalo da troca do lubrificante ;

$>$ Centro de serviço (mão de obra) qualificado para execução das tarefas; 
> Tempo previsto para execução (hora/homem);

> Condição do equipamento para execução (equipamento pode ser seguramente lubrificado enquanto opera ou se deve ser desligado para execução da tarefa);

> Manter registros de consumo completos (controle de estoque e custos);

> Registrar e analisar todas as falhas de lubrificação identificadas durante a execução do plano preventivo;

> Identificar os equipamentos de proteção coletiva e individual que devem ser usados durante a execução das tarefas, eliminando e/ou reduzindo os riscos de acidentes relacionados com a lubrificação.

As exigências fundamentais para selecionar o lubrificante apropriado para cada tipo de atividade de lubrificação são as características físico-químicas do óleo base, como a viscosidade, a velocidade operacional (variável ou fixa) do ponto de aplicação, o tipo específico de atrito (por exemplo, deslizamento ou rolamento), condições ambientais para qual o lubrificante está sujeito, o tempo de relubrificação, estabilidade, oxidação, calor (ponto de gota), entre outras características do lubrificante.

Também é importante focar no modo de aplicação dos lubrificantes e na segurança do funcionário que a executa, pois um dos pontos de uma boa administração, além de propiciar bons resultados técnicos, é gerir adequadamente seus recursos humanos, diminuindo ao máximo o risco de acidentes de trabalho.

Branco Filho (2003) enfatiza a importância de todos os planos de lubrificação, bem como de seus recursos, serem administrados adequadamente a fim de alcançar bons resultados em termos de custos e desempenho de máquinas e equipamentos, pois somente através de um planejamento adequado de manutenção é que é possível alcançar melhores níveis de disponibilidade do equipamento e, consequentemente, do processo produtivo, sendo a disponibilidade operacional o grande indicador da excelência da manutenção e da garantia de produtividade.

Uma das principais consequências de uma gestão inadequada de lubrificação é o aumento do consumo de energia e perda de eficiência do maquinário, pois antes dos componentes de máquina falharem, ocorre força de atrito excessiva entre eles que acarreta sobrecarga em equipamentos elétricos, motores e atuadores, provocando a interrupção da operação de máquinas e equipamentos, 
consequentemente redução de produtividade e eficiência da planta industrial. (KISTER e HAWKINS, 2006; MANG e DRESEL, 2007).

Os fatores que impactam a rentabilidade e competitividade da empresa é a eficiência da produção, bem como, a programação e cumprimento da entrega dos produtos. Para manter cronogramas com cumprimentos mais estáveis, a planta industrial deve manter seus equipamentos com confiabilidade e disponibilidade de operação máxima para produção, sendo assim, a confiabilidade no processo de lubrificação do maquinário é componente chave na competitividade global da empresa mediante a redução e/ou eliminação da probabilidade de ocorrência de falhas em máquinas e equipamentos por atrito, desgaste e/ou redução de desempenho.

2.2.2 Gestão do Processo de Lubrificação em Maquinário Aplicado à Produção de Alimentos

Produzir alimento é, sobretudo trabalhar com a saúde humana, para tantas indústrias deste ramo devem manter o nível máximo de qualidade de seus produtos, ou seja, manter os alimentos isentos de qualquer tipo de contaminação e com total qualidade.

A manufatura de alimentos e bebidas requer operações processuais como limpeza, esterilização, aquecimento, resfriamento, cozimento, corte, empacotamento entre outros. Para a execução destas operações, necessita-se de máquinas e equipamentos como: bombas, misturadores, tanques, tubulações, motores, balanças, eixos, entre outros. Tal maquinário contém elementos mecânicos ou rotativos que requerem fluídos hidráulicos, graxas, óleos lubrificantes que asseguram seu pleno funcionamento. (TOTTEN, 2006; MANG e DRESSEL, 2007).

Porém, o mesmo lubrificante que auxilia no funcionamento de máquinas e equipamentos é considerado um risco (um perigo) à qualidade do produto, o qual pode vir a afetar a coloração, sabor, odor ou composição do produto por substâncias de origens biológicas (leveduras e fungos) e/ou química. (KUNG, 2003; GEBARIN, 2009). 
"A execução da lubrificação, seja como atividade de manutenção preventiva, preditiva ou corretiva, em equipamentos de processo de fabricação de alimentos é muitas vezes difícil de conciliar com as exigências e normas sanitárias impostas a este seguimento industrial". (GIRARD, 2002).

Em indústrias do ramo de fabricação de alimentos é recomendado, por normas e legislações específicas a utilização de lubrificantes de grau alimentício, os chamados Food Grades Lubricants ou "white oils" (óleos brancos).

Este tipo de lubrificante, em sua maioria, é sintético, pois além de atenderem uma gama maior de aplicações que os minerais tóxicos, possuem melhor desempenho, pela relação custo benefício, já que tem elevado período de troca. (TOTTEN, 2006; GEBARIN, 2009; CARRETEIRO e BELMIRO, 2009)

Os tipos de lubrificantes de grau alimentício são divididos em categorias, as quais se baseiam na probabilidade do lubrificante entrar em contato com o alimento (risco que oferecem a qualidade do alimento) e nas substâncias contidas em sua composição. (WILLIANSON, 2003; TURNER, 2007).

Durante a elaboração dos planos de lubrificação deve-se identificar o lubrificante de grau alimentício, ou seja, lubrificantes de uso permitido na indústria de alimentos, apropriado para cada ponto de lubrificação das máquinas e equipamentos, estes estão distribuídos em três categorias conhecidas como: H1, H2 e H3. As categorias de lubrificantes de grau alimentício são detalhadas no quadro 2.1 abaixo.

Quadro 2.1 - Categorias Food Grades Lubricants

\begin{tabular}{|c|l|}
\hline $\begin{array}{c}\text { Grau } \\
\text { Alimentício }\end{array}$ & \multicolumn{1}{c|}{ Descrição das propriedades do lubrificante } \\
\hline \multirow{H}{*}{1} & $\begin{array}{l}\text { Lubrificantes de grau alimentício usados em ambiente de processamento } \\
\text { de alimentos onde existe alguma possibilidade de incidental contato } \\
\text { alimentar. As formulações lubrificantes devem ser compostas de mais de } \\
\text { um componente aprovado, para base, aditivo e espessante engrossador } \\
\text { (se for graxa). Somente a mínima quantia de lubrificante exigida deve ser } \\
\text { aplicada no equipamento (contato incidental permitido até 10 ppm). }\end{array}$ \\
\hline
\end{tabular}

(Continua) 
(Conclusão)

\begin{tabular}{|c|l|}
\hline $\begin{array}{c}\text { Grau } \\
\text { Alimentício }\end{array}$ & \multicolumn{1}{|c|}{ Descrição das propriedades do lubrificante } \\
\hline H2 & $\begin{array}{l}\text { Lubrificantes usados em partes de equipamentos e máquinas que estão em } \\
\text { locais onde não há nenhuma possibilidade que o lubrificante ou a face } \\
\text { lubrificada entre em contato com os alimentos. } \\
\text { Por não haver risco de contato com o alimento, lubrificantes de H2 não têm } \\
\text { uma lista definida de ingredientes aceitáveis. Porém, eles não podem } \\
\text { conter metais pesados: antimônio, arsênio, cádmio, chumbo, mercúrio ou } \\
\text { selênio. Também, os ingredientes não devem incluir substâncias que são } \\
\text { carcinogênicas, mutagênicas (radiação), teratogênicas (provocam má } \\
\text { formação do feto por anomalias causadas no útero) ou minerais ácidos. } \\
\text { Este tipo de lubrificante é mais aplicado em sistemas fechados } \\
\text { (hidráulicos). }\end{array}$ \\
\hline H3 & $\begin{array}{l}\text { São lubrificantes conhecidos como óleo solúvel ou comestível, sendo } \\
\text { usados para limpeza e prevenção de oxidação em ganchos, talhas, } \\
\text { carretilhas e equipamentos semelhantes. }\end{array}$ \\
\hline
\end{tabular}

Fonte: Adaptado de: Margaroni (1999); Eldridge (2007); Girard (2002); Turner (2007); Lawate (2007) e Koel (2012)

Rajewski, Fokens e Watson (2000) e Mang e Dressel (2007), enfatizam que além dos lubrificantes de classificação alimentícia serem de origem atóxica, sem cor e/ou odor, também não pode conter em sua formulação substâncias carcinogênicas, mutagênicas, teratogênicas, ou químicas que provoquem mal a saúde do consumidor e sua fabricação deve estar de acordo com normas regulamentadoras de órgãos fiscalizadores.

O Departamento de Agricultura dos Estados Unidos USDA (United States Department of Agriculture) e a Agência Americana de Medicamentos e Alimentos FDA (Food and Drug Administration), listaram as substâncias permitidas para uso na fabricação de lubrificantes de grau alimentício. Estas substâncias estão dispostas em vários códigos contidos no Título 21 do Código de Regulamentações Federais (Guidelines of Security Code of Federal Regulations) formando as diretrizes da FDA CRF. 
Com base nos regulamentos do Título 21 estão descritos os óleos base, aditivos e espessantes admissíveis na composição dos lubrificantes de grau alimentícios, sendo alguns destes parágrafos apresentados resumidamente no quadro 2.2 a seguir.

Quadro 2.2 - Parágrafos do Título 21 das Diretrizes da FDA CRF- "Food Grades Lubricants"

\begin{tabular}{|c|l|}
\hline $\begin{array}{c}\text { FDA CRF Título } \\
\text { 21- Parágrafo }\end{array}$ & \multicolumn{1}{|c|}{ Descrição } \\
\hline 21.CFR 178.3570 & $\begin{array}{l}\text { Apresenta as substâncias permitidas para a fabricação de graxas } \\
\text { lubrificantes de classe H1 como os aditivos, espessantes, } \\
\text { antioxidantes, inibidores de corrosão, anti-desgaste, aditivos de } \\
\text { extrema pressão. Alguns espessantes: estearato de alumínio, } \\
\text { complexo de alumínio, sulfonato de cálcio, argila organo e poliureia. } \\
\text { O complexo de alumínio é o espessante mais comum na composição } \\
\text { de graxa H1, pois suportam altas temperaturas e são resistentes à } \\
\text { água, propriedades as quais são importantes para aplicações no } \\
\text { processamento de alimentos. }\end{array}$ \\
\hline 21. CFR 178.3620 & $\begin{array}{l}\text { Descreve os óleos base presentes em lubrificantes H1 (óleos } \\
\text { brancos). Eles são altamente refinados, incolores, insípidos, inodoros } \\
\text { e não mancham. }\end{array}$ \\
\hline $21 . C F R ~ 172.878$ & $\begin{array}{l}\text { Especificação dos óleos lubrificantes de classe H1 destinados a } \\
\text { serem utilizados em contato direto com a fabricação de alimentos }\end{array}$ \\
\hline 21 CFR 172.882 & $\begin{array}{l}\text { Tipos de hidrocarbonetos isoparafínicos sintéticos aplicados na } \\
\text { fabricação de lubrificantes de grau alimentício }\end{array}$ \\
\hline 21.CFR 182 & $\begin{array}{l}\text { Elenca as substâncias geralmente reconhecidas como seguras na } \\
\text { composição de lubrificantes de grau alimentício, como óxido de zinco } \\
\text { e tocoferóis (vitamina E). }\end{array}$ \\
\hline
\end{tabular}

Fonte: Adaptado de Girard (2002); Mang e Dressel (2007); www.fda.gov e www.nsf.org acessados online (2012)

Atualmente o órgão responsável pela avaliação do lubrificante e sua inclusão nas diretrizes da FDA CRF é a Fundação Nacional de Saúde Pública NSF ( National Sanitation Foundation), que assumiu o papel do USDA pelo desenvolvimento de normas e certificação de produtos usados na indústria de alimentos. Cada componente da formulação é submetida a NSF pelo fabricante do lubrificante, juntamente com outras documentações de suporte.

O lubrificante é então analisado para verificar se seus componentes estão em conformidade com as diretrizes da FDA CRF (substâncias autorizadas) e 
posteriormente é disponibilizada a certtificação do produto em seu White Book TM disponível no site www.nsfwhitebook.org.

O quadro 2.3 exemplifica alguns tipos de óleos base, aditivos e espessantes que integram a composição de lubrificantes de grau alimentício $\mathrm{H} 1$.

Quadro 2.3 - Substâncias Aprovadas para Lubrificantes H1 pelo Parágrafo 21.CFR 178.3570

Substâncias aprovadas param Lubrificantes H1 (parágrafo 21.CFR 178.3570)

\begin{tabular}{|c|c|}
\hline Substâncias & Limitações \\
\hline $\begin{array}{l}\text { Ácido fosfórico, monohexilíco e diehixílico, } \\
\text { ésteres, compostos com tetrametil } \\
\text { nonilamina e } C 11-14 \text { alquilaminas }\end{array}$ & $\begin{array}{l}\text { Para uso somente como um adjuvante } \\
\text { (auxiliar) em nível não excedente á } 0,5 \% \text { por } \\
\text { peso do lubrificante }\end{array}$ \\
\hline $\begin{array}{l}\text { Ácido fosfórico, ésteres monoisooctil e } \\
\text { diisooctil, reagidos com terc-alquil }\left(\mathrm{C}_{12-14}\right) \text { e } \\
\text { aminas primárias. }\end{array}$ & $\begin{array}{l}\text { Para uso somente como um inibidor de } \\
\text { corrosão ou prevenção de ferrugem em } \\
\text { lubrificantes em nível não excedente á } 0,5 \% \\
\text { por peso do lubrificante }\end{array}$ \\
\hline $\begin{array}{l}\text { Ácido Fosforotioamídicos, trifenil éster, } \\
\text { derivados de tercbutil }\end{array}$ & $\begin{array}{l}\text { Somente uso como adjuvante (auxiliar) com } \\
\text { propriedades de extrema pressão em nível não } \\
\text { excedente á } 0,5 \% \text { por peso do lubrificante }\end{array}$ \\
\hline $\begin{array}{l}\text { Poliuréia, contendo um teor de nitrogênio } \\
\text { de } 9 \text { á } 14 \% \text { baseado no Peso de Poliuréia } \\
\text { seca, produzida pela reação de diisocianato } \\
\text { de totileno com ácidos graxos de óleo }\left(C_{16}\right. \\
\left.\text { e } C_{18}\right) \text {, amina e etilenodiamina em uma } \\
\text { proporção molar } 2: 2: 1\end{array}$ & $\begin{array}{l}\text { Para uso somente como adjuvante (auxiliar) } \\
\text { em nível percentual não excedente á } 10 \% \text { da } \\
\text { substância por peso do óleo mineral }\end{array}$ \\
\hline Polibuteno & Adição para alimento não excedente a 10 ppm. \\
\hline Polibuteno hidrogenado & Adição para alimento não excedente a 10 ppm. \\
\hline Polietileno & Adição para alimento não excedente a 10 ppm. \\
\hline Polisobutileno & $\begin{array}{l}\text { Para uso somente como um agente } \\
\text { espessante (engrossador) }\end{array}$ \\
\hline Nitrito de sódio & $\begin{array}{l}\text { Uso somente como uma proteção contra } \\
\text { ferrugem (anti-ferrugem) em lubrificantes de } \\
\text { óleo mineral, em nível não excedente á } 3 \% \text { por } \\
\text { peso de lubrificante }\end{array}$ \\
\hline
\end{tabular}


(Conclusão)

Substâncias aprovadas param Lubrificantes H1 (parágrafo 21.CFR 178.3570)

\begin{tabular}{|l|l|}
\hline \multicolumn{1}{|c|}{ Substâncias } & \multicolumn{1}{c|}{ Limitações } \\
\hline $\begin{array}{l}\text { Tiodietileno bis (3,5-di-terc-butil-4- } \\
\text { hidroxihidrocinamato) }\end{array}$ & $\begin{array}{l}\text { Para uso como um antioxidante em nível não } \\
\text { excedente á 0,5\% por peso do lubrificante }\end{array}$ \\
\hline $\begin{array}{l}\text { Tetraquis (metileno (3,5-di-terc-butil-4- } \\
\text { hidroxi-hidrocinamato)) metano }\end{array}$ & $\begin{array}{l}\text { Para uso como um antioxidante em } \\
\text { lubrificantes em nível não excedente á 0,5\%por } \\
\text { peso do lubrificante }\end{array}$ \\
\hline $\begin{array}{l}\text { Tri[2(ou 4)-C9--10-ramificada alquilfenil] } \\
\text { fosforotionatos }\end{array}$ & $\begin{array}{l}\text { Somente uso como lubrificante auxiliar com } \\
\text { propriedades antidesgaste e pressão-extrema } \\
\text { em níveis que não deve exceder 0,5\%, em } \\
\text { peso do lubrificante }\end{array}$ \\
\hline Trifenil fosforotionatos & $\begin{array}{l}\text { Para uso como um adjuvante (auxiliar) em } \\
\text { lubrificantes, em nível não excedente á 0,5\% } \\
\text { por peso do lubrificante }\end{array}$ \\
\hline Tris(2,4-di-terc-butilfenil) fosfito & $\begin{array}{l}\text { Para uso somente como um estabilizador em } \\
\text { nível não excedente á 0,5\% por peso do } \\
\text { lubrificante }\end{array}$ \\
\hline $\begin{array}{l}\text { Tio (derivados de amino) dietileno bis (3,5 } \\
\text { di - terc- butil - 4-hidroxihidrocinamato) }\end{array}$ & $\begin{array}{l}\text { Para uso como um antioxidante em nível não } \\
\text { excedente á 0,5\%por peso do lubrificante }\end{array}$ \\
\hline Sulfeto de Zinco & $\begin{array}{l}\text { Para uso como um antioxidante em nível não } \\
\text { excedente á 10\% por peso do lubrificante }\end{array}$ \\
\hline
\end{tabular}

Fonte: Adaptado de: Margaroni (1999); Totten (2006) e 21 CFR 3570 - Lubricants with incidental food contact. Acessado online em http://www.gpo.gov/fdsys/pkg/CFR-2012-title21vol3/pdf/CFR-2012-title21-vol3-sec178-3570.pdf, paginas 420-421 (2013)

As empresas do ramo de alimentos estão exigindo maior disponibilidade, menor tempo de parada e maior rendimento de seu equipamento para atender à demanda crescente. Prevenir a falha de equipamentos, a fim de aumentar a produção e reduzir os custos é o foco principal da organização para manter-se competitiva no mercado.

É fundamental gerenciar o processo de lubrificação em máquinas e equipamentos aplicados em industriais de alimentos, a fim de garantir a qualidade e integridade do alimento concomitantemente proporcionar confiabilidade e disponibilidade operacional do maquinário, atendendo as necessidades financeiras da empresa. 


\subsection{ENGENHARIA DA CONFIABILIDADE APLICADA A MANUTENÇÃO INDUSTRIAL}

$\mathrm{O}$ aumento de qualidade e capacidade produtiva do processo industrial exigido pela competitividade de mercado tem levado a automatização do sistema produtivo com aplicação de grande investimento em máquinas e equipamentos.

Para que haja retorno deste investimento, o maquinário fabril deve ser capaz de manter seu funcionamento sem interrupções em suas operações, para reparos e/ou redução de seu desempenho operacional, apresentando máxima disponibilidade e redução de custo com manutenção industrial.

Os conceitos de confiabilidade, disponibilidade e capacidade produtiva tornaram-se o foco principal do ambiente industrial em face do cenário ecônomico atual. Crescente concorrência de mercado, redução de gastos e desperdícios e aumento da demanda, tem gerado a necessidade cada vez maior da aplicação de ferramentas ofertadas pela engenharia de manutenção e confiabilidade para alcançar desempenho eficaz de sistemas industriais.

\footnotetext{
“...a confiabilidade é o principal ponto de referência para o planejamento, pois analisa previamente as consequencias das falhas e riscos envolvidos nas atividades de manutenção afim de minimizar suas ocorrências, indicando as melhores politicas de manutenção, conferindo disponibilidade, segurança, qualidade do processo". (EISINGER e RAKOWSKY, 2000).
}

Lewis (1996), Dhillon (2005), Hayworth (2008) e Faulin et al. (2010) definem o conceito de confiabilidade como sendo a probabilidade de um dispositivo operar com desempenho satisfatório dentro de um período de tempo determinado, quando usado nas suas condições especificadas sem a ocorrência de falhas.

Moubray (2000), Lafraia (2001) e Myers (2010) explicam que a falha consiste na interrupção ou alteração da capacidade de um item desempenhar as funções para o qual ele foi projetado. A falha é o resultado do desvio de características além dos limites especificados, causando perda total ou parcial da função requerida do equipamento, sendo a ocorrência da falha ocasionada por diversos fatores, denominados mecanismos de falha ou modos de falhas.

E ainda tem-se pela NBR 5462 (1994) a definição de disponibilidade como " a capacidade de um item estar em condições de executar uma certa função em um 
dado instante ou durante um intervalo de tempo determinado, levando em conta os aspectos combinados de confiabilidade, mantenabilidade e suporte de manutenção, supondo que os recursos externos requeridos estejam assegurados".

\begin{abstract}
"No sentido mais amplo, a confiabilidade está associada com segurança, com operação bem-sucedida, e com a ausência de falhas ou avarias, por isto, em engenharia de confiabilidade o foco principal é sobre a análise de falhas e o desenvolvimento de métodos e ferramentas para sua prevenção". (LEWIS, 1996).
\end{abstract}

Kister (2006) e Mobley (2004), enfatizam que obter confiabilidade no processo fabril através da manutenção industrial de máquinas e equipamentos envolve os métodos de gerenciamento e execução das tarefas relativas a esta função, e assim aplicar o plano de manutenção mais apropriado, otimizando os recursos humanos e materiais para executar as melhores práticas de manutenção.

Um dos fatores que impactam na disponibilidade e confiabilidade do maquinário é a mantenabilidade, conceito o qual deve ser intrínseco desde o projeto da máquina, pois tem por objetivo analisar e otimizar as características do projeto quanto a sua manutenção, determinando a facilidade de maior e menor grau em realizar as ações de manutenção, através de procedimentos e normas, mão-de-obra habilitada, custos minimizados e tempos reduzidos. (LAFRAIA, 2001; DHILLON, 2006; EBELING, 2010).

\footnotetext{
“...a mantenabilidade como a facilidade e a rapidez com que se pode realizar uma atividade de manutenção de um item, seu desenvolvimento pode conferir disponibilidade operacional ao sistema produtivo por meio de uma rápida e eficiente restauração do funcionamento de máquinas e equipamentos, proporcionar aumento de vida útil do maquinário e garantindo assim confiabilidade ao processo fabril”.(SIQUEIRA,2005).
}

A diferença entre a confiabilidade e mantenabilidade é que enquanto a primeira está relacionada a probabilidade de um item não falhar, a última está relacionada ao tempo necessário para a manutenção industrial reestabelecer o funcionamento do dispositivo, visando redução de tempo de reparo e horas de trabalho, sendo que ambos os fatores afetam diretamente na disponibilidade do sistema industrial.

A confiabilidade aplicada à manutenção industrial envolve a reformulação, modificação ou melhoramento de procedimentos de trabalho que visam aumentar a 
disponibilidade e vida útil de máquinas e equipamentos industriais. A figura 2.1 mostra algumas atividades e conceitos ligados à obtenção da confiabilidade na manutenção industrial.

Figura 2.1 - Conceitos de Confiabilidade na Manutenção Industrial

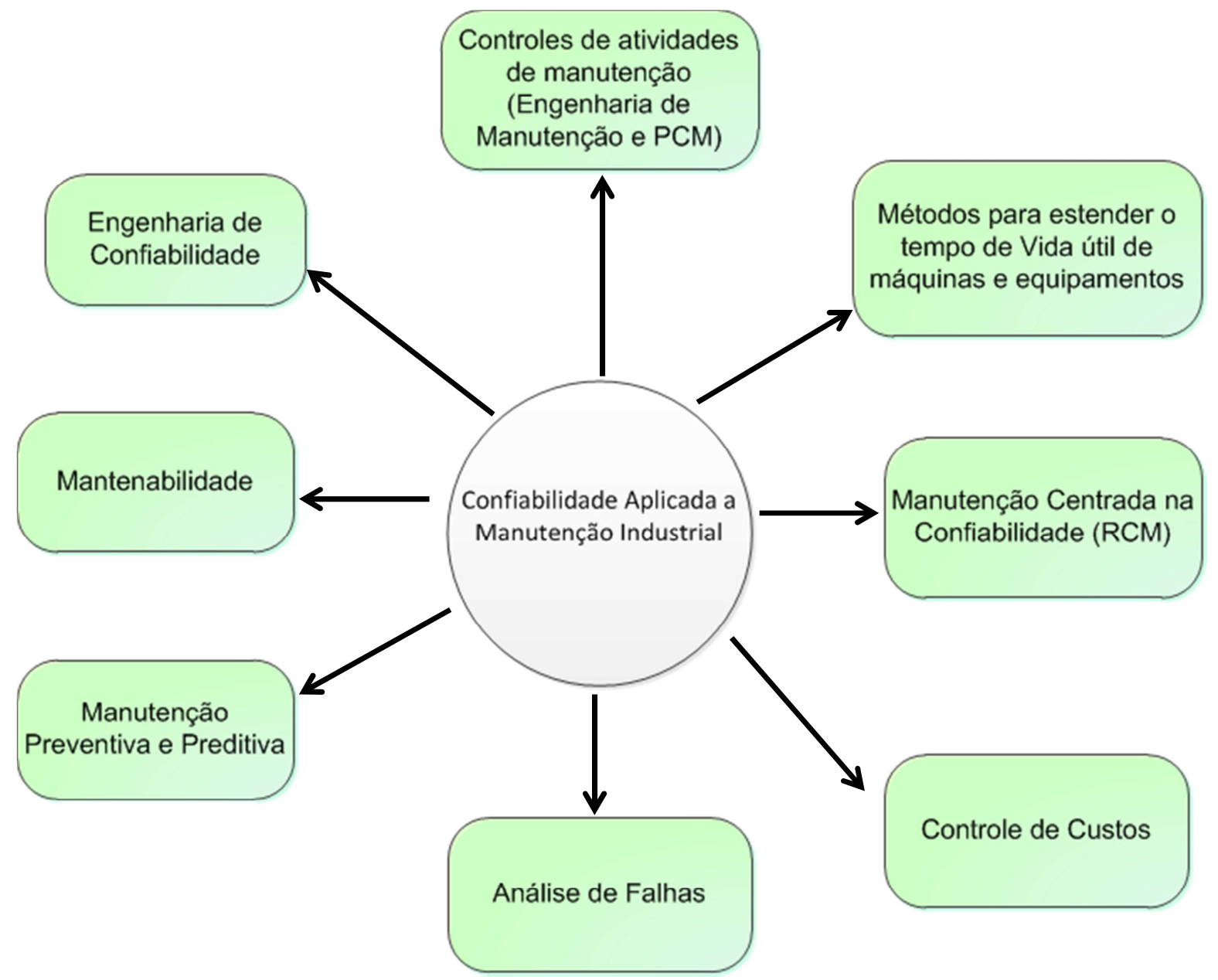

Fonte: Adaptado de Kobbacy e Murthy (2008)

Organizações industriais do ramo alimentício também buscam cada vez mais ferramentas e métodos de trabalho e gestão que direcionem para uma maior competitividade no mercado através de qualidade e aumento de produtividade de seus produtos. Neste ambiente industrial, a lubrificação se apresenta como função estratégica garantindo a disponibilidade das instalações e auxiliando na geração de resultados, e ao mesmo tempo um potencial risco de contaminação alimentar. 
Logo, obter confiabilidade no processo de lubrificação industrial é administrar o uso de ferramentas e ações de lubrificação, prevenir contaminação do lubrificante (fator que reduz a suas propriedades físico-químicas e agride o material de construção do elemento de máquina), padronizar as tarefas de lubrificação para otimizar o uso de lubrificantes, eliminar vazamentos contribuindo para a segurança pessoal e do produto e eliminar as falhas associadas com as atividades de lubrificação, conferindo qualidade ao produto e disponibilidade do maquinário para produção. (NEALE, 2006; PEENS, 2007).

Assim, existe uma necessidade definitiva para gerenciamento de ativos eficazes e práticas de lubrificação industrial que irão influenciar positivamente os fatores críticos de sucesso, tais como a inocuidade, a qualidade do produto, velocidade de produção e confiabilidade.

Analisar a confiabilidade e disponibilidade de um sistema industrial implica em vários fatores sendos os principais a complexidade do maquinário fabril, custos e recursos humanos, assim, empregam-se análises estatísticas, metodos e ferramentas para modelagem e caracterização da confiabilidade de um sistema.

\subsubsection{Caracterização do Sistema Industrial}

Para analisar o comportamente das falhas ocorridas em um sistema fabril, análise a qual aponta para confiabilidade e disponibilidade das instalações industriais, deve-se conhecer o processo de fabricação da unidade fabril em todos os seus aspectos qualitativos e quantitivos como:

> Tipo do produto a ser fabricado;

> Impactos da matéria-prima em máquinas e equipamentos;

> Estratégias de manutençào implantadas;

> Capacidade produtiva em função da demanda de mercado;

> Qualificação da mão- de - obra aplicada a operação e manutenção de máquina e equipamentos, entre outros. 
E posteriormente definir o modo de ligacão entre o maquinário em função do processo de fabricação, ou seja, identificar o modo como as máquinas e equipamentos interagem entre si durante seu funcionamento, seja interligado em sistema em série ou paralelo ou ainda em série-paralelo caracterizando-se um sistema misto.

A identificação de como a rede do maquinário se estabelece é a base para obtenção dos índices de confiabilidade, disponibilidades adicionados dos demais indicadores de desempenho de manutenção. O tipo de sistema (série, paralelo ou misto) de disposição do maquinário mostra se a ocorrência de uma falha pode impactar somente em item ou até interromper o funcionamento do sistema fabril por inteiro ou parcialmente.

Outro fator para carcterizar do sistema produtivo são os tipos de equipamentos que o integram quanto a sua manutenção, se são capazes de serem reparáveis ou não. A classificação de um maquinário em sistemas reparáveis ou não reparáveis impacta na ferramenta estatística para análise da tendência de falhas e probalilidade de ocorrência destas.

Logo a caracterização do sistema produtivo em seus aspectos operacionais e técnicos é essencial para definição da metodologia a ser adotada na análise de suas falhas, modo de coleta de dados, escolha das ferramentas de engenharia de qualidade e manutenção para compor planos de ação e definição das estratégias de manutenção a serem implantadas no sistema industrial.

\subsubsection{Sistemas Reparáveis e Sistemas não Reparavéis}

Ao iniciar qualquer estudo de confiabilidade de máquinas e equipamentos é fundamental analisar a tendência das falhas ocorridas durante o tempo de operação desses. Indentificar o maquinário industrial como sistema reparável ou não reparável determina a adequada metodologia estatística a ser aplicada na análise do comportamento das falhas e assim obter os índices relacionados a confiabilidade do sistema industrial.

Para Modarres (1992) e Lindqvist (2008) um sistema reparável é aquele que, depois de não realizar uma ou mais funções satisfatoriamente, pode ser restaurado 
voltando à condição ideal de funcionamento, sem ser substituído e são estes os tipos de sistemas mais empregados nas linhas de produção de uma indústria.

\begin{abstract}
"Qualquer sistema reparável pode ser considerado um conjunto de sistemas/componentes, que são reparados ou substituídos quando falham. Um sistema reparável pode também conter alguns componentes não reparáveis que são substituídos quando falham, sendo eles a representação de uma pequena porcentagem da constituição do sistema". (ASSIS, 2013).
\end{abstract}

Já os sistemas não reparáveis são descartados e substituídos por novos componentes quando falham, sendo que a confiabilidade, para este tipo de sistema, é expressa em termos de tempo até a falha (TTF), ou seja, dá-se pela probabilidade de sobrevivência durante certo período de sua vida útil. (MODARRES, 1992).

Os sistemas reparáveis estão sujeitos à manutenção preventiva, corretiva ou preditiva, as quais influenciam os intervalos de tempo entre falhas, sendo que por meio destes valores é possível compreender o comportamento das falhas e consequentemente se existe um aumento ou diminuição da disponibilidade. (DIAS e PEREIRA; 2005; LINDQVIST, 2008).

Os sistemas reparáveis podem não apresentar um padrão entre os valores de TBF (Time Between Failure) e TTR (Time to Repair) devido à taxa de falhas apresentar-se variável em função do tempo, assim os valores de confiabilidade e disponibilidade deste tipo de sistema também variam ao longo do tempo, obtendo um valor pontual em um instante de tempo t e não uma média destes índices em um dado período de tempo de operação. (MODARRES,1992).

Enfatiza-se na fundamentação teórica da presente tese os sistemas reparáveis, pois o método desenvolvido para analisar falhas relacionados ao processo de lubrificação de maquinário empregado nas indústrias de alimentos, é voltado para sistemas reparáveis, os quais compõe a maior parte do processo de fabricação deste tipo de indústria.

\title{
2.3.3 Análise Estatística de Falhas em Sistema Reparáveis
}

O objetivo principal da análise estatística de falhas é determinar a taxa e o tempo médio entre a ocorrência delas e assim verificar o comportamento dos 
eventos ocorridos (falhas) ao longo do tempo. Com esta análise é possível estruturar métodos de ação para elevar disponibilidade e assegurar confiabilidade em sistemas industriais.

Para analisar a confiabilidade de um sistema faz-se necessário identificar a probabilidade de falhas, a qual é obtida através do apontamento da frequência de ocorrência das mesmas. Os dados identificados nesta frequência de eventos (falhas) podem ser enquadrados em uma função de distribuição estatística e representada graficamente pela curva de tendência.

\begin{abstract}
"A degradação e falhas ocorrem de forma incerta. Como tal, a análise de tais dados requer a utilização de técnicas estatísticas. As estatísticas fornecem os conceitos e ferramentas para extrair informações a partir de dados e para o planejamento da coleta eficiente destes dados dentro do sistema". (KOBBACY e MURTHY, 2008).
\end{abstract}

A ocorrência de falhas impactam diretamente na confiabilidade e na disponibilidade operacional do sistema industrial inteiro ao qual está inserido, para tanto faz-se necessário avaliar estatisticamente a tendência do comportamento das falhas conjuntamente com seus modos, a fim de implantar estratégias de manutenção viáveis para redução e/ou elmincacao delas.

Para identificar a confiabilidade e disponibilidade operacional, a engenharia de manutenção e confiabilidade empregam indicadores, os quais têm por objetivo mostrar o desempenho das atividades de manutenção perante a produtividade do sistema fabril. (LAFRAIA, 2001; DHILLON, 2002; KARDEC e NASCIF, 2009).

Assis (2004) e Dhillon (2006) corroboram que o indicador de disponibilidade operacional é influenciado pelos índices de confiabilidade e mantenabilidade de máquinas e equipamentos, os quais estão diretamente relacionados pelos indicadores operacionais de tempos entre falhas (TBF) e para reparos das mesmas (TPR). A figura 2.2 ilustra a interação dos indicadores de desempenho de manutenção e produtividade influenciando o índice de disponibilidade do sistema industrial. 
Figura 2.2 - Influência da Confiabilidade e Mantenabilidade sobre a Disponibilidade

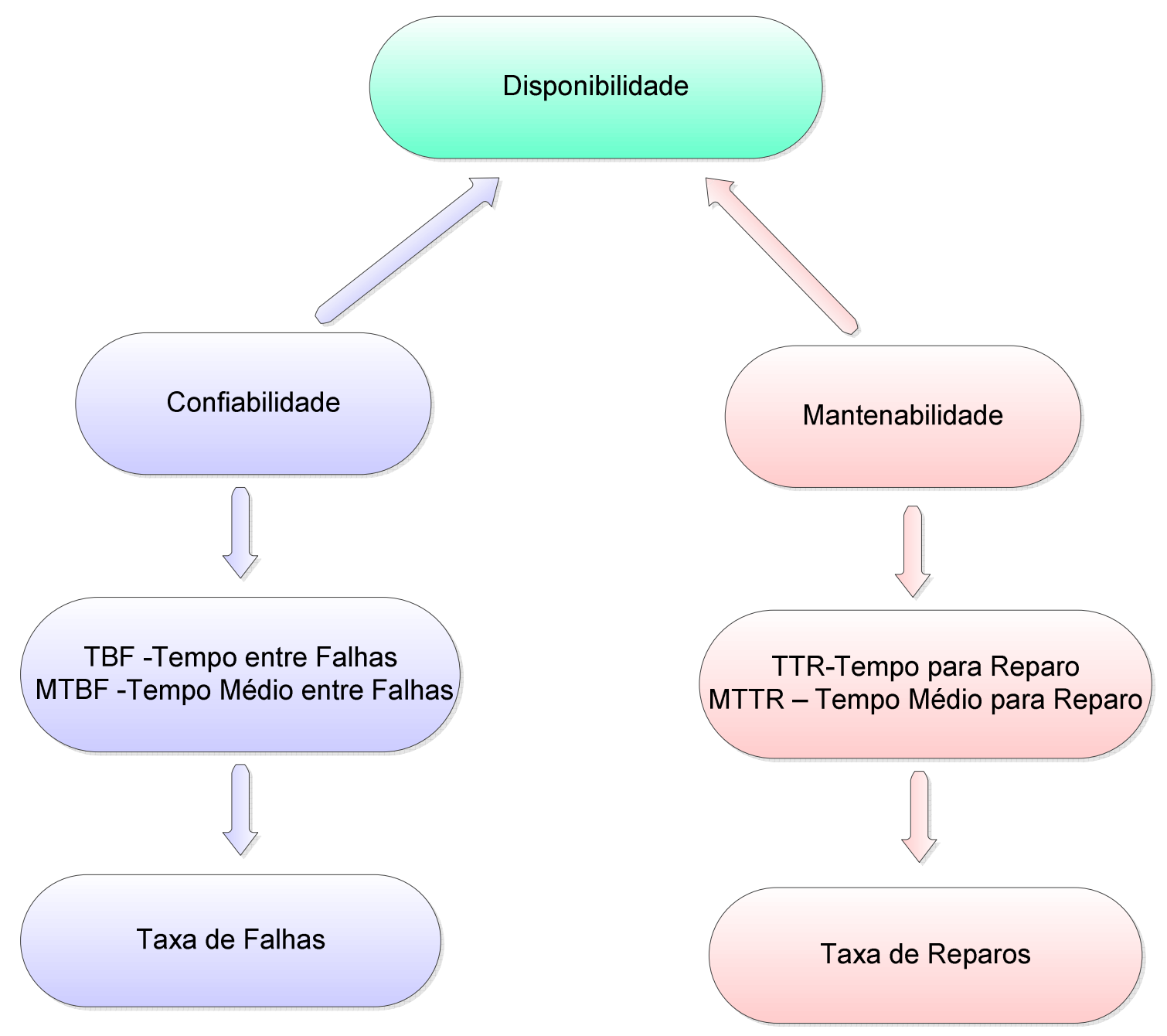

Fonte: Adaptado de Kardec e Nascif (2009)

A confiabilidade está relacionada ao TBF (tempo em operacão do maquinário entre falhas, ou seja, o tempo de funcionamento do sistema sem ocorrência de falhas) assim como a mantenabilidade está ligada ao TTR (o qual indica a facilidade ou dificuldade de realizar reparos no maquinário em função do tempo de manutenção).

Estes indicadores (confiabilidade e mantenabilidade) direcionam ao índice de disponibilidade, por meio da razão entre o tempo total em operação sem a ocorrência de eventos de falhas (MTBF - média dos TBF's em dado período de tempo) e o tempo total indicado em um dado período de tempo (MTBF adicionado dos tempos de reparos obtidos pelo valor médio destes - MTTR).

O indicador MTBF (Mean Time Between Failures), identifica o tempo médio de ocorrência entre as falhas do sistema fabril. É basicamente a estatística estimada 
do tempo de um dispositivo operar antes da ocorrência da falha, usualmente é expresso em horas. A equação (2.1) representa o cálculo do MTBF. (MOBLEY, 2004; BENBOWN e BROOME, 2009).

$$
\text { MTBF = (Tempo Total de Operação) / (Número de Falhas) }
$$

A mantenabilidade de máquinas e equipamentos fundamenta-se na capacidade de um sistema ser mantido em boas condições operacionais, sendo quantificada pelo tempo médio entre reparos (MTTR - Mean Time to Repair).

"O MTTR agrega todo o tempo necessário para diagnosticar a avaria e reunir os recursos logísticos, o tempo de execução do trabalho propriamente dito e ainda teste e entrega do equipamento". (MARTINS e LEITÃO, 2009).

O tempo médio entre reparos (MTTR) é provavelmente a medida mais utilizada para mensurar a mantenabilidade. Ele representa o tempo médio necessário que a equipe de manutenção gasta para reestabelecer a operação e/ou desempenho requerido, de máquinas e/ou equipamento após a ocorrência de falhas e pode ser calculado conforme a equação (2.2). (BERTOLINI; BEVILACQUA e MASON, 2006; KARDEC e NASCIF, 2009; MARTINS e LEITÃO, 2009).

$$
\text { MTTR = (Tempo Total de duração das Falhas) / (Número de Falhas) }
$$

A engenharia de confiabilidade tem por finalidade auxiliar a manutenção industrial em atender sua principal premissa a de elevar a disponibilidade de máquinas e equipamentos industriais e consequentemente valorizar os fatores fundamentais como a confiabilidade e a mantenabilidade.

A análise probabilística e estatística usadas para determinar as caraterísticas da tendência das falhas em sistema reparáveis é fundamentada na aplicação de processos estocásticos e a definição da tendência da taxa de intensidade de falha (ROCOF). Para tanto é necessário identificar os modos de ocorrências de falhas e o comportamento do intervalo de ocorrências delas, as quais variam sua intensidade em função do tempo. 
A figura 2.3 exemplifica periodos entre sucessivas falhas, os quais não são necessariamente independentes, já que uma avaria pode vir a provocar outra devido a diferença de tempo de vida util dos componentes que integram um sistema reparável.

Figura 2.3 - Casos de Ocorrência de Falhas em Sistemas Reparáveis

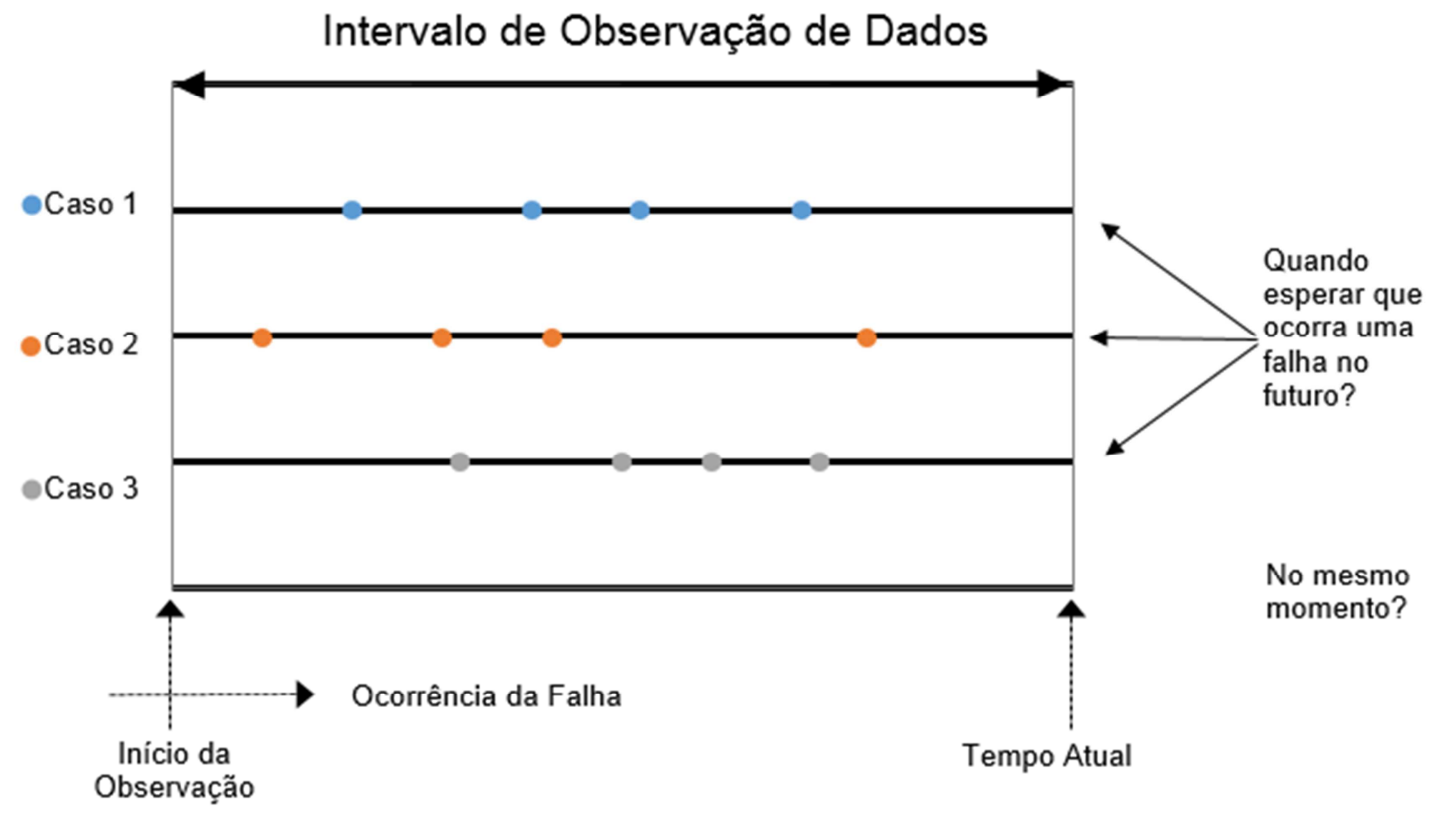

Fonte: Adaptado de Modarres, Kaminskiy e Krivtsov (2009)

Um sistema reparável pode sofrer intervenções de manutenção (preventiva, preditiva e/ou corretiva) para recolocá-lo em seu estado de funcionamento mediante desempenho requerido. Sendo que, durante as intervenções de manutenção, podese substituir ou não um componente, o qual geralmente enquadra-se como sistema não reparável (tempo de vida útil definido até a ocorrência de falhas).

Dentro de um sistema reparável existem componentes com tempo de utilização diferentes entre si, gerando uma taxa de falhas variável em função do tempo, ou seja, as falhas não ocorrem em mesmo ou similar espaço de tempo e nem mesmo apresentam-se de mesmo modo ou causa.

Logo, no tratamento da análise de falhas em sistemas reparáveis aplicam-se modelos que consideram esta variação da taxa de falha ao longo do tempo, como os processos estocásticos pontuais como Poisson Homogêneos (PPH) e processos de Poisson Não Homogêneos (PPNH) e a curva de tendência das falhas descritas por 
meio da taxa de ocorrência de falhas (ROCOF -Rate of Occurrence of Failures).(PERCY,2008 apud ASCHER e FEINGOLD, 1984).

\begin{abstract}
"Para antes de se aplicar qualquer distribuição estatística a um conjunto de dados, previamente, dever-se-á analisar qual a tendência dos dados sob o ponto de vista do processo estocástico. A análise de tendência é um processo de inferência estatística, baseado na metodologia dos testes de hipóteses, a cuja utilização se recorre sempre que se queira verificar se os dados amostrais são ou não compatíveis com determinadas populações. Este procedimento deve ser efectuado distintamente, consoante se trate de sistemas reparáveis (SR) ou de sistemas não reparáveis (SNR)". (MARTINS e LEITÂO, 2009).
\end{abstract}

Falhas ocorridas em sistemas reparáveis são eventos discretos (não podem ser representadas por distribuições contínuas) e são representadas por distribuições discretas, chamadas processos estocásticos pontuais (processos de Poisson).

A análise estatísticas das ocorrências de falhas em sistema reparáveis permite a construção de indicadores de desempenho relacionados a confiabilidade, mantenabilidade e disponibilidade por meio da obtenção dos valores da taxa de ocorrência de falhas (ROCOF - Rate of Occurrence of Failure), o tempo médio entre falhas (MTBF - Mean Time Between Failures), o tempo médio para reparação (MTTR - Mean Time to Repair) e tempo médio de funcionamento (MTTF - Mean Time to Failure).

Os equipamentos reparáveis, ou seja, aqueles que, tendo falhado, podem ser restaurados e postos em condição de operação por alguma ação corretiva, o registro da ocorrência é feito apenas na forma de intervalos. Neste, são registradas o número de falhas de cada equipamento, o momento de cada ocorrência e o tempo inicial e final de operação e por meio deste registro é possível obter a taxa de ocorrência de falhas (ROCOF).

A taxa de de ocorrência de falhas (ROCOF) expressa instantaneamente a probabilidade de falha por unidade de tempo, a qual é definida pela função de intensidade de ocorrência de falhas $\rho(t)$, uma função que expressa a taxa de variação do número esperado de fahas em relação ao tempo t. (ASSIS, 2013; MODARRES; KAMINSKIY; KRIVTSOV,2009). A equação (2.3) apresenta a taxa de ocorrência de falhas (ROCOF). 


$$
\rho(t)=\lambda * \beta * t n^{\beta-1} \quad \text { para } \lambda, \beta>0
$$

Em que: $\rho(t)=$ Função intensidade de falha (taxa de ocorrência de falhasROCOF); $t_{n}=$ Tempo da última falha; $\lambda$ e $\beta=$ Parâmetros do modelo de Crow.

Os parâmetros $\beta$ e $\lambda$ (parâmetros do modelo de Crow) são estimados pelo método da verossimilhança devido os dados históricos de ocorrências de falhas a serem utilizados são dados limitados pelo tempo até a última falha $\left(t_{n}\right)$, como mostra as equações (2.4 e 2.5) a seguir:

$$
\begin{gathered}
\beta=\frac{\mathrm{nf}}{(\mathrm{nf}-1) * \ln (t n)-\sum_{1}^{n f-1} \ln (t i)} \\
\lambda=\frac{\mathrm{nf}}{t n^{\beta}}
\end{gathered}
$$

Onde: $\mathrm{n}_{\mathrm{f}}=$ Número de falhas; $t_{\mathrm{n}}=$ Tempo da última falha; $\ln \left(t_{n}\right)=$ Logaritmo do tempo da última falha.

Com a obtenção dos valores da taxa de intensidade de ocorrência de falhas $\rho(t)$, ao longo do tempo, é possível calcular os valores de MTBF, o qual relacionado a taxa de ocorrência de falhas (ROCOF), também apresenta valores variáveis ao longo do tempo. (DIAS e PEREIRA, 2005; ASSIS, 2013). A equação (2.6) apresenta a função do MTBF.

$$
\operatorname{MTBF}=\frac{1}{\rho(t)}
$$

Conforme Modarres (1992) e Percy (2008), para sistemas reparáveis identifica-se três tipos de comportamento que a taxa de ocorrência de falhas pode tomar, decrescente, crescente ou constante, para verificar esta tendência deve-se analisar o valor tomado pelo parâmetro de Crow $\beta$. As referências quanto a forma de tendência da taxa de ocorrência de falhas em função do valor de $\beta$ apresenta-se na tabela 2.1. 
Tabela 2.1 - Valores $\beta$ para Indicar Tendência da Curva do Comportamento das Ocorrências de Falhas em Sistemas Reparáveis

$\begin{array}{ccc}\beta>1 & \text { Crescente } & \text { NHP } \\ 0<\beta<1 & \text { Descrescente } & \text { NHP } \\ \beta=1 & \text { Constante } & \text { HP }\end{array}$

Fonte: Adaptado de Modarres,Kaminskiy e Krivtsov (2009)

O valor do parâmetro $\beta$ (modelo de Crow) indica a tendência do comportamento da taxa de ocorrência de falhas (ROCOF) em sistemas reparáveis, podendo ser crescente, decrescente ou constante. Se a curva da tendência da ROCOF for crescrente ou decrescente caracteriza um processo estocástico pontual Poisson não Homogêneo (NHP) e se apresenta uma taxa de ocorrência de falhas constante caracteriza-se como um processo Poisson Homogêneo (HP).

Assis (2013) define que um processo de Poisson Homogêneo, aplicado a equipamentos reparáveis, caracteriza-se quando, a taxa de ocorrência de falhas (ROCOF) é constante.

Dias e Pereira (2005) define um processo de Poisson Não Homogêneo (NHP), como um processo que "caracteriza-se por taxa de falhas que apresenta uma tendência de dependência em relação ao tempo. Esta situação significa que as falhas apresentam uma tendência de aumentarem (taxa de falhas crescente) ou por outro lado diminuirem com o passar do tempo (taxa de falhas decrescente)".

\footnotetext{
" Perante sistemas reparáveis, a análise efetuada tem como objetivo indagar qual a tendência que a frequência de avarias apresenta, isto é, se há indícios estatísticos de taxa de avarias decrescente, constante ou crescente. Quando a análise incidir sobre um sistema reparável, o teste tem como objetivo indagar se os tempos de avaria são independentementes distribuídos ou não, constituindo um processo de Poisson homogêneo e tendo, portanto, uma taxa de avarias constante ou um processo Poisson não Homogêneo, tendo uma taxa de falhas apresentando-se com formato crescente ou decrescente". (MARTINS e LEITÃO ,2009).
}

Por meio dos MTBF $(t)$ a Taxa de ocorrência de falhas (ROCOF) é possível construir os demais indicadores de confiabilidade e desempenho da manutenção 
como a Disponibilidade $A(t)$, Mantenabilidade (referente ao cálculo do MTTR) e Confiabilidade $\mathrm{R}(t)$ e o número acumulado de falhas $\mathrm{m}(t)$, todos variáveis em função do tempo. (MODARRES; KAMINSKIY; KRIVTSOV,1999; DIAS e PEREIRA,2005; ASSIS, 2013).

As equações para cálculo destes indicadores são apresentadas nas expressões (2.7, 2.8, 2.9 e 2.10) abaixo indicadas:

$$
\begin{gathered}
\operatorname{MTTR}(t)=\frac{\operatorname{TTR}(f 1)+\operatorname{TTR} 2(f 2)+\cdots+T T R(f n)}{n f} \\
A(t)=\frac{\operatorname{MTBF}(t)}{\operatorname{MTBF}(t)+\operatorname{MTTR}(t)}=A(t)=\frac{1}{1+\rho(t) * \Gamma} \\
R(t)=e^{-\int_{0}^{t} \rho(t) d(t)} \\
m(t)=\lambda * t^{\beta}
\end{gathered}
$$

Onde: $\operatorname{MTTR}(t)=$ Tempo médio para reparo em função do tempo; TTR = Tempo para reparo; $f 1, f n=$ Falhas; $\mathrm{n}_{\mathrm{f}}=$ Número de falhas $; \boldsymbol{\Gamma}=\operatorname{MTTR} ; \rho(t)=$ Função intensidade de Falha (ROCOF); $\mathrm{R}(t)=$ Confiabilidade em sistemas reparáveis $; \mathrm{m}(t)=$ Número acumulado de falhas ao longo do tempo; $\beta$ e $\lambda=$ Parâmetros de Crow; $\operatorname{MTBF}(t)=$ Tempo médio entre falhas variável ao longo do tempo.

Martins e Leitão (2009) enfatizam que a disponibilidade é uma característica dos sistemas reparáveis e compõe-se de atributos: confiabilidade e mantenabilidade. Poder-se-à dizer que a função Disponibilidade $A(t)$ traduz a proporção de tempo em que o sistema se encontra em condições para ser usado e assim poder realizar as suas funções específicas e a Confiabilidade $R(t)$ traduz-se na probabilidade da falha não ocorrer num determinado período estipulado.

Em um sistema reparável a avaria de qualquer de seus componentes pode ser influenciada por várias ocorridas anteriormente. Com efeito, se a qualidade das atividades de manutenção estiver melhorando ou se as tomadas de decisão, provenientes da análise da tendência de falhas, estiverem sendo e implementadas 
de forma eficaz é de se esperar que a frequência de avarias diminua progressivamente, aumentando o TBF entre elas.

Logo, o estudo do comportamento de falhas em sistemas reparáveis faz importante, pois, por meio desta análise é possível adotar procedimentos e intervenções de manutenção para manter certo nível de confiabilidade e prover melhorias no desempenho do sistema industrial.

\subsubsection{Metodologias e Ferramentas para Análise de Falhas Aplicadas à Engenharia de Manutenção e Confiabilidade}

A manutenção centrada em confiabilidade (MCC ou RCM- Reliability Centered Maintenance) fundamentalmente é uma metodologia aplicada a manutenção industrial de máquinas e equipamentos, para determinar ações que assegurem o funcionamento das instalações industriais continuamente, cumprindo sua função em nivel de desempenho requerido durante a campanha operacional.

\footnotetext{
"Manutenção Centrada na Confiabilidade (RCM) é um processo utilizado para determinar os requesitos de manutenção de qualquer ativo físico em seu contexto operacional". (MOUBRAY, 2000).
}

A RCM conduz a um programa de manutenção que se concentra na análise de falhas e identificação do adequado tipo de manutenção, visando aumentar a confiabilidade do sistema operacional, com os seguintes objetivos principais (KOBBACY e MURTHY, 2008; FOGLIATTO e RIBEIRO, 2009):

> Decisão de estratégia de manutenção, apontando os parâmetros necessários das tarefas de manutenção como: intervalos de manutenção preventiva, quantidade de lubrificante utilizado, tempo esperado para intervenção de manutenção, entre outros;

> Análise do projeto de máquina a fim de melhorar a mantenabilidade. Desenvolver tarefas de manutenção preventiva e/ou preditiva que podem estabelecer a confiabilidade e segurança de máquinas e equipamentos levando em consideração a otimização dos recursos humanos e materiais utilizados para 
execução dos trabalhos como: custo de manutenção, alocação de mão-de-obra, contratação de terceiros, modificação de projeto, entre outros. Assim, atingindo os objetivos de manutenção e produtividade com custos minimos;

$>$ Estabelecer procedimentos de manutenção que visam a redução e/ou eliminação de ocorrência de falhas ou amenizar danos secundários resultantes da falha;

$>\quad$ Estabelecer políticas de manutenção que incluam melhoria na segurança dos trabalhadores, proteção ambiental e qualidade do produto.

Essencialmente, processo de RCM é aplicado durante a fase de projeto do maquinário para influenciar a confiabilidade e mantenabilidade do mesmo. Posteriormente, conforme o caso pode-se replicar as análises durante a fase operacional do maquinário, para sustentar um eficaz programa de manutenção com base na experiência no campo e melhorias no projeto.

Assis (2004), Siqueira (2005), Bloom (2006), Rausand e Vatn (2008) e Ferjencik (2014), sustentam que para implantação do processo de manutenção centrada na confiabilidade, deve-se garantir que todas as seguintes perguntas sejam respondidas de forma eficaz, como por sua sequência, indicada na figura 2.4.

Figura 2.4- Perguntas que direcionam a implantação de MCC

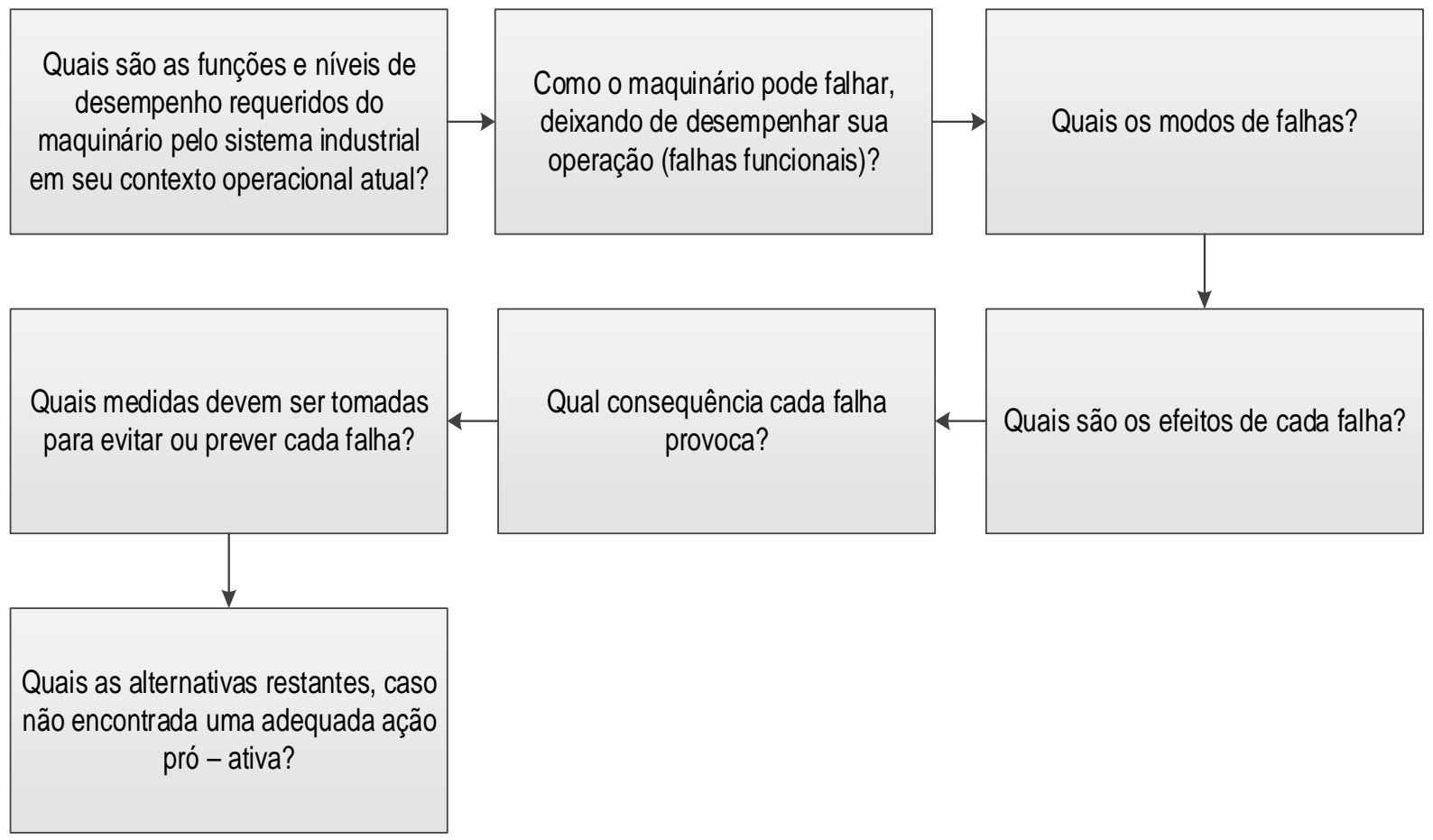

Fonte: Adaptado de: Assis (2004); Siqueira (2005); Bloom (2006); Rausand e Vatn (2008) 
Para Ferjencik (2014), a solução para estas questões (figura 2.4) é estruturada através da aplicação de métodos e ferramentas, direcionadas a análise de falhas e das causas.

Existem várias técnicas utilizadas (relacionadas a RCM) para realizar análise falhas e riscos, os quais influenciam na confiabilidade de máquinas e equipamentos, as mais amplamente utilizadas na área industrial são o FMEA ou modos de falha e análise de efeitos (Failure Mode and Effects Analysis), a FTA - Árvore de Falhas (Fault Tree Analysis) e os diagramas de rede de confiabilidade (blocos funcionais) que auxiliam nas decisões da RCM.

\subsubsection{1 Árvore funcional}

Diagrama funcional de sistemas, também conhecido por árvore funcional, auxilia no processo de análise de falhas por mostrar herarquicamente os sistemas e os subsistemas que compõe, bem como, identificar as funções dos componentes e a dependência entre eles durante o funcionamento do sistema principal.

Este diagrama ilustra a estrutura hierárquica do sistema, caracterizada por um nível superior, composto por níveis progressivamente mais baixos. A hierarquia é representada em forma de árvore, onde o nó raiz representa a função ou nível principal do sistema, e cada ramo descreve um nível mais baixo de detalhe, até o nível de componente. (SIQUEIRA, 2005; FOGLIATTO e RIBEIRO,2009).

A árvore funcional é basicamente a representação gráfica das funções dos susbsistemas e componentes de um sistema principal, sendo este uma máquina e/ou equipamento. A figura 2.5 ilustra um modelo de estrutura de árvore funcional de um helicóptero de caça. 
Figura 2.5 - Árvore Funcional de um Helicóptero de Caça

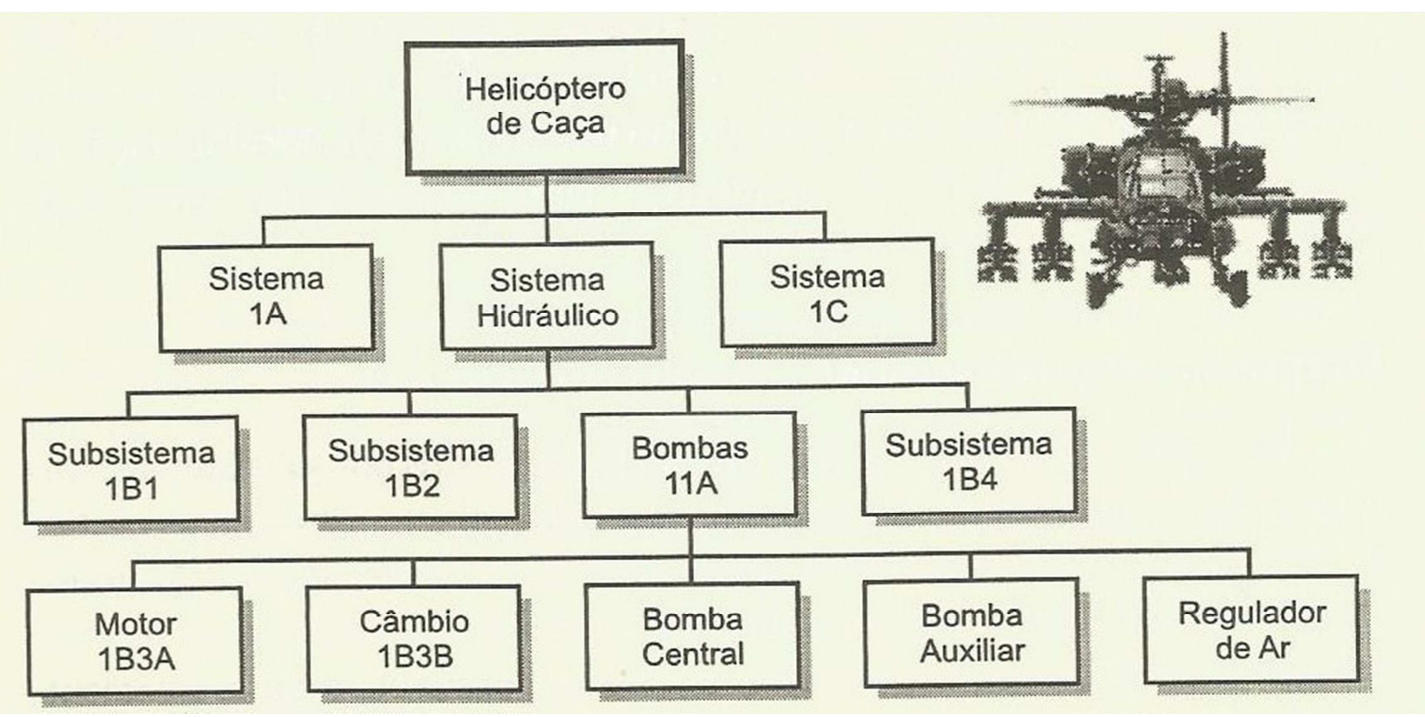

Fonte: Adaptado de Siqueira (2005)

Permite identificar detalhadamente cada parte que compõe o dispositivo ou sistema proporcionando melhor conhecimento da funcionalidade de cada parte do sistema. Isto permite uma acuracidade na análise de falhas, pois é possível verificar o impacto do modo de falha na função de cada componente do sistema e a consequência da ocorrência de falha no sistema como um todo.

2.3.4.2 Método de análise de risco de falha: Árvore de falhas ( FTA )

Análise de falhas com aplicação do método da árvore de falhas (FTA- Fault Tree Analysis) é amplamente utilizada para avaliação da confiabilidade e da engenharia de segurança em sistemas e/ou processos produtivos complexos e críticos. Esta análise de risco de falha suporta as decisões de manutenção em atividades críticas e complexas.

O foco da análise por meio da FTA é caracterizado pela identificação das falhas que provocam o evento crítico, o qual pode provocar riscos elevados em aspectos de segurança patrimonial, integridade pessoal e econômica para as empresas. (SIQUEIRA, 2005; AVEN, 2008). 
Assis (2004), Siqueira (2005), Fogliatto e Ribeiro (2009), definem o conceito de árvore de falha como sendo uma representação gráfica de várias combinações de falhas básicas que levam à ocorrência de eventos (evento topo) indesejáveis, considerando um evento de falha um estado anormal do sistema, ou seja, falhas críticas e/ou crônicas. O evento indesejado aparece como o evento de topo e está ligado a eventos primários (causas) por declarações de eventos e portas lógicas, formando a estrutura da árvore de falhas.

“ A FTA oferece opções para a realização de análise qualitativa e quantitativa de confiabilidade de um sistema com a definição de seu estado indesejável. Em seguida, analisa-se todo sistema, em termos do seu funcionamento e do meio de operação, para determinar todas as formas possíveis em que pode ocorrer o evento indesejável. (RAUSAND e VATN,2008).

A figura 2.6 mostra os passos envolvidos na realização de uma análise de falhas árvore (FTA).

Figura 2.6 - Característica da Análie FTA

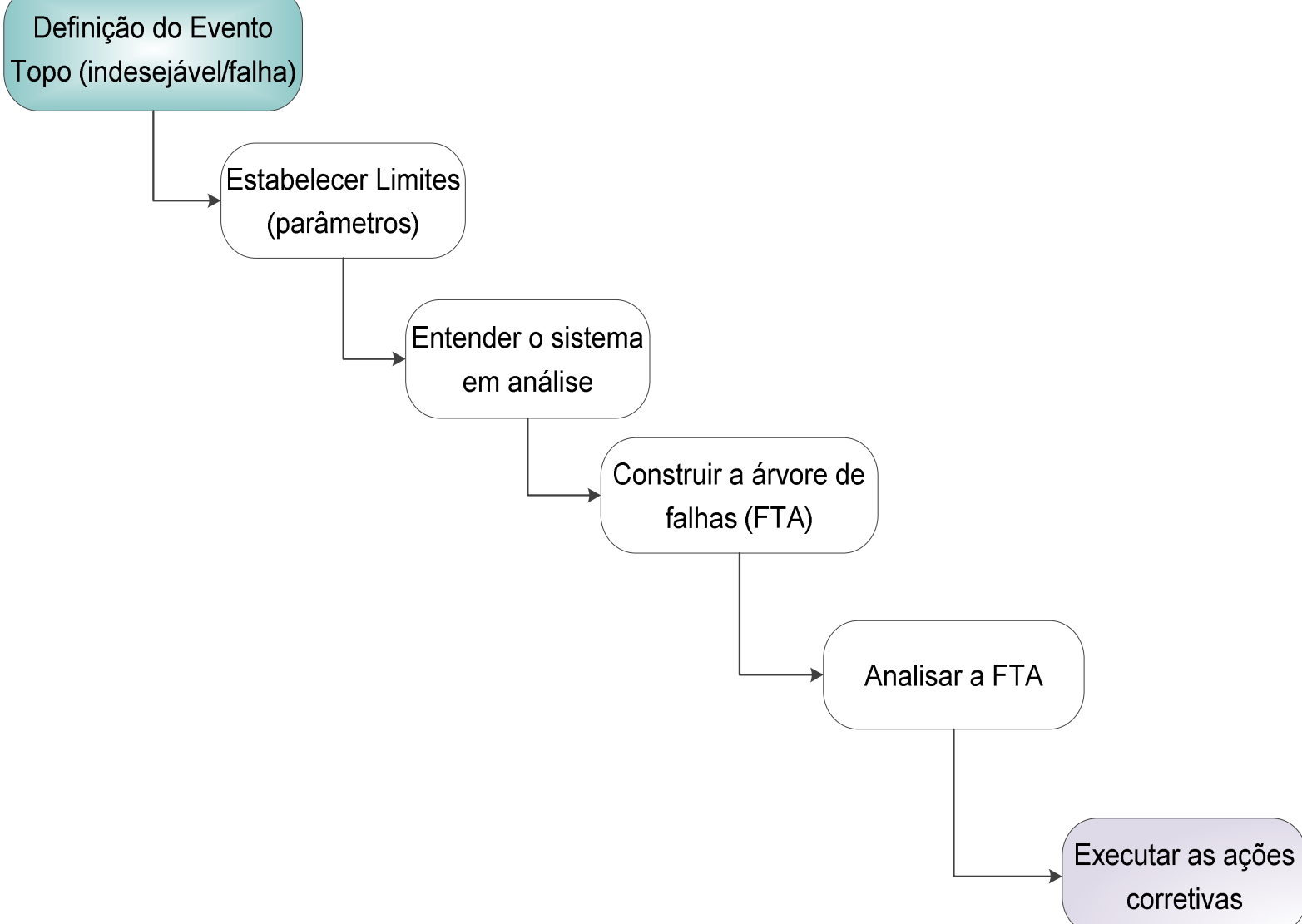


A metodologia de análise de falha por meio da FTA estrutura-se através da associação entre as falhas básicas ou causas (eventos primários), por meio da lógica booleana. Os eventos primários são estatísticamente independentes, e estão ligados ao evento topo (falha crítica), a base das probabilidades atribuídas aos eventos primários direciona a obtenção do valor da probabilidade de ocorrência do evento de topo (falha crítica). (CHAPMAN e WARD, 2003; MYERS, 2010; SHARMA e SHARMA, 2010; RAO et al., 2010).

Para construção gráfica da FTA utliza-se os símbolos e portões lógicos apresentados no quadro 2.4 .

Quadro 2.4 - Portões Lógicos da FTA

\begin{tabular}{|c|c|c|}
\hline Símbolo & Portão Lógico & Função \\
\hline & Inibição & $\begin{array}{l}\text { Evento de entrada sé é permitido ao } \\
\text { evento de saída se o evento condicional } \\
\text { ocorrer. }\end{array}$ \\
\hline & Evento básico & Eventos associados a falhas básicas. \\
\hline & $\mathrm{E}$ (prioridade) & $\begin{array}{l}\text { Evento de saída ocorre se os eventos de } \\
\text { entrada ocorrerem na ordem da esquerda } \\
\text { para a direita. }\end{array}$ \\
\hline & Ou (exclusivo) & $\begin{array}{l}\text { Evento de saida ocorre se um, mas não } \\
\text { ambos, dos eventos de entrada ocorrer. }\end{array}$ \\
\hline & Evento & Eventos de saída de portões lógicos. \\
\hline & Condicional & $\begin{array}{l}\text { Evento condicional, usado em conectores } \\
\text { de inibicão. }\end{array}$ \\
\hline & $\begin{array}{l}\text { Evento não } \\
\text { desenvolvido }\end{array}$ & $\begin{array}{l}\text { Eventos não realizados por não ter maior } \\
\text { importância ou não haver informacões } \\
\text { suficiente que o fundamentem. }\end{array}$ \\
\hline
\end{tabular}


(Conclusão)

\begin{tabular}{|c|c|c|}
\hline Símbolo & Portão Lógico & Função \\
\hline & ou & $\begin{array}{c}\text { Evento de saída que só ocorre se todos } \\
\text { os eventos de entrada ocorrer. }\end{array}$ \\
\hline & Transferência & $\begin{array}{c}\text { Evento de saída que ocorre se pelo } \\
\text { menos um dos eventos de entrada } \\
\text { ocorrer. }\end{array}$ \\
\hline possivelmente em outra página.
\end{tabular}

Fonte: Adaptado de: Siqueira (2005); Fogliatto e Ribeiro (2009); Souza (2003)

Os eventos estruturados na FTA possuem relações entre as portas lógicas, tais portas possuem propriedades associativas, distributivas, comutativas, etc. Estas propriedades possibiltam o cálculo da probabilidade e confiabilidade do sistema e/ou componente analisado. Conhecendo esta probabilidade é importante determinar uma ação sobre os componentes cuja probabilidade de causar as falhas seja elevada em comparação as demais a fim de reduzir o risco de ocorrência.

Esta ferramenta é utilizada para analisar vários problemas relacionados à manutenção industrial, sendo útil para identificar todas as possíveis causas da falha (evento topo) em todos os possíveis níveis associados com o sistema, além de identificar a relação entre causas (eventos primários). Ela pode, assim, melhorar a concepção de qualquer sistema especificado, produto ou processo, além de apontar conformidade ou não do sistema em relação com os requisitos ambientais e de segurança.

"A FTA é um recurso valido para análise de confiabilidade de sistemas e/ou dispositivos basicamente é uma técnica gráfica utilizada para ajudar na identificação de todas as causas potenciais de uma falha, ou seja, estrutura lógica que permite definir a origem do problema". (SOUZA, 2003). 
As consequências e incertezas associadas aos eventos de falhas geram impacto econômico indesejado, além de provocarem possíveis acidentes com a perda de vidas e / ou danos ao meio ambiente, assim as análises de risco nestas falhas catastróficas são de extrema importância para identificar o problema (análise qualitativa) e verificar a sua probabilidade de ocorrência (análise quantitativa) determinando as melhores práticas de manutenção, redução e/ou eliminação dos riscos.

2.3.4.3 FMEA (Failure Mode and Effects Analysis) - Análise de modo e efeito de falhas

Outra ferramenta aplicada na análise de confiabilidade é a análise de modo e efeito de falha ou FMEA (Failure Mode and Effects Analysis). Esta técnica determina sistematicamente as causas básicas de falhas e define medidas para reduzir seus efeitos.

\footnotetext{
"FMEA pode ser descrito como um grupo de atividades sistemática destinadas a: (a) reconhecer e avaliar uma falha potencial de um produto / processo e os efeitos dessa falha, (b) identificar ações que possam eliminar ou reduzir a probabilidadeque a falha potencial ocorra, e (c) documentar todo o processo". (DOWN,2008).
}

Para Moubray (2000), Wang e Goel (2010) e Sharma e Sharma (2010), a análise FMEA é basicamente uma abordagem qualitativa para determinar a confiabilidade, manutenção e segurança de um determinado projeto ou processo, levando em consideração potenciais falhas e seus efeitos resultantes, para tanto, durante a análise são identificadas e descritas as funções necessárias dos sistemas, propriedades de entrada para o seu pleno funcionamento e assim apontar as maneiras nas quais o sistema pode deixar de funcionar. A figura 2.7 ilustra uma tabela modelo de aplicação da análise FMEA. 
Figura 2.7 - Modelo de Roteiro para Tabela FMEA

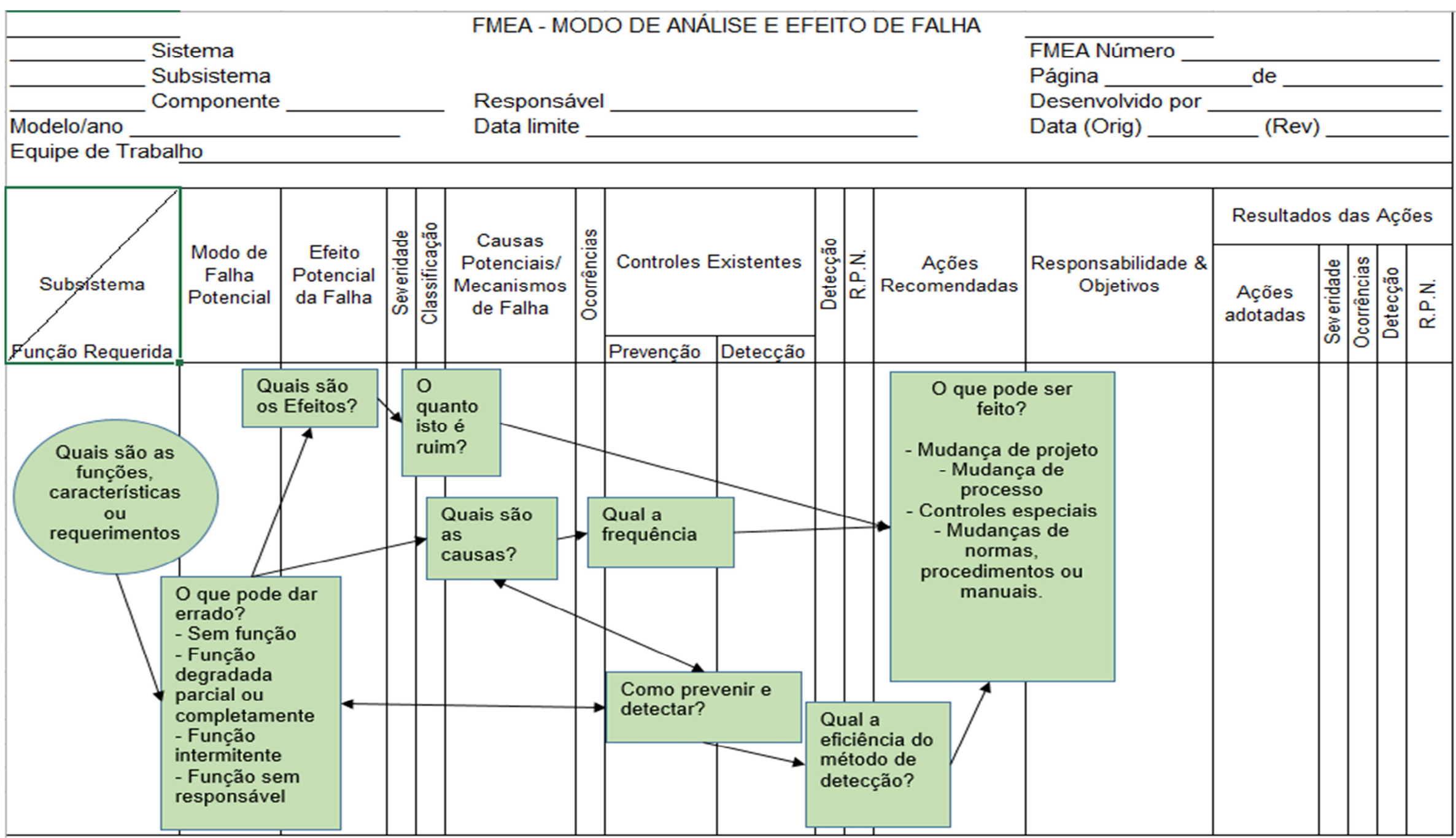

Fonte: Adaptado de Down (2008) 
A análise de modos e efeitos de falha (FMEA) permite a análise funcional, de forma qualitativa, mais aprofundada e detalhada dos efeitos da causa raiz (que origina a falha) no funcionamento do sistema, possibilitando maior entendimento das particularidades deste. (SIQUEIRA, 2005; ISENHOUR; 2008; RAUSAND e VATN, 2008; SHARMA e SHARMA, 2010).

Algumas das vantagens do método FMEA é que ele emprega um procedimento sistemático para categorizar falhas e identifica todos os possíveis modos de falha e seus efeitos sobre o desempenho de máquinas e equipamentos, sendo de grande aplicabilidade na manutenção industrial para comparar o projeto de máquinas quanto a mantenabilidade destes, auxiliando a identificação de métodos de detecção de várias falhas possíveis e ações corretivas para evitá-las.

Para Fogliatto e Ribeiro (2009), a análise FMEA é uma técnica cuja aplicação está voltada para aspectos qualitativos, por isso aborda as causas operacionais das falhas para avaliação do sistema industrial. A figura 2.8 mostra os passos usuais de aplicação da análise de falha funcional por meio do FMEA.

Figura 2.8 - Passos para Aplicação da Análise FMEA

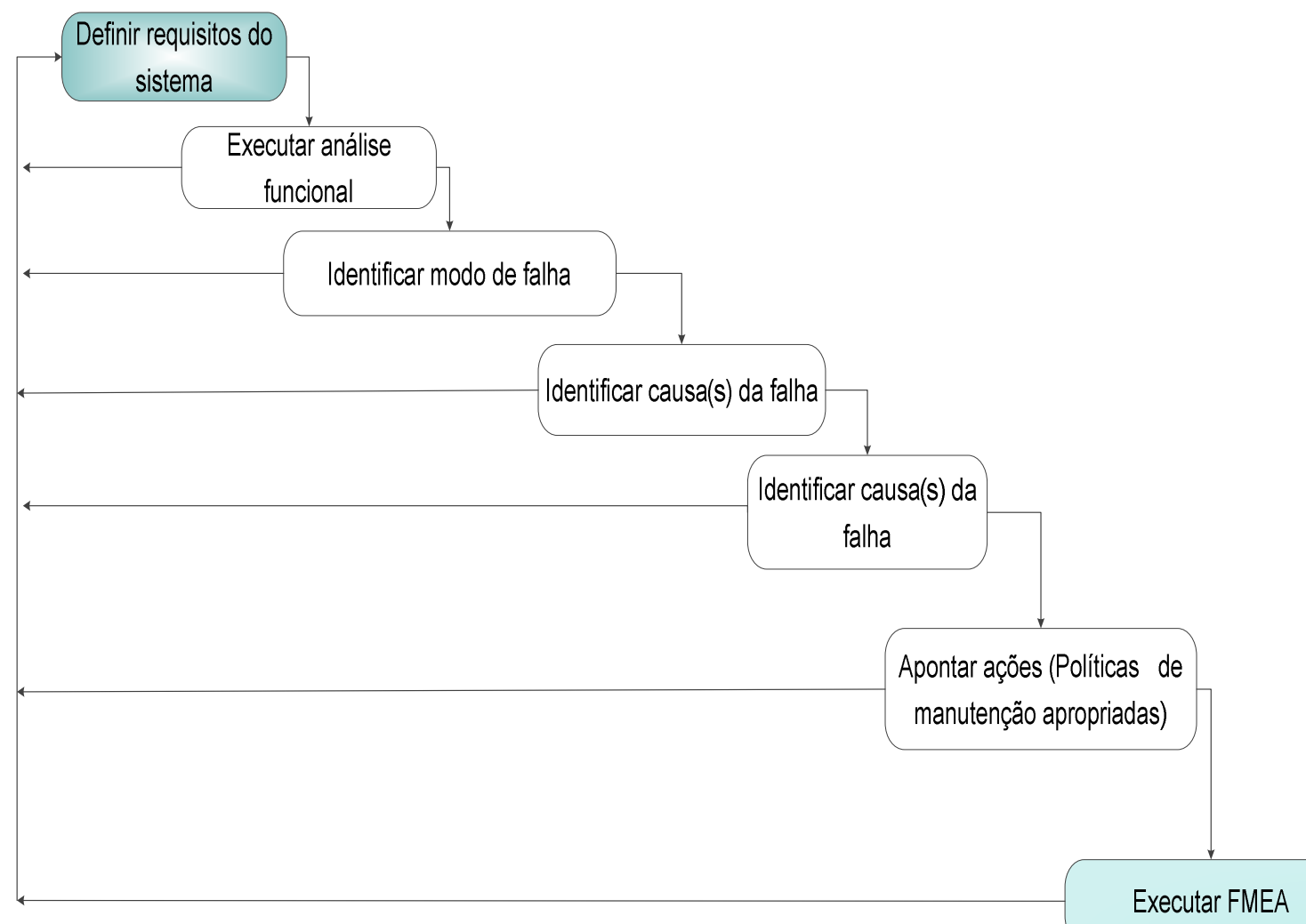

Fonte: Adaptado de Lafraia (2001) 
A aplicação do FMEA faz parte do processo de implantação da RCM(Reliability Centered Maintenance). FMEA auxila na identificação e no detalhamento das potencias falhas que podem ocorrer em máquinas e equipamentos e assim direciona a adoção de adequada estratégia de manutenção para eliminar e/ou reduzir a probabilidade de ocorrer a falha potencial identificada.

Logo, a aplicação do FMEA no processo de análise de falhas facilita a tomada de decisão quanto a execução das atividades de manutenção sob o maquinário e consequentemente proporcionar garantia de confiabilidade e disponibilidade no processo e produto.

\subsection{GESTÃO DE RISCOS - ISO 31000 APLICADA À MANUTENÇÃO INDUSTRIAL}

Sistemas industriais sofrem influência de fatores externos e internos que impactam no atingimento de suas metas, estes impactos gera uma incerteza sobre os objetivos da corporação, a este efeito de incerteza dá-se o nome de risco.

Todas as atividades de uma organização envolvem risco. As organizações gerenciam o risco, identificando-o e analisando-o e, em seguida, avaliando se o risco deve ser modificado pelo tratamento do risco a fim de atender a seus critérios de risco. Ao longo de todo este processo, elas comunicam e consultam as partes interessadas e monitoram e analisam criticamente o risco e os controles que o modificam, a fim de assegurar que nenhum tratamento de risco adicional seja requerido. (ABNT NBR ISO 31000 Gestão de riscos - Principios e diretrizes, 2009).

\footnotetext{
"A gestão de risco e segurança envolve todo tipo de sistema produtivo e objetiva definir uma sistemática de aplicação de ferramentas e técnicas para reduzie e/ou eliminar a expoisção ao risco e garantir um nível de segurança desejado". (MANZINI et al., 2011).
}

Para a ABNT NBR ISO 31000 (2009), intitulada Gestão de Riscos-Princípios e diretrizes, a análise de risco é o processo de compreender a natureza do risco e determinar seu nível de criticidade, dando base para avaliação do risco e assim 
tomar decisão sobre o tratamento deste. A figura 2.9 apresenta o processo cíclico de tratamento de risco.

Figura 2.9 - Princípios Básicos de Análise de Risco

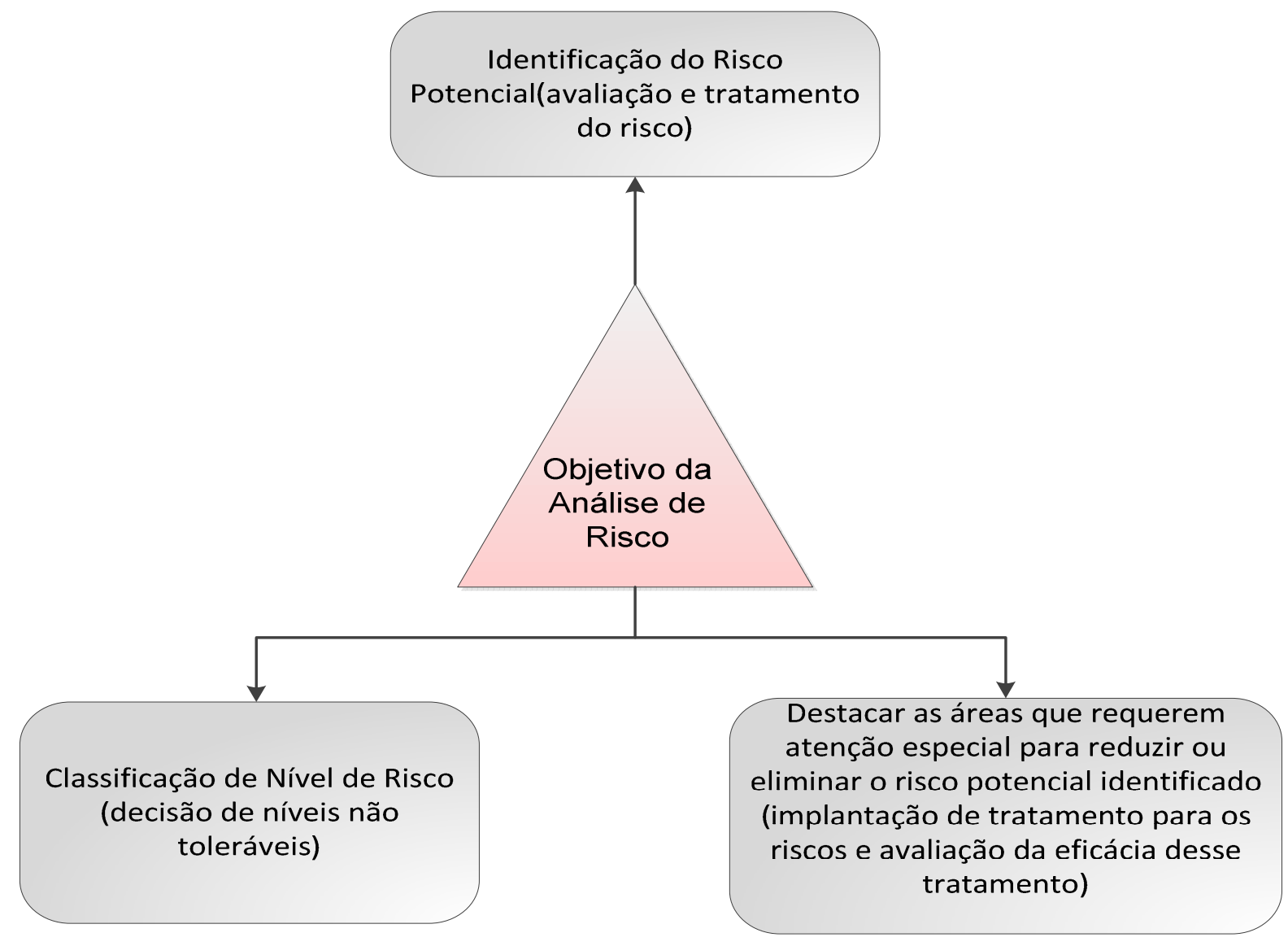

Fonte: Adaptado da Norma ISO 31000 (2009)

Conforme ABNT NBR ISO 31000 (2009), a aplicação da gestão de risco em processos produtivos, através de uma estrutura física e administrativa adequada proporciona benefícios como:

Aumento da probabilidade de atingir as metas definidas pela empresa;

$>\quad$ Implantar uma gestão pró-ativa em identificar e tratar os riscos através de toda organização;

Atender normas internacionais e requesitos legais e regulatórios pertinentes;

Melhorar o retorno financeiro;

Estabelecer base confiável das partes interessadas;

Otimizar os recursos e ferramentas para gestão de risco; 
$>\quad$ Minimizar perdas;

$>\quad$ Prevenção de acidentes;

$>\quad$ Melhorar a aprendizagem organizacional.

A gestão de risco é ampla para toda a organização, sendo assim necessária uma comunicação eficaz entre os responsáveis pela implementação dos princípios da gestão de riscos e as partes interessadas.

Desta forma, todos podem compreender os fundamentos sobre quais decisões devem ser tomadas e as razões pelas quais especificamente são requeridas, a fim de promover uma análise crítica da estrutura da gestão de risco e avaliar a eficácia desta através de monitoramento e vigilância. O fluxograma da figura 2.10 resume o processo de gestão de risco estabelecido na ABNT NBR ISO 31000:2009.

Figura 2.10 - Processo de Gestão de Risco: Visão Geral da Norma 31000:2009

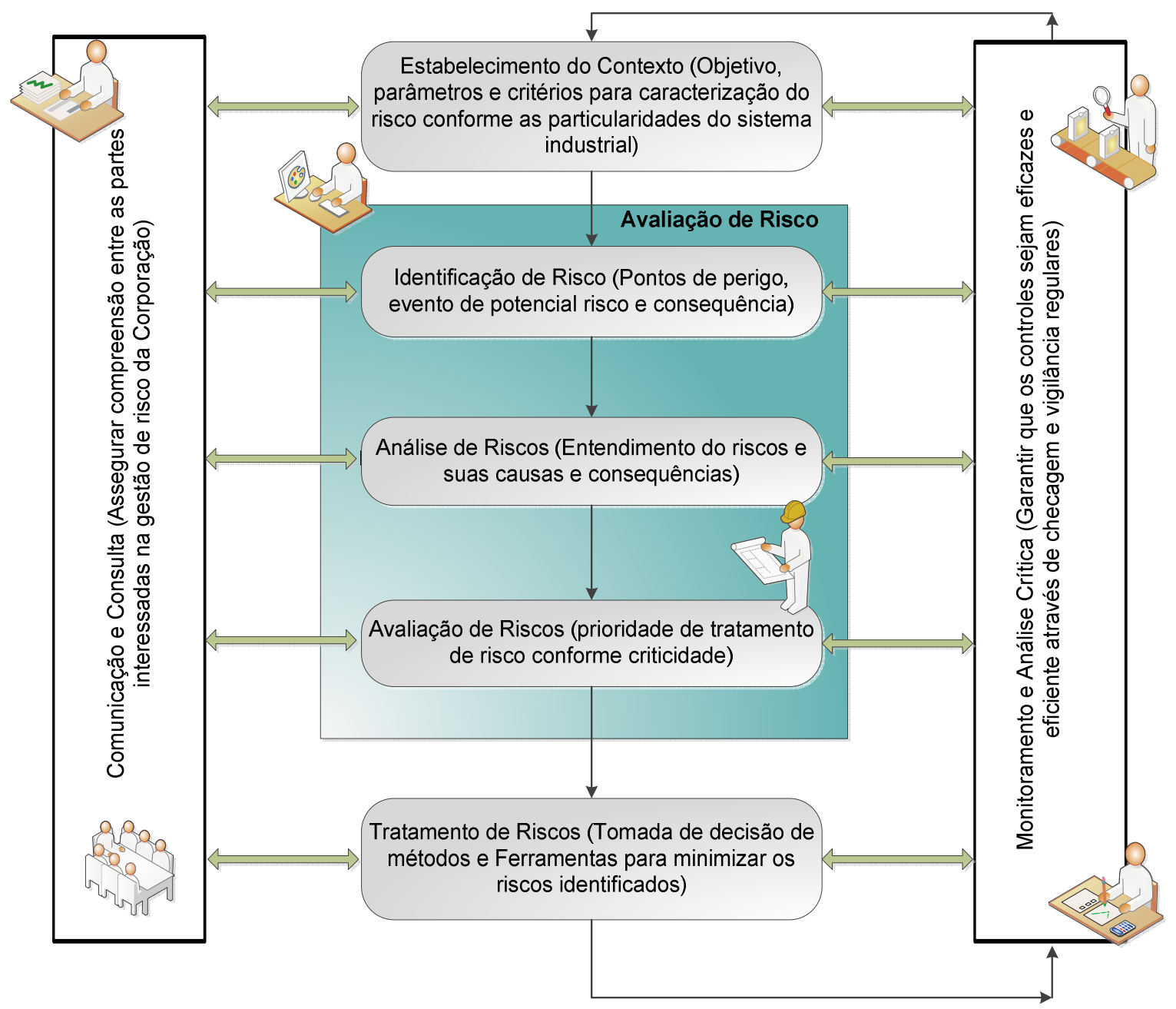

Fonte: Adaptado da Norma ISO 31000 (2009) 
A confiabilidade na manutenção industrial tem estreita relação para com o gerenciamento de risco, a qual se aplica métodos e técnicas para análise de falhas, causas e seus perigos (consequências), sendo a maioria destes métodos são aplicados no meio industrial pela implantação da metodologia RCM.

Dentro da manutenção industrial é necessário aplicar a gestão de risco durante a execução dos serviços bem como na análise de falhas, quando estas possam originar perigo a vidas humanas e/ou perdas econômicas importantes (valores consideráveis). Para tanto se desenvolvem e aplicam-se métodos de análise de riscos para identificação das possíveis causas de falha e o grau de riscos que estes representam. (AVEN e VINNEM, 2007).

Dey (2001), Assis (2004) e Manzin et al. (2011), para aplicar a gestão de riscos em análise de falhas na manutenção segue-se as principais etapas:

I - Identificação das potenciais causas de falhas e suas classificações segundo a um grau de criticidade que elas representam ao processo produtivo;

II - Estabelecimento das condições sob as quais as falhas apresentam a maior probabilidade de ocorrência e/ou maior gravidade;

III - Estabelecimento das ações preventivas e corretivas para minimizar a gravidade das consequências das falhas;

IV - Análise dos custos e benefícios para justificar o investimento nas ações identificadas para reduzir e/ou eliminar a fonte de risco;

V - Monitoramento da eficiência das ações executadas, bem como, sugerir melhorias no projeto, construção e operação dos ativos industriais buscando melhoria contínua.

A análise das probabilidades de eventos de risco e sua gravidade (criticidade) levam em consideração as consequências de dano físico as instalações industriais, aos funcionários e ao meio ambiente, bem como, o impacto finaceiro das perdas que o potencial evento de risco pode ocasionar a corporação. 
" O maior desafio da gestão de risco na manutenção é determinar os pontos de maior risco, estabelecer programas de manutenção que não somente descubram as causas das falhas, mas também reduzam e/ou eliminem 0 risco da falha do equipamento, sendo eficaz em custo, reduzindo a probabilidade do evento catastrófico resultante da falha do equipamento". (LAFRAIA, 2001).

A figura 2.11 apresenta um modelo de fluxo do processo de avaliação de risco aplicado na manutenção industrial, o qual visa auxiliar no planejamento das tarefas de manutenção, de forma que elas sejam executadas e obtenham como resultado a redução dos riscos e a um custo mínimo necessário.

Figura 2.11 - Elementos de Análise para Identificação de Potencial Risco nas Tarefas de Manutenção Industrial

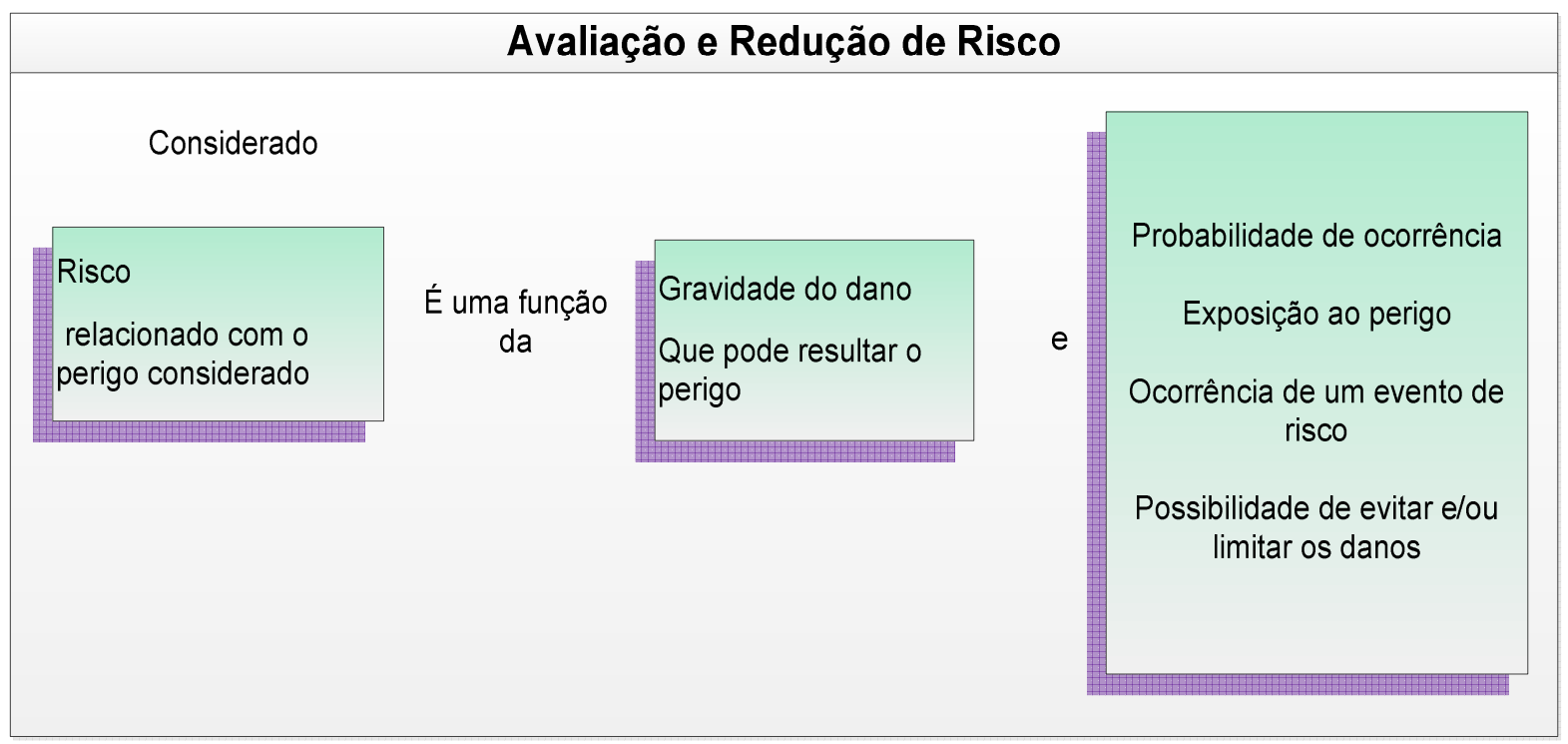

Fonte: Adaptado de Manzini et al. (2011)

A exposição ao perigo durante as tarefas rotineiras de manutenção industrial é proveniente de vários fatores, que vão desde estruturais até gerenciais. Estes fatores podem causar o evento de risco e expor ao perigo tanto a instalação fabril quanto dos colaboradores da empresa. Dentre os principais motivos relacionados a manutenção industrial (que podem provocar potencial risco), elenca-se, na figura 2.12, os mais comuns identificados nas tarefas deste setor. 
Figura 2.12 - Ações Relacionadas à Área de Manutenção Industrial que Podem Causar Potencial Evento de Risco

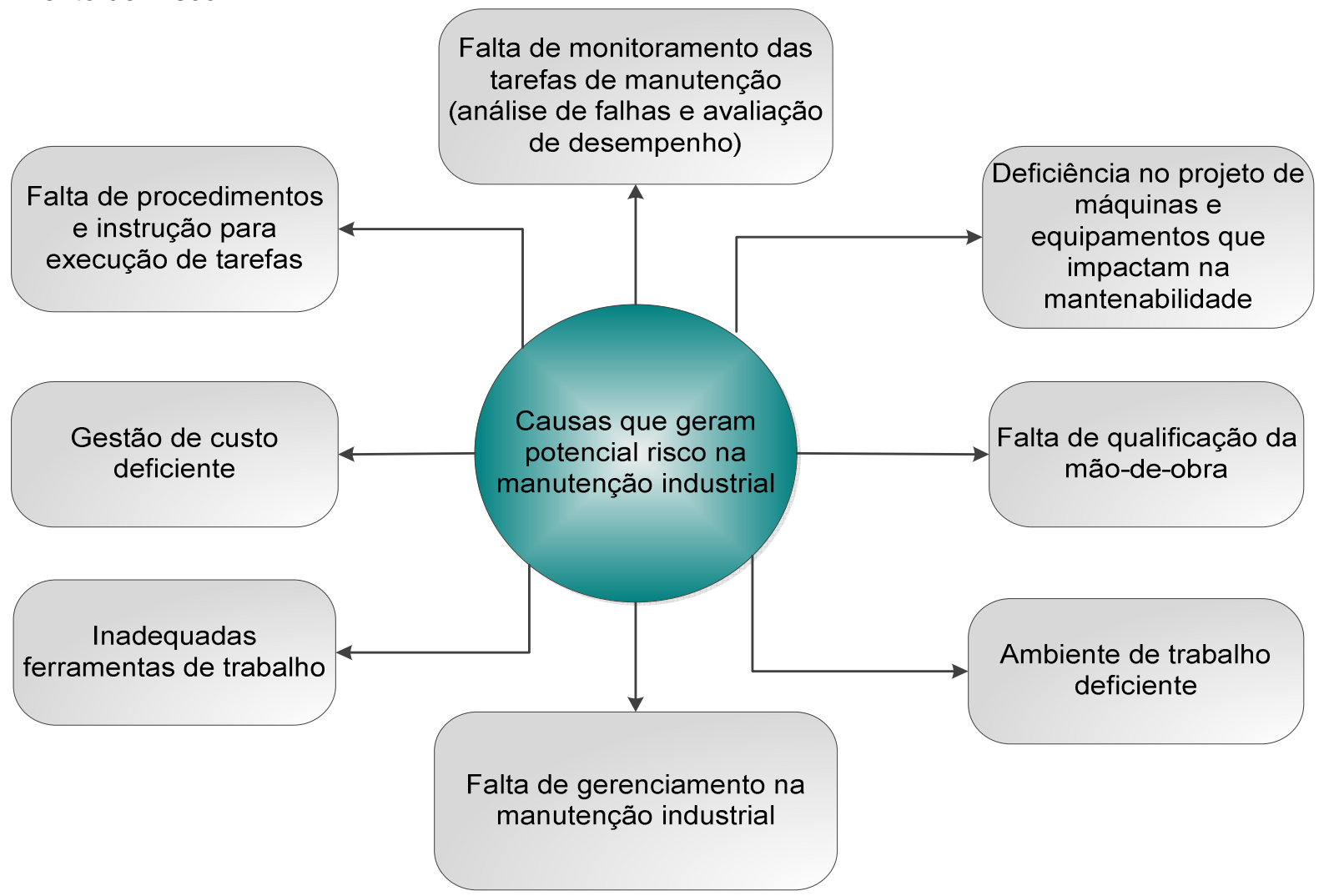

Fonte: Adaptado de Manzini et al.(2011)

Logo, a avaliação de risco nas atividades de manutenção industrial deve ser estruturada e cumprida de forma eficaz, objetivando a redução e/ou eliminação dos riscos de falha de máquinas e equipamentos, principalmente as quais, durante a sua ocorrência, podem expor riscos a segurança humana e operacional da planta industrial.

A implantação de gestão de risco nas tarefas de manutenção reverte-se não só em segurança, mas também na redução de custos com o aumento de vida útil do maquinário (diminuição de desgaste e reparos) e aumento de produtividade através da prevenção de falhas.

A engenharia de manutenção incorpora-se no processo de análise de risco de um sistema industrial por meio dos efeitos das ações e políticas de manutenção adotadas sobre o maquinário e a relação entre o desempenho e operação de máquinas e equipamentos (e até mesmo no nível de componentes) no indicador global de risco. A figura 2.13 apresenta-se uma visão geral entre a integração das atividades de manutenção e a análise de risco em um complexo industrial. 
Figura 2.13 - Relação entre as Ações de Manutenção Industrial e Análise de Risco

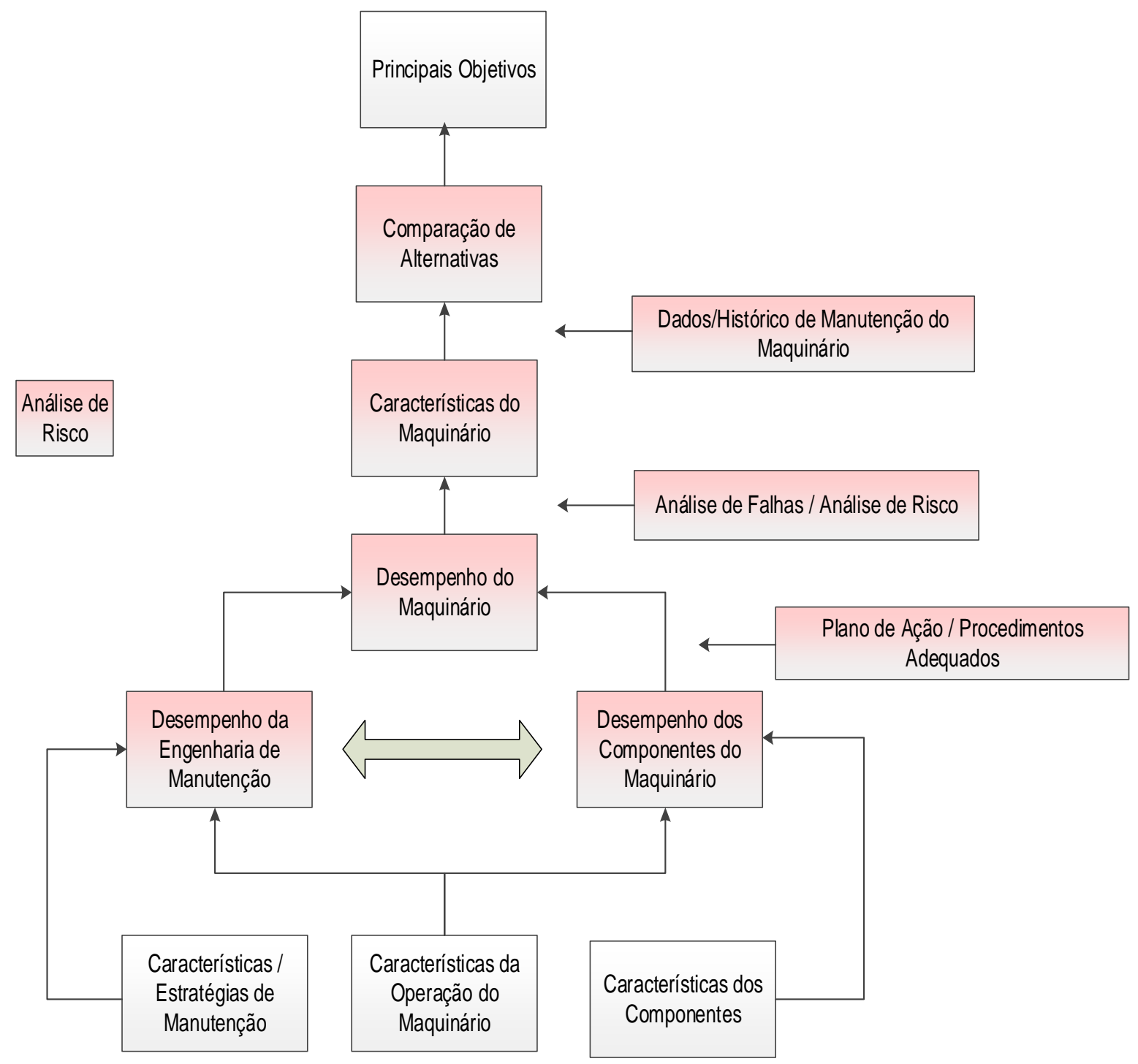

Fonte: Adaptado de Aven (2008)

E evidente que ações de manutenção inferem diretamente no sistema industrial tanto para prevenir quanto para gerar um potencial foco de risco a seguranca humana e ou a integridade estrutural de máquinas e equipamentos.

Logo, a análise de risco feita conjuntamente com a análise de falhas em complexo industrial, direcionando ações e estratégias de manutenção para evitar as ocorrências de falhas e ao mesmo tempo eliminar risco nas instalações industriais. 


\subsection{HACCP (HAZARD ANALYSIS AND CRITICAL CONTROL POINTS) - ANÁLISE DE PERIGOS E PONTOS CRÍTICOS DE CONTROLE}

Análise de Perigos e Pontos Críticos de Controle (APPCC), mais comumente utilizada à nomenclatura em inglês Hazard Analysis and Critical Control Point (HACCP) é um sistema de gestão de qualidade do produto. Fundamenta-se em analisar as diversas etapas da cadeia de produção de alimentos indicando e analisando os riscos potenciais de contaminação dos alimentos devido a perigos físicos, químicos ou microbiológicos que podem interfeir na qualidade e integridade do produto, determinando medidas preventivas para controlar esses perigos através da técnica de controle e monitoramento desses pontos críticos (PCC's).

O HACCP é uma técnica de sentido comum para o controle de perigos e segurança dos alimentos por meio de um sistema preventivo de controle dos riscos e perigos, porém não é um sistema livre de riscos, mas desenhado para minimizálos durante as etapas do processo de fabricação de alimentos. (USA FDA Code 21, Title 9, Part 416: HACCP, 2013).

O sistema de Análise de Perigos e Pontos Críticos de Controle (HACCP) é adotado pela Comissão do Codex Alimentarius (Lei ou Códigos dos Alimentos), a qual define o HACCP como uma ferramenta que permite avaliar os perigos e estabelecer sistemas de controle focados. (CODEX ALIMENTARIUS, CAC/RCP rev. 4, 2003).

\footnotetext{
"Este Sistema (HACCP) é uma abordagem científica e sistemática para o controle de processo, elaborado para prevenir a ocorrência de problemas, assegurando que os controles são aplicados em determinadas etapas no sistema de produção de alimentos, onde possam ocorrer perigos ou situações críticas". (PORTARIA n 46 - MAPA, 1998).
}

A metodologia e método de aplicação do sistema HACCP é padronizado e regido pela Comissão da Higiene e Segurança de Alimentos do Codex Alimentarius (CAC) e consiste na abordagem sistemática e estruturada de identificação de perigos e da probabilidade da sua ocorrência em todas as etapas da produção de alimentos, definindo medidas para o seu controle e monitoramento. (CODEX ALIMENTARIUS, CAC/RCP rev. 4, 2003; GEBARIN, 2009; MENSAH e JULIEN, 2011). 
Uma empresa pode obter o certificado da aplicacao do sistema HACCP por meio da norma ISO 22000, mas para implantação do HACCP deve ter como prérequisito a execução das Boas Práticas Fabricação (BPF) e os Princípios Gerais de Higiene dos Alimentos pertinentes ao Codex Alimentarius. (SCHMIDT e RODRICK, 2003; ARVANITOYANNIS, 2009).

A figura 2.14 aponta a estrutura a ser implantada para aplicação do sistema HACCP em plantas industriais fabricantes de alimentos.

Figura 2.14 - Sequência para Aplicação do Sistema HACCP

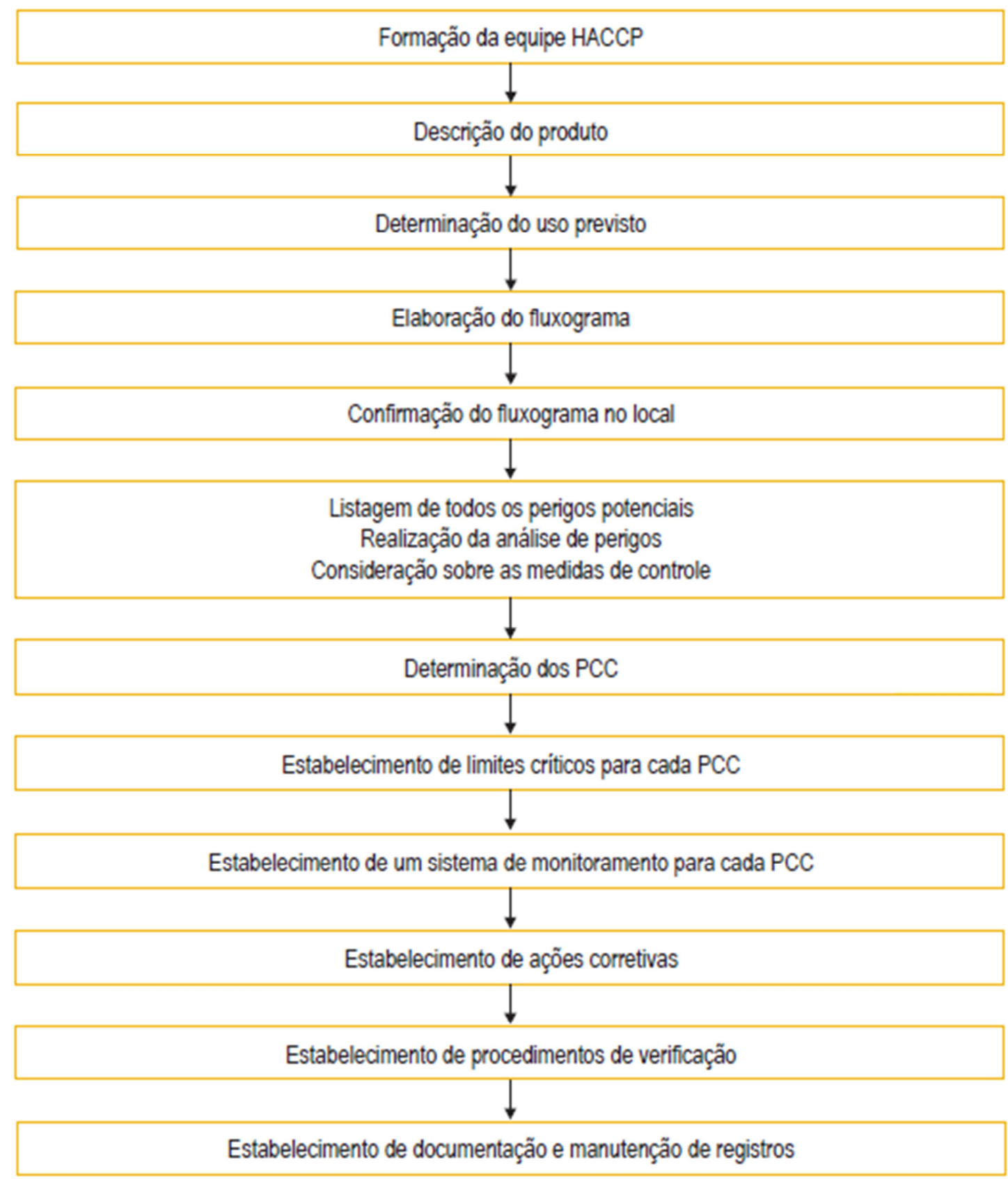

Fonte: Adaptado de: Portaria $n^{\circ} 40$ - MAPA (1997); Portaria $n^{\circ} 46$ - MAPA (1998); Vaz, Moreira e Hog (2000) e Codex Alimentarius Commission CAC/RCP- rev. 4 (2003) 
Mediante a ABNT NBR ISO 22000 (2006), intitulada sistemas de gestão da segurança de alimentos - requisitos para qualquer organização na cadeia produtiva de alimentos, todos os prováveis perigos, considerando toda a cadeia produtiva de alimentos, sejam identificados e avaliados, incluindo os que podem estar associados ao tipo de processo e instalações utilizadas. Assim, esta norma fornece os meios para determinar e documentar certos perigos identificados e o modo que precisam ser controlados por uma organização do ramo de fabricação de alimentos e bebidas.

A ISO 22000 contribui para o melhor entendimento do HACCP, pois visa estruturar um sistema industrial específico de gestão de risco aplicável em qualquer tipo de processamento de alimentos e de comercialização que pode ser incorporado ao sistema de gestão da qualidade. (FAERGEMAND, 2008; MENSAH e JULIEN, 2011).

O HACCP aplica técnicas e instrumentos para identificar os riscos associados com o processamento de alimentos e os pontos dentro do processo produtivo onde esses riscos podem ser eliminados, estabelecendo medidas preventivas e ações corretivas para cada foco de risco alimentar identificado.

Conforme a Portaria $n^{\circ} 46$ emitida pelo órgão MAPA (98), entende-se como benefícios do sistema de APPCC:

> Conferir um caráter preventivo às operações do processo de industrialização;

$>$ Orientar para uma atenção seletiva nos pontos críticos de controle;

> Sistematizar e documentar os pontos críticos;

> Garantir a produção de alimentos inócuos;

$>$ Oferecer oportunidade de incrementar a produtividade e a competitividade.

Para alcançar estes benefícios, as indústrais de alimentos devem controlar os potenciais perigos aos alimentos por meio do uso de sistemas como o HACCP, devendo:

> Identificar todas as etapas críticas do processo para a segurança do alimento;

> Implementar os procedimentos efetivos de controle nessas etapas;

> Monitorar os procedimentos de controle para garantir sua eficácia contínua; e

$>$ Revisar os procedimentos de controle periodicamente e sempre que houver mudança nas operações. 
O Codex Alimentarius (2003) define análise de perigos como "o processo de coleta e avaliação de informações sobre os perigos e as condições que determinam a sua presença, para decidir quais são significativos para a segurança dos alimentos, devendo, portanto, ser tratados no plano HACCP”.

Para efetuar a análise de perigos, por meio da sistemática do HACCP, identifica-se os pontos críticos de controle do processo (PCC's) e analisa seus impactos quanto a qualidade e integridade do produto durante as etapas do processo produtivo, a fim de executar ações preventivas e até mesmo corretivas para a contaminação do produto. A figura 2.15 mostra o fluxograma para identificação de um PCC e modo de tratamento para monitorá-lo.

Figura 2.15 - Sete Princípios Envolvidos no Desenvolvimento e Operação do Programa HACCP

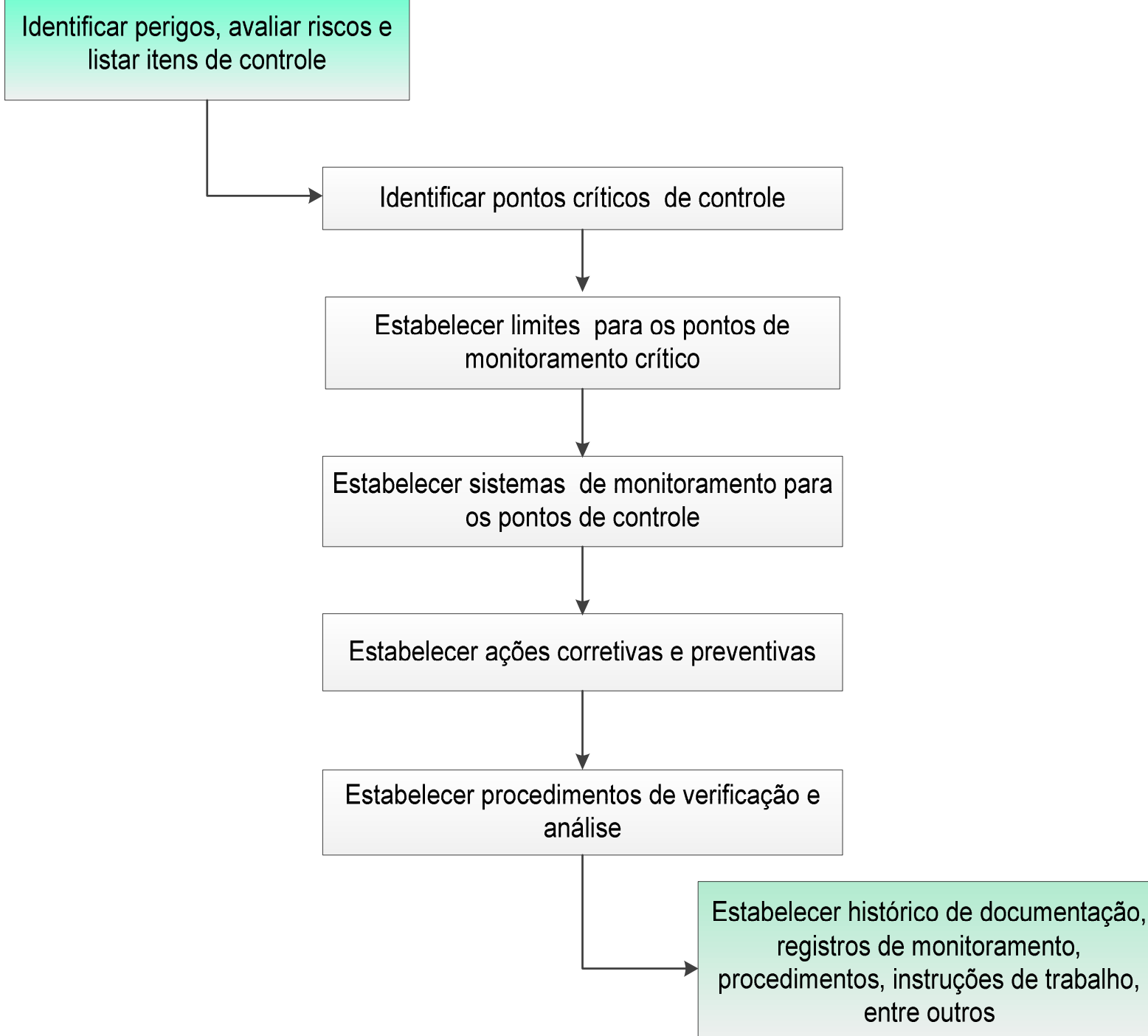

Fonte: Adaptado de: Furtini e Abreu (2005) e Arvanitoyannis (2009) 
Um PCC é definido no Código Federal de Regulamentações dos EUA (referente à FDA no título 9, capítulo 111, parte 417.1, 2013) como qualquer ponto, etapa ou procedimento no qual se aplicam medidas preventivas para manter um perigo identificado sob controle, com objetivo de eliminar, prevenir ou reduzir os riscos ao processo produtivo.

Schmidt e Rodrick (2003), Furtini e Abreu (2005) enfatizam que o sistema HACCP é recomendado por organismos internacionais como a OMC (Organização Mundial do Comércio), FAO (Food and Agriculture Organization of the United Nations - Organização das Nações Unidas para Alimentação e Agricultura), OMS (Organização Mundial de Saúde em inglês WHO - World Health Organization) e pelo MERCOSUL e é exigido pela Comunidade Européia e pelos Estados Unidos.

No Brasil, o Ministério da Saúde (MS), MAPA e ANVISA dispõem de portarias e normativas com o objetivo de adoção do Sistema APPCC pelas Indústrias Alimentícias como nas portarias $n^{\text {os }} 1428$ (93), 326 (97), 40 (97), 46 (98) e resolução RDC 10 (2003), entre outras.

Em sua essência, estas legislações dispõem de instruções para elaboração, implantação e fiscalização do APPCC enfatizando:

> Importância do HACCP como um sistema para garantir a qualidade do processo e produto;

> Estrutura de gestão de risco por meio da identificação e análise dos pontos críticos de controle (PCC's), considerando-se os perigos biológicos, químicos e físicos, gerando ações corretivas e preventivas, incluindo todas as ações tomadas em resposta a um desvio;

$>$ Manutenção de registros e documentos quanto aos registros das etapas de implantação do sistema HACCP, os quais são passíveis de fiscalização pelos órgãos competentes;

$>$ Necessidade de atendimento às legislações nacionais e internacionais, no que tange aos aspectos sanitários de qualidade e de integridade econômica;

$>$ Descrições técnicas quanto às instalações industriais, processo de limpeza e desinfecção, materiais de construção de equipamentos e utensílios aplicados à área de manipulação de alimentos, estrutura de Utilidades (ventilação, climatização, temperatura, entre outros);

$>$ Requisitos de higiene e capacitação profissional dos trabalhadores; 
> Monitoramento da qualidade da água e matéria prima aplicada a produção de alimentos;

> Fluxogramas de etapas para construção do sistema de gestão e certificação.

Resalta-se que a implantação de um sistema HACCP também depende do modelo do processo produtivo, do desempenho de máquinas e equipamentos e da qualificação da mão-de-obra operacional e administrativa, fatores chaves para qualquer estratégia preventiva. (USA FDA Code 21 CRF, Title 9, Part 416: HACCP, 2013).

O sistema HACCP contribui para uma maior satisfação do consumidor, torna as empresas mais competitivas, amplia as possibilidades de conquista de novos mercados, nacionais e internacionais, além de propiciar a redução de perdas de matérias-primas, embalagens e produto.

\subsection{NORMAS E LEGISLAÇÕES APLICADAS A INDÚSTRIAS DE ALIMENTOS DIRECIONADAS A ENGENHARIA DE MANUTENÇÃO}

A indústria de alimentos tem crescido muito nos últimos anos, tanto no volume de produção interna quanto no volume das exportações, tornando as questões de qualidade e segurança o principal foco no setor de processamento de alimentos, exigindo cada vez mais minimizar os riscos e impacto da contaminação de alimentos.

Azevedo (2007) argumenta que, embora o Brasil tenha tido um crescimento no setor de manufatura de alimentos, com aproximadamente 43.200 empresas, sendo $85 \%$ micro, $11 \%$ pequenas, $3 \%$ médias e $1 \%$ grande, o país ainda não possui uma legislação específica para a realização das atividades de lubrificação e seleção dos tipos de lubrificantes voltados para este segmento. Utiliza-se de normas e legislação internacionais como o HACCP e ISO 22000, geridas e auditadas pelo MAPA e ANVISA.

No Brasil não existem regras específicas para lubrificantes de grau alimentício e os agentes envolvidos parecem não possuir condições suficientes para fiscalizar 
este setor. A ANVISA define apenas que as indústrias alimentícias devem seguir as Boas Práticas de Fabricação (BPF). Já a ANP (Agência Nacional do Petróleo, Gás Natural e Biocombustíveis), para registrar um lubrificante de grau alimentício, solicita o registro do produto na organização sanitária dos Estados Unidos, a NSF (National Sanitization Foundation) (BNDES, Relatório Potencial de Diversificação da Indústria Química Brasileira - Parte 3 Óleos Lubrificantes, 2014).

Este cenário possibilita que muitas indústrias brasileiras (do ramo de alimentos) utilizem lubrificantes minerais (tóxicos) comuns ou empreguem 0 lubrificante de grau alimentício de modo inadequado, ou ainda, não tenham obrigatoriedade de manter uma política de lubrificação adequada, gerando assim um potencial risco a qualidade do produto por meio de vazamentos, gotejamentos, excesso de lubrificante, entre outros.

\footnotetext{
"Hoje não existe obrigatoriedade de uso de lubrificantes de grau alimentício, existem hoje no mercado aproximadamente $80 \%$ das empresas de alimentos que utilizam lubrificantes convencionais (minerais tóxicos) em seus processos produtivos". (KOLYA, 2012).
}

Logo, "o resultado desta lacuna regulatória é, de acordo com especialistas, que muitas fábricas brasileiras de alimentos não obedecem à determinação internacional de utilizar lubrificantes específicos food grades. Com regras mais claras e fiscalização mais rigorosa, as empresas que operam no ramo de alimentos teriam de se adequar”. (BNDES, Relatório Potencial de Diversificação da Indústria Química Brasileira - Parte 3 Óleos Lubrificantes, 2014).

Instruções normativas e manuais emitidos pelos órgãos ANVISA e MAPA, indicam uso de óleo branco (white oils) na lubrificação de máquinas e equipamentos empregado em fabricação de alimentos, referenciando que estes são aprovados pelo pelo Código de Regulamentações para alimentos e medicamento dos Estados Unidos contidas nas diretrizes da FDA (Agência Americana de Medicamentos e Alimentos - Food and Drug Administration).

As instruções normativas e legislações, emitidas principalmente pela ANVISA e MAPA, fundamentam-se em conceitos e nomenclaturas específicas relacionadas à gestão da qualidade e gestão de risco no ramo industrial de alimentos, assim o quadro 2.5 apresenta as definições dos conceitos aplicados às atividades tanto de 
engenharia de manutenção quanto de engenharia de qualidade deste tipo de ramo industrial.

Quadro 2.5 - Conceitos Aplicados em Indústria de Alimentos Direcionados para Engenharia de Manutenção e Qualidade

\begin{tabular}{|c|c|c|c|}
\hline Conceito & Definição & Normativa & $\begin{array}{l}\text { Órgão } \\
\text { Competente } \\
\text { Emissor }\end{array}$ \\
\hline \multirow[t]{2}{*}{ Alimento } & \multirow{2}{*}{$\begin{array}{l}\text { I - Toda substância ou mistura de } \\
\text { substâncias, no estado sólido, líquido, } \\
\text { pastoso ou qualquer outra forma } \\
\text { adequada, destinadas a fornecer ao } \\
\text { organismo humano os elementos normais } \\
\text { à sua formação, manutenção e } \\
\text { desenvolvimento. } \\
\text { II - É qualquer substância, destinada ao } \\
\text { consumo humano, seja processada, semi- } \\
\text { processada ou em seu estado natural, } \\
\text { incluídas as bebidas, goma de mascar e } \\
\text { qualquer outra substância utilizada em } \\
\text { sua elaboração, preparo ou tratamento }\end{array}$} & $\begin{array}{c}\text { Decreto-Lei } \\
\text { no 986 } \\
(1969)\end{array}$ & $\begin{array}{c}\text { Repúlblica } \\
\text { Federativa } \\
\text { do Brasil: } \\
\text { Ministros da } \\
\text { Marinha de } \\
\text { Guerra, do } \\
\text { Exército e da } \\
\text { Aeronáutica } \\
\text { Militar }\end{array}$ \\
\hline & & $\begin{array}{l}\text { Portaria no } \\
1428(1993)\end{array}$ & $\begin{array}{c}\text { MS } \\
\text { (Ministério da } \\
\text { Saúde) }\end{array}$ \\
\hline $\begin{array}{l}\text { Produto } \\
\text { alimentício }\end{array}$ & $\begin{array}{l}\text { Todo alimento derivado de matéria-prima } \\
\text { alimentar ou de alimento in natura, ou } \\
\text { não, de outras substâncias permitidas, } \\
\text { obtido por processo tecnológico adequado }\end{array}$ & $\begin{array}{c}\text { Decreto-Lei } \\
\text { no 986 } \\
(1969)\end{array}$ & $\begin{array}{c}\text { Repúlblica } \\
\text { Federativa } \\
\text { do Brasil: } \\
\text { Ministros da } \\
\text { Marinha de } \\
\text { Guerra, do } \\
\text { Exército e da } \\
\text { Aeronáutica } \\
\text { Militar }\end{array}$ \\
\hline $\begin{array}{l}\text { Alimento apto } \\
\text { para o } \\
\text { consumo } \\
\text { humano }\end{array}$ & $\begin{array}{l}\text { Considerado como alimento que atende } \\
\text { ao padrão de identidade e qualidade pré- } \\
\text { estabelecido, nos aspectos higiênico- } \\
\text { sanitários e nutricionais }\end{array}$ & $\begin{array}{l}\text { Portaria } n^{0} \\
326(1997)\end{array}$ & $\begin{array}{l}\text { MS } \\
\text { (Ministério da } \\
\text { Saúde) }\end{array}$ \\
\hline Adequado & $\begin{array}{l}\text { Entende-se como suficiente para alcançar } \\
\text { a finalidade proposta }\end{array}$ & $\begin{array}{l}\text { Portaria no } \\
326(1997)\end{array}$ & $\begin{array}{l}\text { MS } \\
\text { (Ministério da } \\
\text { Saúde) }\end{array}$ \\
\hline $\begin{array}{l}\text { Produção de } \\
\text { Alimentos }\end{array}$ & $\begin{array}{l}\text { É o conjunto de todas as operações e } \\
\text { processos efetuados para obtenção de um } \\
\text { alimento acabado }\end{array}$ & $\begin{array}{l}\text { Portaria } n^{0} \\
326(1997)\end{array}$ & $\begin{array}{l}\text { MS } \\
\text { (Ministério da } \\
\text { Saúde) }\end{array}$ \\
\hline
\end{tabular}


(Continuação)

\begin{tabular}{|c|c|c|c|}
\hline Conceito & Definição & Normativa & $\begin{array}{l}\text { Órgão } \\
\text { Competente } \\
\text { Emissor }\end{array}$ \\
\hline $\begin{array}{l}\text { Elaboração de } \\
\text { Alimentos }\end{array}$ & $\begin{array}{l}\text { É o conjunto de todas as operações e } \\
\text { processos praticados para a obtenção } \\
\text { de um alimento terminado }\end{array}$ & $\begin{array}{l}\text { Portaria no } \\
368 \text { (1997) }\end{array}$ & MAPA \\
\hline $\begin{array}{l}\text { Fracionamento } \\
\text { de Alimentos }\end{array}$ & $\begin{array}{l}\text { São as operações pelas quais se } \\
\text { fraciona um alimento sem modificar sua } \\
\text { composição original. }\end{array}$ & $\begin{array}{l}\text { Portaria no } \\
368(1997)\end{array}$ & MAPA \\
\hline $\begin{array}{l}\text { Manipulação de } \\
\text { Alimentos }\end{array}$ & $\begin{array}{l}\text { São as operações que se efetuam } \\
\text { sobre a matéria prima até o produto } \\
\text { terminado, em qualquer etapa do seu } \\
\text { processamento, armazenamento e } \\
\text { transporte }\end{array}$ & $\begin{array}{l}\text { Portaria no } \\
368 \\
(1997)\end{array}$ & MAPA \\
\hline $\begin{array}{l}\text { Cadeia } \\
\text { Alimentar }\end{array}$ & 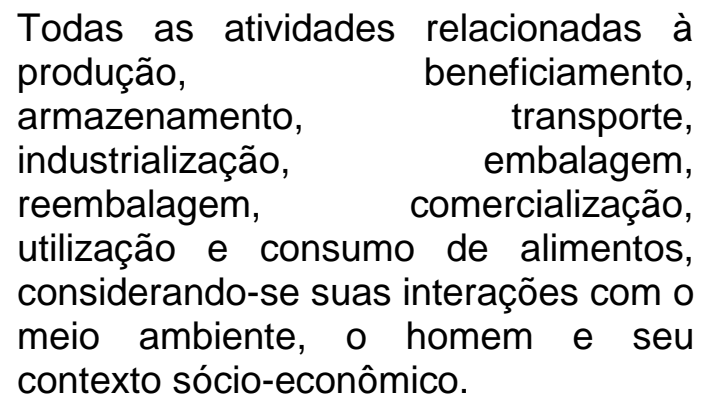 & $\begin{array}{l}\text { Portaria no } \\
1428 \\
(1993)\end{array}$ & $\begin{array}{l}\text { MS (Ministério } \\
\text { da Saúde) }\end{array}$ \\
\hline \multirow{3}{*}{$\begin{array}{l}\text { Estabelecimento } \\
\text { de Alimentos } \\
\text { Elaborados/ } \\
\text { Industrializados }\end{array}$} & \multirow{3}{*}{$\begin{array}{l}\text { I - Local onde se fabrique, produza, } \\
\text { manipule, beneficie, acondicione, } \\
\text { conserve, transporte, armazene, } \\
\text { deposite para venda, distribua ou } \\
\text { venda alimento, matéria-prima } \\
\text { alimentar, alimento in natura, aditivos } \\
\text { intencionais, materiais, artigos e } \\
\text { equipamentos destinados a entrar em } \\
\text { contato com os mesmos. } \\
\text { II - É o espaço delimitado que } \\
\text { compreende o local e a área que o } \\
\text { circunda, onde se efetiva um conjunto } \\
\text { de operações e processos que tem } \\
\text { como finalidade a obtenção de um } \\
\text { alimento elaborado, assim como o } \\
\text { armazenamento e transporte de } \\
\text { alimentos e/ou matéria prima }\end{array}$} & $\begin{array}{l}\text { Decreto-Lei } \\
\text { no } 986 \\
(1969)\end{array}$ & $\begin{array}{l}\text { Repúlblica } \\
\text { Federativa do } \\
\text { Brasil: } \\
\text { Ministros da } \\
\text { Marinha de } \\
\text { Guerra, do } \\
\text { Exército e da } \\
\text { Aeronáutica } \\
\text { Militar. }\end{array}$ \\
\hline & & $\begin{array}{l}\text { Portaria } n^{\circ} \\
368(1997)\end{array}$ & MAPA \\
\hline & & $\begin{array}{l}\text { Portaria no } \\
326 \text { (1997) }\end{array}$ & $\begin{array}{l}\text { MS (Ministério } \\
\text { da Saúde) }\end{array}$ \\
\hline $\begin{array}{l}\text { Equipamentos } \\
\text { para produção } \\
\text { de alimentos }\end{array}$ & $\begin{array}{l}\text { I - É aquele em contato direto com } \\
\text { alimentos que se utiliza durante a } \\
\text { elaboração, funcionamento, armazena- } \\
\text { mento, comercialização e consumo de } \\
\text { alimentos. }\end{array}$ & $\begin{array}{c}\mathrm{RDC} \mathrm{n}^{\circ}=91 \\
(2001)\end{array}$ & ANVISA \\
\hline
\end{tabular}


(Continuação)

\begin{tabular}{|c|c|c|c|}
\hline Conceito & Definição & Normativa & $\begin{array}{l}\text { Órgão } \\
\text { Competente } \\
\text { Emissor }\end{array}$ \\
\hline $\begin{array}{c}\text { Equipamentos } \\
\text { para produção } \\
\text { de alimentos }\end{array}$ & $\begin{array}{l}\text { Estão incluídos nesta denominação os } \\
\text { recipientes, máquinas, correias } \\
\text { transportadoras, tubulações, válvulas, } \\
\text { utensílios e similares } \\
\text { II - Equipamentos para indústria de } \\
\text { alimentos como aqueles que em } \\
\text { contato direto com alimentos que se } \\
\text { utiliza durante a elaboração, } \\
\text { funcionamento, armazenamento, } \\
\text { comercialização e consumo de } \\
\text { alimentos. Estão incluídos nesta } \\
\text { denominação os recipientes, máquinas, } \\
\text { correias transportadoras, tubulações, } \\
\text { aparelhagens, acessórios, válvulas, } \\
\text { utensílios e similares. }\end{array}$ & $\begin{array}{c}\text { Portaria } \mathrm{n}^{\circ} \\
1428 \\
(1993)\end{array}$ & $\begin{array}{c}\text { MS (Ministério } \\
\text { da Saúde) }\end{array}$ \\
\hline \multirow[t]{4}{*}{$\begin{array}{l}\text { Embalagem } \\
\text { para produtos } \\
\text { alimentícios }\end{array}$} & \multirow{4}{*}{$\begin{array}{l}\text { I - Qualquer forma pela qual o alimento } \\
\text { tenha sido acondicionado, guardado, } \\
\text { empacotado ou envasado. } \\
\text { II - Todos os recipientes como latas, } \\
\text { garrafas, caixas de papelão, outras } \\
\text { caixas, sacos ou materiais para } \\
\text { envolver ou cobrir tais como papel } \\
\text { laminado, películas, plástico, papel } \\
\text { enverado e tela. } \\
\text { III - É o material que está em contato } \\
\text { direto com alimentos destinado a } \\
\text { contê-los, desde sua produção até sua } \\
\text { entrega ao consumidor, com a } \\
\text { finalidade de protegê-los de agentes } \\
\text { externos, de alterações e de } \\
\text { contaminações, assim como de } \\
\text { adulterações. }\end{array}$} & $\begin{array}{c}\text { Decreto-Lei } \\
\text { no 986 } \\
(1969)\end{array}$ & $\begin{array}{c}\text { Repúlblica } \\
\text { Federativa do } \\
\text { Brasil: } \\
\text { Ministros da } \\
\text { Marinha de } \\
\text { Guerra, do } \\
\text { Exército e da } \\
\text { Aeronáutica } \\
\text { Militar. }\end{array}$ \\
\hline & & $\begin{array}{l}\text { Portaria } n^{\circ} \\
326(1997)\end{array}$ & $\begin{array}{l}\text { MS (Ministério } \\
\text { da Saúde) }\end{array}$ \\
\hline & & $\begin{array}{c}\text { Portaria no } \\
1428 \text { (1993) }\end{array}$ & $\begin{array}{c}\text { MS (Ministério } \\
\text { da Saúde) }\end{array}$ \\
\hline & & $\begin{array}{c}\mathrm{RDC} \mathrm{n}^{\circ} 91 \\
(2001)\end{array}$ & ANVISA \\
\hline
\end{tabular}


(Continuação)

\begin{tabular}{|c|c|c|c|}
\hline Conceito & Definição & Normativa & $\begin{array}{l}\text { Órgão } \\
\text { Competente } \\
\text { Emissor }\end{array}$ \\
\hline \multirow{3}{*}{$\begin{array}{l}\text { Manual de } \\
\text { Boas } \\
\text { Práticas de } \\
\text { Fabricação }\end{array}$} & \multirow{3}{*}{$\begin{array}{l}\text { Documento que descreve as operações } \\
\text { realizadas pelo estabelecimento, } \\
\text { incluindo, no mínimo, os requisitos } \\
\text { sanitários dos edifícios, a manutenção } \\
\text { e higienização das instalações, dos } \\
\text { equipamentos e dos utensílios, o } \\
\text { controle da água de abastecimento, o } \\
\text { controle integrado de vetores e pragas } \\
\text { urbanas, controle da higiene e saúde } \\
\text { dos manipuladores e o controle e } \\
\text { garantia de qualidade do produto final. }\end{array}$} & $\begin{array}{l}\text { Portaria no } \\
368(1997)\end{array}$ & MAPA \\
\hline & & $\begin{array}{l}\mathrm{RDC} \mathrm{n}^{\circ} \mathrm{2} 275 \\
(2002)\end{array}$ & ANVISA \\
\hline & & $\begin{array}{l}\text { RDC no } 216 \\
(2004)\end{array}$ & ANVISA \\
\hline \multirow{4}{*}{$\begin{array}{l}\text { Boas } \\
\text { Práticas de } \\
\text { Fabricação } \\
\text { (BPF) }\end{array}$} & \multirow{2}{*}{$\begin{array}{l}\text { I - São os procedimentos necessários } \\
\text { para garantir a qualidade dos } \\
\text { alimentos. }\end{array}$} & $\begin{array}{l}\text { Portaria no } \\
1428(1993)\end{array}$ & $\begin{array}{l}\text { MS (Ministério } \\
\text { da Saúde) }\end{array}$ \\
\hline & & $\begin{array}{l}\text { Portaria } n^{\circ} \\
326(1997)\end{array}$ & $\begin{array}{l}\text { MS (Ministério } \\
\text { da Saúde) }\end{array}$ \\
\hline & \multirow[t]{2}{*}{$\begin{array}{l}\text { II - São normas de procedimentos para } \\
\text { atingir um determinado padrão de } \\
\text { identidade e qualidade de um produto } \\
\text { e/ou de um serviço na área de } \\
\text { alimentos, cuja eficácia e efetividade } \\
\text { deve ser avaliada através da inspeção } \\
\text { e/ou da investigação. }\end{array}$} & $\begin{array}{l}\text { Code of } \\
\text { Practice - } \\
\text { General } \\
\text { Principles of } \\
\text { Food } \\
\text { Hygiene } \\
(1999) \\
\end{array}$ & $\begin{array}{l}\text { CAC (Codex } \\
\text { Alimentarius } \\
\text { Commission) }\end{array}$ \\
\hline & & $\begin{array}{l}21 \text { CRF FDA } \\
\text { (2013) }\end{array}$ & FDA USA \\
\hline $\begin{array}{l}\text { Procedimen- } \\
\text { to } \\
\text { Operacional } \\
\text { Padronizado } \\
\text { - POP }\end{array}$ & $\begin{array}{l}\text { Procedimento escrito de forma objetiva } \\
\text { que estabelece instruções sequenciais } \\
\text { para a realização de operações } \\
\text { rotineiras e específicas na produção, } \\
\text { armazenamento e transporte de } \\
\text { alimentos. }\end{array}$ & $\begin{array}{c}\mathrm{RDC} \text { no } 275 \\
(2002)\end{array}$ & ANVISA \\
\hline \multirow{4}{*}{$\begin{array}{l}\text { Processo de } \\
\text { Limpeza. }\end{array}$} & \multirow{4}{*}{$\begin{array}{l}\text { Operação de remoção de terra, } \\
\text { resíduos de alimentos, sujidades e ou } \\
\text { outras substâncias indesejáveis. }\end{array}$} & $\begin{array}{c}\text { Portaria no } 26 \\
\text { (1997) }\end{array}$ & $\begin{array}{l}\text { MS (Ministério } \\
\text { da Saúde) }\end{array}$ \\
\hline & & $\begin{array}{c}\mathrm{RDC} \mathrm{n}^{\circ} 275 \\
(2002)\end{array}$ & ANVISA \\
\hline & & CAC (2003) & $\begin{array}{l}\text { Codex } \\
\text { Alimentarius } \\
\text { Commission) }\end{array}$ \\
\hline & & $\begin{array}{c}\mathrm{RDC} \mathrm{n}^{\circ} 216 \\
(2004)\end{array}$ & ANVISA \\
\hline
\end{tabular}


(Continuação)

\begin{tabular}{|c|c|c|c|}
\hline Conceito & Definição & Normativa & $\begin{array}{l}\text { Órgão } \\
\text { Competente } \\
\text { Emissor }\end{array}$ \\
\hline \multirow{5}{*}{$\begin{array}{l}\text { Processo de } \\
\text { Desinfecção }\end{array}$} & \multirow{4}{*}{$\begin{array}{l}\text { I - Operação de redução, por método } \\
\text { físico e ou agente químico, do número } \\
\text { de micro-organismos a um nível que } \\
\text { não comprometa a inocuidade do } \\
\text { alimento. } \\
\text { II - É a redução, através de agentes } \\
\text { químicos ou métodos físicos } \\
\text { adequados, do número de micro- } \\
\text { organismos no prédio, instalações, } \\
\text { maquinários e utensílios, a um nível } \\
\text { que não origine contaminação do } \\
\text { alimento que será elaborado. }\end{array}$} & $\begin{array}{l}\text { Portaria no } \\
326(1997)\end{array}$ & $\begin{array}{c}\text { MS (Ministério } \\
\text { da Saúde) }\end{array}$ \\
\hline & & $\begin{array}{l}\text { Portaria no } \\
368(1997)\end{array}$ & MAPA \\
\hline & & $\begin{array}{l}\operatorname{RDC} 275 \\
(2002)\end{array}$ & ANVISA \\
\hline & & $\begin{array}{l}\text { Portaria } n^{\circ} \\
368(1997)\end{array}$ & MAPA \\
\hline & $\begin{array}{l}\text { III - É a redução, por intermédio de } \\
\text { agentes químicos ou métodos físicos } \\
\text { adequados, do número de } \\
\text { microorganismos no prédio, } \\
\text { instalações, maquinaria e utensílios, a } \\
\text { um nível que impeça a contaminação } \\
\text { do alimento que se elabora. }\end{array}$ & $\begin{array}{l}\text { International } \\
\text { Code of } \\
\text { Practice - } \\
\text { General } \\
\text { Principles of } \\
\text { Food } \\
\text { Hygiene (199 } \\
\text { 9) }\end{array}$ & $\begin{array}{l}\text { CAC (Codex } \\
\text { Alimentarius } \\
\text { Commission) }\end{array}$ \\
\hline $\begin{array}{l}\text { Processo de } \\
\text { Higienização }\end{array}$ & $\begin{array}{l}\text { Operação que se divide em duas } \\
\text { etapas, limpeza e desinfecção. }\end{array}$ & $\begin{array}{l}\mathrm{RDC} \mathrm{n}^{\circ} 275 \\
\quad(2002)\end{array}$ & ANVISA \\
\hline $\begin{array}{l}\text { Higiene } \\
\text { alimentar }\end{array}$ & $\begin{array}{l}\text { Todas as condições e medidas } \\
\text { necessárias para garantir } r \text { a } \\
\text { segurança e adequação dos } \\
\text { alimentos em todas as fases da } \\
\text { cadeia alimentar. }\end{array}$ & $\begin{array}{l}\text { International } \\
\text { Code of } \\
\text { Practice - } \\
\text { General } \\
\text { Principles of } \\
\text { Food } \\
\text { Hygiene: } \\
\text { Section III - } \\
\text { reproduced } \\
\text { below in } \\
\text { shaded } \\
\text { boxes (1999) }\end{array}$ & $\begin{array}{l}\text { CAC (Codex } \\
\text { Alimentarius } \\
\text { Commission) }\end{array}$ \\
\hline Contaminantes & $\begin{array}{l}\text { Substâncias ou agentes de origem } \\
\text { biológica, química ou física, estranhos } \\
\text { ao alimento, que sejam considerados } \\
\text { nocivos à saúde humana ou que } \\
\text { comprometam a sua integridade }\end{array}$ & $\begin{array}{l}\mathrm{RDC} \mathrm{n}^{\circ} 216 \\
\quad(2004)\end{array}$ & ANVISA \\
\hline
\end{tabular}


(Continuação)

\begin{tabular}{|c|c|c|c|}
\hline Conceito & Definição & Normativa & $\begin{array}{l}\text { Órgão } \\
\text { Competente } \\
\text { Emissor }\end{array}$ \\
\hline \multirow{4}{*}{ Contaminação } & \multirow{4}{*}{$\begin{array}{l}\text { I- Presença de substâncias ou agentes } \\
\text { estranhos, de origem biológica, química } \\
\text { ou física que sejam considerados } \\
\text { nocivos ou não para saúde humana ou } \\
\text { que comprometem a sua integridade. }\end{array}$} & $\begin{array}{l}\text { Portaria no } \\
326 \text { (1997) }\end{array}$ & $\begin{array}{l}\text { MS (Ministério } \\
\text { da Saúde) }\end{array}$ \\
\hline & & $\begin{array}{l}\text { Portaria no } \\
368(1997)\end{array}$ & MAPA \\
\hline & & $\begin{array}{l}\text { Internationa } \\
\text { I Code of } \\
\text { Practice - } \\
\text { General } \\
\text { Principles } \\
\text { of Food } \\
\text { Hygiene }\end{array}$ & $\begin{array}{c}\text { CAC/RCP } \\
(1999)\end{array}$ \\
\hline & & $\begin{array}{c}21 \text { CRF } \\
\text { FDA (2013) }\end{array}$ & FDA USA \\
\hline Resíduos & $\begin{array}{l}\text { Materiais a serem descartados, } \\
\text { oriundos da área de produção e das } \\
\text { demais áreas do estabelecimento. }\end{array}$ & $\begin{array}{c}\text { RDC no } 275 \\
(2002)\end{array}$ & ANVISA \\
\hline $\begin{array}{l}\text { Padrão de } \\
\text { identidade e } \\
\text { qualidade }\end{array}$ & $\begin{array}{l}\text { Denominação, definição e composição } \\
\text { de alimentos, matérias-primas } \\
\text { alimentares, alimentos in natura e } \\
\text { aditivos intencionais, fixando requisitos } \\
\text { de higiene, normas de envasamento e } \\
\text { rotulagem medidos de amostragem e } \\
\text { análise; }\end{array}$ & $\begin{array}{l}\text { Decreto-Lei } \\
\text { no } 986 \\
(1969)\end{array}$ & $\begin{array}{c}\text { Repúlblica } \\
\text { Federativa do } \\
\text { Brasil: } \\
\text { Ministros da } \\
\text { Marinha de } \\
\text { Guerra, do } \\
\text { Exército e da } \\
\text { Aeronáutica } \\
\text { Militar. }\end{array}$ \\
\hline & & $\begin{array}{c}\text { RDC no } 216 \\
(2004)\end{array}$ & ANVISA \\
\hline $\begin{array}{l}\text { Inocuidade do } \\
\text { Produto }\end{array}$ & $\begin{array}{l}\text { Garantir a ausência de contaminantes } \\
\text { biológicos, radiológicos, químicos ou } \\
\text { físicos, em toda cadeia de alimentos, } \\
\text { por meio de ações higiênico - } \\
\text { sanitárias, ou seja, garantir a produção } \\
\text { de alimentos sem risco para ser } \\
\text { consumido. }\end{array}$ & $\begin{array}{c}\text { Internationa } \\
\text { I Code of } \\
\text { Practice - } \\
\text { General } \\
\text { Principles } \\
\text { of Food } \\
\text { Hygiene } \\
\text { (1999) }\end{array}$ & $\begin{array}{l}\text { CAC (Codex } \\
\text { Alimentarius } \\
\text { Commission) }\end{array}$ \\
\hline
\end{tabular}


(Continuação)

\begin{tabular}{|c|c|c|c|}
\hline Conceito & Definição & Normativa & $\begin{array}{l}\text { Órgão } \\
\text { Competente } \\
\text { Emissor }\end{array}$ \\
\hline $\begin{array}{c}\text { Aditivo } \\
\text { incidental }\end{array}$ & $\begin{array}{l}\text { Toda substância residual ou migrada } \\
\text { presente no alimento em decorrência } \\
\text { dos tratamentos prévios a que } \\
\text { tenham sido submetidos à matéria- } \\
\text { prima e ao alimento in natura e do } \\
\text { contato do alimento com os artigos e } \\
\text { utensílios empregados nas suas } \\
\text { diversas fases de fabrico, } \\
\text { manipulação, embalagem, transporte } \\
\text { ou venda; }\end{array}$ & $\begin{array}{c}\text { Decreto-Lei } \\
\text { no } 986 \text { (1969) }\end{array}$ & $\begin{array}{l}\text { Repúlblica } \\
\text { Federativa do } \\
\text { Brasil: } \\
\text { Ministros da } \\
\text { Marinha de } \\
\text { Guerra, do } \\
\text { Exército e da } \\
\text { Aeronáutica } \\
\text { Militar. }\end{array}$ \\
\hline \multirow[t]{2}{*}{$\begin{array}{c}\text { Órgão } \\
\text { competente }\end{array}$} & \multirow[t]{2}{*}{$\begin{array}{l}\text { O órgão técnico específico do } \\
\text { Minintério da Saúde, bem como os } \\
\text { órgãos federais, estaduais, } \\
\text { municipais, dos Territórios e do } \\
\text { Distrito Federal, congêneres, } \\
\text { devidamente credenciados; }\end{array}$} & $\begin{array}{c}\text { Decreto-Lei } \\
\text { no } 986 \text { (1969) }\end{array}$ & $\begin{array}{l}\text { Repúlblica } \\
\text { Federativa do } \\
\text { Brasil: } \\
\text { Ministros da } \\
\text { Marinha de } \\
\text { Guerra, do } \\
\text { Exército e da } \\
\text { Aeronáutica } \\
\text { Militar. }\end{array}$ \\
\hline & & $\begin{array}{c}\text { Portaria no } \\
326 \\
(1997)\end{array}$ & $\begin{array}{l}\text { MS (Ministério } \\
\text { da Saúde) }\end{array}$ \\
\hline $\begin{array}{l}\text { Inspeção } \\
\text { Sanitária }\end{array}$ & $\begin{array}{l}\text { É o procedimento da fiscalização } \\
\text { efetuado pela autoridade sanitária } \\
\text { que avalia em toda a cadeia alimentar } \\
\text { as Boas Práticas de Produção e/ou as } \\
\text { Boas Práticas de Prestação de } \\
\text { Serviços com vistas ao atingimento } \\
\text { do Padrão de Identidade e Qualidade } \\
\text { (PIQ) estabelecido através da } \\
\text { verificação do cumprimento dos } \\
\text { procedimentos previstos nos seus } \\
\text { manuais, na utilização do Sistema de } \\
\text { APPCC, e no atendimento à } \\
\text { Legislação Sanitária. }\end{array}$ & $\begin{array}{c}\text { Portaria no } \\
326 \\
(1997)\end{array}$ & $\begin{array}{l}\text { MS (Ministério } \\
\text { da Saúde) }\end{array}$ \\
\hline
\end{tabular}

(Continua) 
(Conclusão)

\begin{tabular}{|c|c|c|c|}
\hline Conceito & Definição & Normativa & $\begin{array}{c}\text { Órgão } \\
\text { Competente } \\
\text { Emissor }\end{array}$ \\
\hline \multirow[b]{2}{*}{$\begin{array}{c}\text { Sistema de } \\
\text { Análise de } \\
\text { Perigos em } \\
\text { Pontos Críticos } \\
\text { de Controle } \\
\text { (APPCC) }\end{array}$} & \multirow[b]{2}{*}{$\begin{array}{l}\text { I Metodologia sistemática de } \\
\text { identificação, avaliação e controle de } \\
\text { perigos de contaminação dos } \\
\text { alimentos. } \\
\text { II - Um sistema que identifica, avalia e } \\
\text { controla perigos que são significativos } \\
\text { para a segurança alimentar. }\end{array}$} & $\begin{array}{c}\text { Portaria } n^{0} \\
1428(1993)\end{array}$ & $\begin{array}{c}\text { MS (Ministério } \\
\text { da Saúde) }\end{array}$ \\
\hline & & $\begin{array}{l}\text { Internationa } \\
\text { I Code of } \\
\text { Practice - } \\
\text { General } \\
\text { Principles of } \\
\text { Food } \\
\text { Hygiene } \\
\text { (1999) }\end{array}$ & $\begin{array}{l}\text { CAC (Codex } \\
\text { Alimentarius } \\
\text { Commission) }\end{array}$ \\
\hline PCC & $\begin{array}{l}\text { Ponto Crítico de Controle é um ponto } \\
\text { do processso produtivoonde aplica-se } \\
\text { medidas preventivas de controle com o } \\
\text { objetivo de eliminar, prevenir ou reduzir } \\
\text { riscos ao produto final. }\end{array}$ & $\begin{array}{c}\text { Portaria no } \\
40 \\
(1997)\end{array}$ & MAPA \\
\hline Perigo & $\begin{array}{l}\text { Agente de origem biológica, química ou } \\
\text { agente físico que em contato com o } \\
\text { alimento, possa causar um efeito danos } \\
\text { a qualidade e integridade do produto } \\
\text { e/ou danos adverso à saúde. }\end{array}$ & $\begin{array}{l}\text { Internationa } \\
\text { I Code of } \\
\text { Practice - } \\
\text { General } \\
\text { Principles of } \\
\text { Food } \\
\text { Hygiene } \\
\text { (1999) }\end{array}$ & $\begin{array}{l}\text { CAC (Codex } \\
\text { Alimentarius } \\
\text { Commission) }\end{array}$ \\
\hline \multirow{2}{*}{$\begin{array}{l}\text { Análise de } \\
\text { Risco / Perigo }\end{array}$} & \multirow{2}{*}{$\begin{array}{l}\text { I - Avaliação de todas as etapas } \\
\text { envolvidas na produção de um } \\
\text { alimento, desde a obtenção da matéria } \\
\text { - prima até o uso pelo consumidor final } \\
\text { para identificar a presença de perigos } \\
\text { na matéria-prima e/ou no processo } \\
\text { prodututivo e identificar as fontes } \\
\text { potencias de ocorrência dos perigos e } \\
\text { prover plano de ação de medidas } \\
\text { preventivas. } \\
\text { II - Processo que compreende a } \\
\text { identificação do perigo, caracterização } \\
\text { do perigo, avaliação e carcterização da } \\
\text { exposição ao risco. }\end{array}$} & $\begin{array}{c}\text { Portaria } \mathrm{n}^{\circ} \\
40 \\
(1997)\end{array}$ & MAPA \\
\hline & & $\begin{array}{c}\mathrm{RDC} \mathrm{N}^{\circ} 17 \\
(2008)\end{array}$ & ANVISA \\
\hline
\end{tabular}

Fonte: Adaptado de : Ministros da Marinha de Guerra, do Exército e da Aeronáutica Militar, Decreto de Lei $n^{\circ} 986$ (1969); Portaria $n^{\circ} 1428$ - MS (1993); Portaria $n^{\circ} 368$ - MAPA (1997); Portaria ${ }^{\circ} 26-$ MS (1997); Portaria n 40 - MAPA (1997); Portaria $n^{\circ} 326$ - MS (1997); Resolução RDC $n^{\circ} 17$ ANVISA (2008); CAC - Codex Alimentarius Comission: International Code of Practice - General Principles of Food Hygiene (1999); Resolução RDC n 91 - ANVISA (2001); Resolução RDC $n^{\circ} 275$ ANVISA (2002); Resolução RDC n 216 - ANVISA (2004) e 21CRF FDA USA(Code of Federal Regulations of Food and Drug Administration - United States of América) acessado online em http://www.gpo.gov/fdsys/pkg/CFR-2012-title21-vo/3/pdf/CFR-2012-title21-vol3-sec178-3570.pdf (2013) 
As definições contidas no quadro 2.5, embasadas em normativas e legislações, são comuns em âmbito nacional e internacional, pois os órgãos nacionais baseiam-se em grande parte no conteúdo do Codex Alimentarius (Código de Alimentos) e nas regulamentações contidas no Código de Alimentos da Agência Norte Americana de Administração de Alimentos e Medicamentos (USA FDA - Food and Drugs Administration).

Estas definições propiciam melhor entendimento dos termos e conceitos empregados no ambiente de desenvolvimento da pesquisa, a qual descrita na presente tese. Seguidamente detalhar-se-á normativas aplicadas a engenharia de qualidade e engenharia de manutenção em ambiente industrial de alimentos.

2.6.1 Instruções Normativas relacionadas à Engenharia de Qualidade e Engenharia de Manutenção

A engenharia de qualidade dentro de indústrias de ramo de alimentos tem por finalidade estruturar um SGQ (Sistema de Gestão da Qualidade) direcionado a conter os riscos e perigos ao produto em cada etapa do processo de fabricação, direcionando a obtenção de qualidade no produto e processo.

Um produto com qualidade não pode apresentar substâncias estranhas a sua composição e estar suscetível a agentes contaminantes que possam alterar o sabor, odor e/ou coloração, interferindo em seu padrão de qualidade, para tanto se deve implantar, em indústriais de alimentos, sistemas de qualidade que elimine os focos de perigos a composição e características organoléticas (sensoriais) do produto, de forma manter um padrão de qualidade.

Em um processo de fabricação de alimentos, substâncias como gordura e o açúcar absorvem odores e trazem cheiro para o produto final, se dentro do processo produtivo estas substâncias estiverem suscetíveis a contaminantes químicos, estes podem interferir na qualidade do produto por meio da alteração de suas características sensoriais. (DEMAN, 1999; ASQ - American Society Quality: The Quality Auditor's HACCP Handbook, 2014).

Logo, estrutrar um sistema de gestão de qualidade em indústrias de alimentos é essencial para evitar riscos e perigos de contaminantes no processo, os quais 
podem interferir nas propriedades organolépticas (características de cor, odor, sabor, textura, entre outras identificadas pelo sentido sensorial humano) e muitas vezes modificar a composição, tornando o produto impróprio para consumo.

$\mathrm{Na}$ engenharia de qualidade são aplicados sistemas de gestão da qualidade como HACCP e BPF, sendo este pré-requisito para implantação daquele, os quais visam gerenciar de riscos e perigos ao produto durante as etapas de fabricação.

Basicamente o BPF são normas estruturadas em procedimentos, os quais são necessários para garantir a qualidade dos alimentos, a estes procedimentos dáse o nome de os PPHO's - procedimentos padrão de higiene operacional (PPHO ou do inglês SSO Standard Sanitizing Operating Procedures), cuja eficácia e efetividade devem ser avaliada através da inspeção e/ou da investigação. (Portaria no 1428 MAPA, 1993; Portaria n 326 - MS, 1997).

\footnotetext{
"As boas práticas de fabricação procedimentam as condições requeridas pelo processo de fabricação objetivando evitar a presença dos riscos indesejáveis (perigo de contaminação de origem física, química ou biológica) e métodos de controle de processo e produto. Os PPHO's são representados por requisitos de BPF considerados críticos na cadeia produtiva de alimentos, para estes procedimentos, recomenda-se a adoção de monitoramento, registros, ações corretivas e aplicação constante de check lists". (FURTINI; ABREU, 2005).
}

No Brasil, as normas básicas para fabricação de alimentos contidas no decreto de lei no 986 (1969) - Legislação Básica de Alimentos, evoluíram para a introdução das Boas Práticas de Fabricação e do HACCP na indústria de alimentos, assim as normas do programa BPF são regulamentadas basicamente pelas Portarias $n^{\circ} 1428$ - MS (93), Portarias $n^{0} 326$ - MS (97), Portarias $n^{\circ} 368$ - MAPA (1997) e pela Resolução 275 - ANVISA(2002). Dentre essas normativas, os conceitos relacionados conjuntamente a engenharia de manutenção e qualidade são:

$>$ Procedimento de higienização das instalações, equipamentos, móveis e utensílios;

$>$ Manutenção preventiva e calibração de equipamentos relacionados ao controle de temperatura, pressão, umidade; 
> Equipamentos e utensílios que são utilizados nos diversos processos produtivos não devem constituir um risco a qualidade do produto e nem permitir contaminação direta e/ou cruzada da matéria prima em processamento. Deverão ser tomadas medidas eficazes para evitar a contaminação do material alimentício por contato direto ou indireto com o material contaminado, que se encontre nas fases iniciais do processamento;

$>$ Equipamentos e utensílios que possam entrar em contato direto com o produto devem ser confeccionados de material que não transmitam substâncias tóxicas, odores, sabores e deve ser resistente a corrosão e sem rugosidade (absorção de substância que podem provocar contaminação ao alimento). Possuam superfícies lisas e isentas de rugosidades e frestas e/ou outras imperfeições que possam comprometer a higiene dos alimentos e/ou sejam fontes de contaminantes.

$>$ As peças, máquinarias, utensílios e equipamentos destinados a entrar em contato com alimentos, nas diversas fases de fabricação, manipulação, estocagem, acondicionamento ou transporte não deverão interferir nocivamente na elaboração do produto, nem alterar o seu valor nutritivo ou as suas características organoléticas;

> Todo equipamento e utensílio utilizado nos locais de processamento, que entre em contato direto ou indireto com o alimento, devem ser confeccionados em material atóxico, que não lhe transmita odores e sabores, resistente à corrosão e capaz de suportar repetidas operações de limpeza e desinfecção. As superfícies devem ser lisas, sem frestas e outras imperfeições que possam servir de fonte de contaminação e comprometer a higiene.

Salienta-se que essas normativas baseam-se no conteúdo do Codex Alimentarius e nas regulamentações da Food and Drug Administration (FDA) dos Estados Unidos, e tem por objetivo estabelecer um manual de BPF e modo de estruturação dos POP's (Procedimentos Operacionais Padronizados), os quais são relativos aos PPHO'S, visando à garantia das condições higiênica- sanitárias necessárias ao processamento/industrialização de alimentos.

Quanto a normativas sobre a gestão do processo de lubrificação no Brasil, como já explicitadas, são deficientes, porém lubrificantes aplicados a máquinas e 
equipamentos, os quais compõe uma planta industrial de alimentos, caracteriza-se como potencial contaminante químico, tornando um risco a qualidade do produto.

\begin{abstract}
"Perigos/Riscos químicos em meio industrial de produção de alimentos, como exemplo, são substâncias químicas industriais como detergentes e sanitizantes aplicados a limpeza das instalações industriais e componentes relacionados aos equipamentos como óleo, combustível e lubrificantes". (SCHMIDT e RODRICK, 2003).
\end{abstract}

A portaria de $\mathrm{n}^{\circ} 1210$ (2006) emitida pelo Ministério da Saúde e a normativa $\mathrm{n}^{\circ} 4$ (2007) emitida pelo MAPA, citam que os lubrificantes utilizados nos equipamentos, os quais podem vir em contato direto ou indireto com os produtos, devem ser de grau alimentício e referenciam que estes lubrificantes são regulamentados no código de alimentos da FDA USA, o qual indica a NSF como órgão regulamentador dos tipos de lubrificantes, fonte de cadastro e consulta desses.

Porém as normativas estruturadas para área de fabricação de alimentos não determinam um procedimento técnico que aponte quais tipos de equipamentos devem utilizar $\mathrm{H} 1, \mathrm{H} 2$ e $\mathrm{H} 3$ e nem mesmo contempla um procedimento para efetuar auditorias em estabelecimentos produtores de alimentos, e ainda, não dispõe de sistemáticas para gestão de lubrificação e lubrificantes dentro deste tipo de indústria.

É importante salientar que apesar da nomenclatura, lubrificantes de grau alimentício não são destinados a consumo humano e/ou contato com a pele ou mucosa, são indicados apenas para contato incidental com os alimentos, devendo ao máximo ser evitada a contaminação de alimentos por estes, além disto, lubrificante de grau alimentício pode ser contaminado pelo seu manuseio ou por contaminação (com outro fluido e/ou substância química e/ou biológica nociva) e assim proporcionar uma contaminação do lubrificante industrial. (SCHMIDT e RODRICK, 2003; ASQ - American Society for Quality: Food, Drug, and Cosmetic Division, 2014).

\footnotetext{
"A maioria dos equipamentos empregados no processamento de alimentos e bebidas precisam de lubrificação para seu funcionamento e muitos já possuem uma estrutura que minimize a contaminação durante as etapas de produção. No entanto, o potencial risco de contato incidental do lubrificante com o produto não pode ser completamente negado". (KUDA;IWAI;YANO, 2004).
} 
A legislação brasileira também sustenta "como um dos procedimentos de higiene para garantir a qualidade do produto, não se deve utilizar substâncias odorizantes e/ou desodorantes em qualquer etapa de produção de alimentos, com vistas a evitar contaminação pelos mesmo que se misturem os odores (PORTARIA $n^{0} 326$ - MS, 1997).

E que um dos quesitos de padrão de qualidade e identidade do produto é justamente que esse possua características sensoriais próprias como aspecto, sabor, odor, textura, etc., as quais devem ser mantidas durante as etapas de fabricação do produto alimentício (PORTARIA nº 1428 - MS, 1993).

\footnotetext{
"Equipamentos empregados na área de fabricação de alimentos devem ser construídos de forma que suas partes em contato com o alimento, bem como as substâncias que este utiliza para operação, como lubrificantes e fluidos refrigerantes, não deve entram en contato com os produtos, pois podem interferir na segurança, identifade, pureza e qualidade do produto". (USA FDA Code of Federal Regulations 21CRF211 - Title 21, Vol. 4, Part 211, Section 211.67: Equipment Cleaning and Maintenance, 2013).
}

Neste aspecto o lubrificante industrial torna-se um potencial perigo de contaminação química ao produto, pois usado de classificação inadequada (mineral comum) ou contato incidental pode ocasionar contaminação por odor, sabor, composição, entre outros, interferindo no padrão de qualidade e identidade do produto.

Outro aspecto determinado pela legislação brasileira é que as peças de máquinas e equipamentos destinados a entrar em contato com alimento, nas diversas fases de fabricação, manipulação, estocagem, armazenamento ou transporte não deverão interferir nocivamente na elaboração do produto nem alterar seu valor nutritivo ou as suas propriedades organolépticas.

Logo, todo equipamento utilizado na fabricação de alimentos e que podem entrar em contato com alimento deve ser de material e características que não transmitam substâncias tóxicas, odor, sabor, sendo que equipamentos constituem uma fonte de potencial contaminação cruzada para o produto alimentício. (CAC/RCP: Code of Hygienic Practice for Precooked and Cooked Foods In Mass, 1993)

Assim o lubrificante, o qual faz parte do maquinário empregado em indústria de alimentos, constitui um potencial foco de contaminação química, contaminação microbiana através do crescimento de micro-organismos, tais como leveduras e 
fungos em locais com vazamento e acúmulo de lubrificantes e até mesmo promover contaminação cruzada para o produto em processamento, a qual ocorre por meio de seu contato com demais resíduos e substâncias não adequadas ao processo de fabricação de alimentos.

\subsubsection{ISO 21649 segurança de máquinas}

Órgãos reguladores como a USDA e NSF fiscalizam e padronizam os componentes liberados para fabricação de lubrificantes usados no maquinário de processamento de alimentos, cosméticos, produtos farmacêuticos e bebidas, a norma ISO 21469 complementa este escopo com a análise e monitoramento do processo de fabricação do lubrificante.

A norma internacional ISO 21469 (2006) intitulada Segurança de máquinas lubrificantes com o contato do produto incidental - higiene programa de certificação de requisitos, é destinada a todo o processo de lubrificante desde o projeto, fabricação, embalagem até o transporte, especificando os requesitos de higiene para formulação, produção, uso e manuseio de lubrificantes de grau alimentício, os quais, durante o processo produtivo pode vir a ter contato incidental com produtos e embalagens usadas em indústrias do ramo alimentício.

Esta norma auxilia tanto na garantia de que as substâncias químicas utilizadas na composição de lubrificantes de grau alimentício sejam atóxicas e/ou livres de componentes prejudiciais à saúde humana quanto na eliminação de potenciais riscos de contaminação física do lubrificante durante a sua fabricação, armazenamento e logistica de distribuição, contaminação a qual pode ser transmitida ao alimento durante seu processamento no maquinário, o qual utiliza lubrificantes para operação.

Lawate (2007) e Labs (2011) enfatizam que a norma ISO 21469 apesar de objetivar a segurança dos consumidores quanto aos efeitos de contaminação alimentar e de produtos relacionados com o lubrificante, aborda em seu conteúdo apenas os lubrificantes destinados para contato acidental direto com o produto, os de classificação $\mathrm{H} 1$ na terminologia do grau alimentício, não abrangendo a fabricação das categorias $\mathrm{H} 2$ e H3, lubrificantes os quais também podem sofrer 
contaminação físico-quimica durante seu processamento e distribuição, colaborando com o risco de contaminação alimentar na área de manufatura de alimentos.

Implementar a ISO 21469 basicamente é aplicar um sistema HACCP para no processo de fabricação de lubrificantes com foco na garantia da qualidade por meio demonitoramento dos pontos críticos do processo industrial.

\subsubsection{Halal e kosher}

Crenças encontradas em religiões como muçulmana e judaica influenciam na formulação de lubrificantes de grau alimentício. A lei da Kosher (leis de alimentação judaica) e a Halal (termo árabe que significa "permissão" a produtos alimentícios) restringem os ingredientes a serem utilizados na composição dos lubrificantes. (CHAUDRY e REGENSTEIN, 1994; LAWATE, 2007).

A recomendação Kosher proibe o uso de carne de porco, moluscos e seus subprodutos, além de, excluirem qualquer mistura de carnes e laticínios e ovos. Semelhante às leis Kosher, os alimentos permitidos pelo Halal exclui a utilização de vísceras e restos de animais mortos, carne de porco, sangue e seus subprodutos, restos de animais carnívoros inclusive aves de rapina,bem como, substâncias tóxicas como o álcool e drogas, o que limita potencialmente alguns dos aditivos utilizados em lubrificantes de grau alimentício. (CHAUDRY e REGENSTEIN, 1994; TOTTEN, 2006).

Empresas de fabricação de lubrificantes aplicados em maquinário produtor de alimentos são auditadas por representantes de religiões que adotam as normas Halal e Kosher para analisar tecnicamente os ingredientes utilizados na composição dos lubrificantes e assim emitir os certificados de conformidades conforme as essas normas. (SPIEGEL et al., 2012). 


\subsection{CONSIDERAÇÕES FINAIS}

A ocorrência de falhas em máquinas e equipamentos que compõe um processo produtivo de alimentos pode acarretar prejuízos a indústria de alimentos, pois as consequências destas falhas podem vir a impactar a qualidade do produto por meio de contaminação por resíduos químicos, físicos e/ou biológicos.

A perda de qualidade consequentemente aumenta o custo do ciclo de produção de alimentos, afetando diretamente a competitividade a empresa com a perda de produto, retrabalho ou até mesmo dificuldades com a comercialização de alimentos por não atender os requisitos mínimos de qualidade.

Estabelecimentos de produção de alimentos são compostos por maquinário e instalações que executam funções para fabricação de produtos. Para estas realizar estas funções são necessários equipamentos e componentes mecânicos e/ou rotativos que precisam de lubrificantes para garantir seu pleno funcionamento. Porém, o mesmo lubrificante que auxilia o funcionamento do maquinário oferece um risco potencial à qualidade do produto, pois pode provocar contaminação por meio das substâncias químicas que o constituem.

Apesar da Engenharia de Qualidade direcionar seus esforços para implantar normas e legislações vigentes a área de produção de alimentos, nem todos os pontos críticos de controle (PCC's) fundamentados pelo sistema HACCP (Hazard Analysis and Critical Control Point) são de fácil identificação e monitoramento do risco, vindo o risco a existir e impactar na qualidade e integridade do produto, como no caso das atividades de lubrificação industrial.

A manufatura de alimentos e bebidas requer operações processuais como limpeza, esterilização, aquecimento, resfriamento, cozimento, corte, empacotamento entre outros. Para a execução destas operações, necessita-se de máquinas e equipamentos como: bombas, misturadores, tanques, tubulações, motores, balanças, eixos, entre outros. Tal maquinário contém elementos mecânicos ou rotativos que requerem fluídos hidráulicos, graxas, óleos lubrificantes que asseguram seu pleno funcionamento.

A execução da lubrificação, seja como atividade de manutenção preventiva, preditiva ou corretiva, em equipamentos de processo de fabricação de alimentos, é muitas vezes difícil de conciliar com as exigências e normas sanitárias impostas a 
este seguimento industrial, pois o mesmo lubrificante que auxilia no funcionamento de máquinas e equipamentos em uma planta industrial de fabricação de alimentos também é considerado um potencial risco (um perigo) ao padrão a qualidade e identidade do produto, o qual pode vir a afetar a coloração, sabor, odor ou composição do produto por substâncias de origens biológicas (fungos e leveduras) e/ou química (lubrificante de classificante inadequada e/ou contato incidental).

É importante salientar que apesar da nomenclatura, lubrificantes de grau alimentício, os quais indicados para aplicação em maquinário aplicado na fabricação de alimentos, não são destinados a consumo humano e/ou contato com a pele ou mucosa, sendo indicados apenas para contato incidental com os alimentos, devendo ao máximo ser evitada a contaminação de alimentos por estes.

É fundamental gerenciar o processo de lubrificação em máquinas e equipamentos aplicados em industriais de alimentos, a fim de garantir a qualidade $e$ integridade do alimento e concomitantemente proporcionar confiabilidade e disponibilidade operacional do maquinário, atendendo as necessidades financeiras e normativas da empresa.

Além do fator de risco potencial (como contaminante), a inadequada gestão do lubrificante conjuntamente com os procedimentos de sua aplicação (atividade de lubrificação) pode gerar falhas potenciais em máquinas e equipamentos e impactar na disponibilidade e confiabilidade desses, provocando redução de produtividade e aumento nos custos de manutenção e processo.

A engenharia de manutenção deve gerenciar o processo de lubrificação em indústriais de alimentos como uma funcão essencial e estratégica, devendo adotar a adequada politica de manutenção e lubrificação com o propósito de cumprir os requisitos legais impostos orgãos regulamentadores e fiscalizadores (a nível federal, estadual e municipal) e assim agir de forma ética com o estado e principalmente com a sociedade, assegurando a qualidade do produto e aumentando a disponibilidade das instalações industriais.

A gestão da manutenção de máquinas e equipamentos tem recebido atenção significativa durante os últimos anos na indústria de transformação devido à característica dinâmica da mudança constante do complexo industrial e o custo crescente de bens de capital. Estes fatores impactam diretamente na competitividade da empresa e assim tem aumentado a importância da confiabilidade e disponibilidade dos equipamentos envolvidos no processo produtivo, fazendo-se 
necessário cada vez mais gerenciar as atividades de manutenção com qualidade e com custo reduzido, com intuito de atender as metas da organização.

Apesar dos métodos de gestão da manutenção industrial terem avançado desde a revolução industrial até a atualidade, ainda é um desafio o controle do custo e a complexidade técnica e das ações humanas envolvidas nas atividades de manutenção. Há uma clara necessidade de estruturação da engenharia de manutenção no âmbito industrial, para gerenciar os ativos e práticas de manutenção, pois esta função influencia positivamente fatores críticos no meio industrial, tais como a qualidade do produto, preço, rentabilidade e entrega do produto acabado em tempo acordado. Logo, a engenharia de manutenção torna-se uma vantagem competitiva, pois influencia positivamente na qualidade total do produto final e na estrutura de custos gerais da organização.

A engenharia de manutenção é a função da manutenção que aplica conceitos técnicos de manutenção, qualidade e tecnologias disponíveis, para a otimização dos recursos humanos e materiais envolvidos na manutenção de máquinas e equipamentos conjuntamente com o controle dos custos aplicados nas atividades da manutenção, com o objetivo de aumentar disponibilidade e mantenabilidade e assim garantir a confiabilidade no sistema industrial.

A engenharia de manutenção faz a ligação entre a aplicação de métodos e ferramentas da qualidade e atividades técnicas de manutenção (preventiva, corretiva, preditivas, TPM, RCM, entre outros) com auxílio de conhecimentos estatísticos e financeiros objetivando a redução de falhas obtendo confiabilidade e disponibilidade do maquinário fabril com custos adequados a realidade financeira da empresa.

Os conceitos de confiabilidade, disponibilidade e capacidade produtiva tornaram-se o foco principal do ambiente industrial em face do cenário ecônomico atual. Crescente concorrência de mercado, redução de gastos e desperdícios e aumento da demanda, tem gerado a necessidade cada vez maior da aplicação de ferramentas ofertadas pela engenharia de manutenção e confiabilidade para alcançar desempenho eficaz de sistemas industriais.

Tem-se o conceito de confiabilidade como sendo a probabilidade de um dispositivo operar com desempenho satisfatório dentro de um período de tempo determinado, quando usado nas suas condições especificadas,sem a ocorrência de falhas. 
No sentido mais amplo, a confiabilidade está associada com segurança, com operação bem-sucedida, e com a ausência de falhas ou avarias, por isso, em engenharia de confiabilidade o foco principal é sobre a análise de falhas e o desenvolvimento de métodos e ferramentas para sua prevenção.

Disponibilidade é a capacidade de um item estar em condições de executar uma certa função em um dado instante ou durante um intervalo de tempo determinado, levando em conta os aspectos combinados de confiabilidade, mantenabilidade e suporte de manutenção, supondo que os recursos externos requeridos estejam assegurados.

Um dos fatores que impactam na disponibilidade do maquinário é a mantenabilidade, conceito o qual deve ser deve ser intrínseco desde o projeto da máquina, pois tem por objetivo analisar e otimizar as características do projeto quanto a sua manutenção, determinando a facilidade de maior e menor grau em realizar as ações de manutenção, através de procedimentos e normas, mão-de-obra habilitada, custos minimizados e tempos reduzidos.

Avaliar a confiabilidade e disponibilidade de um sistema industrial implica em analisar vários fatores sendos os principais a complexidade do maquinário fabril, custos e recursos humanos, assim, empregam-se análises estatísticas, metodos e ferramentas para modelagem e caracterização da confiabilidade de um sistema.

A ocorrência de falhas impacta diretamente na confiabilidade e na disponibilidade operacional do sistema industrial. Para tanto faz-se necessário avaliar estatisticamente a tendência do comportamento das falhas com a finalidade de implantar estratégias que reduzam e/ou eliminem as causas raízes dos eventos de falhas.

A análise probabilística e estatística usadas para determinar as caraterísticas da tendência das falhas em sistema reparáveis é fundamentada na aplicação de processos estocásticos e na definição da tendência da taxa da variação temporal de intensidade de falha (ROCOF - Rate of Occurrence of Failures).

Define-se sistema reparável como aquele que pode sofrer intervenções de manutenção (preventiva, preditiva e/ou corretiva) para recolocá-lo em seu estado de funcionamento mediante desempenho requerido, sendo que, durante as intervenções de manutenção, pode-se substituir ou não um componente, o qual geralmente enquadra-se como sistema não reparável (tempo de vida útil definido até a ocorrência de falhas). 
Falhas ocorridas em sistemas reparáveis são eventos discretos e assim representadas por distribuições discretas, chamadas processos estocásticos pontuais, ou seja, os processos de Poisson. No tratamento da análise de falhas em sistemas reparáveis aplicam-se modelos que consideram esta variação da taxa de falha ao longo do tempo, como os processos estocásticos pontuais Poisson Homogêneos (PPH) e processos de Poisson Não Homogêneos (PPNH) conjuntamente com a curva de tendência das falhas descritas por meio da taxa de ocorrência de falhas (ROCOF).

A análise estatísticas das ocorrências de falhas em sistema reparáveis permite a construção de indicadores de desempenho relacionados à confiabilidade, mantenabilidade e disponibilidade por meio da obtenção dos valores da taxa de ocorrência falhas (ROCOF), indicadores como: o MTBF - Mean Time Between Failures, o MTTR - Mean Time to Repair, o MTTF - Mean Time to Failure, ou seja, o tem e tempo médio de funcionamento e a própria Disponibilidade em função do tempo $A(t)$.

Enfatiza-se que disponibilidade é uma característica dos sistemas reparáveis e compõe-se de atributos: confiabilidade e mantenabilidade. Poder-se-á dizer que a função Disponibilidade $A(t)$ traduz a proporção de tempo em que o sistema se encontra em condições para ser usado e assim poder realizar as suas funções específicas e a Confiabilidade $R(t)$ traduz-se na probabilidade da falha não ocorrer num determinado período estipulado.

A taxa de ocorrência de falhas (ROCOF) expressa instantaneamente a probabilidade de falha por unidade de tempo. Esta é definida pela função de intensidade de ocorrência de falhas $\rho(t)$, função, a qual expressa a taxa de variação do número esperado de falhas em relação ao tempo $(t)$. A equação que representa a taxa de ocorrência de falhas está indicada na equação 2.3 (pág.70).

Os parâmetros $\beta$ e $\lambda$ (modelo de Crow) são estimados pelo método da verossimilhança devido os dados histórico de ocorrências de falhas a serem utilizados são dados limitados pelo tempo até a última falha $\left(t_{n}\right)$, como mostrados nas equações 2.4 e 2.5, presentes na página 70 .

Para sistemas reparáveis identifica-se três tipos de comportamento que a taxa de ocorrência de falhas pode tomar, decrescente, crescente ou constante. Para verificar esta tendência deve-se analisar o valor tomado pelo parâmetro de Crow $\beta$ ,se $\beta>1$ a $\rho(t)$ é crescente apresentando um processo estocástico NHP, caso $0<\beta$ 
$<1$, a $\rho(t)$ é decrescente apresentando um processo estocástico NHP e por último se $\beta=1$ a $\rho(t)$ é constate tomando um processo estocástico HP.

Com a obtenção dos valores da taxa de intensidade de ocorrência de falhas $\rho(t)$, ao longo do tempo, é possível calcular os demais indicadores de desempenho de manutenção e confiabilidade como:

> $\operatorname{MTBF}(t)$ - Tempo médio entre falhas variável ao longo do tempo;

$>\operatorname{MTTR}(t)$ - Tempo médio para reparo em função do tempo;

Disponibilidade $-\mathrm{A}(t)$;

> $\mathrm{R}(t)$ - Confiabilidade em sistemas reparáveis;

$>\mathrm{m}(t)$ - número acumulado de falhas ao longo do tempo.

Tais indicadores são calculados através das equações 2.6 (pág.70), 2.7, 2.8, 2.9 e 2.10 presentes na página 72 .

Logo, o estudo do comportamento de falhas em sistemas reparáveis se faz importante, pois, por meio desta análise é possível adotar procedimentos e intervenções de manutenção para manter certo nível de confiabilidade e prover melhorias no desempenho do sistema industrial.

Além da análise quantitativa das falhas em sistemas reparáveis, as quais indicam o impacto dos eventos de ocorrências de falhas na produtividade e disponibilidade do sistema industrial, a confiabilidade compreende a análise qualitativa dos modos e consequências destas falhas.

Para análise qualitativa dos modos de falhas, ou seja, dos mecanismos como essas ocorrem, aplica-se ferramentas da engenharia de qualidade e/ou engenharia de manutenção para auxiliar na caracterização funcional destas falhas, aborda-se aqui, dentre várias ferramentas os conceitos de árvore funcional, FTA e FMEA, as quais, aplicadas na presente pesquisa.

O diagrama funcional de sistemas, também conhecido por árvore funcional, auxilia no processo de análise de falhas por mostrar herarquicamente os subsistemas que compõe um sistema, bem como, identificar as funções dos 
componentes e a dependência entre eles durante o funcionamento do sistema principal.

Já a análise de falhas aplicada na análise dos modos de falhas, com foco em confiabilidade é a análise de modo e efeito de falha - FMEA. Esta análise é basicamente uma abordagem qualitativa para determinar a confiabilidade, manutenção e segurança de um determinado projeto ou processo, levando em consideração potenciais falhas e seus efeitos resultantes. Para tanto, durante a análise FMEA são identificadas e descritas às funções necessárias dos sistemas, ou seja, as propriedades de entrada para o seu pleno funcionamento, e assim, apontar as maneiras nas quais o sistema pode deixar de funcionar.

A aplicação de ferramentas e metodologias no processo de análise de falhas facilita a tomada de decisão quanto à execução das atividades de manutenção, fator que consequentemente, direciona a garantia de confiabilidade e disponibilidade no sistema industrial. 


\section{CAPÍtUlO 3 DESENVOLVIMENTO DE MÉtodo PARA SELEÇÃO DE POLÍTICA DE LUBRIFICAÇÃO INDUSTRIAL CENTRADA EM CONFIABILIDADE: APLICAÇÃO NA INDÚSTRIA DE ALIMENTOS}

\subsection{DESENVOLVIMENTO DO MÉTOdO PARA SELEÇÃO DE POLÍTICA DE LUBRIFICAÇÃO}

O método para seleção de política de lubrificação, aplicado a máquinas e equipamentos utilizados na produção de alimentos, baseia-se nos fatores de análise de falhas e potencial risco a qualidade do produto relacionados com as atividades de lubrificação industrial. Ele visa equilibrar o cumprimento dos requisitos da engenharia da qualidade (qualidade do processo e de produto exigidas pelas normas e legislações vigentes associadas ao ramo de alimentos) com a engenharia de manutenção, cujo objetivo é garantir a disponibilidade e confiabilidade de máquinas e equipamentos industriais.

A integração das atividades de lubrificação e a garantia da qualidade são identificadas por meio do mapeamento das etapas do processo de fabricação de alimentos e pelo detalhamento dos impactos ocasionados pela lubrificação do maquinário, impactos esses que podem gerar ocorrência de falhas e/ou comprometer a qualidade do produto.

As informações relativas à engenharia de manutenção e engenharia de qualidade englobam a estrutura da gestão da manutenção de máquinas e equipamentos (cadastro de máquinas e equipamentos, ficha técnica, TAG, materiais de fabricação, especificação da mão de obra ou centro de serviço, indicadores de desempenho, histórico de falhas, evidência de estratégias de manutenção aplicadas, entre outras informações) e as normas e sistemáticas de qualidade relacionadas a engenharia de manutenção, dispostas em códigos de lei e normas direcionadas a estabelecimentos produtores de alimentos.

A figura 3.1 representa a estrutura geral da integração entre as atividades da engenharia da manutenção e as necessidades da engenharia de qualidade. 
Figura 3.1 - Visão Geral da Estrutura do Método de Seleção de Política de Lubrificação com Objetivo de Equilibrar a Gestão da Manutenção Industrial com as Atividades Exercidas pela Engenharia da Qualidade em Indústrias de Alimentos

\begin{tabular}{|c|c|}
\hline Engenharia de Manutenção Industrial & Engenharia da Qualidade \\
\hline $\begin{array}{c}\text { Lista Técnica de Equipamentos } \\
\text { Identificação do Local de Instalação - TAG } \\
\text { Estratégias de Manutenção } \\
\text { Indicadores de Desempenho } \\
\text { Gestão da Lubrificação e Lubrificantes } \\
\text { Procedimentos de Trabalho } \\
\text { Qualificação de Mão de obra (Centro de } \\
\text { Serviço) } \\
\text { Engenharia da Confiabilidade } \\
\text { Gerenciamento das Informações/Dados } \\
\text { referentes as Atividades de Manutenção }\end{array}$ & $\begin{array}{c}\text { Normativas e legislações aplicadas ao sistema } \\
\text { industrial de alimentos } \\
\text { Sistemas de Gestão da Qualidade: HACCP e } \\
\text { BPF } \\
\text { Garantia da Qualidade do Processo Produtivo e } \\
\text { do Produto } \\
\text { Controle e Monitoramento dos PCC's - Pontos } \\
\text { Críticos do Processo (riscos/perigos a qualidade } \\
\text { e identidade do produto) }\end{array}$ \\
\hline
\end{tabular}

Estrutura Funcional do Método de Seleção de Política de Lubrificação Industrial Centrada em Confiabilidade

Mapeamento do processo produtivo de alimentos para identificação das variáveis envolvidas no processo de lubrificação industrial

Identificação dos Pontos de Lubrificação do Maquinário Industrial

Avaliação qualitativa e quantitativa dos riscos e perigos a qualidade do produto relacionados ao processo de Lubrificação Industrial

Classificação da criticidade do maquinário quanto a sua importância no processo produtivo (Classificação $A B C$ )

Classificação da criticidade do maquinário quanto ao processo de Lubrificação (Zonas de Criticidade)

Análise do comportamento dos eventos de falhas, destacando as falhas relacionadas a Lubrificação Industrial

Construção de Indicador de Nível de Confiabilidade Operacional e Potencial Risco a qualidade do produto ligado ao processo de Lubrificação Industrial

Tomada de decisão na estrutura adequada a política de lubrificação a ser aplicada em maquinário industrial de alimentos em prol de melhorar a capacidade produtiva e conter os riscos de perda de inocuidade e qualidade do produto relacionados as atividades de Lubrificação

Construção de Planos de Ação para melhorar o desempenho da Disponibilidade e Confiabilidade operacional de Máquinas e Equipamentos

Avaliação do comportamento de falhas e riscos associados as atividades de Lubrificação Industrial Estrutura da política de lubrificação industrial a ser adotada

Fonte: Autoria própria 
As informações relativas à engenharia de qualidade representam a adequação às normas e legislações vigentes associadas a fabricação de alimentos. Já as informações ligadas a engenharia de manutenção direcionam-se aos dados técnicos do maquinário industrial e ao histórico das atividades executadas para manter e/ou melhorar o desempenho operacional desses.

A ligação funcional entre estas duas bases de informações (qualidade e manutenção) possibilita o desenvolvimento de um método de análise acerca do risco potencial de ocorrência de falhas do maquinário e o impacto na qualidade do produto (possível contaminação e/ou defeito) que podem ser ocasionados por meio da execução das atividades de lubrificação do maquinário industrial.

Através da aplicação deste método pretende-se estabelecer uma união entre as tarefas de lubrificação e o cumprimento das exigências de qualidade aplicadas ao setor de manutenção em indústrias de alimentos, permitindo poupar recursos, garantir disponibilidade e confiabilidade do maquinário do sistema industrial conjuntamente com a garantia da qualidade do produto.

Com o auxílio de métodos estatísticos, apontam-se as variáveis que impactam na ocorrência de falhas e riscos a elas associados (que podem afetar a qualidade e inocuidade do produto e impactar na disponibilidade e confiabilidade do funcionamento de máquinas e equipamentos) direcionando a construção de um indicador de confiabilidade operacional e risco de perda de qualidade e inocuidade do produto.Este indicador é gerado a partir de uma função caracterizada pela ponderação de pesos atribuídos as variáveis que influenciam o processo de lubrificação do maquinário.

Estes pesos, ou seja, os valores atribuídos as variáveis identificadas no processo de lubrificação, são obtidos pela tabela de identificação da zona crítica, a qual é fundamentada pelos efeitos que o processo de lubrificação sobre a qualidade do produto, pela atribuição de número binário (evidência ou não da variável) e por meio de análise estatística do comportamento das ocorrências de falhas. $O$ fluxograma da figura 3.2 apresenta, de forma resumida, as fases de desenvolvimento do método. 
Figura 3.2- Etapas de Construção do Método para Seleção de Política de Lubrificação Centrada em Confiabilidade

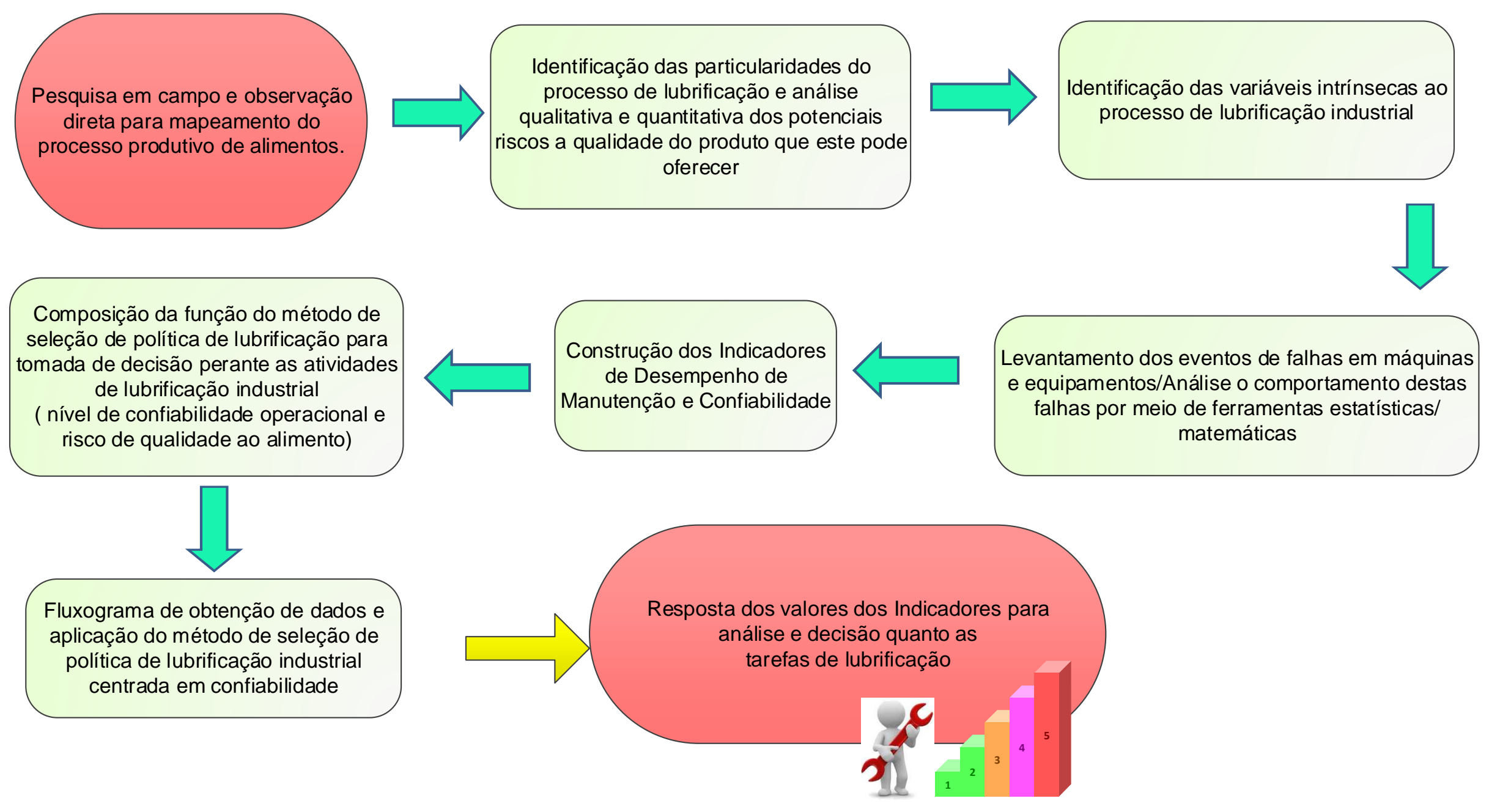

Fonte: Autoria própria 
Este método, que visa estruturar uma adequada política de lubrificação industrial no processo de fabricação de alimentos, é fundamentado nos seguintes aspectos:

> Levantar e analisar as falhas ocorridas nos ativos industriais, dando ênfase às falhas ocorridas em função das atividades de lubrificação industrial;

$>$ Definir as variáveis envolvidas no processo de lubrificação e apontar os potenciais riscos que estas podem acarretar na qualidade e inocuidade do produto e/ou prover potencial ocorrência de falhas (redução de desempenho e disponibilidade);

> Analisar os indicadores de manutenção e confiabilidade a fim de prover medidas para melhorá-los concomitantemente com ações que promovam garantia da qualidade no processo produtivo;

> Decidir a adequada política de lubrificação industrial para cada ativo a fim de melhorar o desempenho da máquina e/ou equipamento garantindo confiabilidade e disponibilidade do maquinário;

$>$ Decidir os modos de execução das tarefas de lubrificação direcionando a resultados satisfatórios de disponibilidade das instalações industriais e minimizando os riscos que possam interferir na qualidade e inocuidade do produto;

> Aperfeiçoar as tarefas de lubrificação quanto à habilidade técnica da mão de obra, ferramental e gestão de lubrificantes e com esta ação atender as normas e legislações vigentes no ramo de fabricação de alimentos e/ou até complementá-las;

> Verificar e validar os resultados por meio de indicadores de desempenho de manutenção e disponibilidade operacional.

E assim, o método de seleção de política de lubrificação centrada em confiabilidade voltado para maquinário de fabricação de alimentos, segue as seguintes etapas:

I - Identificação e Caracterização do Sistema Industrial: compreende o mapeamento do processo produtivo para compreensão dos impactos das atividades de lubrificação na qualidade e inocuidade do produto e na geração de eventos de 
falhas. Este mapeamento estrutura-se de: fluxograma do processo produtivo juntamente com o leiaute deste processo (onde o maquinário está inserido) e a árvore funcional do maquinário, neste identificando os pontos de lubrificação e dispositivos de aplicação do lubrificante;

II - Identificação dos Eventos de Riscos e Ocorrência de Falhas: esta etpa compreende:

a) A Identificação das variáveis envolvidas no processo de lubrificação industrial $\left(x_{1}, x_{2}\right.$ e $\left.x_{3}\right)$ para atribuir os valores binários as suas evidências no processo produtivo analisado;

b) Enquadramento do maquinário em sua Zona de Criticidade: atribuição do valor da $Z_{C}$ ao maquinário do processo produtivo de fabricação de alimentos;

c) Calculo do $I_{C R}$ : Cálculo do $I_{C R}$ e análise da faixa de valor, a qual identifica a deficiência do processo de lubrificação quanto as variáveis binárias e o grau de risco de perda de qualidade e inocuidade do produto em processamento;

d) Cálculo de análise dos indicadores de manutenção e qualidade para identificação das falhas críticas que impactam na disponibilidade.

III - Tomada de Decisão: compreende a aplicação de ferramentas da qualidade e manutenção para composição das ações que devem estruturadas na adequada política de lubrificação a ser adotadas para o processo produtivo;

IV - Avaliação de Eficácia do Método: análise dos resultados por meio dos indicadores de manutenção e disponibilidade aliados ao $I_{C R}$.

$\mathrm{Na}$ composição do indicador do nível de confiabilidade e potencial risco de perda de qualidade e inocuidade do produto (impacto nas características do produto), analisa-se cada etapa do processo de fabricação de alimentos, identificando as variáveis que inferem no processo de lubrificação de suas máquinas e equipamentos.

Para cada variável identificada estabelecem-se categorias de classificação atribuídas a valores de criticidade (pesos) relativos à sua influência nas tarefas de lubrificação, as quais podem tornar-se um potencial foco de risco a qualidade e 
inocuidade do produto e/ou ocasionar falhas, influenciando diretamente na disponibilidade e confiabilidade do processo.

Estas variáveis tornam-se os pilares de composição do indicador disposto no método para seleção da adequada política de lubrificação a ser adotada para o maquinário e estas variáveis estão intrinsicamente relacionadas às particularidades identificadas no processo de fabricação de alimentos frente às atividades de lubrificação, as quais são:

> Modos de execução das tarefas de lubrificação e da limpeza e higienização da área industrial;

> Qualificação de mão de obra técnica;

> Proximidade do ponto de lubrificação com a matéria prima em processo e/ou produto embalado e estrutura da instalação e/ou projeto de construção do maquinário e seus pontos de lubrificação;

> Gestão do processo de lubrificação e lubrificantes;

$>$ Instruções normativas, legislações e sistemáticas dispostas pela engenharia de qualidade dentro do sistema industrial de fabricação de alimentos;

> Histórico das ocorrências de falhas (manutenção) do maquinário industrial;

> Estratégias de Manutenção adotadas (Preventiva, Preditiva, Corretiva, ou combinação destas) e índices de disponibilidade, confiabilidade e mantenabilidade de máquinas e equipamentos;

> Particularidades relacionadas com as atividades de lubrificação industrial, que possam interferir (negativamente) na qualidade do produto e/ou gerar eventos de falhas.

Salienta-se que estas particularidades evidenciadas dentro do sistema industrial, as quais influenciam o processo de lubrificação industrial, foram identificadas em campo durante o mapeamento do processo industrial de fabricação de alimentos.

Este mapeamento, bem como sua análise, procedeu-se mediante observação direta, pesquisa em campo, pesquisa ação, pesquisa bibliográfica e documental. $\mathrm{O}$ diagrama exposto na figura 3.3 resume, esquematicamente, o raciocínio da construção das categorias e atribuição dos pesos/valores de cada variável englobada no método desenvolvido. 
Figura 3.3 - Fluxo de Caracterização e Análise Quantitativa/Qualitativa das Variáveis Envolvidas no Processo de Lubrificação Industrial

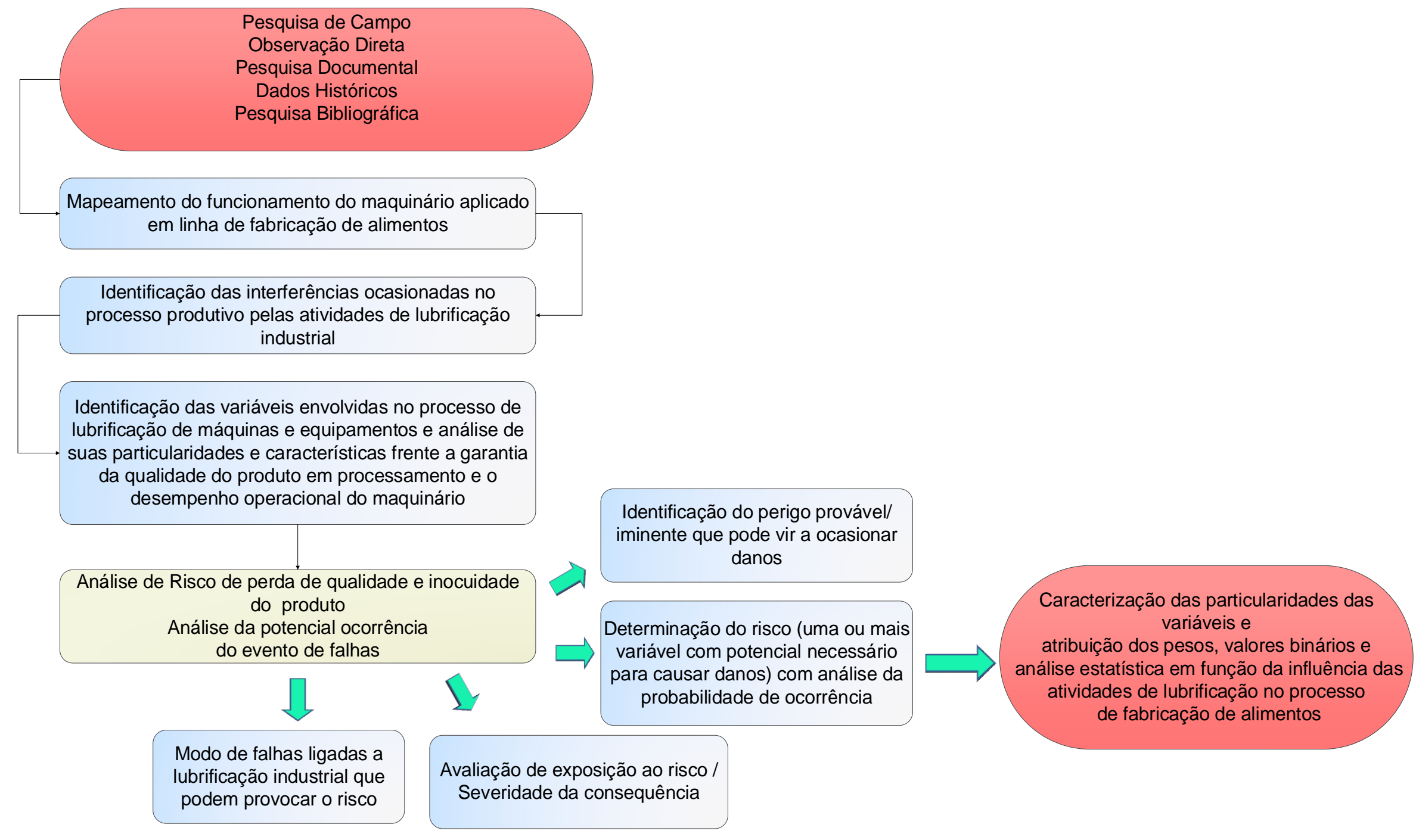

Fonte: Autoria própria 
Para a análise qualitativa das particularidades de cada variável (perante o seu impacto no processo de lubrificação industrial) em função da atribuição de seus pesos/valores (análise quantitativa) são analisados os fatores humanos, técnicos e sistemáticas aplicadas pela engenharia de qualidade no sistema fabril, os quais influenciam no processo de lubrificação de máquinas e equipamentos do ambiente industrial de alimentos. Para os valores atribuídos a cada variável identificada considera-se as particularidades relacionadas ao processo produtivo ponderando a participação de cada variável na gestão do risco de ocorrência de falhas e impacto na qualidade do produto.

O método visa identificar essas variáveis e analisá-las conjuntamente com o objetivo de apontar os impactos delas sobre o processo de lubrificação e assim direcionar a tomada de decisões, as quais consigam, ao mesmo tempo, otimizar a gestão do processo de lubrificação e cumprir as exigências da engenharia de qualidade, promovendo qualidade ao produto e melhores índices de desempenho de manutenção e confiabilidade.

Enfatiza-se que para aplicação do método desenvolvido é necessária uma estrutura consolidade de engenharia de manutenção na empresa, a qual deve contemplar os seguintes aspectos:

$>$ Centro de serviço com mão de obra técnica suficiente para execução das atividades de lubrificação e manutenção em geral;

$>$ Identificação dos locais de instalação de máquinas e equipamentos através de TAG's e leiautes;

$>$ Histórico de máquinas e equipamentos com dados de falhas, tempo até as falhas, insumos gastos, treinamentos, análises de falhas, troca de peças, entre outros;

> Dados de produtividades e gestão de custos de manutenção;

$>$ Sistema informatizado para gerenciamento das informações e planejamento das atividades de lubrificação.

Seguidamente, apresenta-se detalhadamente as etapas de contrução e características do método de seleção de política de lubrificação desenvolvido. 


\subsection{INDICADOR DE CONFIABILIDADE OPERACIONAL E RISCO DE PERDA DE QUALIDADE E INOCUIDADE DO PRODUTO}

Para o desenvolvimento do método de análise de falhas e potenciais riscos na perda de qualidade e inocuidade do produto no âmbito da lubrificação industrial em processo de fabricação de alimentos (com propósito de selecionar a política de lubrificação adequada a ser adotada pela planta industrial), deve-se mapear todo o sistema de manufatura do ambiente fabril, identificando, os pontos críticos quanto ao potencial risco de perda de qualidade e inocuidade do produto e a ocorrência de falhas do maquinário, considerando a relação destes fatores com o processo de lubrificação e atividades operacionais no maquinário industrial.

Salienta-se que para a fabricação de alimentos, a qualidade do produto é avaliada desde a obtenção da matéria prima (in natura), transporte logístico, armazenamento e condicionamento interno a fábrica, sistema industrial de transformação da matéria prima, distribuição (logística), armazenamento e disposição em atacado e varejo até o consumo final, ou seja, durante toda cadeia alimentar, como designado pela portaria no 1428 de 1993 emitida pelo Ministério da Saúde, a qual define cadeia alimentar como sendo "todas as atividades relacionadas à produção, beneficiamento, armazenamento, transporte, industrialização, embalagem, reembalagem, comercialização, utilização e consumo de alimentos, considerando-se suas interações com o meio ambiente, o homem e seu contexto socioeconômicos".

Porém, a presente pesquisa limita-se a analisar os riscos de perda de qualidade e inocuidade ao produto devido ao processo de lubrificação do maquinário fabril na etapa de fabricação, ou seja, no processo produtivo da indústria de transformação (setor secundário ou de transformação), como identificado na figura 3.4, a qual detalha o ciclo de avaliação da qualidade do produto perante as normas e legislações vigentes associadas a área de manufatura de alimentos. 
Figura 3.4 - Ciclo da Cadeia Alimentar para Análise de Qualidade desde a Obtenção de Matéria Prima até Consumo Final

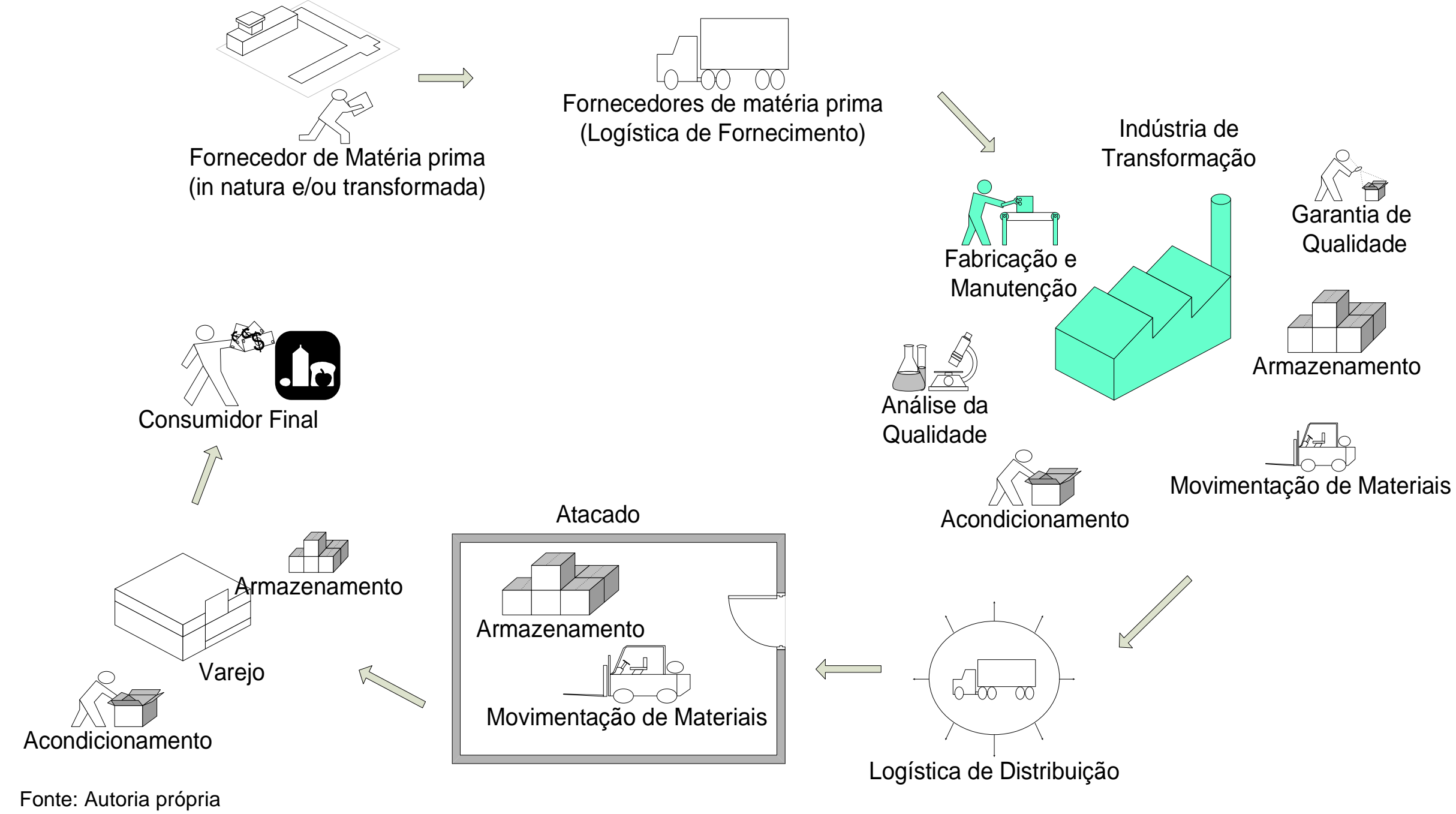


Destaca-se a importância do processo produtivo de fabricação de alimentos devido, neste ambiente, a matéria prima processada estar em contato direto e/ou indireto com os dispositivos que compõem máquinas e equipamentos industriais, fator que pode ocasionar risco de perda de qualidade e inocuidade do produto em processamento ou final.

Assim, nesta pesquisa são identificados os pontos de lubrificação de máquinas e equipamentos, detalhando suas características de operação e estrutura de construção do maquinário, bem como, as particularidades do processo de lubrificação e como este pode apresentar-se como um potencial risco de perda de qualidade e inocuidade do produto em processamento como também causar falhas em máquinas e equipamentos empregados na fabricação de alimentos.

$O$ indicador de confiabilidade operacional e potencial risco de perda de qualidade e inocuidade do produto (que pode ocorrer por meio das tarefas de lubrificação industrial) é composto pela análise qualitativa das zonas críticas do local de instalação da máquina e/ou equipamento com a junção das variáveis, quantificadas por valores binários ( 1 ou 0 ) envolvidas no processo de lubrificação.

$A$ análise das informações obtidas (com pesquisa em ambiente real de fabricação de alimentos e bibliográfica) é a base para construção das categorias das zonas críticas de fabricação do alimento em relação aos processos de lubrificação e manutenção de máquinas e equipamentos, relacionando os pontos de lubrificação e a sua proximidade da matéria prima em processamento.

Já o detalhamento da influência do processo de lubrificação direciona a identificação das variáveis envolvidas neste processo ligadas a engenharia de manutenção e atribuir pesos a elas para avaliar sua influência dentro do universo das consequências do processo de lubrificação na operação de uma indústria de alimentos.

Para execução do mapeamento do processo com a finalidade da classificação do zoneamento do local de instalação da máquina em função do potencial risco e impacto do processo de lubrificação na qualidade do produto, estruturam-se as seguintes etapas:

I - Pesquisa em campo, bibliográfica, documental e entrevista (com funcionários de estabelecimentos de produção de alimentos) para identificação das variáveis envolvidas no processo de lubrificação e o modo de interferência dessas na 
qualidade do produto durante o processo produtivo, bem como, o impacto destas variáveis na disponibilidade e confiabilidade do maquinário fabril;

II - Pesquisa em campo e documental para identificação dos pontos de lubrificação da máquina, análise de sua característica estrutural (projeto) e funcional, esta última obtida pela construção de árvore funcional da máquina e /ou equipamento destacando seus pontos de lubrificação;

III - Composição de categorias de zonas críticas de instalação de maquinário quanto às características do processo de lubrificação e sua influência no desempenho do maquinário fabril e ao potencial risco quanto a perda de qualidade e inocuidade do produto, com base em dados elencados e observados em pesquisa em campo, documental, entrevistas e pesquisa bibliográfica.

IV - Elaboração do leiaute da área industrial, identificando visualmente a categoria de zoneamento atribuído a cada máquina do sistema produtivo de alimentos a fim de facilitar a análise do funcionamento do maquinário e sua relação com a produtividade da linha de produção na qual este está inserido.

Para seleção das variáveis envolvidas no processo de lubrificação industrial, elencam-se e analisam-se aspectos do processo de lubrificação industrial (interferência na funcionalidade do processo produtivo de alimentos e na qualidade e inocuidade do produto), aspectos os quais são oriundos de:

> Informação estrutural (parte estática das instalações industriais, a estrutura do projeto de máquinas e equipamentos e identificação dos pontos de lubrificação);

> Informação dinâmica (como o processo de lubrificação industrial interfere no comportamento do processo produtivo quanto a qualidade do produto $\mathrm{e}$ produtividade);

$>$ Informação funcional (procedimento de execução das tarefas de lubrificação e limpeza do maquinário industrial).

Com análise destas informações, expõem-se na figura 3.5, as variáveis que influenciam no processo de lubrificação, conjuntamente com os valores que elas podem assumir. 
Figura 3.5 - Variáveis Envolvidas no Processo de Lubrificação com seus Valores/Pesos Identificados para Obtenção do Indicador de Nível de Confiabilidade Operacional e Potencial Risco à Perda de Qualidade e Inocuidade do Produto por meio das Atividades de Lubrificação

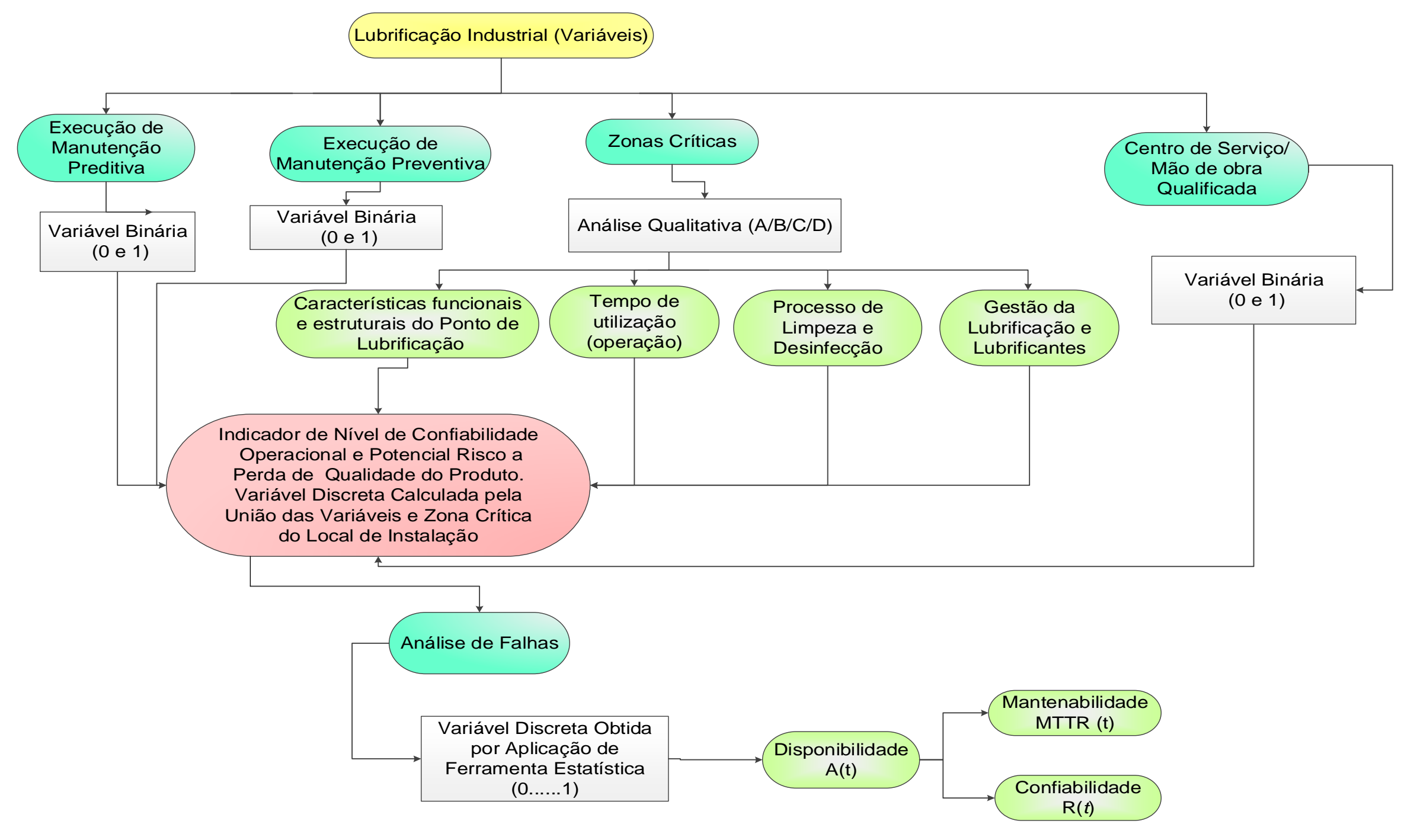

Fonte: Autoria própria 
Como apontado na figura 3.5 , os indicadores de confiabilidade e disponibilidade de máquinas e equipamentos constituem-se como parte do método desenvolvido, pois a análise destes indicadores evidencia o desempenho das atividades de lubrificação sobre o sistema industrial, auxiliando a tomada de decisão na adoção da politica de lubrificação adequada para garantir confiabilidade e disponibilidade das instalações industriais conjuntamente com a garantia de qualidade do produto.

Estas variáveis, intrínsicas ao processo de lubrificação industrial (as quais apresentadas na figura 3.5) trata-se de fatores que podem impactar diretamente no desempenho do maquinário industrial (interferir na disponibilidade e confiabilidade operacional) e que ao mesmo tempo podem tornar-se um risco a perda de qualidade e inocuidade do produto (por meio de contaminação química e/ou biológica) durante as etapas de fabricação alimentos.

A análise e classificação ponderada da influência das ações de manutenção, principalmente da lubrificação industrial, no processo produtivo de alimentos é essencial para identificar a política adequada de realização das tarefas de lubrificação e otimização de seus recursos financeiros e materiais, contribuindo para a confiabilidade e disponilidade operacional de máquinas e equipamentos industriais, sendo estas os principais objetivos da engenharia de manutenção.

Redução proporcional do tempo de vida útil e das falhas que interrompem e/ou diminuem o desempenho do maquinário industrial e contenção dos pontos críticos relacionados ao processo de lubrificação, os quais representam um foco de risco à perda de qualidade e inocuidade do produto (por meio de contaminação), são parâmetros do modelo proposto para melhorar as estratégias de manutenção quanto aos procedimentos e gestão da lubrificação no âmbito industrial de produção de alimentos.

Para composição do método estruturam-se tabelas de classificação (peso), atribuição de valores binários e aplicação de ferramentas estatísticas/matemáticas na obtenção dos valores quantitativos das variáveis e indicadores de desempenho envolvidos no processo de lubrificação industrial de maquinário aplicado na produção de alimentos.

A análise conjunta destas variáveis compõe o indicador de nível que visa equilibrar os efeitos dos eventos de falhas e potencial risco de perda de qualidade e inocuidade ao produto, sendo este indicador apresentado na expressão (3.1): 


$$
I_{C R}=\left(x_{1}+x_{2}+x_{3}\right) * Z_{c}
$$

Em que : $\mathbf{I}_{\mathbf{C R}}=$ indicador de nível de equilíbrio entre a confiabilidade operacional de máquinas e equipamentos e potencial risco de perda de qualidade e inocuidade do produto mediante o processo de lubrificação industrial; $x_{1}, x_{2}, x_{3}=$ variável binária $x_{i}$ que impacta no risco de perda de qualidade e inocuidade do produto e/ou foco de ocorrência de falhas; $Z_{C}=$ Coeficiente multiplicador do peso da zona crítica do local de instalação da máquina e/ou equipamento.

Esta equação que expressa o indicador de confiabilidade operacional e risco de perda de qualidade e inocuidade do produto, envolve e analisa, de forma conjunta, as consequências ocasionadas pelas variáveis identificadas no processo de lubrificação industrial, consequências as quais podem impactar também na qualidade do produto durante as etapas do processo produtivo de alimentos.

Os valores atribuídos aos coeficientes/pesos as variáveis (medida de sensibilidade entre a variável relacionada à lubrificação e seu impacto no processo industrial) e a identificação da Zona de Criticidade $\left(Z_{C}\right)$ são obtidos pela análise dos parâmetros:

> Estrutural (projeto e disposição física do ponto de lubrificação no maquinário);

> Dinâmico (impacto do processo de lubrificação industrial sobre a qualidade do produto e potencial foco gerador de eventos de falhas);

> Funcional (impacto do modo de execução das atividades industriais sobre a qualidade do produto e potencial foco gerador de eventos de falhas) relacionados ao processo de lubrificação de máquinas e equipamentos.

A análise do comportamento e particularidades destes parâmetros possibilita a distinta atribuição de valores, conforme cada variável participante do processo de lubrificação industrial e a descrição das características de cada categoria das Zonas de Criticidade $\left(\mathrm{Z}_{\mathrm{C}}\right)$.

Logo, identificada a variável $x_{i}$ conjuntamente com a $Z_{C}$ do local de instalação do maquinário, sendo ambos os fatores relacionados ao processo de lubrificação de maquinário aplicado a produção de alimentos, tem-se o esquema detalhado no 
quadro 3.1, o qual mostra a relação entre estas variáveis e $Z_{C}$ para apropriação de seus valores (quantitativos e qualitativos) e inferência no indicador $\mathrm{I}_{\mathrm{CR}}$.

Quadro 3.1 - Estrutura da Relação entre as Variáveis Envolvidas no Processo de Lubrificação na Construção do Indicador de Nível de Confiabilidade Operacional e Potencial Risco de Perda de Qualidade e Inocuidade do Produto

\begin{tabular}{|c|c|}
\hline \multicolumn{2}{|c|}{$\begin{array}{l}\text { Relação dos Pesos/Valores das Variáveis Envolvidas no Processo de Lubrificaçãa } \\
\text { Industrial na Construção do Indicador de Nível de Confiabilidade Operacional } \\
\text { Potencial Risco de Perda de Qualidade e Inocuidade do Produto }\end{array}$} \\
\hline \multicolumn{2}{|r|}{$\begin{array}{l}x_{i}=\text { Variável envolvida no processo de lubrificação de } \\
\text { máquinas e equipamentos empregados em indústria de } \\
\text { alimentos; } \\
Z_{c} \text { Zona de Criticidade do processo de lubrificação sobre } \\
\text { o local de instalação da máquina e/ou equipamento } \\
\text { Espaço amostral = processo de lubrificação em indústria } \\
\text { de alimentos }\end{array}$} \\
\hline \multicolumn{2}{|c|}{$\rightarrow I_{C R} \mid \begin{array}{l}x_{i} \text { e } Z_{C} \text { implicam em } I_{C R} \text {, obtido valor de } I_{C R} \text { conhecida a } \\
\text { ocorrência e o peso da variável } \\
\text { Valor de } I_{C R} \text { apresenta de forma qualitativa e quantitativa } \\
\text { o desempenho das atividades de lubrificação sobre a } \\
\text { gestão da manutenção industrial }\end{array}$} \\
\hline $\begin{array}{r}\quad I_{C R}\left(x_{1} \cup x_{2} \cup x_{3} Z c_{)}\right)= \\
=\left(x_{1}+x_{2}+x_{3}\right)^{*} Z_{c} \\
I_{C R}=\text { Indicador } \\
x_{i}=\text { variável identificada; } \\
Z_{c}=\text { Zona de criticidade }\end{array}$ & $\begin{array}{l}\mathrm{I}_{\mathrm{CR}}=\text { indicador de nível de confiabilidade operacional e } \\
\text { potencial risco de perda de qualidade e inocuidade do } \\
\text { produto (mediante o processo de lubrificação industrial de } \\
\text { máquinas e equipamentos empregados na produção de } \\
\text { alimentos). }\end{array}$ \\
\hline
\end{tabular}

Fonte: Autoria própria

O indicador de nível de confiabilidade operacional e potencial risco a perda de qualidade e inocuidade do produto é composto pela união dos eventos não exclusivos, mas independentes, das variáveis $\left(\mathrm{x}_{\mathrm{i}}\right)$ entre si e da Zona de Criticidade $\left(Z_{C}\right)$ do local de instalação do item avaliado, sendo os valores possíveis tomados pelo indicador e sua respectiva avaliação apresentados no quadro 3.2. 
Quadro 3.2 - Análise do Indicador de Nível de Confiabilidade Operacional e Potencial Risco de Perda de Qualidade e Inocuidade do Produto - I IR

\begin{tabular}{|c|c|c|c|c|c|}
\hline $\begin{array}{l}\text { Valor } \\
I_{C R}\end{array}$ & $\begin{array}{c}\text { Manutenção } \\
\text { Preventiva }\end{array}$ & $\begin{array}{l}\text { Manutenção } \\
\text { Preditiva }\end{array}$ & Mão-de-obra & $\begin{array}{l}\text { Potencial Risco de Perda de Qualidade e } \\
\text { Inocuidade do Produto }\end{array}$ & Produtividade \\
\hline $3 \mathrm{~A}$ & $\begin{array}{c}\text { Análise para } \\
\text { melhoria } \\
\text { contínua }\end{array}$ & $\begin{array}{l}\text { Análise para } \\
\text { melhoria } \\
\text { contínua }\end{array}$ & $\begin{array}{l}\text { Análise para } \\
\text { melhoria } \\
\text { contínua }\end{array}$ & $\begin{array}{l}\text { Processo de Lubrificação oferece potencial } \\
\text { de e inocuidade com perdas total da } \\
\text { produção } \\
\text { Risco monitorado e controlado por meio de } \\
\text { estratégias de manutenção eficazes }\end{array}$ & $\begin{array}{c}\text { Indicadores de Disponibilidade e } \\
\text { Confiabilidade operacional atendem } \\
\text { a demanda da produtividade }\end{array}$ \\
\hline $2 \mathrm{~A}$ & $\begin{array}{c}\text { Deficiência } \\
\text { na } \\
\text { Manutenção } \\
\text { Preventiva } \\
\text { ou Preditiva } \\
\text { Análise de } \\
\text { Falhas }\end{array}$ & $\begin{array}{l}\text { Deficiência } \\
\text { na } \\
\text { Manutenção } \\
\text { Preventiva ou } \\
\text { Preditiva } \\
\text { Análise de } \\
\text { Falhas }\end{array}$ & $\begin{array}{l}\text { Análise para } \\
\text { melhoria } \\
\text { contínua }\end{array}$ & $\begin{array}{l}\text { Processo de Lubrificação oferece potencial } \\
\text { de risco de perda de qualidade e } \\
\text { inocuidade do produto com perdas total da } \\
\qquad \text { produção } \\
\text { Intensificação do risco por meio de } \\
\text { deficiência das estratégias de manutenção }\end{array}$ & $\begin{array}{l}\text { Potencial ocorrência de eventos de } \\
\text { falhas gerando impacto nos } \\
\text { indicadores de Disponibilidade e } \\
\text { Confiabilidade operacional } \\
\text { Horas extras de trabalho = aumento } \\
\text { de custo de produção }\end{array}$ \\
\hline
\end{tabular}

(Continua) 
(Continuação)

\begin{tabular}{|c|c|c|c|c|c|}
\hline Valor & $\begin{array}{c}\text { Manutenção } \\
\text { Preventiva }\end{array}$ & $\begin{array}{c}\text { Manutenção } \\
\text { Preditiva }\end{array}$ & Mão-de-obra & $\begin{array}{l}\text { Potencial Risco de Perda de } \\
\text { Qualidade e Inocuidade do Produto }\end{array}$ & Produtividade \\
\hline $1 \mathrm{~A}$ & $\begin{array}{c}\text { Deficiência } \\
\text { na } \\
\text { Manutenção } \\
\text { Preventiva } \\
\text { Análise de } \\
\text { Falhas }\end{array}$ & $\begin{array}{c}\text { Deficiência } \\
\text { na } \\
\text { Manutenção } \\
\text { Preditiva } \\
\text { Análise de } \\
\text { Falhas }\end{array}$ & $\begin{array}{c}\text { Análise para } \\
\text { melhoria } \\
\text { contínua }\end{array}$ & $\begin{array}{c}\text { Processo de Lubrificação oferece } \\
\text { potencial de risco de perda de } \\
\text { qualidade e inocuidade do produto com } \\
\text { perdas total da produção } \\
\text { Intensificação do risco por meio de } \\
\text { deficiência das estratégias de } \\
\text { manutenção }\end{array}$ & $\begin{array}{l}\text { Potencial ocorrência de eventos de } \\
\text { falhas gerando impacto nos indicadores } \\
\text { de Disponibilidade e Confiabilidade } \\
\text { operacional } \\
\text { Horas extras de trabalho = aumento de } \\
\text { custo de produção } \\
\text { Atraso entrega = insatisfação do } \\
\text { mercado consumidor }\end{array}$ \\
\hline OA & $\begin{array}{c}\text { Deficiência } \\
\text { na } \\
\text { Manutenção } \\
\text { Preventiva } \\
\text { Análise de } \\
\text { Falhas }\end{array}$ & $\begin{array}{c}\text { Deficiência } \\
\text { na } \\
\text { Manutenção } \\
\text { Preditiva } \\
\text { Análise de } \\
\text { Falhas }\end{array}$ & $\begin{array}{c}\text { Falta e/ou } \\
\text { deficiência } \\
\text { na } \\
\text { qualificação } \\
\text { da Mão de } \\
\text { Obra } \\
\text { Análise de } \\
\text { Falhas }\end{array}$ & $\begin{array}{c}\text { Processo de Lubrificação oferta } \\
\text { potencial de risco de perda de } \\
\text { qualidade e inocuidade do produto com } \\
\text { perdas total da produção } \\
\text { Intensificação do risco por meio de } \\
\text { deficiência das estratégias de } \\
\text { manutenção }\end{array}$ & $\begin{array}{l}\text { Potencial ocorrência de eventos de } \\
\text { falhas gerando impacto nos indicadores } \\
\text { de Disponibilidade e Confiabilidade } \\
\text { operacional } \\
\text { Horas extras de trabalho = aumento de } \\
\text { custo de produção } \\
\text { Atraso entrega = insatisfação do } \\
\text { mercado consumidor }\end{array}$ \\
\hline
\end{tabular}

(Continua) 
(Continuação)

\begin{tabular}{|c|c|c|c|c|c|}
\hline $\begin{array}{l}\text { Valor } \\
I_{C R}\end{array}$ & $\begin{array}{l}\text { Manutenção } \\
\text { Preventiva }\end{array}$ & $\begin{array}{c}\text { Manutenção } \\
\text { Preditiva }\end{array}$ & Mão-de-obra & $\begin{array}{l}\text { Potencial Risco de Perda de Qualidade e } \\
\text { Inocuidade do Produto }\end{array}$ & Produtividade \\
\hline $3 \mathrm{~B}$ & $\begin{array}{l}\text { Análise para } \\
\text { melhoria } \\
\text { contínua }\end{array}$ & $\begin{array}{l}\text { Análise para } \\
\text { melhoria } \\
\text { contínua }\end{array}$ & $\begin{array}{l}\text { Análise para } \\
\text { melhoria } \\
\text { contínua }\end{array}$ & $\begin{array}{l}\text { Processo de Lubrificação oferece potencial } \\
\text { de risco de perda de qualidade e } \\
\text { inocuidade do produto com perdas total da } \\
\qquad \text { produção. } \\
\text { Risco monitorado e controlado por meio de } \\
\text { estratégias de manutenção eficazes. }\end{array}$ & $\begin{array}{c}\text { Indicadores de Disponibilidade e } \\
\text { Confiabilidade operacional atendem } \\
\text { à demanda da produtividade }\end{array}$ \\
\hline 2B & $\begin{array}{c}\text { Deficiência } \\
\text { na } \\
\text { Manutenção } \\
\text { Preventiva } \\
\text { ou Preditiva } \\
\text { Análise de } \\
\text { Falhas }\end{array}$ & $\begin{array}{c}\text { Deficiência } \\
\text { na } \\
\text { Manutenção } \\
\text { Preventiva ou } \\
\text { Preditiva } \\
\text { Análise de } \\
\text { Falhas }\end{array}$ & $\begin{array}{l}\text { Análise para } \\
\text { melhoria } \\
\text { contínua }\end{array}$ & $\begin{array}{l}\text { Processo de Lubrificação oferece potencial } \\
\text { de risco de perda de qualidade e } \\
\text { inocuidade do produto com perdas total da } \\
\qquad \text { produção. } \\
\text { Intensificação do risco por meio de } \\
\text { deficiência das estratégias de manutenção. }\end{array}$ & $\begin{array}{c}\text { Potencial ocorrência de eventos de } \\
\text { falhas gerando impacto nos } \\
\text { indicadores de Disponibilidade e } \\
\text { Confiabilidade operacional, porém } \\
\text { demanda de produtividade pode ser } \\
\text { atendida }\end{array}$ \\
\hline
\end{tabular}

(Continua) 
(Continuação)

\begin{tabular}{|c|c|c|c|c|c|}
\hline $\begin{array}{l}\text { Valor } \\
I_{C R}\end{array}$ & $\begin{array}{l}\text { Manutenção } \\
\text { Preventiva }\end{array}$ & $\begin{array}{l}\text { Manutenção } \\
\text { Preditiva }\end{array}$ & Mão-de-obra & $\begin{array}{l}\text { Potencial Risco de Perda de } \\
\text { Qualidade e Inocuidade do Produto }\end{array}$ & Produtividade \\
\hline $1 \mathrm{~B}$ & $\begin{array}{l}\text { Deficiência } \\
\text { na } \\
\text { Manutenção } \\
\text { Preventiva } \\
\text { Análise de } \\
\text { Falhas }\end{array}$ & $\begin{array}{c}\text { Deficiência na } \\
\text { Manutenção } \\
\text { Preditiva } \\
\text { Análise de } \\
\text { Falhas }\end{array}$ & $\begin{array}{c}\text { Análise para } \\
\text { melhoria } \\
\text { contínua }\end{array}$ & $\begin{array}{c}\text { Processo de Lubrificação oferece } \\
\text { potencial de risco de perda de qualidade } \\
\text { e inocuidade do produto com perdas } \\
\text { total da produção } \\
\text { Intensificação do risco por meio de } \\
\text { deficiência das estratégias de } \\
\text { manutenção }\end{array}$ & $\begin{array}{l}\text { Potencial ocorrência de eventos de } \\
\text { falhas gerando impacto nos } \\
\text { indicadores de Disponibilidade e } \\
\text { Confiabilidade operacional. } \\
\text { Redução do desempenho da } \\
\text { produtividade devido backup ativo }\end{array}$ \\
\hline $0 \mathrm{~B}$ & $\begin{array}{l}\text { Deficiência } \\
\text { na } \\
\text { Manutenção } \\
\text { Preventiva } \\
\text { Análise de } \\
\text { Falhas }\end{array}$ & $\begin{array}{c}\text { Deficiência na } \\
\text { Manutenção } \\
\text { Preditiva } \\
\text { Análise de } \\
\text { Falhas }\end{array}$ & $\begin{array}{c}\text { Falta e/ou } \\
\text { deficiência na } \\
\text { qualificação da } \\
\text { Mão de Obra } \\
\text { Análise de } \\
\text { Falhas }\end{array}$ & $\begin{array}{c}\text { Processo de Lubrificação oferece } \\
\text { potencial de risco de perda de qualidade } \\
\text { e inocuidade do produto com perdas } \\
\text { total da produção } \\
\text { Intensificação do risco por meio de } \\
\text { deficiência das estratégias de } \\
\text { manutenção }\end{array}$ & $\begin{array}{c}\text { Potencial ocorrência de eventos de } \\
\text { falhas gerando impacto nos } \\
\text { indicadores de Disponibilidade e } \\
\text { Confiabilidade operacional } \\
\text { Horas extras de trabalho = aumento } \\
\text { de custo de produção }\end{array}$ \\
\hline
\end{tabular}

(Continua) 
(Continuação)

\begin{tabular}{|c|c|c|c|c|c|}
\hline $\begin{array}{l}\text { Valor } \\
I_{C R}\end{array}$ & $\begin{array}{c}\text { Manutenção } \\
\text { Preventiva }\end{array}$ & $\begin{array}{l}\text { Manutenção } \\
\text { Preditiva }\end{array}$ & Mão-de-obra & $\begin{array}{l}\text { Potencial Risco de Perda de } \\
\text { Qualidade e Inocuidade do Produto }\end{array}$ & Produtividade \\
\hline $3 C$ & $\begin{array}{c}\text { Análise para } \\
\text { melhoria } \\
\text { contínua }\end{array}$ & $\begin{array}{l}\text { Análise para } \\
\text { melhoria } \\
\text { contínua }\end{array}$ & $\begin{array}{l}\text { Análise para } \\
\text { melhoria } \\
\text { contínua }\end{array}$ & $\begin{array}{c}\text { Processo de Lubrificação oferece } \\
\text { potencial de risco de perda de qualidade } \\
\text { e inocuidade do produto com perdas } \\
\text { parciais (perda de embalagem) } \\
\text { Risco monitorado e controlado por meio } \\
\text { de estratégias de manutenção eficazes }\end{array}$ & $\begin{array}{c}\text { Indicadores de Disponibilidade e } \\
\text { Confiabilidade operacional atendem a } \\
\text { demanda da produtividade }\end{array}$ \\
\hline $2 \mathrm{C}$ & $\begin{array}{l}\text { Deficiência } \\
\text { na } \\
\text { Manutenção } \\
\text { Preventiva } \\
\text { ou Preditiva } \\
\text { Análise de } \\
\text { Falhas }\end{array}$ & $\begin{array}{l}\text { Deficiência na } \\
\text { Manutenção } \\
\text { Preventiva ou } \\
\text { Preditiva } \\
\text { Análise de } \\
\text { Falhas }\end{array}$ & $\begin{array}{l}\text { Análise para } \\
\text { melhoria } \\
\text { contínua }\end{array}$ & $\begin{array}{c}\text { Processo de Lubrificação oferece } \\
\text { potencial de risco de perda de qualidade } \\
\text { e inocuidade do produto com perdas } \\
\text { parciais (perda de embalagem) } \\
\text { Intensificação do risco por meio de } \\
\text { deficiência das estratégias de } \\
\text { manutenção }\end{array}$ & $\begin{array}{l}\text { Potencial ocorrência de eventos de } \\
\text { falhas gerando impacto nos } \\
\text { indicadores de Disponibilidade e } \\
\text { Confiabilidade operacional, porém } \\
\text { demanda de produtividade atendida } \\
\text { devido presença de Redução do } \\
\text { desempenho da produtividade devido } \\
\text { backup ativo e/ou passivo }\end{array}$ \\
\hline
\end{tabular}

(Continua) 
(Continuação)

\begin{tabular}{|c|c|c|c|c|c|}
\hline $\begin{array}{l}\text { Valor } \\
I_{C R}\end{array}$ & $\begin{array}{c}\text { Manutenção } \\
\text { Preventiva }\end{array}$ & $\begin{array}{c}\text { Manutenção } \\
\text { Preditiva }\end{array}$ & Mão-de-obra & $\begin{array}{l}\text { Potencial Risco de Perda de } \\
\text { Qualidade e Inocuidade do } \\
\text { Produto }\end{array}$ & Produtividade \\
\hline 1C & $\begin{array}{c}\text { Deficiência } \\
\text { na } \\
\text { Manutenção } \\
\text { Preventiva } \\
\text { Análise de } \\
\text { Falhas }\end{array}$ & $\begin{array}{c}\text { Deficiência na } \\
\text { Manutenção } \\
\text { Preditiva } \\
\text { Análise de } \\
\text { Falhas }\end{array}$ & $\begin{array}{l}\text { Análise para } \\
\text { melhoria } \\
\text { contínua }\end{array}$ & $\begin{array}{l}\text { Processo de Lubrificação oferece } \\
\text { potencial de risco de perda de } \\
\text { qualidade e inocuidade do } \\
\text { produto com perdas parciais } \\
\text { (perda de embalagem) } \\
\text { Intensificação do risco por meio } \\
\text { de deficiência das estratégias de } \\
\text { manutenção. }\end{array}$ & $\begin{array}{l}\text { Potencial ocorrência de eventos de falhas } \\
\text { gerando impacto nos indicadores de } \\
\text { Disponibilidade e Confiabilidade operacional. } \\
\text { Demanda de produtividade atendida devido } \\
\text { backup passivo e/ou ativo } \\
\text { Aumento de manutenção corretiva para } \\
\text { restabelecimento do funcionamento do ativo } \\
\text { principal }\end{array}$ \\
\hline OC & $\begin{array}{c}\text { Deficiência } \\
\text { na } \\
\text { Manutenção } \\
\text { Preventiva } \\
\text { Análise de } \\
\text { Falhas }\end{array}$ & $\begin{array}{c}\text { Deficiência na } \\
\text { Manutenção } \\
\text { Preditiva } \\
\text { Análise de } \\
\text { Falhas }\end{array}$ & $\begin{array}{l}\text { Falta e/ou } \\
\text { deficiência } \\
\text { na } \\
\text { qualificação } \\
\text { da Mão de } \\
\text { Obra. } \\
\text { Análise de } \\
\text { Falhas }\end{array}$ & $\begin{array}{l}\text { Processo de Lubrificação oferece } \\
\text { potencial de risco de perda de } \\
\text { qualidade e inocuidade do } \\
\text { produto com perdas parciais } \\
\text { (perda de embalagem) } \\
\text { Intensificação do risco por meio } \\
\text { de deficiência das estratégias de } \\
\text { manutenção }\end{array}$ & $\begin{array}{l}\text { Potencial ocorrência de eventos de falhas } \\
\text { gerando impacto nos indicadores de } \\
\text { Disponibilidade e Confiabilidade operacional. } \\
\text { Horas extras de trabalho = aumento de custo } \\
\text { de produção } \\
\text { Aumento de manutenção corretiva para } \\
\text { restabelecimento do funcionamento do ativo } \\
\text { principal e seu backup }\end{array}$ \\
\hline
\end{tabular}

(Continua) 
(Continuação)

\begin{tabular}{|c|c|c|c|c|c|}
\hline $\begin{array}{l}\text { Valor } \\
I_{C R}\end{array}$ & $\begin{array}{c}\text { Manutenção } \\
\text { Preventiva }\end{array}$ & $\begin{array}{l}\text { Manutenção } \\
\text { Preditiva }\end{array}$ & Mão-de-obra & $\begin{array}{c}\text { Potencial Risco de Perda de } \\
\text { Qualidade e Inocuidade do Produto }\end{array}$ & Produtividade \\
\hline 2D & $\begin{array}{l}\text { Deficiência } \\
\text { na } \\
\text { Manutenção } \\
\text { Preventiva } \\
\text { ou Preditiva } \\
\text { Análise de } \\
\text { Falhas }\end{array}$ & $\begin{array}{l}\text { Deficiência na } \\
\text { Manutenção } \\
\text { Preventiva ou } \\
\text { Preditiva } \\
\text { Análise de } \\
\text { Falhas }\end{array}$ & $\begin{array}{c}\text { Análise para } \\
\text { melhoria } \\
\text { contínua }\end{array}$ & $\begin{array}{c}\text { Processo de Lubrificação oferece } \\
\text { potencial de risco de perda de qualidade } \\
\text { e inocuidade do produto com perdas } \\
\text { parciais (perda de embalagem terciária) } \\
\text { Intensificação do risco por meio de } \\
\text { deficiência das estratégias de } \\
\text { manutenção }\end{array}$ & $\begin{array}{c}\text { Potencial ocorrência de eventos de } \\
\text { falhas gerando impacto nos } \\
\text { indicadores de Disponibilidade e } \\
\text { Confiabilidade operacional } \\
\text { Demanda de produtividade atendida } \\
\text { devido backup passivo }\end{array}$ \\
\hline
\end{tabular}

(Continua) 
(Conclusão)

\begin{tabular}{|c|c|c|c|c|c|}
\hline $\begin{array}{l}\text { Valor } \\
I_{C R}\end{array}$ & $\begin{array}{c}\text { Manutenção } \\
\text { Preventiva }\end{array}$ & $\begin{array}{c}\text { Manutenção } \\
\text { Preditiva }\end{array}$ & Mão-de-obra & $\begin{array}{l}\text { Potencial Risco de Perda de } \\
\text { Qualidade e Inocuidade do } \\
\text { Produto }\end{array}$ & Produtividade \\
\hline 1D & $\begin{array}{c}\text { Deficiência } \\
\text { na } \\
\text { Manutenção } \\
\text { Preventiva } \\
\text { Análise de } \\
\text { Falhas }\end{array}$ & $\begin{array}{c}\text { Deficiência na } \\
\text { Manutenção } \\
\text { Preditiva } \\
\text { Análise de } \\
\text { Falhas }\end{array}$ & $\begin{array}{l}\text { Análise para } \\
\text { melhoria } \\
\text { contínua }\end{array}$ & $\begin{array}{l}\text { Processo de Lubrificação oferece } \\
\text { potencial de risco de perda de } \\
\text { qualidade e inocuidade do produto } \\
\text { com perdas parciais (perda de } \\
\text { embalagem terciária) } \\
\text { Intensificação do risco por meio de } \\
\text { deficiência das estratégias de } \\
\text { manutenção }\end{array}$ & $\begin{array}{l}\text { Potencial ocorrência de eventos de falhas } \\
\text { gerando impacto nos indicadores de } \\
\text { Disponibilidade e Confiabilidade } \\
\text { operacional. } \\
\text { Aumento de manutenção corretiva para } \\
\text { restabelecimento do funcionamento do } \\
\text { ativo principal. }\end{array}$ \\
\hline
\end{tabular}

Fonte: Autoria própria 
A relação entre as variáveis envolvidas no processo de lubrificação com seus respectivos coeficientes (pesos) determina se cada condição (ocorrência do evento e grau de criticidade) produz um efeito na resposta observada (indicador de confiabilidade e potencial risco de perda de qualidade e inocuidade do produto), ou seja, indica uma relação causa-efeito entre o indicador e a ocorrência da variável que o influencia.

Já a análise qualitativa da Zona de Criticidade $\left(Z_{C}\right)$ retorna as características dos riscos (que possam provocar a perda de qualidade e inocuidade do produto) envolvidos em cada categoria ( $A, B, C$, e D), apontando os principais pontos críticos relacionados ao processo de lubrificação que devam ser melhorados e/ou monitorados para esses riscos devam ser reduzidos e/ou eliminados.

A junção dos valores das variáveis binárias e as categorias que compõe as Zonas Críticas (referente ao local de instalação do ativo industrial analisado), retornam um valor/nível - $I_{C R}$, o qual visa identificar o potencial risco de perda de qualidade e inocuidade do produto e os focos de geração de eventos de falhas que as atividades de lubrificação industrial possam ocasionar ao sistema fabril.

O valor do indicador $\mathrm{I}_{\mathrm{CR}}$ é analisado mediante as faixas de níveis descritas no quadro 3.2, sendo que em cada faixa de valor é descrita, de forma qualitativa, o diagnóstico da influência do atual do processo de lubrificação sobre o processo de fabricação de alimentos.

Esta análise qualitativa das faixas de valores/níveis do indicador possibilita analisar o comportamento do processo de lubrificação e assim tomar decisão quanto à estrutura da adequada política de lubrificação que venha a equilibrar os objetivos da engenharia de manutenção (confiabilidade e disponibilidade de operação) com o cumprimento do sistema de gestão da qualidade.

Ainda, para estruturação da política de lubrificação industrial adequada a cada ativo industrial que compõe as instalações de uma indústria de alimentos, fazse necessário verificar o comportamento da tendência de falhas ocorridas no ativo industrial, obtendo assim os indicadores que mostram a disponibilidade e a confiabilidade operacional.

Estes indicadores proporcionam identificar os eventos de falhas que influenciam no desempenho operacional do maquinário, e assim torna-se possível analisar as causas destes eventos para tomada de decisão que direcionam a medidas de contenção destas falhas. 
Além disto, os indicadores de desempenho de manutenção e disponibilidade operacional são aplicados para monitoramento da eficácia das ações contidas na política de lubrificação adotada, possibilitando verificar os resultados quanto a disponibilidade operacional e ganho de produtividade.

Este indicador de nível de confiabilidade operacional e potencial risco a perda de qualidade e inocuidade do produto tem como principais características e funcionalidade dentro do método de seleção de política de lubrificação industrial centrada em confiabilidade:

I - Construção pelo raciocínio dedutivo retirado pelas observações dados em campo, direcionando de um ponto específico (processo de lubrificação de máquinas e equipamentos) para o geral (risco de perda de qualidade e inocuidade do produto por meio de contaminação oriunda das atividades de lubrificação e desempenho das atividades manutenção industrial);

II - Possibilitar que as análises das propriedades verificadas na amostra (processo de lubrificação) sejam inferidas nos resultados das propriedades para o todo parque fabril (processo de fabricação);

III - Expõem variáveis com valores discretos, os quais são obtidos pelos coeficientes obtidos através dos níveis de criticidade, estes atrelados a cada categoria de classificação das tarefas de lubrificação industrial;

IV - Apontar os principais fatores que relacionada a lubrificação industrial que impactam na qualidade do produto durante as etapas de produção de alimentos e apresentar diagnóstico para análise e tomada de decisão na contenção dos Pontos Críticos de Controle identificados e assim identificar um ponto de equilíbrio entre a otimização das tarefas e recursos aplicados.

A figura 3.6 mostra a interação do indicador de confiabilidade e risco com a aplicação do método de seleção em politica de lubrificação centrada em confiabilidade. 
Figura 3.6 - Ciclo de Implantação e Avaliação do Método de Seleção de Política de Lubrificação Centrada em Confiabilidade

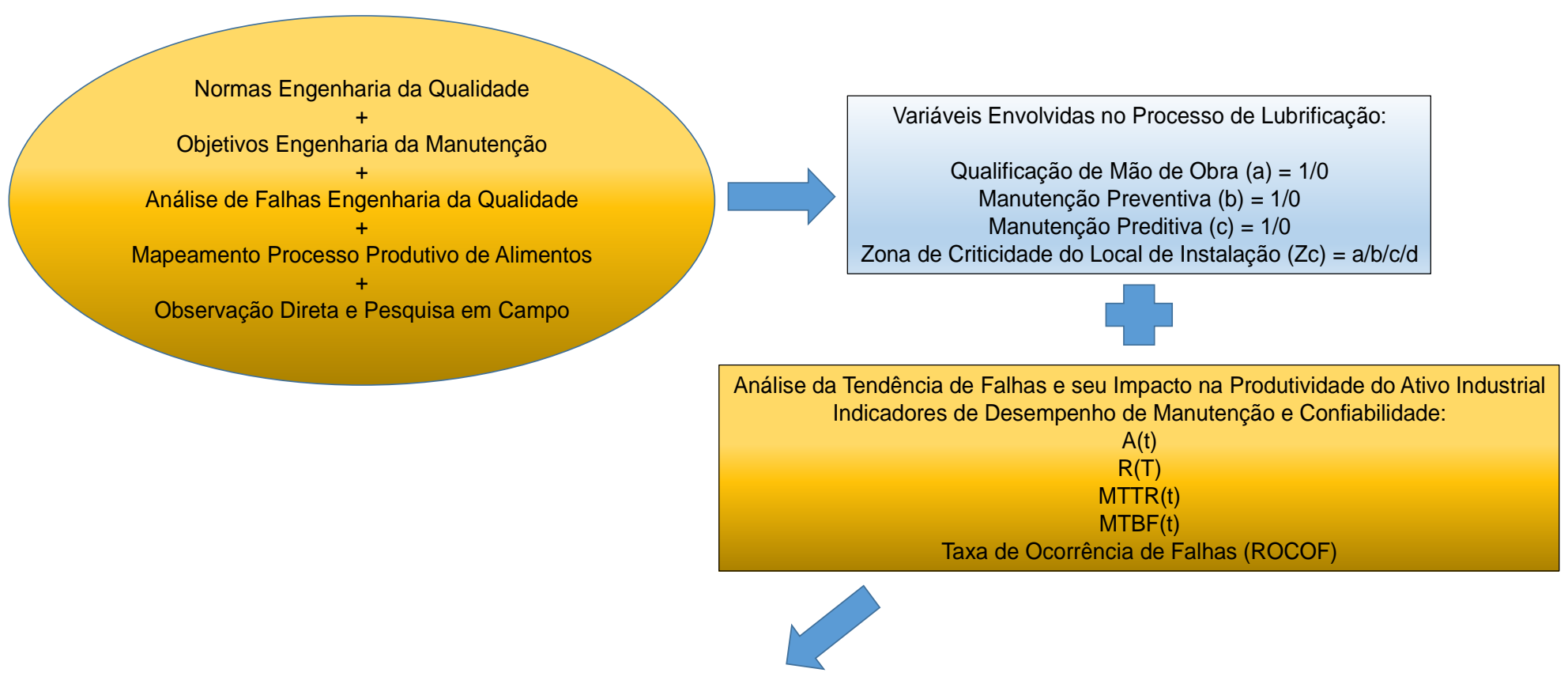

Indicador de Nível de Confiabilidade Operacional e Risco à Confiabilidade do Produto: $\mathrm{I}_{\mathrm{CR}}=\left(\mathrm{x}_{1}+\mathrm{x}_{2}+\mathrm{x}_{3}\right){ }^{*} \mathrm{Z}_{\mathrm{C}}$

Matriz de Análise do Indicador do Nível de Confiabilidade Operacional e Potencial Risco de Perda de Qualidade do Produto Conjuntamente com Indicadores de Desempenho de Manutenção e Confiabilidade $=$ Análise de Risco e Falhas

$$
\checkmark
$$

Plano de Ação = Ferramentas da Engenharia de Qualidade + Metodologia RCM + Ferramentas Engenharia de Manutenção

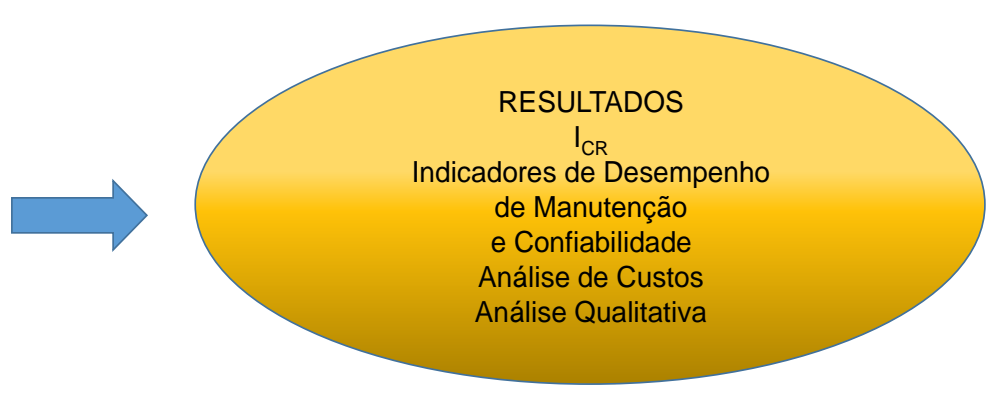

Fonte: Autoria própria 
A figura mostra que a aplicação da adequada política de lubrificação a ser adotada para cada ativo industrial , a qual estruturada mediante análise do método de seleção desenvolvido na presente tese, estabelece a junção das atividades de manutenção e qualidade, objetivando reduzir e/ou eliminar o foco de risco de perda de qualidade e inocuidade do produto e ao mesmo tempo garantir confiabilidade e disponibilidade operacional ao sistema industrial de fabricação de alimentos, foco de ambas as estratégias de gestão destes setores (engenharia de manutenção e qualidade).

Seguidamente detalha-se a etapa de identificação e caracterização do sistema industrial, o qual compreende o mapeamento do processo produtivo.

3.2.1 Identificação e Caracterização do Sistema Industrial: Mapeamento do Processo de Fabricação de Alimentos

A avaliação do comportamento do sistema produtivo de alimentos mediante a gestão de lubrificação de máquinas e equipamentos direciona a caracterização de cada categoria das Zonas de Criticidade na qual está o maquinário está instalado.

A análise de cada categoria de zona de criticidade é estruturada de forma qualitativa analisando os impactos que o processo de lubrificação pode acarretar na qualidade do produto em processamento, levando em consideração a estrutura dos pontos de lubrificação e a etapa do processo produtivo do alimento a qual a máquina e/ou equipamento encontra-se envolvido.

Para composição das particularidades de cada zona da área de fabricação, faz-se necessário conhecer as características e particularidades de operação e estrutura de construção de cada componente de máquina a ser lubrificado, bem como, o estado do alimento em processamento (sem embalagem, embalado, sólido, líquido, pastoso, entre outros).

A representação dos pontos de lubrificação dá-se através da construção da árvore funcional do ativo industrial ao qual pertencem. A árvore funcional visa identificar os pontos de lubrificação e assim auxiliar na análise estrutural do ponto de lubrificação (exposto, fechado, com proteção, sem proteção, transmissão de força e/ou movimento, refrigeração, entre outros.), e na influência de sua operação quanto ao risco de perda de qualidade e inocuidade do produto e durante o funcionamento 
do maquinário fabril. A figura 3.7 ilustra o modelo da estrutura de árvore funcional a ser utilizada na análise do maquinário industrial.

Figura 3.7 - Modelo de Árvore Funcional para Identificação dos Pontos de Lubrificação

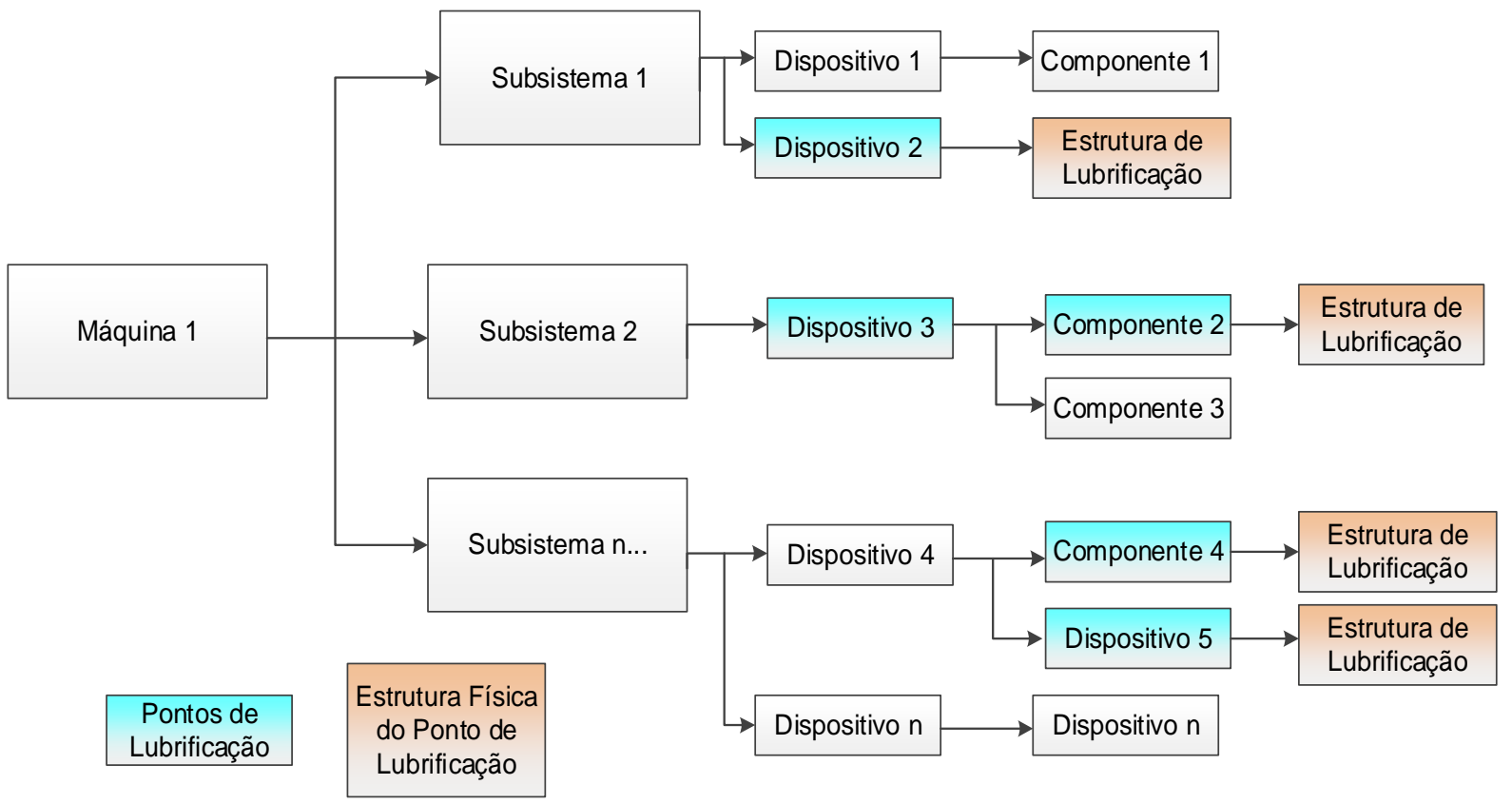

Fonte: Autoria própria

Mediante os critérios dos sistemas de gestão da qualidade, os quais baseiamse em normas (como BPF e HACCP) e legislações vigentes sobre a fabricação de alimentos, pode-se concluir que os pontos de lubrificação devem ser considerados pontos críticos de controle (PCC) e cada zona de criticidade potencializa o risco a perda de qualidade e inocuidade do produto mediante o processo de lubrificação de cada ponto de lubrificação do maquinário fabril.

Logo a construção das zonas de criticidade do local de instalação do maquinário visa identificar, por meio de análise qualitativa, a caracterização da etapa de fabricação de alimentos que visa apresentar maior e/ou menor risco a perda de qualidade e inocuidade do produto que o processo de lubrificação industrial possa ofertar.

A caracterização de cada categoria de zona crítica do local de instalação dáse por meio de observação direta e pesquisa em campo, a qual possibilita estruturar 
o mapeamento do processo produtivo e avaliar os aspectos técnico-operacionais do processo de lubrificação de máquinas e equipamento e as particularidades do processo produtivo de alimentos (este delimitado pela parte da cadeia de alimentar apresentada na figura 3.4).

Assim, para composição das categorias das zonas críticas, avalia-se os impactos que o lubrificante usado e o modo de execução das atividades de lubrificação sobre a qualidade do produto (alteração de propriedades cor, odor, sabor, cor e até composição, entre outros) conjuntamente com o potencial evento de falhas no maquinário, fator que afetando a disponibilidade e confiabilidade deste e de todo sistema industrial.

Para determinação da zona critica na qual deve ser enquadrado o ativo industrial analisado, identificam-se as características do ativo quanto:

I - Frequência de limpeza e desinfecção e modo de execução;

II - Modo de operação do ativo;

III - Estrutura do ponto de lubrificação;

IV - Perda de produtividade;

V - Estado do produto em processamento.

$\mathrm{Na}$ sequência se analisam as informações relativas a estes requisitos e compara-se com as particularidades de cada Zona de Criticidade $\left(Z_{C}\right)$, assim, a $Z_{C}$ que apresentar características aproximadas e/ou idênticas com as particularidades dos requisitos de lubrificação e operação do ativo industrial analisado, enquadra-se como Zona de Criticidade $\left(Z_{C}\right)$ do mesmo. O quadro 3.3 apresenta, detalhadamente, as características de cada Zona de Criticidade $\left(Z_{C}\right)$. 
Quadro 3.3 - Classificação do Zoneamento do Sistema Industrial para Grau de Risco de Perda de Qualidade e Inocuidade do Produto

\begin{tabular}{|c|c|c|c|c|c|c|c|}
\hline $\mathbf{Z}_{c}$ & $\begin{array}{l}\text { Potencial } \\
\text { Risco de } \\
\text { Perda de } \\
\text { Qualidade e } \\
\text { inocuidade } \\
\text { do Produto }\end{array}$ & $\begin{array}{l}\text { Estrutura } \\
\text { do Ponto }\end{array}$ & $\begin{array}{l}\text { Estado do } \\
\text { Produto em } \\
\text { processo }\end{array}$ & Modo de Operação do Ativo & $\begin{array}{l}\text { Perda de } \\
\text { Produção }\end{array}$ & $\begin{array}{l}\text { Freq. } \\
\text { FLD / } \\
\text { Semana }\end{array}$ & Modo de Execução FLD \\
\hline $\mathbf{A}$ & Muito Alto & $\begin{array}{l}\text { Aberto / } \\
\text { Fechado }\end{array}$ & $\begin{array}{c}\text { Sem } \\
\text { Embalagem }\end{array}$ & $\begin{array}{l}\text { Variação de temperatura e } \\
\text { velocidade / Presença de } \\
\text { vapor e pressão }\end{array}$ & Total & FLD $>2$ & $\begin{array}{l}\text { Utilização de água quente } \\
\text { e/ou pressurizada } \\
\text { Utilização de produtos } \\
\text { sanitizantes }\end{array}$ \\
\hline B & Alto & $\begin{array}{l}\text { Aberto / } \\
\text { Fechado }\end{array}$ & $\begin{array}{l}\text { Embalagem } \\
\text { primária / } \\
\text { Secundária }\end{array}$ & $\begin{array}{l}\text { Variação de temperatura e } \\
\text { velocidade / Proximidade de } \\
\text { áreas de fabricação dos } \\
\text { alimentos sem embalagem }\end{array}$ & $\begin{array}{l}\text { Total / Parcial - } \\
\text { retrabalho com } \\
\text { perda de } \\
\text { embalagem }\end{array}$ & FLD $>=2$ & $\begin{array}{l}\text { Utilização de água quente } \\
\text { e/ou pressurizada } \\
\text { Utilização de produtos } \\
\text { sanitizantes }\end{array}$ \\
\hline C & Médio & $\begin{array}{l}\text { Aberto / } \\
\text { Fechado }\end{array}$ & $\begin{array}{l}\text { Embalagem } \\
\text { primária / } \\
\text { Secundária }\end{array}$ & $\begin{array}{l}\text { Variação de temperatura e } \\
\text { velocidade / Local de } \\
\text { instalação não está próximo } \\
\text { de áreas de fabricação dos } \\
\text { alimentos sem embalagem }\end{array}$ & $\begin{array}{l}\text { Parcial - } \\
\text { retrabalho com } \\
\text { perda de } \\
\text { embalagem } \\
\text { secundária }\end{array}$ & FLD $<2$ & $\begin{array}{l}\text { Utilização de água quente } \\
\text { e/ou pressurizada } \\
\text { Utilização de produtos } \\
\text { sanitizantes }\end{array}$ \\
\hline D & Baixo & $\begin{array}{l}\text { Aberto / } \\
\text { Fechado }\end{array}$ & $\begin{array}{l}\text { Embalagem } \\
\text { terciária }\end{array}$ & $\begin{array}{l}\text { Variação de temperatura e } \\
\text { velocidade }\end{array}$ & $\begin{array}{l}\text { Parcial - } \\
\text { retrabalho com } \\
\text { perda de } \\
\text { embalagem } \\
\text { terciária }\end{array}$ & FLD $<2$ & $\begin{array}{lccr}\text { Utilização } & \text { a } & \text { seco } & \text { com } \\
\text { utilização de } & \text { panos de } \\
\text { limpeza ("tipo } & \text { perfex") / } \\
\text { Utilização de } & \text { de } & \text { produtos } \\
\text { sanitizantes } & & & \end{array}$ \\
\hline \multicolumn{8}{|c|}{ Legenda } \\
\hline
\end{tabular}


Enfatiza-se, para agregar valor à análise qualitativa dos aspectos relacionados a composição das Zonas de Criticidade $\left(Z_{C}\right)$, que os procedimentos de operação, limpeza e higienização do maquinário fabril (procedimento exigido pelos sistemas HACCP, BPF e normativas), bem como, a frequência da realização dessas ações, promovem consequências ao processo de lubrificação industrial como:

> Aumento da possibilidade de contaminação do lubrificante e sua degradação direcionando a ocorrência de falhas;

> Aumento de custo de lubrificante e mão de obra por meio de relubrificação de máquinas e equipamentos antes do tempo pré-determinado em manutenção preventiva;

> Impacto na disponibilidade do maquinário devido relubrificação e/ou manutenção corretiva de falhas relacionadas ao processo de lubrificação;

> Contaminação cruzada do produto devido contaminação do lubrificante por substâncias químicas e/ou biológicas nocivas.

Mediante o mapeamento do sistema industrial de processamento de alimentos e avaliação das áreas de fabricação do sistema industrial de produção de alimentos, estabelece-se uma classificação das zonas do processo produtivo considerando as atividades de lubrificação.

Para facilitar a identificação das zonas de criticidade mediante o processo de fabricação estabelece-se o fluxograma e o leiaute da área fabril enquadrado em cada zona conforme sua classificação.

A montagem das zonas críticas em leiaute auxilia na análise da proximidade do maquinário em relação a matéria prima em processo, como também, otimiza a visualização da quantidade e estrutura dos componentes de máquina a serem lubrificados. As figuras 3.8 e 3.9 ilustram o modelo de fluxograma e leiaute a serem aplicado para auxiliar no mapeamento do processo produtivo de alimentos, visando estruturar a classificação do zoneamento da área fabril quanto a criticidade apresentada pelo processo de lubrificação industrial. 
Figura 3.8 - Fluxograma do Modelo para Mapeamento do Sistema Industrial

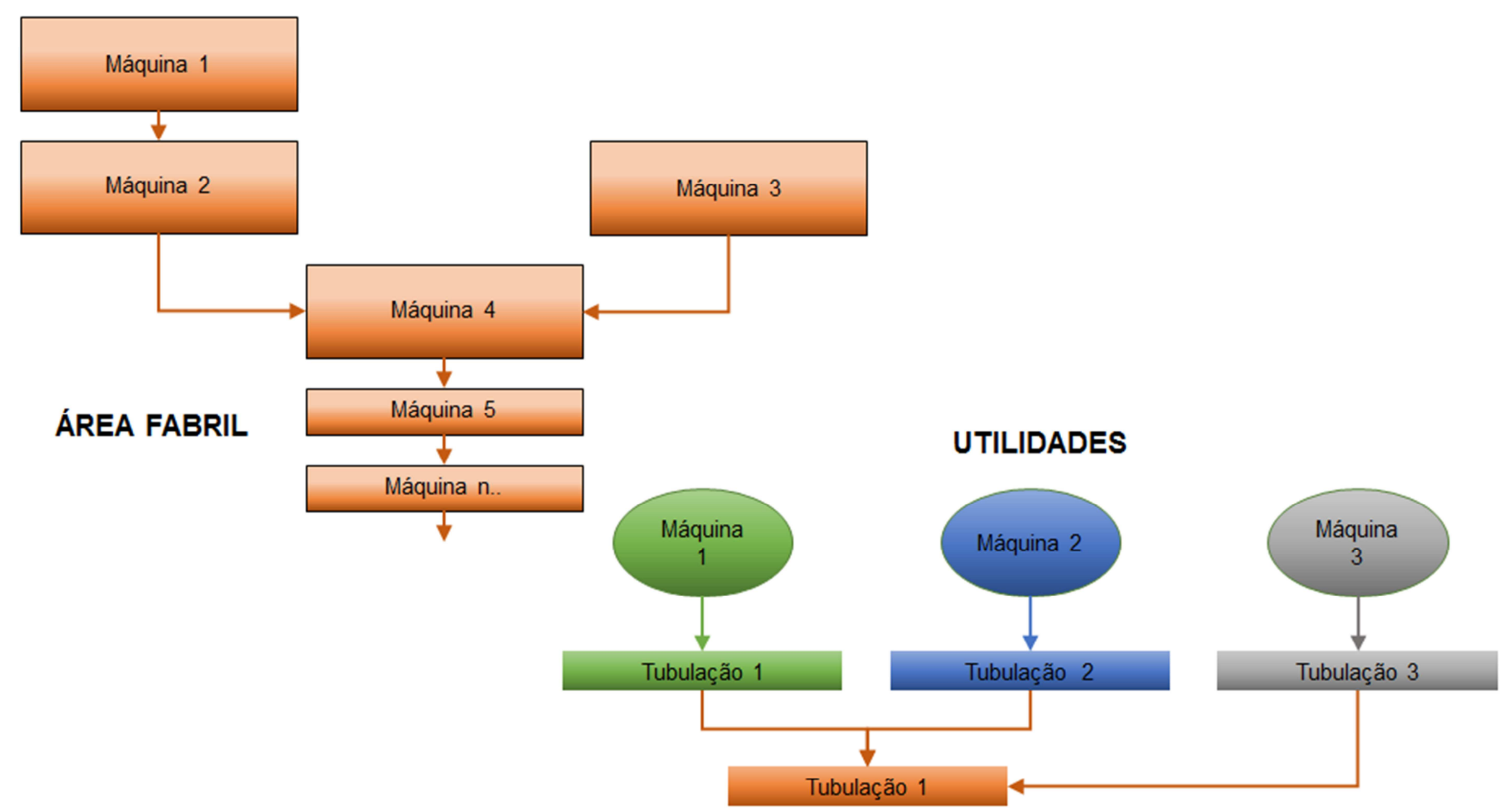

Fonte: Autoria própria 
Figura 3.9 - Leiaute do Modelo para Zoneamento do Sistema Industrial

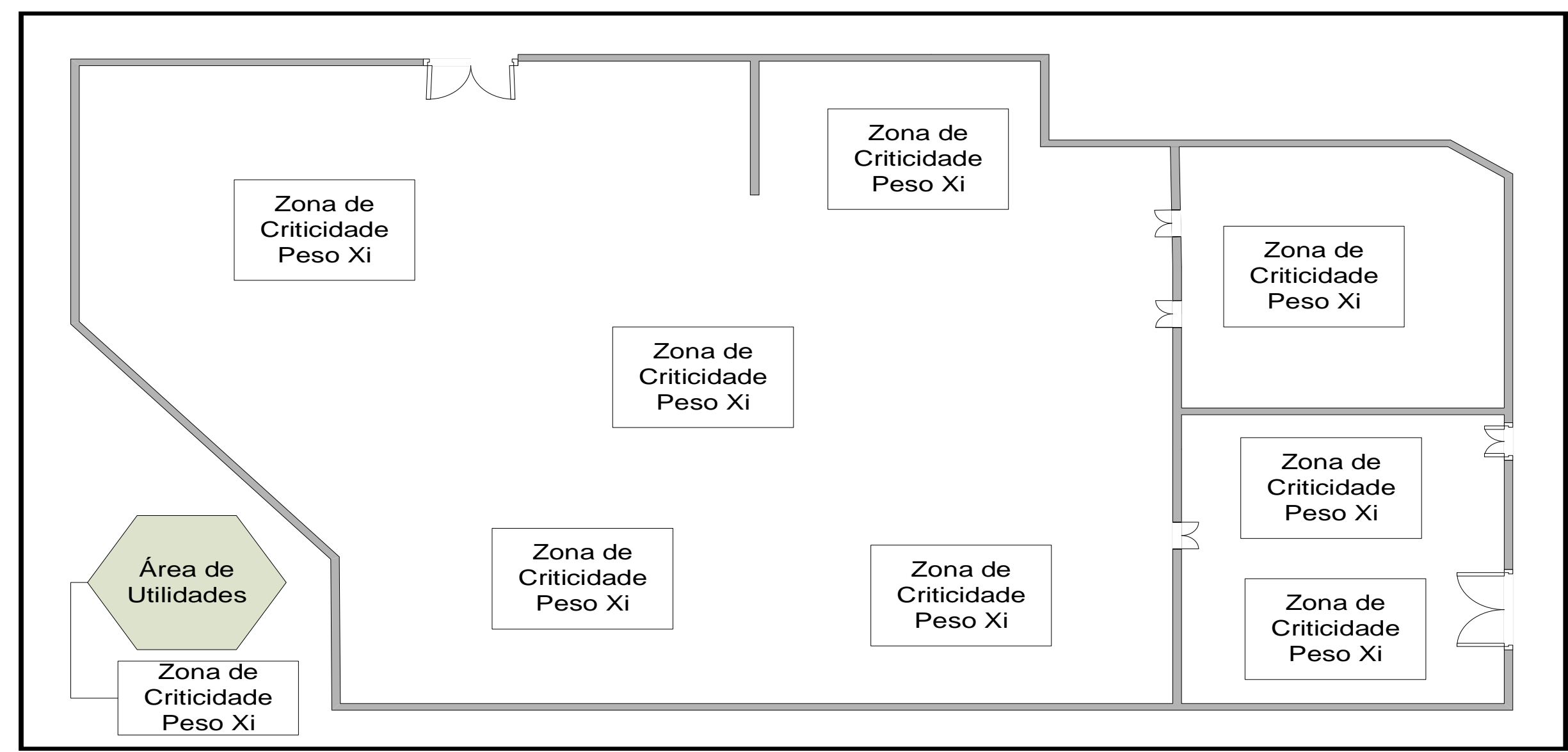

LEGENDA

\begin{tabular}{|c|c|c|}
\hline$X i=A$ & \multirow{2}{*}{$\begin{array}{c}\text { Zona de } \\
\text { Criticidade } \\
\text { Peso Xi }\end{array}$} & $X i=C$ \\
\hline $\mathrm{Xi}=\mathrm{B}$ & & $X i=D$ \\
\hline
\end{tabular}

Fonte: Autoria própria 
Esta variável relativa à zona de criticidade, adicionada as demais variáveis envolvidas identificadas no método da presente pesquisa, direciona a análise dos modos de ocorrência de eventos de falhas e focos de potencial risco de perda de qualidade e inocuidade do produto que podem ocorrer mediante a realização das atividades da lubrificação industrial dos ativos da indústria de alimentos. Isto visa levantar informações que direcionem a tomada de decisão pela seleção da apropriada política de lubrificação a ser aplicada em cada ambiente de produção de alimentos, a fim de obter disponibilidade operacional e garantia da qualidade.

3.2.2 Identificação de Eventos de Riscos e Ocorrência de Falhas: Variáveis Envolvidas no Pocesso de Lubrificação Industrial de Indústrias de Alimentos

O método de seleção de política de lubrificação centrada em confiabilidade em desenvolvimento, baseia-se na decomposição das atividades de lubrificação em subconjunto de atividades, as quais são caracterizadas como variáveis envolvidas no processo de lubrificação do maquinário empregado na fabricação de alimentos.

As variáveis que influenciam no processo de lubrificação são relacionadas a fatores técnicos e humanos e atribui-se valor binário para sua quantificação, sendo:

Variável $x_{i}=\left\{\begin{array}{l}1 \\ 0\end{array}, 1\right.$ quando da ocorrência do evento de interesse e 0 quando não ocorre o evento.

A tabela 3.1 identifica as variáveis binárias relacionadas ao processo de realização da lubrificação industrial em ambiente de fabricação de alimentos. 
Tabela 3.1 - Variáveis Binárias Envolvidas no Processo de Lubrificação Industrial de Maquinário Empregado na Fabricação de Alimentos

Descrição da Variável

Valor Binário de Valor Binário de não Ocorrência Ocorrência

Qualificação de mão de obra na

execução da lubrificação em maquinário alimentício

Execução de Manutenção Preventiva

Execução de Manutenção Preditiva

1

0

Fonte: Autoria própria

Para que a variável assuma o valor binário que indique sua existência efetiva (1) ou não (0), considera -se o atendimento aos requisitos, os quais estão ligados ao modo de execução e acompanhamento dos resultados das ações englobadas na variável, ou seja, as variáveis de manutenção preventiva, preditiva e qualificação de mão-de-obra são determinadas como efetivas (valor binário $=1$ ) quando são satisfeitos todos os requisitos conforme as respectivas tabelas $3.2,3.3$ e 3.4 apresentadas na sequência.

Tabela 3.2 - Requisitos para Determinação de Evidência ou Não Evidência da Variável Relacionada à Manutenção Preventiva

\begin{tabular}{lcc}
\hline \multicolumn{1}{c}{ Requisitos - Manutenção Preventiva } & $\begin{array}{c}\text { Valor Binário de } \\
\text { Ocorrência }\end{array}$ & $\begin{array}{c}\text { Valor Binário de } \\
\text { não Ocorrência }\end{array}$ \\
\hline Roteiro de atividades & 1 & 0 \\
$\begin{array}{l}\text { Recursos e Insumos adequados para execução das } \\
\text { Atividades }\end{array}$ & 1 & 0 \\
$\begin{array}{l}\text { Monitoramento das Ações } \\
\text { Evidência de Resultados sob a Disponibilidade Operacional }\end{array}$ & 1 & 0 \\
Valor da variável Manutenção Preventiva & $\mathbf{1}$ & 0 \\
\hline
\end{tabular}

Fonte: Autoria própria 
Tabela 3.3 - Requisitos para Determinação de Evidência ou Não Evidência da Variável Relacionada à Manutenção Preditiva

\begin{tabular}{lcc}
\hline \multicolumn{1}{c}{ Requisitos - Manutenção Preditiva } & $\begin{array}{c}\text { Valor Binário de } \\
\text { Ocorrência }\end{array}$ & $\begin{array}{c}\text { Valor Binário de } \\
\text { não Ocorrência }\end{array}$ \\
\hline Roteiro de atividades & 1 & 0 \\
$\begin{array}{l}\text { Recursos e Insumos adequados para execução das } \\
\text { Atividades } \\
\text { Monitoramento das Ações }\end{array}$ & 1 & 0 \\
$\begin{array}{l}\text { Evidência de Resultados sob a Disponibilidade Operacional } \\
\text { Valor da variável Manutenção Preditiva }\end{array}$ & 1 & 0 \\
\hline
\end{tabular}

Fonte: Autoria própria

Tabela 3.4 - Requisitos para Determinação de Evidência ou Não Evidência da Variável Relacionada à Qualificação de Mâo de Obra

\begin{tabular}{lcc}
\hline \multicolumn{1}{c}{ Requisitos - Manutenção Preditiva } & $\begin{array}{c}\text { Valor Binário de } \\
\text { Ocorrência }\end{array}$ & $\begin{array}{c}\text { Valor Binário de } \\
\text { não Ocorrência }\end{array}$ \\
\hline Conhecimento de Normativas e Legislações & 1 & 0 \\
Conhecimento de Lubrificantes de Grau Alimentício & 1 & 0 \\
Execução de Limpeza e Higienização do Ferramental & 1 & 0 \\
$\begin{array}{l}\text { Execução de Limpeza e Higienização do Ponto de } \\
\text { Lubrificação }\end{array}$ & 1 & 0 \\
Valor da variável Manutenção Preditiva & $\mathbf{1}$ & $\mathbf{0}$ \\
\hline
\end{tabular}

Fonte: Autoria própria

Caso qualquer um dos requisitos presentes na tabela 3.1 apresentem valor binário diferente de 1 , a variável assume o valor binário 0 , ou seja, considera-se não evidenciada, pois não apresenta todos os requisitos necessárias para sua efetiva execução. Para determinação do atendimento aos requisitos abordados na tabela 3.1, deve-se considerar as seguintes características para cada requisito, as quais indicadas na figura 3.10 . 
Figura 3.10 - Requisitos para Identificação de Evidência ou Não Evidência das Variáveis Envolvidas no Processo de Lubrificação

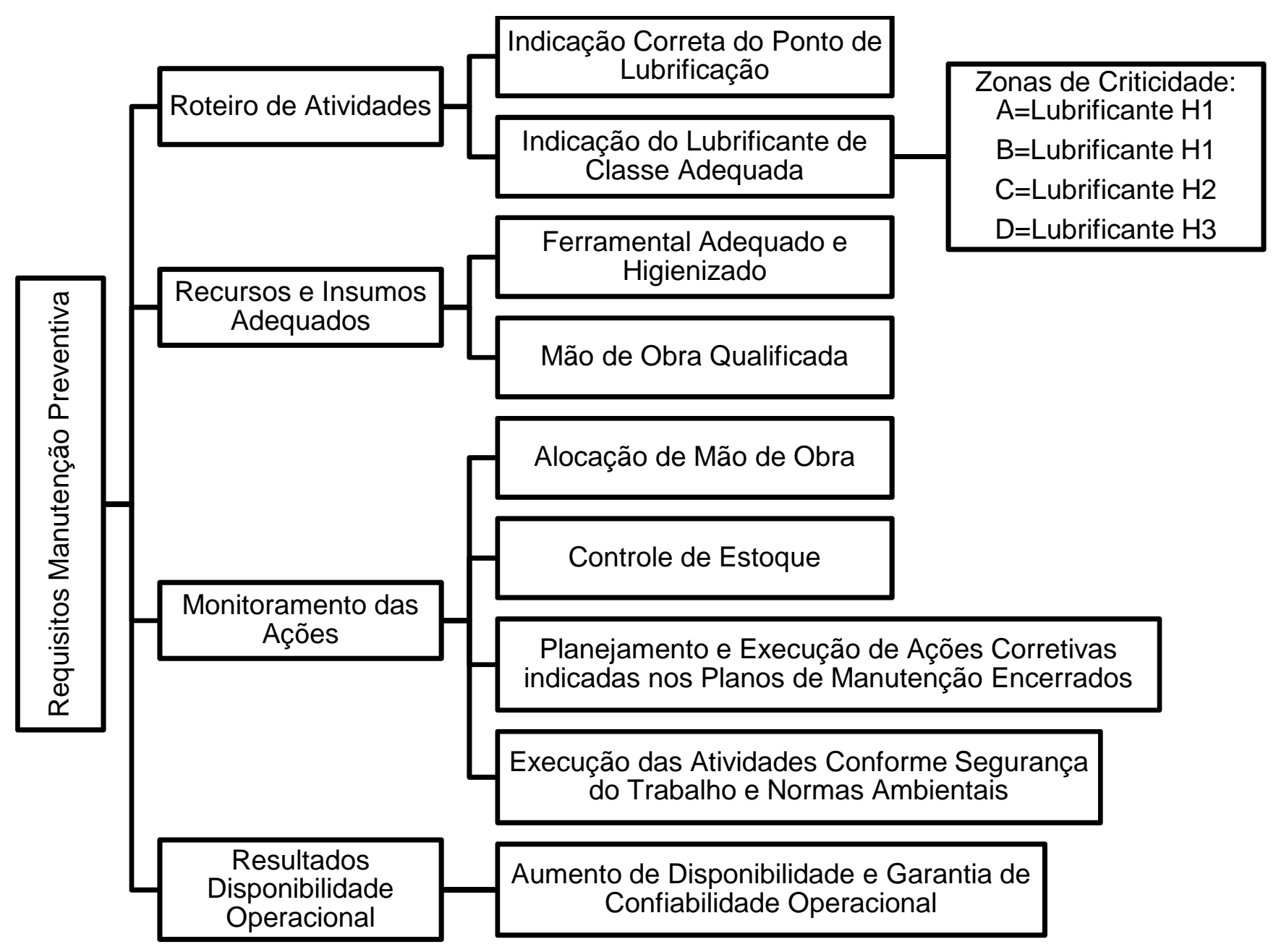

(Continua) 
(Continuação)

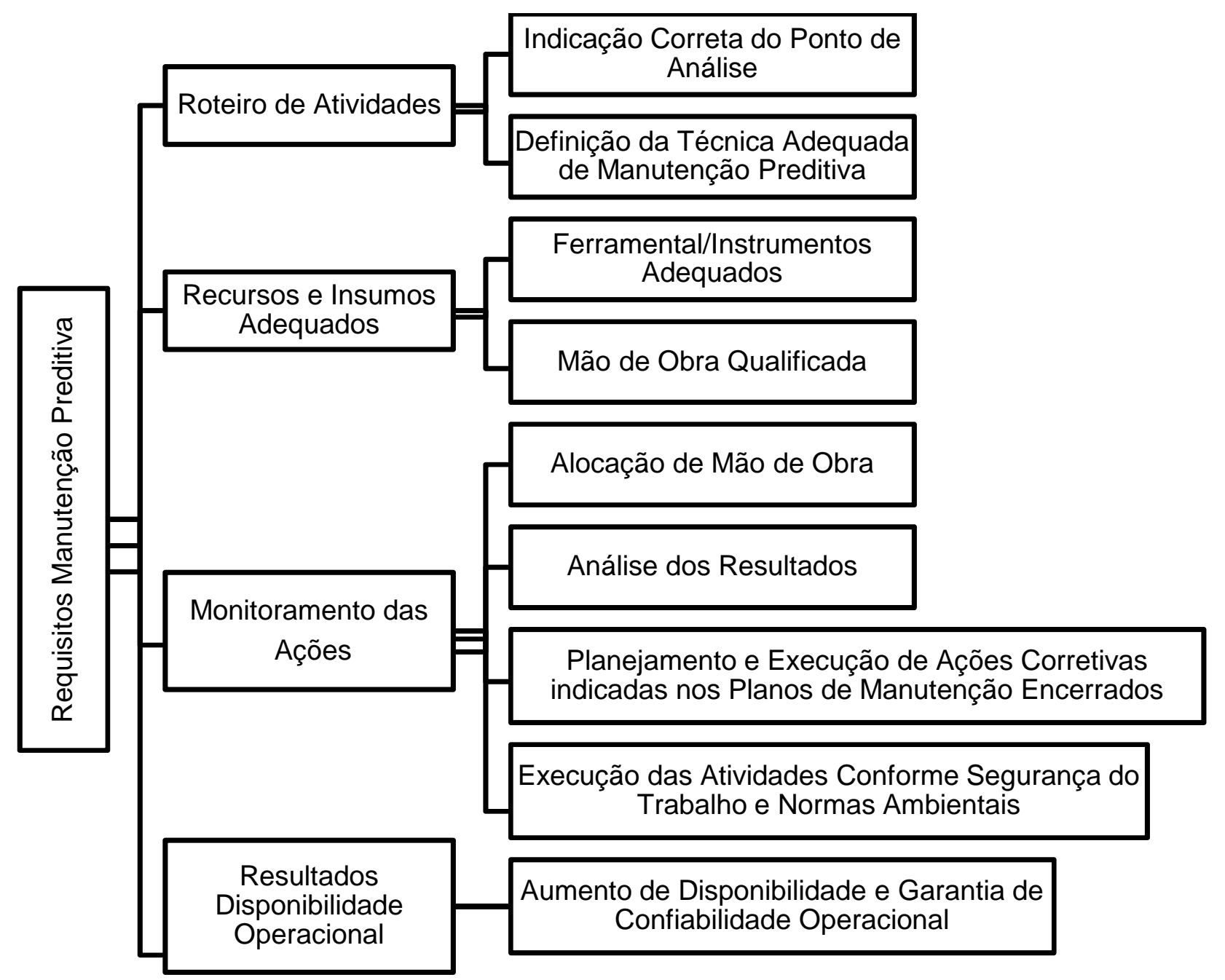

(Continua) 
(Conclusão)

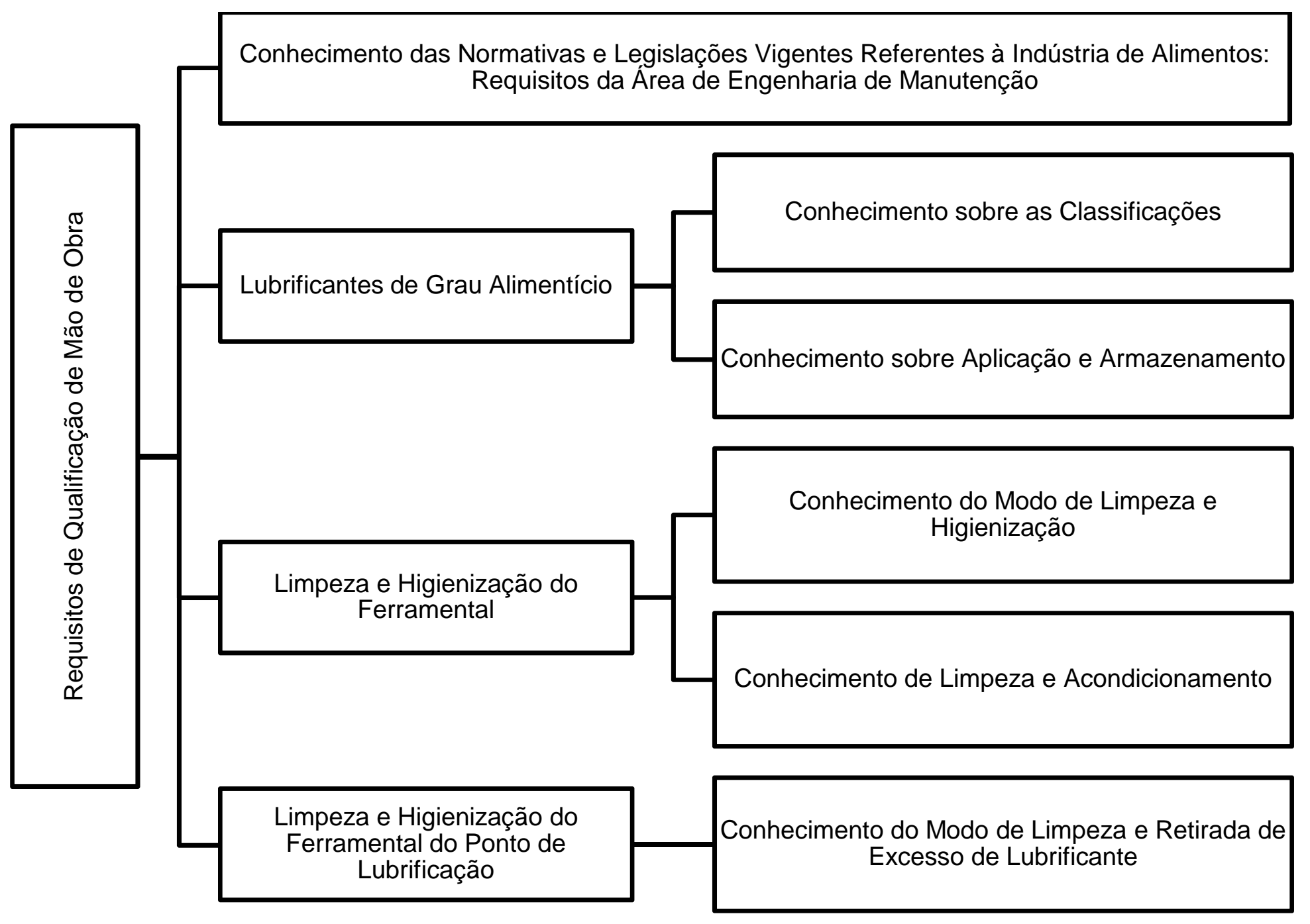


A exposição do processo produtivo de alimentos a ocorrência e/ou não destas variáveis interfere diretamente no risco a perda de qualidade e inocuidade do produto, bem como, impacta na disponibilidade operacional do maquinário industrial.

A falta da aplicação de manutenção preditiva e/ou preventiva pode acarretar em falhas de máquinas e equipamentos por motivos de desgaste, gerando aquecimento e vazamento, sendo este último um risco potencial para a qualidade e inocuidade do produto em processamento. Já um quadro de funcionários sem qualifcação para execução das atividades de lubrificação em indústria de alimentos podem gerar foco de ambos os fatores: potencial risco para qualidade e inocuidade do produto e proporcionar evento de falhas.

Porém a adequada execução destas variáveis eleva a disponibilidade operacional das instalações industriais, bem como, proporciona garantia de qualidade ao produto em processamento.

\subsection{IDENTIFICAÇÃO DE EVENTOS DE RISCOS E OCORRÊNCIA DE FALHAS E AVALIAÇÃO DE EFICÁCIA DO MÉTODO: INDICADORES DE DESEMPENHO DE CONFIABILIDADE E DISPONIBILIDADE EM SISTEMAS REPARÁVEIS}

A confiabilidade operacional e mantenabilidade de máquinas e equipamentos estão intrinsicamente ligados à disponibilidade operacional do maquinário industrial.

Máquinas e/ou equipamentos que não possuem grau de mantenabilidade (que não possam ser reparados de maneira fácil e rápida), apresentam o TTR (tempo para reparo superior ao tempo de conserto esperado), impactando diretamente na disponibilidade operacional do sistema industrial.

Assim, a inferência da confiabilidade relacionada ao TBF (tempo entre falhas), e a mantenabilidade ligada ao TTR (tempo para reparos), podem ser expressadas pelos indicadores de desempenho de manutenção, sendo os dados para composição destes indicadores, obtidos por meio da análise estatística da tendência das falhas ocorridas no sistema industrial.

Para analisar o desempenho das variáveis identificadas no processo de lubrificação industrial, as quais estruturam o indicador de confiabilidade operacional 
e risco de perda de inocuidade e qualidade ao produto, avalia-se a mantenabilidade das máquinas e equipamentos aliados a tendência da variação da taxa de ocorrência de falhas, destacando as de falhas relacionadas a lubrificação industrial, as quais são o foco principal do desenvolvimento da pesquisa.

Por se tratar de sistemas reparáveis, a análise estatística da tendência de falhas aplicada ao maquinário empregado em indústria de alimentos, se dá pela probabilidade de ocorrência de falhas por unidade de tempo denominada, ou seja, avalia-se o comportamento da tendência de falhas pela função de intensidade de ocorrência de falhas (ROCOF - Rate of Occurrence of Failures), descrito no capítulo 2.

Enfatiza-se que o detalhamento e as descrições de origem e aplicação das equações e métodos de análise estatística de processos reparáveis estão detalhados na fundamentação teórica (capitulo 2) com a identificação de suas respectivas referências (fonte de pesquisa).

A aplicação destas equações e parâmetros destina-se a avaliação do comportamento da tendência de falhas dos sistemas reparáveis de ambiente industrial de produção de alimentos e a obtenção de valores da disponibilidade (em função do tempo) para composição do método de seleção de política de lubrificação centrada em confiabilidade.

Com a obtenção da taxa de ocorrência de falhas (ROCOF) é possível estruturar os indicadores de desempenho: $A(t), R(t), \operatorname{MTBF}(t)$ e $\operatorname{MTTR}\left({ }_{t}\right)$. Estes indicadores proporcionam evidenciar, durante a distribuição da frequência de falhas, os eventos relacionados ao processo de lubrificação industrial.

A identificação destes eventos específicos permite avaliar as características de suas causas e consequências, direcionando a tomada de decisão para adoção de medidas que devam ser estruturadas na política de lubrificação adotada (para cada ativo industrial), e que promovam a redução e/ou eliminação de ocorrência desses eventos de falhas, contribuindo para melhoria dos indicadores de desempenho de manutenção e produtividade.

Também é por meio da taxa de ocorrência de falhas (ROCOF) e dos indicadores estruturados a partir dela, que avalia-se a eficácia das ações estruturadas na política de lubrificação industrial adotada (a qual estruturada a partir da aplicação do método desenvolvido na presente tese) quanto a promover a garantia de disponibilidade e confiabilidade operacional do maquinário. 


\subsection{FLUXOGRAMA DE APLICAÇÃO DO MÉTODO DE SELEÇÃO DE POLÍTICA DE LUBRIFICAÇÃO CENTRADA EM CONFIABILIDADE}

A aplicação do método de seleção de política de lubrificação industrial centrada em confiabilidade requer dados e informações relacionadas ao modo de lubrificação e ao comportamento de máquinas e equipamentos industriais (frente às atividades de lubrificação), as quais fazem parte do processo produtivo de alimentos.

O método fundamentalmente consiste em atribuir valores quantitativos as variáveis envolvidas nas atividades de lubrificação adicionado de análise qualitativa das zonas críticas onde o maquinário encontra-se instalado, e assim, avaliar o quanto estas atividades podem impactar na qualidade do produto e/ou propiciar eventos de falhas no maquinário, seguindo o raciocínio básico da gestão de risco e : identificar o risco e perigo, quantificar este risco e perigo, implantar medidas de contenção dos riscos e perigos, e da análise de falhas: modo/mecanismos de falhas, causa raiz, consequências, severidade e plano de ação.

A análise conjunta dos efeitos das variáveis envolvidas no processo de lubrificação industrial permitem avaliar ações de lubrificação e efetuar tomadas de decisão para melhoria no processo de execução destas tarefas, com objetivo de reduzir os riscos envolvidos na atividade de lubrificação para o maquinário e o processo de fabricação de alimentos, obtendo um equilíbrio entre a manutenção do maquinário e a qualidade do produto final.

Para cada variável identificada são atribuídos valores binários (por meio de análise quantitativa das descrições qualitativas apontadas nos requisitos), conforme a sua criticidade identificada durante a execução de trabalhos de lubrificação industrial.

Posteriormente estes valores estruturam um indicador de nível de confiabilidade operacional e potencial risco a qualidade e inocuidade do produto, o qual visa equilibrar a otimização das atividades da lubrificação conjuntamente com a execução de medidas que atendam a engenharia de qualidade.

Assim, para prover toda estrutura de desenvolvimento do método de seleção de política de lubrificação centrada em confiabilidade voltado para o maquinário empregado em fabricação de alimentos e atingir o objetivo de analisar falhas e 
potenciais riscos a perda de qualidade e inocuidade do produto e, assim tomar decisão pela adequada politica de lubrificação a ser adotadas ao cenário industrial pesquisado, faz-se necessário a execução das seguintes etapas:

I - Efetuar levantamento bibliográfico quanto à legislação e normas aplicadas a lubrificação de máquinas e equipamentos ligados à fabricação de alimentos;

II - Analisar métodos de limpeza e operação que possam interferir no funcionamento do maquinário e/ou degradar as propriedades do lubrificante empregado;

III - Identificar os tipos de lubrificantes aplicados no maquinário (em ambiente real) e comparar se suas propriedades e composição são adequadas ao seu local de instalação conjuntamente com sua funcionalidade;

IV - Analisar as particularidades do maquinário e determinar o adequado lubrificante a ser aplicado, levando em consideração seu contato com a matéria prima e área de localização;

V - Elaborar tabela que classifica a proximidade entre os pontos de lubrificação e a matéria prima em processo, objetivando identificar o risco que as atividades de lubrificante podem ocasionar ao produto, bem como, garantir o procedimento adequado de lubrificação para garantir disponibilidade do maquinário a produção;

VI - Levantar histórico das ocorrências de falhas, destacando as falhas ligadas ao processo de lubrificação e analisar quantitativamente (análise estatística e probabilística) e qualitativa (análise funcional dos modos de falha);

VII - Aplicar as ferramentas ligadas a MCC (RCM -Reliability Centered Maintenance) - Manutenção Centrada na Confiabilidade como FMEA (Failure Mode Effects Analysis - Análise de Modo e Efeito de Falha) para efetuar a análise funcional das falhas a fim de propor plano de ação para solução das mesmas; 
VIII - Propor modelo de plano preventivo de lubrificação contendo as informações necessárias a adequada execução das tarefas de lubrificação em máquinas e equipamentos aplicados na fabricação de alimentos;

IX - Propor indicadores de criticidade quanto a potencial ocorrência de falhas no maquinário e potencial risco a qualidade e inocuidade do produto que podem ocorrer por meio da execução das tarefas de lubrificação;

$X$ - Aplicar o método desenvolvido em ambiente real de estabelecimento de produção de alimentos com finalidade de coleta de dados e comparação das condições de produtividade e qualidade após a aplicação;

XI - Analisar custos de manutenção envolvidos e otimizados nas operações de lubrificação industrial;

XII - Apresentar resultados (indicadores de desempenho de manutenção e disponibilidade) da aplicação do método de seleção de política de lubrificação em ambiente real de manufatura de alimentos para sua validação e avaliação quanto a sua adequação de uso e eficácia no ganho de qualidade e confiabilidade da função lubrificação industrial.

A figura 3.11 mostra a visão global de desenvolvimento e aplicação do método de seleção de política de lubrificação centrada em confiabilidade, bem como, dos resultados esperados quanto a disponibilidade operacional e garantia de qualidade do produto. 
Figura 3.11 - Ciclo de Desenvolvimento e Aplicação do Método de Seleção de Política de Lubrificação em Indústria de Alimentos

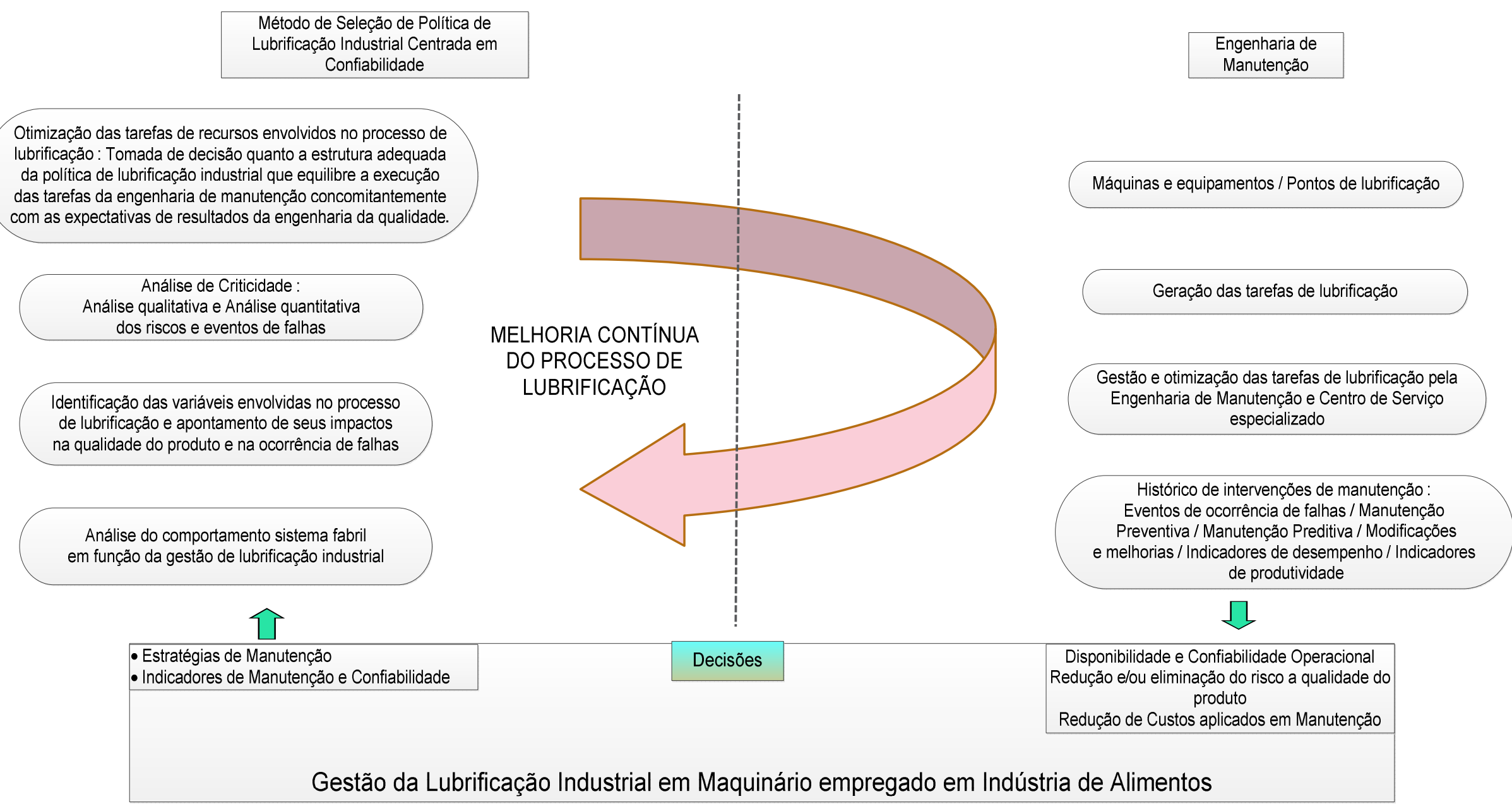

Fonte: Autoria própria 
A figura 3.11 mostra o ciclo de desenvolvimento e aplicação do método de seleção de uma adequada política de lubrificação em ativos industrias, os quais compõe o parque fabril de uma indústria de alimentos, com a visão dos benefícios que este pode prover ao ambiente fabril, os quais focados na garantia da qualidade e aumento de produtividade.

É por meio do valor gerado pelo indicador de nível de confiabilidade operacional e potencial risco a perda de qualidade e inocuidade do produto - $I_{C R}$, que torna-se possível apontar os equipamentos críticos dentro do sistema fabril, bem como, os modos de execução das tarefas de lubrificação que contribuem para aumentar o risco à qualidade e inocuidade do produto (por meio de contaminação química, física, biológica e/ou contaminação cruzada) e que possam tornar-se foco de potencial evento de ocorrência de falhas, fatores que, conjuntamente, impactam na confiabilidade e disponibilidade operacional do sistema fabril, como também, na qualidade do processo e produto.

Assim, apoia-se na introdução de conceitos de RCM (manutenção centrada na confiabilidade) para identificar as ações adequadas quanto aos procedimentos de lubrificação na área fabril, adaptando-os a uma sistemática que equilibra as exigências do SGQ gerido pela engenharia da qualidade concomitantemente com a gestão de lubrificação por parte da engenharia de manutenção, direcionando assim a medidas para tomada de decisão na adequada politica de lubrificação a ser adotada dentro do ambiente fabril de fabricação de alimentos.

Com objetivo de apontar os pontos fortes e a inovação tecnológica do método desenvolvido para auxiliar na escolha da adequada política de lubrificação em indústria de alimentos, apresenta-se no quadro 3.4 a comparação deste método com demais sistemáticas e metodologias apresentadas por referênciais bibliográficas estudadas. 
Quadro 3.4 - Comparação do Método de Seleção de Política de Lubrificação Centrada em Confiabilidade perante Características de Outros Métodos

\begin{tabular}{|c|c|c|c|c|c|c|c|c|c|c|c|c|c|c|c|c|c|}
\hline \multirow[b]{2}{*}{ Autor } & \multirow[b]{2}{*}{ Aplicação } & \multicolumn{5}{|c|}{ Identificação e Caracterização do Sistema Industrial } & \multicolumn{4}{|c|}{$\begin{array}{l}\text { Identificação de Eventos de Riscos e Ocorrência } \\
\text { de Falhas }\end{array}$} & \multicolumn{3}{|c|}{ Tomada de Decisão } & \multicolumn{4}{|c|}{ Avaliação de Eficácia do Método } \\
\hline & & $\begin{array}{c}\text { Dados } \\
\text { Históricos }\end{array}$ & \begin{tabular}{|c|} 
Mapeamento \\
Processo
\end{tabular} & $\begin{array}{c}\text { Fluxograma do } \\
\text { Processo }\end{array}$ & Leiaute & \begin{tabular}{|c|} 
Árvore \\
Funcional
\end{tabular} & $\begin{array}{c}\text { Dados } \\
\text { Históricos }\end{array}$ & $\begin{array}{c}\text { Zona de } \\
\text { Criticidade - } Z_{\circ}\end{array}$ & ROCOF & $\begin{array}{c}\text { Análise Variáveis } \\
\text { Binárias } \\
\text { (Lubrificaçāo } \\
\text { Industrial) }\end{array}$ & $\begin{array}{c}\text { Ferramentas de } \\
\text { Engenharia: } \\
\text { Qualidade / } \\
\text { Manutenção }\end{array}$ & $\mathrm{RCM}$ & $\begin{array}{c}\text { Estrutura de } \\
\text { Poltica de } \\
\text { Lubrificação } \\
\text { Industrial }\end{array}$ & ROCOF & $\begin{array}{l}\text { Indicadores de } \\
\text { Desempenho de } \\
\text { Manutenção e } \\
\text { Disponibilidade }\end{array}$ & $\left|\begin{array}{c}\text { Analise de } \\
\text { Custos }\end{array}\right|$ & \begin{tabular}{|l} 
Análise de \\
Vida UUtil
\end{tabular} \\
\hline $\begin{array}{l}\text { Assis } \\
(2013)\end{array}$ & Metalúrgica & $\mathrm{x}$ & & & & & $\mathrm{x}$ & & $x$ & & & & & $x$ & $x$ & $x$ & $x$ \\
\hline $\begin{array}{l}\text { Aven } \\
(2008)\end{array}$ & $\begin{array}{c}\text { Válvulas } \\
\text { Pneumáticas }\end{array}$ & $x$ & & & & & $x$ & & & & $x$ & $x$ & & & & & \\
\hline $\begin{array}{l}\text { Belinelli } \\
\text { (2015) }\end{array}$ & $\begin{array}{c}\text { Indústria de } \\
\text { Alimentos }\end{array}$ & $x$ & $x$ & $x$ & $x$ & $x$ & $x$ & $x$ & $x$ & $x$ & $x$ & $x$ & $x$ & $x$ & $x$ & $x$ & \\
\hline $\begin{array}{l}\text { Ferjencik } \\
(2014)\end{array}$ & $\begin{array}{l}\text { Indústria } \\
\text { Química }\end{array}$ & $x$ & & $x$ & $x$ & & $x$ & & & & $x$ & & & & & & \\
\hline $\begin{array}{c}\text { Martins e } \\
\text { Leitẫo (2009) }\end{array}$ & $\begin{array}{c}\text { Montadora de } \\
\text { Automóveis }\end{array}$ & $x$ & & & & & $x$ & & $\mathrm{x}$ & & & & & $\mathrm{x}$ & $x$ & & $x$ \\
\hline $\begin{array}{c}\text { Modarres } \\
(1992)\end{array}$ & $\begin{array}{l}\text { Método } \\
\text { ROCOF }\end{array}$ & $x$ & & & & & $x$ & & $x$ & & $x$ & & & $x$ & $x$ & & \\
\hline $\begin{array}{c}\text { Rausand e } \\
\text { Vatn } \\
(2008) \\
\end{array}$ & $\begin{array}{l}\text { Produção de } \\
\text { Gás Natural }\end{array}$ & $x$ & & $x$ & & & $x$ & & & & $x$ & $x$ & & & $x$ & $x$ & \\
\hline $\begin{array}{c}\text { Silva,Cabrita } \\
\text { e Matias } \\
(2008)\end{array}$ & $\begin{array}{l}\text { Indústria de } \\
\text { Alimentos }\end{array}$ & $x$ & & & & & $x$ & & & & & & & & $x$ & $x$ & \\
\hline
\end{tabular}

Fonte: Autoria própria 
No quadro comparativo (quadro 3.4) são observadas as diferenças existentes entre o método proposto na presente tese com as outras propostas, bem como as contribuições da proposta na análise de risco e de falhas como ferramenta para tomada de decisão em busca de aumento de produtividade do sistema fabril e garantia de qualidade do produto fabricado.

No método de seleção de política de lubrificação centrada em cofiabilidade são aplicados os conceitos de análise funcional das falhas e análise do potencial risco que estas falhas possam gerar (por meio de contaminação/perda de qualidade e inocuidade do produto) direcionando a tomada de decisão quanto à adequadada estrutura de política de lubrificação industrial a ser adotada para cada ativo dentro de indústria de alimentos.

O modelo integra os objetivos da engenharia de manutenção $e$ as necessidasdes da engenharia de qualidade, constituindo uma solução viável para a tomada de decisão, visando reduzir a possibilidade de que ocorram falhas e riscos que venham a afetar o desempenho ou causar perda de qualidade e inocuidade do produto que originem consequências de grandes magnitudes ou de alto risco, gerando um modelo matemático e uma medida quantitativa e qualitativa como suporte ao processo de tomada de decisão.

A modelagem proposta permite representar a dinâmica das interações das variáveis envolvidas no processo de lubrificação industrial e as características de cada Zona de Criticidade $-Z_{C}$, através de um indicador de nível de confiabilidade operacional e potencial risco de perda de qualidade e inocuidade do produto ( $\left.I_{C R}\right)$.

Por meio deste indicador é possível analisar as relações de causa e efeito pertencentes ao contexto, possibilitando um melhor entendimento sobre a relevância dos fatores de desempenho nas atividades de lubrificação industrial, permitindo assim a providência de medidas que atenuem suas consequências quanto ao risco de perda de qualidade e inocuidade do produto e geração de eventos de falhas que impactem na disponibilidade operacional do maquinário industrial. 


\subsection{CONSIDERAÇÕES FINAIS}

O método desenvolvido na presente pesquisa direciona a tomada de decisão quanto à adequada política de lubrificação, a qual deve garantir o cumprimento de normas e legislações vigentes concomitantemente com garantia da disponibilidade e confiabilidade operacional e qualidade do produto.

O método de seleção de política de lubrificação centrada em confiabilidade tem por diferencial a unificação das técnicas de engenharia de manutenção e engenharia da qualidade aplicadas a um meio industrial complexo (produção de alimentos). A integração destas informações permite o desenvolvimento de um método para analisar os potenciais risco e falhas envolvidos nas atividades da lubrificação industrial aplicada em máquinas e equipamentos instalados em indústria deste segmento industrial de alimentos, as quais podem influenciar na qualidade e inocuidade do produto (por meio de contaminação química, física e até biológica).

O principal objetivo do método é definir o ponto de equilíbrio entre a execução da lubrificação industrial em maquinário instalado em estabelecimentos de fabricação de alimentos e o cumprimento das normas e legislações requeridas a este ramo de atividade industrial, conferindo disponibilidade e confiabilidade ao sistema industrial.

Este método é fundamentado nos seguintes aspectos:

> Levantar e analisar as falhas ocorridas nos ativos industriais, dando ênfase às falhas ocorridas em função das atividades de lubrificação industrial;

> Definir as variáveis envolvidas no processo de lubrificação e apontar os potenciais riscos que estas podem acarretar na qualidade e inocuidade do produto e/ou prover potencial ocorrência de falhas (redução de desempenho e disponibilidade);

> Analisar os indicadores de manutenção e confiabilidade a fim de prover medidas para melhorá-los concomitantemente com ações que promovam garantia da qualidade no processo produtivo; 
> Decidir a adequada política de lubrificação industrial para cada ativo a fim de melhorar o desempenho da máquina e/ou equipamento garantindo confiabilidade e disponibilidade do maquinário;

$>$ Decidir os modos de execução das tarefas de lubrificação direcionando a resultados satisfatórios de disponibilidade das instalações industriais e minimizando os riscos que possam interferir na qualidade e inocuidade do produto;

> Aperfeiçoar as tarefas de lubrificação quanto à habilidade técnica da mão de obra, ferramental e gestão de lubrificantes e com esta ação atender as normas e legislações vigentes no ramo de fabricação de alimentos e/ou até complementá-las;

$>$ Verificar e validar os resultados por meio de indicadores de desempenho de manutenção e disponibilidade operacional.

O método de seleção de política de lubrificação centrada em confiabilidade voltado para maquinário de fabricação de alimentos segue as seguintes etapas:

I - Identificação e Caracterização do Sistema Industrial: compreende o mapeamento do processo produtivo para compreensão dos impactos das atividades de lubrificação na qualidade e inocuidade do produto e na geração de eventos de falhas. Este mapeamento estrutura-se de: fluxograma do processo produtivo juntamente com o leiaute deste processo (onde o maquinário está inserido) e a árvore funcional do maquinário, neste identificando os pontos de lubrificação e dispositivos de aplicação do lubrificante;

II - Identificação dos Eventos de Riscos e Ocorrência de Falhas: esta etpa compreende:

a) A Identificação das variáveis envolvidas no processo de lubrificação industrial $\left(x_{1}, x_{2}\right.$ e $\left.x_{3}\right)$ para atribuir os valores binários as suas evidências no processo produtivo analisado;

b) Enquadramento do maquinário em sua Zona de Criticidade: atribuição do valor da $Z_{C}$ ao maquinário do processo produtivo de fabricação de alimentos; 
c) Calculo do $I_{C R}$ : Cálculo do $I_{C R}$ e análise da faixa de valor, a qual identifica a deficiência do processo de lubrificação quanto as variáveis binárias e o grau de risco de perda de qualidade e inocuidade do produto em processamento;

d) Cálculo de análise dos indicadores de manutenção e qualidade para identificação das falhas críticas que impactam na disponibilidade.

III - Tomada de Decisão: compreende a aplicação de ferramentas da qualidade e manutenção para composição das ações que devem estruturadas na adequada política de lubrificação a ser adotadas para o processo produtivo;

IV - Avaliação de Eficácia do Método: análise dos resultados por meio dos indicadores de manutenção e disponibilidade aliados ao $\mathrm{I}_{\mathrm{CR}}$.

O $I_{C R}$ - indicador de nível de confiabilidade operacional e potencial risco de perda de qualidade e inocuidade do produto é influenciado pelo processo de lubrificação em maquinário aplicado em indústria de alimentos e intensificado mediante o comportamento conjunto das variáveis envolvidas no processo de lubrificação e pela Zona de Criticidade $\left(Z_{C}\right)$ a qual pertence cada ativo industrial (maquinário) do complexo industrial. A expressão que representa este indicador está exposta na equação 3.1 contida na página 134 .

Este indicador é composto de variáveis binárias, sendo estas: manutenção preventiva, manutenção preditiva e nível da qualificação de mão de obra conjuntamente com o peso da adequada da Zona de Criticidade (peso qualitativo), a qual refere-se ao local de instalação do ativo industrial dentro das etapas do processo produtivo. Os valores tomados por este indicador, bem como a análise de cada faixa de valores, apresentam-se estão detalhados no quadro 3.2 apresentado na página 136.

A atribuição dos valores binários as variáveis de manutenção preventiva, preditiva e nível de qualificação de mão de obra, são obtidos mediante a análise do processo de lubrificação aplicado no maquinário industrial.

Para que a variável apresente o valor binário 1 (variável evidenciada) ou valor binário 0 (variável não evidenciada), deve-se analisar alguns requisitos relacionados ao modo de execução, estado dos recursos e insumos aplicados na execução da variável e resultados da mesma na disponibilidade operacional, entre outros. Para 
que a variável binária apresente estado de evidência (1), esta deve atender a todos os requisitos identificados em seu processo, caso não atenda a quaisquer um dos requisitos, atribui-se valor binário 0 , ou seja, não é considerada evidência da variável. Os requisitos estão expostos nas figuras 3.10 (pág. 157) e o modo de análise deste para cada variável apresentam-se nas tabelas 3.1 (pág 155), 3.2 (pág. 155), 3.3 (pág. 156) e 3.4 (pág. 156).

Para identificação da zona de criticidade do local de instalação do ativo industrial, analisa-se as características de funcionamento, modo de operação, limpeza e higienização do ativo em relação ao processo de lubrificação industrial aplicado a ele. Compara-se estas características com as particularidades descritas em cada Zona de Criticidade $\left(Z_{C}\right)$ apresentadas no quadro 3.3 (pág. 150). A $Z_{C}$ que apresentar compatibilidade com a maioria ds características do ativo (impactos do processo de lubrificação sobre o processo produtivo) é a qual se enquadra o ativo industrial analisado.

Calcula-se também os indicadores de manutenção e disponibilidade operacional, estes aplicados para sistemas reparáveis, para verificar o impacto das falhas (relacionadas ao processo de lubrificação industrial) sobre a disponibilidade operacional e produtividade do processo produtivo de alimentos.

Posteriormente aplicam-se ferramentas da engenharia de qualidade e manutenção para direcionar as ações a serem estruturadas na política de lubrificação adequada a cada máquina do sistema produtivo.Para verificação dos resultados, anlaisa-se os indiscadores de manutenção e desempnho e o grau de risco que possam impactar na qualidade e inocuidade do produto. 


\section{CAPÍTULO 4 APLICAÇÃo do MÉTOdo PARA SELEÇÃo DE POLÍTICA DE LUBRIFICAÇÃO DE MÁQUINAS CENTRADA EM CONFIABILIDADE: APLICAÇÃO NA INDÚSTRIA ALIMENTÍCIA}

\subsection{CONSIDERAÇÕES INICIAIS}

É aplicado um teste do método de seleção de política de lubrificação centrada em confiabilidade (proposto no capítulo 3) em um ambiente real de fabricação de alimentos, escolhendo uma máquina cobrideira de produtos para desenvolvimento do caso exemplo.

Este teste do método tem como intuito de avaliar a eficácia da pesquisa desenvolvida quanto a sua contribuição na confiabilidade e disponibilidade operacional do maquinário e na identificação e monitoramento dos riscos de perda de qualidade e inocuidade do produto que o processo de lubrificação possam promover.

Os indicadores (base do método) auxiliam na avaliação do efeito da atividade de lubrificação industrial aplicada no processo produtivo de alimentos, e assim identificam a criticidade das áreas do sistema fabril quanto ao potencial risco de perda de qualidade e inocuidade do produto e probabilidade de ocorrência de falhas no maquinário, direcionando a tomada de decisão para melhoria no processo de gestão da lubrificação de máquinas e equipamentos.

\subsection{APLICAÇÃO DO MÉTOdO PARA SELEÇÃO DE POLÍTICA DE LUBRIFICAÇÃO CENTRADA EM CONFIABILIDADE}

Para a verificação da funcionalidade do método proposto na presente pesquisa, aplicou-se este em um sistema reparável dentro de um ambiente real de produção de alimentos. 
Para realização do teste de avaliação do método de seleção de política de lubrificação desenvolvido foram realizadas as seguintes etapas:

I - Apresentação do ambiente real de fabricação de alimentos, o qual contém em sua instalação a máquina cobrideira de produtos (sistema reparável para aplicação do método de seleção de política de lubrificação desenvolvido na pesquisa);

II - Identificação e Caracterização do Sistema Industrial, etapa que compreende:

a) Mapeamento do processo produtivo, o qual compreende a construção do fluxograma e leiaute do processo produtivo onde está instalada a máquina objeto de aplicação do método desenvolvido;

b) Construção da árvore funcional para identificação dos componentes que necessitam de lubrificação (pontos de lubrificação da máquina);

III - Identificação de Eventos de Riscos e Ocorrência de Falhas, etapa composta por:

a) Classificação da Zona de Criticidade- $Z_{C}$ do sistema reparável em estudo;

b) Atribuição dos valores binários as variáveis envolvidas no processo de lubrificação;

c) Cálculo do $I_{C R}$ da máquina em estudo e análise da faixa de nível do valor deste indicador;

d) Análise estatística dos dados de falhas referentes ao sistema reparável (máquina cobrideira) e obtenção dos indicadores de desempenho de manutenção do estado de operação anterior a aplicação do método;

IV- Suporte para Tomada de Decisão, etapa na qual desenvolve-se a:

a) Aplicação de ferramentas (qualidade e/ou manutenção) para estruturar plano de ação para otimização do processo de lubrificação;

b) Aplicação da nova política de lubrificação industrial estruturada e avaliação da incidência de falhas e riscos associados a atividade de lubrificação da 
máquina cobrideira por meio dos indicadores de desempenho de manutenção e disponibilidade operacional e $I_{\mathrm{CR}}$.

Posteriormente a aplicação do método desenvolvido na presente tese, faz-se a análise estatística das falhas do sistema reparável (a qual é apresentada no capítulo 5) para verificar as mudanças no comportamento da taxa de ocorrência de falhas relacionadas às atividades de lubrificação industrial, sendo este resultado utilizado para a validação do método de seleção de política de lubrificação quanto a melhoria da produtividade do maquinário e garantia da qualidade do produto em meio ao processo produtivo de alimentos.

\subsubsection{Apresentação do Sistema Produtivo de Fabricação de Alimentos}

A empresa onde o estudo foi desenvolvido é de origem brasileira situada na região metropolitana de Curitiba, no estado do Paraná. O sistema reparável escolhido para aplicação do método é uma máquina cobrideira de produtos alimentícios instalada na linha de produção de maior demanda de vendas desta empresa.

Denomina-se a linha de produção 1 o processo produtivo que contempla a máquina cobrideira por motivos de confidencialidade da empresa. A linha de produção 1 é composta de cinco áreas de processamento do alimento, as quais possuem em sua particularidade as seguintes características:

I - Área de fabricação: Transporte mistura e cozimento da matéria prima. Possui máquinas e equipamentos que são submetidos a ciclos de pressão e temperatura (faixa de temperatura de trabalho entre $5^{\circ} \mathrm{C}$ e $8^{\circ} \mathrm{C}$ para o túnel de resfriamento e $80^{\circ} \mathrm{C}$ e $110^{\circ} \mathrm{C}$ para tanques de cozimento e pulmão). Executa-se processo de higienização e limpeza com aplicação de água e produtos sanitizantes com frequência maior que 2 vezes por semana, conforme procedimento da engenharia da qualidade da empresa, por se tratar de uma área que possui maquinário em contato direto com a matéria prima. 
II - Área de Corte e Resfriamento: Resfriamento da massa, corte e cobertura do produto cortado (em dimensões e pesos adequados conforme ficha técnica do produto). Possui máquinas e equipamentos que sofrem ciclagem de temperatura (aquecimento e resfriamento). Executa-se processo de higienização e limpeza com aplicação de água e produtos sanitizantes com frequência de até 2 vezes por semana, conforme procedimento da engenharia da qualidade da empresa. Maquinário trabalha em contato direto com a matéria prima em processamento (produto sem embalagem primária).

III - Área de Embalagem de Produto: Embalagem de produto (embalagem primária e secundária) e formação de caixas (blisters). Executa-se processo de higienização e limpeza com aplicação de água e produtos sanitizantes com frequência de até 2 vezes por semana, conforme procedimento da engenharia da qualidade da empresa. Esta área comporta máquinas e equipamentos que trabalham com o produto em processamento sem embalagem primária e com embalagem primária e secundária.

IV - Área de Paletização: Embalagem do produto em embalagens terciárias e paletização para armazenamento e transporte adicionado da etapa impressão de lotes e validade do produto. Aplica-se processo de higienização pelo menos 1 vez por semana com a aplicação de água e produtos sanitizantes.

V - Área de Utilidades: Chiller (sistema de resfriamento), Unidade Compressora, Tubulação de água, tubulação de vapor (aquecimento e energia) proveniente da caldeira e tubulação de ar comprimido (para sistema pneumático e limpeza de máquina e equipamentos.)

As máquinas da linha de produção 1 estão interligadas entre si como um sistema em série, particularidade que impacta na disponibilidade deste sistema produtivo, pois a interrupção do funcionamento de um componente do sistema em série interrompe o funcionamento do sistema produtivo por inteiro.

Enfatiza-se que a Linha de produção 1 é o sistema produtivo com maior demanda do mercado da empresa em estudo, e entre todos seus ativos industriais (máquinas e equipamentos), os que possuem backup ativo são as máquinas embaladoras e os tanques encamisados para cozimento de massa, caso uma 
destas máquinas apresentem falha, o sistema produtivo reduz seu desempenho produtivo mas não interrompe o funcionamento da linha de produção por inteiro.

O sistema reparável, máquina cobrideira de cobertura de alimentos, foi adotado para aplicação do método desenvolvido na pesquisa devida sua importância para o processo produtivo da empresa. Sua taxa de ocupação é total dentro da campanha operacional (3 turnos de trabalho ininterruptos), sua ligação com a linha de produção é modelo em série e não possui um backup passivo e/ou ativo desta máquina, adiciona-se a estes fatores elencados que a linha de produção, denominada Linha de Produção 1 na pesquisa, a qual a máquina cobrideira pertence, fabrica o produto de maior demanda e rentabilidade financeira para empresa em estudo (representa por volta de $30 \%$ das vendas da empresa).

Os ativos que possuem backup passivo são das áreas de embalagem e transporte de materiais como as: empilhadeiras, paleteiras, impressoras de blisters e caixotes, paletizadoras e seladoras, o restante do maquinário não apresentam qualquer tipo de redundância. O quadro 4.1 aponta as máquinas lotadas em suas respectivas áreas de fabricação que formam a linha de produção 1.

Quadro 4.1 - Maquinário da Linha de Produção 1

\begin{tabular}{|c|l|}
\hline $\begin{array}{c}\text { Área de } \\
\text { Fabricação }\end{array}$ & \multicolumn{1}{|c|}{ Máquinas } \\
\hline $\begin{array}{c}\text { Área de } \\
\text { Fabricação }\end{array}$ & $\begin{array}{l}\text { Tanques encamisados de cozimento (formação de massa), Tanques } \\
\text { encamisados de armazenamento (pulmão), Rede de tubulação (água, } \\
\text { vapor e ar comprimido), Esteira transportadora, Silo de } \\
\text { armazenamento de matéria prima, Rolo formador (formador de } \\
\text { massa), Misturador, Túnel de resfriamento. }\end{array}$ \\
\hline Área de Corte e & $\begin{array}{l}\text { Túnel de resfriamento, Máquina de corte transversal, Máquina de } \\
\text { Resfriamento horizontal, Máquina cobrideira, Rede de tubulação (água, } \\
\text { vapor e ar comprimido), Esteira transportadora. }\end{array}$ \\
\hline
\end{tabular}

(Continua) 
(Conclusão)

\begin{tabular}{|c|l|}
\hline $\begin{array}{c}\text { Área de } \\
\text { Fabricação }\end{array}$ & \multicolumn{1}{|c|}{ Máquinas } \\
\hline $\begin{array}{c}\text { Área de } \\
\text { Embalagem de } \\
\text { Produto }\end{array}$ & $\begin{array}{l}\text { Rede de tubulação (água, vapor e ar comprimido), Esteira } \\
\text { transportadora, Máquinas embaladoras, Formadora de caixa (blisters), } \\
\text { Máquina de comportar produtos unitários em blister, Seladoras de } \\
\text { blisters, Balança, Detector de metais, Mesa separadora de produto } \\
\text { (manual) }\end{array}$ \\
\hline $\begin{array}{c}\text { Área de } \\
\text { Paletização }\end{array}$ & $\begin{array}{l}\text { Rede de tubulação (água e ar comprimido), Esteiras transportadoras, } \\
\text { Impressoras, Seladoras, Paletizadoras, Paleteiras (transporte), } \\
\text { Empilhadeira. }\end{array}$ \\
\hline Área de Utilidades & Caldeira, Compressor, Chiller, Rede de tubulação. \\
\hline
\end{tabular}

Fonte: Autoria própria

A função da máquina cobrideira dentro do processo produtivo da Linha de Produção 1 é promover aplicação de calda sobre a superfície do produto em processamento. Esta máquina tem como principal material utilizado na fabricação de seus componentes o aço inoxidável AISI 304 A, além de partes fabricadas com polímeros como nylon e policarbonato (proteções da máquina). A figura 4.1 ilustra a máquina cobrideira da linha de produção 1

Figura 4.1 - Máquina Cobrideira

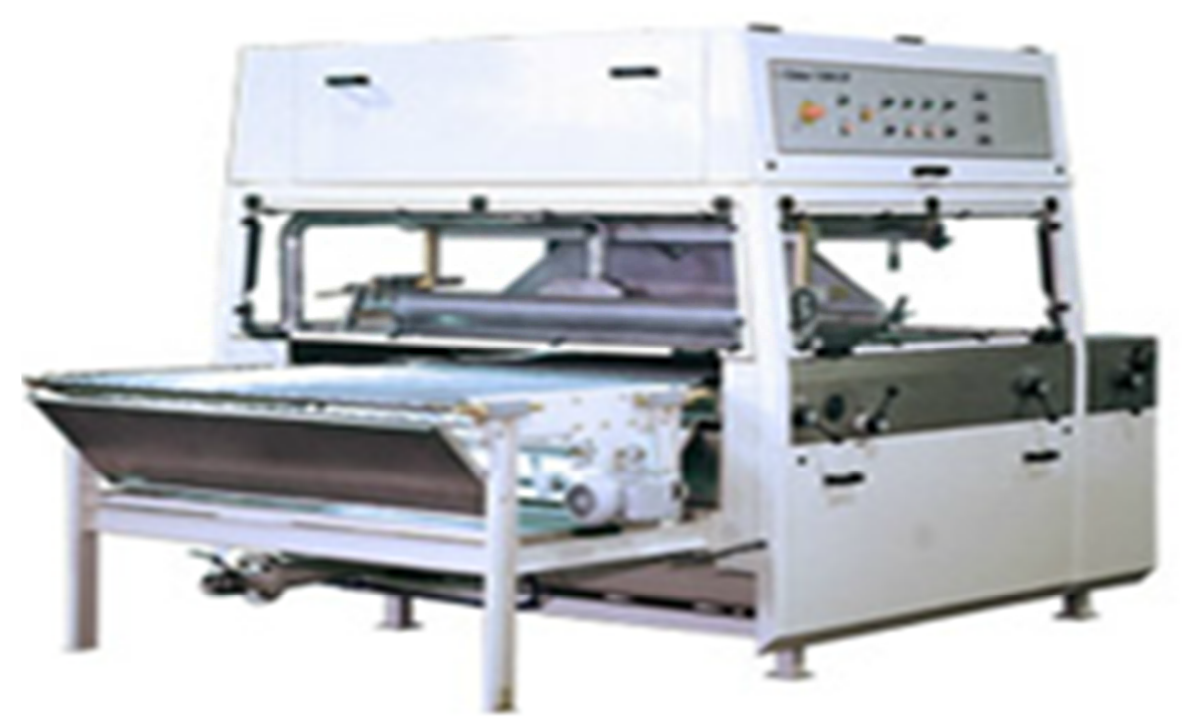

Fonte: Manual do Fabricante (documentação técnica da empresa em estudo) 
$\mathrm{Na}$ máquina cobrideira, os produtos podem ser cobertos por completo ou somente nas partes inferiores ou superiores. Por meio da cortina de ar regulável insuflada sobre os produtos e/ou com a grade vibratória (esteira metálica), controlase a quantidade de chocolate no produto, ou seja, o excesso de cobertura do produto é retirado pelo sistema de ventilação e vibração.

Por final, na saída do produto da cobrideira, este passa por um sistema de raspagem (rolo raspador) para a retirada da rebarba que se deposita no final do produto, seguindo assim para o túnel de resfriamento.

A máquina cobrideira tem capacidade produtiva de cobrir em média 408 produtos/min e o início de sua operação data desde 2002 na Linha de Produção 1. Durante o seu funcionamento apresenta contato com a matéria prima em processamento, ou seja, após o produto ser cortado transversamente e horizontalmente, ele é transportado através da máquina cobrideira para receber a camada de calda (geralmente de chocolate), sem embalagem primária. Esta máquina pode ser dividida nos seguintes sistemas:

> Caixa de cobertura superior: recipiente que comporta e controla o fluxo de calda (geralmente chocolate) sobre a superfície do produto em processamento, cobrindo a parte superior e lateral do produto;

> Caixa de cobertura inferior: possui conjunto de válvulas e unidade de bombeamento que controlam a quantidade e vazão de chocolate para cobertura do produto;

> Ventilador: retira calda excedente do produto, controlando a espessura da camada de chocolate sobre o produto;

> Sistema vibratório: propicia vibração (controlada) para retirada de excesso de calda de chocolate no produto (auxilia no controle da espessura do camada de cobertura do produto e evita formação de bolhas de ar na superfície do produto);

> Sistema inibidor de borra de calda (chocolate): sistema de raspagem na saída da esteira metálica (transportadora de produto ao longo da máquina cobrideira) para reter a borra de calda (chocolate) formada durante a passagem do produto;

> Sistema de aquecimento interno: possui tanque reservatório construído em aço inox com câmara dupla de aquecimento e circulação de água. A cobrideira possui sistema de aquecimento por meio de resistência e controle digital de 
temperatura superior/inferior e para facilitar acesso de controle e comando do painel eletrônico este está instalado na parte superior da máquina.

A seguir descreve-se as etapas de aplicação do método de seleção de política de lubrificação centrada em confiabilidade na máquina cobrideira.

\subsection{IDENTIFICAÇÃO E CARACTERIZAÇÃO DO SISTEMA INDUSTRIAL}

Para compreensão do funcionamento e comportamento da máquina cobrideira em relação ao processo de lubrificação, faz-se necessário o mapeamento e identificação das características do processo produtivo no qual a máquina está instalada, ou seja, o mapeamento e conhecimento da cada etapa da linha de produção onde a máquina cobrideira está lotada.

\subsubsection{Mapeamento do Processo Produtivo}

O mapeamento tem por finalidade identificar as características e particularidades de cada área de fabricação da linha de produção e analisar o impacto que cada área pode acarretar a outra durante a ocorrência de falhas e/ou execução da lubrificação industrial, uma vez que o maquinário desta linha de produção encontra-se disposto como um sistema em série.

O mapeamento da linha de produção 1 e o apontamento das características de cada ponto deste processo produtivo, foram realizados por meio de observação direta e pesquisa em campo, entrevistas com os funcionários envolvidos diretamente com a engenharia de manutenção e qualidade e acesso a documentos da empresa (histórico de manutenção, indicadores de produtividade e manuais técnicos).

Os dados e informações obtidos por meio do mapeamento da linha de produção 1 formam a base que possibilita a aplicação do método de seleção de política de lubrificação para o maquinário utilizado na fabricação de alimentos. A figura 4.2 apresenta o sequenciamento do processo produtivo da Linha de Produção 1 para melhor entendimento do seu ciclo produtivo, o qual a máquina cobrideira esta inserida. 
Figura 4.2 Fluxograma do Processo Produtivo - Linha de Produção 1

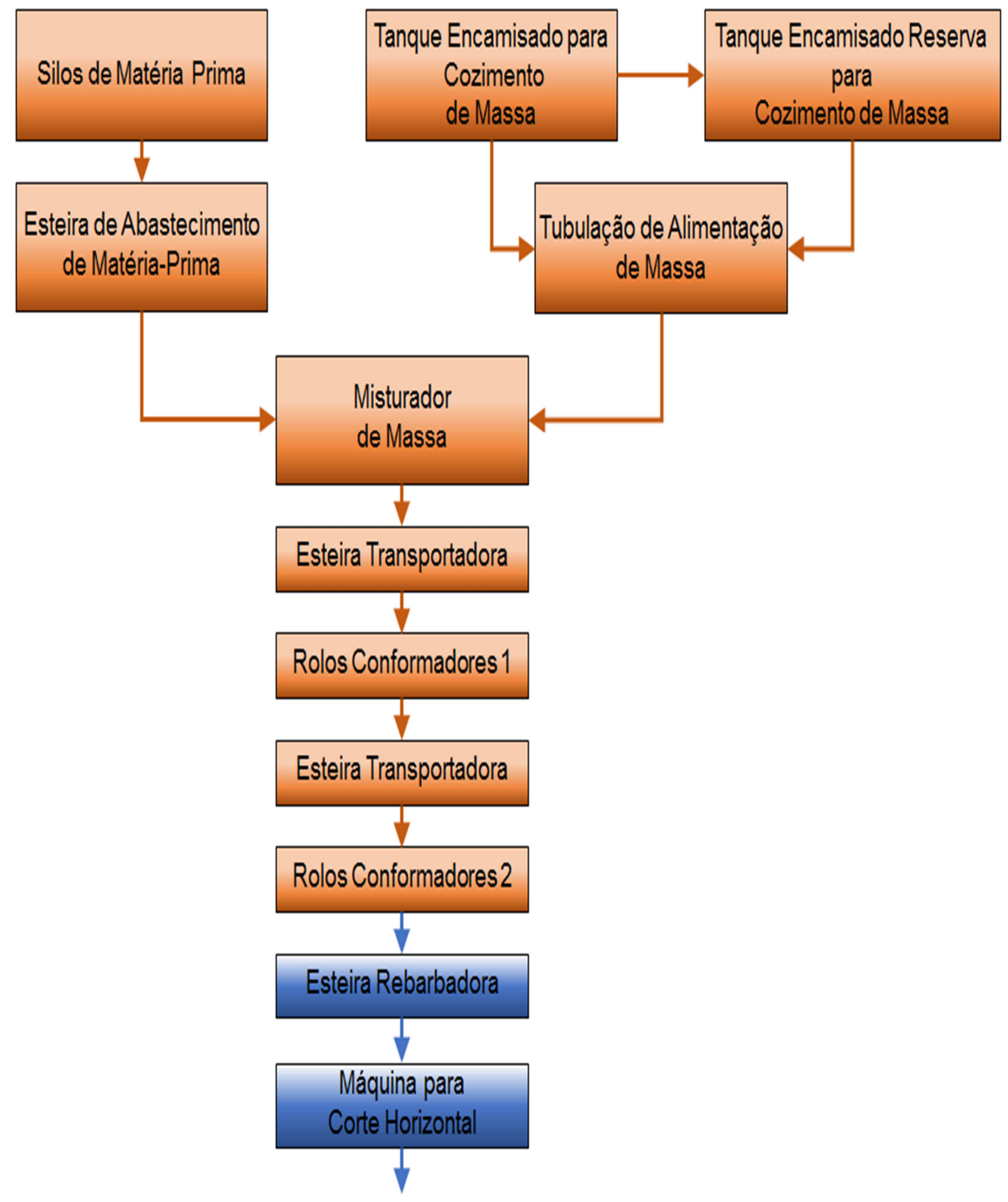

(Continua) 
(Continuação)

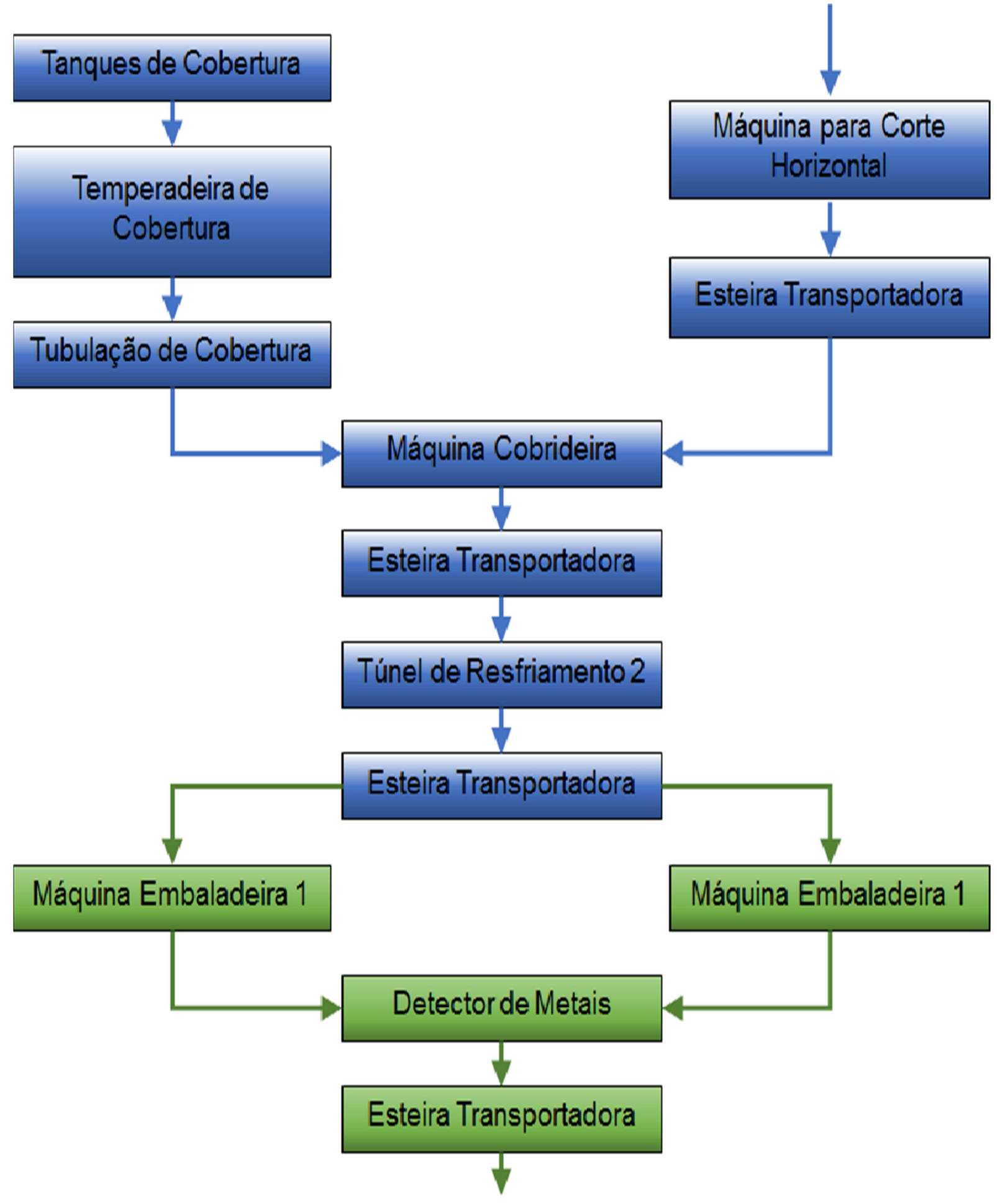

(Continua) 
(Conclusão)

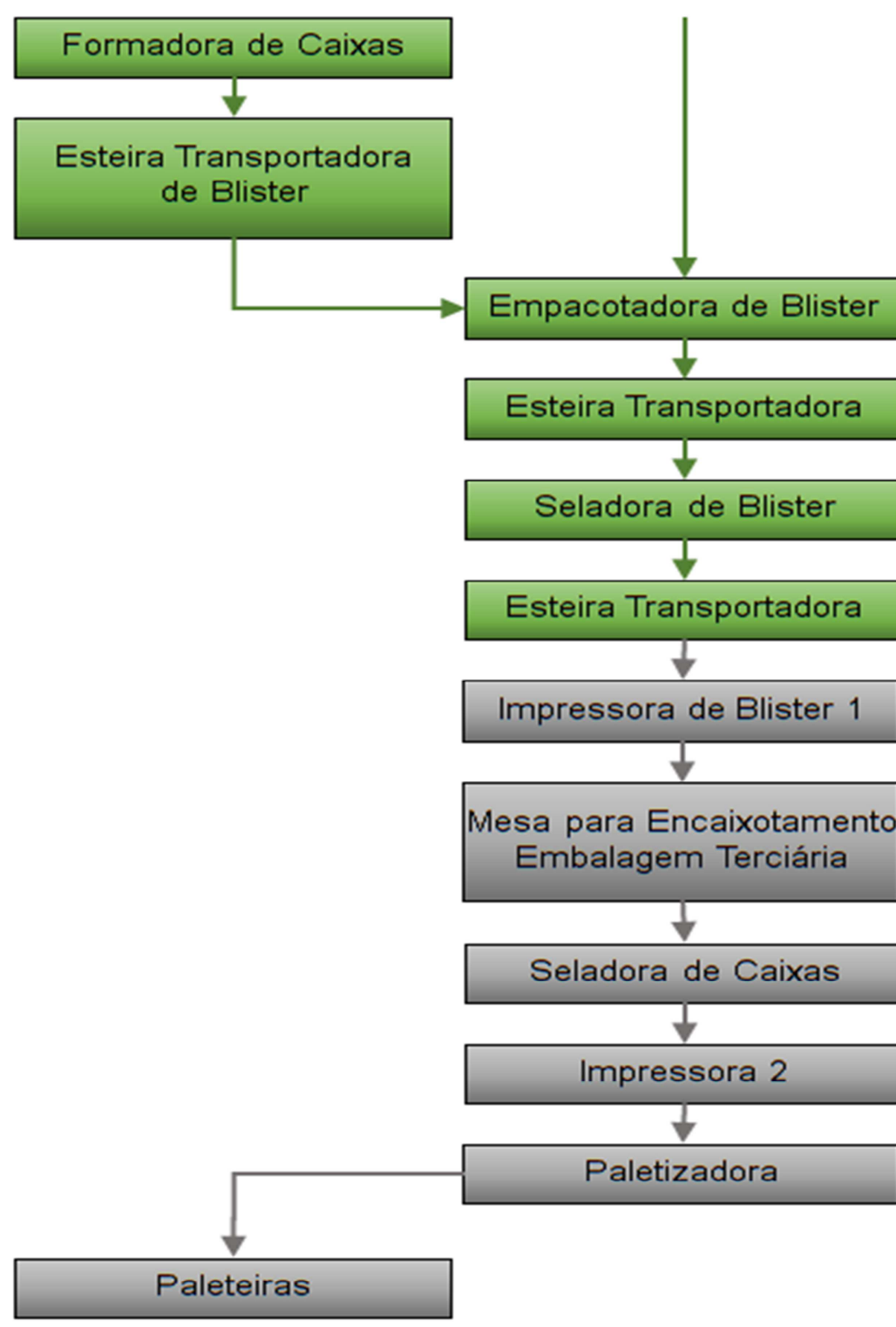

Empilhadeira

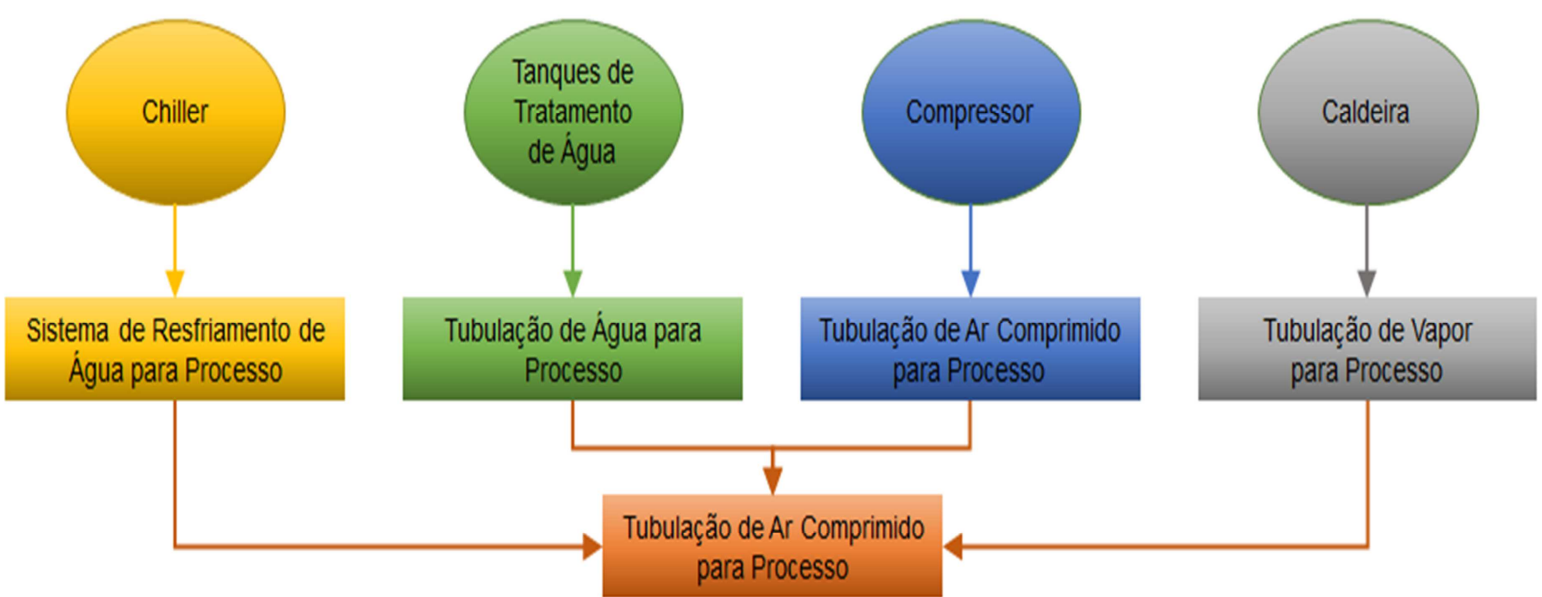

Fonte: Autoria própria 
Para identificar as características do processo de lubrificação, estrutura-se a árvore funcional da máquina cobrideira, identificando nesta os pontos que recebem lubrificante. A árvore funcional auxilia na visualização da estrutura da máquina cobrideira com o intuito de compreender seu funcionamento e os impactos da lubrificação quanto a proximidade dos elementos de máquina com a matéria prima em processamento. A figura 4.3 apresenta árvore funcional, destacando os pontos de lubrificação.

E para melhor visualização da relação da máquina cobrideira com o sistema produtivo da Linha de produção 1, apresenta-se na figura 4.4 o leiaute deste processo produtivo, destacando a máquina cobrideira com o peso atribuído ao zoneamento crítico (quanto ao processo de lubrificação industrial e potencial risco de perda de qualidade e inocuidade do produto) do local de instalação no qual a máquina esta instalada.

O leiuate ressalta a ligação dos ativos industriais (Linha de Produção 1) em sistema em série, apontando uma área crítica de fabricação, pois além de estar ligada em sistema em série ( fator que afeta a disponibilidade operacional dos demais ativos industriais da linha de produção 1 com a ocorrência de falhas na máquina cobrideira), o produto está sem embalagem primária durante seu estágio de processamento, fator que, propicia maior risco de contaminação por meio do processo de lubrificação, vindo a interferir na qualidade do produto e possível perda de produtividade.

Para melhor visualização da relação da máquina Cobrideira com o sistema produtivo da Linha de Produção 1, apresenta-se na figura 4.4 o leiaute do processo produtivo dessa Linha, destacando a máquina cobrideira em sua respetiva zona de criticidade $\left(Z_{C}=A\right)$. $O$ processo de enquadramento da $Z_{C}=A$ para a máquina cobrideira, identificada no leiaute, está descrito no quadro 4.2. presente na seção 4.4 . 
Figura 4.3 - Árvore Funcional da Máquina Cobrideira

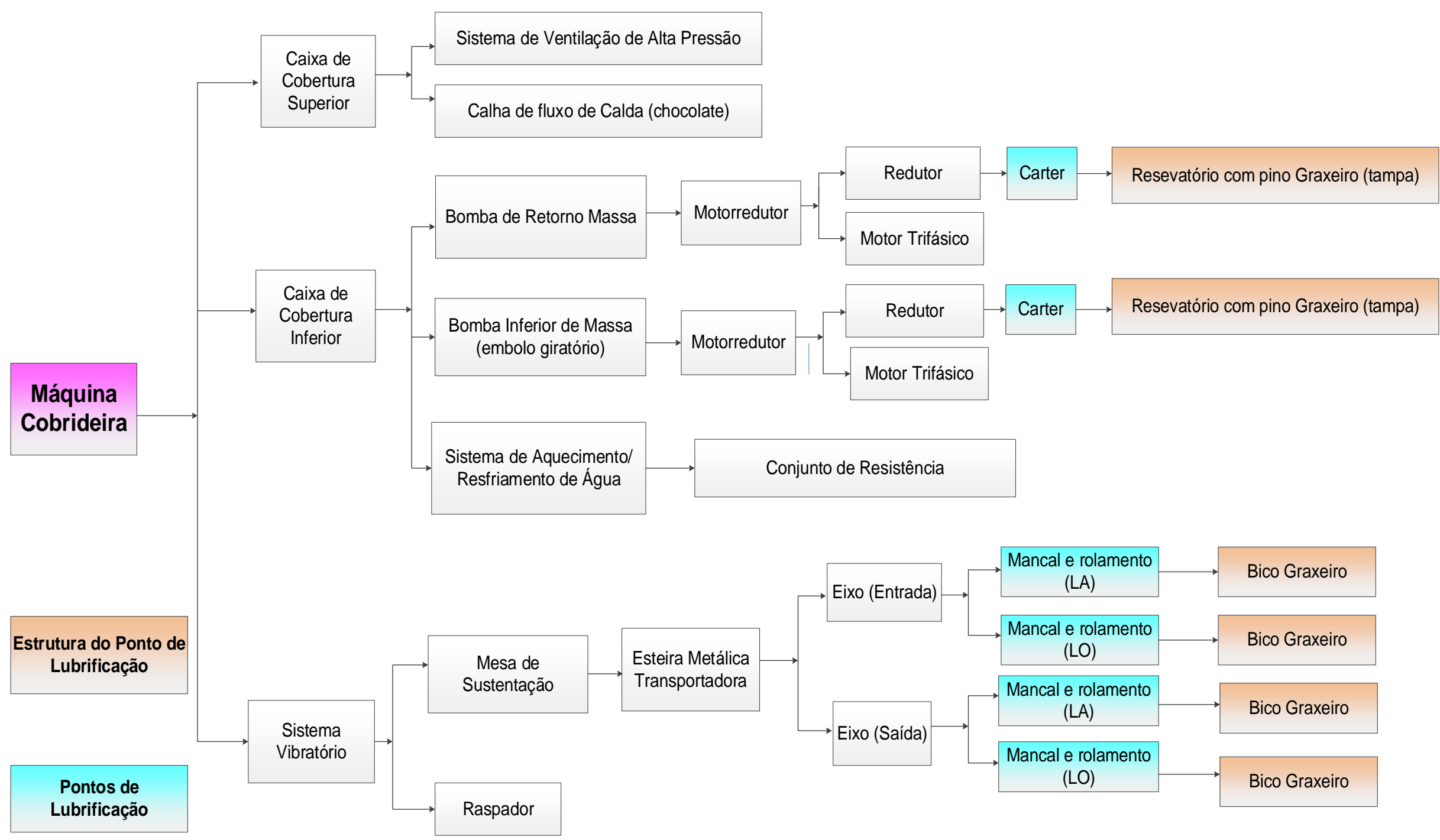

(Continua) 
(Conclusão)

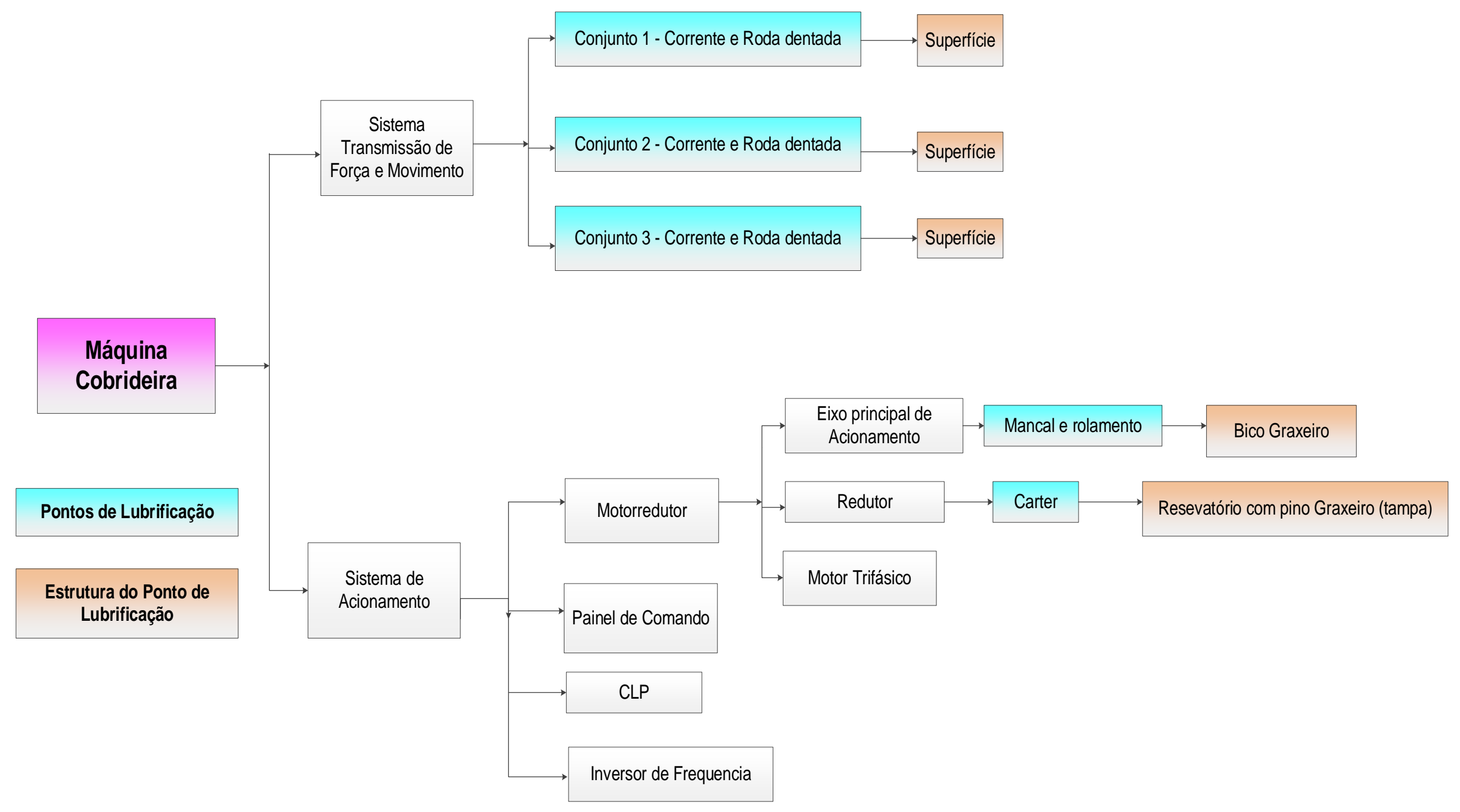

Fonte: Autoria própria 
Figura 4.4 - Leiaute da Linha de Produção 1 no Formato de Ligação em Série com Identificação da Máquina Cobrideira dentro da sua Zona Critíca - ZC

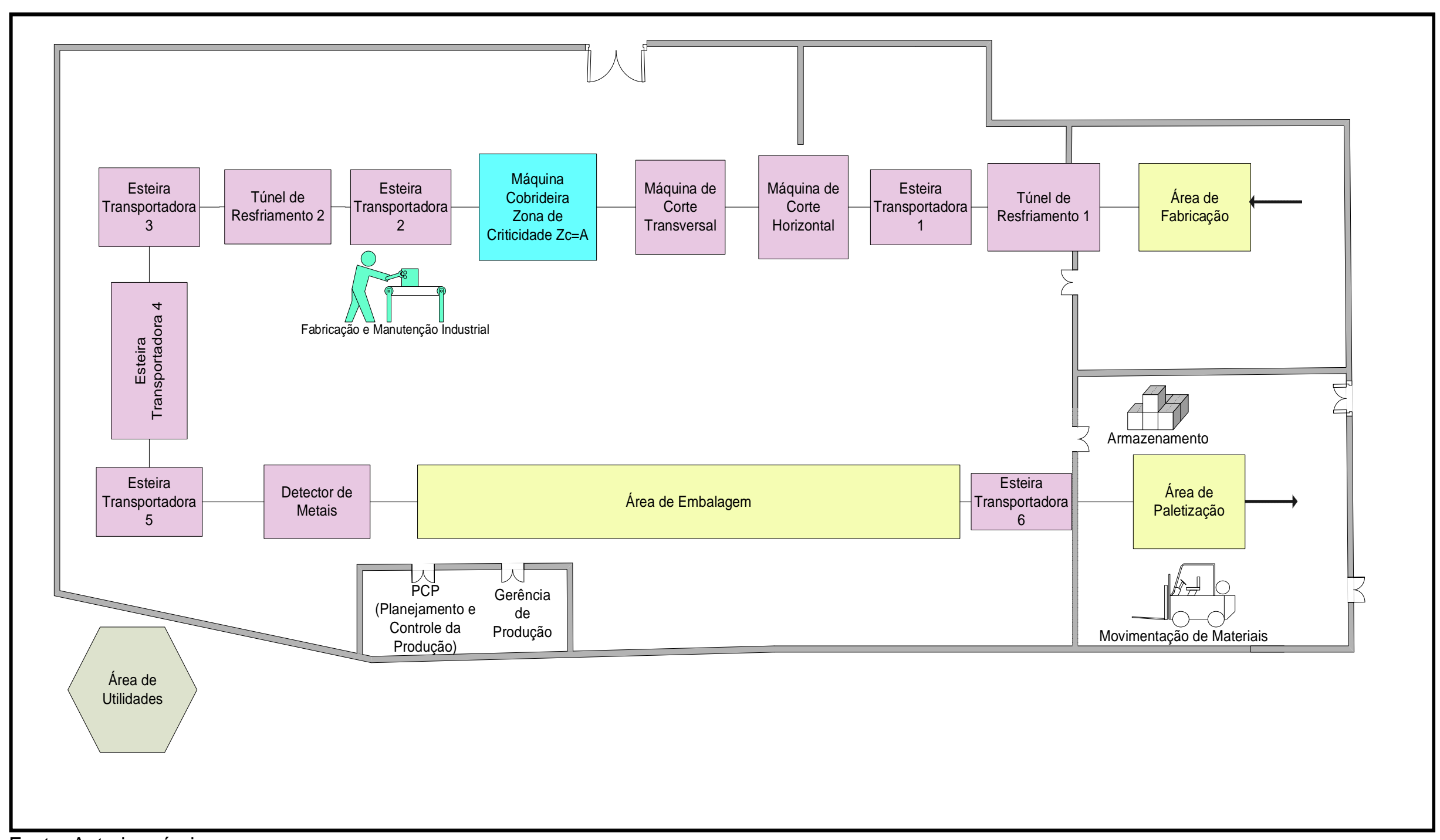

Fonte: Autoria própria 


\subsection{IDENTIFICAÇÃO DE EVENTOS DE RISCOS E OCORRÊNCIAS DE FALHAS}

Nesta etapa apresenta-se o enquadramento da máquina Cobrideira na Zona de Criticidade e análise das particularidades do processo de lubrificação e operação desta máquina para atribuição dos valores as variáveis binárias.

Também se mostra a análise estatísticas das falhas na máquina cobrideira ocorridas entre o período de 2010 à 2013 para verificação do impacto das falhas relacionadas ao processo de lubrificação na disponibilidade operacional e produtividade da Linha de Produção 1.

\subsubsection{Classificação da Zona Crítica - ZC e Atribuição de Valores das Variáveis Binárias}

Para enquadramento da máquina cobrideira dentro das categorias descritas na Zona de Criticidade - $Z_{C}$ (quadro 3.3),bem como, atribuir valor binário as demais variáveis envolvidas no processo de lubrificação industrial, faz-se necessário o levantamento de informações qualitativas e quantitativas do sistema produtivo da linha de produção 1 e da máquina cobrideira, informações estas, relacionadas aos impactos que o processo de lubrificação pode ocasionar na geração de eventos de falhas e/ou foco de potencial risco a perda de qualidade e inocuidade do produto em processamento.

A obtenção de dados dá-se por meio de pesquisa documental (histórico da empresa) e entrevista com as pessoas envolvidas na manutenção e operação da Linha de Produção 1. Estes dados e informações foram estruturadas para atribuição dos valores quantitativos e qualitativos para as variáveis envolvidas no processo de lubrificação industrial e das particularidades relacionadas a zona de criticidade do local de instalação da máquina cobrideira.

Estas informações e dados foram estruturados no quadro 4.2 para enquadramento da $Z_{C}$ referente a máquina cobrideira e a definição do valor binário a ser atribuídos as variáveis de manutenção preventiva, manutenção preditiva e nível de qualificação de mão de obra. 
Quadro 4.2 - Análise Quantitativa e Qualitativa das Variáveis Envolvidas no Processo de Lubrificação da Máquina Cobrideira

\begin{tabular}{|c|c|c|c|}
\hline $\begin{array}{l}\text { Valor Variável } \\
\text { Binária / Zona } \\
\text { de Criticidade }\end{array}$ & $\begin{array}{l}\text { Requisito Variável } \\
\text { Binária / Requisito } \\
\text { Zona de Criticidade }\end{array}$ & Descrição & $\begin{array}{l}\text { Resultado do } \\
\text { Valor Binário } \\
\text { / Resultado } \\
\text { Z }_{\mathrm{C}}\end{array}$ \\
\hline \multirow{3}{*}{$\begin{array}{c}\text { Manutenção } \\
\text { Preventiva = } 0\end{array}$} & $\begin{array}{l}\text { Roteiro de } \\
\text { Atividades }\end{array}$ & $\begin{array}{l}\text { Máquina cobrideira apresenta roteiro de lubrificação porém este não } \\
\text { contempla todos os pontos de lubrificação e não indica o lubrificante } \\
\text { adequado quanto a sua Zona de Criticidade }\left(Z_{C}=A\right) \text {; } \\
\text { Planos de Manutenção Preventiva são executados de forma adequada } \\
\text { (periodicidade, utilização do correto lubrificante de grau alimentício, } \\
\text { ferramental adequado). }\end{array}$ & 0 \\
\hline & $\begin{array}{l}\text { Recursos e Insumos } \\
\text { adequados para } \\
\text { execução das } \\
\text { Atividades }\end{array}$ & $\begin{array}{l}\text { Não possui instrumentos individualizados para cada tipo de lubrificante; } \\
\text { Não possui procedimento de limpeza/higienização; } \\
\text { Não possui local/procedimento de acondicionamento adequado do } \\
\text { ferramental e insumos aplicados nas atividades de lubrificação. }\end{array}$ & 0 \\
\hline & $\begin{array}{c}\text { Monitoramento das } \\
\text { Ações }\end{array}$ & $\begin{array}{l}\text { Possui abertura e encerramento de OS's relativas às manutenções } \\
\text { corretivas; } \\
\text { Possui planejamento e controle de alocação de mão de obra e controle de } \\
\text { estoque (materiais e insumos). }\end{array}$ & 1 \\
\hline
\end{tabular}


(Continuação)

\begin{tabular}{|c|c|c|c|}
\hline $\begin{array}{l}\text { Valor Variável } \\
\text { Binária / Zona } \\
\text { de Criticidade }\end{array}$ & $\begin{array}{l}\text { Requisito Variável } \\
\text { Binária / Requisito } \\
\text { Zona de Criticidade }\end{array}$ & Descrição & $\begin{array}{c}\text { Resultado do } \\
\text { Valor Binário } \\
\text { / Resultado } \\
\mathrm{Z}_{\mathrm{C}}\end{array}$ \\
\hline $\begin{array}{c}\text { Manutenção } \\
\text { Preventiva = } 0\end{array}$ & $\begin{array}{l}\text { Evidência de } \\
\text { Resultados sob a } \\
\text { Disponibilidade } \\
\text { Operacional }\end{array}$ & $\begin{array}{l}\text { Possui indicadores de monitoramento das atividades de manutenção de } \\
\text { forma geral (cálculo realizado com base em todas as falhas ocorridas na } \\
\text { Linha de Produção 1), não possibilitando acompanhar os impactos das } \\
\text { atividades de lubrificação industrial sobre o ativo industrial; } \\
\text { Não possui análise de falhas e aplicação de plano de ação para sanar as } \\
\text { avarias. }\end{array}$ & 0 \\
\hline \multirow[t]{2}{*}{$\begin{array}{l}\text { Manutenção } \\
\text { Preditiva }=0\end{array}$} & Roteiro de atividades & $\begin{array}{l}\text { Existência de Roteiro de Manutenção Preditiva, porém não contempla as } \\
\text { técnicas preditivas necessárias para garantir a qualidade do produto final e } \\
\text { melhoria na produtividade da maquina cobrideira; } \\
\text { Existência de análise de vibração, porém sem acompanhamento dos } \\
\text { relatórios (evolução da falha identificada) e sem planejamento das correções } \\
\text { necessárias das falhas identificadas. }\end{array}$ & 0 \\
\hline & $\begin{array}{c}\text { Recursos e Insumos } \\
\text { adequados para } \\
\text { execução das } \\
\text { Atividades }\end{array}$ & $\begin{array}{l}\text { Apresenta mão de obra qualificada; } \\
\text { Apresenta instrumentos adequados para execução das atividades de } \\
\text { manutenção preditiva. }\end{array}$ & 1 \\
\hline
\end{tabular}


(Continuação)

\begin{tabular}{|c|c|c|c|}
\hline \multirow{2}{*}{$\begin{array}{l}\text { Manutenção } \\
\text { Preditiva = } 0\end{array}$} & $\begin{array}{l}\text { Monitoramento das } \\
\text { Ações }\end{array}$ & $\begin{array}{l}\text { Não apresenta acompanhamento da evolução das falhas identificadas } \\
\text { nos laudos de análise de vibração; } \\
\text { Não apresenta planejamento e controle dos alarmes (avarias) indicadas } \\
\text { nos laudos, avarias as quais podem evoluir para um evento de falha. }\end{array}$ & 0 \\
\hline & $\begin{array}{l}\text { Evidência de Resultados } \\
\text { sob a Disponibilidade } \\
\text { Operacional }\end{array}$ & $\begin{array}{l}\text { Não apresenta indicadores de desempenho que permita acompanhar a } \\
\text { influência das ações de manutenção preditiva sobre a produtividade da } \\
\text { maquina cobrideira. }\end{array}$ & 0 \\
\hline
\end{tabular}


(Continuação)

\begin{tabular}{|c|c|c|c|}
\hline $\begin{array}{l}\text { Valor Variável } \\
\text { Binária / Zona } \\
\text { de Criticidade }\end{array}$ & $\begin{array}{l}\text { Requisito Variável } \\
\text { Binária / Requisito } \\
\text { Zona de Criticidade }\end{array}$ & Descrição & $\begin{array}{c}\text { Resultado do } \\
\text { Valor Binário } \\
\text { / Resultado } \\
\mathrm{Z}_{\mathrm{C}}\end{array}$ \\
\hline \multirow{2}{*}{$\begin{array}{c}\text { Nível de } \\
\text { Qualificação de } \\
\text { Mão de Obra = } \\
0\end{array}$} & $\begin{array}{l}\text { Utilização de } \\
\text { ferramental adequado }\end{array}$ & $>\quad$ Apresenta ferramental adequado e em bom estado de conservação. & 1 \\
\hline & $\begin{array}{l}\text { Execução de Limpeza } \\
\text { e Higienização do } \\
\text { Ponto de Lubrificação }\end{array}$ & $\begin{array}{l}\text { Apresenta evidência de execução de limpeza/higienização do ponto de } \\
\text { lubrificação ao término das atividades de manutenção. }\end{array}$ & 1 \\
\hline
\end{tabular}


(Continuação)

\begin{tabular}{|c|c|c|c|}
\hline $\begin{array}{l}\text { Valor Variável } \\
\text { Binária / Zona } \\
\text { de Criticidade }\end{array}$ & $\begin{array}{l}\text { Requisito Variável } \\
\text { Binária / Requisito } \\
\text { Zona de Criticidade }\end{array}$ & Descrição & $\begin{array}{l}\text { Resultado do } \\
\text { Valor Binário } \\
\text { / Resultado } \\
\mathrm{Z}_{\mathrm{C}}\end{array}$ \\
\hline \multirow{3}{*}{$\begin{array}{c}\text { Zona de } \\
\text { Criticidade } \\
\mathrm{Z}_{\mathrm{C}}=\mathrm{A}\end{array}$} & $\begin{array}{l}\text { Estado do produto em } \\
\text { processamento }\end{array}$ & $\begin{array}{l}\text { Produto em processamento recebe cobertura de calda (geralmente de } \\
\text { chocolate) sem embalagem primária. }\end{array}$ & $A$ \\
\hline & $\begin{array}{c}\text { Potencial Risco de } \\
\text { Perda de Qualidade e } \\
\text { inocuidade do Produto }\end{array}$ & $\begin{array}{l}\text { Risco alto de perda de qualidade e inocuidade do produto, devido apresentar } \\
\text { pontos de lubrificação expostos com processamento de produto sem } \\
\text { embalagem; } \\
\text { Risco intensificado devido deficiência nas estratégias de manutenção } \\
\text { aplicadas. }\end{array}$ & $A$ \\
\hline & Perda de Produção & $\begin{array}{l}\text { Potencial ocorrência de falhas, devido deficiência nas estratégias de } \\
\text { manutenção e inexistência de análise de falhas } \\
\text { Apresenta potencial perda total da produtividade na ocorrência de } \\
\text { contaminação do produto durante o processamento. }\end{array}$ & $A$ \\
\hline
\end{tabular}


(Conclusão)

\begin{tabular}{|c|c|c|c|}
\hline $\begin{array}{c}\text { Valor Variável } \\
\text { Binária / Zona } \\
\text { de Criticidade }\end{array}$ & $\begin{array}{c}\text { Requisito Variável } \\
\text { Binária / Requisito } \\
\text { Zona de Criticidade }\end{array}$ & $\begin{array}{c}\text { Resultado do } \\
\text { Valor Binário } \\
\text { / Resultado - } \\
\mathbf{Z}_{\mathrm{C}}\end{array}$ \\
\hline $\begin{array}{c}\text { Zona de } \\
\text { Criticidade } \\
Z_{\mathrm{C}}=\mathrm{A}\end{array}$ & Limpeza /Higienização & $\begin{array}{l}\text { Frequência de Limpeza e Desinfecção (FLD) com frequência mínima de } 1 \\
\text { vez por semana ( FLD > 2) } \\
\text { Utilização de água quente e/ou pressurizada e de produtos sanitizantes } \\
\text { para execução da limpeza/higienização do ativo industrial e do local de } \\
\text { instalação. }\end{array}$ \\
\hline
\end{tabular}

Fonte: Autoria própria 
Por meio das respostas indicadas no quadro 4.2, as quais são relativas as variáveis associadas ao processo de lubrificação industrial da máquina cobrideira e suas características de funcionamento, identifica-se o estado atual destas variáveis possibilitando assim, a apropriação de seus respectivos pesos para composição do indicador de nível de confiabilidade e potencial risco de perda de qualidade e inocuidade do produto, bem como, possibilita, analisar os fatores deficientes para composição de um plano de ação para estruturar uma adequada política de lubrificação, objetivo do método desenvolvido na presente pesquisa.

A decisão do valor/peso a ser atribuído a cada variável binária dá-se, conforme descrito no capítulo 3 , pela análise dos requisitos de cada variável envolvida no processo de lubrificação, caso a variável analisada apresente todos os requisitos, atribui-se a ela 0 valor binário 1 , caso a variável deixe de evidenciar quaisquer um dos requisitos, atribui-se a ela valor binário 0 .

Já a decisão para o enquadramento da zona de criticidade da máquina cobrideira, efetua-se o levantamento de seus modos de operação, manutenção e limpeza e particularidades, e assim, compara-os com as características descritas em cada categoria de Zonas de Criticidade $\left(Z_{C}\right)$ expostas no quadro 3.3 (capítulo 3 da presente tese), a $Z_{C}$ que apresentar características de igual ou próxima descrição das características reais elencadas da maquina cobrideira é atribuída como $Z_{C}$ de enquadramento da mesma.

Enfatiza-se que para decisão dos valores binários adotados nas variáveis de decisão, tanto, para o enquadramento do zoneamento crítico $\left(Z_{C}\right)$ da máquina cobrideira, deu-se através de uma reunião entre as pessoas envolvidas no processo de lubrificação e controle da produção da máquina cobrideira, sendo estes técnicos mecânicos, supervisor de manutenção, planejador de manutenção, operador de produção e a autora da pesquisa desenvolvida nesta tese.

Atribui-se valores binários 1 somente para as variáveis que apresentaram evidências concretas, ou seja, com 100\% de ocorrência e/ou aceitação pelas pessoas envolvidas na operação e manutenção da máquina cobrideira. Variáveis apontadas como evidências incertas ou com aderência de execução por alguns dos envolvidos e não para os outros foram consideradas com valor binário 0 (não ocorrência e/ou não execução). Assim, a máquina cobrideira é caracterizada pelas seguintes informações: 
I - Classe de zoneamento crítico do local de instalação: A, pois evidência pontos de lubrificação de estrutura exposta, máquina opera com produto sem embalagem, possui dispositivos para lubrificação e/ou método de lubrificação manual, características de grande maioria que se aproxima da descrição da zona crítica $\mathrm{A}$;

II - Manutenção Preventiva e Preditiva $=0$, pois não atendem a todos os requisitos relacionados ao modo execução, estrutura e resultados sobre a produtividade, assim não garante sua efetiva existência;

III - Estado da Qualificação de Mão de Obra $=0$, apesar dos técnicos de manutenção apresentarem qualificação técnica para as atividades gerais da manutenção industrial, não possuem conhecimento das normativas e legislações vigentes direcionadas a área de engenharia de manutenção aplicada em indústrias de alimentos. Adicionado a este fator, os técnicos de manutenção não cumprem e/ou admitem não conhecer os regulamentos internos do SGQ (Sistema de Gestão da Qualidade), este gerenciado pela engenharia de qualidade da empresa em estudo.

\subsubsection{Cálculo do ICR}

Com atribuição destes valores as variáveis binárias e o enquadramento da $Z_{C}$ adequada a máquina cobrideira (quadro 4.2), o $\mathrm{I}_{\mathrm{CR}}$ - indicador de nível de confiabilidade e potencial risco de perda de qualidade e inocuidade do produto (por meio das atividades de lubrificação), obteve o seguinte resultado exposto na equação (4.1).

$$
I_{C R}=\left(x_{1}+x_{2}+x_{3}\right) * Z_{C}=0 A
$$

Tem-se o valor do $I_{\mathrm{CR}}=0 \mathrm{~A}$ e com avaliação de sua faixa de nível do indicador (conforme quadro 3.2), a máquina cobrideira encontra-se em uma $Z_{C}$ que apresenta 
deficiência nas estratégias de manutenção tanto preventiva como preditiva, fator esse, que propicia a ocorrência de eventos de falhas.

Mediante o valor do $I_{C R}=0 A$, a atual condição do modo de operação e manutenção da máquina cobrideira promove potencial ocorrência de eventos de falhas, estes relacionados ao processo de lubrificação industrial, e este fator aliado à mão de obra com baixa qualificação na execução de atividades de lubrificação em indústria de alimentos, intensifica o potencial risco de perda de qualidade e inocuidade do produto em processamento, o qual pode provocar perda total da produtividade.

Assim verifica-se a necessidade de implantar e/ou melhorar o nível de qualificação do quadro técnico da manutenção industrial quanto às normas $e$ procedimentos de realização das atividades de lubrificação, bem como, implantar/melhorar as estratégias de manutenção preditiva e preventiva, a fim de, reduzir e/ou eliminar as causas que possam gerar eventos de falhas e focos de risco, os quais podem impactar na qualidade do produto, garantindo qualidade ao produto e disponibilidade ao sistema industrial.

Seguidamente efetua-se a análise estatística dos eventos de falhas com intuito de apontar as falhas relacionadas à lubrificação industrial e analisar seu impacto na disponibilidade operacional da máquina cobrideira.

\subsubsection{Análise Estatística de Falhas do Sistema Reparável - Máquina Cobrideira}

A mantenabilidade de máquinas e equipamentos é expressa em termos de facilidade e redução de tempo para manutenção, impactando diretamente na disponibilidade do equipamento e precisão das ações de manutenção.

Para análise de confiabilidade e disponibilidade do maquinário faz-se necessário conhecer o comportamento das falhas através dos dados obtidos a partir do registro (histórico) de falhas.

Este histórico de ocorrência de falhas, estruturado em uma ordem cronológica, é essencial para se testar e analisar a evolução da tendência da taxa de falhas. Para tal, a base de dados deve ter uma dimensão definida, sendo o histórico do sistema reparável em estudo o espaço delimitado por número de falhas e o tempo até a última ocorrência. 
Para análise do comportamento das falhas da máquina cobrideira efetuou-se o levantamento de falhas em período entre 2010 a 2013, conjuntamente com uma análise das causas associadas às paradas de máquina (análise FMEA), destacando as falhas relacionadas aos problemas de lubrificação, as quais são foco da pesquisa.

Por se tratar de um sistema reparável, calcula-se a taxa de ocorrência de falhas (ROCOF), a qual expressa instantaneamente a probabilidade de falha por unidade de tempo, por meio desta é possível obter os valores para cálculo dos indicadores de manutenção e confiabilidade operacional da máquina cobrideira

Os valores dos indicadores de disponibilidade e demais indicadores de desempenho das atividades de manutenção, são analisados em função do tempo, pois estão relacionados as variações na taxa de falhas, caracterizando estatisticamente, um comportamento das falhas aleatórias com um processo estocástico de Poisson Não Homogêneo (NHP), ou seja, a taxa de falhas apresenta uma dependência em relação ao tempo, podendo a tendência do comportamento das falhas ser classificada como crescente ou decrescente.

Os indicadores de desempenho de manutenção auxiliam na análise do comportamento da ocorrência das falhas influenciando o desempenho da máquina quanto a sua exigência de produtividade. Por meio destes indicadores, também é possível verificar a influência das variáveis envolvidas no processo de lubrificação na ocorrência de falhas, as quais podem gerar potencial foco de risco a qualidade do produto, e com esta análise propor plano de ação para minimizar os problemas crônicos relacionados a estas variáveis e consequentemente melhorar os indicadores de manutenção e confiabilidade.

Para calcular estes indicadores de desempenho de manutenção e confiabilidade é necessário estruturar os dados de falhas da máquina cobrideira. Os dados de eventos de falhas foram obtidos entre os anos de 2010 à 2013, anos anteriores à aplicação do método desenvolvido na presente pesquisa (posteriormente no capítulo 5, apresentar-se-á os resultados obtidos no ano de 2014).

Conjuntamente com os indicadores de desempenho de manutenção entre o período analisado (2010 à 2013), construíram-se os mesmos indicadores excluindo os eventos de falhas relacionados à lubrificação da máquina cobrideira, 
possibilitando análise dos impactos destes eventos de falhas sobre a disponibilidade e desempenho deste sistema reparável.

Os dados dos eventos de falhas ocorridos na máquina cobrideira entre $2010 \mathrm{e}$ 2013, já com os indicadores de desempenho de manutenção calculados e o comportamento da tendência de falhas indicado são apresentados na tabela APÊNDICE A. A tabela dos dados relativos aos valores dos indicadores sem a evidência das falhas relacionadas ao processo de lubrificação, esta disponíveis no APÊNDICE C, parte integrante da presente tese.

Estes dados de falhas permitem calcular a taxa de ocorrência de falha (ROCOF) e o comportamento da tendência dos eventos de falhas ao longo do tempo, por meio dos parâmetros $\beta$ e $\alpha$ obtidos.

Os valores identificados nos parâmetros $\beta$ e a possibilitam calcular as demais variáveis envolvidas na análise estatística da tendência de falhas da máquina cobrideira, como a taxa de ocorrência de falhas (ROCOF), o valor de MTBF $\left(_{t}\right)$ ao longo do tempo e a sua disponibilidade (está também variável em função do tempo), bem como, verificar a tendência da variação da taxa de falhas mediante esta comportar-se como um sistema NHP.

As equações (4.2 e 4.3) a seguir mostram o cálculo do valor de $\beta$ para verificar a tendência dos eventos de falhas da máquina cobrideira dentro do período analisado entre 2010 à 2013, sendo o valor de $\beta_{1}$ contabilizando todos os eventos de falhas e o valor de $\beta_{2}$ excluindo os eventos de falhas relacionados ao processo de lubrificação, com intuito de analisar o impacto destas falhas no comportamento da tendência de falhas.

$$
\begin{aligned}
& \boldsymbol{\beta}_{1}=\frac{124}{[(124-1) * 10,21]-1107,05}=0,83467215 \\
& \boldsymbol{\beta}_{2}=\frac{92}{[(92-1) * 10,23]-815,95}=0,802215079
\end{aligned}
$$

As figuras 4.5 e 4.6 mostram os gráficos de $\rho(t)$ e $A(t)$ com dados relativos ao período de 2010 à 2013, conjuntamente, com os gráficos referentes a simulação (sem eventos de falhas específicos). 
Figura 4.5 - (a) Gráfico dos Valores de Disponibilidade - $\mathrm{A}_{(\mathrm{t})}$ ao Longo do Período de 2010 à 2013 com Todos os Eventos de Falhas Ocorridos na Máquina Cobrideira e (b) Gráfico com Simulação dos Valores de $A_{(t)}$ da Máquina Cobrideira sem Contabilização dos Eventos de Ocorrência de Falhas Relacionados ao Processo de Lubrificação Industrial

\section{Disponibilidade A(t) - 2010 à 2013}

(a)

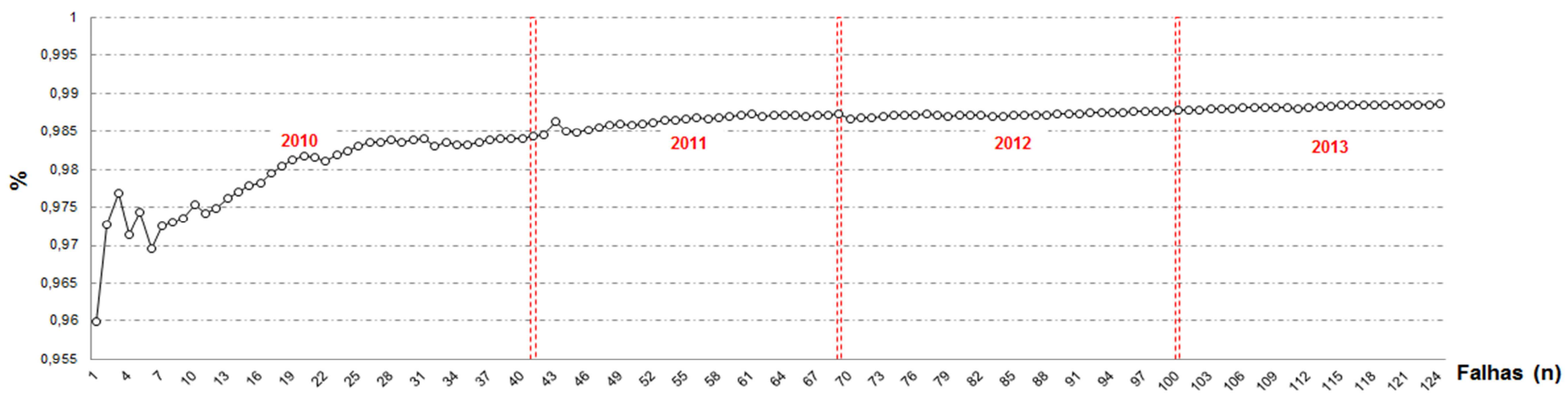

\section{Disponibilidade $A(t)-2010$ à 2013}

(b)

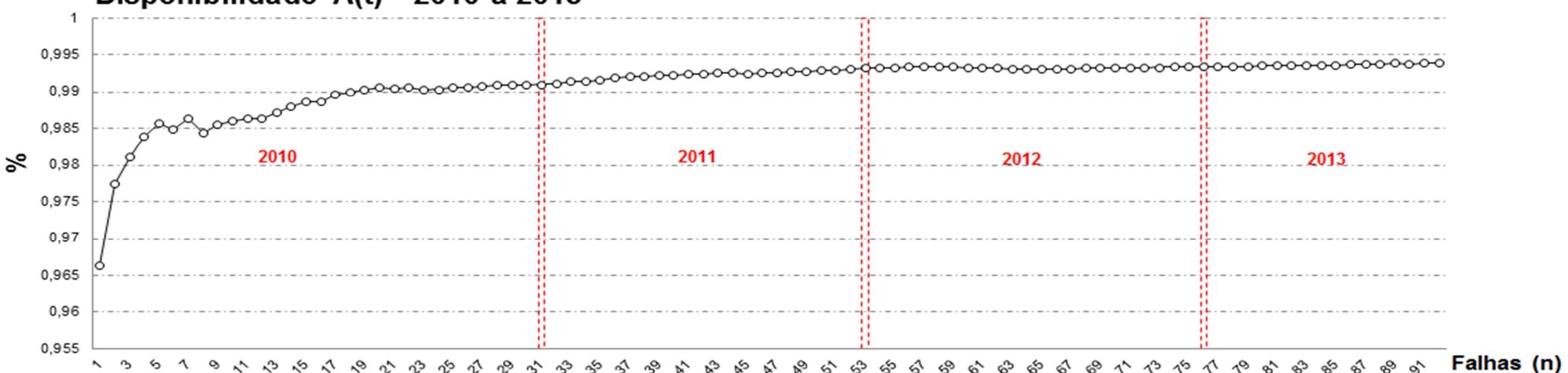

Fonte: Autoria própria 
Figura 4.6 - (a) Gráfico dos Valores da Taxa de Intensidade de Ocorrência de Falhas - $\rho_{\mathrm{t}}$ ) ao Longo do Período de 2010 à 2013 com Todos os Eventos de Falhas Ocorridos na Máquina Cobrideira e (b) Gráfico com Simulação dos Valores de $\rho_{t}$ ) da Máquina Cobrideira sem Contabilização dos Eventos de Ocorrência de Falhas Relacionados ao Processo de Lubrificação Industrial

Taxa de Ocorrência de Falhas (ROCOF) - 2010 à 2013

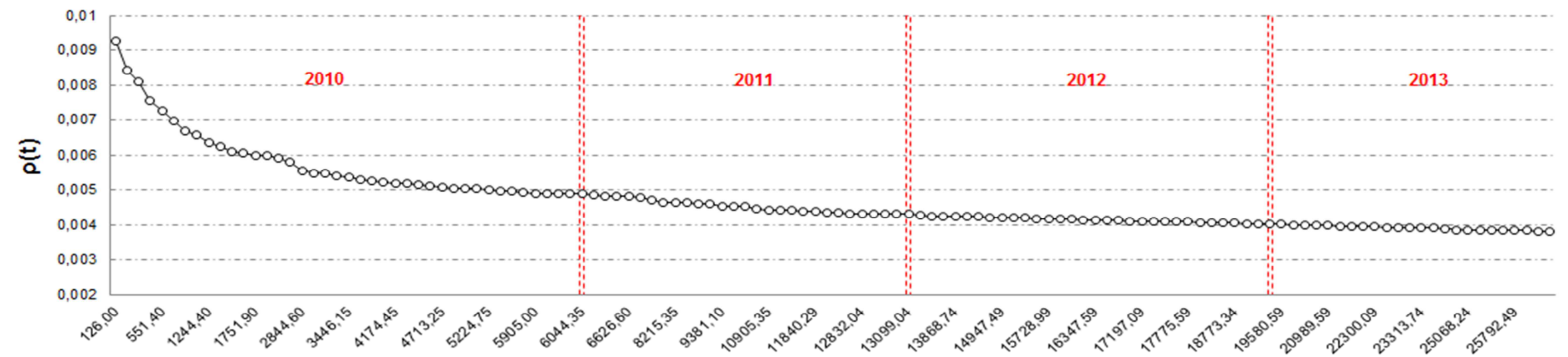

Taxa de ocorrência de falhas (ROCOF)- 2010 à 2013

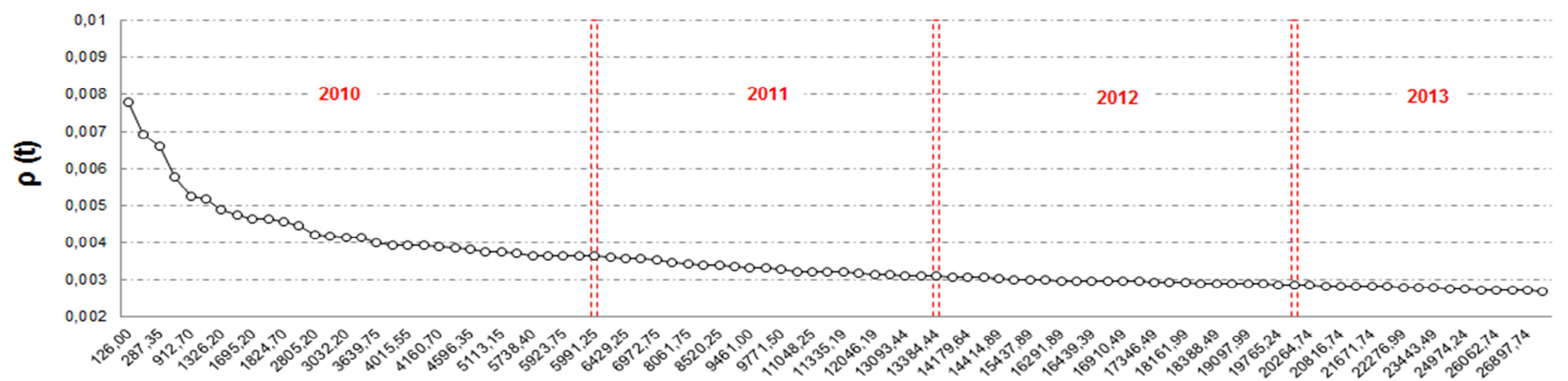

Fonte: Autoria própria 
Ambos os valores de $\beta$ apresentam-se valores abaixo de $1(\beta 1<0$ e $\beta 2<0)$, apontando uma tendência de falhas descrescente e processo estocástico Poisson Não homogêneo, ou seja, a taxa de falhas varia seus valores em função do tempo.

Apesar da tendência de ocorrência dos eventos de falhas mostrar-se decrescente, em ambos as análises (com e sem eventos de falhas relacionados à lubrificação industrial), a disponibilidade - $A(t)$ e a taxa de intensidadede falhas - $\rho(t)$, referentes aos dados do histórico de manutenção da máquina cobrideira entre o período de 2010 à 2013, apontam para resultados melhores com a redução destes eventos de falhas específicos, expostos nos indicadores de desempenho simulado sem os eventos de falhas referentes ao processo de lubrificação.

Analisando os valores de disponibilidade, ao final de 2013 o valor de $\left.A_{t}\right)$ é de $98,858002 \%$ com todos os eventos de falhas reais ocorridos na máquina cobrideira no período verificado (2010 à 2013), porém, ao calcular a disponibilidade neste mesmo período, simulando a exclusão dos eventos de falhas relacionados ao processo de lubrificação, a $\left.A_{(t}\right)$ apresenta um valor de $99,390236 \%$ ao final de 2013 , ou seja, um ganho de $0,538382 \%$ de disponibilidade ( em relação de $A(t)$ obtida em 2013) para operação da máquina cobrideira.

Este percentual de ganho de disponibilidade aumentaria a produção em 2.736 produtos por dia, contabilizando ao final do ano um adicional de 943.920 unidades (equivalente a 23,6 toneladas) no balanço produtivo da Linha Produtiva 01.

A tabela 4.1 detalha os dados e cálculos da perda de produtividade da máquina cobrideira com a evidência dos eventos de falhas relacionados à lubrificação industrial, com valores de perda de produção diária, mensal e prospecção em até um ano.

Tabela 4.1 - Dados Comparativos de Produtividade da Máquina Cobrideira

Informação de Produtividade

Horas trabalhadas por dia

Capacidade de produção nominal (unidade por h)

Capacidade de produção nominal (unidade por dia)

Peso por unidade $(\mathrm{Kg})$
Valores

$21 \mathrm{~h}$

24.480 unidades

514.080 unidades

$0,025 \mathrm{Kg}$ 
(Conclusão)

\begin{tabular}{|c|c|}
\hline Informação de Produtividade & Valores \\
\hline Capacidade de produção nominal diária em Kg & $12.852 \mathrm{Kg}$ \\
\hline $\begin{array}{l}\text { Disponibilidade de horas trabalhadas por dia } \\
\text { para } A(t)=98,858002 \%\end{array}$ & $20,76018 \mathrm{~h}$ \\
\hline $\begin{array}{l}\text { Capacidade de produção (unidade por dia) } \\
\text { para } A(t)=98,858002 \%\end{array}$ & 508.209 unidades \\
\hline $\begin{array}{l}\text { Capacidade de produção diária em kg } \\
\text { para } A(t)=98,858002 \%\end{array}$ & $12.705,225 \mathrm{Kg}$ \\
\hline Capacidade de produção anual em kg & \\
\hline $\begin{array}{l}\text { para } A(t)=98,858002 \% \text { (valor aproximado de dias úteis de } \\
\text { trabalho no ano }=345 \text { ) }\end{array}$ & 4.383.302,6 Kg \\
\hline $\begin{array}{l}\text { Disponibilidade de horas trabalhadas por dia } \\
\text { para } A(t)=99,390236 \%\end{array}$ & $20,87195 \mathrm{~h}$ \\
\hline $\begin{array}{l}\text { Capacidade de produção (unidade por dia) } \\
\text { para } A(t)=99,390236 \%\end{array}$ & 510.945 unidades \\
\hline $\begin{array}{l}\text { Capacidade de produção (unidade por dia) em kg } \\
\text { para } A(t)=99,390236 \%\end{array}$ & $12.773,625 \mathrm{Kg}$ \\
\hline Capacidade de produção anual em kg & \\
\hline $\begin{array}{l}\text { para } A(t)=99,390236 \% \text { (valor aproximado de dias úteis de } \\
\text { trabalho no ano }=345 \text { ) }\end{array}$ & $4.406 .900,6 \mathrm{Kg}$ \\
\hline Perda de produção diária em Kg & $68,4 \mathrm{Kg}$ \\
\hline Perda de produção diária em unidades & 2.736 unidades \\
\hline $\begin{array}{l}\text { Perda de produção anual em } \mathrm{Kg} \text { (valor aproximado de dias } \\
\text { úteis de trabalho no ano }=345 \text { ) }\end{array}$ & $23.598 \mathrm{Kg}$ \\
\hline
\end{tabular}

Fonte: Autoria prória

Analisando os dados e cálculos expostos na tabela 4.1, verifica-se que com a redução e/ou eliminação dos eventos de falhas ligados aos problemas de lubrificação industrial, a máquina cobrideira poderia aumentar sua produtividade diária em $68,4 \mathrm{~kg}$, totalizando ao final do ano 4.406,9 toneladas de produtos disponíveis para o mercado consumidor, ao invés das $4.383,3$ toneladas obtidas como resultado ao final de $2013 \mathrm{com}$ a $\mathrm{A}(t)=98,858002 \%$. 
Outro indicador a ser analisado é a taxa de ocorrência de falhas, a qual é a base para cálculo da disponibilidade (que também varia em função do tempo) e também propicia verificar o comportamento da tendência de falhas aleatórias em função do tempo.

Assim, a taxa de intensidade de ocorrência de falhas - $\rho\left(t_{t}\right)$, influencia diretamente na disponibilidade operacional da máquina cobrideira, analisando o gráfico da $\rho(t)$ nas figuras 4.5 e 4.6, verifica-se que com aumento da $A(t)$ ao longo do tempo, a taxa de intensidade de ocorrência de falhas decresce.

Ao final de 2013, a probabilidade de ocorrência de falhas por unidade de tempo, esta a interpretação da taxa de intensidade de ocorrência de falhas (ROCOF) é de $\rho(t)=0,00381566$ com para $A(t)=98,858002 \%$ contabilizando todos os eventos de falhas, e neste mesmo período, os valores simulados para $A(t)=99,390236 \%$ tem-se $\rho(t)=0,00267108$.

Analisando os valores reais e simulados, é possível verificar que a redução e/ou eliminação destes eventos de falhas relacionados ao processo de lubrificação, não só aumentaria a produtividade de máquina, mas também reduziria a probabilidade de ocorrência de eventos de falhas, os quais interferem na confiabilidade e disponibilidade operacional do sistema industrial.

Assim conclui-se, que, para aumento de disponibilidade operacional faz-se necessário adotar uma política de lubrificação que contemple ações que reduzem a probabilidade de ocorrência de falhas ao longo da campanha operacional da máquina cobrideira.

Posteriormente analisa-se o tempo disponível para a produtividade da máquina cobrideira entre a ocorrência dos eventos de falhas, bem como, o tempo gasto para reparo de cada evento de falhas mostrados nos gráficos presentes nas figuras 4.7 e 4.8, representados pelos indicadores de $\operatorname{MTTR}(t)$ e $\operatorname{MTBF}(t)$.

Enfatiza-se, novamente, que os indicadores estão acompanhados de seu respectivo indicador de desempenho com simulação de valores sem a presença dos eventos de falhas relacionados ao processo de lubrificação industrial, o que possibilita verificar com maior objetividade os impactos destes eventos de falhas sobre o desempenho operacional da máquina cobrideira. 
Figura 4.7 - (a) Gráfico dos Valores de MTTR ( ${ }_{\mathrm{t}}$ e TTR Referentes aos Eventos de Falhas Ocorridos Entre o Período de 2010 à 2013 com Todos os Eventos de Falhas Ocorridos na Máquina Cobrideira e (b) Gráfico com Simulação dos Valores de MTTR $\left(_{t}\right.$ ) e TTR dos Eventos de Falhas Ocorridos na Máquina Cobrideira sem Contabilização dos Eventos de Ocorrência de Falhas Relacionados ao Processo de Lubrificação Industrial

\section{MTTR(t)e TTR - 2010 à 2013}

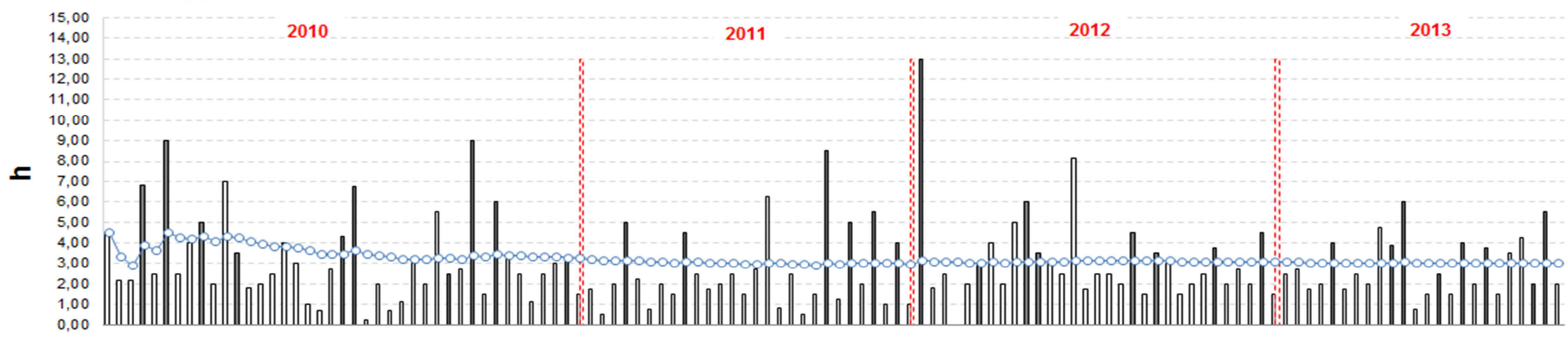

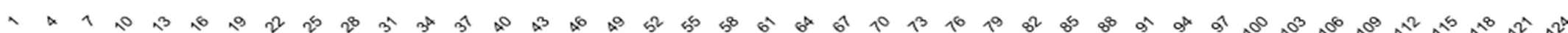
Falhas(n) Eventos de falhas relacionados com o processo de ubrificação industrial

$$
\begin{aligned}
& \text { Demais eventos } \\
& \text { defalhas }
\end{aligned}
$$

MTTR (t) e TTR - 2010 à 2013

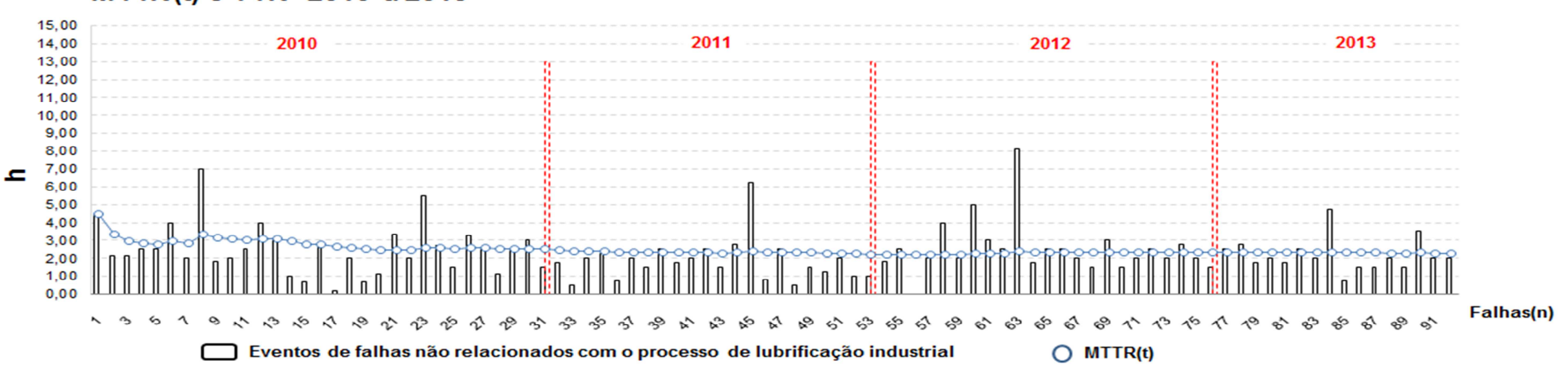


Figura 4.8 - (a) Gráfico dos Valores de $\operatorname{MTBF}_{\mathrm{t}}$ ) Variando ao Longo do Período de 2010 à 2013 com Todos os Eventos de Falhas Ocorridos na Máquina Cobrideira e (b) Gráfico com Simulação dos Valores de MTTR $\left(_{t}\right)$ da Máquina Cobrideira sem Contabilização dos Eventos de Ocorrência de Falhas Relacionados ao Processo de Lubrificação Industrial

\section{$\operatorname{MTBF}(\mathrm{t})$ - 2010 à 2013}

(a)

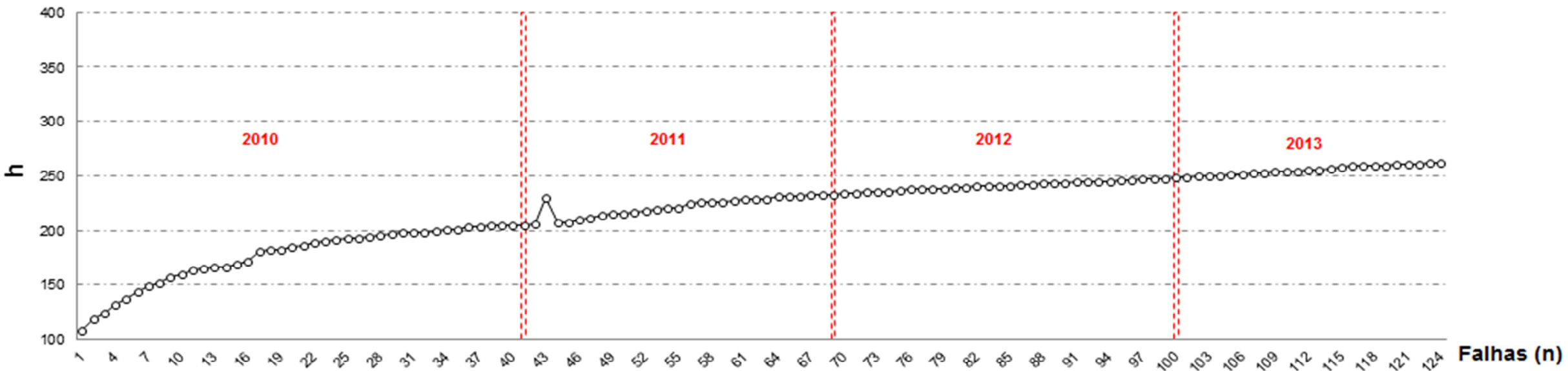

$\operatorname{MTBF}(t)-2010$ à 2013

(b)

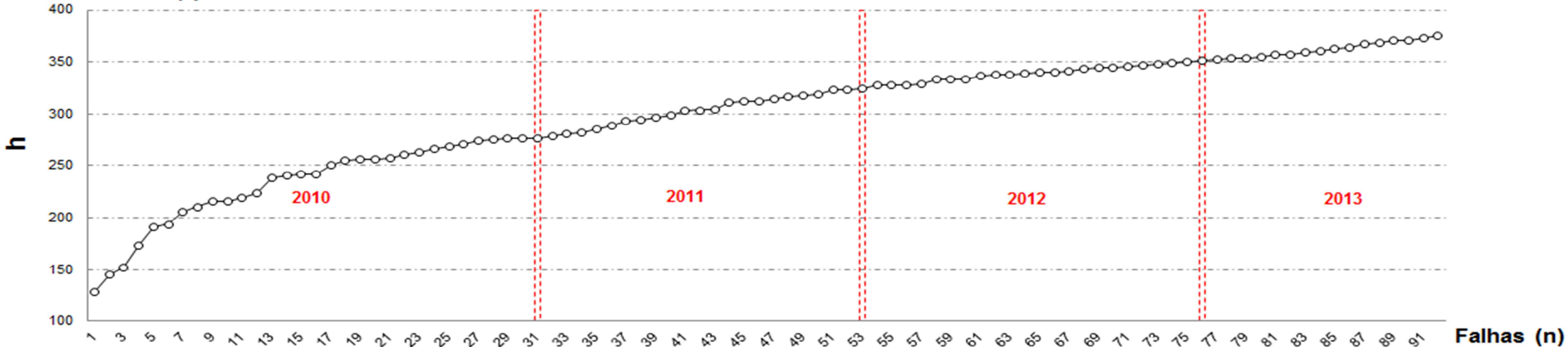

Fonte: Autoria própria 
Os gráficos referentes aos TTR's e $\operatorname{MTTR}(t)$ dos eventos de falhas da máquina cobridiera ocorridos entre 2010 à 2013 (figura 4.8), evidencia os eventos de falhas relacionados com o processo de lubrificação da maquina cobrideira, com intuiro de analisar os impactos de seus TTR's e frequência de ocorrência sobre a disponibilidade e confiabilidade operacional dessa máquina.

Considera-se como eventos de falhas relacionados ao processo de lubrifcacao insutrial, falhas com as seguintes descrições encontradas no histórico de manutenção relativo ao período de 2010 à 2013:

> Travamento de rolamento;

$>$ Desgastes de elementos de máquina;

> Vazamento de óleo;

> Aquecimento de elementos de máquina rotativos;

$>$ Fratura de elementos de máquina;

> Outros eventos de falhas ocasionados pelas descrições anteriores como: alargamento da esteira metálica, danos a vedações, etc.

A análise estatística dos tempos entre as falhas (TBF) e dos tempos gastos para reparo (TTR) dos eventos de falhas apontados compõe a teoria da confiabilidade e mantenabilidade do sistema reparável em análise. O tempo de reparo e a frequência de ocorrência de falhas influenciam nestes indicadores de desempenho do maquinário.

No gráfico da figura 4.7 é possível comparar a redução do $\operatorname{MTTR}(t)$ dos eventos de falhas ocorridos no período de 2010 à 2013, pois as falhas relacionadas aos eventos de falhas relacionados ao processo de lubrifcação representam em torno de 26\% (32 falhas em 124 eventos de falhas no total) de todos os eventos de falhas do perído registrados no período analisado (2010 à 2013).

Além disto, é visível no gráfico da figura 4.7 (o qual contempla todos os eventos de falhas) que os eventos de falhas ligados diretamente ao processo de lubrificação industrial apresentam com TTR individual acima do valor do $\operatorname{MTTR}(t)=$ $3,03 \mathrm{~h}$ encontrado ao final de 2013 , sendo que este valor contempla o conjunto total de eventos de falhas.

Especificamente 30 das 32 falhas relacionadas a problemas de lubrificação industrial, levaram a um tempo de conserto maior de 3,03 h, ou seja, tempo para 
conserto acima do valor do $\operatorname{MTTR}(t)$ geral do período analisado. Sendo que, o $\operatorname{MTTR}(t)$ encontrado no final de 2013, excluindo esses os eventos específicos (falhas ligadas ao processo de lubrificação), seria $\operatorname{MTTR}(t)=2,2968 \mathrm{~h}$ para conserto de cada evento de falhas ocorrido. Conclui-se então, que esses eventos aumentam, em média, 44 minutos no TTR(h) de cada evento de falha ocorrido no período analisado (2010 à 2013).

Assim como o $\operatorname{MTTR}(t)$, o indicador de desempenho $\operatorname{MTBF}(t)$ também apresenta, no gráfico b da figura 4.8 (valores simulados sem a evidência dos eventos de falhas ligados a problemas de lubrificação industrial), um aumento de 112,3 horas, as quais poderiam estar disponíveis para operação da máquina cobrideira se não ocorressem os eventos de falhas relacionados ao processo de lubrificação industrial (comparando $\operatorname{MTBF}(t)=262,08 \mathrm{~h}$ ao final de 2013 com todos os eventos de falhas e $\operatorname{MTBF}(t)=374,38 \mathrm{~h}$ no mesmo período porém com a exclusão eventos de falhas específicos anteriormente citados).

Em termos de produtividade, estas 112,3 horas ampliadas entre a ocorrência de falhas, aumentaria a produtividade em 2.749.104 unidades (sendo capacidade nominal de produção por hora $=24480$ unidades), o equivalente a 68,73 toneladas de produtos produzidas a mais até a próxima ocorrência de falha que interromperia 0 funcionamento da máquina cobrideira.

Outra consequência da ocorrência dos eventos de falhas ligados a problemas de lubrificação da máquina cobrideira, além de impactar na disponibilidade operacional deste ativo industrial, e que muitas intervenções podem gerar potencial foco de risco para a qualidade e inocuidade do produto em processamento, como a aplicação de lubrificante mineral comum, sem conter grau alimentício e/ou gerar resíduos de lubrificantes sobre a superfície da máquina, Ivando a uma contaminação cruzada do produto e interferindo em suas propriedades organolépticas odor, sabor, etc).

Logo, a necessidade de reduzir a ocorrência destas falhas atende tanto os objetivos da engenharia de manutenção, quanto os quesitos da engenharia da qualidade, ou seja, ganho de disponibilidade operacional com redução de risco a qualidade e inocuidade do produto por meio da execução de atividades relacionadas à lubrificação industrial. 


\subsection{SUPORTE PARA TOMADA DE DECISÃO}

Analisando os indicadores de desempenho de manutenção, principalmente o indicador referente ao $\operatorname{MTTR}(t)$ exposto na figura 4.8, é possível verificar que os eventos de falhas relacionados ao processo de lubrificação são problemas crônicos e/ou repetitivos, pois os valores do tempo gasto para reparo são, em muitas vezes, maiores que o valor do tempo médio para reparo - $\operatorname{MTBF}(t)$ de todas as falhas ocorridas no período analisado (2010 à 2013).

Logo, faz-se necessário analisar o modo de cada falha relacionada ao processo de lubrificação, a fim de identificar sua causa e consequência, com propósito de implantar medidas que eliminam e/ou reduzam as reincidências destes eventos de falhas.Para tanto aplica-se ferramentas de qualidade e manutenção para análise funcional das falhas e assim apontar para as ações necessárias a serem tomadas na estrutura adequada de lubrificação industrial para máquina Cobrideira.

\subsubsection{Análise Funcional dos Modos de Falhas Relacionados à Lubrificação Industrial}

Para tanto se aplicou a Análise de Modo e Efeito de Falha - FMEA ( Failure Mode and Effect Analysis), como ferramenta de análise funcional dessas falhas específicas. Enfatiza-se que para elaboração desta análise (FMEA) houve colaboração dos setores envolvidos diretamente com a máquina cobrideira como: Engenharia e gerência de manutenção industrial, Engenharia de Qualidade e setor de Produção (supervisor e operadores de máquina) conjuntamente com a autora da presente pesquisa.

Com o envolvimento dos colaboradores destas áreas foi possível levantar informações sobre todas as falhas ocorridas e também potencias modos de falhas que possam ocorrer e assim estruturar uma gestão de lubrificação com maior efetividade para contenção da reincidência e/ou ocorrência dos eventos de falhas identificados e analisados. 
A análise FMEA direcionada análise dos modos de falhas relacionados com 0 processo de lubrificação, apresenta-se no APÊNDICE B - Análise FMEA dos Modos de Falhas Relacionados á Lubrificação Industrial - Máquina Cobrideira.

A análise FMEA para os modos de falhas relacionados com o processo de lubrificação industrial, possibilitou identificar as medidas necessárias a serem tomadas para estruturar uma adequada política de lubrificação industrial para a máquina cobrideira, tais medidas contemplam:

I - Melhoria no plano de manutenção preventiva existente: identificação de todos os pontos de lubrificação e análise de sua estrutura para determinação do correto lubrificante e modo de limpeza, levando em consideração as particulatidades da $Z_{C}$ do local de instalação da máquina cobrideira;

II - Implantação do plano de manutenção preditiva: identificação das técnicas preditivas adequadas ao ativo industrial analisado, visando evitar a ocorrência de eventos de falhas, os quais possam gerar riscos que interfiram na qualidade e inocuidade do produto (por meio de contaminação por: vazamento, excesso de lubrifcacante, lubrificante inadequado, contato com lubrificante, contaminação cruzada do produto, etc). Com a redução das falhas também espera-se melhorar os índices de desempenho de produtividade e disponibilidade operacional;

III - Padronização do modo de execução das atividades de lubrificação industrial: elaborar PPT (procedimento padrão de trabalho) adequado a execução das atividades de lubrificação de cada ativo industrial, visando evitar focos de riscos (contaminação do lubrificante e/ou do produto, excesso de lubrificante, aplicação de lubrificante inadequado a $Z_{C}$ do ativo industrial, geração de eventos de falhas, etc.) que interfiram na qualidade do produto durante a execução das atividades de lubrificação;

IV - Organização do local de armazenamento do ferramental e lubrificantes empregados nas atividades de lubrificação, com intuito de evitar o risco de contaminação do lubrificante; 
V - Gestão da eficiência da política de lubrificação estruturada por meio de indicadores de desempenho de manutenção e disponibilidade operacional.

Durante a análise FMEA, foi possível verificar os impactos que os modos de falhas relacionadas ao processo de lubrificação industrial podem gerar sobre de a disponibilidade operacional e na perda de qualidade e inocuidade do produto.

Assim, como medida de contenção das causas e consequências desses eventos de falhas analisados, direciona-se para a estrutura da adequada politica de lubrificação para máquina cobrideira, a qual é fundamentada na implantação de estratégias de manutenção e procedimento padrão para execução das atividades adotadas, conjuntamente com o monitoramento dos resultados dos indicadores de desempenho de dispobilidade e confiabilidade operacional.

A análise FMEA aponta para as deficiências na gestão da lubrificação que ocosionam os eventos de falhas, deficiências estas que corroboram com a análise da faixa de nível do $I_{C R}$ da máquina cobrideira $\left(I_{C R}=0\right)$, ou seja, deficiência tanto nas estratégias de manutenção preventiva e preditiva, deficiência esta intensificada pelo baixo nível de qualificação da mão de obra quanto as normativas e legislações vigentes para área de engenharia de manutenção industrial gerida em indústria de alimentos.

\subsubsection{Estrutura da Política de Lubrificação Centrada em Confiabilidade}

Para implantação destas medidas foram impostas algumas etapas e prazos de estruturação, as quais encontra-se detalhadas na figura 4.9 referente ao cronograma de implantação da política de lubrificação adequada para máquina cobrideira. 
Figura 4.9 - Cronograma da Implantação das Medidas Contempladas na Estrutura da Política Adequada de Lubrificação Industrial da Máquina Cobrideira

\begin{tabular}{|c|c|c|c|c|c|c|c|c|}
\hline \multicolumn{2}{|c|}{$\begin{array}{l}\text { CRONOGRAMA - FMEA MÁQUINA COBRIDEIRA } \\
2014\end{array}$} & \multicolumn{5}{|c|}{ JANEIRO } & \multicolumn{2}{|c|}{ FEVEREIRO } \\
\hline SEQ & ATIVIDADES & $\underset{1}{S e m a n a}$ & $\underset{2}{\text { Semana }}$ & $\underset{3}{\operatorname{Semana}}$ & $\underset{4}{S e m a n a}$ & $\underset{5}{S e m a n a}$ & $\underset{6}{\operatorname{Semana}}$ & $\underset{7}{\text { Semana }}$ \\
\hline 1 & $\begin{array}{l}\text { Estruturar plano de lubrificação conforme } \\
\text { zona de criticidade do local de instalação. }\end{array}$ & & & & & & & \\
\hline 2 & Estruturar plano de manutenção preditiva & & & & & & & \\
\hline 3 & $\begin{array}{l}\text { Elaborar procedimento de execução das } \\
\text { atividade de lubrificação }\end{array}$ & & & & & & & \\
\hline 4 & $\begin{array}{l}\text { Treinamento para qualificação da mão de } \\
\text { obra em lubrificação industrial para } \\
\text { indústria de alimentos }\end{array}$ & & & & & & & \\
\hline 5 & $\begin{array}{l}\text { Obtenção de ferramental adequado à } \\
\text { lubrificação industrial }\end{array}$ & & & & & & & \\
\hline 6 & $\begin{array}{l}\text { Organização de local para armazenamento } \\
\text { de lubrificantes e acondicionamento do }\end{array}$ & & & & & & & \\
\hline & ferramental & & & & & & & \\
\hline 7 & $\begin{array}{l}\text { Implantação de Gestão á Vista : Indicadores } \\
\text { de Desempenho de Manutenção e } \\
\text { Disponibilidade Operacional (Estrutura) }\end{array}$ & & & & & & & \\
\hline
\end{tabular}

Fonte: Autoria própria 
Todas as etapas que compõe o cronograma (figura 4.9) foram cumpridas com êxito dentro dos prazos estabelecidos, e, como resultados construiu-se uma estrutura adequada para implantação da política de lubrificação adotada para máquina cobrideira.

Foram elaborados planos de manutenção preventiva e preditiva conforme o real comportamento da máquina cobrideira durante seu funcionamento e modo de operação, conjuntamente com as características da Zona de Criticidade $\left(\mathrm{Z}_{\mathrm{C}}\right)$ do local de instalação da máquina cobrideira.

A modificação e/ou melhoria nestas estratégias manutenção (contempladas na nova política de lubrificação) é conter a geração de ocorrência dos eventos de falhas e com isto eliminar os riscos associadas a estes eventos, riscos os quais podem gerar perda de qualidade e inocuidade do produto por meio de vazamento, contaminação do alimento por substâncias químicas, alternado suas propriedades organolépticas.

Para reduzir a influência dos erros relacionados a mão de obra durante a execução das atividades de lubrificação industrial, elaborou-se um procedimento padrão de trabalho, descrevendo os modos apropriados de execução da lubrificação, limpeza e organização do local de execução das atividades e conservação de materiais e insumos aplicados nas atividades de lubrificação, com intuito de evitar contaminação e ao mesmo tempo evitar acidentes de trabalho e ambientais (vazamento e descarte de material de limpeza).

Também disponibilizou-se, em quadro de gestão à vista, os indicadores de desempenho de manutenção e disponibilidade da máquina cobrideira (ativo industrial piloto) para acompanhamento de todos os funcionários envolvidos nas áreas de manutenção, produção e qualidade a fim de gerar motivação e assim dar continuidade da aplicação da política de lubrificação estruturada.

Os quadros 4.3 e 4.4 apresentam os planos de manutenção preventiva e preditiva respectivamente, detalhando cada tarefa a ser executada e suas particularidades. 
Quadro 4.3 - Plano de Manutenção Preventiva: Rota de Lubrificação da Máquina Cobrideira

\begin{tabular}{|c|c|c|c|c|c|c|c|c|c|c|c|}
\hline \multirow{2}{*}{\multicolumn{2}{|c|}{ LOGO DA EMPRESA }} & \multirow{2}{*}{\multicolumn{3}{|c|}{ 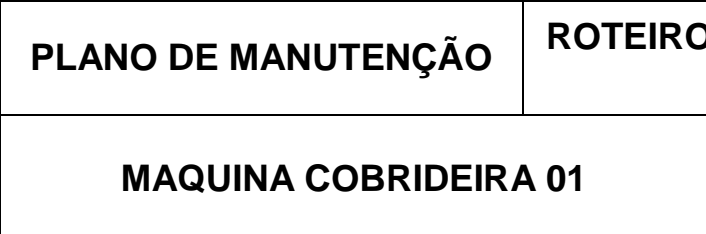 }} & \multirow{2}{*}{\multicolumn{3}{|c|}{$\begin{array}{r}\text { DE LUBRIFICAÇÃO DA MÁQUIN } \\
\text { PRODUTIVA } 01 \\
\text { LINHA PRODUTIVA } 01 \\
\text { TABLETES } 01\end{array}$}} & BRID & IRA & - LINHA & \multirow{2}{*}{$\begin{array}{l}\text { DATA } \\
-1+1\end{array}$} \\
\hline & & & & & & & & & PLAN & no. & \\
\hline \multirow[b]{2}{*}{ Seq. } & Tarefa & \multicolumn{2}{|c|}{ Ponto de Lubrificação } & \multirow{2}{*}{$\begin{array}{l}\text { Dispositivo } \\
\text { de } \\
\text { Lubrificação }\end{array}$} & \multirow[b]{2}{*}{$\begin{array}{c}\text { Método de } \\
\text { Aplicação }\end{array}$} & \multicolumn{4}{|c|}{ Lubrificante } & \multirow{2}{*}{$\begin{array}{l}\text { Tempo } \\
\text { Previsto } \\
\text { (h) }\end{array}$} & \multirow[b]{2}{*}{ Período } \\
\hline & (Ação) & Local & Quant. & & & \multicolumn{2}{|l|}{ Descrição } & \multicolumn{2}{|c|}{$\begin{array}{l}\text { Quant. } \\
\text { Prevista }\end{array}$} & & \\
\hline 01 & $\begin{array}{l}\text { Verificar nível } \\
\text { de óleo e } \\
\text { completar se } \\
\text { necessário }\end{array}$ & $\begin{array}{l}\text { Motorredutor da } \\
\text { Unidade de } \\
\text { Bombeamento de } \\
\text { Retorno de Massa }\end{array}$ & $\begin{array}{c}1 \\
\text { Ponto }\end{array}$ & $\begin{array}{c}\text { Reservatório } \\
\text { de óleo }\end{array}$ & $\begin{array}{c}\text { Manual/ } \\
\text { Funil }\end{array}$ & $\begin{array}{l}\text { Óleo Lubrificante } \\
\text { DIN 51517- Parte } 3 \\
\text { (CLP) VG - 150- } \\
220\end{array}$ & $\mathrm{H} 1$ & 4 & $\mathrm{LT}$ & 0,10 & Semanal \\
\hline 02 & Lubrificar & $\begin{array}{l}\text { Rolamento LOA } \\
\text { do Motor de } \\
\text { Acionamento da } \\
\text { Unidade de } \\
\text { Bombeamento de } \\
\text { Retorno de Massa }\end{array}$ & $\begin{array}{c}1 \\
\text { Ponto }\end{array}$ & $\begin{array}{c}\text { Bico } \\
\text { Graxeiro }\end{array}$ & $\begin{array}{c}\text { Bomba } \\
\text { Automática }\end{array}$ & $\begin{array}{l}\text { Graxa Atóxica } \\
\text { complexo de } \\
\text { Aluminio, com VG } \\
100, \text { NLGI 0.DIN } \\
51825\end{array}$ & $\mathrm{H} 1$ & $\begin{array}{c}0,02 \\
5\end{array}$ & $\mathrm{Kg}$ & 0,15 & Bimestral \\
\hline 03 & Lubrificar & $\begin{array}{l}\text { Rolamento LA do } \\
\text { Motor de } \\
\text { Acionamento da } \\
\text { Unidade de } \\
\text { Bombeamento de } \\
\text { Retorno de Massa }\end{array}$ & $\begin{array}{c}1 \\
\text { Ponto }\end{array}$ & $\begin{array}{c}\text { Bico } \\
\text { Graxeiro }\end{array}$ & $\begin{array}{c}\text { Bomba } \\
\text { Automática }\end{array}$ & $\begin{array}{l}\text { Graxa Atóxica } \\
\text { complexo de } \\
\text { Alumínio, com VG } \\
\text { 100, NLGI } 0 . \\
\text { DIN } 51825\end{array}$ & $\mathrm{H} 1$ & $\begin{array}{c}0,02 \\
5\end{array}$ & $\mathrm{Kg}$ & 0,15 & Bimestral \\
\hline
\end{tabular}

(Continua) 
(Continuação)

\begin{tabular}{|c|c|c|c|c|c|c|c|c|c|c|c|}
\hline \multirow{2}{*}{ Seq. } & \multirow{2}{*}{$\begin{array}{l}\text { Tarefa } \\
\text { (Ação) }\end{array}$} & \multicolumn{2}{|c|}{ Ponto de Lubrificação } & \multirow{2}{*}{$\begin{array}{c}\text { Dispositivo } \\
\text { de } \\
\text { Lubrificação }\end{array}$} & \multirow{2}{*}{$\begin{array}{l}\text { Método de } \\
\text { Aplicação }\end{array}$} & \multicolumn{4}{|c|}{ Lubrificante } & \multirow{2}{*}{$\begin{array}{l}\text { Tempo } \\
\text { Previsto } \\
\text { (h) }\end{array}$} & \multirow{2}{*}{ Período } \\
\hline & & Local & Quant. & & & Descrição & & dant. Pr & vista & & \\
\hline 03 & Lubrificar & $\begin{array}{l}\text { Rolamento LA do } \\
\text { Motor de } \\
\text { Acionamento da } \\
\text { Unidade de } \\
\text { Bombeamento de } \\
\text { Retorno de Massa }\end{array}$ & $\begin{array}{c}1 \\
\text { Ponto }\end{array}$ & $\begin{array}{c}\text { Bico } \\
\text { Graxeiro }\end{array}$ & $\begin{array}{c}\text { Bomba } \\
\text { Automática }\end{array}$ & $\begin{array}{c}\text { Graxa Atóxica } \\
\text { complexo de } \\
\text { Alumínio, com VG } \\
100, \text { NLGI } 0 . \\
\text { DIN } 51825\end{array}$ & $\mathrm{H} 1$ & 0,020 & $\mathrm{Kg}$ & 0,15 & Bimestral \\
\hline 04 & $\begin{array}{l}\text { Verificar nível } \\
\text { de óleo e } \\
\text { completar se } \\
\text { necessário }\end{array}$ & $\begin{array}{l}\text { Motorredutor da } \\
\text { Unidade de } \\
\text { Bombeamento } \\
\text { Inferior de Massa }\end{array}$ & $\begin{array}{c}1 \\
\text { Ponto }\end{array}$ & $\begin{array}{c}\text { Reservatório } \\
\text { de óleo }\end{array}$ & $\begin{array}{c}\text { Manual/Fun } \\
\text { il }\end{array}$ & $\begin{array}{c}\text { Óleo Lubrificante } \\
\text { DIN 51517- Parte } 3 \\
\text { (CLP) VG - 150- } \\
220\end{array}$ & $\mathrm{H} 1$ & 4 & $\mathrm{~L}$ & 0,10 & Semanal \\
\hline 05 & Lubrificar & $\begin{array}{c}\text { Rolamento LOA do } \\
\text { Motor de } \\
\text { Acionamento da } \\
\text { Unidade de } \\
\text { Bombeamento } \\
\text { Inferior de Massa }\end{array}$ & $\begin{array}{c}1 \\
\text { Ponto }\end{array}$ & $\begin{array}{c}\text { Bico } \\
\text { Graxeiro }\end{array}$ & $\begin{array}{c}\text { Bomba } \\
\text { Automática }\end{array}$ & $\begin{array}{c}\text { Graxa Atóxica } \\
\text { complexo de } \\
\text { Aluminio, com VG } \\
100, \text { NLGI 0.DIN } \\
51825\end{array}$ & $\mathrm{H} 1$ & 0,020 & $\mathrm{Kg}$ & 0,15 & Bimestral \\
\hline 06 & Lubrificar & $\begin{array}{l}\text { Rolamento LA do } \\
\text { Motor de } \\
\text { Acionamento da } \\
\text { Unidade de } \\
\text { Bombeamento } \\
\text { Inferior de Massa }\end{array}$ & $\begin{array}{c}1 \\
\text { Ponto }\end{array}$ & $\begin{array}{l}\text { Bico } \\
\text { Graxeiro }\end{array}$ & $\begin{array}{c}\text { Bomba } \\
\text { Automática }\end{array}$ & $\begin{array}{c}\text { Graxa Atóxica } \\
\text { complexo de } \\
\text { Aluminio, com VG } \\
100, \text { NLGI 0.DIN } \\
51825\end{array}$ & $\mathrm{H} 1$ & 0,020 & $\mathrm{Kg}$ & 0,15 & Bimestral \\
\hline
\end{tabular}

(Continua) 
(Continuação)

\begin{tabular}{|c|c|c|c|c|c|c|c|c|c|c|c|}
\hline \multirow{2}{*}{ Seq. } & \multirow{2}{*}{$\begin{array}{l}\text { Tarefa } \\
\text { (Ação) }\end{array}$} & \multicolumn{2}{|c|}{ Ponto de Lubrificação } & \multirow{2}{*}{$\begin{array}{c}\text { Dispositivo } \\
\text { de } \\
\text { Lubrificação }\end{array}$} & \multirow{2}{*}{$\begin{array}{l}\text { Método de } \\
\text { Aplicação }\end{array}$} & \multicolumn{4}{|c|}{ Lubrificante } & \multirow{2}{*}{$\begin{array}{l}\text { Tempo } \\
\text { Previsto } \\
\text { (h) }\end{array}$} & \multirow{2}{*}{ Período } \\
\hline & & Local & Quant. & & & Descriccão & & iant. $\operatorname{Pr}$ & vista & & \\
\hline 07 & Lubrificar & $\begin{array}{l}\text { Mancal LA do Eixo de } \\
\text { Entrada da Esteira } \\
\text { Transportadora }\end{array}$ & $\begin{array}{c}1 \\
\text { Ponto }\end{array}$ & $\begin{array}{c}\text { Bico } \\
\text { Graxeiro }\end{array}$ & $\begin{array}{c}\text { Bomba } \\
\text { Automática }\end{array}$ & $\begin{array}{c}\text { Graxa Atóxica } \\
\text { complexo de } \\
\text { aluminio, com VG } \\
\text { 100, NLGI 0.DIN } \\
51825\end{array}$ & $\mathrm{H} 1$ & 0,015 & $\mathrm{Kg}$ & 0,15 & Bimestral \\
\hline 08 & Lubrificar & $\begin{array}{l}\text { Mancal LOA do Eixo } \\
\text { de Entrada da Esteira } \\
\text { Transportadora }\end{array}$ & $\begin{array}{c}1 \\
\text { Ponto }\end{array}$ & $\begin{array}{c}\text { Bico } \\
\text { Graxeiro }\end{array}$ & $\begin{array}{c}\text { Bomba } \\
\text { Automática }\end{array}$ & $\begin{array}{l}\text { Graxa Atóxica } \\
\text { complexo de } \\
\text { alumínio, com VG } \\
\text { 150-220, NLGI } \\
\text { 0.DIN 51825 }\end{array}$ & $\mathrm{H} 1$ & 0,015 & $\mathrm{Kg}$ & 0,15 & Bimestral \\
\hline 09 & Lubrificar & $\begin{array}{l}\text { Mancal LA do Eixo de } \\
\text { Saída da Esteira } \\
\text { Transportadora }\end{array}$ & $\begin{array}{c}1 \\
\text { Ponto }\end{array}$ & $\begin{array}{c}\text { Bico } \\
\text { Graxeiro }\end{array}$ & $\begin{array}{c}\text { Bomba } \\
\text { Automática }\end{array}$ & $\begin{array}{c}\text { Graxa Atóxica } \\
\text { complexo de } \\
\text { alumínio, com VG } \\
\text { 150-220, NLGI } \\
\text { 0.DIN 51825 }\end{array}$ & $\mathrm{H} 1$ & 0,015 & $\mathrm{Kg}$ & 0,15 & Bimestral \\
\hline 10 & Lubrificar & $\begin{array}{l}\text { Mancal LOA do Eixo } \\
\text { de Saída da Esteira } \\
\text { Transportadora }\end{array}$ & $\begin{array}{c}1 \\
\text { Ponto }\end{array}$ & $\begin{array}{c}\text { Bico } \\
\text { Graxeiro }\end{array}$ & $\begin{array}{c}\text { Bomba } \\
\text { Automática }\end{array}$ & $\begin{array}{l}\text { Graxa Atóxica } \\
\text { complexo de } \\
\text { alumínio, com VG } \\
\text { 150-220, NLGI } \\
\text { 0.DIN 51825 }\end{array}$ & $\mathrm{H} 1$ & 0,015 & $\mathrm{Kg}$ & 0,15 & Bimestral \\
\hline
\end{tabular}

(Continua) 
(Continuação)

\begin{tabular}{|c|c|c|c|c|c|c|c|c|c|c|c|}
\hline \multirow{3}{*}{$\begin{array}{c}\text { Seq. } \\
\\
\\
11\end{array}$} & \multirow{3}{*}{$\begin{array}{l}\text { Tarefa } \\
\text { (Ação) } \\
\text { Lubrificar }\end{array}$} & \multicolumn{2}{|c|}{ Ponto de Lubrificação } & \multirow{3}{*}{$\begin{array}{l}\begin{array}{c}\text { Dispositivo } \\
\text { de } \\
\text { Lubrificação }\end{array} \\
\text { Superfície }\end{array}$} & \multirow{3}{*}{$\begin{array}{c}\text { Método de } \\
\text { Aplicação } \\
\\
\text { Spray }\end{array}$} & \multicolumn{4}{|c|}{ Lubrificante } & \multirow{2}{*}{$\begin{array}{c}\text { Tempo } \\
\text { Previsto } \\
\text { (h) }\end{array}$} & \multirow{2}{*}{ Período } \\
\hline & & Local & Quant. & & & \multicolumn{2}{|l|}{ Descrição } & \multicolumn{2}{|c|}{$\begin{array}{l}\text { Quant. } \\
\text { Prevista }\end{array}$} & & \\
\hline & & $\begin{array}{l}\text { Conjunto 01-Corrente e } \\
\text { Roda Dentada do } \\
\text { Sistemade Transmissão } \\
\text { de Movimento e Força }\end{array}$ & $\begin{array}{c}2 \\
\text { Pontos }\end{array}$ & & & $\begin{array}{c}\text { Spray Lubrificante } \\
\text { Boa adesividade, } \\
\text { aditivo EP, } \\
\text { anticorrosivo - ISO } \\
\text { VG } 15 \text { - Fin Food } \\
\text { Lube }\end{array}$ & $\mathrm{H} 1$ & 15 & $\mathrm{ml}$ & 0,15 & Semanal \\
\hline 12 & Lubrificar & $\begin{array}{l}\text { Conjunto 02-Corrente e } \\
\text { Roda Dentada do } \\
\text { Sistemade Transmissão } \\
\text { de Movimento e Força }\end{array}$ & $\begin{array}{c}2 \\
\text { Pontos }\end{array}$ & Superfície & Spray & $\begin{array}{c}\text { Spray Lubrificante } \\
\text { Boa adesividade, } \\
\text { aditivo EP, } \\
\text { anticorrosivo - ISO } \\
\text { VG } 15 \text { - Fin Food } \\
\text { Lube }\end{array}$ & $\mathrm{H} 1$ & 15 & $\mathrm{ml}$ & 0,15 & Semanal \\
\hline 13 & Lubrificar & $\begin{array}{l}\text { Conjunto 03-Corrente e } \\
\text { Roda Dentada do } \\
\text { Sistemade Transmissão } \\
\text { de Movimento e Força }\end{array}$ & $\begin{array}{c}2 \\
\text { Pontos }\end{array}$ & Superfície & Spray & $\begin{array}{c}\text { Spray Lubrificante } \\
\text { Boa adesividade, } \\
\text { aditivo EP, } \\
\text { anticorrosivo - ISO } \\
\text { VG } 15 \text { - Fin Food } \\
\text { Lube }\end{array}$ & $\mathrm{H} 1$ & 15 & $\mathrm{ml}$ & 0,15 & Semanal \\
\hline
\end{tabular}

(Continua) 
(Conclusão)

\begin{tabular}{|c|c|c|c|c|c|c|c|c|c|c|c|}
\hline \multirow{2}{*}{ Seq. } & Tarefa & Ponto de Lubrificação & & & & \multicolumn{4}{|c|}{ Lubrificante } & \multirow{2}{*}{$\begin{array}{l}\text { Tempo } \\
\text { Previsto } \\
\text { (h) }\end{array}$} & \multirow{2}{*}{ Período } \\
\hline & (Ação) & Local & Quant. & Lubrificação & & \multicolumn{2}{|l|}{ Descrição } & \multicolumn{2}{|c|}{$\begin{array}{l}\text { Quant. } \\
\text { Prevista }\end{array}$} & & \\
\hline 14 & Lubrificar & $\begin{array}{c}\text { Mancal do Eixo de } \\
\text { Acionamento Principal }\end{array}$ & $\begin{array}{c}1 \\
\text { Ponto }\end{array}$ & Bico Graxeiro & $\begin{array}{c}\text { Bomba } \\
\text { Automática }\end{array}$ & $\begin{array}{l}\text { Graxa Atóxica } \\
\text { complexo de } \\
\text { alumínio, com VG } \\
\text { 150-220, NLGI } \\
\text { 0.DIN 51825 }\end{array}$ & $\mathrm{H} 1$ & 0,025 & $\mathrm{Kg}$ & 0,15 & Bimestral \\
\hline 15 & $\begin{array}{l}\text { Verificar } \\
\text { nível de } \\
\text { óleo e } \\
\text { completar } \\
\text { se } \\
\text { necessário }\end{array}$ & $\begin{array}{c}\text { Motorredutor do } \\
\text { Sistema de } \\
\text { Acionamento Principal }\end{array}$ & $\begin{array}{c}1 \\
\text { Ponto }\end{array}$ & Bico Graxeiro & $\begin{array}{l}\text { Bomba } \\
\text { Automáti- } \\
\text { ca }\end{array}$ & $\begin{array}{l}\text { Graxa Atóxica } \\
\text { complexo de } \\
\text { alumínio, com VG } \\
\text { 150-220, NLGI } \\
\text { 00.DIN 51825 }\end{array}$ & $\mathrm{H} 1$ & 4 & $\mathrm{~L}$ & 0,10 & Semanal \\
\hline
\end{tabular}

Fonte: Autoria própria 
Quadro 4.4 - Plano de Manutenção Preditiva: Rota de Lubrificação da Máquina Cobrideira

\begin{tabular}{|c|c|c|c|c|c|c|c|}
\hline \multicolumn{2}{|c|}{ LOGO DA EMPRESA } & \multicolumn{2}{|c|}{ PLANO DE MANUTENÇÃO PREDITIVA } & \multicolumn{4}{|c|}{ MÁQUINA COBRIDEIRA - LINHA DE PRODUÇÃO 01} \\
\hline \multirow{2}{*}{ Sequência } & Tarefa & \multicolumn{2}{|l|}{ Ponto de Lubrificação } & \multirow{2}{*}{ Método } & \multicolumn{2}{|c|}{ Tempo de Execução } & \multirow{2}{*}{ Periodicidade } \\
\hline & (Ação) & Local de Instalação & Quantidade & & Previsto & Unidade & \\
\hline 01 & $\begin{array}{l}\text { Análise de } \\
\text { Vibração }\end{array}$ & $\begin{array}{l}\text { Motorredutor da Unidade de } \\
\text { Bombeamento de Retorno de Massa }\end{array}$ & 3 Pontos & $\begin{array}{l}\text { Coletor de Análise } \\
\text { de Vibração }\end{array}$ & 0,25 & $\mathrm{~h}$ & Quinzenal \\
\hline 02 & $\begin{array}{l}\text { Análise de } \\
\text { Vibração }\end{array}$ & $\begin{array}{l}\text { Motorredutor da Unidade de } \\
\text { Bombeamento Inferior de Massa }\end{array}$ & 3 Pontos & $\begin{array}{l}\text { Coletor de Análise } \\
\text { de Vibração }\end{array}$ & 0,25 & $\mathrm{~h}$ & Quinzenal \\
\hline 03 & $\begin{array}{l}\text { Análise de } \\
\text { Vibração }\end{array}$ & $\begin{array}{l}\text { Motorredutor do Sistema de } \\
\text { Acionamento Principal }\end{array}$ & 3 Pontos & $\begin{array}{l}\text { Coletor de Análise } \\
\text { de Vibração }\end{array}$ & 0,25 & $\mathrm{~h}$ & Quinzenal \\
\hline 04 & $\begin{array}{l}\text { Coletar } \\
\text { amostra }\end{array}$ & $\begin{array}{l}\text { Motorredutor da Unidade de } \\
\text { Bombeamento de Retorno de Massa }\end{array}$ & 1 Ponto & Análise de óleo & 0,17 & $\mathrm{~h}$ & Mensal \\
\hline 05 & $\begin{array}{l}\text { Coletar } \\
\text { amostra }\end{array}$ & $\begin{array}{l}\text { Motorredutor da Unidade de } \\
\text { Bombeamento Inferior de Massa }\end{array}$ & 1 Ponto & Análise de óleo & 0,17 & $\mathrm{~h}$ & Mensal \\
\hline 06 & $\begin{array}{l}\text { Coletar } \\
\text { amostra }\end{array}$ & $\begin{array}{l}\text { Motorredutor do Sistema de } \\
\text { Acionamento Principal }\end{array}$ & 1 Ponto & Análise de óleo & 0,17 & $\mathrm{~h}$ & Mensal \\
\hline
\end{tabular}

(Continua) 
(Conclusão)

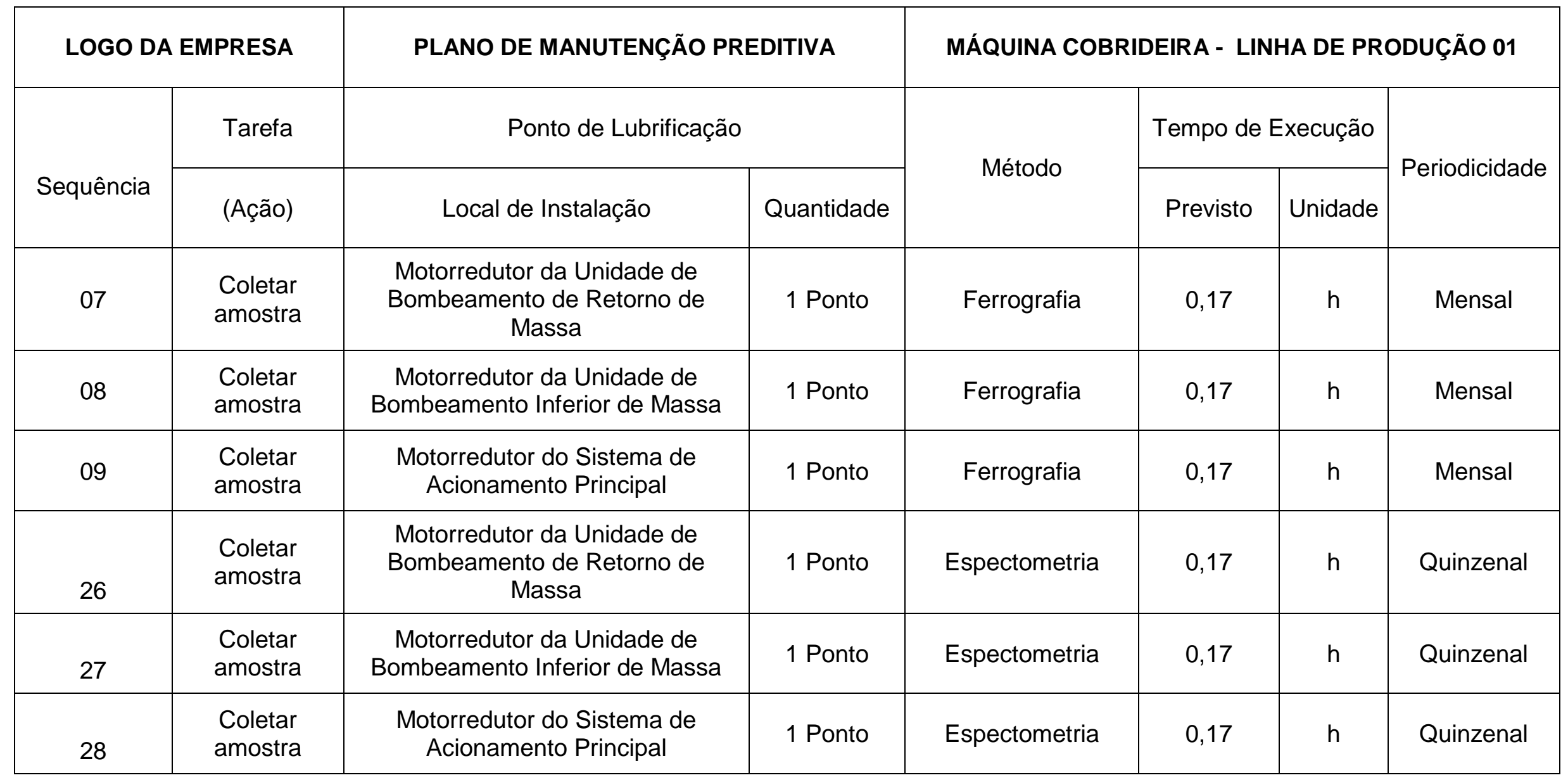

Fonte: Autoria própria 
Os processos de fabricação de produtos alimentícios empregam em suas instalações industriais máquinas e equipamentos que requerem lubrificação adequada para operar com desempenho e confiabilidade ideal.

Porém, o próprio processo de lubrificação industrial apresenta probabilidade de contaminação cruzada dos alimentos, a qual pode ocorrer devido a vazamento de lubrificante ou contato com mesmos.

Para ajudar a combater esse potencial risco de contaminação, o qual pode gerar perda de qualidade e inocuidade do produto, deve-se empregar regimes de lubrificação adequados, visando manter disponibilidade operacional e garantia de qualidade do produto em processamento.

Logo, para que o processo de lubrifcação industrial seja adequado, este deve manter roteiros de lubrificação com a identificação correta do lubrficante e insumos corretos a serem utilizados na realização das tarefas contempladas no plano de mantenção.

A aplicacão de técnicas de manutenção preditiva auxilia na previsão de ocorrência de falhas, possibilitando que elas sejam sanadas em momento oportuno que não interfira na produtividade do ativo industrial em análise.

A manutenção preditiva também possibilitar verificar o estado do lubrificante físico-químico do lubrificante e assim garantir que esses seja adequado Zona de Criticidade $\left(\mathrm{Z}_{\mathrm{C}}\right)$ a qual máquina cobrideira esta instalada.

Ainda, a realização das tarefas de lubrificação industrial, é influenciada por fatores de criticidade como segurança operacional, ciclo de funcionamento, estrutura de ligação (série e/ou paralelo) que o máquinário mantém com o sistema produtivo e da praticabilidade da aplicação do lubrificante, esta última é dependente diretamente da utilização do adequado ferramental e da estrutura do dispositivo de lubrificação da máquina.

Logo, para garantir que as tarefas de manutenção preventiva sejam executadas com segurança dos funcionários e de forma adequada que não permita contaminação do lubrificante e/ou do produto, estrutura-se um procedimento Padrão de Trabalho (PPT) para execução dessas tarefas. O quadro 4.5 mostra O PPT para atividades contidas no roteiro de lubrificação da máquina cobrideira. 
Quadro 4.5 - Procedimento Padrão de Trabalho para as Atividades de Lubrificação da Máquina Cobrideira

\begin{tabular}{|c|c|c|c|c|}
\hline \multicolumn{5}{|c|}{ IT - INSTRUÇÃO DE TRABALHO } \\
\hline \multirow{3}{*}{ LOGO DA EMPRESA } & TITULO: & $\begin{array}{c}\text { Execução do Plano de Lubrificação da } \\
\text { Maquina Cobrideira }\end{array}$ & Data & $08 / 01 / 2014$ \\
\hline & & & Número & CTBA 009-2014 \\
\hline & SETOR: & Manutenção Industrial & Revisão & A \\
\hline
\end{tabular}

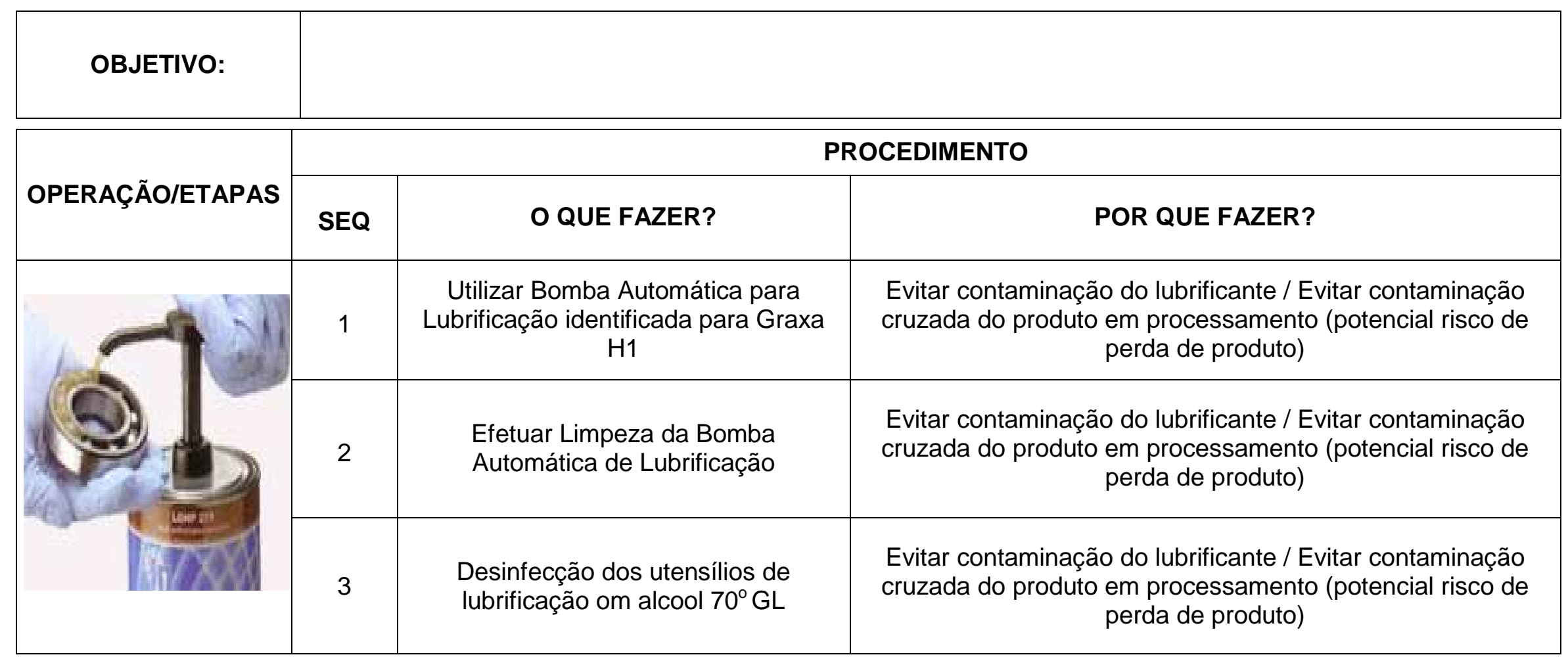

(Continua) 


\begin{tabular}{|c|c|c|c|}
\hline \multirow{2}{*}{ OPERAÇÃO/ETAPAS } & \multicolumn{3}{|c|}{ PROCEDIMENTO } \\
\hline & SEQ & O QUE FAZER? & POR QUE FAZER? \\
\hline & 4 & $\begin{array}{l}\text { Utilizar EPI / EPC adequados para realização } \\
\text { das atividades de lubrificação industrial, os quais } \\
\text { identificados no procedimento }\end{array}$ & Evitar acidente de trabalho \\
\hline & 5 & Utilizar roupas limpas & $\begin{array}{l}\text { Evitar contaminação biológica e/ou física do } \\
\text { produto em processamento }\end{array}$ \\
\hline & 6 & Utilizar luvas limpas & $\begin{array}{l}\text { Evitar contaminação biológica e/ou física do } \\
\text { produto em processamento }\end{array}$ \\
\hline & 7 & $\begin{array}{l}\text { Utilizar touca acondicionando toda área do } \\
\text { cabelo e mangotes limpos encobrindo toda área } \\
\text { do braço (pêlos) }\end{array}$ & $\begin{array}{l}\text { Evitar contaminação biológica e/ou física do } \\
\text { produto em processamento }\end{array}$ \\
\hline & 8 & Utilizar máscara descartável (fluídos) & $\begin{array}{l}\text { Evitar contaminação biológica e/ou física do } \\
\text { produto em processamento }\end{array}$ \\
\hline & 9 & Lavar e higienizar as mãos & $\begin{array}{l}\text { Evitar contaminação biológica e/ou física do } \\
\text { produto em processamento }\end{array}$ \\
\hline & 10 & $\begin{array}{c}\text { Desligar a máquina e colocar cadeado trava no } \\
\text { painel de acionamento/comando da maquina } \\
\text { durante as atividades de lubrifcacao }\end{array}$ & Evitar acidente de trabalho \\
\hline
\end{tabular}




\begin{tabular}{|c|c|c|c|}
\hline \multirow{2}{*}{ OPERAÇÃO/ETAPAS } & \multicolumn{3}{|c|}{ PROCEDIMENTO } \\
\hline & SEQ & O QUE FAZER? & POR QUE FAZER? \\
\hline & 12 & $\begin{array}{l}\text { Utilizar ferramental, materiais e } \\
\text { lubrificante identificados na rota de } \\
\text { lubrificação }\end{array}$ & $\begin{array}{l}\text { Evitar contaminação do lubrificante / Evitar contaminação } \\
\text { cruzada do produto em processamento (potencial risco de } \\
\text { perda de produto) }\end{array}$ \\
\hline & 13 & $\begin{array}{l}\text { Aplicar quantidade correta do } \\
\text { lubrificante, a qual indicada na rota de } \\
\text { lubrificação }\end{array}$ & $\begin{array}{c}\text { Evitar falta ou excesso de lubrificante / Evitar ocorrência de } \\
\text { eventos de falhas }\end{array}$ \\
\hline & 14 & $\begin{array}{c}\text { Efetuar limpeza da área da máquina } \\
\text { após término da atividade de lubrificação } \\
\text { (Efetuar limpeza e desinfecção com } \\
\text { panos "tipo perfex" e álcool) }\end{array}$ & $\begin{array}{c}\text { Evitar contaminação do lubrificante / Evitar contaminação } \\
\text { cruzada do produto em processamento (potencial risco de } \\
\text { perda de produto) / Evitar proliferação de fungos e leveduras } \\
\text { por restos de lubrificantes (potencial risco de perda de } \\
\text { qualidade e inocuidade do produto) / Evitar acidentes de } \\
\text { trabalho }\end{array}$ \\
\hline 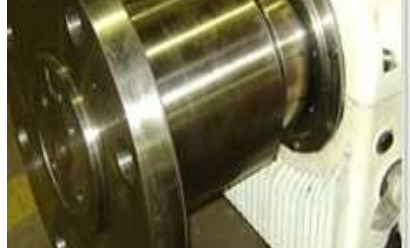 & 15 & $\begin{array}{c}\text { Atentar para resíduos de lubrificantes na } \\
\text { superficie da máquina }\end{array}$ & $\begin{array}{l}\text { Evitar contaminação do lubrificante / Evitar contaminação } \\
\text { cruzada do produto em processamento (potencial risco de } \\
\text { perda de produto)/ Evitar proliferação de fungos e leveduras } \\
\text { por restos de lubrificantes (potencial risco de perda de } \\
\text { qualidade e inocuidade do produto) }\end{array}$ \\
\hline & 16 & $\begin{array}{l}\text { Efetuar limpeza da superficie do ponto } \\
\text { de lubrificação, retirando resíduos. }\end{array}$ & $\begin{array}{c}\text { Evitar contaminação do lubrificante / Evitar contaminação } \\
\text { cruzada do produto em processamento (potencial risco de } \\
\text { perda de qualidade e inocuidade do produto)/ Evitar } \\
\text { proliferação de fungos e leveduras por restos de } \\
\text { lubrificantes (potencial risco de perda de qualidade e } \\
\text { inocuidade do produto) }\end{array}$ \\
\hline
\end{tabular}


(Continuação)

\begin{tabular}{|c|c|c|c|}
\hline \multirow{2}{*}{ OPERAÇÃO/ETAPAS } & \multicolumn{3}{|c|}{ PROCEDIMENTO } \\
\hline & SEQ & O QUE FAZER? & POR QUE FAZER? \\
\hline & 17 & $\begin{array}{l}\text { Liberar máquina/equipamento para operação, } \\
\text { efetuando teste de funcionamento. }\end{array}$ & $\begin{array}{c}\text { Ajustar parâmetros da máquina/ equipamento evitando } \\
\text { perda de produtividade e proporcionando aumento de } \\
\text { disponibilidade operacional }\end{array}$ \\
\hline & 18 & $\begin{array}{l}\text { Anotar corretamente no plano de manutenção } \\
\text { os dados referentes a execução das atividades } \\
\text { de lubrificação industrial (quantidade real de } \\
\text { lubrificante, tempo real de duração da } \\
\text { atividade, insumos aplicados, centro de } \\
\text { serviço alocado nas atividades, entre outras } \\
\text { informações contidas no plano de } \\
\text { manutenção). }\end{array}$ & $\begin{array}{c}\text { Dados para composição dos indicadores de } \\
\text { desempenho das atividades de lubrificação e } \\
\text { acompanhamento da evolução da produtividade da } \\
\text { máquina/equipamento }\end{array}$ \\
\hline & 19 & $\begin{array}{c}\text { Limpar e desinfectar o ferramental/utensílios } \\
\text { utilizados na execução das tarefas de } \\
\text { lubrificação industrial }\end{array}$ & $\begin{array}{c}\text { Evitar contaminação do lubrificante / Evitar } \\
\text { contaminação cruzada do produto em processamento } \\
\text { (potencial risco de perda de produto) / Evitar } \\
\text { proliferação de fungos e leveduras por restos de } \\
\text { lubrificantes (potencial risco de perda de qualidade e } \\
\text { inocuidade do produto) }\end{array}$ \\
\hline & 20 & $\begin{array}{l}\text { Acondicionar ferramental e utensilos utilizados } \\
\text { nas atividades de lubrificação em local } \\
\text { adequado (arejado, limpo e identificado) }\end{array}$ & $\begin{array}{l}\text { Evitar contaminação do lubrificante / Evitar } \\
\text { contaminação cruzada do produto em processamento } \\
\text { (potencial risco de perda de produto) }\end{array}$ \\
\hline
\end{tabular}

(Continua) 
(Conclusão)

\begin{tabular}{|c|c|c|c|}
\hline \multirow{2}{*}{ OPERAÇÃO/ETAPAS } & \multicolumn{3}{|c|}{ PROCEDIMENTO } \\
\cline { 2 - 4 } & SEQ & O QUE FAZER? & POR QUE FAZER? \\
\hline & 21 & $\begin{array}{c}\text { Acondicionar o lubrificante em ambiente } \\
\text { adequado (limpo, arejado e identificado) }\end{array}$ & $\begin{array}{c}\text { Evitar contaminação do lubrificante / Evitar } \\
\text { contaminação cruzada do produto em processamento } \\
\text { (potencial risco de perda de produto) / Evitar risco da } \\
\text { segurança patrimonial e pessoal da empresa }\end{array}$ \\
\hline
\end{tabular}

\begin{tabular}{|l|c|c|c|}
\hline \multicolumn{3}{|c|}{ OBSERVAÇÕES } \\
\hline ELABORADO POR: & MARJORIE BELINELLI / ENGENHARIA DE MANUTENÇÃO/ENGENHARIA DE QUALIDADE \\
\hline
\end{tabular}


Após elaborar planos de manutenção e procedimentos de trabalho, efetuouse treinamento para apresentação da nova estrutura da política de lubrificação a ser adotada para máquina cobrideira, dentro deste treinamento, no qual participaram técnicos de manutenção e supervisores de produção da Linha de Produção 1, foram abordados os seguintes temas:

> Apresentação dos planos de manutenção prevetiva e preditiva;

> Apresentação e treinamento on the job sobre o PPT de execução das tarefas de manutenção;

$>$ Explicações de normas e legislações referentes a gestão da engenharia de manutenção a ser empregada em indústria de alimentos;

Importância dos sistemas HACCP e BPF nas atividades rotineiras de manutenção, principalmente lubrificação;

> Modo de gerenciamento dos resultados por meio da exposição dos indicadores de desempenho da manutenção da máquina cobrideira (Gestão à vista);

O treinamento foi elaborado e aplicado pela engenharia da qualidade, engenharia de manutenção, a pesquisadora da presente pesquisa e a empresa fornecedora de lubrificantes para indústria de alimentos no local de aplicação do método.

Além dos planos e procedimento, foi organizada uma estrutura adequada para acondicionamento de lubrificantes e utensílios utilizados nas atividades de lubrificação, um ambiente limpo, identificado e monitorado acesso para manutenção da organização do local, visando evitar contaminação do lubrificante e ferramental através de substâncias químicas e/ou biológicas.

Como meio de disponibilização dos resultados aos colaboradores, referentes as ações tomadas em função da aplicação de método de seleção de política de lubrificação, implantou-se gestão à vista (quadro com os indicadores de desempenho de manutenção) no setor de manutenção, especificamente na oficina e no setor da Linha de Produção 1. A figura 4.10 a seguir apresenta o modelo do 
quadro de gestão para exposição dos indicadores de desempenho da máquina cobrideira, a qual é o ativo industrial piloto de implantação do método desenvolvido.

Figura 4.10- Foto do Quadro de Gestão para Expor os Indicadores de Desempenho da Máquina Cobrideira

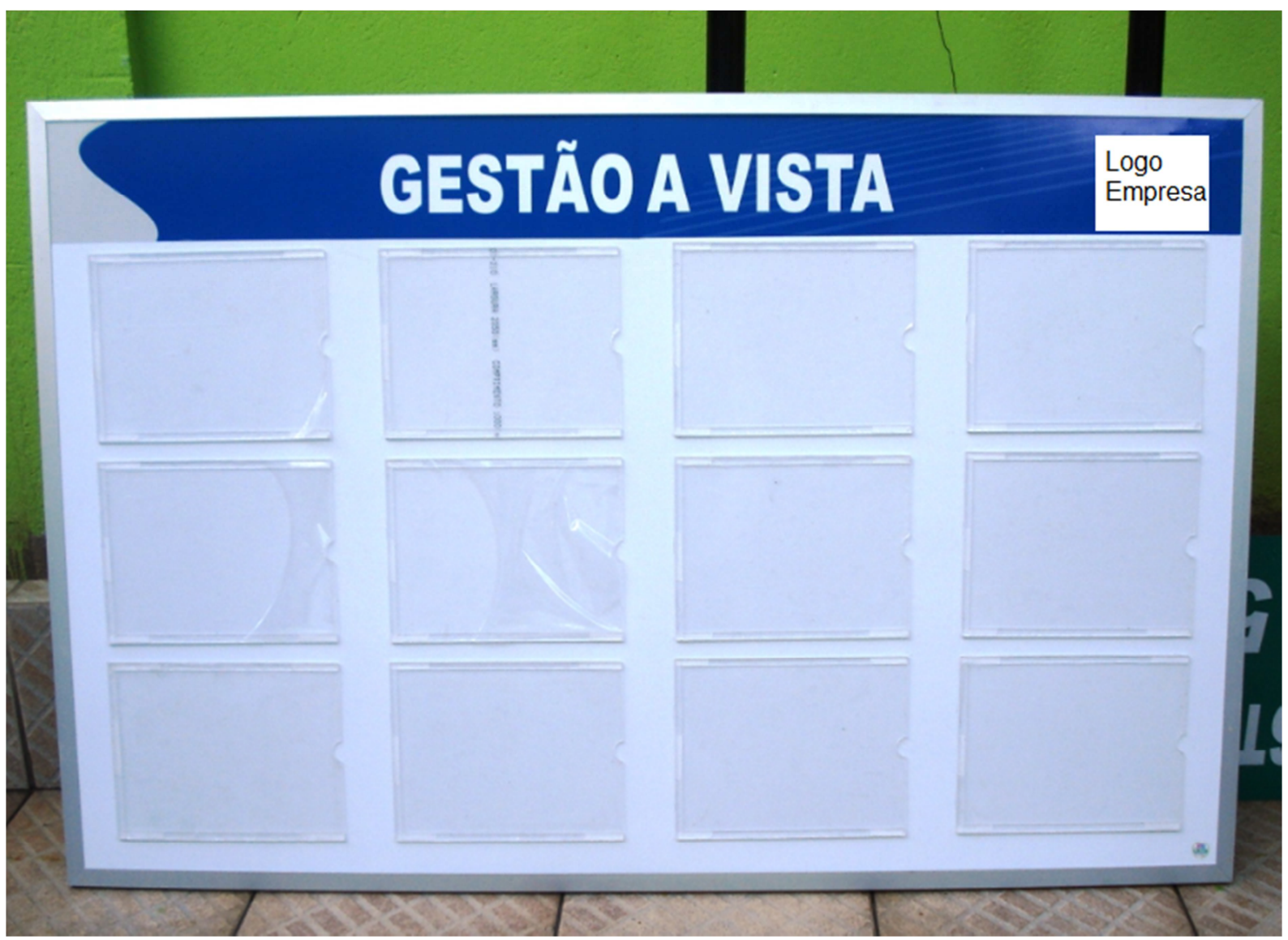

Fonte: Arquivos da empresa de aplicação da pesquisa

A disposição dos resultados da implantação do método tem como foco, além da transparência das informações, obter motivação dos colaboradores. Ao gerar e manter motivação dos técnicos de manutenção e operadores de produção espera-se a continuação da execução das medidas adotadas para a estrutura da política de lubrificação da máquina cobrideira e assim ampliar a aplicação do método de seleção de política de lubrificação centrada em confiabilidade para os demais ativos da Linha de Produção 1, e, dependendo dos resultados, expandir futuramente para todos os ativos industriais da empresa. 


\subsection{CONSIDERAÇÕES FINAIS}

A empresa de aplicação do método de seleção de política de lubrificação centrada em confiabilidade está localizada na região metropolitana de Curitiba. O sistema reparável escolhido foi uma máquina cobrideira, devido esta ser a máquina que apresenta maior número de falhas relacionadas ao processo de lubrificação identificadas no período analisado entre 2010 à 2013.

Esta aplicação visa demonstrar a eficácia da pesquisa desenvolvida, quanto a sua contribuição na confiabilidade e disponibilidade operacional do maquinário, identificação e monitoramento dos riscos a perda de qualidade do produto envolvidos nas atividades de lubrificação industrial em indústria de alimentos.

Para a verificação da funcionalidade do método proposto na presente pesquisa, aplicou-se o método em um sistema reparável dentro de um ambiente real de produção de alimentos. Assim, para realização do teste de avaliação do método de seleção de política de lubrificação desenvolvido foram realizadas seguintes etapas:

I - Apresentação do ambiente real de fabricação de alimentos, o qual contém em sua instalação a máquina cobrideira de produtos (sistema reparável para aplicação do método de seleção de política de lubrificação desenvolvido na pesquisa);

II - Identificação e Caracterização do Sistema Industrial, etapa que compreende:

a) Mapeamento do processo produtivo, o qual compreende a construção do fluxograma e leiaute do processo produtivo onde está instalada a máquina objeto de aplicação do método desenvolvido;

b) Construção da árvore funcional para identificação dos componentes que necessitam de lubrificação (pontos de lubrificação da máquina);

III - Identificação de Eventos de Riscos e Ocorrência de Falhas, etapa composta por:

a) Classificação da Zona de Criticidade- $Z_{C}$ do sistema reparável em estudo; 
b) Atribuição dos valores binários as variáveis envolvidas no processo de lubrificação;

c) Cálculo do $I_{C R}$ da máquina em estudo e análise da faixa de nível do valor deste indicador;

d) Análise estatística dos dados de falhas referentes ao sistema reparável (máquina cobrideira) e obtenção dos indicadores de desempenho de manutenção do estado de operação anterior a aplicação do método;

IV- Suporte para Tomada de Decisão, etapa na qual desenvolve-se a:

a) Aplicação de ferramentas (qualidade e/ou manutenção) para estruturar plano de ação para otimização do processo de lubrificação;

b) Aplicação da nova política de lubrificação industrial estruturada e avaliação da incidência de falhas e riscos associados a atividade de lubrificação da máquina cobrideira por meio dos indicadores de desempenho de manutenção e disponibilidade operacional e $I_{\mathrm{CR}}$.

Para compreensão do funcionamento e comportamento da máquina cobrideira, em relação ao processo de lubrificação, faz-se necessário o mapeamento e identificação das características do processo produtivo a qual esta máquina está instalada, ou seja, o mapeamento e conhecimento da cada etapa da linha de produção onde a máquina cobrideira está lotada.

Este mapeamento tem por finalidade identificar as características e particularidades de cada área de fabricação da linha de produção e analisar o impacto que cada área pode acarretar a outra durante a ocorrência de falhas e/ou execução da lubrificação industrial, uma vez que o maquinário desta linha de produção encontra-se ligado por um sistema em série.

Para identificar as características do processo de lubrificação em relação ao seu funcionamento e operação da máquina cobrideira, estrutura-se o fluxograma e o leiaute do processo produtivo conjuntamente com a árvore funcional da máquina cobrideira, identificando nela os pontos que recebem lubrificante para funcionamento da máquina. 
A árvore funcional, o fluxograma e o leiaute auxiliam na visualização da estrutura da máquina cobrideira com intuito de compreender e analisar seu funcionamento e os impactos que o processo de lubrificação pode oferecer a perda de qualidade do produto e potencial ocorrência de evento de falhas.

Para enquadramento da máquina cobrideira dentro das categorias descritas na zona de criticidade - $Z_{C}$ (quadro 3.3),bem como, atribuir valor binário as demais variáveis envolvidas no processo de lubrificação industrial, faz-se necessário o levantamento de informações qualitativas e quantitativas do sistema produtivo da linha de produção 1 e da máquina cobrideira, informações estas, relacionadas aos impactos que o processo de lubrificação pode ocasionar na geração de eventos de falhas e/ou foco de potencial risco a perda de qualidade e inocuidade do produto em processamento.

A obtenção de dados dá-se por meio de pesquisa documental (histórico da empresa) e entrevista com as pessoas envolvidas na manutenção e operação da Linha de Produção 1. Estes dados e informações foram estruturadas para atribuição dos valores quantitativos e qualitativos para as variáveis envolvidas no processo de lubrificação industrial e das particularidades relacionadas a zona de criticidade do local de instalação da máquina cobrideira.

Estas informações e dados foram estruturados no quadro 4.2(pág. 186) para enquadramento da $Z_{C}$ referente a máquina cobrideira e a definição do valor binário a ser atribuídos as variáveis de manutenção preventiva, manutenção preditiva e nível de qualificação de mão de obra.

Com atribuição destes valores as variáveis binárias e o enquadramento da ZC adequada a máquina cobrideira (quadro 4.2), o $\mathrm{I}_{\mathrm{CR}}$ - indicador de nível de confiabilidade e potencial risco de perda de qualidade e inocuidade do produto (por meio das atividades de lubrificação

Tem-se o valor do $I_{C R}=0 A$ e com avaliação de sua faixa de nível do indicador (conforme quadro 3.2), a máquina cobrideira encontra-se em uma $Z_{C}$ que apresenta deficiência nas estratégias de manutenção tanto preventiva como preditiva, fator esse, que propicia a ocorrência de eventos de falhas.

Mediante o valor do $\mathrm{I}_{\mathrm{CR}}=0 \mathrm{~A}$, a atual condição do modo de operação $\mathrm{e}$ manutenção da máquina cobrideira promove potencial ocorrência de eventos de falhas, estes relacionados ao processo de lubrificação industrial, e este fator aliado à mão de obra com baixa qualificação na execução de atividades de lubrificação 
em indústria de alimentos, intensifica o potencial risco de perda de qualidade e inocuidade do produto em processamento, o qual pode provocar perda total da produtividade.

Posteriormente faz-se a análise estatística de falhas no maquinário para verificar o comportamento da tendência de falhas e analisar o cenário fabril quanto a sua disponibilidade e confiabilidade operacional, revelando os eventos de falhas crônicos e/ou repetitivos, relacionadas ao processo de lubrificação industrial, a fim efetuar analise de modo destes eventos para eliminar causa raíz.

Analisando os gráficos de desempenho de disponibilidade e confiabilidade operacional, verifica-se que, apesar dos dados apresentarem uma taxa de ocorrência de falhas com comportamento decrescente $(\beta 1=0,83467215$ enquadrando um processo Poisson Não Homogêneo), a máquina cobrideira poderia obter uma produtividade maior sem a ocorrência dos eventos de falhas relacionados a lubrificação industrial, pois a $\mathrm{A}_{\mathrm{t}}$ ) entre 2010 à 2013 é de 98,858002\% e sem este eventos de falhas esta seria de 99,390236\%ao final deste período analisado.

Além disto, o gráfico de $\operatorname{MTTR}(\mathrm{t})$, o qual evidencia as falhas relacionadas ao processo de lubrificação, aponta que o TRR destas falhas específicas, na maioria das ocorrências, é maior que o $\operatorname{MTTR}(\mathrm{t})$ geral de todos os eventos de falhas. Além disto, estas falhas (relacionados ao processo de lubrificação) são frequentes pois representam 32 falhas em relação do total de 124 falhas ocorridas entre 2010 à 2013.

Assim os eventos de falhas ligados a lubrificação industrial caracterizando-se como crônicos e repetitivos, eles impactam diretamente no tempo disponível de operação da maquina cobrideira, pois o $\left.\operatorname{MTBF}_{(t}\right)$ ao fim de 2013 é de 262,08h de atividade do ativo industrial a cada falha, sendo que, conforme a simulação sem os eventos de falhas por lubrificação, este indicador poderia ser de $374,38 \mathrm{~h}$ de operação do ativo a cada evento de falha.

Assim, com a identificação as falhas crônicas e repetitivas (relacionadas a lubrificação industrial) e dos impactos que estas podem influenciar na produtividade e na intensificação do potencial risco de perda de qualidade e inocuidade (fatores evidenciados pela análise estatística de falhas e pelo indicador de nível de confiabilidade operacional e potencial risco de perda de qualidade e inocuidade do produto), aplica-se a ferramenta FMEA para análise funcional das falhas e direcionamento do plano de ação para estruturar a adequada politica de lubrificação 
industrial, esta centrada em confiabilidade, para a maquina cobrideira. A análise FMEA realizada, a qual descreve as ações que devem estruturadas na política de lubrificação da máquina cobrideira, apresenta-se no APÊNDICE B.

Esta estrutura da politica de lubrificação para maquina cobrideira foi implantada entre os meses de dezembro de 2013 ao início de fevereiro de 2014, conforme calendário apresentado na figura 4.9 presente na página 208.

Posteriormente, a engenharia de manutenção conjuntamente com os técnicos de manutenção, aplicaram as ações e procedimentos contidos na estrutura da política de lubrificação da maquina cobrideira, bem como, efetuaram monitoramento para avaliação dos resultados, os quais descritos no capítulo a 5 a seguir. 


\section{CAPÍTULO 5 RESULTADOS E DISCUSSÕES}

\subsection{CONSIDERAÇÕES INICIAIS}

A validação do método de seleção de política de lubrificação centrada em confiabilidade, voltada para o maquinário empregado na fabricação de alimentos foi realizado com a sua aplicação em ambiente real de uma indústria de alimentos.

O sistema reparável piloto foi uma máquina cobrideira de produtos instalada na Linha de Produção denominada 1, escolhida devido fabricar o produto de maior demanda de mercado desta empresa, com exigência em disponibilidade e confiabilidade operacional.

Como resultado da aplicação do método desenvolvido, obteve-se resultados nos seguintes âmbitos:

I - Aumento de disponibilidade operacional da máquina cobrideira e redução do potencial risco de perda de qualidade e inocuidade de produto por meio da implantação de estratégias de manutenção eficaz e monitorada;

II - Redução de custo manutenção da máquina cobrideira, fator que deu-se com a redução de ocorrência de falhas e que consequentemente reduziu a substituição de peças e ocupação de mão de obra;

Na sequência do texto, descreve-se detalhadamente os resultados e discussões dos aspectos elencados.

\subsection{RESULTADOS QUANTO AOS INDICADORES DE DESEMPENHO DE MANUTENÇÃO E ICR DA MÁQUINA COBRIDEIRA}

Com análise estatística do comportamento de falhas (destacando os eventos relacionados à lubrificação industrial), conjuntamente com tratamento de suas causas e consequências por meio da ferramenta FMEA, direcionou a tomada de 
decisão quanto a estruturação da adequada política de lubrificação a ser adotada para máquina cobrideira.

Esta politica de lubrificação visa implantar estratégias de manutenção, sendo a execução das tarefas contempladas nas estratégias efetuadas de forma padronizadas por procedimentos de trabalho. Esta padronização tem por objetivo garantir a execução das atividades de lubrificação de forma segura, eliminando os riscos (contaminação do produto em processamento) de perda de qualidade e inocuidade do produto e, ao mesmo tempo, promovendo medidas de contenção das causas que possam gerar eventos de falhas (as quais interferem na disponibilidade operacional da máquina cobrideira).

Para tanto, faz-se uma análise qualitativa das medidas implantadas na política de lubrificação adotada para máquina cobrideira a fim de expor as melhorias que influenciaram positivamente nos indicadores de desempenho de manutenção para o sistema reparável de aplicação do método. Esta análise qualitativa apresenta-se no quadro 5.1 a seguir.

Quadro 5.1 - Medidas implantadas na Estrutura da Política de Lubrificação da Máquina Cobrideira

\begin{tabular}{|c|c|}
\hline Medida/Ação & Análise Qualitativa \\
\hline $\begin{array}{c}\text { Manutenção } \\
\text { preventiva }\end{array}$ & $\begin{array}{l}\text { Melhoria no plano de lubrificação existente; } \\
\text { Inclusão de todos os pontos de lubrificação (havia pontos de } \\
\text { lubrificação faltantes na rota de lubrificação existente anteriormente } \\
\text { a aplicação do método de seleção de política de lubrificação } \\
\text { centrada em confiabilidade); } \\
\text { Definição da correta periodicidade de relubrificação e quantidade } \\
\text { ideal de lubrificante a ser aplicado, informações baseadas nas } \\
\text { informações baseadas nas propriedades físico - químicas do } \\
\text { lubrificante (informação disponibilizada pelo fabricante); } \\
\text { Implantação de método de controle da execução (cronograma para } \\
\text { manutenção planejada); } \\
\text { Indicação do lubrificante de grau alimentício conforme Zc = A do } \\
\text { local de instalacão da máquina cobrideira. }\end{array}$ \\
\hline
\end{tabular}


(Continuação)

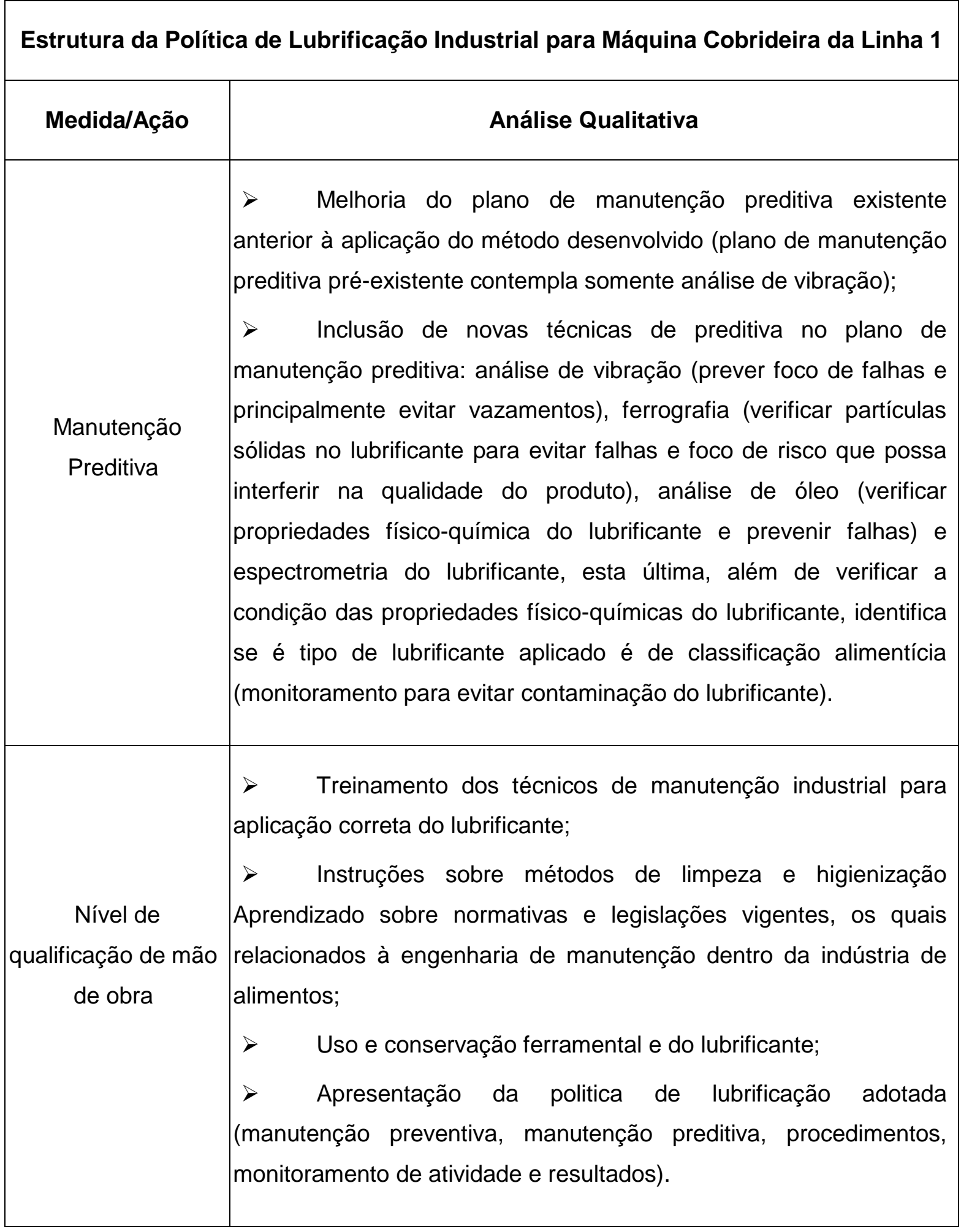

(Continua) 
(Continuação)

Estrutura da Política de Lubrificação Industrial para Máquina Cobrideira da Linha 1

\begin{tabular}{|c|c|}
\hline Mec & Análise Qualitativa \\
\hline $\begin{array}{c}\text { PPT - } \\
\text { Procedimento } \\
\text { Padrão de } \\
\text { Trabalho }\end{array}$ & $\begin{array}{l}\text { Descrição das etapas de execução das tarefas de lubrificação } \\
\text { que detalha as fases necessárias para garantir disponibilidade } \\
\text { operacional e qualidade do produto; } \\
\text { Facilitar para os técnicos de manutenção, disponibilizando o } \\
\text { sequenciamento das etapas necessárias para o cumprimento } \\
\text { das atividades de lubrificação; } \\
\text { Evitar erro humano na execução das atividades de lubrificação } \\
\text { industrial, os quais podem gerar contaminação do lubrificante } \\
\text { e do produto, além de, acarretar eventos de falhas por } \\
\text { deficiência na lubrificação dos ativos industriais; } \\
\text { Normas de segurança do trabalho para execução das } \\
\text { atividades e legislação ambiental (modo correto para descarte } \\
\text { de lubrificantes e demais insumos); } \\
>\text { Modo de conservação, acondicionamento e limpeza dos } \\
\text { utensílios empregados nas atividades de lubrificação } \\
\text { industrial). }\end{array}$ \\
\hline $\begin{array}{c}\text { Monitoramento das } \\
\text { Ações e } \\
\text { Resultados }\end{array}$ & $\begin{array}{l}\text { Planejamento e controle das atividades de lubrificação } \\
\text { industrial (cronograma dos Planos de Manutenção e análise de } \\
\text { falhas oriundas das Ordens de serviço- Manutenção } \\
\text { Corretiva); } \\
\text { Análise estatística de falhas e geração de indicadores de } \\
\text { desempenho de manutenção da maquina cobrideira; } \\
\text { Disponibilização dos resultados no quadro de gestão à vista } \\
\text { com o com intuito de promover motivação para continuação do } \\
\text { trabalho dentro dos procedimentos e padrões estipulados. }\end{array}$ \\
\hline
\end{tabular}


(Conclusão)

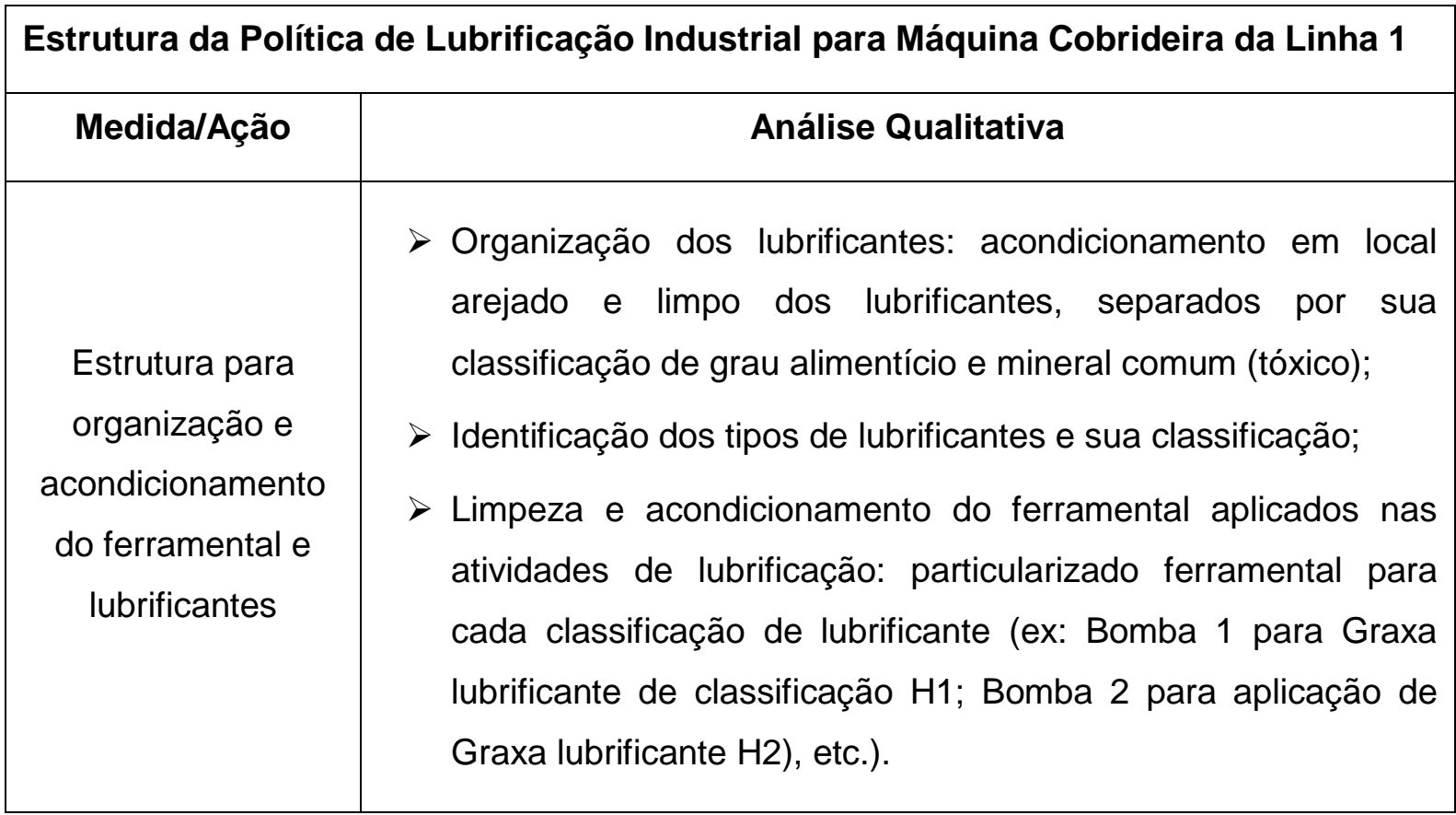

Fonte: Autoria própria

Aliadas a estas ações e maior comprometimento da gerência de manutenção e produção no monitoramento da execução das mesmas, obteve-se evolução nos indicadores de desempenho de manutenção e disponibilidade operacional da máquina cobrideira.

Os gráficos referentes a figuras 5.1 apresentam o comportamento dos eventos de falhas (taxa de intensidade de ocorrência de falhas - ROCOF) e a disponibilidade operacional da máquina cobrideira, entre o período de 2010 até novembro de 2014, ou seja, com dados de histórico de manutenção obtidos após 10 meses de implantação de método de seleção de política de lubrificação na máquina cobrideira, sendo os dados para cálculo destes indicadores disponíveis no APÊNDICE $\mathbf{C}$ da presente tese.

Salienta-se que a curva de tendência de falhas continua com comportamento decrescente, com valor de $\beta_{(2010-2014)}=0,799202987$, valor abaixo deste mesmo parâmetro $\beta_{(2010-2013)}=0,834667215$ obtido ao final de 2013 (período anterior a aplicação do método na máquina cobrideira). 
Figura 5.1 - (a) Gráfico de $\rho(t)$ da Máquina Cobrideira entre 2010 à 2014 e (b) Gráfico de $A(t)$ da Máquina Cobrideira entre 2010 à 2014

\section{Taxa de ocorrência de falhas (ROCOF) - 2010 à 2014}

(a)

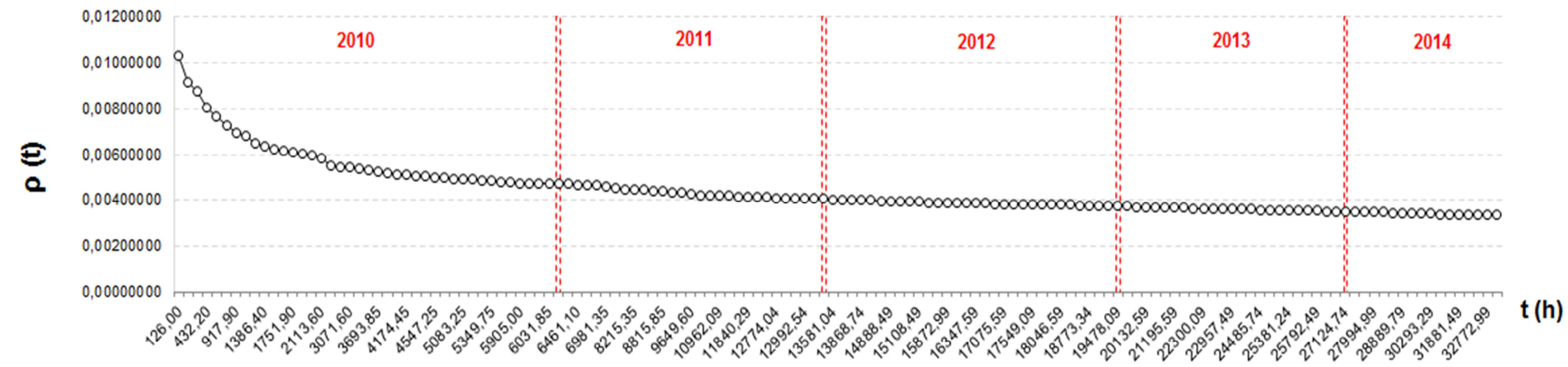

Disponibilidade $A(t)-2010$ à 2014

(b)

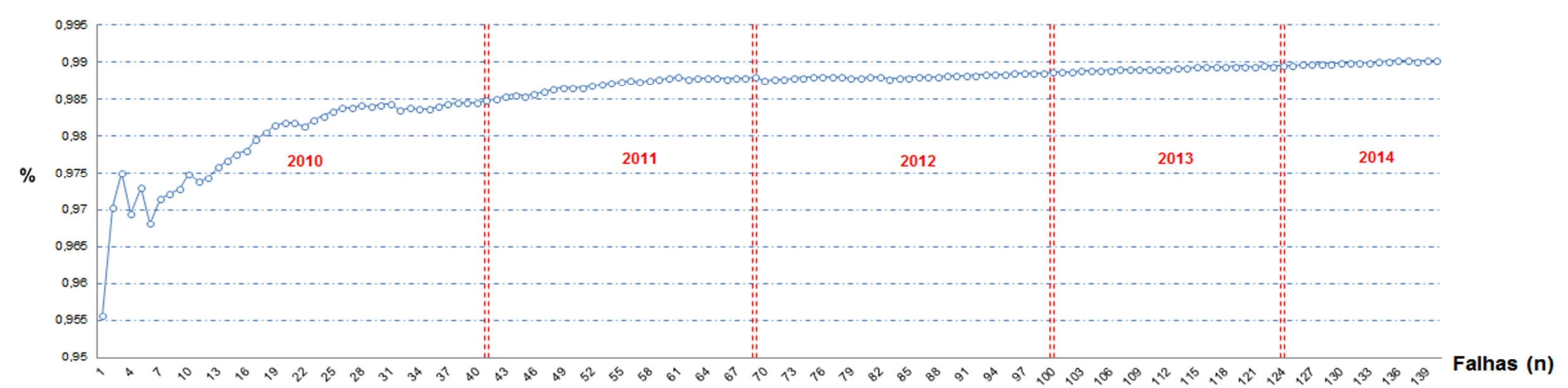

Fonte: Autoria própria 
A disponibilidade da máquina cobrideira ao final de 2013 (período anterior a aplicação do método) foi de $\mathrm{A}(t)=0,98858002$ (98,858002\%), com a aplicação do método para seleção da política de lubrificação), a disponibilidade elevou-se para $A(t)=0,99016383(99,016383 \%)$ ao final de novembro de 2014 , apresentando um aumento de $0,16 \%$ pontos percentuais (em relação ao valor de $A(t)$ obtido em 2013) na disponibilidade operacional do ativo industrial analisado.

Para análise do ganho de produtividade, por meio do aumento da disponibilidade operacional da máquina cobrideira, apresenta-se a tabela 5.1, a qual detalha os cálculos de produtividade com os valores comparativos entre $A(t)$ anterior e posterior a aplicação do método desenvolvido.

Tabela 5.1 - Resultados de Produtividade da Máquina Cobrideira com a Aplicação do Método de Seleção de Política de Lubrificação Centrada em Confiabilidade

Informação de Produtividade

Horas trabalhadas por dia

Capacidade de produção nominal (unidade por h)

Capacidade de produção nominal (unidade por dia)

Peso por unidade $(\mathrm{Kg})$

Capacidade de produção nominal diária em $\mathrm{Kg}$

Disponibilidade de horas trabalhadas por dia

para $A(t)=98,858002 \%$

Capacidade de produção (unidade por dia)

para $A(t)=98,858002 \%$

Capacidade de produção diária em kg

para $A(t)=98,858002 \%$

Capacidade de produção anual em kg

para $A(t)=98,858002 \%$ (valor aproximado de dias úteis de

trabalho no ano $=345$ )

Disponibilidade de horas trabalhadas por dia

para $A(t)=99,016383 \%$

Capacidade de produção (unidade por dia)

para $A(t)=99,016383 \%$

\section{Valores}

$21 \mathrm{~h}$

24.480 unidades

514.080 unidades

$$
\begin{gathered}
0,025 \mathrm{Kg} \\
12.852 \mathrm{Kg}
\end{gathered}
$$

$20,76018 \mathrm{~h}$

508.209 unidades

$12.705,225 \mathrm{Kg}$

$4.383 .302,6 \mathrm{Kg}$

$20,79344 \mathrm{~h}$

509.023 unidades 
(Conclusão)

Capacidade de produção (unidade por dia) em kg para $A(t)=99,016383 \%$

$12.725,575 \mathrm{Kg}$

Capacidade de produção anual em $\mathrm{kg}$ para $\left.A_{t}\right)=99,016383 \%$ (valor aproximado de dias úteis de trabalho no ano $=345$ )

$4.390 .323,4 \mathrm{Kg}$

Aumento de produção diária em Kg

$20,35 \mathrm{Kg}$

Aumento de produção diária em unidades

814 unidades

Aumento de produção anual em Kg (valor aproximado de dias úteis de trabalho no ano $=345$ )

$7.020,8 \mathrm{Kg}$

Aumento de produção anual em unidades (valor aproximado de dias úteis de trabalho no ano $=345$ )

Fonte: Autoria prória

Logo, o aumento da disponibilidade operacional da máquina cobrideira proporcionou um ganho de produtividade médio de 7 toneladas no ano, em unidades isto representa 280.830 unidades de produtos adicionados no balanço da produção anual no final de 2014, em relação ao ano anterior (2013) da aplicação do método na indústria em estudo.

A redução da ocorrência dos eventos de falhas, também influenciou no aumento de tempo de operação da máquina cobrideira entre as ocorrências de eventos de falhas, bem como, reduziu o tempo médio para reparo das mesmas.

A figura 5.2 apresenta os gráficos de $\operatorname{MTBF}(\mathrm{t})$ e $\operatorname{MTTR}(\mathrm{t})$ da máquina cobrideira entre os anos de 2010 e 2014, mostrando os resultados obtidos sobre estes indicadores com a aplicação das medidas estruturadas na politica de lubrificação adotada para máquina cobrideira. 
Figura 5.2 - (a) Gráfico dos Valores de $\operatorname{MTBF}_{(t)}$ e (b) Gráfico de $\operatorname{MTTR}\left({ }_{t}\right)$ e TTR's dos Eventos de Falhas Ocorridos no Período de 2010 á 2014

$\operatorname{MTBF}(t)-2010$ à 2014

(a)

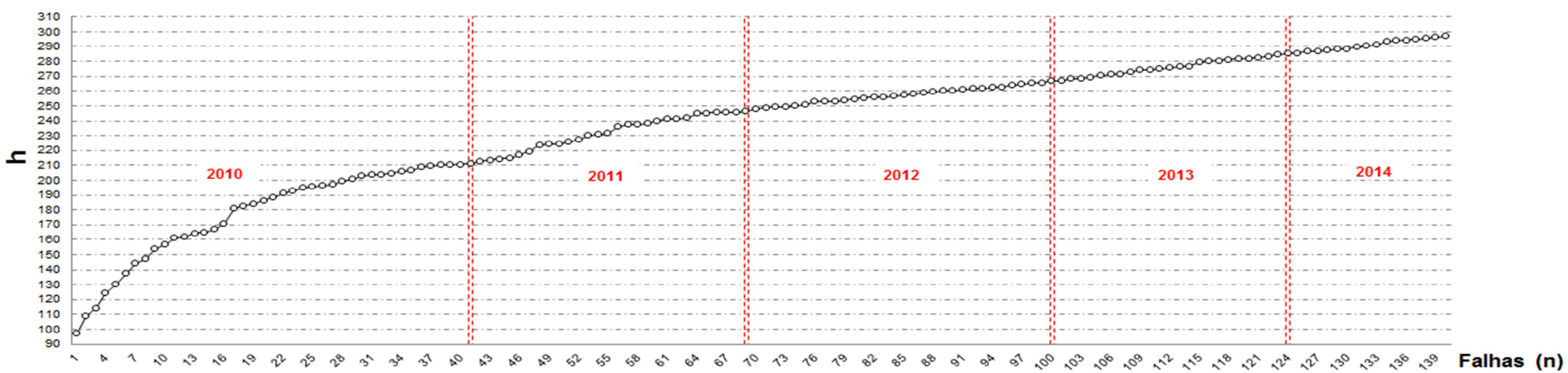

$\operatorname{MTTR}(\mathrm{t})$ e TRR - 2010 à 2014

(b)

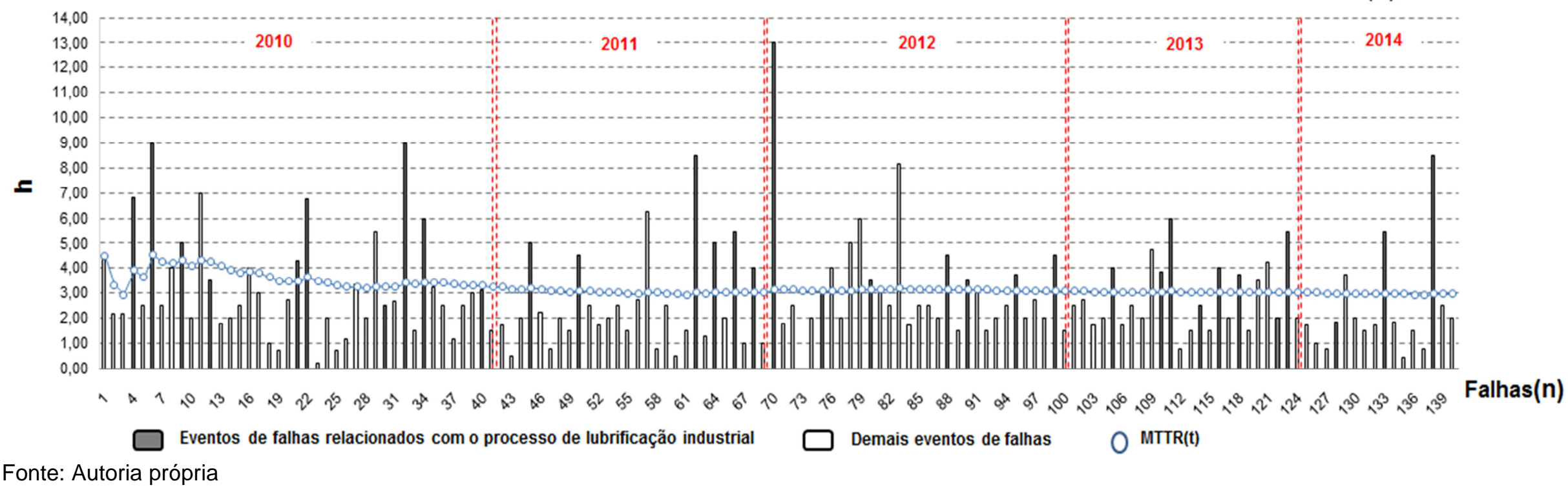


O indicador de $\operatorname{MTBF}(t)$ aponta para comportamento crescente dos tempos de operação da máquina cobrideira entre a ocorrência dos eventos de falhas, sendo seu resultado $\operatorname{MTBF}(t)=296,83 \mathrm{~h}$ obtido ao final do ano de 2014. Isto representa de um aumento de $34,75 \mathrm{~h}$ de operação da máquina cobrideira (entre a ocorrência dos eventos de falhas) em relação ao valor de $\operatorname{MTBF}(t)=262,08 \mathrm{~h}$ obtido no final de 2013 (período anterior a aplicação do método).

Em termos de produtividade, este aumento do $\operatorname{MTBF}_{(t)}$ em $34,75 \mathrm{~h}$ resulta em um adicional de 850.680 unidades (produtividade nominal 24.480 unidades/hora) na produção da máquina cobrideira entre a ocorrência dos eventos de falhas.

Além disto, o $\operatorname{MTTR}(t)$ reduziu no período avaliado de 2010 à 2014, isto se deve a redução da ocorrência dos eventos de falhas relacionados ao processo de lubrificação industrial. A frequência de ocorrência destes eventos específicos durante $o$ ano de 2014 foram de 3 falhas, número de falhas menor em 5 eventos, comparando com os dados obtidos entre o período de 2010 à 2013, neste período ocorreram, em média, 8 eventos de falhas/ano relacionados ao processo de lubrificação industrial.

A redução da ocorrência dos eventos de falhas relacionados ao processo de lubrificação, contribuíram com a redução do tempo médio de reparo das falhas no ano de 2014, apresentando neste ano um $\operatorname{MTTR}(t)=2,95 \mathrm{~h}$, representando uma redução média de 5 minutos por conserto em relação ao $\operatorname{MTTR}(t)=3,03 \mathrm{~h}$ obtido no final do ano de 2013.

Conjuntamente com o aumento de produtividade (consequência do aumento de disponibilidade operacional), a máquina cobrideira também reduziu o potencial risco de perda de qualidade e inocuidade do produto.

Analisando as medidas implantadas pela política de lubrificação estruturada para as particularidades da máquina cobrideira, o valor de seu indicador $I_{C R}$ (indicador de confiabilidade operacional e nível de potencial risco de perda de qualidade e inocuidade do produto) modificou para uma faixa de nível que apresenta um risco menor, conforme análise das variáveis e $Z_{C}$ mostrada no quadro 5.2 abaixo. 
Quadro 5.2 - Análise Quantitativa e Qualitativa das Variáveis Envolvidas no Processo de Lubrificação da Máquina Cobrideira (Resultado)

\begin{tabular}{|c|c|c|c|}
\hline $\begin{array}{l}\text { Valor Variável } \\
\text { Binária / Zona } \\
\text { de Criticidade }\end{array}$ & $\begin{array}{l}\text { Requisito Variável } \\
\text { Binária / Requisito } \\
\text { Zona de Criticidade }\end{array}$ & Descrição & $\begin{array}{l}\text { Resultado do } \\
\text { Valor Binário / } \\
\text { Resultado } Z_{C}\end{array}$ \\
\hline \multirow{3}{*}{$\begin{array}{c}\text { Manutenção } \\
\text { Preventiva = } 1\end{array}$} & $\begin{array}{l}\text { Roteiro de } \\
\text { Atividades }\end{array}$ & $\begin{array}{l}\text { Máquina cobrideira apresenta roteiro de lubrificação o qual contempla } \\
\text { todos os pontos de lubrificação e indica o adequado lubrificante quanto a } \\
\text { Zona de Criticidade }\left(\mathrm{Z}_{\mathrm{C}}=\mathrm{A}\right) \text { do local de instalação da máquina; } \\
\text { Planos de Manutenção Preventiva são executados de forma adequada } \\
\text { (periodicidade, utilização do correto lubrificante de grau alimentício, } \\
\text { ferramental adequado). }\end{array}$ & 1 \\
\hline & $\begin{array}{l}\text { Recursos e Insumos } \\
\text { adequados para } \\
\text { execução das } \\
\text { Atividades }\end{array}$ & $\begin{array}{l}\text { Possui instrumentos individualizados para cada tipo de lubrificante; } \\
\text { Possui PPT para realização das atividades de: lubrificação, } \\
\text { limpeza/higienização do ponto de lubrificação e do modo de conservação } \\
\text { de lubrificantes e ferramental; } \\
\text { Possui local/procedimento de acondicionamento adequado do ferramental } \\
\text { e insumos aplicados nas atividades de lubrificação. }\end{array}$ & 1 \\
\hline & $\begin{array}{c}\text { Monitoramento das } \\
\text { Ações }\end{array}$ & $\begin{array}{l}\text { Possui registro das ocorrências dos eventos de falhas relacionados ao } \\
\text { processo de lubrificação para monitoramento da gestão de lubrificação } \\
\text { industrial; }\end{array}$ & 1 \\
\hline
\end{tabular}

(Continua) 
(Continuação)

\begin{tabular}{|c|c|c|c|}
\hline $\begin{array}{l}\text { Valor Variável } \\
\text { Binária / Zona } \\
\text { de Criticidade }\end{array}$ & $\begin{array}{l}\text { Requisito Variável } \\
\text { Binária / Requisito } \\
\text { Zona de Criticidade }\end{array}$ & Descrição & $\begin{array}{l}\text { Resultado do } \\
\text { Valor Binário } / \\
\text { Resultado } Z_{C}\end{array}$ \\
\hline & $\begin{array}{l}\text { Monitoramento das } \\
\text { Ações }\end{array}$ & $\begin{array}{l}\text { Possui planejamento e controle de alocação de mão de obra e controle } \\
\text { de estoque (materiais e insumos). }\end{array}$ & 1 \\
\hline $\begin{array}{l}\text { Manutenção } \\
\text { Preventiva = } 1\end{array}$ & $\begin{array}{l}\text { Evidência de } \\
\text { Resultados sob a } \\
\text { Disponibilidade } \\
\text { Operacional }\end{array}$ & $\begin{array}{l}\text { Possui monitoramento da eficácia da política de lubrificação industrial } \\
\text { implantada por meio de indicadores de desempenho de manutenção e } \\
\text { disponibilidade operacional; } \\
\text { Possui análise de falhas e identificação dos riscos envolvidos na } \\
\text { ocorrência destas falhas; } \\
\text { Possui estrutura de plano de ação para tratar a causa raiz de cada } \\
\text { evento de falha relacionado ao processo de lubrificação industrial; }\end{array}$ & 1 \\
\hline $\begin{array}{l}\text { Manutenção } \\
\text { Preditiva }=1\end{array}$ & $\begin{array}{l}\text { Roteiro de } \\
\text { atividades }\end{array}$ & $\begin{array}{l}\text { Existência de Roteiro de Manutenção Preditiva, o qual contempla as } \\
\text { técnicas preditivas necessárias para garantir qualidade ao produto final e } \\
\text { melhoria na produtividade da maquina cobrideira; } \\
\text { Existência acompanhamento dos relatórios dos planos de manutenção } \\
\text { preditiva e planejamento das correções necessárias das falhas } \\
\text { identificadas. }\end{array}$ & 1 \\
\hline
\end{tabular}

(Continua) 
(Continuação)

\begin{tabular}{|c|c|c|c|}
\hline $\begin{array}{l}\text { Valor Variável } \\
\text { Binária / Zona } \\
\text { de Criticidade }\end{array}$ & $\begin{array}{l}\text { Requisito Variável } \\
\text { Binária / Requisito } \\
\text { Zona de Criticidade }\end{array}$ & Descrição & $\begin{array}{l}\text { Resultado do } \\
\text { Valor Binário / } \\
\text { Resultado }-\mathrm{Z}_{\mathrm{C}}\end{array}$ \\
\hline $\begin{array}{l}\text { Manutenção } \\
\text { Preditiva = } 1\end{array}$ & $\begin{array}{l}\text { Recursos e Insumos } \\
\text { adequados para } \\
\text { execução das } \\
\text { Atividades }\end{array}$ & $\begin{array}{l}\text { Apresenta mão de obra qualificada (terceirizada); } \\
\text { Apresenta instrumentos adequados para execução das atividades de } \\
\text { manutenção preditiva. }\end{array}$ & 1 \\
\hline \multirow[t]{2}{*}{$\begin{array}{l}\text { Manutenção } \\
\text { Preditiva = } 1\end{array}$} & $\begin{array}{c}\text { Monitoramento das } \\
\text { Ações }\end{array}$ & $\begin{array}{l}\text { Apresenta acompanhamento da evolução das falhas identificadas nos laudos } \\
\text { de análise de vibração; } \\
\text { Apresenta planejamento e controle dos alarmes (avarias) indicadas nos } \\
\text { laudos, avarias as quais podem evoluir para um evento de falha. }\end{array}$ & 1 \\
\hline & $\begin{array}{l}\text { Evidência de } \\
\text { Resultados sob a } \\
\text { Disponibilidade } \\
\text { Operacional }\end{array}$ & $\begin{array}{l}\text { Apresenta indicadores de desempenho que permita acompanhar a influência } \\
\text { das ações de manutenção preditiva sobre a produtividade da maquina } \\
\text { cobrideira. }\end{array}$ & 1 \\
\hline $\begin{array}{l}\text { Nível de } \\
\text { Qualificação de } \\
\text { Mão de Obra = } \\
1\end{array}$ & $\begin{array}{l}\text { Conhecimento de } \\
\text { Normativas e } \\
\text { Legislações }\end{array}$ & $\begin{array}{l}\text { Aplicação de treinamento para os técnicos de manutenção sobre lubrificação } \\
\text { de maquinário empregado em indústria de alimentos, conscientizando sobre } \\
\text { os riscos que esta atividade pode acarretar quanto a perda de qualidade e } \\
\text { inocuidade do produto (contaminação) e geração de evntos de falhas; }\end{array}$ & 1 \\
\hline
\end{tabular}

(Continua) 
(Continuação)

\begin{tabular}{|c|c|c|c|}
\hline $\begin{array}{l}\text { Valor Variável } \\
\text { Binária / Zona } \\
\text { de Criticidade }\end{array}$ & $\begin{array}{l}\text { Requisito Variável } \\
\text { Binária / Requisito } \\
\text { Zona de Criticidade }\end{array}$ & Descrição & $\begin{array}{l}\text { Resultado do } \\
\text { Valor Binário } \\
\text { / Resultado } \\
\mathrm{Z}_{\mathrm{C}}\end{array}$ \\
\hline \multirow{4}{*}{$\begin{array}{l}\text { Nível de } \\
\text { Qualificação de } \\
\text { Mão de Obra = } \\
1\end{array}$} & $\begin{array}{l}\text { Conhecimento de } \\
\text { Normativas e } \\
\text { Legislações }\end{array}$ & $\begin{array}{l}\text { Técnicos de manutenção apresentam conhecimentos sobre lubrificantes } \\
\text { de grau alimentício (Treinamento); } \\
\text { Técnicos de manutenção apresentam conhecimentos sobre normativas e } \\
\text { legislações específicas para indústria de alimentos (Treinamento); } \\
\text { Técnicos de manutenção apresentam conhecimentos do Manual de } \\
\text { Gestão da Qualidade da empresa (Treinamento). }\end{array}$ & 1 \\
\hline & $\begin{array}{c}\text { Utilização de } \\
\text { ferramental adequado }\end{array}$ & $>$ Apresenta ferramental adequado e em bom estado de conservação & 1 \\
\hline & $\begin{array}{c}\text { Execução de Limpeza } \\
\text { e Higienização do } \\
\text { Ferramental }\end{array}$ & $\begin{array}{l}\text { Apresenta procedimento de limpeza/higienização do ferramental e } \\
\text { materiais aplicados nas atividades de lubrificação industrial; } \\
\text { Possui local/procedimento de acondicionamento adequado do ferramental } \\
\text { e insumos aplicados nas atividades de lubrificação. }\end{array}$ & 1 \\
\hline & $\begin{array}{l}\text { Execução de Limpeza } \\
\text { e Higienização do } \\
\text { Ponto de Lubrificação }\end{array}$ & $\begin{array}{l}\text { Apresenta evidência de execução de limpeza/higienização do ponto de } \\
\text { lubrificação ao término das atividades de manutenção. }\end{array}$ & 1 \\
\hline
\end{tabular}

(Continua) 
(Continuação)

\begin{tabular}{|c|c|c|c|}
\hline $\begin{array}{l}\text { Valor Variável } \\
\text { Binária / Zona } \\
\text { de Criticidade }\end{array}$ & $\begin{array}{l}\text { Requisito Variável } \\
\text { Binária / } \\
\text { Requisito Zona de } \\
\text { Criticidade }\end{array}$ & Descrição & $\begin{array}{l}\text { Resultado do } \\
\text { Valor Binário / } \\
\text { Resultado } Z_{C}\end{array}$ \\
\hline \multirow{3}{*}{$\begin{array}{c}\text { Zona de } \\
\text { Criticidade } \\
Z_{C}=A\end{array}$} & $\begin{array}{l}\text { Modo de Operação } \\
\text { e Funcionamento }\end{array}$ & $\begin{array}{l}\text { Apresenta ligação em série com os demais ativos da Linha de Produção 1, } \\
\text { assim os eventos de falhas ocorridos na máquina cobrideira impacta na } \\
\text { disponibilidade total da Linha de Produção 1; } \\
\text { Não possui backup ativo e/ou passivo; } \\
\text { Apresenta variação de pressão e temperatura durante funcionamento (caixa } \\
\text { inferior com sistema banho - maria evitando cristalizar a calda e } \\
\text { pressurização da cortina de ar utilizada para retirar excesso de cobertura). }\end{array}$ & A \\
\hline & $\begin{array}{l}\text { Estado do produto } \\
\text { em processamento }\end{array}$ & $\begin{array}{l}\text { Produto em processamento recebe cobertura de calda (geralmente de } \\
\text { chocolate) sem embalagem primária. }\end{array}$ & A \\
\hline & $\begin{array}{l}\text { Estrutura do Ponto } \\
\text { de Lubrificação }\end{array}$ & $\begin{array}{l}\text { Apresenta pontos de lubrificação fechados com aplicação de lubrificantes por } \\
\text { meio de bico graxeiro, central de lubrificação e reservatório (cartér); } \\
\text { Apresenta pontos de lubrificação expostos (abertos) com aplicação de } \\
\text { lubrificantes por meio de pincel, e spray (engrenagens, pinos, roda dentada). }\end{array}$ & A \\
\hline
\end{tabular}

(Continua) 
(Conclusão)

\begin{tabular}{|c|c|c|c|}
\hline $\begin{array}{l}\text { Valor Variável } \\
\text { Binária / Zona } \\
\text { de Criticidade }\end{array}$ & $\begin{array}{l}\text { Requisito Variável } \\
\text { Binária / Requisito } \\
\text { Zona de Criticidade }\end{array}$ & Descrição & $\begin{array}{l}\text { Resultado do } \\
\text { Valor Binário / } \\
\text { Resultado } Z_{C}\end{array}$ \\
\hline \multirow{3}{*}{$\begin{array}{c}\text { Zona de } \\
\text { Criticidade } \\
\mathrm{Z}_{\mathrm{C}}=\mathrm{A}\end{array}$} & $\begin{array}{c}\text { Potencial Risco de } \\
\text { Perda de Qualidade e } \\
\text { inocuidade do Produto }\end{array}$ & $\begin{array}{l}\text { Risco muito de perda de qualidade e inocuidade do produto, devido } \\
\text { apresentar pontos de lubrificação expostos com processamento de } \\
\text { produto sem embalagem; } \\
\text { Risco contido e controlado por meio de aplicação de estratégias de } \\
\text { manutenção e gestão da lubrificação industrial eficaz. }\end{array}$ & A \\
\hline & Perda de Produção & $\begin{array}{l}\text { Apresenta potencial ocorrência de falhas; } \\
\text { Apresenta potencial perda total da produtividade na ocorrência de } \\
\text { contaminação do produto durante o processamento; } \\
\text { Risco contido e controlado por meio de aplicação de estratégias de } \\
\text { manutenção e gestão da lubrificação industrial eficaz. }\end{array}$ & A \\
\hline & Limpeza /Higienização & $\begin{array}{l}>\text { Frequência de Limpeza e Desinfecção (FLD) com frequência mínima de } \\
1 \text { vez por semana }(\text { FLD > 2); } \\
\text { Utilização de água quente e/ou pressurizada e de produtos sanitizantes } \\
\text { para execução da limpeza/higienização do ativo industrial e do local de } \\
\text { instalação. }\end{array}$ & A \\
\hline
\end{tabular}


Após a nova análise para atribuição dos valores/pesos das variáveis (envolvidas no processo de lubrificação) e a $Z_{C}$ da máquina cobrideira após a implantação do método, identificou que, mediante as características do local de instalação desta máquina e de seu projeto de construção, essa ainda apresenta $Z_{C}=$ A.

Apesar da máquina cobrideira apresentar $Z_{C}=A$, zona a qual aponta para um potencial de alto risco de perda de qualidade e inocuidade do produto e ocorrência de eventos de falhas (devido as atividades de lubrificação industrial), estes fatores estão contidos e controlados por meio da eficiência da política de lubrificação implantada.

Os valores atribuídos as variáveis e o valor obtido do $\mathrm{I}_{\mathrm{CR}}$ após a implantação do método de seleção de política de lubrificação centrada em confiabilidade são mostrados no quadro 5.3 a seguir.

Quadro 5.3 - Análise $I_{C R}$ da Máquina Cobrideira após Aplicação do Método de Seleção de Política de Lubrificação Centrada em Confiabilidade

\begin{tabular}{|c|c|c|c|c|c|}
\hline $\begin{array}{c}\text { Variáveis e } \\
\text { Indicador / } \\
\text { Valor }\end{array}$ & $\begin{array}{c}\text { Manutenção } \\
\text { Preventiva }\end{array}$ & $\begin{array}{c}\text { Manutenção } \\
\text { Preditiva }\end{array}$ & $\begin{array}{c}\text { Nível de } \\
\text { Qualificação } \\
\text { de Mão de } \\
\text { Obra }\end{array}$ & $\begin{array}{c}\text { Zona de } \\
\text { Criticidade - } \\
\mathbf{Z}_{\mathrm{C}}\end{array}$ & $\mathbf{I}_{\mathrm{CR}}$ \\
\cline { 2 - 6 } & 1 & 1 & 1 & $\mathrm{~A}$ & $3 \mathrm{~A}$ \\
\hline
\end{tabular}

Fonte: Autoria própria

Analisando a faixa de nível do valor de $\mathrm{I}_{\mathrm{CR}}=3 \mathrm{~A}$, a máquina cobrideira encontra-se em uma zona crítica que apresenta particularidades que intensificam a possibilidade de contaminação do produto por meio das atividades do lubrificante (produto em processamento sem embalagem, maior frequência de limpeza e higienização, pontos de lubrificação com estrutura expostas, entre outros), porém estes riscos são contidos e controlados por meio da aplicação de estratégias de manutenção contempladas na política de lubrificação adotada para máquina cobrideira.

Estas atividades de manutenção (preventiva e preditiva) são executadas de forma adequada, garantidas pela sequência de ações descritas em procedimento padrão de trabalho (PPT), o qual descreve o modo de execução destas atividades (evitar riscos como contaminação do ferramental e/ou lubrificante, excesso de 
lubrificante na superfície da máquina, aplicação do correto lubrificante a $Z_{C}$ do ativo industrial, limpeza e desinfecção da área de trabalho, etc.), com medidas que visem evitar a geração dos focos de riscos que possam interferir na qualidade do produto, garantindo assim produtividade ao sistema industrial.

\subsection{RESULTADOS QUANTO A REDUÇÃO DE CUSTOS COM EVENTOS DE FALHAS RELACIONADOS À LUBRIFICAÇÃO INDUSTRIAL}

Com a implantação, de forma adequada, de estratégias de manutenção preditiva e preventiva, aliadas, a melhoria da gestão dos procedimentos e insumos aplicados às atividades de lubrificação industrial, obteve-se redução dos eventos de falhas relacionados ao processo de lubrificação industrial.

A redução destes eventos resultou na redução de custos de manutenção corretiva aplicados nos reparos das falhas ocorridas no ano de 2014, em relação aos anos anteriores de 2010 à 2014 (anterior a aplicação do método). Para mostrar os resultados na redução de custos a tabela 5.2 mostra as falhas relacionadas ao processo de lubrificação, atrelados seus custos com manutenção corretiva, com intuito de apresentar a efetiva redução destes custos com a aplicação do método desenvolvido.

Tabela 5.2 - Custos Manutenção Corretiva - Máquina Cobrideira

\begin{tabular}{|c|c|c|c|c|}
\hline Ano & Data & $\begin{array}{c}\text { TTR } \\
\text { (h) }\end{array}$ & Resumo das atividades - OS & $\begin{array}{c}\text { Custo com } \\
\text { Manutenção } \\
\text { Corretiva (R\$) }\end{array}$ \\
\hline 2010 & $22 / 01$ & 6,8 & Manutenção: eixo, mancal e rolamentos & 820 \\
\hline 2010 & $05 / 02$ & 9 & $\begin{array}{c}\text { Manutenção: Rolamentos, esteira metálica } \\
\text { (troca) }\end{array}$ & 1425 \\
\hline 2010 & 03/03 & 5 & Manutenção: eixo, bucha e rolamentos & 725 \\
\hline 2010 & $19 / 03$ & 3,5 & Manutenção: vazamento motorredutor & 350 \\
\hline 2010 & $18 / 08$ & 4,3 & Manutenção: vazamento motorredutor & 350 \\
\hline
\end{tabular}


(Continuação)

\begin{tabular}{|c|c|c|c|c|}
\hline Ano & Data & $\begin{array}{c}\text { TTR } \\
\text { (h) }\end{array}$ & Resumo das atividades - OS & $\begin{array}{c}\text { Custo com } \\
\text { Manutenção } \\
\text { Corretiva (R\$) }\end{array}$ \\
\hline 2010 & $31 / 08$ & 6,75 & Manutenção: eixo, mancal e rolamentos & 820 \\
\hline 2010 & $07 / 11$ & 2,5 & Manutenção: rolamento e bucha & 250 \\
\hline 2010 & $11 / 11$ & 9 & $\begin{array}{c}\text { Manutenção: Rolamentos, esteira metálica } \\
\text { (troca) }\end{array}$ & 1425 \\
\hline 2010 & $25 / 11$ & 6 & $\begin{array}{c}\text { Manutenção: Rolamentos, esteira metálica } \\
\text { (troca) }\end{array}$ & 1425 \\
\hline 2010 & $29 / 12$ & 3,15 & Manutenção : vazamento motorredutor & 350 \\
\hline 2011 & $29 / 01$ & 5 & Manutenção : vazamento motorredutor & 350 \\
\hline 2011 & $22 / 04$ & 4,5 & Manutenção : vazamento motorredutor & 350 \\
\hline 2011 & $22 / 10$ & 8,5 & $\begin{array}{c}\text { Manutenção: Rolamentos, esteira metálica } \\
\text { (troca) }\end{array}$ & 1425 \\
\hline 2011 & $06 / 12$ & 5 & $\begin{array}{c}\text { Manutenção: Rolamentos, esteira metálica } \\
\text { (troca) }\end{array}$ & 1425 \\
\hline 2011 & $13 / 12$ & 5,5 & Manutenção : vazamento motorredutor & 350 \\
\hline 2011 & $18 / 12$ & 4 & $\begin{array}{c}\text { Manutenção: Sistema Transmissão de força e } \\
\text { movimento }\end{array}$ & 1600 \\
\hline 2012 & $18 / 01$ & 13 & $\begin{array}{c}\text { Manutenção: Rolamentos, esteira metálica } \\
\text { (troca) }\end{array}$ & 1425 \\
\hline 2012 & $08 / 03$ & 3 & $\begin{array}{c}\text { Manutenção: Sistema Transmissão de força e } \\
\text { movimento }\end{array}$ & 1600 \\
\hline 2012 & $13 / 04$ & 6 & $\begin{array}{c}\text { Manutenção: Rolamentos, esteira metálica } \\
\text { (troca) }\end{array}$ & 1425 \\
\hline 2012 & $04 / 05$ & 3,5 & Manutenção : mancal e rolamentos & 539,80 \\
\hline 2012 & $25 / 08$ & 4,5 & $\begin{array}{c}\text { Manutenção: Sistema Transmissão de força e } \\
\text { movimento }\end{array}$ & 1600 \\
\hline 2012 & 05/09 & 3,5 & Manutenção : bucha, mancal e rolamentos & 590 \\
\hline 2012 & $21 / 10$ & 3,75 & Manutenção : vazamento motorredutor & 350 \\
\hline 2012 & $12 / 12$ & 4,5 & Manutenção : vazamento motorredutor & 350 \\
\hline 2013 & $03 / 03$ & 4 & $\begin{array}{c}\text { Manutenção: Sistema Transmissão de força e } \\
\text { movimento }\end{array}$ & 1600 \\
\hline 2013 & $08 / 05$ & 3,85 & Manutenção : vazamento motorredutor & 350 \\
\hline
\end{tabular}


(Conclusão)

\begin{tabular}{ccccc}
\hline Ano & Data & $\begin{array}{c}\text { TTR } \\
\text { (h) }\end{array}$ & Resumo das atividades - OS & $\begin{array}{c}\text { Custo com } \\
\text { Manutenção } \\
\text { Corretiva (R\$) }\end{array}$ \\
\hline 2013 & $20 / 05$ & 6 & Manutenção: Rolamentos, esteira metálica (troca) & 1425 \\
2013 & $30 / 06$ & 2,5 & Manutenção : vazamento motorredutor & 350 \\
2013 & $12 / 09$ & 4 & Manutenção: Sistema Transmissão de força e & 1600 \\
2013 & $30 / 09$ & 3,75 & Manutenção : vazamento motorredutor & 350 \\
2013 & $20 / 10$ & 4,25 & Manutenção: Sistema Transmissão de força e & 1600 \\
2013 & $10 / 12$ & 5,5 & Manutenção: Rolamentos, esteira metálica (troca) & 1425 \\
2014 & $28 / 04$ & 3,75 & Manutenção: Sistema Transmissão de força e & 1600 \\
2014 & $08 / 08$ & 5,5 & Manutenção: Rolamentos, bucha, mancal & 565 \\
2014 & $20 / 10$ & 8,5 & Manutenção: Rolamentos, esteira metálica (troca) & 1425 \\
\hline
\end{tabular}

Fonte: Autoria própria

Enfatiza-se que os dados da tabela 5.2 são valores atualizados (referentes à 2014) para peças e serviços aplicados na manutenção corretiva da máquina cobrideira. Para comparação destes custos de manutenção corretiva apresentados, relaciona-se os gastos anuais (2010 à 2014) em percentual do orçamento total de 2013 , este equivalente a $R \$ 210.000,00$ destinado para manutenção corretiva da Linha de Produção 1, valor o qual estabelecido pela empresa em seu planejamento estratégico. Esta comparação dos valores percentuais de gastos está exposta no gráfico da figura 5.3 á seguir. 
Figura 5.3 - (a) Gráfico dos valores de custos com manutenção corretiva da máquina cobrideira entre o período de 2010 á 2014 x Valor orçado para custos de manutenção corretiva na linha de produção 1 no ano 2013.

\section{Custo Anual de Manutenção Manutenção Corretiva - Máquina}
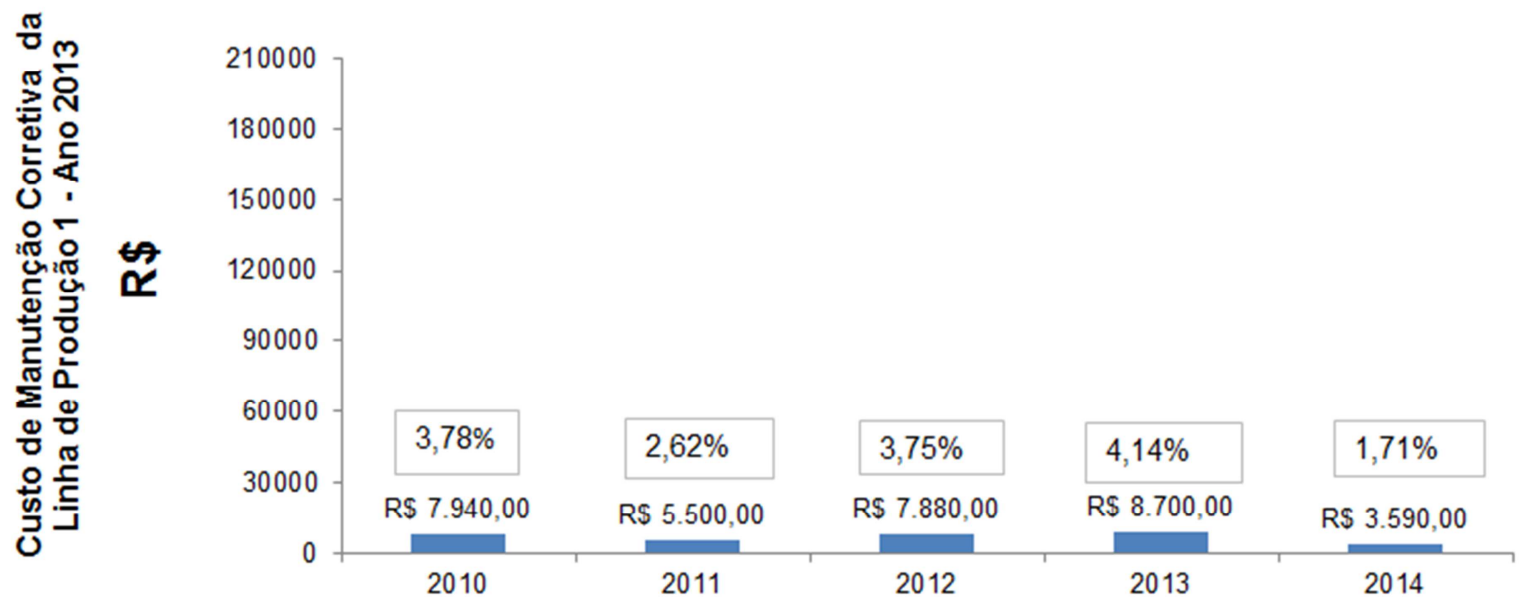

Fonte: Autoria própria

Enfatiza-se que os valores de manutenção corretiva contidos na tabela $6.3 \mathrm{e}$ no gráfico da figura 5.3, não contemplam custos com mão de obra interna (técnicos de manutenção da empresa), pois a empresa de aplicação do método desenvolvido planeja e estabelece o valor monetário orçado para execução das atividades de manutenção corretiva com base de custos variáveis (peças, insumos e serviços) a serem utilizados.

Enfatiza-se que os valores mostrados no gráfico da figura 5.3 foram obtidos sobre o valor de peças e insumos apontados nas ordens de serviços (O.S.'s) referentes as ocorrências de falhas relacionadas ao processo de lubrificação industrial.

O valor monetário dessas peças e insumos foram estimados com base de seus valores de mercado no ano de 2013. Isto se deveu por falta de histórico de controle de custos aplicados na manutenção industrial no período analisado (2010 à 2013).

O gráfico de custos com manutenção corretiva mostra que em 2014 os valores gastos com manutenção corretiva das falhas (relacionados com o processo de lubrificação industrial) ocorridas na máquina cobrideira foram equivalentes a 
$1,71 \%$ (em valor monetário $R \$ 3.590,00$ ) do custo total orçado para gastos com manutenção corretiva na Linha de Produção 1 (relacionando o valor orçado de 2013 de $R \$ 210.000,00)$.

Isto aponta para uma economia de $\mathrm{R} \$ 3.915,00$ em gastos com peças e materiais para conserto dessas falhas específicas (relacionadas ao processo de lubrificação industrial), representando uma redução de $52,2 \%$ do gasto com este tipo de manutenção em comparação com o valor médio de $R \$ 7.505,00$ gastos em cada ano entre o período de 2010 á 2013 (anos anteriores a aplicação do método).

Assim, verifica-se que além do aumento de produtividade operacional do maquinário, o método de seleção de politica de lubrificação centrada em confiabilidade também possibilita a redução de gastos com manutenção corretiva do ativo industrial em fábricas de alimentos, corroborando com a competitividade de mercado dessas empresas.

Os ganhos como disponibilidade e $\operatorname{MTBF}(t)$ oferecem maior continuidade operacional da máquina cobrideira e consequente redução de seus custos diretos com manutenção corretiva (como mostrados no gráfico da figura 5.5) e indiretos tais como:

> Redução de lotes de produtos interditados pela Engenharia da Qualidade, por motivos de perda de qualidade e inocuidade (contaminação) ocasionada pela ocorrência dos eventos de falhas relacionados com o processo de lubrificação industrial. Com a redução da interdição destes lotes, consequentemente também se diminui os custos com armazenamento deste produto no estoque;

> Diminuição da necessidade de horas extras para fabricação de produtos faltantes devido atraso na produção ocorrido por falhas relacionadas ao processo de lubrificação industrial;

> Redução do consumo de insumos e lubrificantes devido a redução de ocorrência de eventos de falhas relacionadas ao processo de lubrificação industrial (vazamentos e relubrificação);

> Redução da perda de produto devido defeito;

> Redução substancial do consumo de energia elétrica devido a redução do desgaste dos componentes e melhoria da eficiência do funcionamento do maquinário; 
> Aumento estimado da vida útil do maquinário direcionando assim a redução do custo de aquisição de peças e insumos para manutenção industrial;

> Maior limpeza e organização local de trabalho;

> Aplicação da manutenção pró-ativa devido motivação pessoal dos funcionários;

> Redução do consumo de ar comprimido utilizado na limpeza do local da manutenção corretiva (devido redução das ocorrências de eventos de falhas relacionados com o processo de lubrificação industrial).

Assim, o método de seleção de política de lubrificação centrada bem confiabilidade, aplicado de forma eficaz pode proporcionar ganhos econômicos e aumento significativo da disponibilidade operacional, comprovando a sua viabilidade e funcionalidade para o meio industrial de fabricação de alimentos. 


\section{CAPÍtUlO 6 CONCLUSÕES E RECOMENDAÇÕES PARA TRABALHOS FUTUROS}

\subsection{CONCLUSÕES}

Cada vez mais as indústrias fabricantes de alimentos estão buscando métodos que agreguem qualidade e produtividade ao seu sistema industrial, com o propósito de gerar um diferencial em meio ao seu ramo de atuação. Este cenário se deve à competitividade e a exigência do mercado consumidor presentes no mercado global na atualidade.

Obter qualidade nos produtos alimentícios é fabricar um produto livre de defeitos e de elementos que não façam parte da sua composição, livre de substâncias que possam interferir nas suas propriedades organolépticas, ou seja, que não alterem sua coloração, odor, sabor, entre outros).

Inferir qualidade no processo de manufatura de alimentos é controlar e monitorar as atividades envolvidas neste processo produtivo para manter as propriedades dos produtos em conformidade com as características para as quais foram criados conjuntamente com a totalidade de suas características físico-químicas relacionada com sua habilidade em atender as necessidades explícitas e implícitas dos alimentos.

Um dos aspectos que a manutenção industrial enfrenta, em estabelecimentos de fabricação de alimentos, não se direciona somente em aplicar as técnicas utilizadas na manutenção, mas decidir quais delas realmente são ou não são importantes para melhorar o desempenho do maquinário em termos de confiabilidade e disponibilidade operacional e ao mesmo tempo atender as normas e legislações vigentes relacionadas a neste tipo de indústria.

Apesar de existirem normativas e sistemáticas como o HACCP e BPF, ainda encontra-se empresas de alimentos que utilizam lubrificantes inapropriados em seu sistema fabril. Esta ação, aliada a fatores como: possível contaminação dos lubrificantes; limpeza de máquinas e equipamentos (aplicação de água, vapor, produtos químicos desinfetantes oriundos da limpeza geral obrigatória pelos sistemas HACCP e BPF); execução da lubrificação de forma desorganizada, etc; 
desencadeiam a probabilidade de ocorrências de falhas, impacto na qualidade do alimento (risco) e do lubrificante, aumento do custo com manutenção com relubrificação e tempo de paradas de máquinas, provoca indisponibilidade de equipamento e até prejuízo financeiro com o descarte de produto acabado que apresentem desvios na qualidade.

A proposta desenvolvida no método de seleção de política de lubrificação industrial centrada em confiabilidade para maquinário empregado na fabricação de alimentos tem por diferencial a unificação das técnicas de engenharia de manutenção para atendimento das necessidades da engenharia de qualidade, visando atingir os objetivos de ambos os setores: confiabilidade e disponibilidade operacional do maquinário e redução do risco á qualidade do produto durante a execução das atividades de lubrificação industrial.

O método de seleção de política de lubrificação centrada em confiabilidade voltado para maquinário utilizado na fabricação de alimentos apresenta uma análise proativa do processo de lubrificação dos ativos industriais. Esta análise tem a finalidade de evidenciar as variáveis que impactam este processo, e assim adotar medidas (ações) que evitem potenciais riscos (contaminação) que impactem na qualidade do produto em processamento, e que ao mesmo tempo, reduzam e/ou eliminem os eventos de falhas, os quais impactam na disponibilidade operacional do maquinário.

Este método possibilita verificar a dinâmica participativa de cada variável no sistema que explica a ocorrência de falhas mecânicas e riscos a qualidade do produto (que pode ser provocado por meio da contaminação do produto pelo processo de lubrificação do maquinário) durante a execução das atividades de manutenção relacionadas à lubrificação, como também, permite a verificar a tendência destes valores obtidos, de falhas e riscos, com base na alteração de uma ou mais variáveis, direcionando a tomada de decisão ao adequado procedimento de lubrificação.

Assim, é aplicado um teste do método em um ambiente real de fabricação de alimentos (indústria), escolhendo uma máquina cobrideira de produto (sistema reparável piloto), com intuito de avaliar a eficácia da pesquisa desenvolvida quanto a sua contribuição para garantia de disponibilidade operacional do maquinário e identificação e monitoramento dos riscos á qualidade do produto envolvidos nas 
atividades de lubrificação industrial. Para tanto são evidenciados os seguintes resultados:

I - Mapeamento do sistema produtivo, o qual está instalada a máquina cobrideira, construindo o seu leiaute e identificando a relação da ligação em série entre os ativos da Linha de Produção 1;

II - Analisando as particularidades e características da Linha de produção 1 e o modo de funcionamento/operação da máquina cobrideira, evidencia-se as particularidades das variáveis envolvidas no processo de lubrificação industrial, bem como, descrimina-se seus impactos sobre a ocorrência de eventos de falhas e potencial risco de perda de qualidade e inocuidade do produto;

III - Construção da árvore funcional da máquina cobrideira, permitindo analisar a estrutura do sistema e assim mapear as relações entre seus componentes. Identifica-se na árvore funcional os pontos de lubrificação (componentes críticos), o que permite analisar sua estrutura (aberto ou fechado) e definir os potenciais riscos de perda de qualidade e inocuidade de produto que possam ocorrer com a execução das atividades de lubrificação e, assim propor medidas para contenção;

IV - Com o mapeamento da Linha de Produção 1 e identificação da influência do comportamento das atividades de lubrificação na máquina cobrideira pode exercer na qualidade do produto em processamento classifica-se as Zonas Críticas $\left(Z_{C}\right)$ deste processo produtivo, enquadrando a máquina cobrideira na $Z_{C}=A$, apontando as características e funcionalidades que possam gerar riscos de perda de qualidade e inocuidade do produto (contaminação) e assim direcionar a tomada de decisão na execução de medidas de contenção;

V - Análise das características e atribuição dos valores binários das variáveis envolvidas no processo de lubrificação industrial (manutenção preventiva, manutenção preditiva e nível da qualificação de mão de obra quanto à lubrificação industrial de maquinário empregado em indústrias de alimento) para cálculo do indicador $\mathrm{I}_{\mathrm{CR}}$ (indicador de confiabilidade operacional e nível de potencial risco de perda de qualidade e inocuidade do produto). $\mathrm{O}$ valor de $\mathrm{I}_{\mathrm{CR}}=\mathrm{OA}$ da máquina 
cobrideira identificou, em sua faixa de análise de nível, as principais deficiências da gestão de lubrificação exercida sobre o ativo industrial conjuntamente com as possíveis consequências que estas deficiências poderiam afetar na geração de eventos de falhas e riscos (contaminação) a perda de qualidade e inocuidade do produto, direcionando a tomada de decisão para contenção correção destas anomalias;

VI - Aplicação de ferramenta estatística para análise da tendência de falhas e identificação dos eventos relacionados ao processo de lubrificação industrial, com a finalidade de efetuar análise funcional e assim propor medidas para redução e/ou eliminação da causa raiz destes eventos de falhas;

VII - Análise funcional e de risco das falhas e variáveis envolvidas no processo de lubrificação industrial com a aplicação da ferramenta FMEA, a qual apontou a adequada estratégia de manutenção e o modo correto de execução de suas tarefas (PPT- Procedimento Padrão de Trabalho). Estas medidas estruturaram a a politica de lubrificação da maquina cobrideira, objetivando disponibilidade e operacional e contenção dos potenciais riscos de perda de qualidade e inocuidade do produto;

VIII - Implantação e execução de medidas (contempladas na política de lubrificação adotada para máquina cobrideira), as quais proporcionaram ganho de produtividade com aumento da disponibilidade da máquina cobrideira. A disponibilidade desta máquina aumentou de $A(t)=98,858002 \%$ obtido ao final de 2013 (período anterior a aplicação do método) para $A(t)=99,016383$ ao final de 2014, refletindo um aumento de 7 toneladas de produtos adicionados ao balanço da produção anual de 2014 (4.390.323,4 Kg), em relação ao balanço de produtividade total de 2013 (4.383.302,4 $\mathrm{Kg}$;

IX - Redução da ocorrência dos eventos de falhas relacionados ao processo de lubrificação, foram 3 eventos ocorridos ao longo do ano de 2014, sendo que a média anual entre o período de 2010 à 2013 eram de 8 eventos/ano ocorridos por deficiência nas atividades de lubrificação da maquina cobrideira; 
$X$ - Aumento do tempo de produtividade da máquina cobrideira entre os eventos de falhas, sendo $\operatorname{MTBF}(t)=296,83 \mathrm{~h}$ alcançado ao fim de 2014 , adicionando $34,75 \mathrm{~h}$ de operação deste ativo (entre as falhas) em relação ao $\operatorname{MTBF}(t)=262,08 \mathrm{~h}$ obtido no final de 2013;

XI - Ganhos diretos com a redução de custos aplicados com a manutenção corretiva da máquina Cobrideira (redução de mais de $50 \%$ do custo posteriormente a aplicação do método) e ganhos indiretos (redução de perda de produto por falta de qualidade e/ou inocuidade, redução do desgaste de componentes de máquina, aumento de vida útil, redução de horas extras para reposição de produtos atrasados devido indisponibilidade da máquina cobrideira, entre outros).

O método de seleção de política de lubrificação centrada em confiabilidade permite identificar e analisar as particularidades envolvidas no processo de lubrificação industrial em ativos industriais que compõe o parque fabril de indústria de alimentos.

Esta análise torna possível identificar as variações que interferem nesse processo de lubrificação permitindo definir abordagens para corrigir as deficiências evidenciadas e assim garantir disponibilidade operacional concomitantemente com contenção de focos de riscos de contaminação (os quais possam interferir na qualidade e inocuidade do produto).

Logo, o método desenvolvido, demonstra com a sua aplicação e apresentação de resultados, o atingindo de seu objetivo principal: o garantir eficiência nas atividades de lubrificação de forma a atender as necessidades da engenharia de qualidade, ou seja, manter produtividade e bom desempenho dos ativos industriais e o mesmo tempo garantir qualidade do produto em processamento.

\subsection{RECOMENDAÇÕES PARA TRABALHOS FUTUROS}

O método de seleção de política de lubrificação centrada em confiabilidade é uma ferramenta para a tomada de decisão. Permite uma avaliação quantitativa e 
qualitativas das particularidades do processo de lubrificação de ativos empregados em indústria de alimentos, e por meio desta, estruturar uma politica de lubrificação adequada que contemple ações direcionadas a garantir produtividade ao sistema fabril e qualidade ao produto em cada etapa de seu processo de fabricação. Neste sentido, para evolução do método, propõem-se como futuros trabalhos:

I - Aplicação do método para outras partes da cadeia de alimentos: área de armazenamento (refrigeração) e movimentação de materiais (empilhadeiras, paleteiras, pontes rolantes, etc.), efetuando as devidas adequações necessárias para o maquinário presente nestas instalações;

II - Extensão da aplicação do método para indústrias que possuam o SGQ pautado sobre normas e legislações similares a indústrias de alimentos como: indústria de bebidas, cosméticas e farmacêuticas. Efetuando, sempre, as devidas adequações necessárias no método em função das particularidades do processo de lubrificação aplicado no maquinário presente nestas instalações, e monitorando os resultados de disponibilidade operacional e redução e/ou eliminação de foco de risco de perda de qualidade e inocuidade do produto, a fim de, verificar a eficácia do método desenvolvido em outros processos de fabricação que apresentem complexidade quanto a realização das atividades de lubrificação;

III - Apropriação do método de seleção de política de lubrificação centrada em confiabilidade como projeto de lei, com o objetivo de adicionar os resultados do método como ferramenta para fiscalização dos órgãos competentes, a fim de assegurar qualidade ao produto e ao processo. Com a aplicação do método é possível assegurar a redução de falhas, as quais possam gerar foco de risco a perda de qualidade e inocuidade do produto (como por exemplo: vazamentos) e também garantir a aplicação do lubrificante de grau alimentício adequado a cada Zona de Criticidade $\left(Z_{C}\right)$;

IV- Ampliação do método para auxilio na gestão de estoques para gestão da lubrificação industrial e com esta medida evitar a falta e/ou excesso de materiais sobressalentes, os quais necessários a execução de todas as atividades de lubrificação e demais atividades relacionadas a engenharia de manutenção; 
V - Incorporar o pilar de Manutenção Autônoma (devido aos aspectos de limpeza e etiquetagem de defeitos visualizados pelos operadores de produção) pertencente à metodologia Manutenção Produtiva Total -TPM (Total Productive Maintenance);

E por final recomenda-se a ampliação do método para auxilio a análise de vida útil e do valor de depreciação, direcionando a tomada decisão quanto a melhoria das estratégias de manutenção e/ou aquisição de novo ativo industrial. 


\section{REFERÊNCIAS}

AHUJA, I.P.S.; KHAMBA, J.S. Assessment of contributions of successful TPM initiatives towards competitive manufacturing. Journal of Quality in Maintenance Engineering, n. 14, p. $356-374,2008$.

ALVERSON, F. et al. The organization and management of lubrication. In: MOBLEY, $\mathrm{K}$. et al. Maintenance engineering handbook, $7^{\text {th }}$ ed. New York: McGrawHill, 2008.p. 979 - 984.

ALVES, R.; FALSARELLA, O. M. Modelo conceitual de inteligência organizacional aplicada à função manutenção. Revista Gestão da Produção, São Carlos, n. 2, p. 313 - 324, 2009.

ARVANITOYANNIS, I.S. HACCP and ISO 22000: application to foods of animal origin. $1^{\text {st }}$ ed. Oxford: Blackwell; lowa: Blackwell, 2009. 549 p.

ASSIS, R. Apoio à decisão em gestão de manutenção: fiabilidade e manutenibilidade. Porto: Lidel Editora, 2004. 386 p.

ASSIS, R. Como avaliar se um equipamento deve ou não ser substituído na perspectiva de um gestor de activos. In: Congresso APMI - Associação Portuguesa de Manutenção, 2013. Lisboa. Anais do Congresso APMI, Portugal, 2013.

ASSOCIAÇÃO BRASILEIRA DE NORMAS TÉCNICAS. NBR22000: Sistemas de gestão da segurança de alimentos - Requisitos para qualquer organização na cadeia produtiva de alimentos. Rio de Janeiro, 2006.35 p.

ASSOCIAÇÃO BRASILEIRA DE NORMAS TÉCNICAS. NBR31000: Gestão de Risco-Princípios e Diretrizes. Rio de Janeiro, 2009.18p. 
ASSOCIAÇÃO BRASILEIRA DE NORMAS TÉCNICAS. NBR 5462: Confiabilidade e Mantenabilidade.Rio de Janeiro,1994. 37 p.

ASQ - AMERICAN SOCIETY FOR QUALITY FOOD, DRUG AND COSMETIC DIVISION. The Certified Quality Auditors HACCP Handbook. $3^{\text {rd }}$ ed. Wisconsin: Quality Press, 2014. 312 p.

AVEN, T. Risk analysis in maintenance . In : KOBBACY, K.A.H.; MURTHY, D.N. P. Complex system maintenance handbook. $1^{\text {st }}$ ed. London: Springer-Verlag, 2008. p. 437 - 458. (Springer Series in Reliability Engineering).

AVEN, T.; VINNEM, J.E. Risk management: with applications from the offshore petroleum industry. $1^{\text {st }}$ ed. London: Springer-Verlag, 2007.203p. (Springer Series in Reliability Engineering).

AZEVEDO, A. A lubrificação na indústria alimentícia de alimentos: consumo de óleos lubrificantes "food grade lubricants" chega a 830 toneladas ano. Revista SINDILUBE, n. 23, p. $14-16,2007$.

BELMIRO, P.N.A.; CARRETEIRO, R.P. Lubrificantes \& lubrificação industrial. $1^{\text {a }}$ ed. Rio de Janeiro: Interciência, 2006. 504 p.

BENBOW, D.W.; BROOME, H. W. The certified reliability engineer handbook. $1^{\text {st }}$ ed. Milwaukee: Quality Press, 2009. 320 p.

BEN-DAYA, M.; DUFFUAA, S.O. Maintenance and quality: the missing link. Journal of Quality in Maintenance Engineering, n. 1, p. $20-6,1995$.

BERTOLINI, M. ; BEVILACQUA, M.; MASON, G. Reliability design of industrial plants using petri nets. Journal of Quality in Maintenance Engineering, n. 12,p. 397 -411, 2006.

BRASIL. Agência Nacional de Vigilância Sanitária - ANVISA. Resolução RDC no 77, de 17 de agosto de 2000. Dispõe sobre a extensão de uso do aditivo INS 905a 
Óleo Mineral, como coadjuvante de tecnologia nas funções de agente de moldagem em balas de goma e de gelatina e de agente supressor de pó em grãos de cereais. Brasília: Diário Oficial da União, 2000.2 p.

BRASIL. Agência Nacional de Vigilância Sanitária - ANVISA. Resolução RDC ㄲo 91, de 11 de maio de 2001. Regulamento Técnico - Critérios Gerais e Classificação de Materiais para Embalagens e Equipamentos em Contato com Alimentos. Brasília: Diário Oficial da União, 2001. 6 p.

BRASIL. Agência Nacional de Vigilância Sanitária - ANVISA. Resolução RDC no 275, de 21 de outubro de 2002. Dispõe sobre o Regulamento Técnico de Procedimentos Operacionais Padronizados Aplicados aos Estabelecimentos Produtores/ Industrializadores de Alimentos e a Lista de Verificação das Boas Práticas de Fabricação - BPF em Estabelecimentos Produtores / Industrializadores de Alimentos. Brasília: Diário Oficial da União, 2003. 20 p.

BRASIL. Agência Nacional de Vigilância Sanitária - ANVISA. Resolução RDC no 216, de 15 de setembro de 2004. Dispõe sobre o Regulamento Técnico de Boas Práticas para Serviços de Alimentação. Brasília: Diário Oficial da União, 2004. $14 p$.

BRASIL. Agência Nacional de Vigilância Sanitária - ANVISA. Resolução RDC № 17, de de 17 de março de 2008. Regulamento Técnico sobre Lista Positiva de Aditivos para Materiais Plásticos destinados à Elaboração de Embalagens e Equipamentos em Contato com Alimentos. Brasília: Diário Oficial da União, 2008. $65 \mathrm{p}$.

BRASIL. Banco Nacional de Desenvolvimento Econômico e Social - BNDES. Relatório de Potencial de Diversificação da Indústria Química Brasileira - Parte 3 Óleos Lubrificantes. Rio de Janeiro: BNDES, 2014. 33 p.

BRASIL. Ministério da Agricultura e do Abastecimento - MAPA. Portaria ํㅜ 40, de 20 de janeiro de 1997. Manual de Procedimentos no Controle da Produção de Bebidas e Vinagres, em anexo baseado nos princípios do Sistema de Analise 
de Perigo e Pontos Críticos de Controle - APPCC. Brasília: Diário Oficial da União, 1997. 8 p.

BRASIL. Ministério da Agricultura e do Abastecimento - MAPA. Portaria ํo 368, de 4 de setembro de 1997. Regulamento Técnico sobre as Condições HigiênicoSanitárias e de Boas Práticas de Fabricação para Etabelecimentos Elaboradores / Industrializadores de Alimentos. Brasília: Diário Oficial da União, 1997. $12 \mathrm{p}$.

BRASIL. Ministério da Agricultura e do Abastecimento - MAPA. Portaria oํ 46, de 10 de fevereiro de 1998. Estabelecimento do Manual de Procedimentos para implantação do sistema APPCC nas indústrias de produtos de origem animal. Brasília: Diário Oficial da União, 1998.28 p.

BRASIL. Ministério da Agricultura e do Abastecimento - MAPA. Resolução RDC no 10, de 22 de maio de 2003. Programa Genérico de Procedimentos - Padrão de Higiene Operacional - PPHO, a ser utilizado nos Estabelecimentos de Leite e Derivados que funcionam sob o regime de Inspeção Federal, como etapa preliminar e essencial dos Programas de Segurança Alimentar do tipo APPCC (Análise de Perigos e Pontos Críticos de Controle). Brasília: Diário Oficial da União, 2003.5 p.

BRASIL. Ministério da Agricultura e do Abastecimento - MAPA. Instrução Normativa № 04, de 01 de março de 2007. Regulamento Técnico sobre as Condições Higiênico- sanitárias e de Boas Práticas de Fabricação para Estabelecimentos Fabricantes de Produtos Destinados á Alimentação Animal e o Roteiro de Inspeção. Brasília: Diário Oficial da União, 2007. 18 p.

BRASIL. Ministério da Marinha de Guerra, do Exército e da Aeronáutica Militar. Decreto de Lei oo 986, de 21 de outubro de 1969. Legislação Básica de Alimentos.Brasília: Repúlblica Federativa do Brasil, 1969, 13p.

BRASIL. Ministério da Saúde - MS. Portaria № 1428, de 26 de novembro de 1993. Aprova o Regulamento Técnico para Inspeção Sanitária de Alimentos, as 
Diretrizes para o Estabelecimento de Boas Práticas de Produção e de Prestação de Serviços na Área de Alimentos e o Regulamento Técnico para o Estabelecimento de Padrão de Identidade e Qualidade (PIQ's) para Serviços e Produtos na Área de Alimentos. Brasília: Diário Oficial da União, 1993.18 p.

BRASIL. Ministério da Saúde - MS. Portaria no 326, de 30 de julho de 1997. Regulamento Técnico para Condições Higiênicos-Sanitárias e de Boas Práticas de Fabricação para Estabelecimentos Produtores/Industrializadores de Alimentos. Brasília: Diário Oficial da União, 1997. 8 p.

BRASIL. Ministério da Saúde - MS. Portaria no 1210, de 03 de agosto de 2006. Regulamento Técnico de Boas Práticas, que estabelece os critérios e parâmetros para a produção/fabricação, importação, manipulação, fracionamento, armazenamento, distribuição, venda para o consumo final e transporte de alimentos e bebidas. Brasília: Diário Oficial da União, 2006. 34 p.

BLOOM, N. Reliability centered maintenance (RCM): implementation made simple. $1^{\text {st }}$ ed. New York: McGraw-Hill; San Francisco: McGraw-Hill; Sydney: McGraw-Hill, 2006. 292 p.

CABRAL, J. P. Organização e gestão da manutenção. Lisboa: Lidel, 2006. 384 p.

CASTLE, M. Full Circle Reliability. In: GRESHAM, R.M.; TOTTEN, G.E. Lubrication and maintenance of industrial machinery: best practices and reliability. $2^{\text {nd }}$ ed.New York: CRR Press. 2006. p. 1 - 6.

CHAPMAN,C.; WARD,S. Project risk management processes, techniques and insights. $2^{\text {nd }}$. New York: Wiley \& Sons,2003. 408 p.

CHAUDRY, M.M.; REGENSTEIN, J.M. 1994. Implications of biotechnology and genetic engineering for Kosher and Halal foods. Trends in Food Science \& Technology , n. 5 , p.165-168, 1994. 
CODEX ALIMENTARIUS COMMISSION. Code of hygienic practice for precooked and cooked foods in mass catering. CAC/RCP 39, $1993.18 p$.

CODEX ALIMENTARIUS COMMISSION. Food higiene and basic texts. 2 nd. Rome: FAO - food and agriculture organization of the united nations world health organization, 1999.77p.

CODEX ALIMENTARIUS COMMISSION. General principles of food hygiene. CAC/RCP 1-1969, Rev. 4 -2003, 2003. 28 p.

DABBS, T. Operating policies of effective maintenance. In: MOBLEY, K. et al. Maintenance engineering handbook, $7^{\text {th }}$ ed . New York: McGrawHill, 2008.p.65-79.

DEMAN, J.M. Principles of food chemistry. Maryland: Aspen, 1999. 645 p.

DEY, P.K. A risk-based model for inspection and maintenance of cross-country petroleum pipeline. Journal of Quality in Maintenance Engineering, n. 7, p. $25-$ 41, 2001.

DHILLON, B. S. Engineering maintenance: a modern approach. New York: CRC PRESS LLC, 2002. 224 p.

DHILLON, B. S. Maintainability, maintenance and reliability for engineers. $1^{\mathrm{st}}$ ed. New York: CRC Press, 2006.228 p.

DHILLON, B.S. Reliability, quality and safety for engineers. New York: CRC PRESS LLC, 2005. 240 p.

DIAS, J.A.M.; Pereira, Z.L.; Fiabilidade e gestão da manutenção de sistemas reparáveis. In: SOARES, C.G.; TEIXEIRA, A.P.; ANTÃO, P. Análise e gestão de riscos, segurança e fiabilidade. v.ll. Lisboa: Edições Salamandra, 2005. P. 591 602. 
DOWN, M. et al. FMEA - potential failure mode and effects analysis: reference manual. $4{ }^{\text {th }}$ ed. Southfield: AIAG, 2008. p. 141.

DUFFUAA, S.O.; RAOUF, A.; CAMPBELL, J.D. Planning and control of maintenance systems: modeling and analysis. $1^{\text {st }}$ ed. New York: John Wiley \& sons, 1999.371p.

EBELING, C. E. An introduction to reliability and maintainability engineering. $2^{\text {nd }}$ ed. Illinois: Waveland Press Incorporated, 2010.544 p.

EDWARDS, D,; HOLT, J. G. D.; HARRIS, F.C. Predictive maintenance techniques and their relevance to construction plant. Journal of Quality in Maintenance Engineering, n. 4 , p. $25-37,1998$.

EISINGER, S.; RAKOWSKY, U.K. Modeling of uncertainties in reliability centered maintenance: a probabilistic approach. Reliability Engineering \& System Safety , n. 71 , p. $159-164,2000$.

ELDRIDGE, K. How to make your food or beverage facility successful. Machinery Lubrication, 2007. Disponível em:< http://www.machinerylubrication.com/

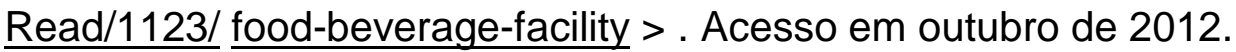

ESTADOS UNIDOS DA AMÉRIA. CFR - code of federal regulations title 21. U.S. Food and Drug Administration - FDA. Disponível em: < http://www. www.fda.gov >. Acessado em agosto 2012.

ESTADOS UNIDOS DA AMÉRICA. White Book ${ }^{\mathrm{TM}}$ nonfood compounds listings directory. NSF National Science Foundation. Disponível em: < http://www.nsf.org/usda/psnclistings.asp >. Acessado em agosto 2012.

FAERGEMAND, J. The ISO 22000 series global standards for safe food supply chains. New Food Magazine, n.5, p.4 - 7, 2008. 
FAULIN, J. et al. Simulation methods for reliability and availability of complex systems. $1^{\text {st }}$ ed. London: Springer-Verlag, 2010.315p.(Springer Series in Reliability Engineering).

FERJENCIK, M. IPICA_Lite-Improvements to root cause analysis. Journal Reliability Engineering and System Safety, n. 131, p. 1 - 13, 2014.

FIGUEIREDO, V. F. F.; NETO, P.L. O. C. Implantação do haccp na indústria de alimentos. Gestão \& Produção, v.8, n.1, p.100-111, 2001.

FILHO, G.B. Dicionário de termos de manutenção, confiabilidade e qualidade. $3^{\mathrm{a}}$ ed. Rio de Janeiro: Ciência Moderna Ltda, 2004. 273 p.

FILHO, G.B. PCM - planejamento e controle de manutenção. Curitiba: ABRAMAN, 2003. 233p. Apostila para o curso de planejamento e controle de manutenção.

FITCH, J.C.; GEBARIN, S. WILLIAMSON, M. Food-grade lubricants and the food processing industry. In: TOTTEN, G.E. Handbook of lubrication and tribology: application and maintenance. $2^{\text {nd }}$ ed. Portland: CRC Press ,2006. p. $484-503$.

FOGLIATTO, F. S.; RIBEIRO, J.L.D. Confiabilidade e manutenção industrial. $1^{\mathrm{a}}$ ed. São Paulo: Campus-Elsevier, 2009. 288 p.

FURTINI, L.L. R.; ABREU, L.R.; Utilização de APPCC na indústria de alimentos. Ciência Agrotécnica. Lavras, v.30, n.2, p. 358 - 363,2005.

GEBARIN, S. The basics of food-grade lubricant. Machinery Lubrication Magazine, 2009. Disponível em: < http://www.machinerylubrication.com/Read/1857// food-grade- lubricants-basics >. Acesso em outubro de 2012.

GIRARD, J. The continuing evolution of food-grade lubricants. Machinery Lubrication, 2002. Disponível em: < http://www.machinerylubrication.com/Read/366 /food-lubes $>$. Acesso em outubro de 2012. 
GRESHAM, R.M.; TOTTEN, G.E. Lubrication and maintenance of industrial machinery: best practices and reliability. $2^{\text {nd }}$ ed.New York: CRR Press, 2006.284p.

HAVET, L. et al.Tribological characteristics of some environmentally friendly lubricant. Wear Journal, n. 248, p. $140-146,2001$.

HAWKINS, B.; KISTER, T.C. Maintenance planning and scheduling handbook. $1^{\text {st }}$ ed .New Jersey: Elsevier Science \& Technology Books, 2006.331p.

HAYWORTH, G. I. Reliability engineering advances. $1^{\text {st }}$ ed. New York: Nova Science, 2008. 441 p.

HEISLER, R. Effective maintenance organizations. In: MOBLEY, K. et al. Maintenance engineering handbook. $7^{\text {th }}$ ed. New York: McGrawHill, 2008. p. 57 64.

HODSON, D. Food-grade lubricants reduce contamination threats for food and beverage manufacturers. Machinery Lubrication Magazine, 2004. Disponível em: $<$ http://www.machinerylubrication.com/Read/572/food-grade-contamination>. Acesso em outubro de 2012.

INTERNATIONAL ORGANIZATION FOR STANDARDIZATION. ISO 21469: Safety of Machinery -- Lubricants with Incidental Product Contact -- Hygiene Requirements. Geneve, 2006. 7 p.

ISENHOUR, S. Maintenance engineer's toolbox. In: MOBLEY, K. et al. Maintenance engineering handbook. $7^{\text {th }}$ ed. New York: McGrawHill, 2008.p. 339358.

JOHNSON, M.Lubrication program development and scheduling. In: GRESHAM, R. M.; TOTTEN, G.E. Lubrication and maintenance of industrial machinery: best practices and reliability. $2^{\text {nd }}$ ed.New York: CRR Press. 2006. p.169 -198. 
KARDEC, A.; NASCIF, J. Manutenção: função estratégica. $2^{a}$ ed. Rio de Janeiro: Qualitymark Ltda, 2009.368p.

KELLY, A. Managing Maintenance Resources. $1^{\text {st }}$ ed. New York: ButterworthHeinemann, 2006. 309 p.

KOBBACY, K.A.H.; MURTHY, D.N.P. Complex system maintenance handbook. $1^{\text {st }}$ ed. London: Springer-Verlag, 2008.657p. (Springer Series in Reliability Engineering).

KOEL, J. Food-grade lubricants come of age: past trade-offs between performance and safety have disappeared. Food Engineering Magazine, n.7, p.73 - 79, 2012.

KOLYA, L. Legislação para lubrificantes alimentícios. Blog Food Safety Brazil Interativo de Segurança de Alimentos, 2012. Disponível em: $<$ http://foodsafetybrazil.com/legislacao-de-lubrificantes-de-grau-alimenticio $>$. Acesso em dezembro de 2013.

KUDA, T.; IWAI, A.; YANO, T. Nutrition and sciences. Food and Chemical Toxicology, v.5, p.1695 - 1700, 2004.

KUNG, P.R. Validation and verification of HACCP plans in retail food establishments. Massachusetts: Department of Public Health, 2003. 98p Course for retail food regulators.

LABS, W. Keep the gears running. Food engineering magazine, n.2, p. $6-13$, 2011.

LAFRAIA, J.R. B. Manual de confiabilidade, mantenabilidade e disponibilidade. Rio de Janeiro: Qualitymark, 2001.388 p.

LANSDOWN, A.R. Lubrication and lubricant selection: a practical guide. $3^{\text {rd }}$ ed. London: Professional Engineering Limited, 2004. 285 p. 
LAWATE, S. What you need to know about food-grade lubricants. Machinery Lubrication, 2007.Disponível em: < http://www.machinerylubrication.com/Read/1069 /food-grade $>$. Acesso em outubro de 2012.

LEE, J.; WANG, H. New technologies for maintenance. In: KOBBACY, K.A.H.; MURTHY, D.N. P. Complex system maintenance handbook. $1^{\text {st }}$ ed. London: Springer-Verlag, 2008.p.49-78. (Springer Series in Reliability Engineering).

LEVITT, J. The Handbook of maintenance management. $1^{\text {st }}$ ed. New York: Industrial Press Incorporation, 1997.488 p.

LEWIS, E. E. Introduction to reliability engineering. $2^{\text {nd }}$ ed. New York: John Wiley \& Sons; Toronto: John Wiley \& Sons; Singapore: John Wiley \& Sons, 1996. $464 \mathrm{p}$.

LINDQVIST, B.H. Maintenance of repairable systems. In: KOBBACY, K. A.H.; MURTHY, D.N. P. Complex system maintenance handbook. $1^{\text {st }}$ ed. London: Springer-Verlag, 2008. p.235 -262. (Springer Series in Reliability Engineering).

MANG, T.; DRESEL, W. Lubricants and lubrication. $2^{\text {nd }}$ ed. Weinheim: Wiley-VCH Verlag GmbH \& Co, 2007.850p.

MANZINI,R. et al.Maintenance from industrial systems. $1^{\text {st }}$ ed. London: SpringerVerlag, 2011.478p. (Springer Series in Reliability Engineering).

MARGARONI, D. White oils and the food industry. Industrial Lubrication and Tribology, n. 51, p. $6-12,1999$.

MARTINS, M.P.G.; LEITÃO, A.L.F. Predição de falhas no apoio á decisão na gestão de manutenção. In: CONFENG - Conferência de Engenharia ",5, 2009, Covilhã, Portugal. Anais da 5a COFENG - "Engenharia 2009: Inovação e Desenvolvimento". Covilhã: UBI - Universidade da Beira Interior Portugal, 2009. 
MENSAH, L. D.; JULIEN, D. Implementation of food safety management systems in the UK. Food Control , n. 22 ,p.1216-1225,2011.

MISHRA, R.C. Reliability and maintenance engineering. ${ }^{\text {st }}$ ed.New Delhi: New Age International Publishers, 2006. 202 p.

MJEMA, E.A.M. An analysis of personnel capacity requirement in the maintenance department by using a simulation method. Journal of Quality in Maintenance Engineering, n.8, p. 253-273, 2002.

MOBLEY, K. R. Maintenance fundamentals. $2^{\text {nd }}$ ed. New York: Elsevier Butterworth-Heinemann, 2004. 418 p.

MOBLEY, K.R. et al. Maintenance engineering handbook, $7^{\text {th }}$ ed. New York: McGrawHill, 2008.1200p.

MODARRES, M. What every engineer should know about reliability and risk analysis. New York: Marcel Dekker, 1992. 351 p.

MODARRES, M. ; KAMINSKIY,M.; KRIVTSOV,V. Reliability engineering and risk analysis: a practical guide . $2^{\text {nd }}$ ed. New York :Taylor and Francis Group LIC. 2009, $471 \mathrm{p}$.

MOUBRAY, J. RCM II: reliability centered maintenance. $2^{\text {nd }}$ ed. New York: Industrial Press Incorporation, 2000. 426 p.

MURTHY, D.N.P.; PONGPECH,J. Maintenance of leased equipment. In: KOBBACY, K.A.H.; MURTHY, D.N. P. Complex system maintenance handbook. $1^{\text {st }}$ ed. London: Springer-Verlag, 2008.p.394-436. (Springer Series in Reliability Engineering).

MYERS, A. Complex system reliability: multichannel systems with imperfect fault coverage. $2^{\text {nd }}$ ed. London: Springer-Verlag, 2010. 238 p. (Springer Series in Reliability Engineering). 
NARAYAN, V. The raison d'être of maintenance. Journal of Quality in Maintenance Engineering, v. 4, p. $38-50,1998$.

NEALE, M. J. Lubrication and reliability handbook. Boston: ButterworthHeinemann ; Oxford: Butterworth-Heinemann; Melbourne: Butterworth-Heinemann. 2006. 256 p.

PALMER, R. D. Maintenance planning and scheduling handbook. $2^{\text {nd }}$ ed. New York: McGraw-Hill; Chicago: McGraw-Hill; London: McGraw-Hill; Milan: McGraw-Hill; Madrid: McGraw-Hill, 2006. 820 p.

PARIDA, A.; KUMAR, U. Maintenance performance measurement (MPM): issues and challenges. Journal of Quality in Maintenance , n.12, p. 239 - 251, 2006.

PEENS, J. The missing link in reliability lubrication maintenance. Machinery Lubrication, 2007. Disponível em : < http://www.machinerylubrication.com/Read/1126 /reliability-lubrication-maintenance >. Acessado em outubro de 2013.

PERCY, D.F. Maintenance based on limited data. In: KOBBACY, K.A.H.; MURTHY, D.N. P. Complex system maintenance handbook. $1^{\text {st }}$ ed. London: Springer-Verlag, 2008.p.133-154. (Springer Series in Reliability Engineering).

PIRRO, D.M; WESSOL, A.A. Lubrication fundamental. $2^{\text {nd }}$ ed. New York: Marcel Dekker Incorporation, 2001.540p.

RAJEWSKI, T.E; FOKENS, J.S.; WATSON, M.C. The development and application of synthetic food grade lubricants. Industrial Lubrication and Tribology, n. 52, p. $110-115,2000$.

RAO,K.D. et al. Dynamic fault tree analysis: simulation approach. In: FAULIN, J. Simulation methods for reliability and availability of complex systems. $1^{\text {st }}$ ed. London: Springer-Verlag, 2010. p.41 - 63. (Springer Series in Reliability Engineering). 
RAUSAND, M.; VATN, J. Reliability centred maintenance. In: KOBBACY, K. A.H.; MURTHY, D.N. P. Complex system maintenance handbook. $1^{\text {st }}$ ed. London: Springer-Verlag, 2008. p.79 - 108. (Springer Series in Reliability Engineering).

SCHMIDT, R.H.; RODRICK,G. E. Food safety handbook. $1^{\text {st }}$ ed. New Jersey: John Wiley \& Sons, 2003.799p.

SHARMA, R. K.; SHARMA, P. System failure behavior and maintenance decision making using, RCA, FMEA and FM. Journal of Quality in Maintenance Engineering, n. 16, p. $64-88,2010$.

SHARMA, A.; YADAVA, G.S; DESHMUKH, S.G. A literature review and future perspectives on maintenance optimization. Journal of Quality in Maintenance Engineering, n. 17 , p. $5-25,2011$.

SILVA, C. M. I.; MATIAS, J.C.O; CABRITA, C.M.P.Proactive reliability maintenance: a case study concerning maintenance service costs. Journal of Quality in Maintenance Engineering, n.14, p. 343 - 355, 2008.

SILVA, M. B; WALLBANK, J. Lubrication and apllication method in machining. Industrial Lubrication and Tribology, n. 50, p. 149 - 152, 1998.

SIQUEIRA, I. P. Manutenção centrada na confiabilidade: manual de implementação. Rio de Janeiro: Qualitymark, 2005.408 p.

SPIEGEL , M. van der et al. Halal assurance in food supply chains: verification of halal certificates using audits and laboratory analysis.Trends in Food Science \& Technology, n.27, p.109-119, 2012.

SOUZA, G.F.M. Análise de confiabilidade aplicada ao projeto de sistema mecânicos. São Paulo: Epusp, 2003. 210 p. Apostila para disciplina de pósgraduação em engenharia mecânica do Departamento de Engenharia Mecatrônica e Sistemas Mecânicos, PMR-5201: Análise de Confiabilidade Aplicada ao Projeto de Sistema Mecânicos. 
TAVARES, L. Excelência na manutenção. $2^{\circ}$ ed. Salvador: Casa da Qualidade, 2001. $160 \mathrm{p}$.

TOTTEN, G. E. Handbook of lubrication and tribology: application and maintenance. $2^{\text {nd }}$ ed. Portland: CRC Press, $2006.1224 \mathrm{p}$.

TURNER, D. Food-grade greases. Machinery Lubrication, 2007. Disponível em : < http://www.machinerylubrication.com/Read/1129/food-grade-grease>. Acesso em: Out.2012.

VAZ, A.; MOREIRA, R.; HOGG, T. Introdução ao HACCP. $1^{\text {a }}$ ed. Porto : Orgal, 2000. $52 \mathrm{p}$.

VIANA, H. R. G. PCM - planejamento e controle de manutenção. $1^{\circ}$ ed. Rio de Janeiro: Qualitymark, 2002.167 p.

WANG, P.; GOEL, L. Power distribution system reliability evaluation using both analytical reliability network equivalent technique and time-sequential simulation approach. In: FAULIN, J. Simulation methods for reliability and availability of complex systems. $1^{\text {st }}$ ed. London: Springer-Verlag, 2010.p. 145171.(Springer Series in Reliability Engineering).

WILLIANSON, M. Understanding food-grade lubricants. Machinery Lubrication, 2003. Disponível em: < http://www.machinerylubrication.com/Read/445/food-gradelubricants $>$. Acesso em outubro de 2012. 


\section{APÊNDICE A - DADOS DE FALHAS DA MÁQUINA COBRIDEIRA (2010 Á 2013)}

\begin{tabular}{|c|c|c|c|c|c|c|c|c|c|c|c|c|c|c|}
\hline Ano & $\begin{array}{l}\text { Falhas } \\
\text { (n) }\end{array}$ & OS & Data & $\begin{array}{c}\text { TTR } \\
\text { (h) }\end{array}$ & $\begin{array}{l}\text { TBF } \\
\text { (h) }\end{array}$ & $t(h)$ & $\ln (\mathrm{t})$ & $\sum \ln (t)$ & $n(t)$ & $\rho(t)$ & $\begin{array}{c}\text { MTBF } \\
\left(t_{t}\right)\end{array}$ & $\begin{array}{c}\text { MTTRR } \\
(\mathrm{t})\end{array}$ & $A(t)$ & $\mathrm{R}(\mathrm{t})$ \\
\hline 2010 & 1 & 818 & /01 & 4,50 & 126,00 & 126,00 & 4,84 & & 1,40 & 0,00927449 & 107,82 & 4,50 & 3684 & \\
\hline 2010 & 2 & 48808 & $2 / 01$ & 2,15 & 100,50 & 226,50 &, 42 & 10,26 & 2,28 & 0,00841744 & 118,80 & 3,33 & 0,972774005 & ,991618 \\
\hline 2010 & 3 & 49467 & $15 / 01$ & 2,15 & 60,85 & 287,35 & 5,66 & 15,92 & 2,79 & 0,00809271 & 57 & 2,93 & 29 & 940 \\
\hline 2010 & 4 & 1 & /01 & 6,80 & 1 & 432 & 607 & & 92 & & & 0 & & \\
\hline 2010 & 5 & 49934 & $28 / 01$ & 2,50 & 119,20 & 551,40 & 6,31 & 28,30 & 4,80 & 0,00726601 & 137,63 & 3,62 & 0,974371169 & 0,992760 \\
\hline 2010 & 6 & 49954 & $05 / 02$ & 9,00 & 165,50 & 716,90 & 6,57 & 34,88 & 5,98 & 0,00695744 & 143,73 & 4,52 & 0,969532989 & 0,993067 \\
\hline 2010 & 7 & 49973 & $15 / 02$ & 2 & 201,00 & 917,90 & 6,82 & 41,70 & 7,34 & 0,00667887 & 3 & 4,23 & 0,0 (ט) & 993343 \\
\hline 2010 & 8 & 19091 & $19 / 02$ & 4,00 & 81,50 & 999,40 & 6,91 & 1861 & 7,89 & 0,00658559 & 151,85 & 4,20 & 0,973084966 & 0,993436 \\
\hline 2010 & 9 & 49995 & $03 / 03$ & 5,00 & 245,00 & 1244,40 & 7,13 & 55,73 & 9,47 & 0,00635114 & 157,45 & 4,29 & 0,973482967 & 0,993669 \\
\hline 2010 & 10 & 50040 & $07 / 03$ & 2,00 & 142,00 & 1386,40 & 7,23 & 62,97 & 10,36 & 0,00623868 & 160,29 & 4,06 & 0,975296657 & 781 \\
\hline 2010 & 11 & 50064 & $16 / 03$ & 7,00 & 187,00 & 1573,40 & 7,36 & 70,33 & 11,52 & 0,00610953 & 163,68 & 4,33 & 0,974243341 & 0,993909 \\
\hline 2010 & 12 & 37205 & $19 / 03$ & 3,50 & 56,00 & 1629,40 & 7,40 & 77,72 & 11,86 & 0,00607431 & 164,63 & 4,26 & 0,974785783 & 44 \\
\hline 2010 & 13 & 42965 & $25 / 03$ & 1,80 & 122,50 & 1751,90 & 7,47 & 85,19 & 12,60 & 0,00600194 & 166,61 & 4,07 & 0,976158993 & 0,994016 \\
\hline 2010 & 14 & 43618 & $25 / 03$ & 2,00 & 11,00 & 1762,90 & 7,47 & 92,67 & 12,66 & 0,00599573 & 166,79 & 3,92 & 0,97702827 & 0,994022 \\
\hline 2010 & 15 & 996870 & 1/03 & 2,50 & 122,20 & 1885,10 & 7,54 & 100,21 & 13,39 & 0,00592966 & 168,64 & 3,83 & 0,977812609 & 0,994088 \\
\hline 2010 & 16 & 996901 & $11 / 04$ & 4,00 & 228,50 & 2113,60 & 7,66 & 107,86 & 14,73 & 0,00581855 & 171,86 & 3,84 & 0,978158991 & 0,994198 \\
\hline
\end{tabular}

(Continua) 
(Continuação)

\begin{tabular}{|c|c|c|c|c|c|c|c|c|c|c|c|c|c|c|}
\hline Ano & $\begin{array}{c}\text { Falhas } \\
\text { (n) }\end{array}$ & OS & Data & $\begin{array}{c}\text { TTR } \\
\text { (h) }\end{array}$ & $\begin{array}{l}\text { TBF } \\
\text { (h) }\end{array}$ & $t(h)$ & $\ln (\mathrm{t})$ & $\sum \ln (\mathrm{t})$ & $m(t)$ & $\rho(t)$ & $\begin{array}{c}\text { MTBF } \\
\left(t_{t}\right)\end{array}$ & $\begin{array}{c}\text { MTTR } \\
(\mathrm{t})\end{array}$ & $A(t)$ & $R(t)$ \\
\hline 2010 & 17 & 997083 & $17 / 05$ & 3,00 & 731,00 & 2844,60 & 7,95 & 115,82 & 18,88 & 0,00553971 & 180,51 & 3,79 & 0,979445616 & 0,994476 \\
\hline 2010 & 18 & 997105 & $23 / 05$ & 1,00 & 123,00 & 2967,60 & 8,00 & 123,81 & 19,56 & 0,00550108 & 181,78 & 3,63 & 0,980404417 & 0,994514 \\
\hline 2010 & 19 & 997796 & $28 / 05$ & 0,70 & 104,00 & 3071,60 & 8,03 & 131,84 & 20,13 & 0,00546984 & 182,82 & 3,48 & 0,981326075 & 545 \\
\hline 2010 & 20 & 997825 & $05 / 06$ & 2,75 & 209,30 & 3280,90 & 8,10 & 139,94 & 21,27 & 0,00541055 & 184,82 & 3,44 & 0,981714767 & 0,994604 \\
\hline 2010 & 21 & 998168 & $18 / 08$ & 4,30 & 165,25 & 3446,15 & 8,15 & 148,08 & 22,16 & 0,00536677 & 186,33 & 3,48 & 0,981648819 & 0,994648 \\
\hline 2010 & 22 & 100234 & $31 / 08$ & 6,75 & 247,70 & 3693,85 & 8,21 & 156,30 & 23,48 & 0,00 & 188,48 & 3,63 & 41 & 09 \\
\hline 2010 & 23 & 1001516 & 08/09 & 0,20 & 146,80 & 3840,65 & 8,25 & 164,55 & 24,26 & 0,00527146 & 189,70 & 3,48 & 0,98197254 & 0,994742 \\
\hline 2010 & 24 & 1001183 & $22 / 09$ & 2,00 & 251,80 & 4092,45 & 8,32 & 172,87 & 25,58 & 0,00521640 & 191,70 & 3,42 & 0,982468407 & 0,994797 \\
\hline 2010 & 25 & 1001556 & $26 / 09$ & 0,70 & 82,00 & 4174,45 & 8,34 & 181,21 & 26,00 & 0,00519932 & 192,33 & 3,31 & 0,983071372 & 0,994814 \\
\hline 2010 & 26 & 1001557 & $28 / 09$ & 1,15 & 62,30 & 4236,75 & 8,35 & 189,56 & 26,33 & 0,00518660 & 192,80 & 3,23 & 0,983529103 & 0,994827 \\
\hline 2010 & 27 & 1001855 & $03 / 10$ & 3,35 & 103,85 & 4340,60 & 8,38 & 197,93 & 26,86 & 0,00516588 & 193,58 & 3,23 & 0,983571411 & 0,994847 \\
\hline 2010 & 28 & 1002333 & $15 / 10$ & 2,00 & 206,65 & 4547,25 & 8,42 & 206,35 & 27,93 & 0,00512630 & 195,07 & 3,19 & 0,983913751 & 0,994887 \\
\hline 2010 & 29 & 10030121 & $24 / 10$ & 5,50 & 166,00 & 4713,25 & 8,46 & 214,81 & 28,78 & 0,00509600 & 196,23 & 3,27 & 0,9836143 & 0,994917 \\
\hline 2010 & 30 & 1003445 & $07 / 11$ & 2,50 & 288,50 & 5001,75 & 8,52 & 223,33 & 30,24 & 0,00504619 & 198,17 & 3,24 & 0,983897057 & 0,994967 \\
\hline 2010 & 31 & 1003500 & $11 / 11$ & 2,7 & 81,5 & 5083,25 & 8,53 & 231,86 & 30,65 & 0,00503273 & 198,70 & 3,23 & 0,984024746 & 0,994980 \\
\hline 2010 & 32 & 1003790 & $11 / 11$ & 9 & 5 & 5088,25 & 8,53 & 240,40 & 30,68 & 0,00503191 & 198,73 & 3,41 & 0,983148884 & 0,994981 \\
\hline 2010 & 33 & 1003798 & $18 / 11$ & 1,5 & 136,5 & 5224,75 & 8,56 & 248,96 & 31,36 & 0,00500993 & 199,60 & 3,35 & 0,983501092 & 0,995003 \\
\hline
\end{tabular}

(Continua) 
(Continuação)

\begin{tabular}{|c|c|c|c|c|c|c|c|c|c|c|c|c|c|c|}
\hline Ano & $\begin{array}{l}\text { Falhas } \\
\text { (n) }\end{array}$ & OS & Data & $\begin{array}{c}\text { TTR } \\
\text { (h) }\end{array}$ & $\begin{array}{l}\text { TBF } \\
\text { (h) }\end{array}$ & $t(h)$ & $\ln (t)$ & $\sum \ln (t)$ & $m(t)$ & $\rho(t)$ & $\begin{array}{c}\text { MTBF } \\
(t)\end{array}$ & $\begin{array}{c}\text { MTTR } \\
(t)\end{array}$ & $A(t)$ & $\mathrm{R}(\mathrm{t})$ \\
\hline 2010 & 34 & 1005146 & $25 / 11$ & 6 & 125 & 5349,75 & 8,58 & 257,54 & 31,99 & 0,00499039 & 200,39 & 3,43 & 0,983188054 & 0,995022 \\
\hline 2010 & 35 & 1004041 & $02 / 12$ & 3,25 & 141 & 5490,75 & 8,61 & 266,16 & 32,69 & 0,00496897 & 201,25 & 3,42 & 0,983283224 & 995043 \\
\hline 2010 & 36 & 1005146 & $18 / 12$ & 2,5 & 311,75 & 5802,50 & 8,67 & 274,82 & 34,23 & 0,00492381 & 203,09 & 3,40 & 0,983554542 & 0,995088 \\
\hline 2010 & 37 & 1005223 & $22 / 12$ & 1,15 & 102,5 & 5905,00 & 8,68 & 283,51 & 34,73 & 0,00490957 & 203,68 & 3,34 & 0,983889698 & 0,995102 \\
\hline 2010 & 38 & 1005255 & $27 / 12$ & 2,5 & 82,85 & 5987,85 & 8,70 & 292,20 & 35,14 & 0,00489828 & 204,15 & 3,31 & 0,984030399 & 0,995114 \\
\hline 2010 & 39 & 1005467 & $27 / 12$ & 3 & 7,5 & 5995,35 & 8,70 & 300,90 & 35,18 & 0,00489726 & 204,20 & 3,31 & 0,98407173 & 0,995115 \\
\hline 2010 & 40 & 10061778 & $29 / 12$ & 3,15 & 36,5 & 6031,85 & 8,70 & 309,61 & 35,36 & 0,00489235 & 204,40 & 3,30 & 0,984105827 & 0,995120 \\
\hline 2010 & 41 & 1006884 & $30 / 12$ & 1,5 & 12,5 & 6044,35 & 8,71 & 318,31 & 35,42 & 0,00489068 & 204,47 & 3,26 & 0,984319312 & 0,995121 \\
\hline 2011 & 42 & 1006884 & $10 / 01$ & 1,75 & 208,5 & 6252,85 & 8,74 & 327,05 & 36,43 & 0,00486333 & 205,62 & 3,22 & 0,984574786 & 0,995148 \\
\hline 2011 & 43 & 1006915 & $21 / 01$ & 0,5 & 208,25 & 6461,10 & 8,77 & 335,83 & 37,44 & 0,00483706 & 229,25 & 3,16 & 0,986411235 & 0,995175 \\
\hline 2011 & 44 & 1017351 & $26 / 01$ & 2 & 104,5 & 6565,60 & 8,79 & 344,62 & 37,95 & 0,00482425 & 207,29 & 3,13 & 0,98511621 & 0,995187 \\
\hline 2011 & 45 & 1017352 & $29 / 01$ & 5 & 61 & 6626,60 & 8,80 & 353,42 & 38,24 & 0,00481688 & 207,60 & 3,17 & 0,984944576 & 0,995195 \\
\hline 2011 & 46 & 1017534 & $16 / 02$ & 2,25 & 354,75 & 6981,35 & 8,85 & 362,27 & 39,94 & 0,00477552 & 209,40 & 3,15 & 0,985164924 & 0,995236 \\
\hline 2011 & 47 & 1017565 & $08 / 03$ & 0,75 & 396,75 & 7378,10 & 8,91 & 371,17 & 41,83 & 0,00473208 & 211,32 & 3,10 & 0,985532854 & 0,995279 \\
\hline 2011 & 48 & 1017609 & $10 / 04$ & 2 & 671,25 & 8049,35 & 8,99 & 380,17 & 44,98 & 0,00466444 & 214,39 & 3,08 & 0,985840765 & 0,995346 \\
\hline 2011 & 49 & 1017716 & $19 / 04$ & 1,5 & 166 & 8215,35 & 9,01 & 389,18 & 45,76 & 0,00464873 & 215,11 & 3,05 & 0,986033439 & 0,995362 \\
\hline 2011 & 50 & 1007865 & $22 / 04$ & 4,5 & 61,5 & 8276,85 & 9,02 & 398,20 & 46,04 & 0,00464300 & 215,38 & 3,08 & 0,985919235 & 0,995368 \\
\hline
\end{tabular}

(Continua) 
(Continuação)

\begin{tabular}{|c|c|c|c|c|c|c|c|c|c|c|c|c|c|c|}
\hline Ano & $\begin{array}{c}\text { Falhas } \\
\text { (n) }\end{array}$ & OS & Data & $\begin{array}{l}\text { TTR } \\
\text { (h) }\end{array}$ & $\begin{array}{l}\text { TBF } \\
\text { (h) }\end{array}$ & $t(h)$ & $\ln (t)$ & $\sum \ln (\mathrm{t})$ & $m(t)$ & $\rho(t)$ & $\begin{array}{c}\text { MTBF } \\
(t)\end{array}$ & $\begin{array}{l}\text { MTTR } \\
(\mathrm{t})\end{array}$ & $A(t)$ & $R(t)$ \\
\hline 2011 & 51 & 1017929 & $03 / 05$ & 2,5 & 205,5 & 8482,35 & 9,05 & 407,25 & 46,99 & 0,00462421 & 216,25 & 3,06 & 0,986026189 & 0,995386 \\
\hline 2011 & 52 & 1018012 & $20 / 05$ & 1,75 & 333,5 & 8815,85 & 9,08 & 416,33 & 48,53 & 0,00459482 & 217,64 & 3,04 & 0,986226746 & 0,995416 \\
\hline 2011 & 53 & 1018040 & $17 / 06$ & 2 & 565,25 & 9381,10 & 9,15 & 425,48 & 51,11 & 0,00454785 & 219,88 & 3,02 & 0,986452402 & 0,995462 \\
\hline 2011 & 54 & 1018106 & $24 / 06$ & 2,5 & 124 & 9505,10 & 9,16 & 434,64 & 51,68 & 0,00453799 & 220,36 & 3,01 & 0,986523898 & 0,995472 \\
\hline 2011 & 55 & 1018067 & $02 / 07$ & 1,5 & 144,5 & 9649,60 & 9,17 & 443,81 & 52,33 & 0,00452668 & 220,91 & 2,98 & 0,98667801 & 0,995484 \\
\hline 2011 & 56 & 1018095 & $18 / 08$ & 2,75 & 964,5 & 10614,10 & 9,27 & 453,08 & 56,66 & 0,00445594 & 224,42 & 2,98 & 0,986901502 & 0,995554 \\
\hline 2011 & 57 & 1008171 & 02/09 & 6,26 & 291,25 & 10905,35 & 9,30 & 462,38 & 57,96 & 0,00443604 & 225,43 & 3,04 & 0,986710534 & 0,995574 \\
\hline 2011 & 58 & 1018173 & $05 / 09$ & 0,8 & 56,74 & 10962,09 & 9,30 & 471,68 & 58,21 & 0,00443224 & 225,62 & 3,00 & 0,986888181 & 0,995578 \\
\hline 2011 & 59 & 1018311 & $16 / 09$ & 2,5 & 209,2 & 11171,29 & 9,32 & 481,00 & 59,14 & 0,00441841 & 226,33 & 2,99 & 0,98696486 & 0,995591 \\
\hline 2011 & 60 & 1018481 & $05 / 10$ & 0,5 & 375,5 & 11546,79 & 9,35 & 490,36 & 60,79 & 0,00439432 & 227,57 & 2,95 & 0,987212632 & 0,995615 \\
\hline 2011 & 61 & 1018745 & $20 / 10$ & 1,5 & 293,5 & 11840,29 & 9,38 & 499,74 & 62,08 & 0,00437613 & 228,51 & 2,92 & 0,987366152 & 0,995633 \\
\hline 2011 & 62 & 1018934 & $22 / 10$ & 8,5 & 40,5 & 11880,79 & 9,38 & 509,12 & 62,26 & 0,00437366 & 228,64 & 3,01 & 0,98698986 & 0,995636 \\
\hline 2011 & 63 & 1019012 & $30 / 10$ & 1,25 & 138,5 & 12019,29 & 9,39 & 518,51 & 62,86 & 0,00436528 & 229,08 & 2,99 & 0,987133523 & 0,995644 \\
\hline 2011 & 64 & 1019256 & $06 / 12$ & 5 & 754,75 & 12774,04 & 9,46 & 527,97 & 66,14 & 0,00432155 & 231,40 & 3,02 & 0,987128244 & 0,995688 \\
\hline 2011 & 65 & 1019283 & $09 / 12$ & 2 & 58 & 12832,04 & 9,46 & 537,43 & 66,39 & 0,00431831 & 231,57 & 3,00 & 0,987203622 & 0,995691 \\
\hline 2011 & 66 & 1019328 & $13 / 12$ & 5,5 & 82 & 12914,04 & 9,47 & 546,89 & 66,74 & 0,00431377 & 231,82 & 3,04 & 0,987057803 & 0,995696 \\
\hline 2011 & 67 & 1019425 & $18 / 12$ & 1 & 78,5 & 12992,54 & 9,47 & 556,37 & 67,08 & 0,00430945 & 232,05 & 3,01 & 0,987198426 & 0,995700 \\
\hline
\end{tabular}


(Continuação)

\begin{tabular}{|c|c|c|c|c|c|c|c|c|c|c|c|c|c|c|}
\hline Ano & $\begin{array}{l}\text { Falhas } \\
\text { (n) }\end{array}$ & OS & Data & $\begin{array}{c}\text { TTR } \\
\text { (h) }\end{array}$ & $\begin{array}{c}\text { TBF } \\
\text { (h) }\end{array}$ & $t(h)$ & $\ln (\mathrm{t})$ & $\sum \ln (\mathrm{t})$ & $m(t)$ & $\rho\left({ }_{t}\right)$ & $\begin{array}{c}\text { MTBF } \\
\left(t_{t}\right)\end{array}$ & $\begin{array}{c}\text { MTTR } \\
(t)\end{array}$ & $A(t)$ & $\mathrm{R}(\mathrm{t})$ \\
\hline 2011 & 68 & 1019429 & $18 / 12$ & 4 & 6,5 & 12999,04 & 9,47 & 565,84 & 67,11 & 0,00430909 & 232,07 & 3,02 & 0,98713828 & 0,995700 \\
\hline 2011 & 69 & 1019706 & $23 / 12$ & 1 & 100 & 13099,04 & 9,48 & 575,32 & 67,54 & 0,00430364 & 232,36 & 2,99 & 0,98727737 & 0,995706 \\
\hline 2012 & 70 & 1045671 & $18 / 01$ & 13 & 482 & 13581,04 & 9,52 & 584,84 & 69,61 & 0,00427800 & 233,75 & 3,14 & 0,986756437 & 0,995731 \\
\hline 2012 & 71 & 1067245 & $31 / 01$ & 1,8 & 239 & 13820,04 & 9,53 & 594,37 & 70,63 & 0,00426568 & 234,43 & 3,12 & 0,986872318 & 0,995743 \\
\hline 2012 & 72 & 1073458 & $02 / 02$ & 2,5 & 40,2 & 13860,24 & 9,54 & 603,91 & 70,80 & 0,00426363 & 234,54 & 3,11 & 0,986914207 & 0,995745 \\
\hline 2012 & 73 & 1047789 & 02/02 & 4.25 & 8,5 & 13868,74 & 9,54 & 613,44 & 70,84 & 0,00426320 & 234,57 & 3,07 & 0,987092442 & 0,995746 \\
\hline 2012 & 74 & 1047811 & $13 / 02$ & 2 & 226,75 & 14095,49 & 9,55 & 623,00 & 71,80 & 0,00425178 & 235,20 & 3,05 & 0,987186316 & 0,995757 \\
\hline 2012 & 75 & 1049999 & $08 / 03$ & 3 & 313 & 14408,49 & 9,58 & 632,57 & 73,13 & 0,00423637 & 236,05 & 3,05 & 0,987235076 & 0,995773 \\
\hline 2012 & 76 & 1050023 & $01 / 04$ & 4 & 480 & 14888,49 & 9,61 & 642,18 & 75,16 & 0,00421348 & 237,33 & 3,06 & 0,987251953 & 0,995795 \\
\hline 2012 & 77 & 1055273 & $04 / 04$ & 2 & 59 & 14947,49 & 9,61 & 651,79 & 75,41 & 0,00421073 & 237,49 & 3,05 & 0,987316927 & 0,995798 \\
\hline 2012 & 78 & 1055347 & $06 / 04$ & 5 & 40 & 14987,49 & 9,61 & 661,41 & 75,58 & 0,00420887 & 237,59 & 3,08 & 0,987219939 & 0,995800 \\
\hline 2012 & 79 & 1062777 & $13 / 04$ & 6 & 121 & 15108,49 & 9,62 & 671,03 & 76,08 & 0,00420328 & 237,91 & 3,11 & 0,987085085 & 0,995806 \\
\hline 2012 & 80 & 1062853 & $04 / 05$ & 3,5 & 414 & 15522,49 & 9,65 & 680,68 & 77,82 & 0,00418453 & 238,98 & 3,12 & 0,987122202 & 0,995824 \\
\hline 2012 & 81 & 1004460 & $15 / 05$ & 3 & 206,5 & 15728,99 & 9,66 & 690,34 & 78,68 & 0,00417540 & 239,50 & 3,12 & 0,987155856 & 0,995833 \\
\hline 2012 & 82 & 1063744 & $23 / 05$ & 2,5 & 144 & 15872,99 & 9,67 & 700,02 & 79,28 & 0,00416911 & 239,86 & 3,11 & 0,987205477 & 0,995840 \\
\hline 2012 & 83 & 1074368 & $24 / 05$ & 8,15 & 3,5 & 15876,49 & 9,67 & 709,69 & 79,30 & 0,00416896 & 239,87 & 3,17 & 0,986959218 & 0,995840 \\
\hline 2012 & 84 & 1121391 & $09 / 07$ & 1,75 & 283,85 & 16160,34 & 9,69 & 719,38 & 80,48 & 0,00415676 & 240,57 & 3,15 & 0,987065303 & 0,995852 \\
\hline
\end{tabular}

(Continua) 
(Continuação)

\begin{tabular}{|c|c|c|c|c|c|c|c|c|c|c|c|c|c|c|}
\hline Ano & $\begin{array}{l}\text { Falhas } \\
\text { (n) }\end{array}$ & OS & Data & $\begin{array}{c}\text { TTR } \\
\text { (h) }\end{array}$ & $\begin{array}{l}\text { TBF } \\
\text { (h) }\end{array}$ & $t(h)$ & $n(t)$ & $\sum \ln (t)$ & $m(t)$ & $\rho(t)$ & $\begin{array}{c}\text { MTBF } \\
\left({ }_{t}\right)\end{array}$ & $\begin{array}{c}\text { MTTR } \\
(t)\end{array}$ & $A(t)$ & $\mathrm{R}(\mathrm{t})$ \\
\hline 2012 & 85 & 1124561 & $19 / 07$ & 2,5 & 187,25 & 16347,59 & 9,70 & 729,08 & 81,26 & 0,00414885 & 241,03 & 3,14 & 0,98712063 & 0,995860 \\
\hline 2012 & 86 & 1138907 & $01 / 08$ & 2,5 & 249,5 & 16597,09 & ,72 & 738,80 & 82,29 & 0,00413848 & 241,63 & 3,14 & 0,987182669 & 0,995870 \\
\hline 2012 & 87 & 1177309 & $10 / 08$ & 2 & 186,5 & 16783,59 & 9,73 & 748,53 & 83,06 & 0,00413084 & 242,08 & 3,12 & 0,987258655 & 0,995878 \\
\hline 2012 & 88 & 1180031 & $25 / 08$ & 4,5 & 292 & 17075,59 & 9,75 & 758,27 & 84,27 & 0,00411907 & 242,77 & 3,14 & 0,987231711 & 0,995889 \\
\hline 2012 & 89 & 1181391 & $02 / 09$ & 1,5 & 121,5 & 17197,09 & 9,75 & 768,02 & 84,77 & 0,00411425 & 243,06 & 3,12 & 0,987320371 & 0,995894 \\
\hline 2012 & 90 & 5 & $05 / 09$ & 3,5 & 6 & 17 & 6 & 8 & 85,02 & 0 & 0 & 3,13 & 9 & 97 \\
\hline 2012 & 91 & 1182559 & $19 / 09$ & 3 & 290,5 & 17549,09 & 9,77 & 787,55 & 86,21 & 0,00410049 & 243,87 & 3,12 & 0,987350948 & 0,995908 \\
\hline 2012 & 92 & 1213440 & $26 / 09$ & 1,5 & 123 & 17672,09 & 9,78 & 797,33 & 86,72 & 0,00409576 & 244,16 & 3,11 & 0,987435862 & 0,995913 \\
\hline 2012 & 93 & 1220001 & $02 / 10$ & 2 & 103,5 & 17775,59 & 9,79 & 807,12 & 87,14 & 0,00409180 & 244,39 & 3,09 & 0,987495312 & 0,995917 \\
\hline 2012 & 94 & 1221259 & $15 / 10$ & 2,5 & 271 & 18046,59 & 9,80 & 816,92 & 88,25 & 0,00408158 & 245,00 & 3,09 & 0,987551349 & 0,995927 \\
\hline 2012 & 95 & 1225499 & $21 / 10$ & 3,75 & 102,5 & 18149,09 & 9,81 & 826,73 & 88,67 & 0,00407776 & 245,23 & 3,10 & 0,98753516 & 0,995931 \\
\hline 2012 & 96 & 1230043 & $05 / 11$ & 2 & 290,25 & 18439,34 & 9,82 & 836,55 & 89,85 & 0,00406708 & 245,88 & 3,08 & 0,987612669 & 0,995941 \\
\hline 2012 & 97 & 1232111 & $22 / 11$ & 2,75 & 334 & 18773,34 & 9,84 & 846,39 & 91,21 & 0,00405503 & 246,61 & 3,08 & 0,987662545 & 0,995953 \\
\hline 2012 & 98 & 1237531 & $09 / 12$ & 2 & 333,25 & 19106,59 & 9,86 & 856,25 & 92,56 & 0,00404325 & 247,33 & 3,07 & 1434 & 965 \\
\hline 2012 & 99 & 1237902 & $12 / 12$ & 4,5 & 61 & 19167,59 & 9,86 & 866,11 & 92,80 & 0,00404112 & 247,46 & 3,08 & 0,987690847 & 0,995967 \\
\hline 2012 & 100 & 1239322 & $28 / 12$ & 1,5 & 310,5 & 19478,09 & 9,88 & 875,98 & 94,05 & 0,00403039 & 248,11 & 3,07 & 0,98778539 & 0,995978 \\
\hline 2013 & 101 & 1244675 & 05/01 & 2,5 & 102,5 & 19580,59 & 9,88 & 885,87 & 94,47 & 0,00402690 & 248,33 & 3,06 & 0,987817957 & 0,995981 \\
\hline
\end{tabular}

(Continua) 
(Continuação)

\begin{tabular}{|c|c|c|c|c|c|c|c|c|c|c|c|c|c|c|}
\hline Ano & $\begin{array}{c}\text { Falhas } \\
\text { (n) }\end{array}$ & OS & Data & $\begin{array}{c}\text { TTR } \\
\text { (h) }\end{array}$ & $\begin{array}{c}\text { TBF } \\
\text { (h) }\end{array}$ & $t(h)$ & $\ln (\mathrm{t})$ & $\sum \ln (t)$ & $n(t)$ & $\rho(t)$ & $\begin{array}{c}\text { MTBF } \\
(\mathrm{t})\end{array}$ & $\underset{\left(\begin{array}{l}(t) \\
\text { MTTR }\end{array}\right.}{\text { MTT }}$ & $A(t)$ & $\mathrm{R}(\mathrm{t})$ \\
\hline 2013 & 102 & 124 & & 2,75 & 543,25 & 20123,84 & 9,91 & & & 872 & 249,46 & 3,06 & 34269 & \\
\hline 2013 & 103 & 1275690 & $31 / 01$ & 1,75 & 8,75 & 20132,59 & 9,91 & 905,69 & 96,69 & 0,00400843 & 249,47 & 3,05 & 0,98793 & 0,996000 \\
\hline 13 & 104 & 78888 & $18 / 02$ & 2 & 374 & 20506 & ,93 & 1 & 98,18 & ( & 3 & 3,04 & 42 & 012 \\
\hline 2013 & 105 & 1294562 & 03/03 & 4 & 483 & 20989,59 & 9,95 & 925,57 & 100,11 & 0,00398090 & 251,20 & 3,05 & 0,988020195 & 0,996027 \\
\hline 2013 & 106 & 1300005 & $13 / 03$ & 1,75 & 206 & 21195,59 & 9,96 & 935,53 & 100,93 & 0,00397448 & 251,61 & 3,03 & 0,988086726 & 996033 \\
\hline 201 & 107 & 12 & $22 / 03$ & 2,5 & 5 & 2 & 7 & 0 & 1 & 0,00 & 7 & 3,03 & 5 & 39 \\
\hline 2013 & 108 & 1300085 & $11 / 04$ & 2 & 418 & 21800,84 & 990 & 955,49 & 103,33 & 0,00395602 & 252,78 & 3,02 & 7452 & 052 \\
\hline 2013 & 109 & 1300113 & $05 / 05$ & 4,75 & 499,25 & 22300,09 & 10,01 & 965,50 & 105,30 & 0,00394124 & 253,73 & 3,03 & 0,988179914 & 0,996067 \\
\hline 2013 & 110 & 1300176 & 08/05 & 3,85 & 58,25 & 22358,34 & 10,01 & 975,52 & 105,53 & 0,00393954 & 253,84 & 3,04 & 0,988156447 & 0,996068 \\
\hline 2013 & 111 & 1300347 & $20 / 05$ & 6 & 248,15 & 22606,49 & 10,03 & 985,54 & 106,51 & 0,00393235 & 254,30 & 3,07 & 0,988075479 & 0,996075 \\
\hline 2013 & 112 & 1300393 & $06 / 06$ & 0,75 & 351 & 22957,49 & 10,04 & 995,58 & 107,88 & 0,00392235 & 254,95 & 3,05 & 4755 & 0,996085 \\
\hline 2013 & 113 & 1300403 & $23 / 06$ & 1,5 & 356,25 & 23313,74 & 10,06 & 1005,64 & 109,28 & 0,00391238 & 255,60 & 3,03 & 0,988266797 & 0,996095 \\
\hline 2013 & 114 & 1300499 & $30 / 06$ & 2,5 & 145,5 & 23459,24 & 10,06 & 1015,70 & 109,85 & 0,00390835 & 255,86 & 3,03 & 0,988296619 & 0,996099 \\
\hline 2 & 115 & 1300654 & /08 & 1,5 & 10 & 2448 & 10,1 & 102 & 113 & 0,00388 & 257,68 & 2 & 72 & 27 \\
\hline 2013 & 116 & 1300671 & $12 / 09$ & 4 & 523,5 & 25009,24 & 10,13 & 1035,94 & 115,87 & 0,00386723 & 258,58 & 3,03 & 0,988436575 & 0,996140 \\
\hline 2013 & 117 & 1300712 & $15 / 09$ & 2 & 59 & 25068,24 & 10,13 & 1046,06 & 116,10 & 0,00386572 & 258,68 & 3,02 & 0,988474119 & 0,996142 \\
\hline 2013 & 118 & 1300753 & $30 / 09$ & 3,75 & 313 & 25381,24 & 10,14 & 1056,21 & 117,31 & 0,00385780 & 259,22 & 3,02 & 0,988474032 & 0,996150 \\
\hline
\end{tabular}

(Continua) 
(Conclusão)

\begin{tabular}{|c|c|c|c|c|c|c|c|c|c|c|c|c|c|c|}
\hline Ano & $\begin{array}{l}\text { Falhas } \\
\text { (n) }\end{array}$ & OS & Data & $\begin{array}{c}\text { TTR } \\
\text { (h) }\end{array}$ & $\begin{array}{l}\text { TBF } \\
\text { (h) }\end{array}$ & $t(h)$ & $\ln (\mathrm{t})$ & $\sum \ln (t)$ & $m(t)$ & $\rho(t)$ & $\begin{array}{c}\text { MTBF } \\
(t)\end{array}$ & $\begin{array}{c}\text { MTTR } \\
(\mathrm{t})\end{array}$ & $A(t)$ & $R(t)$ \\
\hline 2013 & 119 & 1300806 & $09 / 10$ & 1,5 & 185,25 & 25566,49 & 10,15 & 1066,36 & 118,03 & 0,00385316 & 259,53 & 3,01 & 0,988535895 & 0,996154 \\
\hline 2013 & 120 & 1300845 & $15 / 10$ & 3,5 & 124,5 & 25690,99 & 10,15 & 1076,51 & 118,50 & 0,00385007 & 259,74 & 3,01 & 0,988529623 & 0,996157 \\
\hline 2013 & 121 & 1300878 & $20 / 10$ & 4,25 & 101,5 & 25792,49 & 10,16 & 1086,67 & 118,90 & 0,00384756 & 259,90 & 3,02 & 0,988498602 & 0,996160 \\
\hline 2013 & 122 & 1301023 & $18 / 11$ & 2 & 604,75 & 26397,24 & 10,18 & 1096,85 & 121,22 & 0,00383285 & 260,90 & 3,02 & 0,988573525 & 0,996174 \\
\hline 2013 & 123 & 1301229 & $10 / 12$ & 5,5 & 460 & 26857,24 & 10,20 & 1107,05 & 122,98 & 0,00382192 & 261,65 & 3,04 & 0,988530304 & 0,996185 \\
\hline 2013 & 124 & 1301281 & $23 / 12$ & 2 & 267,5 & 27124,74 & 10,21 & 1117,25 & 124,00 & 0,00381566 & 262,08 & 3,03 & 0,98858002 & 0,996192 \\
\hline
\end{tabular}

Legenda:

TTF $($ Time to Repair) $=$ Tempo para reparo mensurado em horas $(\mathrm{h})$

$A(t)=$ Disponibilidade para sistemas reparáveis com falhas reveladas

Falhas $(\mathrm{n})=$ Número de falhas

$\mathrm{R}(\mathrm{t})=$ Confiabillidade para sistemas reparáveis

$\rho(t)=$ Função intensidade de falhas dos sistemas reparáveis (ROCOF)

$\mathrm{MTBF}=$ Tempo medio entre falhas mensurado em horas $(\mathrm{h})$ $\mathrm{t}=$ Tempo acumulado até $\mathrm{a}$ falha

$\mathrm{m}(\mathrm{t})=$ Número acumulado de falhas ao longo do tempo.

MTTR = Tempo médio para reparo

Fonte: Autoria própria 
APÊNDICE B - ANÁLISE FMEA DOS MODOS DE FALHAS RELACIONADOS À LUBRIFICAÇÃO INDUSTRIAL - MÁQUINA COBRIDEIRA

\begin{tabular}{|c|c|c|c|c|c|c|c|}
\hline \multirow{3}{*}{\multicolumn{2}{|c|}{ LOGO DA EMPRESA }} & \multirow{4}{*}{\multicolumn{2}{|c|}{$\begin{array}{c}\begin{array}{c}\text { FMEA No } \\
001-2014\end{array} \\
\text { Modo de Falha }\end{array}$}} & \multicolumn{4}{|c|}{ FMEA } \\
\hline & & & & \multirow{3}{*}{$\begin{array}{c}\text { Dados Técnicos: } \\
\text { Causa }\end{array}$} & \multirow{3}{*}{$\begin{array}{r}\text { Máquina Cobrideira } \\
\text { Data: 08/01/2014 } \\
\text { Consequência }\end{array}$} & \multirow{2}{*}{\multicolumn{2}{|c|}{$\begin{array}{l}\text { Linha de Produção } 1 \\
\text { Máquina Cobrideira }\end{array}$}} \\
\hline & & & & & & & \\
\hline Dispositivo & Função & & & & & $\mathbf{s}$ & $\begin{array}{l}\text { Definição da } \\
\text { Abordagem }\end{array}$ \\
\hline \multirow{6}{*}{$\begin{array}{l}\text { Caixa de } \\
\text { Cobertura } \\
\text { Superior }\end{array}$} & \multirow{3}{*}{$\begin{array}{c}\text { Primária: } \\
\text { Promover o } \\
\text { fluxo de calda } \\
\text { sobre o } \\
\text { produto }\end{array}$} & \multirow[b]{2}{*}{ M1 } & \multirow{2}{*}{$\begin{array}{c}\text { Presença de } \\
\text { névoa de óleo } \\
\text { no ar } \\
\text { comprimido } \\
\text { presente no } \\
\text { sistema de } \\
\text { ventilação }\end{array}$} & $\begin{array}{l}\text { Contaminação do ar comprimido } \\
\text { por névoa de óleo proveniente do } \\
\text { compressor }\end{array}$ & $\begin{array}{l}\text { Potencial risco de perda de } \\
\text { qualidade e inocuidade } \\
\text { (contaminação) do produto em } \\
\text { processamento }\end{array}$ & II & \multirow{6}{*}{$\begin{array}{c}\text { Plano de } \\
\text { lubrificação } \\
\text { com definição } \\
\text { de lubrificante } \\
\text { adequado aos } \\
\text { pontos de } \\
\text { lubrificação / } \\
\text { Construção de } \\
\text { procedimento } \\
\text { de trabalho } \\
\text { para execução } \\
\text { das atividades } \\
\text { de lubrificação } \\
\text { / Treinamento } \\
\text { para } \\
\text { qualificação da } \\
\text { mão de obra }\end{array}$} \\
\hline & & & & $\begin{array}{l}\text { Saturação do filtro do sistema de } \\
\text { lubrificação do compressor }\end{array}$ & $\begin{array}{l}\text { Potencial risco de perda de } \\
\text { qualidade e inocuidade } \\
\text { (contaminação) do produto em } \\
\text { processamento }\end{array}$ & II & \\
\hline & & \multirow{4}{*}{ M2 } & \multirow{4}{*}{$\begin{array}{l}\text { Falta de massa } \\
\text { na calha de } \\
\text { fluxo de calda }\end{array}$} & $\begin{array}{c}\text { Parada da unidade de } \\
\text { bombeamento de retorno de } \\
\text { massa. }\end{array}$ & $\begin{array}{l}\text { Inoperância da máquina e } \\
\text { perda de produtividade }\end{array}$ & I & \\
\hline & \multirow{3}{*}{\begin{tabular}{|} 
Secundária: \\
Promover \\
ventilação \\
para acelerar a \\
secagem da \\
cobertura \\
sobre o \\
produto
\end{tabular}} & & & $\begin{array}{l}\text { Parada da unidade de } \\
\text { bombeamento de circulação de } \\
\text { massa. }\end{array}$ & $\begin{array}{l}\text { Inoperância da máquina e } \\
\text { perda de produtividade }\end{array}$ & I & \\
\hline & & & & $\begin{array}{l}\text { Parada do motorredutor de } \\
\text { acionamento da unidade de } \\
\text { bombeamento de retorno de } \\
\text { massa }\end{array}$ & $\begin{array}{l}\text { Inoperância da máquina e } \\
\text { perda de produtividade }\end{array}$ & 1 & \\
\hline & & & & $\begin{array}{l}\text { Parada da unidade de } \\
\text { bombeamento de retorno de } \\
\text { massa }\end{array}$ & $\begin{array}{l}\text { Inoperância da máquina e } \\
\text { perda de produtividade }\end{array}$ & 1 & \\
\hline
\end{tabular}

(Continua) 
(Continuação)

\begin{tabular}{|c|c|c|c|c|c|c|c|}
\hline \multirow{3}{*}{\multicolumn{2}{|c|}{ LOGO DA EMPRESA }} & \multirow{4}{*}{\multicolumn{2}{|c|}{$\begin{array}{c}\text { FMEA No } \\
\text { 001-2014 } \\
\text { Modo de Falha }\end{array}$}} & \multicolumn{4}{|c|}{ FMEA } \\
\hline & & & & \multirow{2}{*}{ Dados Técnicos: } & Máquina Cobrideira & \multirow{2}{*}{\multicolumn{2}{|c|}{$\begin{array}{c}\text { Linha de Produção } 1 \\
\text { Máquina Cobrideira }\end{array}$}} \\
\hline & & & & & Data: 08/01/2014 & & \\
\hline Dispositivo & Função & & & Causa & Consequência & $\mathbf{S}$ & $\begin{array}{l}\text { Definição da } \\
\text { Abordagem }\end{array}$ \\
\hline \multirow{5}{*}{$\begin{array}{l}\text { Esteira } \\
\text { Vibratória }\end{array}$} & \multirow{5}{*}{$\begin{array}{c}\text { Primária: } \\
\text { Proporcionar } \\
\text { a vibração } \\
\text { para acelerar } \\
\text { gotejamento } \\
\text { e retirar } \\
\text { excessos de } \\
\text { cobertura } \\
\text { Secundária: } \\
\text { Transportar } \\
\text { produto } \\
\text { através da } \\
\text { calha (fluxo } \\
\text { de calda) } \\
\text { para receber } \\
\text { cobertura }\end{array}$} & \multirow{4}{*}{ M3 } & \multirow{4}{*}{$\begin{array}{l}\text { Desgaste das } \\
\text { buchas de bronze } \\
\text { do eixo de } \\
\text { movimentação da } \\
\text { esteira metálica }\end{array}$} & $\begin{array}{l}\text { Lubrificação } \\
\text { deficiente }\end{array}$ & $\begin{array}{l}\text { Inoperância da máquina / Defeito } \\
\text { e/ou desgaste nos elementos de } \\
\text { máquina }\end{array}$ & I & \multirow{5}{*}{$\begin{array}{c}\text { Abordagem } \\
\text { Plano de } \\
\text { lubrificação (evitar } \\
\text { excesso, falta e/ou } \\
\text { qualquer deficiência } \\
\text { na execução das } \\
\text { atividades e eliminar } \\
\text { foco de } \\
\text { contaminação do } \\
\text { lubrificante) / } \\
\text { Construção de } \\
\text { procedimento de } \\
\text { trabalho } \\
\text { (padronização das } \\
\text { atividades) / } \\
\text { Treinamento para } \\
\text { qualificação da mão } \\
\text { de obra / Gestão da } \\
\text { manutenção } \\
\text { preventiva para } \\
\text { garantir uso de } \\
\text { lubrificantes } \\
\text { adequados para } \\
\text { indústria de } \\
\text { alimentos) }\end{array}$} \\
\hline & & & & $\begin{array}{l}\text { Falta ou excesso } \\
\text { de lubrificação }\end{array}$ & $\begin{array}{l}\text { Inoperância da máquina cobrideira / } \\
\text { Potencial contaminação do produto } \\
\text { processado / Desgastes nos } \\
\text { elementos de máquina por } \\
\text { aquecimento } \\
\end{array}$ & III & \\
\hline & & & & $\begin{array}{c}\text { Contaminação do } \\
\text { lubrificante }\end{array}$ & $\begin{array}{l}\text { Potencial contaminação do produto } \\
\text { processado / Perda de propriedades } \\
\text { físico-químicas do lubrificante } \\
\text { impactando na sua eficência na } \\
\text { redução do atrito entre as superfícies } \\
\text { dos elementos de máquina }\end{array}$ & II & \\
\hline & & & & $\begin{array}{l}\text { Lubrificantes com } \\
\text { propriedades } \\
\text { fisico-químicas } \\
\text { inadequadas }\end{array}$ & $\begin{array}{l}\text { Inoperância da máquina cobrideira / } \\
\text { Potencial contaminação do produto } \\
\text { processado / Desgastes nos } \\
\text { elementos de máquina }\end{array}$ & III & \\
\hline & & M4 & $\begin{array}{l}\text { Travamentos dos } \\
\text { rolamentos dos } \\
\text { eixos de } \\
\text { movimentação da } \\
\text { esteira metálica }\end{array}$ & $\begin{array}{l}\text { Lubrificação } \\
\text { deficiente }\end{array}$ & $\begin{array}{l}\text { Inoperância da máquina / Defeito } \\
\text { e/ou desgaste nos elementos de } \\
\text { máquina. }\end{array}$ & I & \\
\hline
\end{tabular}

(Continua) 
(Continuação)

\begin{tabular}{|c|c|c|c|c|c|c|c|}
\hline \multirow{3}{*}{\multicolumn{2}{|c|}{ LOGO DA EMPRESA }} & \multirow{4}{*}{\multicolumn{2}{|c|}{$\begin{array}{c}\text { FMEA No } \\
\text { 001-2014 } \\
\text { Modo de Falha }\end{array}$}} & \multicolumn{4}{|c|}{ FMEA } \\
\hline & & & & \multirow{3}{*}{$\begin{array}{c}\text { Dados } \\
\text { Técnicos: }\end{array}$} & \multirow{3}{*}{\begin{tabular}{|r|} 
Máquina Cobrideira \\
Data: 08/01/2014 \\
Consequência
\end{tabular}} & \multirow{2}{*}{\multicolumn{2}{|c|}{$\begin{array}{l}\text { Linha de Produção } 1 \\
\text { Máquina Cobrideira }\end{array}$}} \\
\hline & & & & & & & \\
\hline Dispositivo & Função & & & & & $\mathbf{S}$ & $\begin{array}{l}\text { Definição da } \\
\text { Abordagem }\end{array}$ \\
\hline \multirow{5}{*}{$\begin{array}{l}\text { Esteira } \\
\text { Vibratória }\end{array}$} & \multirow{5}{*}{$\begin{array}{l}\text { Primária: } \\
\text { Proporcionar } \\
\text { a vibração } \\
\text { para } \\
\text { acelerar } \\
\text { gotejamento } \\
\text { e retirar } \\
\text { excessos de } \\
\text { cobertura. } \\
\\
\text { Secundária: } \\
\text { Transportar } \\
\text { produto } \\
\text { através da } \\
\text { calha (fluxo } \\
\text { de calda) } \\
\text { para receber } \\
\text { cobertura }\end{array}$} & \multirow{4}{*}{ M4 } & \multirow{4}{*}{$\begin{array}{l}\text { Travamentos } \\
\text { dos rolamentos } \\
\text { dos eixos de } \\
\text { movimentação } \\
\text { da esteira } \\
\text { metálica }\end{array}$} & $\begin{array}{l}\text { Falta ou } \\
\text { excesso de } \\
\text { lubrificação }\end{array}$ & $\begin{array}{c}\text { Inoperância da máquina cobrideira / } \\
\text { Potencial contaminação do produto em } \\
\text { processamento / Desgastes nos elementos } \\
\text { de máquina por aquecimento }\end{array}$ & III & \multirow{5}{*}{$\begin{array}{c}\text { Plano de lubrificação } \\
\text { (evitar excesso, falta } \\
\text { e/ou qualquer } \\
\text { deficiência na } \\
\text { execução das } \\
\text { atividades e eliminar } \\
\text { foco de contaminação } \\
\text { do lubrificante) / } \\
\text { Construção de } \\
\text { procedimento de } \\
\text { trabalho } \\
\text { (padronização das } \\
\text { atividades) / } \\
\text { Treinamento para } \\
\text { qualificação da mão } \\
\text { de obra / Gestão da } \\
\text { manutenção } \\
\text { preventiva para } \\
\text { garantir uso de } \\
\text { lubrificantes } \\
\text { adequados para } \\
\text { indústria de alimentos) }\end{array}$} \\
\hline & & & & $\begin{array}{l}\text { Contaminação } \\
\text { do lubrificante }\end{array}$ & $\begin{array}{l}\text { Potencial contaminação do produto em } \\
\text { processamento / Perda de propriedades } \\
\text { físico-químicas do lubrificante impactando na } \\
\text { sua eficência na redução do atrito entre as } \\
\text { superfícies dos elementos de máquina }\end{array}$ & II & \\
\hline & & & & $\begin{array}{l}\text { Lubrificantes } \\
\text { com } \\
\text { propriedades } \\
\text { fisico-químicas } \\
\text { inadequadas }\end{array}$ & $\begin{array}{c}\text { Inoperância da máquina cobrideira / } \\
\text { Potencial contaminação do produto em } \\
\text { processamento / Desgastes nos elementos } \\
\text { de máquina }\end{array}$ & II & \\
\hline & & & & $\begin{array}{l}\text { Desgaste dos } \\
\text { elementos de } \\
\text { máquina }\end{array}$ & $\begin{array}{l}\text { Inoperância da máquina cobrideira / } \\
\text { Alargamento da esteira metálica }\end{array}$ & 1 & \\
\hline & & M5 & $\begin{array}{l}\text { Derramento de } \\
\text { lubrificante } \\
\text { durante a } \\
\text { manutenção }\end{array}$ & $\begin{array}{l}\text { Falta de } \\
\text { qualifcação de } \\
\text { mão de obra }\end{array}$ & $\begin{array}{l}\text { Potencial risco de perda de qualidade do } \\
\text { produto e inocuidade (contaminação) }\end{array}$ & II & \\
\hline
\end{tabular}

(Continua) 
(Continuação)

\begin{tabular}{|c|c|c|c|c|c|c|c|}
\hline \multirow{3}{*}{\multicolumn{2}{|c|}{ LOGO DA EMPRESA }} & \multicolumn{2}{|c|}{$\begin{array}{c}\text { FMEA No } \\
001-2014 \\
\text { Modo de Falha }\end{array}$} & \multicolumn{4}{|c|}{ FMEA } \\
\hline & & \multirow{3}{*}{\multicolumn{2}{|c|}{\begin{tabular}{|c|}
$001-2014$ \\
Modo de Falha
\end{tabular}}} & \multirow{3}{*}{$\begin{array}{c}\text { Dados Técnicos: } \\
\text { Causa }\end{array}$} & \multirow{3}{*}{\begin{tabular}{|r|} 
Máquina Cobrideira \\
Data: $08 / 01 / 2014$ \\
Consequência
\end{tabular}} & \multirow{2}{*}{\multicolumn{2}{|c|}{$\begin{array}{l}\text { Linha de Produção } 1 \\
\text { Máquina Cobrideira }\end{array}$}} \\
\hline & & & & & & & \\
\hline Dispositivo & Função & & & & & $\mathbf{S}$ & $\begin{array}{l}\text { Definição da } \\
\text { Abordagem }\end{array}$ \\
\hline $\begin{array}{l}\text { Esteira } \\
\text { Vibratória }\end{array}$ & $\begin{array}{l}\text { Primária: } \\
\text { Proporcionar } \\
\text { a vibração } \\
\text { para acelerar } \\
\text { gotejamento } \\
\text { e retirar } \\
\text { excessos de } \\
\text { cobertura }\end{array}$ & M6 & $\begin{array}{l}\text { Contaminação } \\
\text { do lubrificante }\end{array}$ & $\begin{array}{l}\text { Uso de ferramental } \\
\text { inadequado e sem } \\
\text { limpeza com } \\
\text { resíduos de outros } \\
\text { lubrificantes/ Falta } \\
\text { de qualificação de } \\
\text { mão de obra/ } \\
\text { Aplicação de } \\
\text { lubrificante } \\
\text { inadequado }\end{array}$ & $\begin{array}{l}\text { Potencial risco de perda de } \\
\text { qualidade e inocuidade do } \\
\text { produto (contaminação)/ Perda } \\
\text { das propriedades físico- } \\
\text { químicas do lubrificante } \\
\text { promovendo desgaste dos } \\
\text { elementos de máquina }\end{array}$ & II & $\begin{array}{l}\text { Plano de lubrificação } \\
\text { (evitar excesso, falta } \\
\text { e/ou qualquer } \\
\text { deficiência na execução } \\
\text { das atividades e } \\
\text { eliminar foco de } \\
\text { contaminação do } \\
\text { lubrificante) / } \\
\text { Construção de } \\
\text { procedimento de }\end{array}$ \\
\hline & $\begin{array}{l}\text { Secundária: } \\
\text { Transportar } \\
\text { produto } \\
\text { através da } \\
\text { calha (fluxo } \\
\text { de calda) } \\
\text { para receber } \\
\text { cobertura }\end{array}$ & M7 & $\begin{array}{c}\text { Uso de } \\
\text { lubrificantes } \\
\text { desingripantes } \\
\text { WD } 40 \text { para } \\
\text { deixar película } \\
\text { de óleo anti- } \\
\text { corrosivo sobre } \\
\text { a superfície da } \\
\text { peça }\end{array}$ & $\begin{array}{l}\text { Falta de qualificação } \\
\text { de mão de obra/ } \\
\text { Aplicação de } \\
\text { lubrificante } \\
\text { inadequado }\end{array}$ & $\begin{array}{l}\text { Potencial risco de perda de } \\
\text { qualidade e inocuidade do } \\
\text { produto (contaminação) }\end{array}$ & II & $\begin{array}{c}\text { das atividades) / } \\
\text { Treinamento para } \\
\text { qualificação da mão de } \\
\text { obra / Gestão da } \\
\text { manutenção preventiva } \\
\text { para garantir uso de } \\
\text { lubrificantes adequados } \\
\text { para indústria de } \\
\text { alimentos) }\end{array}$ \\
\hline
\end{tabular}

(Continua) 
(Continuação)

\begin{tabular}{|c|c|c|c|c|c|c|c|}
\hline \multirow{2}{*}{\multicolumn{2}{|c|}{ LOGO DA EMPRESA }} & \multirow{3}{*}{\multicolumn{2}{|c|}{$\begin{array}{c}\text { FMEA No } \\
\text { 001-2014 } \\
\text { Modo de Falha }\end{array}$}} & \multicolumn{4}{|c|}{ FMEA } \\
\hline & & & & \multirow{2}{*}{$\begin{array}{c}\begin{array}{c}\text { Dados } \\
\text { Técnicos: }\end{array} \\
\text { Causa }\end{array}$} & \multirow{2}{*}{$\begin{array}{r}\text { Máquina Cobrideira } \\
\text { Data: 08/01/2014 } \\
\text { Consequência }\end{array}$} & \multicolumn{2}{|c|}{$\begin{array}{l}\text { Linha de Produção } 1 \\
\text { Máquina Cobrideira }\end{array}$} \\
\hline Dispositivo & \multirow{3}{*}{\begin{tabular}{|c|} 
Função \\
Primária: \\
Transmitir a \\
potência \\
gerada pelo \\
motor para a \\
unidade de \\
bombeamen- \\
to de \\
alimentação \\
e circulação \\
de massa \\
para \\
cobertura
\end{tabular}} & & & & & $\mathbf{S}$ & $\begin{array}{l}\text { Definição da } \\
\text { Abordagem }\end{array}$ \\
\hline \multirow{4}{*}{$\begin{array}{c}\text { Caixa de } \\
\text { Cobertura } \\
\text { Inferior e } \\
\text { Sistema de } \\
\text { Acionamento } \\
\text { das } \\
\text { Unidades de } \\
\text { bombeamen- } \\
\text { to de massa }\end{array}$} & & \multirow{4}{*}{ M8 } & \multirow{4}{*}{$\begin{array}{l}\text { Travamento dos } \\
\text { rolamentos do } \\
\text { motorredutor } \\
\text { das unidades de } \\
\text { bombeamento. }\end{array}$} & $\begin{array}{l}\text { Lubrificação } \\
\text { deficiente }\end{array}$ & $\begin{array}{l}\text { Inoperância da máquina cobrideira/ } \\
\text { Potencial contaminação do produto em } \\
\text { processamento/ Inoperância das unidades } \\
\text { de bombeamento/ Inoperância do sistema } \\
\text { de circulação e alimentação de massa }\end{array}$ & \multirow{4}{*}{\multicolumn{2}{|c|}{ II $\begin{array}{c}\text { Plano de lubrificação } \\
\text { (evitar excesso, falta } \\
\text { e/ou qualquer } \\
\text { deficiência na } \\
\text { execução das } \\
\text { atividades e eliminar } \\
\text { foco de } \\
\text { contaminação do } \\
\text { lubrificante) / } \\
\text { Construção de } \\
\text { procedimento de } \\
\text { trabalho } \\
\text { (padronização das } \\
\text { atividades) / } \\
\text { Treinamento para } \\
\text { qualificação da mão } \\
\text { de obra / Gestão da } \\
\text { manutenção } \\
\text { preventiva para } \\
\text { garantir uso de } \\
\text { lubrificantes } \\
\text { adequados para } \\
\text { indústria de } \\
\text { alimentos) }\end{array}$}} \\
\hline & & & & $\begin{array}{l}\text { Falta ou } \\
\text { excesso de } \\
\text { lubrificação }\end{array}$ & $\begin{array}{l}\text { Inoperância da máquina cobrideira/ } \\
\text { Potencial contaminação do produto } \\
\text { processado/ Inoperância das unidades de } \\
\text { bombeamento/ Inoperância do sistema de } \\
\text { circulação e alimentação de massa }\end{array}$ & & \\
\hline & \multirow{2}{*}{$\begin{array}{l}\text { Secundária: } \\
\text { Produzir } \\
\text { aquecimento } \\
\text { e } \\
\text { resfriamento } \\
\text { de água no } \\
\text { sistema } \\
\text { banho-maria } \\
\text { de calda para } \\
\text { cobertura }\end{array}$} & & & $\begin{array}{l}\text { Contaminação } \\
\text { do lubrificante }\end{array}$ & $\begin{array}{l}\text { Inoperância da máquina cobrideira/ } \\
\text { Potencial contaminação do produto } \\
\text { processado/ Inoperância das unidades de } \\
\text { bombeamento/ Inoperância do sistema de } \\
\text { circulação e alimentação de massa }\end{array}$ & & \\
\hline & & & & $\begin{array}{l}\text { Lubrificantes } \\
\text { com } \\
\text { propriedades } \\
\text { fisico-químicas } \\
\text { inadequadas }\end{array}$ & $\begin{array}{l}\text { Inoperância da máquina cobrideira/ } \\
\text { Potencial contaminação do produto } \\
\text { processado/ Inoperância das unidades de } \\
\text { bombeamento/ Inoperância do sistema de } \\
\text { circulação e alimentação de massa }\end{array}$ & & \\
\hline
\end{tabular}


(Continuação)

\begin{tabular}{|c|c|c|c|c|c|c|c|}
\hline \multirow{3}{*}{\multicolumn{2}{|c|}{ LOGO DA EMPRESA }} & \multirow{3}{*}{\multicolumn{2}{|c|}{$\begin{array}{l}\text { FMEA No } \\
001-2014\end{array}$}} & \multicolumn{4}{|c|}{ FMEA } \\
\hline & & & & \multirow{3}{*}{$\begin{array}{c}\text { Dados Técnicos: } \\
\text { Causa }\end{array}$} & \multirow{3}{*}{\begin{tabular}{|r|} 
Máquina Cobrideira \\
Data: 08/01/2014 \\
Consequência
\end{tabular}} & \multirow{2}{*}{\multicolumn{2}{|c|}{$\begin{array}{l}\text { Linha de Produção } 1 \\
\text { Máquina Cobrideira }\end{array}$}} \\
\hline & & & & & & & \\
\hline Dispositivo & Função & \multicolumn{2}{|c|}{ Modo de Falha } & & & $\mathbf{S}$ & $\begin{array}{l}\text { Definição da } \\
\text { Abordagem }\end{array}$ \\
\hline \multirow{4}{*}{$\begin{array}{c}\text { Caixa de } \\
\text { Cobertura } \\
\text { Inferior e } \\
\text { Sistema de } \\
\text { Acionamento } \\
\text { das Unidades } \\
\text { de } \\
\text { bombeamento } \\
\text { de massa }\end{array}$} & \multirow{4}{*}{$\begin{array}{c}\text { Primária: } \\
\text { Transmitir a } \\
\text { potência } \\
\text { gerada pelo } \\
\text { motor para a } \\
\text { unidade de } \\
\text { bombeamento } \\
\text { de } \\
\text { alimentação e } \\
\text { circulação de } \\
\text { massa para } \\
\text { cobertura. } \\
\text { Secundária: } \\
\text { Produzir } \\
\text { aquecimento } \\
\text { e resfriamento } \\
\text { de água no } \\
\text { sistema } \\
\text { banho-maria } \\
\text { de calda para } \\
\text { cobertura }\end{array}$} & \multirow{3}{*}{ M9 } & \multirow{3}{*}{$\begin{array}{l}\text { Vazamento } \\
\text { do } \\
\text { motorredutor }\end{array}$} & $\begin{array}{l}\text { Lubrificantes com } \\
\text { propriedades fisico- } \\
\text { químicas } \\
\text { inadequadas que } \\
\text { agridam as } \\
\text { vedações }\end{array}$ & $\begin{array}{l}\text { Desgaste elemento de máquina e } \\
\text { vedações / Potencial risco de perda } \\
\text { de qualidade e inocuidade do produto } \\
\text { em processamento (contaminação) }\end{array}$ & $\|$ & \multirow{4}{*}{\begin{tabular}{|} 
Plano de lubrificação \\
(evitar excesso, falta \\
e/ou qualquer \\
deficiência na \\
execução das \\
atividades e eliminar \\
foco de contaminação \\
do lubrificante) / \\
Construção de \\
procedimento de \\
trabalho \\
(padronização das \\
atividades) / \\
Treinamento para \\
qualificação da mão \\
de obra / Gestão da \\
manutenção \\
preventiva para \\
garantir uso de \\
lubrificantes \\
adequados para \\
indústria de alimentos)
\end{tabular}} \\
\hline & & & & $\begin{array}{l}\text { Defeito nas } \\
\text { vedações }\end{array}$ & $\begin{array}{l}\text { Vazamento de lubrificante/Potencial } \\
\text { risco de perda de qualidade e } \\
\text { inocuidade do produto em } \\
\text { processamento (contaminação) }\end{array}$ & II & \\
\hline & & & & $\begin{array}{l}\text { Vibração excessiva } \\
\text { durante a operação }\end{array}$ & $\begin{array}{l}\text { Desgaste elemento de máquina e } \\
\text { vedações / Vazamento de } \\
\text { lubrificante/Potencial risco de perda } \\
\text { de qualidade e inocuidade do produto } \\
\text { em processamento (contaminação) }\end{array}$ & $\|$ & \\
\hline & & M10 & $\begin{array}{c}\text { Inoperância } \\
\text { do } \\
\text { motorredutor }\end{array}$ & $\begin{array}{l}\text { Travamento dos } \\
\text { elementos de } \\
\text { máquina }\end{array}$ & $\begin{array}{l}\text { Inoperância da máquina cobrideira/ } \\
\text { Potencial contaminação do produto } \\
\text { em processamento/ Inoperância das } \\
\text { unidades de bombeamento/ } \\
\text { Inoperância do sistema de circulação } \\
\text { e alimentação de massa }\end{array}$ & III & \\
\hline
\end{tabular}

(Continua) 
(Continuação)

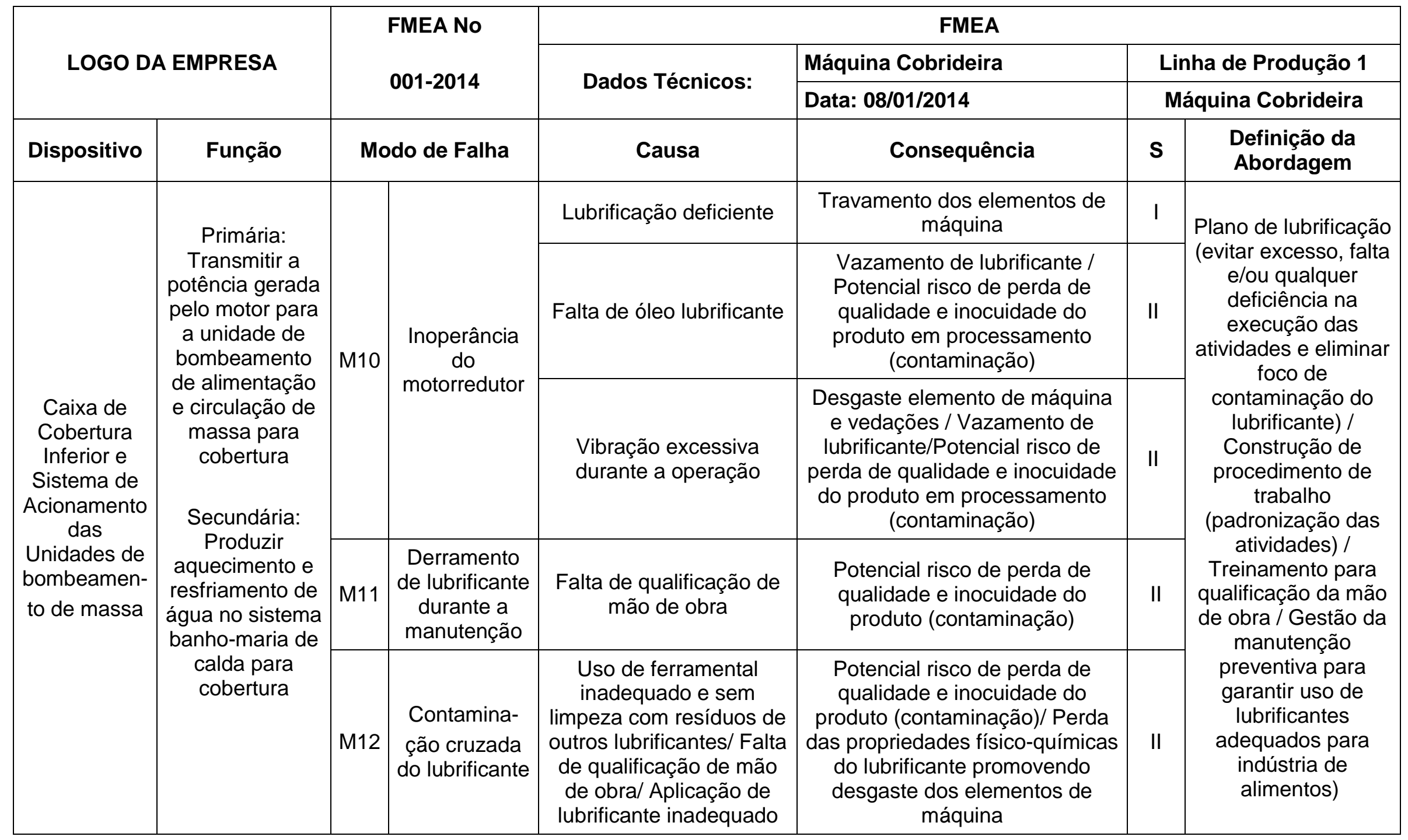

(Continua) 
(Continuação)

\begin{tabular}{|c|c|c|c|c|c|c|c|}
\hline \multirow{3}{*}{\multicolumn{2}{|c|}{ LOGO DA EMPRESA }} & \multirow{3}{*}{\multicolumn{2}{|c|}{$\begin{array}{l}\text { FMEA No } \\
\text { 001-2014 }\end{array}$}} & \multicolumn{4}{|c|}{ FMEA } \\
\hline & & & & \multirow{3}{*}{$\begin{array}{c}\text { Dados Técnicos: } \\
\text { Causa }\end{array}$} & \multirow{3}{*}{\begin{tabular}{|r|} 
Máquina Cobrideira \\
Data: 08/01/2014 \\
Consequência
\end{tabular}} & \multirow{2}{*}{\multicolumn{2}{|c|}{$\begin{array}{l}\text { Linha de Produção } 1 \\
\text { Máquina Cobrideira }\end{array}$}} \\
\hline & & & & & & & \\
\hline Dispositivo & Função & \multicolumn{2}{|c|}{ Modo de Falha } & & & $\mathbf{S}$ & $\begin{array}{l}\text { Definição da } \\
\text { Abordagem }\end{array}$ \\
\hline \multirow{4}{*}{$\begin{array}{l}\text { Sistema de } \\
\text { Transmissão } \\
\text { de Força e } \\
\text { Movimento }\end{array}$} & \multirow{4}{*}{$\begin{array}{c}\text { Primária: } \\
\text { Transmitir a } \\
\text { potência } \\
\text { gerada pelo } \\
\text { motor por } \\
\text { meio do } \\
\text { conjunto de } \\
\text { correntes e } \\
\text { pinhão, de } \\
\text { forma } \\
\text { controlável, } \\
\text { para } \\
\text { acionamen- } \\
\text { to da } \\
\text { esteira } \\
\text { vibratória }\end{array}$} & \multirow{4}{*}{ M13 } & \multirow{4}{*}{$\begin{array}{l}\text { Fratura no } \\
\text { elo da } \\
\text { corrente }\end{array}$} & Desgaste do elo & $\begin{array}{c}\text { Fratura da corrente / Inoperância da } \\
\text { máquina cobrideira }\end{array}$ & I & \multirow{4}{*}{$\begin{array}{c}\text { Plano de lubrificação } \\
\text { (evitar excesso, falta } \\
\text { e/ou qualquer } \\
\text { deficiência na } \\
\text { execução das } \\
\text { atividades e eliminar } \\
\text { foco de } \\
\text { contaminação do } \\
\text { lubrificante) / } \\
\text { Construção de } \\
\text { procedimento de } \\
\text { trabalho } \\
\text { (padronização das } \\
\text { atividades) / } \\
\text { Treinamento para } \\
\text { qualificação da mão } \\
\text { de obra / Gestão da } \\
\text { manutenção } \\
\text { preventiva para } \\
\text { garantir uso de } \\
\text { lubrificantes } \\
\text { adequados para } \\
\text { indústria de } \\
\text { alimentos) }\end{array}$} \\
\hline & & & & Lubrificação deficiente & $\begin{array}{l}\text { Inoperância da máquina / Potencial } \\
\text { contaminação do produto em } \\
\text { processamento / Desgastes nos } \\
\text { elementos de máquina por } \\
\text { aquecimento }\end{array}$ & III & \\
\hline & & & & $\begin{array}{l}\text { Falta ou excesso de } \\
\text { lubrificação }\end{array}$ & $\begin{array}{l}\text { Potencial contaminação do produto } \\
\text { em processamento / Perda de } \\
\text { propriedades físico-químicas do } \\
\text { lubrificante impactando na sua } \\
\text { eficência na redução do atrito entre } \\
\text { as superfícies dos elementos de } \\
\text { máquina }\end{array}$ & II & \\
\hline & & & & $\begin{array}{l}\text { Contaminação do } \\
\text { lubrificante (água, } \\
\text { alimentos, sanitizantes, } \\
\text { etc.) }\end{array}$ & $\begin{array}{l}\text { Potencial contaminação do produto } \\
\text { em processamento / Perda de } \\
\text { propriedades físico-químicas do } \\
\text { lubrificante impactando na sua } \\
\text { eficência na redução do atrito entre } \\
\text { as superfícies dos elementos de } \\
\text { máquina }\end{array}$ & II & \\
\hline
\end{tabular}

(Continua) 
(Continuação)

\begin{tabular}{|c|c|c|c|c|c|c|c|}
\hline \multirow{3}{*}{\multicolumn{2}{|c|}{ LOGO DA EMPRESA }} & \multirow{4}{*}{\multicolumn{2}{|c|}{$\begin{array}{c}\text { FMEA No } \\
\text { 001-2014 } \\
\text { Modo de Falha }\end{array}$}} & \multicolumn{4}{|c|}{ FMEA } \\
\hline & & & & \multirow{3}{*}{\begin{tabular}{c|} 
Dados Técnicos: \\
Causa
\end{tabular}} & \multirow{3}{*}{\begin{tabular}{|r|} 
Máquina Cobrideira \\
Data: 08/01/2014 \\
Consequência
\end{tabular}} & \multirow{2}{*}{\multicolumn{2}{|c|}{$\begin{array}{l}\text { Linha de Produção } 1 \\
\text { Máquina Cobrideira }\end{array}$}} \\
\hline & & & & & & & \\
\hline Dispositivo & Função & & & & & $\mathbf{S}$ & Definição da Abordagem \\
\hline \multirow{5}{*}{$\begin{array}{l}\text { Sistema de } \\
\text { Transmissão } \\
\text { de Força e } \\
\text { Movimento }\end{array}$} & \multirow{5}{*}{$\begin{array}{c}\text { Primária: } \\
\text { Transmitir a } \\
\text { potência } \\
\text { gerada pelo } \\
\text { motor por } \\
\text { meio do } \\
\text { conjunto de } \\
\text { correntes e } \\
\text { pinhão, de } \\
\text { forma } \\
\text { controlável, } \\
\text { para } \\
\text { acionamen- } \\
\text { to da } \\
\text { esteira } \\
\text { vibratória. }\end{array}$} & M13 & $\begin{array}{l}\text { Fratura no } \\
\text { elo da } \\
\text { corrente }\end{array}$ & $\begin{array}{l}\text { Lubrificantes com } \\
\text { propriedades } \\
\text { fisico-químicas } \\
\text { inadequadas }\end{array}$ & $\begin{array}{l}\text { Desgaste dos elementos de máquina / } \\
\text { Potencial contaminação do produto em } \\
\text { processamento. }\end{array}$ & II & \multirow{5}{*}{$\begin{array}{c}\text { Plano de lubrificação } \\
\text { (evitar excesso, falta e/ou } \\
\text { qualquer deficiência na } \\
\text { execução das atividades e } \\
\text { eliminar foco de } \\
\text { contaminação do } \\
\text { lubrificante) / Construção } \\
\text { de procedimento de } \\
\text { trabalho (padronização das } \\
\text { atividades) / Treinamento } \\
\text { para qualificação da mão } \\
\text { de obra / Gestão da } \\
\text { manutenção preventiva } \\
\text { para garantir uso de } \\
\text { lubrificantes adequados } \\
\text { para indústria de } \\
\text { alimentos) }\end{array}$} \\
\hline & & \multirow{4}{*}{ M14 } & \multirow{4}{*}{$\begin{array}{l}\text { Desgaste } \\
\text { do conjunto } \\
\text { de } \\
\text { corrente, } \\
\text { pinhão e } \\
\text { coroa }\end{array}$} & $\begin{array}{l}\text { Lubrificação } \\
\text { deficiente }\end{array}$ & \begin{tabular}{|} 
Ruptura do conjunto devido à deficiência \\
de lubrificação / Inoperância da \\
máquina, devido interrupção da \\
movimentação da esteira metálica.
\end{tabular} & 1 & \\
\hline & & & & $\begin{array}{l}\text { Falta ou excesso } \\
\text { de lubrificação }\end{array}$ & \begin{tabular}{|} 
Potencial contaminação do produto em \\
processamento / Perda de propriedades \\
físico-químicas do lubrificante \\
impactando na sua eficência na redução \\
do atrito entre as superfícies dos \\
elementos de máquina
\end{tabular} & II & \\
\hline & & & & $\begin{array}{l}\text { Contaminação do } \\
\text { lubrificante }\end{array}$ & $\begin{array}{c}\text { Potencial contaminação do produto em } \\
\text { processamento / Perda de propriedades } \\
\text { físico-químicas do lubrificante } \\
\text { impactando na sua eficência na redução } \\
\text { do atrito entre as superfícies dos } \\
\text { elementos de máquina }\end{array}$ & II & \\
\hline & & & & $\begin{array}{l}\text { Lubrificantes com } \\
\text { propriedades } \\
\text { fisico-químicas } \\
\text { inadequadas }\end{array}$ & $\begin{array}{l}\text { Desgaste dos elementos de máquina / } \\
\text { Potencial contaminação do produto em } \\
\text { processamento }\end{array}$ & II & \\
\hline
\end{tabular}

(Continua) 
(Conclusão)

\begin{tabular}{|c|c|c|c|c|c|c|c|}
\hline \multirow{3}{*}{\multicolumn{2}{|c|}{ LOGO DA EMPRESA }} & \multirow{3}{*}{\multicolumn{2}{|c|}{$\begin{array}{l}\text { FMEA No } \\
001-2014\end{array}$}} & \multicolumn{4}{|c|}{ FMEA } \\
\hline & & & & \multirow{3}{*}{\begin{tabular}{|c|} 
Dados Técnicos: \\
Causa
\end{tabular}} & \multirow{3}{*}{\begin{tabular}{|r|} 
Máquina Cobrideira \\
Data: 08/01/2014 \\
Consequência \\
\end{tabular}} & \multirow{2}{*}{\multicolumn{2}{|c|}{$\begin{array}{l}\text { Linha de Produção } 1 \\
\text { Máquina Cobrideira }\end{array}$}} \\
\hline & & & & & & & \\
\hline Dispositivo & Função & \multicolumn{2}{|c|}{ Modo de Falha } & & & $\mathbf{S}$ & $\begin{array}{l}\text { Definição da } \\
\text { Abordagem }\end{array}$ \\
\hline \multirow{3}{*}{$\begin{array}{c}\text { Sistema de } \\
\text { Transmissão } \\
\text { de Força e } \\
\text { Movimento }\end{array}$} & \multirow{3}{*}{$\begin{array}{l}\text { Primária: } \\
\text { Transmitir a } \\
\text { potência } \\
\text { gerada pelo } \\
\text { motor por } \\
\text { meio do } \\
\text { conjunto de } \\
\text { correntes e } \\
\text { pinhão, de } \\
\text { forma } \\
\text { controlável, } \\
\text { para } \\
\text { acionamen- } \\
\text { to da } \\
\text { esteira } \\
\text { vibratória }\end{array}$} & M15 & $\begin{array}{l}\text { Gotejamento } \\
\text { de óleo e/ou } \\
\text { lubrificante }\end{array}$ & $\begin{array}{c}\text { Excesso de } \\
\text { lubrificante / } \\
\text { Lubrificante com } \\
\text { propriedades físico- } \\
\text { químicas } \\
\text { inadequadas }\end{array}$ & $\begin{array}{l}\text { Potencial contaminação do produto } \\
\text { em processamento/ Desgaste dos } \\
\text { elementos de máquina }\end{array}$ & II & \multirow{3}{*}{$\begin{array}{c}\text { Plano de lubrificação } \\
\text { (evitar excesso, falta } \\
\text { e/ou qualquer } \\
\text { deficiência na } \\
\text { execução das } \\
\text { atividades e eliminar } \\
\text { foco de contaminação } \\
\text { do lubrificante) / } \\
\text { Construção de } \\
\text { procedimento de } \\
\text { trabalho } \\
\text { (padronização das } \\
\text { atividades) / } \\
\text { Treinamento para } \\
\text { qualificação da mão } \\
\text { de obra / Gestão da } \\
\text { manutenção } \\
\text { preventiva para } \\
\text { garantir uso de } \\
\text { lubrificantes } \\
\text { adequados para } \\
\text { indústria de alimentos) }\end{array}$} \\
\hline & & M16 & $\begin{array}{l}\text { Derramento de } \\
\text { lubrificante } \\
\text { durante a } \\
\text { manutenção }\end{array}$ & $\begin{array}{c}\text { Falta de qualifcação } \\
\text { de mão de obra }\end{array}$ & $\begin{array}{l}\text { Potencial risco de perda de } \\
\text { qualidade e inocuidade do produto } \\
\text { (contaminação) }\end{array}$ & 1 & \\
\hline & & M17 & $\begin{array}{l}\text { Contaminação } \\
\text { do lubrificante }\end{array}$ & $\begin{array}{l}\text { Uso de ferramental } \\
\text { inadequado e sem } \\
\text { limpeza com } \\
\text { resíduos de outros } \\
\text { lubrificantes/ Falta } \\
\text { de qualificação de } \\
\text { mão de obra/ } \\
\text { Aplicação de } \\
\text { lubrificante } \\
\text { inadequado }\end{array}$ & $\begin{array}{l}\text { Potencial risco de perda de } \\
\text { qualidade e inocuidade do produto } \\
\text { (contaminação)/ Perda das } \\
\text { propriedades físico-químicas do } \\
\text { lubrificante promovendo desgaste } \\
\text { dos elementos de máquina }\end{array}$ & $\|$ & \\
\hline
\end{tabular}

(Continua) 
(Continuação)

\begin{tabular}{|c|c|c|c|c|c|c|c|}
\hline \multirow{3}{*}{\multicolumn{2}{|c|}{ LOGO DA EMPRESA }} & \multirow{3}{*}{\multicolumn{2}{|c|}{$\begin{array}{l}\text { FMEA No } \\
001-2014\end{array}$}} & \multicolumn{4}{|c|}{ FMEA } \\
\hline & & & & \multirow{3}{*}{$\begin{array}{c}\begin{array}{c}\text { Dados } \\
\text { Técnicos: }\end{array} \\
\text { Causa }\end{array}$} & \multirow{3}{*}{\begin{tabular}{|r|} 
Máquina Cobrideira \\
Data: $08 / 01 / 2014$ \\
Consequência
\end{tabular}} & \multirow{2}{*}{\multicolumn{2}{|c|}{$\begin{array}{c}\text { Linha de Produção } 1 \\
\text { Máquina Cobrideira }\end{array}$}} \\
\hline & & & & & & & \\
\hline Dispositivo & Função & \multicolumn{2}{|c|}{ Modo de Falha } & & & $\mathbf{S}$ & $\begin{array}{l}\text { Definição da } \\
\text { Abordagem }\end{array}$ \\
\hline \multirow{4}{*}{$\begin{array}{l}\text { Sistema de } \\
\text { Acionamento } \\
\text { Principal }\end{array}$} & \multirow{4}{*}{$\begin{array}{c}\text { Primária: } \\
\text { Transmitir a } \\
\text { potência } \\
\text { gerada pelo } \\
\text { motor para } \\
\text { acionamento } \\
\text { do sistema de } \\
\text { transmissão e } \\
\text { força de } \\
\text { movimento } \\
\\
\text { Secundária: } \\
\text { Proporcionar } \\
\text { controle das } \\
\text { funções e } \\
\text { operação da } \\
\text { máquina } \\
\text { cobrideira }\end{array}$} & \multirow{4}{*}{ M18 } & \multirow{4}{*}{$\begin{array}{l}\text { Travamento } \\
\text { dos } \\
\text { rolamentos } \\
\text { do } \\
\text { motorredutor }\end{array}$} & $\begin{array}{l}\text { Lubrificação } \\
\text { deficiente }\end{array}$ & $\begin{array}{l}\text { Travamento do eixo de acionamento do } \\
\text { motorredutor devido desgaste dos } \\
\text { elementos de máquina / Inoperância da } \\
\text { máquina cobrideira devido interrupção do } \\
\text { funcionamento do motorredutor de } \\
\text { acionamento principal }\end{array}$ & I & \multirow{4}{*}{$\begin{array}{l}\text { Plano de lubrificação } \\
\text { (evitar excesso, falta } \\
\text { e/ou qualquer } \\
\text { deficiência na } \\
\text { execução das } \\
\text { atividades e eliminar } \\
\text { foco de } \\
\text { contaminação do } \\
\text { lubrificante) / } \\
\text { Construção de } \\
\text { procedimento de } \\
\text { trabalho } \\
\text { (padronização das } \\
\text { atividades) / } \\
\text { Treinamento para } \\
\text { qualificação da mão } \\
\text { de obra / Gestão da } \\
\text { manutenção } \\
\text { preventiva para } \\
\text { garantir uso de } \\
\text { lubrificantes } \\
\text { adequados para } \\
\text { indústria de } \\
\text { alimentos) }\end{array}$} \\
\hline & & & & $\begin{array}{l}\text { Falta ou } \\
\text { excesso de } \\
\text { lubrificação }\end{array}$ & $\begin{array}{l}\text { Travamento do eixo de acionamento do } \\
\text { motorredutor devido desgaste dos } \\
\text { elementos de máquina / Inoperância da } \\
\text { máquina cobrideira devido interrupção do } \\
\text { funcionamento do motorredutor de } \\
\text { acionamento principal /Potencial } \\
\text { contaminação do produto em } \\
\text { processamento }\end{array}$ & III & \\
\hline & & & & $\begin{array}{l}\text { Contaminação } \\
\text { do lubrificante }\end{array}$ & $\begin{array}{c}\text { Desgaste dos elementos de máquina } \\
\text { devido aquecimento / Potencial } \\
\text { contaminação do produto em } \\
\text { processamento }\end{array}$ & II & \\
\hline & & & & $\begin{array}{l}\text { Lubrificantes } \\
\text { com } \\
\text { propriedades } \\
\text { fisico-químicas } \\
\text { inadequadas }\end{array}$ & $\begin{array}{l}\text { Desgaste dos elementos de máquina } \\
\text { devido aquecimento / Potencial } \\
\text { contaminação do produto em } \\
\text { processamento }\end{array}$ & II & \\
\hline
\end{tabular}

(Continua) 
(Continuação)

\begin{tabular}{|c|c|c|c|c|c|c|c|}
\hline \multirow{3}{*}{\multicolumn{2}{|c|}{ LOGO DA EMPRESA }} & \multirow{4}{*}{\multicolumn{2}{|c|}{$\begin{array}{l}\text { FMEA No } \\
\text { 001-2014 } \\
\text { Modo de Falha }\end{array}$}} & \multicolumn{4}{|c|}{ FMEA } \\
\hline & & & & \multirow{3}{*}{$\begin{array}{c}\text { Dados } \\
\text { Técnicos: } \\
\text { Causa }\end{array}$} & \multirow{3}{*}{$\begin{array}{r}\text { Máquina Cobrideira } \\
\text { Data: 08/01/2014 } \\
\text { Consequência }\end{array}$} & \multirow{2}{*}{\multicolumn{2}{|c|}{$\begin{array}{l}\text { Linha de Produção } 1 \\
\text { Máquina Cobrideira }\end{array}$}} \\
\hline & & & & & & & \\
\hline Dispositivo & Função & & & & & $\mathbf{S}$ & $\begin{array}{l}\text { Definição da } \\
\text { Abordagem }\end{array}$ \\
\hline \multirow{6}{*}{$\begin{array}{l}\text { Sistema de } \\
\text { Acionamento } \\
\text { Principal }\end{array}$} & \multirow{6}{*}{$\begin{array}{l}\text { Primária: } \\
\text { Transmitir a } \\
\text { potência } \\
\text { gerada pelo } \\
\text { motor para } \\
\text { acionamento do } \\
\text { sistema de } \\
\text { transmissão e } \\
\text { força de } \\
\text { movimento } \\
\\
\text { Secundária: } \\
\text { Proporcionar } \\
\text { controle das } \\
\text { funções e } \\
\text { operação da } \\
\text { máquina } \\
\text { cobrideira }\end{array}$} & \multirow{3}{*}{ M19 } & \multirow{3}{*}{$\begin{array}{l}\text { Vazamento de } \\
\text { lubrificante no } \\
\text { motorredutor }\end{array}$} & $\begin{array}{l}\text { Lubrificantes } \\
\text { com } \\
\text { propriedades } \\
\text { fisico-químicas } \\
\text { inadequadas }\end{array}$ & $\begin{array}{l}\text { Desgaste elemento de máquina e } \\
\text { vedações / Potencial risco de perda de } \\
\text { qualidade e inocuidade do produto em } \\
\text { processamento (contaminação) }\end{array}$ & II & \multirow{6}{*}{$\begin{array}{l}\text { Plano de lubrificação } \\
\text { (evitar excesso, falta } \\
\text { e/ou qualquer } \\
\text { deficiência na } \\
\text { execução das } \\
\text { atividades e eliminar } \\
\text { foco de } \\
\text { contaminação do } \\
\text { lubrificante) / } \\
\text { Construção de } \\
\text { procedimento de } \\
\text { trabalho } \\
\text { (padronização das } \\
\text { atividades) / } \\
\text { Treinamento para } \\
\text { qualificação da mão } \\
\text { de obra / Gestão da } \\
\text { manutenção } \\
\text { preventiva para } \\
\text { garantir uso de } \\
\text { lubrificantes } \\
\text { adequados para } \\
\text { indústria de } \\
\text { alimentos) }\end{array}$} \\
\hline & & & & $\begin{array}{l}\text { Defeito nas } \\
\text { vedações }\end{array}$ & $\begin{array}{l}\text { Vazamento de lubrificante/Potencial } \\
\text { risco de perda de qualidade e } \\
\text { inocuidade do produto em } \\
\text { processamento (contaminação) }\end{array}$ & II & \\
\hline & & & & $\begin{array}{l}\text { Vibração } \\
\text { excessiva } \\
\text { durante a } \\
\text { operação }\end{array}$ & $\begin{array}{l}\text { Desgaste elemento de máquina e } \\
\text { vedações / Vazamento de } \\
\text { lubrificante/Potencial risco de perda de } \\
\text { qualidade e inocuidade do produto em } \\
\text { processamento (contaminação) }\end{array}$ & II & \\
\hline & & \multirow{3}{*}{ M20 } & \multirow{3}{*}{$\begin{array}{l}\text { Inoperância do } \\
\text { motorredutor }\end{array}$} & $\begin{array}{l}\text { Travamento } \\
\text { dos elementos } \\
\text { de máquina }\end{array}$ & Inoperância da máquina cobrideira & I & \\
\hline & & & & $\begin{array}{l}\text { Lubrificação } \\
\text { deficiente }\end{array}$ & Travamento dos elementos de máquina & I & \\
\hline & & & & $\begin{array}{c}\text { Falta de óleo } \\
\text { lubrificante }\end{array}$ & $\begin{array}{l}\text { Vazamento de lubrificante / Potencial } \\
\text { risco de perda de qualidade e } \\
\text { inocuidade do produto em } \\
\text { processamento (contaminação) }\end{array}$ & II & \\
\hline
\end{tabular}

(Continua) 
(Continuação)

\begin{tabular}{|c|c|c|c|c|c|c|c|}
\hline \multirow{3}{*}{\multicolumn{2}{|c|}{ LOGO DA EMPRESA }} & \multirow{4}{*}{\multicolumn{2}{|c|}{$\begin{array}{c}\text { FMEA No } \\
\text { 001-2014 } \\
\text { Modo de Falha }\end{array}$}} & \multicolumn{4}{|c|}{ FMEA } \\
\hline & & & & \multirow{3}{*}{$\begin{array}{c}\text { Dados Técnicos: } \\
\text { Causa }\end{array}$} & \multirow{3}{*}{\begin{tabular}{|r|} 
Máquina Cobrideira \\
Data: 08/01/2014 \\
Consequência
\end{tabular}} & \multirow{2}{*}{\multicolumn{2}{|c|}{$\begin{array}{l}\text { Linha de Produção } 1 \\
\text { Máquina Cobrideira }\end{array}$}} \\
\hline & & & & & & & \\
\hline Dispositivo & Função & & & & & $\mathbf{S}$ & $\begin{array}{l}\text { Definição da } \\
\text { Abordagem }\end{array}$ \\
\hline \multirow{3}{*}{$\begin{array}{l}\text { Sistema de } \\
\text { Acionamento } \\
\text { Principal }\end{array}$} & \multirow{3}{*}{$\begin{array}{c}\text { Primária: } \\
\text { Transmitir a } \\
\text { potência } \\
\text { gerada pelo } \\
\text { motor para } \\
\text { acionamento do } \\
\text { sistema de } \\
\text { transmissão e } \\
\text { força de } \\
\text { movimento. } \\
\text { Secundária: } \\
\text { Proporcionar } \\
\text { controle das } \\
\text { funções e } \\
\text { operação da } \\
\text { máquina } \\
\text { cobrideira. }\end{array}$} & M20 & $\begin{array}{l}\text { Inoperância do } \\
\text { motorredutor }\end{array}$ & $\begin{array}{l}\text { Vibração excessiva } \\
\text { durante a operação }\end{array}$ & $\begin{array}{l}\text { Desgaste elemento de máquina e } \\
\text { vedações / Vazamento de } \\
\text { lubrificante/Potencial risco de } \\
\text { perda de qualidade e inocuidade } \\
\text { do produto em processamento } \\
\text { (contaminação) }\end{array}$ & II & \multirow{3}{*}{$\begin{array}{l}\text { Plano de lubrificação } \\
\text { (evitar excesso, falta } \\
\text { e/ou qualquer } \\
\text { deficiência na } \\
\text { execução das } \\
\text { atividades e eliminar } \\
\text { foco de contaminação } \\
\text { do lubrificante) / } \\
\text { Construção de } \\
\text { procedimento de } \\
\text { trabalho } \\
\text { (padronização das } \\
\text { atividades) / } \\
\text { Treinamento para } \\
\text { qualificação da mão } \\
\text { de obra / Gestão da } \\
\text { manutenção } \\
\text { preventiva para } \\
\text { garantir uso de } \\
\text { lubrificantes } \\
\text { adequados para } \\
\text { indústria de alimentos) }\end{array}$} \\
\hline & & M21 & $\begin{array}{l}\text { Derramento de } \\
\text { lubrificante } \\
\text { durante a } \\
\text { manutenção }\end{array}$ & $\begin{array}{l}\text { Falta de qualifcação } \\
\text { de mão de obra }\end{array}$ & $\begin{array}{l}\text { Potencial risco de perda de } \\
\text { qualidade do produto } \\
\text { (contaminação) }\end{array}$ & II & \\
\hline & & M22 & $\begin{array}{l}\text { Contaminação } \\
\text { do lubrificante }\end{array}$ & $\begin{array}{l}\text { Uso de ferramental } \\
\text { inadequado e sem } \\
\text { limpeza com } \\
\text { resíduos de outros } \\
\text { lubrificantes/ Falta } \\
\text { de qualificação de } \\
\text { mão de obra/ } \\
\text { Aplicação de } \\
\text { lubrificante } \\
\text { inadequado }\end{array}$ & $\begin{array}{c}\text { Potencial risco de perda de } \\
\text { qualidade e inocuidade do } \\
\text { produto (contaminação)/ Perda } \\
\text { das propriedades físico-químicas } \\
\text { do lubrificante promovendo } \\
\text { desgaste dos elementos de } \\
\text { máquina. }\end{array}$ & II & \\
\hline
\end{tabular}

(Continua) 
(Conclusão)

\begin{tabular}{|c|l|}
\hline Severidade & \multicolumn{1}{|c|}{ Descrição } \\
\hline I & $\begin{array}{l}\text { Evento de falha que reduz desempenho do maquinário e/ou provoca interrupção no funcionamento do ativo industrial, } \\
\text { porém não representa foco de potencial risco de perda de qualidade e inocuidade do produto em processamento. }\end{array}$ \\
\hline II & $\begin{array}{l}\text { Evento de falha que reduz desempenho do maquinário, o qual não provoca interrupção no funcionamento do ativo } \\
\text { industrial, porém apresenta foco de potencial risco de perda de qualidade e inocuidade do produto em processamento. }\end{array}$ \\
\hline III & $\begin{array}{l}\text { Evento que provoca interrupção no funcionamento do ativo industrial e apresenta foco de potencial risco de perda de } \\
\text { qualidade e inocuidade do produto em processamento. }\end{array}$ \\
\hline
\end{tabular}

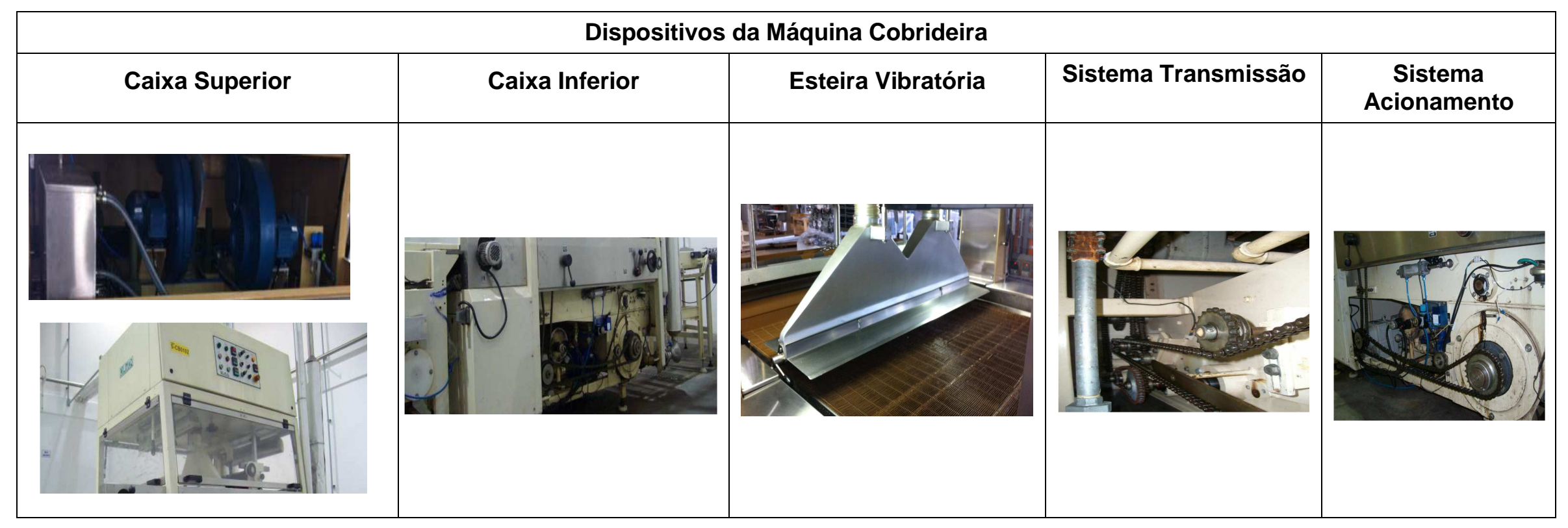

Fonte: Autoria própria 
APÊNDICE C - TABELA DE DADOS E INDICADORES DE DESEMPENHO DE MANUTENÇÃO DA MÁQUINA COBRIDEIRA ENTRE O PERÍODO DE 2010 À 2013 (SIMULAÇÃO DE VALORES COM A EXCLUSÃO DOS EVENTOS DE FALHAS RELACIONADOS COM O PROCESSO DE LUBRIFICAÇÃO INDUSTRIAL)

\begin{tabular}{cccccccccccccc}
\hline Ano & $\begin{array}{c}\text { Falhas } \\
(\mathrm{n})\end{array}$ & Data & $\begin{array}{c}\text { TTR } \\
(\mathrm{h})\end{array}$ & TBF $(\mathrm{h})$ & $\mathrm{t}(\mathrm{h})$ & $\ln (\mathrm{t})$ & $\sum \ln (\mathrm{t})$ & $\mathrm{m}(\mathrm{t})$ & $\rho\left({ }_{\mathrm{t}}\right)$ & $\operatorname{MTBF}\left({ }_{\mathrm{t}}\right)$ & $\mathrm{MTTR}(\mathrm{t})$ & $\mathrm{A}_{(\mathrm{t})}$ & $\mathrm{R}\left({ }_{\mathrm{t}}\right)$ \\
\hline 2010 & 1 & $07 / 01$ & 4,50 & 126,00 & 126,00 & 4,84 & 4,84 & 1,22 & 0,00775720 & 128,91 & 4,50 & 0,96627003 & 0,992273 \\
2010 & 2 & $12 / 01$ & 2,15 & 100,50 & 226,50 & 5,42 & 10,26 & 1,95 & 0,00690764 & 144,77 & 3,33 & 0,97754778 & 0,993116 \\
2010 & 3 & $15 / 01$ & 2,15 & 60,85 & 287,35 & 5,66 & 15,92 & 2,36 & 0,00659007 & 151,74 & 2,93 & 0,98103573 & 0,993432 \\
2010 & 4 & $28 / 01$ & 2,50 & 270,85 & 558,20 & 6,32 & 22,24 & 4,02 & 0,00577900 & 173,04 & 2,83 & 0,98393656 & 0,994238 \\
2010 & 5 & $15 / 02$ & 2,50 & 354,50 & 912,70 & 6,82 & 29,06 & 5,97 & 0,00524346 & 190,71 & 2,76 & 0,98573449 & 0,994770 \\
2010 & 6 & $19 / 02$ & 4,00 & 81,50 & 994,20 & 6,90 & 35,96 & 6,39 & 0,00515551 & 193,97 & 2,97 & 0,98493573 & 0,994858 \\
2010 & 7 & $07 / 03$ & 2,00 & 332,00 & 1326,20 & 7,19 & 43,15 & 8,05 & 0,00486992 & 205,34 & 2,83 & 0,98641226 & 0,995142 \\
2010 & 8 & $16 / 03$ & 7,00 & 187,00 & 1513,20 & 7,32 & 50,47 & 8,95 & 0,00474451 & 210,77 & 3,35 & 0,98435457 & 0,995267 \\
2010 & 9 & $25 / 03$ & 1,80 & 182,00 & 1695,20 & 7,44 & 57,91 & 9,80 & 0,00463912 & 215,56 & 3,18 & 0,98547209 & 0,995372 \\
2010 & 10 & $25 / 03$ & 2,00 & 5,50 & 1700,70 & 7,44 & 65,35 & 9,83 & 0,00463615 & 215,70 & 3,06 & 0,98601184 & 0,995375 \\
2010 & 11 & $31 / 03$ & 2,50 & 124,00 & 1824,70 & 7,51 & 72,86 & 10,40 & 0,00457206 & 218,72 & 3,01 & 0,98642896 & 0,995438 \\
2010 & 12 & $11 / 04$ & 4,00 & 228,50 & 2053,20 & 7,63 & 80,49 & 11,43 & 0,00446661 & 223,88 & 3,09 & 0,98637884 & 0,995543 \\
2010 & 13 & $17 / 05$ & 3,00 & 752,00 & 2805,20 & 7,94 & 88,42 & 14,68 & 0,00419925 & 238,14 & 3,08 & 0,98721258 & 0,995810 \\
2010 & 14 & $23 / 05$ & 1,00 & 123,00 & 2928,20 & 7,98 & 96,41 & 15,20 & 0,00416376 & 240,17 & 2,94 & 0,98792401 & 0,995845 \\
\hline
\end{tabular}

(Continua) 
(Continuação)

\begin{tabular}{|c|c|c|c|c|c|c|c|c|c|c|c|c|c|}
\hline Ano & $\begin{array}{l}\text { Falhas } \\
\text { (n) }\end{array}$ & Data & $\begin{array}{c}\text { TTR } \\
\text { (h) }\end{array}$ & TBF $(\mathrm{h})$ & $t(h)$ & $\ln \left({ }_{t}\right)$ & $\sum \ln (t)$ & $m(t)$ & $\rho(t)$ & $\operatorname{MTBF}(t)$ & $\operatorname{MTTR}(\mathrm{t})$ & $A(t)$ & $R(t)$ \\
\hline 2010 & 15 & $28 / 05$ & 0,70 & 104,00 & 3032,20 & 8,02 & 104,42 & 15,63 & 0,00413511 & 241,83 & 2,79 & 0,98860809 & 0,995873 \\
\hline 2010 & 16 & $05 / 06$ & 2,75 & 17,30 & 3049,50 & 8,02 & 112,45 & 15,70 & 0,00413046 & 242,10 & 2,78 & 0,98863001 & 0,995878 \\
\hline 2010 & 17 & $08 / 09$ & 0,20 & 590,25 & 3639,75 & 8,20 & 120,65 & 18,10 & 0,00398842 & 250,73 & 2,63 & 0,98961017 & 0,996020 \\
\hline 2010 & 18 & $22 / 09$ & 2,00 & 293,80 & 3933,55 & 8,28 & 128,92 & 19,26 & 0,00392765 & 254,61 & 2,60 & 0,98990204 & 0,996080 \\
\hline 2010 & 19 & $26 / 09$ & 0,70 & 82,00 & 4015,55 & 8,30 & 137,22 & 19,58 & 0,00391165 & 255,65 & 2,50 & 0,99032567 & 0,996096 \\
\hline 2010 & 20 & $28 / 09$ & 1,15 & 41,30 & 4056,85 & 8,31 & 145,53 & 19,74 & 0,00390374 & 256,16 & 2,43 & 0,99060304 & 0,996104 \\
\hline 2010 & 21 & $03 / 10$ & 3,35 & 103,85 & 4160,70 & 8,33 & 153,86 & 20,15 & 0,00388428 & 257,45 & 2,47 & 0,99048249 & 0,996123 \\
\hline 2010 & 22 & $15 / 10$ & 2,00 & 248,65 & 4409,35 & 8,39 & 162,25 & 21,11 & 0,00383994 & 260,42 & 2,45 & 0,99067127 & 0,996167 \\
\hline 2010 & 23 & $24 / 10$ & 5,50 & 187,00 & 4596,35 & 8,43 & 170,69 & 21,82 & 0,00380852 & 262,57 & 2,58 & 0,99025176 & 0,996199 \\
\hline 2010 & 24 & $11 / 11$ & 2,70 & 372,50 & 4968,85 & 8,51 & 179,20 & 23,23 & 0,00375027 & 266,65 & 2,59 & 0,99038176 & 0,996257 \\
\hline 2010 & 25 & $18 / 11$ & 1,50 & 144,30 & 5113,15 & 8,54 & 187,74 & 23,77 & 0,00372910 & 268,16 & 2,55 & 0,99059501 & 0,996278 \\
\hline 2010 & 26 & $02 / 12$ & 3,25 & 292,50 & 5405,65 & 8,60 & 196,33 & 24,85 & 0,00368829 & 271,13 & 2,57 & 0,99059895 & 0,996318 \\
\hline 2010 & 27 & $18 / 12$ & 2,50 & 332,75 & 5738,40 & 8,65 & 204,99 & 26,07 & 0,00364497 & 274,35 & 2,57 & 0,99071803 & 0,996362 \\
\hline 2010 & 28 & $22 / 12$ & 1,15 & 81,50 & 5819,90 & 8,67 & 213,66 & 26,37 & 0,00363482 & 275,12 & 2,52 & 0,99092466 & 0,996372 \\
\hline 2010 & 29 & $27 / 12$ & 2,50 & 103,85 & 5923,75 & 8,69 & 222,34 & 26,75 & 0,00362213 & 276,08 & 2,52 & 0,99095848 & 0,996384 \\
\hline 2010 & 30 & $27 / 12$ & 3,00 & 7,50 & 5931,25 & 8,69 & 231,03 & 26,77 & 0,00362122 & 276,15 & 2,54 & 0,99090370 & 0,996385 \\
\hline
\end{tabular}

(Continua) 
(Continuação)

\begin{tabular}{|c|c|c|c|c|c|c|c|c|c|c|c|c|c|}
\hline Ano & $\begin{array}{c}\text { Falhas } \\
\text { (n) }\end{array}$ & Data & $\begin{array}{c}\text { TTR } \\
\text { (h) }\end{array}$ & TBF $(h)$ & $t(h)$ & $\ln (t)$ & $\sum \ln (t)$ & $m(t)$ & $\rho(t)$ & $\operatorname{MTBF}(\mathrm{t})$ & $\operatorname{MTTR}(\mathrm{t})$ & $A(t)$ & $\mathrm{R}(\mathrm{t})$ \\
\hline 2010 & 31 & $30 / 12$ & 1,50 & 60,00 & 5991,25 & 8,70 & 239,73 & 26,99 & 0,00361402 & 276,70 & 2,50 & 0,99104012 & 0,996393 \\
\hline 2011 & 32 & $10 / 01$ & 1,75 & 208,50 & 6199,75 & 8,73 & 248,46 & 27,74 & 0,00358965 & 278,58 & 2,48 & 0,99118283 & 0,996417 \\
\hline 2011 & 33 & $21 / 01$ & 0,50 & 229,50 & 6429,25 & 8,77 & 257,23 & 28,56 & 0,00356394 & 280,59 & 2,42 & 0,99145539 & 0,996442 \\
\hline 2011 & 34 & $26 / 01$ & 2,00 & 104,50 & 6533,75 & 8,78 & 266,02 & 28,93 & 0,00355259 & 281,48 & 2,41 & 0,99152532 & 0,996454 \\
\hline 2011 & 35 & $16 / 02$ & 2,25 & 439,00 & 6972,75 & 8,85 & 274,87 & 30,48 & 0,00350719 & 285,13 & 2,40 & 0,99164808 & 0,996499 \\
\hline 2011 & 36 & $08 / 03$ & 0,75 & 417,75 & 7390,50 & 8,91 & 283,77 & 31,94 & 0,00346706 & 288,43 & 2,36 & 0,99189931 & 0,996539 \\
\hline 2011 & 37 & $10 / 04$ & 2,00 & 671,25 & 8061,75 & 8,99 & 292,77 & 34,25 & 0,00340795 & 293,43 & 2,35 & 0,99206853 & 0,996598 \\
\hline 2011 & 38 & $19 / 04$ & 1,50 & 166,00 & 8227,75 & 9,02 & 301,78 & 34,81 & 0,00339424 & 294,62 & 2,32 & 0,99217457 & 0,996612 \\
\hline 2011 & 39 & $03 / 05$ & 2,50 & 292,50 & 8520,25 & 9,05 & 310,83 & 35,80 & 0,00337087 & 296,66 & 2,33 & 0,99221303 & 0,996635 \\
\hline 2011 & 40 & $20 / 05$ & 1,75 & 354,50 & 8874,75 & 9,09 & 319,92 & 36,99 & 0,00334380 & 299,06 & 2,31 & 0,99232267 & 0,996662 \\
\hline 2011 & 41 & $17 / 06$ & 2,00 & 586,25 & 9461,00 & 9,15 & 329,08 & 38,94 & 0,00330177 & 302,87 & 2,31 & 0,99244334 & 0,996704 \\
\hline 2011 & 42 & $24 / 06$ & 2,50 & 145,00 & 9606,00 & 9,17 & 338,25 & 39,42 & 0,00329185 & 303,78 & 2,31 & 0,99245090 & 0,996714 \\
\hline 2011 & 43 & $02 / 07$ & 1,50 & 165,50 & 9771,50 & 9,19 & 347,44 & 39,96 & 0,00328074 & 304,81 & 2,29 & 0,99253710 & 0,996725 \\
\hline 2011 & 44 & $18 / 08$ & 2,75 & 985,50 & 10757,00 & 9,28 & 356,72 & 43,16 & 0,00321898 & 310,66 & 2,30 & 0,99264354 & 0,996786 \\
\hline 2011 & 45 & $02 / 09$ & 6,26 & 291,25 & 11048,25 & 9,31 & 366,03 & 44,10 & 0,00320202 & 312,30 & 2,39 & 0,99240459 & 0,996803 \\
\hline 2011 & 46 & 05/09 & 0,80 & 56,74 & 11104,99 & 9,32 & 375,35 & 44,28 & 0,00319878 & 312,62 & 2,36 & 0,99252115 & 0,996806 \\
\hline
\end{tabular}

(Continua) 
(Continuação)

\begin{tabular}{|c|c|c|c|c|c|c|c|c|c|c|c|c|c|}
\hline Ano & $\begin{array}{l}\text { Falhas } \\
\text { (n) }\end{array}$ & Data & $\begin{array}{c}\text { TTR } \\
\text { (h) }\end{array}$ & TBF (h) & $t(h)$ & $\ln (\mathrm{t})$ & $\sum \ln (\mathrm{t})$ & $m(t)$ & $\rho(t)$ & $\operatorname{MTBF}(t)$ & $\operatorname{MTTR}(\mathrm{t})$ & $A(t)$ & $\mathrm{R}(\mathrm{t})$ \\
\hline 2011 & 47 & $16 / 09$ & 2,50 & 230,20 & 11335,19 & 9,34 & 384,68 & 45,02 & 0,00318582 & 313,89 & 2,36 & 0,99254157 & 0,996819 \\
\hline 2011 & 48 & $05 / 10$ & 0,50 & 417,50 & 11752,69 & 9,37 & 394,05 & 46,34 & 0,00316311 & 316,14 & 2,32 & 0,99271504 & 0,996842 \\
\hline 2011 & 49 & $20 / 10$ & 1,50 & 293,50 & 12046,19 & 9,40 & 403,45 & 47,27 & 0,00314772 & 317,69 & 2,30 & 0,99280215 & 0,996857 \\
\hline 2011 & 50 & $30 / 10$ & 1,25 & 208,50 & 12254,69 & 9,41 & 412,86 & 47,92 & 0,00313705 & 318,77 & 2,28 & 0,99289151 & 0,996868 \\
\hline 2011 & 51 & $09 / 12$ & 2,00 & 838,75 & 13093,44 & 9,48 & 422,34 & 50,54 & 0,00309625 & 322,97 & 2,28 & 0,99300022 & 0,996909 \\
\hline 2011 & 52 & $18 / 12$ & 1,00 & 187,00 & 13280,44 & 9,49 & 431,84 & 51,11 & 0,00308757 & 323,88 & 2,25 & 0,99309445 & 0,996917 \\
\hline 2011 & 53 & $23 / 12$ & 1,00 & 104,00 & 13384,44 & 9,50 & 441,34 & 51,43 & 0,00308281 & 324,38 & 2,23 & 0,99317685 & 0,996922 \\
\hline 2012 & 54 & $31 / 01$ & 1,80 & 755,00 & 14139,44 & 9,56 & 450,90 & 53,75 & 0,00304954 & 327,92 & 2,22 & 0,99327388 & 0,996955 \\
\hline 2012 & 55 & 02/02 & 2,50 & 40,20 & 14179,64 & 9,56 & 460,46 & 53,87 & 0,00304782 & 328,10 & 2,23 & 0,99326236 & 0,996957 \\
\hline 2012 & 56 & 02/02 & 4.25 & 8,50 & 14188,14 & 9,56 & 470,02 & 53,90 & 0,00304746 & 328,14 & 2,19 & 0,99338265 & 0,996957 \\
\hline 2012 & 57 & $13 / 02$ & 2,00 & 226,75 & 14414,89 & 9,58 & 479,59 & 54,59 & 0,00303792 & 329,17 & 2,18 & 0,99341301 & 0,996967 \\
\hline 2012 & 58 & $01 / 04$ & 4,00 & 964,00 & 15378,89 & 9,64 & 489,23 & 57,50 & 0,00299927 & 333,41 & 2,21 & 0,99340352 & 0,997005 \\
\hline 2012 & 59 & $04 / 04$ & 2,00 & 59,00 & 15437,89 & 9,64 & 498,88 & 57,67 & 0,00299700 & 333,67 & 2,21 & 0,99341920 & 0,997007 \\
\hline 2012 & 60 & 06/04 & 5,00 & 40,00 & 15477,89 & 9,65 & 508,52 & 57,79 & 0,00299547 & 333,84 & 2,26 & 0,99328512 & 0,997009 \\
\hline 2012 & 61 & $15 / 05$ & 3,00 & 814,00 & 16291,89 & 9,70 & 518,22 & 60,22 & 0,00296526 & 337,24 & 2,27 & 0,99331675 & 0,997039 \\
\hline 2012 & 62 & $23 / 05$ & 2,50 & 144,00 & 16435,89 & 9,71 & 527,93 & 60,65 & 0,00296010 & 337,83 & 2,27 & 0,99331742 & 0,997044 \\
\hline
\end{tabular}

(Continua) 
(Continuação)

\begin{tabular}{|c|c|c|c|c|c|c|c|c|c|c|c|c|c|}
\hline Ano & $\begin{array}{c}\text { Falhas } \\
\text { (n) }\end{array}$ & Data & $\begin{array}{c}\text { TTR } \\
\text { (h) }\end{array}$ & TBF $(h)$ & $t(h)$ & $\ln (\mathrm{t})$ & $\sum \ln (\mathrm{t})$ & $m(t)$ & $\rho(t)$ & $\operatorname{MTBF}(t)$ & $\operatorname{MTTR}(\mathrm{t})$ & $A(t)$ & $\mathrm{R}(\mathrm{t})$ \\
\hline 2012 & 63 & $24 / 05$ & 8,15 & 3,50 & 16439,39 & 9,71 & 537,64 & 60,66 & 0,00295997 & 337,84 & 2,37 & 0,99304531 & 0,997044 \\
\hline 2012 & 64 & $09 / 07$ & 1,75 & 283,85 & 16723,24 & 9,72 & 547,36 & 61,50 & 0,00294997 & 338,99 & 2,36 & 0,99309666 & 0,997054 \\
\hline 2012 & 65 & $19 / 07$ & 2,50 & 187,25 & 16910,49 & 9,74 & 557,10 & 62,05 & 0,00294348 & 339,73 & 2,36 & 0,99310533 & 0,997061 \\
\hline 2012 & 66 & $01 / 08$ & 2,50 & 249,50 & 17159,99 & 9,75 & 566,85 & 62,78 & 0,00293497 & 340,72 & 2,36 & 0,99311894 & 0,997069 \\
\hline 2012 & 67 & $10 / 08$ & 2,00 & 186,50 & 17346,49 & 9,76 & 576,61 & 63,33 & 0,00292870 & 341,45 & 2,36 & 0,99314908 & 0,997076 \\
\hline 2012 & 68 & 02/09 & 1,50 & 460,00 & 17806,49 & 9,79 & 586,40 & 64,67 & 0,00291358 & 343,22 & 2,34 & 0,99322037 & 0,997091 \\
\hline 2012 & 69 & $19 / 09$ & 3,00 & 355,50 & 18161,99 & 9,81 & 596,20 & 65,71 & 0,00290221 & 344,57 & 2,35 & 0,99321938 & 0,997102 \\
\hline 2012 & 70 & $26 / 09$ & 1,50 & 123,00 & 18284,99 & 9,81 & 606,02 & 66,06 & 0,00289833 & 345,03 & 2,34 & 0,99326318 & 0,997106 \\
\hline 2012 & 71 & $02 / 10$ & 2,00 & 103,50 & 18388,49 & 9,82 & 615,84 & 66,36 & 0,00289510 & 345,41 & 2,34 & 0,99328433 & 0,997109 \\
\hline 2012 & 72 & $15 / 10$ & 2,50 & 271,00 & 18659,49 & 9,83 & 625,67 & 67,15 & 0,00288674 & 346,41 & 2,34 & 0,99329709 & 0,997117 \\
\hline 2012 & 73 & $05 / 11$ & 2,00 & 438,50 & 19097,99 & 9,86 & 635,53 & 68,41 & 0,00287350 & 348,01 & 2,33 & 0,99334072 & 0,997131 \\
\hline 2012 & 74 & $22 / 11$ & 2,75 & 334,00 & 19431,99 & 9,87 & 645,40 & 69,37 & 0,00286367 & 349,20 & 2,34 & 0,99334744 & 0,997140 \\
\hline 2012 & 75 & $09 / 12$ & 2,00 & 333,25 & 19765,24 & 9,89 & 655,29 & 70,32 & 0,00285405 & 350,38 & 2,33 & 0,99338235 & 0,997150 \\
\hline 2012 & 76 & $28 / 12$ & 1,50 & 397,00 & 20162,24 & 9,91 & 665,21 & 71,45 & 0,00284285 & 351,76 & 2,32 & 0,99343895 & 0,997161 \\
\hline 2013 & 77 & $05 / 01$ & 2,50 & 102,50 & 20264,74 & 9,92 & 675,12 & 71,74 & 0,00284000 & 352,11 & 2,33 & 0,99343904 & 0,997164 \\
\hline 2013 & 78 & $31 / 01$ & 2,75 & 543,25 & 20807,99 & 9,94 & 685,07 & 73,28 & 0,00282518 & 353,96 & 2,33 & 0,99345788 & 0,997179 \\
\hline
\end{tabular}

(Continua) 
(Conclusão)

\begin{tabular}{|c|c|c|c|c|c|c|c|c|c|c|c|c|c|}
\hline Ano & $\begin{array}{c}\text { Falhas } \\
\text { (n) }\end{array}$ & Data & $\begin{array}{c}\text { TTR } \\
\text { (h) }\end{array}$ & TBF (h) & $t(h)$ & $\ln (t)$ & $\sum \ln (t)$ & $m(t)$ & $\rho(t)$ & $\operatorname{MTBF}(t)$ & $\operatorname{MTTR}(\mathrm{t})$ & $A(t)$ & $\mathrm{R}(\mathrm{t})$ \\
\hline 2013 & 79 & $31 / 01$ & 1,75 & 8,75 & 20816,74 & 9,94 & 695,01 & 73,30 & 0,00282494 & 353,99 & 2,32 & 0,99347892 & 0,997179 \\
\hline 2013 & 80 & $18 / 02$ & 2,00 & 374,00 & 21190,74 & 9,96 & 704,97 & 74,36 & 0,00281501 & 355,24 & 2,32 & 0,99351294 & 0,997189 \\
\hline 2013 & 81 & $13 / 03$ & 1,75 & 481,00 & 21671,74 & 9,98 & 714,95 & 75,71 & 0,00280254 & 356,82 & 2,31 & 0,99356094 & 0,997201 \\
\hline 2013 & 82 & $22 / 03$ & 2,50 & 187,25 & 21858,99 & 9,99 & 724,95 & 76,23 & 0,00279778 & 357,43 & 2,31 & 0,99356550 & 0,997206 \\
\hline 2013 & 83 & $11 / 04$ & 2,00 & 418,00 & 22276,99 & 10,01 & 734,96 & 77,40 & 0,00278732 & 358,77 & 2,31 & 0,99359984 & 0,997217 \\
\hline 2013 & 84 & $05 / 05$ & 4,75 & 499,25 & 22776,24 & 10,03 & 744,99 & 78,79 & 0,00277512 & 360,34 & 2,34 & 0,993 & 0,997229 \\
\hline 2013 & 85 & 06/06 & 0,75 & 667,25 & 23443,49 & 10,06 & 755,05 & 80,64 & 0,00275932 & 362,41 & 2,32 & 0,99363557 & 0,997244 \\
\hline 2013 & 86 & $23 / 06$ & 1,50 & 356,25 & 23799,74 & 10,08 & 765,13 & 81,62 & 0,00275110 & 363,49 & 2,31 & 0,99368035 & 0,997253 \\
\hline 2013 & 87 & $18 / 08$ & 1,50 & 1174,50 & 24974,24 & 10,13 & 775,26 & 84,83 & 0,00272502 & 366,97 & 2,30 & 0,99376501 & 0,997279 \\
\hline 2013 & 88 & $15 / 09$ & 2,00 & 565,50 & 25539,74 & 10,15 & 785,40 & 86,37 & 0,00271297 & 368,60 & 2,30 & 0,9938 & 0,997291 \\
\hline 2013 & 89 & $09 / 10$ & 1,50 & 523,00 & 26062,74 & 10,17 & 795,57 & 87,79 & 0,00270212 & 370,08 & 2,29 & 0,99385020 & 0,997302 \\
\hline 2013 & 90 & $15 / 10$ & 3,50 & 124,50 & 26187,24 & 10,17 & 805,75 & 88,12 & 0,00269957 & 370,43 & 2,30 & 0,99382011 & 0,997304 \\
\hline 2013 & 91 & $18 / 11$ & 2,00 & 710,50 & 26897,74 & 10,20 & 815,95 & 90,04 & 0,00268532 & 372,40 & 2,30 & 0,99386139 & 0,997318 \\
\hline 2013 & 92 & $23 / 12$ & 2,00 & 733,00 & 27630,74 & 10,23 & 826,17 & 92,00 & 0,00267108 & 374,38 & 2,30 & 0,99390236 & 0,997332 \\
\hline
\end{tabular}

Fonte: Autoria própria 


\section{APÊNDICE D - TABELA DE DADOS E INDICADORES DE DESEMPENHO DE MANUTENÇÃO DA MÁQUINA COBRIDEIRA}

ENTRE O PERÍODO DE 2010 À 2014

\begin{tabular}{|c|c|c|c|c|c|c|c|c|c|c|c|c|c|}
\hline Ano & $\begin{array}{c}\text { Falhas } \\
\text { (n) }\end{array}$ & Data & TTR (h) & TBF (h) & $t(h)$ & $\ln (\mathrm{t})$ & $\sum \ln (t)$ & $\mathrm{m}(\mathrm{t})$ & $\rho\left({ }_{t}\right)$ & $\left.\operatorname{MTBF}_{(t}\right)$ & $\operatorname{MTTR}(t)$ & $A(t)$ & $R(t)$ \\
\hline 2010 & 1 & $07 / 01$ & 4,50 & 126,00 & 126,00 & 4,84 & 4,84 & 1,63 & 0,01031834 & 96,91 & 4,50 & 0,95562778 & 0,989735 \\
\hline 2010 & 2 & $12 / 01$ & 2,15 & 100,50 & 226,50 & 5,42 & 10,26 & 2,60 & 0,00917207 & 109,03 & 3,33 & 0,97040542 & 0,990870 \\
\hline 2010 & 3 & $15 / 01$ & 2,15 & 60,85 & 287,35 & 5,66 & 15,92 & 3,14 & 0,00874412 & 114,36 & 2,93 & 0,97499201 & 0,991294 \\
\hline 2010 & 4 & $22 / 01$ & 6,80 & 144,85 & 432,20 & 6,07 & 21,99 & 4,36 & 0,00805602 & 124,13 & 3,90 & 0,96953859 & 0,991976 \\
\hline 2010 & 5 & $28 / 01$ & 2,50 & 119,20 & 551,40 & 6,31 & 28,30 & 5,29 & 0,00767149 & 130,35 & 3,62 & 0,97297959 & 0,992358 \\
\hline 2010 & 6 & $05 / 02$ & 9,00 & 165,50 & 716,90 & 6,57 & 34,88 & 6,53 & 0,00727764 & 137,41 & 4,52 & 0,96817543 & 0,992749 \\
\hline 2010 & 7 & $15 / 02$ & 2,50 & 201,00 & 917,90 & 6,82 & 41,70 & 7,95 & 0,00692528 & 144,40 & 4,23 & 0,97154910 & 0,993099 \\
\hline 2010 & 8 & $19 / 02$ & 4,00 & 81,50 & 999,40 & 6,91 & 48,61 & 8,51 & 0,00680800 & 146,89 & 4,20 & 0,97220128 & 0,993215 \\
\hline 2010 & 9 & $03 / 03$ & 5,00 & 245,00 & 1244,40 & 7,13 & 55,73 & 10,14 & 0,00651477 & 153,50 & 4,29 & 0,97281835 & 0,993506 \\
\hline 2010 & 10 & $07 / 03$ & 2,00 & 142,00 & 1386,40 & 7,23 & 62,97 & 11,06 & 0,00637494 & 156,86 & 4,06 & 0,97477073 & 0,993645 \\
\hline 2010 & 11 & $16 / 03$ & 7,00 & 187,00 & 1573,40 & 7,36 & 70,33 & 12,24 & 0,00621502 & 160,90 & 4,33 & 0,97381028 & 0,993804 \\
\hline 2010 & 12 & $19 / 03$ & 3,50 & 56,00 & 1629,40 & 7,40 & 77,72 & 12,58 & 0,00617152 & 162,03 & 4,26 & 0,97439257 & 0,993847 \\
\hline 2010 & 13 & $25 / 03$ & 1,80 & 122,50 & 1751,90 & 7,47 & 85,19 & 13,33 & 0,00608234 & 164,41 & 4,07 & 0,97584733 & 0,993936 \\
\hline 2010 & 14 & $25 / 03$ & 2,00 & 11,00 & 1762,90 & 7,47 & 92,67 & 13,40 & 0,00607470 & 164,62 & 3,92 & 0,97673274 & 0,993944 \\
\hline 2010 & 15 & $31 / 03$ & 2,50 & 122,20 & 1885,10 & 7,54 & 100,21 & 14,14 & 0,00599350 & 166,85 & 3,83 & 0,97757909 & 0,994024 \\
\hline
\end{tabular}

(Continua) 
(Continuação)

\begin{tabular}{|c|c|c|c|c|c|c|c|c|c|c|c|c|c|}
\hline Ano & $\begin{array}{l}\text { Falhas } \\
\text { (n) }\end{array}$ & Data & TTR (h) & TBF $(\mathrm{h})$ & $t(h)$ & $\ln (\mathrm{t})$ & $\sum \ln (\mathrm{t})$ & $m(t)$ & $\rho(t)$ & $\operatorname{MTBF}(t)$ & $\operatorname{MTTR}\left({ }_{t}\right)$ & $A(t)$ & $\mathrm{R}(\mathrm{t})$ \\
\hline 2010 & 16 & $11 / 04$ & 4,00 & 228,50 & 2113,60 & 7,66 & 107,86 & 15,49 & 0,00585738 & 170,72 & 3,84 & 0,97801645 & 0,994160 \\
\hline 2010 & 17 & $17 / 05$ & 3,00 & 731,00 & 2844,60 & 7,95 & 115,82 & 19,64 & 0,00551824 & 181,22 & 3,79 & 0,97952364 & 0,994497 \\
\hline 2010 & 18 & $23 / 05$ & 1,00 & 123,00 & 2967,60 & 8,00 & 123,81 & 20,32 & 0,00547154 & 182,76 & 3,63 & 0,98050759 & 0,994543 \\
\hline 2010 & 19 & $28 / 05$ & 0,70 & 104,00 & 3071,60 & 8,03 & 131,84 & 20,88 & 0,00543382 & 184,03 & 3,48 & 0,98144674 & 0,994581 \\
\hline 2010 & 20 & $05 / 06$ & 2,75 & 209,30 & 3280,90 & 8,10 & 139,94 & 22,01 & 0,00536237 & 186,48 & 3,44 & 0,98187462 & 0,994652 \\
\hline 2010 & 21 & $18 / 08$ & 4,30 & 165,25 & 3446,15 & 8,15 & 148,08 & 22,90 & 0,00530972 & 188,33 & 3,48 & 0,98184034 & 0,994704 \\
\hline 2010 & 22 & $31 / 08$ & 6,75 & 247,70 & 3693,85 & 8,21 & 156,30 & 24,20 & 0,00523623 & 190,98 & 3,63 & 0,98133786 & 0,994777 \\
\hline 2010 & 23 & $08 / 09$ & 0,20 & 146,80 & 3840,65 & 8,25 & 164,55 & 24,97 & 0,00519541 & 192,48 & 3,48 & 0,98222796 & 0,994818 \\
\hline 2010 & 24 & $22 / 09$ & 2,00 & 251,80 & 4092,45 & 8,32 & 172,87 & 26,27 & 0,00512959 & 194,95 & 3,42 & 0,98275514 & 0,994884 \\
\hline 2010 & 25 & $26 / 09$ & 0,70 & 82,00 & 4174,45 & 8,34 & 181,21 & 26,69 & 0,00510919 & 195,73 & 3,31 & 0,98335992 & 0,994904 \\
\hline 2010 & 26 & $28 / 09$ & 1,15 & 62,30 & 4236,75 & 8,35 & 189,56 & 27,00 & 0,00509402 & 196,31 & 3,23 & 0,98381835 & 0,994919 \\
\hline 2010 & 27 & $03 / 10$ & 3,35 & 103,85 & 4340,60 & 8,38 & 197,93 & 27,53 & 0,00506931 & 197,27 & 3,23 & 0,98387356 & 0,994944 \\
\hline 2010 & 28 & $15 / 10$ & 2,00 & 206,65 & 4547,25 & 8,42 & 206,35 & 28,57 & 0,00502219 & 199,12 & 3,19 & 0,98423531 & 0,994990 \\
\hline 2010 & 29 & $24 / 10$ & 5,50 & 166,00 & 4713,25 & 8,46 & 214,81 & 29,41 & 0,00498616 & 200,56 & 3,27 & 0,98396183 & 0,995026 \\
\hline 2010 & 30 & $07 / 11$ & 2,50 & 288,50 & 5001,75 & 8,52 & 223,33 & 30,84 & 0,00492703 & 202,96 & 3,24 & 0,98427134 & 0,995085 \\
\hline 2010 & 31 & $11 / 11$ & 2,70 & 81,50 & 5083,25 & 8,53 & 231,86 & 31,24 & 0,00491107 & 203,62 & 3,23 & 0,98440491 & 0,995101 \\
\hline 2010 & 32 & $11 / 11$ & 9,00 & 5,00 & 5088,25 & 8,53 & 240,40 & 31,26 & 0,00491010 & 203,66 & 3,41 & 0,98355011 & 0,995102 \\
\hline
\end{tabular}

(Continua) 
(Continuação)

\begin{tabular}{|c|c|c|c|c|c|c|c|c|c|c|c|c|c|}
\hline Ano & $\begin{array}{l}\text { Falhas } \\
\text { (n) }\end{array}$ & Data & TTR (h) & TBF (h) & $t(h)$ & $\ln (\mathrm{t})$ & $\sum \ln (\mathrm{t})$ & $m(t)$ & $\rho(t)$ & $\operatorname{MTBF}(t)$ & $\operatorname{MTTR}(\mathrm{t})$ & $A(t)$ & $\mathrm{R}(\mathrm{t})$ \\
\hline 2010 & 33 & $18 / 11$ & 1,50 & 136,50 & 5224,75 & 8,56 & 248,96 & 31,93 & 0,00488407 & 204,75 & 3,35 & 0,98390894 & 0,995128 \\
\hline 2010 & 34 & $25 / 11$ & 6,00 & 125,00 & 5349,75 & 8,58 & 257,54 & 32,54 & 0,00486093 & 205,72 & 3,43 & 0,98361702 & 0,995151 \\
\hline 2010 & 35 & $02 / 12$ & 3,25 & 141,00 & 5490,75 & 8,61 & 266,16 & 33,22 & 0,00483561 & 206,80 & 3,42 & 0,98372458 & 0,995176 \\
\hline 2010 & 36 & $18 / 12$ & 2,50 & 311,75 & 5802,50 & 8,67 & 274,82 & 34,72 & 0,00478228 & 209,11 & 3,40 & 0,98401968 & 0,995229 \\
\hline 2010 & 37 & $22 / 12$ & 1,15 & 102,50 & 5905,00 & 8,68 & 283,51 & 35,21 & 0,00476550 & 209,84 & 3,34 & 0,98435507 & 0,995246 \\
\hline 2010 & 38 & $27 / 12$ & 2,50 & 82,85 & 5987,85 & 8,70 & 292,20 & 35,60 & 0,00475218 & 210,43 & 3,31 & 0,98449932 & 0,995259 \\
\hline 2010 & 39 & $27 / 12$ & 3,00 & 7,50 & 5995,35 & 8,70 & 300,90 & 35,64 & 0,00475099 & 210,48 & 3,31 & 0,98454013 & 0,995260 \\
\hline 2010 & 40 & $29 / 12$ & 3,15 & 36,50 & 6031,85 & 8,70 & 309,61 & 35,81 & 0,00474520 & 210,74 & 3,30 & 0,98457651 & 0,995266 \\
\hline 2010 & 41 & $30 / 12$ & 1,50 & 12,50 & 6044,35 & 8,71 & 318,31 & 35,87 & 0,00474323 & 210,83 & 3,26 & 0,98478487 & 0,995268 \\
\hline 2011 & 42 & $10 / 01$ & 1,75 & 208,50 & 6252,85 & 8,74 & 327,05 & 36,86 & 0,00471104 & 212,27 & 3,22 & 0,98505060 & 0,995300 \\
\hline 2011 & 43 & $21 / 01$ & 0,50 & 208,25 & 6461,10 & 8,77 & 335,83 & 37,84 & 0,00468015 & 213,67 & 3,16 & 0,98543471 & 0,995331 \\
\hline 2011 & 44 & $26 / 01$ & 2,00 & 104,50 & 6565,60 & 8,79 & 344,62 & 38,32 & 0,00466510 & 214,36 & 3,13 & 0,98560015 & 0,995346 \\
\hline 2011 & 45 & $29 / 01$ & 5,00 & 61,00 & 6626,60 & 8,80 & 353,42 & 38,61 & 0,00465644 & 214,76 & 3,17 & 0,98543872 & 0,995354 \\
\hline 2011 & 46 & $16 / 02$ & 2,25 & 354,75 & 6981,35 & 8,85 & 362,27 & 40,25 & 0,00460794 & 217,02 & 3,15 & 0,98567807 & 0,995403 \\
\hline 2011 & 47 & $08 / 03$ & 0,75 & 396,75 & 7378,10 & 8,91 & 371,17 & 42,07 & 0,00455708 & 219,44 & 3,10 & 0,98606043 & 0,995453 \\
\hline 2011 & 48 & $10 / 04$ & 2,00 & 671,25 & 8049,35 & 8,99 & 380,17 & 45,10 & 0,00447809 & 223,31 & 3,08 & 0,98639876 & 0,995532 \\
\hline
\end{tabular}

(Continua) 
(Continuação)

\begin{tabular}{|c|c|c|c|c|c|c|c|c|c|c|c|c|c|}
\hline Ano & $\begin{array}{c}\text { Falhas } \\
\text { (n) }\end{array}$ & Data & TTR (h) & TBF $(\mathrm{h})$ & $t(h)$ & $\ln (t)$ & $\sum \ln (\mathrm{t})$ & $m(t)$ & $\rho(t)$ & $\operatorname{MTBF}(t)$ & $\operatorname{MTTR}(\mathrm{t})$ & $A(t)$ & $R(t)$ \\
\hline 2011 & 49 & $19 / 04$ & 1,50 & 166,00 & 8215,35 & 9,01 & 389,18 & 45,84 & 0,00445977 & 224,23 & 3,05 & 0,98659352 & 0,995550 \\
\hline 2011 & 50 & $22 / 04$ & 4,50 & 61,50 & 8276,85 & 9,02 & 398,20 & 46,12 & 0,00445310 & 224,56 & 3,08 & 0,98648736 & 0,995557 \\
\hline 2011 & 51 & $03 / 05$ & 2,50 & 205,50 & 8482,35 & 9,05 & 407,25 & 47,03 & 0,00443122 & 225,67 & 3,06 & 0,98660156 & 0,995579 \\
\hline 2011 & 52 & $20 / 05$ & 1,75 & 333,50 & 8815,85 & 9,08 & 416,33 & 48,50 & 0,00439704 & 227,43 & 3,04 & 0,98681178 & 0,995613 \\
\hline 2011 & 53 & $17 / 06$ & 2,00 & 565,25 & 9381,10 & 9,15 & 425,48 & 50,97 & 0,00434251 & 230,28 & 3,02 & 0,98705617 & 0,995667 \\
\hline 2011 & 54 & $24 / 06$ & 2,50 & 124,00 & 9505,10 & 9,16 & 434,64 & 51,51 & 0,00433108 & 230,89 & 3,01 & 0,98713043 & 0,995678 \\
\hline 2011 & 55 & $02 / 07$ & 1,50 & 144,50 & 9649,60 & 9,17 & 443,81 & 52,14 & 0,00431798 & 231,59 & 2,98 & 0,98728442 & 0,995691 \\
\hline 2011 & 56 & $18 / 08$ & 2,75 & 964,50 & 10614,10 & 9,27 & 453,08 & 56,26 & 0,00423616 & 236,06 & 2,98 & 0,98753951 & 0,995773 \\
\hline 2011 & 57 & $02 / 09$ & 6,26 & 291,25 & 10905,35 & 9,30 & 462,38 & 57,49 & 0,00421320 & 237,35 & 3,04 & 0,98736970 & 0,995796 \\
\hline 2011 & 58 & 05/09 & 0,80 & 56,74 & 10962,09 & 9,30 & 471,68 & 57,73 & 0,00420881 & 237,60 & 3,00 & 0,98754091 & 0,995800 \\
\hline 2011 & 59 & $16 / 09$ & 2,50 & 209,20 & 11171,29 & 9,32 & 481,00 & 58,61 & 0,00419287 & 238,50 & 2,99 & 0,98762202 & 0,995816 \\
\hline 2011 & 60 & $05 / 10$ & 0,50 & 375,50 & 11546,79 & 9,35 & 490,36 & 60,18 & 0,00416512 & 240,09 & 2,95 & 0,98787151 & 0,995844 \\
\hline 2011 & 61 & $20 / 10$ & 1,50 & 293,50 & 11840,29 & 9,38 & 499,74 & 61,40 & 0,00414418 & 241,30 & 2,92 & 0,98802775 & 0,995864 \\
\hline 2011 & 62 & $22 / 10$ & 8,50 & 40,50 & 11880,79 & 9,38 & 509,12 & 61,56 & 0,00414134 & 241,47 & 3,01 & 0,98767239 & 0,995867 \\
\hline 2011 & 63 & $30 / 10$ & 1,25 & 138,50 & 12019,29 & 9,39 & 518,51 & 62,14 & 0,00413172 & 242,03 & 2,99 & 0,98781356 & 0,995877 \\
\hline 2011 & 64 & $06 / 12$ & 5,00 & 754,75 & 12774,04 & 9,46 & 527,97 & 65,24 & 0,00408150 & 245,01 & 3,02 & 0,98783454 & 0,995927 \\
\hline
\end{tabular}

(Continuação) 
(Continuação)

\begin{tabular}{|c|c|c|c|c|c|c|c|c|c|c|c|c|c|}
\hline Ano & $\begin{array}{l}\text { Falhas } \\
\text { (n) }\end{array}$ & Data & TTR (h) & TBF (h) & $t(h)$ & $\ln (t)$ & $\sum \ln (t)$ & $m(t)$ & $\rho(t)$ & $\operatorname{MTBF}(t)$ & $\operatorname{MTTR}(\mathrm{t})$ & $A(t)$ & $\mathrm{R}(\mathrm{t})$ \\
\hline 2011 & 65 & $09 / 12$ & 2,00 & 58,00 & 12832,04 & 9,46 & 537,43 & 65,47 & 0,00407779 & 245,23 & 3,00 & 0,98790775 & 0,995931 \\
\hline 2011 & 66 & $13 / 12$ & 5,50 & 82,00 & 12914,04 & 9,47 & 546,89 & 65,81 & 0,00407257 & 245,54 & 3,04 & 0,98777259 & 0,995936 \\
\hline 2011 & 67 & $18 / 12$ & 1,00 & 78,50 & 12992,54 & 9,47 & 556,37 & 66,13 & 0,00406762 & 245,84 & 3,01 & 0,98790811 & 0,995941 \\
\hline 2011 & 68 & $18 / 12$ & 4,00 & 6,50 & 12999,04 & 9,47 & 565,84 & 66,15 & 0,00406721 & 245,87 & 3,02 & 0,98785147 & 0,995941 \\
\hline 2011 & 69 & $23 / 12$ & 1,00 & 100,00 & 13099,04 & 9,48 & 575,32 & 66,56 & 0,00406096 & 246,25 & 2,99 & 0,98798616 & 0,995947 \\
\hline 2012 & 70 & $18 / 01$ & 13,00 & 482,00 & 13581,04 & 9,52 & 584,84 & 68,51 & 0,00403160 & 248,04 & 3,14 & 0,98750970 & 0,995977 \\
\hline 2012 & 71 & $31 / 01$ & 1,80 & 239,00 & 13820,04 & 9,53 & 594,37 & 69,47 & 0,00401750 & 248,91 & 3,12 & 0,98762664 & 0,995991 \\
\hline 2012 & 72 & $02 / 02$ & 2,50 & 40,20 & 13860,24 & 9,54 & 603,91 & 69,63 & 0,00401516 & 249,06 & 3,11 & 0,98766740 & 0,995993 \\
\hline 2012 & 73 & $02 / 02$ & 4.25 & 8,50 & 13868,74 & 9,54 & 613,44 & 69,67 & 0,00401467 & 249,09 & 3,07 & 0,98783577 & 0,995993 \\
\hline 2012 & 74 & $13 / 02$ & 2,00 & 226,75 & 14095,49 & 9,55 & 623,00 & 70,58 & 0,00400161 & 249,90 & 3,05 & 0,98793116 & 0,996006 \\
\hline 2012 & 75 & $08 / 03$ & 3,00 & 313,00 & 14408,49 & 9,58 & 632,57 & 71,83 & 0,00398400 & 251,00 & 3,05 & 0,98798637 & 0,996024 \\
\hline 2012 & 76 & $01 / 04$ & 4,00 & 480,00 & 14888,49 & 9,61 & 642,18 & 73,73 & 0,00395787 & 252,66 & 3,06 & 0,98801603 & 0,996050 \\
\hline 2012 & 77 & $04 / 04$ & 2,00 & 59,00 & 14947,49 & 9,61 & 651,79 & 73,97 & 0,00395473 & 252,86 & 3,05 & 0,98807881 & 0,996053 \\
\hline 2012 & 78 & $06 / 04$ & 5,00 & 40,00 & 14987,49 & 9,61 & 661,41 & 74,12 & 0,00395261 & 253,00 & 3,08 & 0,98798871 & 0,996055 \\
\hline 2012 & 79 & $13 / 04$ & 6,00 & 121,00 & 15108,49 & 9,62 & 671,03 & 74,60 & 0,00394623 & 253,41 & 3,11 & 0,98786528 & 0,996062 \\
\hline 2012 & 80 & $04 / 05$ & 3,50 & 414,00 & 15522,49 & 9,65 & 680,68 & 76,23 & 0,00392487 & 254,79 & 3,12 & 0,98791164 & 0,996083 \\
\hline
\end{tabular}

(Continua) 
(Continuação)

\begin{tabular}{|c|c|c|c|c|c|c|c|c|c|c|c|c|c|}
\hline Ano & $\begin{array}{l}\text { Falhas } \\
\text { (n) }\end{array}$ & Data & TTR (h) & TBF $(\mathrm{h})$ & $t(h)$ & $\ln (t)$ & $\sum \ln (\mathrm{t})$ & $m(t)$ & $\rho(t)$ & $\operatorname{MTBF}(\mathrm{t})$ & $\operatorname{MTTR}(\mathrm{t})$ & $A(t)$ & $R(t)$ \\
\hline 2012 & 81 & $15 / 05$ & 3,00 & 206,50 & 15728,99 & 9,66 & 690,34 & 77,04 & 0,00391447 & 255,46 & 3,12 & 0,98794884 & 0,996093 \\
\hline 2012 & 82 & $23 / 05$ & 2,50 & 144,00 & 15872,99 & 9,67 & 700,02 & 77,60 & 0,00390731 & 255,93 & 3,11 & 0,98799926 & 0,996100 \\
\hline 2012 & 83 & $24 / 05$ & 8,15 & 3,50 & 15876,49 & 9,67 & 709,69 & 77,62 & 0,00390714 & 255,94 & 3,17 & 0,98776819 & 0,996100 \\
\hline 2012 & 84 & $09 / 07$ & 1,75 & 283,85 & 16160,34 & 9,69 & 719,38 & 78,72 & 0,00389326 & 256,85 & 3,15 & 0,98787530 & 0,996114 \\
\hline 2012 & 85 & $19 / 07$ & 2,50 & 187,25 & 16347,59 & 9,70 & 729,08 & 79,45 & 0,00388427 & 257,45 & 3,14 & 3208 & 0,996123 \\
\hline 2012 & 86 & $01 / 08$ & 2,50 & 249,50 & 16597,09 & 9,72 & 738,80 & 80,42 & 0,00387247 & 258,23 & 3,14 & 0,98799663 & 0,996135 \\
\hline 2012 & 87 & $10 / 08$ & 2,00 & 186,50 & 16783,59 & 9,73 & 748,53 & 81,14 & 0,00386379 & 258,81 & 3,12 & 0,98807252 & 0,996144 \\
\hline 2012 & 88 & $25 / 08$ & 4,50 & 292,00 & 17075,59 & 9,75 & 758,27 & 82,27 & 0,00385043 & 259,71 & 3,14 & 0,98805450 & 0,996157 \\
\hline 2012 & 89 & $02 / 09$ & 1,50 & 121,50 & 17197,09 & 9,75 & 768,02 & 82,73 & 0,00384496 & 260,08 & 3,12 & 0,98814046 & 0,996162 \\
\hline 2012 & 90 & 05/09 & 3,50 & 61,50 & 17258,59 & 9,76 & 777,78 & 82,97 & 0,00384220 & 260,27 & 3,13 & 0,98813308 & 0,996165 \\
\hline 2012 & 91 & $19 / 09$ & 3,00 & 290,50 & 17549,09 & 9,77 & 787,55 & 84,09 & 0,00382934 & 261,14 & 3,12 & 0,98817748 & 0,996178 \\
\hline 2012 & 92 & $26 / 09$ & 1,50 & 123,00 & 17672,09 & 9,78 & 797,33 & 84,56 & 0,00382398 & 261,51 & 3,11 & 0,98825979 & 0,996183 \\
\hline 2012 & 93 & $02 / 10$ & 2,00 & 103,50 & 17775,59 & 9,79 & 807,12 & 84,95 & 0,00381950 & 261,81 & 3,09 & 0,98831778 & 0,996188 \\
\hline 2012 & 94 & $15 / 10$ & 2,50 & 271,00 & 18046,59 & 9,80 & 816,92 & 85,99 & 0,00380791 & 262,61 & 3,09 & 0,98837634 & 0,996199 \\
\hline 2012 & 95 & $21 / 10$ & 3,75 & 102,50 & 18149,09 & 9,81 & 826,73 & 86,38 & 0,00380358 & 262,91 & 3,10 & 0,98836352 & 0,996204 \\
\hline 2012 & 96 & $05 / 11$ & 2,00 & 290,25 & 18439,34 & 9,82 & 836,55 & 87,48 & 0,00379148 & 263,75 & 3,08 & 0,98844237 & 0,996216 \\
\hline
\end{tabular}

(Continua) 
(Continuação)

\begin{tabular}{|c|c|c|c|c|c|c|c|c|c|c|c|c|c|}
\hline Ano & $\begin{array}{l}\text { Falhas } \\
\text { (n) }\end{array}$ & Data & $\begin{array}{c}\text { TTR } \\
\text { (h) }\end{array}$ & TBF (h) & $t(h)$ & $\ln (\mathrm{t})$ & $\sum \ln (t)$ & $m(t)$ & $\rho(t)$ & $\operatorname{MTBF}(\mathrm{t})$ & $\operatorname{MTTR}(\mathrm{t})$ & $A(t)$ & $R(t)$ \\
\hline 2012 & 97 & $22 / 11$ & 2,75 & 334,00 & 18773,34 & 9,84 & 846,39 & 88,74 & 0,00377784 & 264,70 & 3,08 & 0,98849618 & 0,996229 \\
\hline 2012 & 98 & $09 / 12$ & 2,00 & 333,25 & 19106,59 & 9,86 & 856,25 & 90,00 & 0,00376452 & 265,64 & 3,07 & 0,98857685 & 0,996243 \\
\hline 2012 & 99 & $12 / 12$ & 4,50 & 61,00 & 19167,59 & 9,86 & 866,11 & 90,23 & 0,00376211 & 265,81 & 3,08 & 0,98853095 & 0,996245 \\
\hline 2012 & 100 & $28 / 12$ & 1,50 & 310,50 & 19478,09 & 9,88 & 875,98 & 91,39 & 0,00374999 & 266,67 & 3,07 & 0,98862553 & 0,996257 \\
\hline 2013 & 101 & $05 / 01$ & 2,50 & 102,50 & 19580,59 & 9,88 & 885,87 & 91,78 & 0,00374604 & 266,95 & 3,06 & 0,98865797 & 0,996261 \\
\hline 2013 & 102 & $31 / 01$ & 2,75 & 543,25 & 20123,84 & 9,91 & 895,78 & 93,81 & 0,00372551 & 268,42 & 3,06 & 0,98873058 & 0,996281 \\
\hline 2013 & 103 & $31 / 01$ & 1,75 & 8,75 & 20132,59 & 9,91 & 905,69 & 93,84 & 0,00372518 & 268,44 & 3,05 & 0,98877785 & 0,996282 \\
\hline 2013 & 104 & $18 / 02$ & 2,00 & 374,00 & 20506,59 & 9,93 & 915,61 & 95,23 & 0,00371144 & 269,44 & 3,04 & 0,98885531 & 0,996295 \\
\hline 2013 & 105 & 03/03 & 4,00 & 483,00 & 20989,59 & 9,95 & 925,57 & 97,02 & 0,00369413 & 270,70 & 3,05 & 0,98887357 & 0,996313 \\
\hline 2013 & 106 & $13 / 03$ & 1,75 & 206,00 & 21195,59 & 9,96 & 935,53 & 97,78 & 0,00368690 & 271,23 & 3,03 & 0,98893920 & 0,996320 \\
\hline 2013 & 107 & $22 / 03$ & 2,50 & 187,25 & 21382,84 & 9,97 & 945,50 & 98,47 & 0,00368039 & 271,71 & 3,03 & 0,98897645 & 0,996326 \\
\hline 2013 & 108 & $11 / 04$ & 2,00 & 418,00 & 21800,84 & 9,99 & 955,49 & 100,00 & 0,00366611 & 272,77 & 3,02 & 0,98905291 & 0,996341 \\
\hline 2013 & 109 & $05 / 05$ & 4,75 & 499,25 & 22300,09 & 10,01 & 965,50 & 101,83 & 0,00364948 & 274,01 & 3,03 & 0,98904533 & 0,996357 \\
\hline 2013 & 110 & $08 / 05$ & 3,85 & 58,25 & 22358,34 & 10,01 & 975,52 & 102,04 & 0,00364757 & 274,16 & 3,04 & 0,98902457 & 0,996359 \\
\hline 2013 & 111 & $20 / 05$ & 6,00 & 248,15 & 22606,49 & 10,03 & 985,54 & 102,95 & 0,00363949 & 274,76 & 3,07 & 0,98895374 & 0,996367 \\
\hline 2013 & 112 & $06 / 06$ & 0,75 & 351,00 & 22957,49 & 10,04 & 995,58 & 104,22 & 0,00362825 & 275,61 & 3,05 & 0,98906097 & 0,996378 \\
\hline
\end{tabular}

(Continua) 
(Continuação)

\begin{tabular}{|c|c|c|c|c|c|c|c|c|c|c|c|c|c|}
\hline Ano & $\begin{array}{l}\text { Falhas } \\
\text { (n) }\end{array}$ & Data & $\begin{array}{c}\text { TTR } \\
\text { (h) }\end{array}$ & TBF (h) & $t(h)$ & $\ln (t)$ & $\sum \ln (t)$ & $m(t)$ & $\rho(t)$ & $\operatorname{MTBF}(t)$ & $\operatorname{MTTR}(\mathrm{t})$ & $A(t)$ & $R(t)$ \\
\hline 2013 & 113 & $23 / 06$ & 1,50 & 356,25 & 23313,74 & 10,06 & 1005,64 & 105,51 & 0,00361705 & 276,47 & 3,03 & 0,98914286 & 0,996389 \\
\hline 2013 & 114 & $30 / 06$ & 2,50 & 145,50 & 23459,24 & 10,06 & 1015,70 & 106,04 & 0,00361253 & 276,81 & 3,03 & 0,98917285 & 0,996394 \\
\hline 2013 & 115 & $18 / 08$ & 1,50 & 1026,50 & 24485,74 & 10,11 & 1025,81 & 109,73 & 0,00358160 & 279,20 & 3,02 & 0,98931119 & 0,996425 \\
\hline 2013 & 116 & $12 / 09$ & 4,00 & 523,50 & 25009,24 & 10,13 & 1035,94 & 111,60 & 0,00356642 & 280,39 & 3,03 & 0,98932643 & 0,996440 \\
\hline 2013 & 117 & $15 / 09$ & 2,00 & 59,00 & 25068,24 & 10,13 & 1046,06 & 111,81 & 0,00356473 & 280,53 & 3,02 & 0,98936199 & 0,996442 \\
\hline 2013 & 118 & $30 / 09$ & 3,75 & 313,00 & 25381,24 & 10,14 & 1056,21 & 112,93 & 0,00355586 & 281,23 & 3,02 & 0,98936654 & 0,996450 \\
\hline 2013 & 119 & $09 / 10$ & 1,50 & 185,25 & 25566,49 & 10,15 & 1066,36 & 113,59 & 0,00355067 & 281,64 & 3,01 & 0,98942636 & 0,996456 \\
\hline 2013 & 120 & $15 / 10$ & 3,50 & 124,50 & 25690,99 & 10,15 & 1076,51 & 114,03 & 0,00354721 & 281,91 & 3,01 & 0,98942238 & 0,996459 \\
\hline 2013 & 121 & $20 / 10$ & 4,25 & 101,50 & 25792,49 & 10,16 & 1086,67 & 114,39 & 0,00354440 & 282,13 & 3,02 & 0,98939521 & 0,996462 \\
\hline 2013 & 122 & $18 / 11$ & 2,00 & 604,75 & 26397,24 & 10,18 & 1096,85 & 116,53 & 0,00352795 & 283,45 & 3,02 & 0,98947292 & 0,996478 \\
\hline 2013 & 123 & $10 / 12$ & 5,50 & 460,00 & 26857,24 & 10,20 & 1107,05 & 118,15 & 0,00351573 & 284,44 & 3,04 & 0,98943947 & 0,996490 \\
\hline 2013 & 124 & $23 / 12$ & 2,00 & 267,50 & 27124,74 & 10,21 & 1117,25 & 119,09 & 0,00350874 & 285,00 & 3,03 & 0,98948894 & 0,996497 \\
\hline 2014 & 125 & $21 / 02$ & 1,75 & 294,00 & 27418,74 & 10,22 & 1127,47 & 120,12 & 0,00350115 & 285,62 & 3,02 & 647 & 0,996505 \\
\hline 2014 & 126 & $13 / 03$ & 1,00 & 430,25 & 27848,99 & 10,23 & 1137,71 & 121,62 & 0,00349023 & 286,51 & 3,00 & 0,98963348 & 0,996516 \\
\hline 2014 & 127 & $20 / 03$ & 0,75 & 146,00 & 27994,99 & 10,24 & 1147,95 & 122,13 & 0,00348656 & 286,82 & 2,98 & 0,98970478 & 0,996520 \\
\hline 2014 & 128 & $02 / 04$ & 1,85 & 270,40 & 28265,39 & 10,25 & 1158,20 & 123,07 & 0,00347984 & 287,37 & 2,97 & 0,98975462 & 0,996526 \\
\hline
\end{tabular}

(Continua) 
(Conclusão)

\begin{tabular}{cccccccccccccc}
\hline Ano & $\begin{array}{c}\text { Falhas } \\
(\mathrm{n})\end{array}$ & Data & $\begin{array}{c}\text { TTR } \\
(\mathrm{h})\end{array}$ & TBF $(\mathrm{h})$ & $\mathrm{t}(\mathrm{h})$ & $\ln (\mathrm{t})$ & $\sum \ln (\mathrm{t})$ & $\mathrm{m}(\mathrm{t})$ & $\rho(\mathrm{t})$ & $\operatorname{MTBF}(\mathrm{t})$ & $\mathrm{MTTR}(\mathrm{t})$ & $\mathrm{A}(\mathrm{t})$ & $\mathrm{R}(\mathrm{t})$ \\
\hline 2014 & 129 & $28 / 04$ & 3,75 & 544,15 & 28809,54 & 10,27 & 1168,47 & 124,96 & 0,00346654 & 288,47 & 2,98 & 0,98977296 & 0,996539 \\
2014 & 130 & $03 / 05$ & 2,00 & 80,25 & 28889,79 & 10,27 & 1178,74 & 125,24 & 0,00346461 & 288,63 & 2,97 & 0,98980422 & 0,996541 \\
2014 & 131 & $27 / 05$ & 1,50 & 502,00 & 29391,79 & 10,29 & 1189,03 & 126,98 & 0,00345264 & 289,63 & 2,96 & 0,98987711 & 0,996553 \\
2014 & 132 & $17 / 06$ & 1,75 & 439,50 & 29831,29 & 10,30 & 1199,33 & 128,49 & 0,00344237 & 290,50 & 2,95 & 0,98993790 & 0,996564 \\
2014 & 133 & $08 / 08$ & 5,50 & 462,00 & 30293,29 & 10,32 & 1209,65 & 130,08 & 0,00343176 & 291,40 & 2,97 & 0,98990419 & 0,996574 \\
2014 & 134 & $21 / 08$ & 1,85 & 1086,50 & 31379,79 & 10,35 & 1220,00 & 133,79 & 0,00340756 & 293,46 & 2,96 & 0,99000261 & 0,996598 \\
2014 & 135 & $14 / 09$ & 0,45 & 418,15 & 31797,94 & 10,37 & 1230,37 & 135,22 & 0,00339852 & 294,25 & 2,94 & 0,99009091 & 0,996607 \\
2014 & 136 & $18 / 09$ & 1,50 & 83,55 & 31881,49 & 10,37 & 1240,74 & 135,50 & 0,00339673 & 294,40 & 2,93 & 0,99013146 & 0,996609 \\
2014 & 137 & $03 / 10$ & 0,75 & 313,50 & 32194,99 & 10,38 & 1251,12 & 136,56 & 0,00339006 & 294,98 & 2,92 & 0,99020363 & 0,996616 \\
2014 & 138 & $20 / 10$ & 8,50 & 355,50 & 32550,49 & 10,39 & 1261,51 & 137,77 & 0,00338259 & 295,63 & 2,96 & 0,99009086 & 0,996623 \\
2014 & 139 & $03 / 11$ & 2,50 & 222,50 & 32772,99 & 10,40 & 1271,91 & 138,52 & 0,00337797 & 296,04 & 2,96 & 0,99011520 & 0,996628 \\
2014 & 140 & $24 / 11$ & 2,00 & 438,50 & 33211,49 & 10,41 & 1282,32 & 140,00 & 0,00336897 & 296,83 & 2,95 & 0,99016383 & 0,996637 \\
\hline
\end{tabular}

Fonte: Autoria própria 